\title{
The Future of Thermal Comfort in an Energy- Constrained World
}

\author{
by \\ Teen-Onn LAW \\ B.A. (Architectural Studies), B.A. (Architecture) Honours
}

School of Architecture and Design

School of Engineering

Submitted in fulfilment of the requirements for the degree of Doctor of Philosophy

University of Tasmania

October 2012 


\section{Table of contents}

1: Introduction .................................................................................................................................................................

2: The State of the World ...............................................................................................................................................

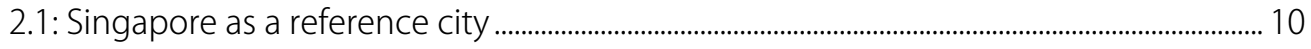

2.2: The role of Air-conditioning in a changed climate.................................................................... 14

2.3: A New Paradigm of Thermal Comfort............................................................................................. 16

3: Literature Review: Thermal Comfort and Air-Conditioning ................................................................... 19

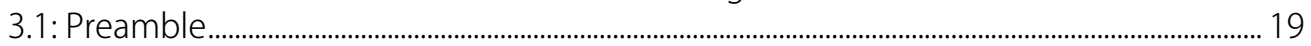

3.2: A background to thermal comfort ................................................................................................... 21

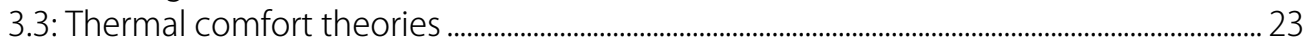

3.4: A critical review of the thermal comfort debate........................................................................... 28

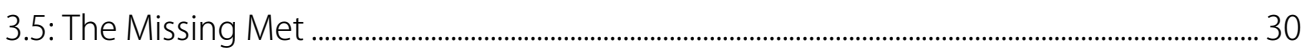

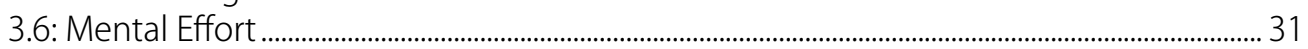

3.7: Studies on Comfort and Productivity ...................................................................................... 34

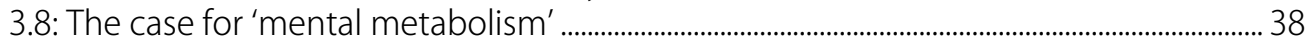

3.9: The 'perfect' temperature, a matter of personal taste ............................................................... 41

3.10: The importance of being "very comfortable" ............................................................................... 44

3.11: Marketing and mass consumption of air-conditioning ....................................................... 46

3.12: Acclimatised Addiction....................................................................................................................... 49

3.13: Comfort and energy ............................................................................................................. 52

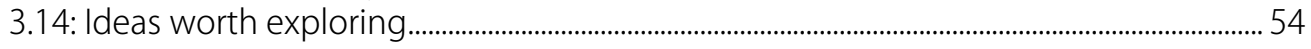

3.15: Concluding thoughts on thermal comfort review....................................................................56

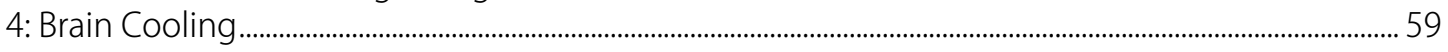

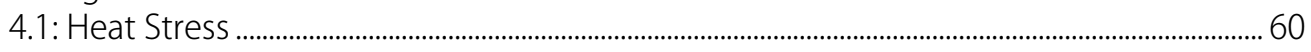

4.2: The neurophysiological stress response.......................................................................................... 61

4.3: Stress and the sympathetic nervous system ...................................................................................6 63

4.4: The perception of temperature......................................................................................................... 67

4.5: Selective brain cooling .......................................................................................................................... 74

4.6: Nasal air-conditioning ...................................................................................................................... 80

4.7: Dehydration, cognitive function and temperature .................................................................... 82

4.8: Sleep, cognitive function and temperature................................................................................. 84

4.9: Stress, blood pressure and ambient temperature ............................................................. 88

4.10: Stress Physiology and Psychology ………………………………………………………………....... 89

4.11: The difficulty of an index ...................................................................................................................... 91

4.12: Concluding thoughts on brain cooling.....................................................................................93

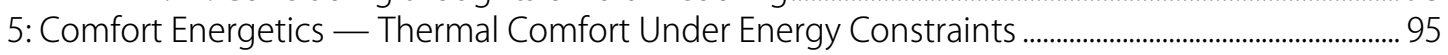

5.1: Case-study: The Windup Girl ............................................................................................................95

5.2: PMV, psychrometrically analysed .................................................................................................. 98

5.3: Comfort Energetics ................................................................................................................................101

5.3.1: Comfort in high humidity........................................................................................... 102

5.3.2: Understanding humidity ..........................................................................................105

5.3.3: Optimum RH and ASHRAE 55 misrepresented ...................................................106

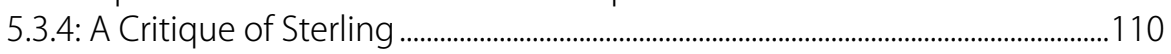

5.3.5: Effects of RH on bacteria and viruses.............................................................. 114

5.3.6: Effects of RH on moulds ..................................................................................................117

5.3.7: Effects of RH on mites.............................................................................................. 118

5.3.8: Summary of findings compared to Sterling (1985) ..........................................118

5.3.9: Humidity and Disease............................................................................................... 120

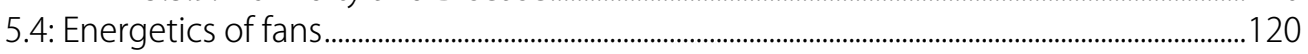

5.4.1: Wind velocity in the PMV model ...........................................................................121

5.4.2: dT as a result of increased cooling with higher wind speed .......................121

5.4.3: How much air movement is considered a draft? ................................................124

5.4.4: Air movement summarised............................................................................................ 126 
5.5: Personalised Ventilation........................................................................................................................... 126

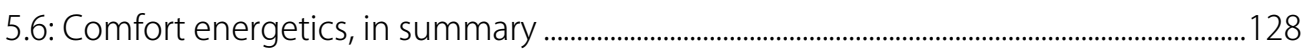

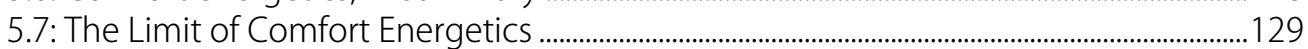

5.8: Conclusion to Comfort Energetics ...............................................................................................129

6: Research Methodology .....................................................................................................................................133

6.1: Apologetics against a falsifiable hypothesis................................................................................134

6.2: Appreciating the difference between false and 'false' ......................................................138

6.2.1: The Role of Criticism .......................................................................................... 142

6.3: Lemma Incorporation .....................................................................................................................145

6.4: The Commercialisation Test .........................................................................................................148

6.5: The Role of Intuition.......................................................................................................................150

6.6: Concluding thoughts on heuristics...............................................................................................155

7: The Rain Tower ………………………………………………………………………………………………………......157

7.1: The Brief..................................................................................................................................157

7.2: Innovation 1: Water as refrigerant.................................................................................................159

7.3: Innovation 2: Water as a Plug to compress R718...........................................................165

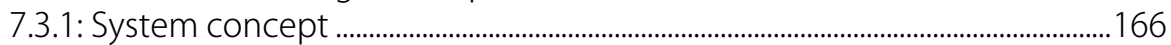

7.3.2: Testing the Water Plug, the Rain Rod ...................................................................173

7.4: Reflections on the Rain Tower .......................................................................................................180

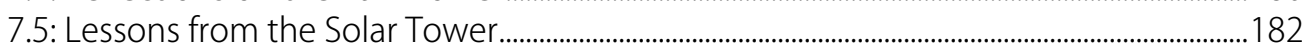

7.6: Lessons from Zero Carbon Australia 2020 Stationary Energy Plan....................................184

7.7: Power conservation is far more important than power generation...............................186

7.8: Lessons for the future........................................................................................................................188

8: Finding a market-oriented solution .....................................................................................................191

8.1: Property developers ..................................................................................................................................193

8.2: Architects and Engineers.............................................................................................................195

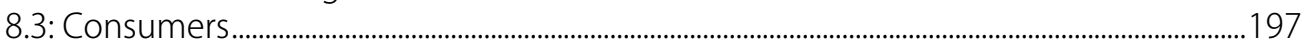

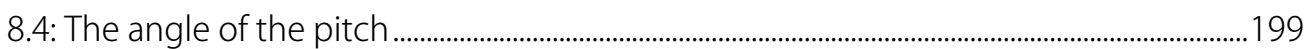

8.5: Using desiccant wheels and radiant cooling .............................................................................201

8.6: Radiant Cooling from the Ceiling ......................................................................................................205

8.7: Reflections on the Desiccant Wheel AHU (DWAHU) ................................................................207

8.8: Case study: The Skytherm Roof .....................................................................................................209

8.9: The Commercial and Scientific Imperatives ............................................................................212

9: Personal air-conditioning............................................................................................................................... 215

9.1: Personal Environmental Modules (PEMs), Task-Ambient Conditioning (TAC) and

Personal Ventilation (PV) ..................................................................................................................216

9.2: An introduction to DTAC ................................................................................................................219

9.3: DTAC, a twist from TAC ..............................................................................................................22

9.4: Background research for DTAC ......................................................................................................22

9.5: Key Parameters..........................................................................................................................................224

9.6: DTAC Prototype design .........................................................................................................................22

9.7: DTAC Performance indicators and methodolodgy ................................................................220

9.8: DTAC Discussion.................................................................................................................................22

9.9: DTAC Energy Comparisson .............................................................................................................234

9.10: DTAC competition: other personal air-conditioners ..........................................................2.

9.11: DTAC markets identified ..................................................................................................................2.

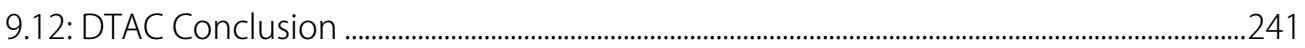

10: Field Testing DTAC, Methodology \& Results ................................................................................................2.

10.1: Background to the field trial ..........................................................................................................243

10.2: Field trials in NV offices .................................................................................................................243

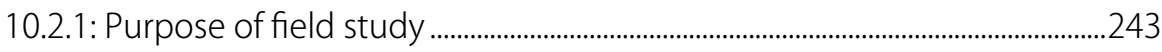

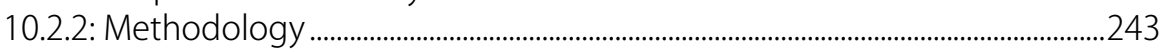

10.2.3: Temperature $(\mathrm{T})$ and Relative Humidity $(\mathrm{RH})$ logging ................................246

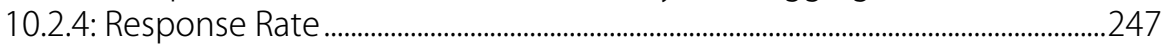

10.2.5: PMV and AMV Results ................................................................................................248 
10.2.6: Thermal sensation results (based on adaptive thermal comfort

studies)

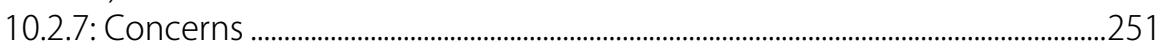

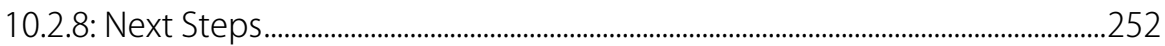

10.3: Climate chamber setup ..................................................................................................................25

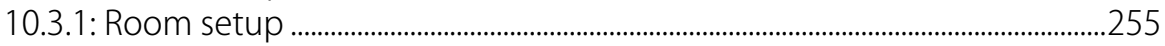

10.3.2: Room Environment with Panel Heater Only .....................................................255

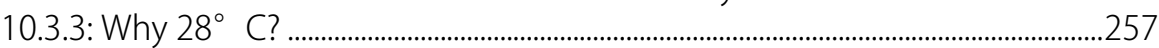

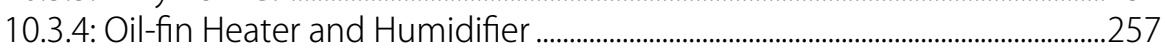

10.3.5: Selection of a suitable proxy ................................................................................2.

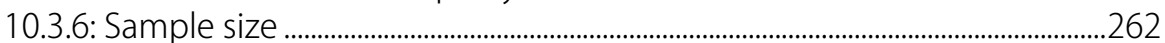

10.3.7: Productivity indexing ...................................................................................................26

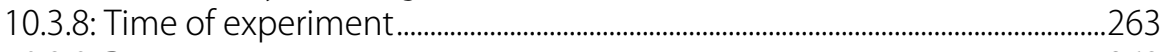

10.3.9: Participants .........................................................................................................................2.

10.3.10: The Design Challenge ...............................................................................................264

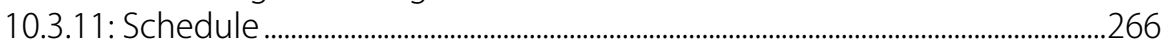

10.3.12: IQ/Memory Test ......................................................................................................2.

10.3.13: Survey questions........................................................................................................2.

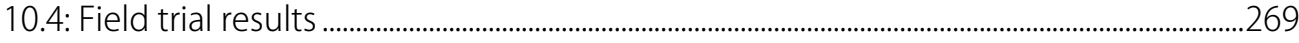

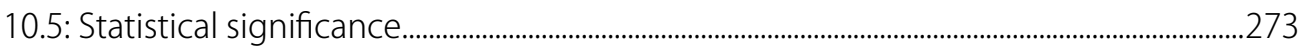

10.5.1: Thermal Sensation (ASHRAE Scale) ......................................................................2.

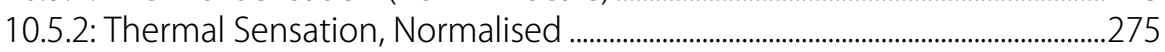

10.5.3: Thermal Comfort ..................................................................................................2.

10.5.4: General comfort (Bedford Scale) ............................................................................279

10.5.5: Karolinska Sleepiness Scale....................................................................................2.

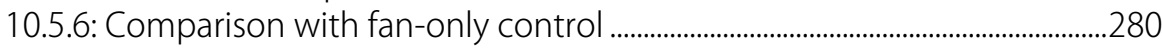

10.5.7: Cognitive Tests $(n=11)$..........................................................................................28

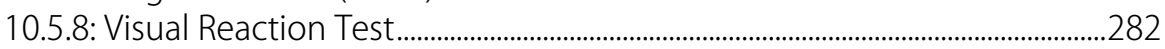

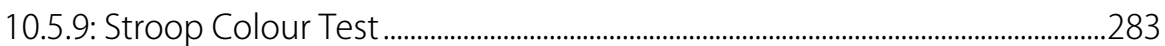

10.5.10: Cognitive Test Results ................................................................................................283

10.5.11: General and Marketing Feedback ........................................................................286

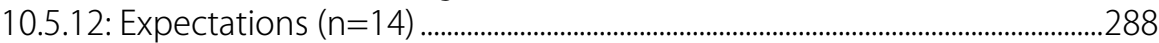

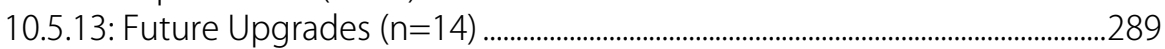

10.6: Target cooling ...................................................................................................................................2 294

10.7: Concluding thoughts on the experiment..................................................................................299

11: Future Research …………………………………………………………………………………………………….....303

11.1: The future of DTAC .........................................................................................................................303

11.2: A possible future for thermal comfort research: research-innovate-

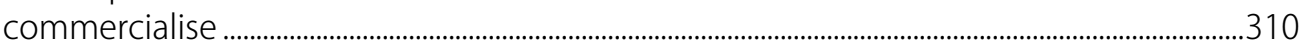

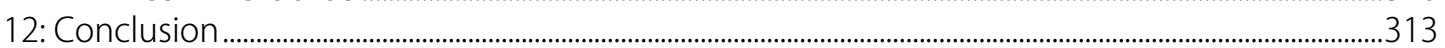




\section{Abbreviations and acronyms}

\begin{tabular}{|c|c|}
\hline ABGR & Australian Building Greenhouse Rating \\
\hline ACMV & Air-conditioning and Mechanical Ventilation \\
\hline $\mathrm{AHU}$ & Air-handling unit \\
\hline AIRAH & Australian Institute for Refrigeration, Air-conditioning and Heating \\
\hline AMV & Actual Mean Vote \\
\hline ASHRAE & American Society for Heating, Refrigeration and Air-conditioning Engineers \\
\hline ATD & Air Terminal Devices \\
\hline ATP & adenosine triphosphate \\
\hline $\mathrm{BAU}$ & business as usual \\
\hline BMR & basal metabolic rate \\
\hline BREEAM & BRE (formerly Building Research Establishment) Environmental Assessment Method \\
\hline CAD & computer-aided design \\
\hline CAM & computer-aided manufacturing \\
\hline $\mathrm{CC}$ & Climate Chamber \\
\hline CFE & cooling fan efficiency \\
\hline CIF & corticotropin inhibiting factor \\
\hline CO2-e & CO2 (carbon dioxide) equivalent \\
\hline COP & coefficient of performance, expressed as an equation, e.g. COP=1. Typical abrreviataion used throughout thesis. \\
\hline COP & conference of the parties, when referring to UN climate conferences, e.g. COP1. Used only in Chapter 2. \\
\hline $\mathrm{CRH}$ & Corticotropin releasing hormone \\
\hline CST & concentrated solar thermal \\
\hline DTAC & Ductless Task Air-Conditioning \\
\hline EHHF & Evelyn and Harold Hay Fund \\
\hline EIT & Economies in transition \\
\hline$f-f$ & floor to floor \\
\hline GBCA & Green Building Council of Australia \\
\hline GHG & greenhouse gases \\
\hline GtCO2-e & giga (billion) tons of CO2 (carbon dioxide) equivalent \\
\hline GWP & global-warming potential \\
\hline $\mathrm{HR}$ & humidity ratio \\
\hline HVAC & Heating, Ventilation and Air-conditioning \\
\hline IDEAS & Innovation Development Early Assessment System \\
\hline IP & Intellectual Property \\
\hline LEED & Leadership in Energy and Environmental Design \\
\hline M\&E & Mechanical and electrical (used in conjunction with engineer/engineering) \\
\hline MDF & Medium density fiberboard \\
\hline $\mathrm{mpg}$ & miles per gallon \\
\hline MRT & Mean Radiant Temperature \\
\hline NOAA & National Oceanic and Atmospheric Administration \\
\hline NV & Naturally Ventilated \\
\hline ODP & Ozone Depleting Potential \\
\hline OECD & Organisation for Economic Co-operation and Development \\
\hline
\end{tabular}




\begin{tabular}{|c|l|}
\hline OEM & Original Equipment Manufacturer \\
\hline PCM & Phase change material \\
\hline PEM & Personal Environmental Modules, a proprietary system of Johnson Controls \\
\hline PMV & Predicted Mean Vote \\
\hline ppm & parts per million \\
\hline PRC & Patent Review Committee \\
\hline PSU & Power Supply Unit \\
\hline PV & Personal Ventilation \\
\hline PV & photovoltaic \\
\hline PVA & Polyvinyl acetate \\
\hline RH & Relative humidity \\
\hline SBC & Selective Brain Cooling \\
\hline SEUI & System energy usage intensity \\
\hline SOAD & School of Architecture and Design (University of Tasmania) \\
\hline TAC & Task-Ambient Conditioning \\
\hline tCO2-e & tons of CO2 (carbon dioxide) equivalent \\
\hline TE & Thermoelectric \\
\hline TIM & Thermal Interface Material \\
\hline T & Technology Transfer \\
\hline VAV & variable air volume \\
\hline WCI & Wind Chill Index \\
\hline & \\
\hline
\end{tabular}




\section{Nomenclature}

For ease of reference, nomenclature is included immediately after each equation in the Equation Notes. A selected list is included here where they appear in the text body.

\begin{tabular}{|c|l|}
\hline $\boldsymbol{T h}$ & hot side temperature, when used in DTAC refers to the temperature read from the underside of the PCM tank \\
\hline $\boldsymbol{T}$ & Temperature \\
\hline $\boldsymbol{T} \boldsymbol{c}$ & cold side temperature, when used in DTAC refers to the temperature of the topmost cooling fin (nearest the TE modules) \\
\hline $\boldsymbol{S}$ & entropy \\
\hline $\boldsymbol{P}$ & Pressure \\
\hline $\boldsymbol{H}$ & enthalpy \\
\hline $\boldsymbol{R} \boldsymbol{H}$ & relative humidity \\
\hline $\boldsymbol{c l} \boldsymbol{o}$ & clothing insulation \\
\hline $\boldsymbol{m e t}$ & metabloic rate \\
\hline $\boldsymbol{M R} \boldsymbol{T}$ & mean radiant temperature \\
\hline $\boldsymbol{H}_{\boldsymbol{s} \boldsymbol{s}}$ & enthalpy of supply air \\
\hline $\boldsymbol{H}_{\boldsymbol{a m} \boldsymbol{b}}$ & enthalpy of ambient air \\
\hline $\boldsymbol{W}_{\boldsymbol{T E}}$ & work (electrical) input to TE modules \\
\hline $\boldsymbol{Q}_{\boldsymbol{T E}}$ & heat produced (on hot side) of TE module \\
\hline
\end{tabular}




\section{List of Figures}

\begin{tabular}{|c|c|c|}
\hline Chapter & No. & Description \\
\hline 1 & 1 & Structure of chapters in this thesis \\
\hline 2 & 1 & Stabilisation wedges \\
\hline 2 & 2 & Share of Australian households with air conditioning or evaporative cooling \\
\hline 2 & 3 & McKinsey Curve \\
\hline 2 & 4 & Relationship between means and extremes \\
\hline 3 & 1 & Office workers going for lunch in Singapore \\
\hline 3 & 2 & Office clothing in typical eateries, known as hawker centres \\
\hline 3 & 3 & $\begin{array}{l}\text { Comparison of adaptive model and PMV model predictions on observed neutralities applied to naturally } \\
\text { ventilated buildings }\end{array}$ \\
\hline 3 & 4 & Loss in productivity as a function of PMV and temperature \\
\hline 3 & 5 & The relationship between temperature and performance \\
\hline 3 & 6 & Carrier air-conditioning advertisements in the 1930s \\
\hline 3 & 7 & Herman Miller C2 advertisement \\
\hline 4 & 1 & Innervation of organs by the autonomous nervous system \\
\hline 4 & 2 & Key areas linked to the expression of fear \\
\hline 4 & 3 & Neuronal model \\
\hline 4 & 4 & Mean density of temperature spots \\
\hline 4 & 5 & Arterial supply to the brain and the meninges \\
\hline 4 & 6 & Schematic diagram illustration the elements that control the temperature regulatory effector responses \\
\hline 4 & 7 & Sagittal (almost median) section of the head and neck, with a portion of the brain included. \\
\hline 4 & 8 & Schematic representation of some of the heat exchange mechanisms of selective brain cooling in humans \\
\hline 4 & 9 & The process of reversible temperature disintegration of protein structure \\
\hline 4 & 10 & Participation of trypsin in hyperthermic proteolysis \\
\hline 4 & 11 & Vasculature involved in selective brain cooling (SBC) in artiodactlys \\
\hline 4 & 12 & $\begin{array}{l}\text { Anecdotal evidence that even with identical environmental conditions, the personal response goes beyond } \\
\text { clothing and physical metabolism }\end{array}$ \\
\hline 4 & 13 & A general view of active immersion-convectional heating of the patient \\
\hline 4 & 14 & Influence of preoptic-anterior hypothalamic diathermic warming on breathing rate during sleep \\
\hline 4 & 15 & Wim Hof, the 'Iceman', running a full marathon in northern Finland in his shorts \\
\hline 5 & 1 & Book cover of Windup Girl illustrated by Raphael Lacoste \\
\hline 5 & 2 & Climate booth to determine energy required to improve PMV by various cooling processes \\
\hline 5 & 3 & Uncertainty in the RH stipulation in the ASHRAE-55 standard in years 1981, 1992 and 1994 \\
\hline 5 & 4 & The widely reproduced premise for recommending the optimum $\mathrm{RH}$ range \\
\hline 5 & 5 & Acceptable T and humidity range (ASHRAE-55, 1981) \\
\hline 5 & 6 & Influenza viability under different exposure of $\mathrm{RH} \%$ and exposure \\
\hline 5 & 7 & Simulated water evaporation from bacteria \\
\hline 5 & 8 & Growth conditions for mould \\
\hline 5 & 9 & Wind speeds under a ceiling fan \\
\hline 5 & 10 & Acceptable operative temperature and air speeds for the comfort zone at humidity ration of 0.010 \\
\hline 5 & 11 & Flow rate of a $120 \mathrm{~mm}$ diameter fan at $3000 \mathrm{rpm}$ \\
\hline 5 & 12 & Fan power versus cooling fan efficiency index for various fans \\
\hline
\end{tabular}




\begin{tabular}{|c|c|c|}
\hline Chapter & No. & Description \\
\hline 6 & 1 & The dogmatic and methodological falsificationist reaction to anomalies \\
\hline 6 & 2 & The Blind Men and an Elephant \\
\hline 6 & 3 & (a) Nathan Myhrvold describing his plan for (b) stratospheric aerosol injection \\
\hline 6 & 4 & Movie celebrities as air-conditioning ambassadors \\
\hline 7 & 1 & Water (R718) compared to natural refrigerant ammonia (R717) and other synthetic refrigerants \\
\hline 7 & 2 & Cloud seeding \\
\hline 7 & 3 & (a) Adiabatic lapse rates (b) Saturation curve \\
\hline 7 & 4 & Rain tower using altitude cooling \\
\hline 7 & 5 & Rain Tower using solar thermal driven absorption chiller \\
\hline 7 & 6 & System Diagram for the Rain Tower \\
\hline 7 & 7 & Compression sequence \\
\hline 7 & 8 & Temperature-Entropy Diagram \\
\hline 7 & 9 & Pressure-Enthalpy Diagram \\
\hline 7 & 10 & Sketch design to test the integrity of a falling column of water \\
\hline 7 & 11 & The premise for using a rod to ascertain the plug integrity \\
\hline 7 & 12 & Extraction of air and creating of an exclusive water-steam internal condition. \\
\hline 7 & 13 & Thermal imagery of top and bottom of rod. \\
\hline 7 & 14 & Non-uniformity in IR temperature of chrome valve as contrasted to black pipe. \\
\hline 7 & 15 & How the geometry of the rod and its reflectance affected thermal imaging accuracy. \\
\hline 7 & 16 & Solar chimney in Spain, viewed trough the polyester collector roof \\
\hline 7 & 17 & (a) The Manzanares 50kW Solar Tower and (b) Solar Tower Power Station conceptualisation \\
\hline 7 & 18 & CST plant \\
\hline 8 & 1 & DWAHU: schematic of air flow \\
\hline 8 & 2 & DWAHU: Processes on psychromtric chart \\
\hline 8 & 3 & Economy and better air quality by avoiding air recycling \\
\hline 8 & 4 & Carat perforated ceiling system \\
\hline 8 & 5 & Loughborough University's ceiling tile cooling unit \\
\hline 8 & 6 & Skytherm house \\
\hline 8 & 7 & Experiment to teach first year students the concept of radiant heating and cooling \\
\hline 9 & 1 & Details of an Environmentally Responsive Workstation \\
\hline 9 & 2 & PEM setup \\
\hline 9 & 3 & TAC setup in UC Berkeley's Control Environment Chamber \\
\hline 9 & 4 & DTAC assembly blow-up \\
\hline 9 & 5 & Various air terminal devices studied by Melikov $\{2002\}$ \\
\hline 9 & 6 & Q-I of TE module \\
\hline 9 & 7 & C.O.P.-dT \\
\hline 9 & 8 & Two drum sizes \\
\hline 9 & 9 & CAD render of proposed DTAC design \\
\hline 9 & 10 & Detail of cooling fin assembly \\
\hline 9 & 11 & Energy balance of cooling fin \\
\hline 9 & 12 & Sensor positions when testing the DTAC. \\
\hline 9 & 13 & Completed prototype, slightly larger than a regular office drawer pedestal. \\
\hline 9 & 14 & (a )T plots of individual loggers and (b) dT plots when DTAC in operation. \\
\hline 9 & 15 & Correlation dT to $\mathrm{T}(\mathrm{amb})$ \\
\hline 9 & 16 & Time taken for fully molten PCM to be regenerated after office hours \\
\hline 10 & 1 & (a) Participant using DTAC unit (b) Participant using fan-only uniy \\
\hline 10 & 2 & Number of responses received for thermal comfort survey in (a) week 1 (b) week 2 \\
\hline
\end{tabular}




\begin{tabular}{|c|c|c|}
\hline Chapter & No. & Description \\
\hline 10 & 3 & $\begin{array}{l}\text { Plots of environmental thermal factors on left vertical axis: dry bulb T, globe T, relative humidity, MRT. Votes } \\
\text { (PMV, AMV-Fan and AMV-DTAC) are the thick horizontal bars read to the right vertical axis. }\end{array}$ \\
\hline 10 & 4 & $\begin{array}{l}\text { All data points of actual votes, and the corresponding effective T plotted for fan-only (red) and DTAC (blue). } \\
\text { Fan votes show a weak correlation }\left(r^{2}=0.3\right) \text { and DTAC votes show no correlation with } \mathrm{T}\left(\mathrm{r}^{2}=0.0\right)\end{array}$ \\
\hline 10 & 5 & Example of measuring set-up with several ellipsoid sensors mounted on rig simulating a seated person \\
\hline 10 & 6 & $\begin{array}{l}\text { Correlation of air temperature (Tair) and globe temperature (Tglobe), verified against a new high accuracy } \\
\text { digital logger (EL2Tair) }\end{array}$ \\
\hline 10 & 7 & $\begin{array}{l}\text { Scatterplot after humidifier installed and run at "ultrasound + heat" mode. Correlation of T-air vs T-globe (blue) } \\
\text { and T-air vs EL2Tair (red) show a near perfect linear correlation and negligible difference in intercept and slope } \\
\text { For all practical purposes, the measurements of air temperature and globe temperature were interchangeable }\end{array}$ \\
\hline 10 & 8 & $\begin{array}{l}\text { Scatterplot of high accuracy }\left( \pm 0.2^{\circ} \mathrm{C}\right) \text { digital loggers at table top height }(750 \mathrm{~mm}) \text { and at ASHRAE } \\
\text { recommended } 1100 \mathrm{~mm} \text {. }\end{array}$ \\
\hline 10 & 9 & Temperature of air at different levels \\
\hline 10 & 10 & $r^{2}$ of different positions compared primarily with centre of table air $T$ at $1100 \mathrm{~mm}$. \\
\hline 10 & 11 & $r^{2}$ of different positions compared to tabletop right \\
\hline 10 & 12 & Design challenge $\mathrm{A} 3$ sheet with reference number, brief and rubric. \\
\hline 10 & 13 & Structure of three-hour climate controlled field trial \\
\hline 10 & 14 & Memory challenge \\
\hline 10 & 15 & One of the field trial participant during the design challenge. \\
\hline 10 & 16 & Overview of survey responses \\
\hline 10 & 17 & Thermal sensation before and after correction for clo variation \\
\hline 10 & 18 & Projection of sleepiness based on trend before DTAC being switched on \\
\hline 10 & 19 & Mean sensation, comfort and sleepiness votes of 'fan-only' participants control group overlaid on DTAC group \\
\hline 10 & 20 & Webshots of the online visual reaction test \\
\hline 10 & 21 & Webshots of the online visual Stroop colour test \\
\hline 10 & 22 & Stroop interference interval for participants in climate chamber. \\
\hline 10 & 23 & End of trial general feedback survey web page. \\
\hline 10 & 24 & $\begin{array}{l}\text { Satisfaction with DTAC in meeting expectations for the criteria of reliability, wase of use, general comfort and } \\
\text { thermal comfort }\end{array}$ \\
\hline 10 & 25 & General feedback upon completion of trial \\
\hline 10 & 26 & $\begin{array}{l}\text { Sound level measured with Digitech QM1589 set to 'Slow', 'A' Rated (dBA). Recorded at } 1.1 \mathrm{~m} \text { height between } \\
\text { two DTAC units both with fans on. Average of readings values taken increasing fan controller ( } 0 \text { to 10) and } \\
\text { decreasing (10 to } 0 \text { ). }\end{array}$ \\
\hline 10 & 27 & Percentage of participants nominating recommended retail value and upgrades. \\
\hline 10 & 28 & Plots of free convction (Churchill) and forced convection at $0.2 \mathrm{~m} / \mathrm{s}$ (Whitaker) \\
\hline 10 & 29 & Convective heat loss at various velocity and temperatures \\
\hline 10 & 30 & Forced convective heat loss ( as a multiple of natural convection) at various wind velocities \\
\hline 10 & 31 & Combined relationship between $\mathrm{dT}$ and $\mathrm{v}$ to effect $20 \mathrm{~W}$ of cooling. \\
\hline 11 & 1 & Renders of DTAC as a product. \\
\hline 11 & 2 & Two main areas of improvement to IAQ. \\
\hline 11 & 3 & (a) Rooftop green house and (b) ACMV system schematic of Paharpur Business Centre \\
\hline 11 & 4 & Indoor air purification system combining houseplants and activated carbon. \\
\hline 11 & 5 & Industrial designer's artist impression (Tiller Design) \\
\hline 11 & 6 & $\begin{array}{l}\text { DTAC in various applications: (a) with blower grille fully retracted, (b) to be used beside a sofa or bed as a } \\
\text { standalone unit, and (c) with the turret raised to meet the table surface so that the grille can be retracted and } \\
\text { made flush with tabletop }\end{array}$ \\
\hline A1 & 1 & DTAC Mark 1 prototype design \\
\hline A1 & 2 & $\begin{array}{l}\text { Experiment setup to test (1) supply of hot-humid air simulating outdoor tropical air (2) desiccant } \\
\text { dehumidification and pre-cooling simulating DWAHU ambient air-conditioning, and (3) personal air- } \\
\text { conditioning of cooled air, simulating DTAC }\end{array}$ \\
\hline A1 & 3 & DWAHU design \\
\hline
\end{tabular}




\begin{tabular}{|c|c|c|}
\hline Chapter & No. & Description \\
\hline A1 & 4 & Design of Mark-2 \\
\hline A1 & 5 & $\begin{array}{l}\text { Circuit diagram to enable selection between battery and PSU operation, and between 2-, 4- or 6-module } \\
\text { operation }\end{array}$ \\
\hline A1 & 6 & Mark 2 with cooling fins and faceplate \\
\hline A1 & 7 & Mark 2 with battery and PCM tank \\
\hline A1 & 8 & Mark 2 in the pelicase \\
\hline A1 & 9 & Use of clamps to minimise TIM thickness was effective and routinely adopted in future prototypes \\
\hline A1 & 10 & Weights in tank for better consistency in lapping process. \\
\hline A1 & 11 & $\begin{array}{l}\text { (a) Duct made of MDF, laser cut and glued (b) A rig was designed to apply pressure evenly on the cooling fin } \\
\text { assembly }\end{array}$ \\
\hline A1 & 12 & (a) Tank being clamped to cooling fins. (b) Testing and melting of PCM \\
\hline A1 & 13 & Completed Mark-3 prototype \\
\hline A1 & 14 & (a) Design of field trial prototype, and (b) assembly of top-shell and casing \\
\hline A1 & 15 & Overview of production at the workshop \\
\hline A1 & 16 & To ensure consistency, (a) the torque applied to the nuts was measured, and (b) weights applied \\
\hline A1 & 17 & $\begin{array}{l}\text { (a-left) Cooling fin assembly being pressed, (a-rear) TE modules being fixed onto cooling fin assembly and (a- } \\
\text { foreground) complete fin and TE modules, (b) TE modules with thermal paste, ready to receive tank }\end{array}$ \\
\hline A1 & 18 & $\begin{array}{l}\text { (a) PCM as delivered (b) On a particularly humid day, the cooling fins were below dew point when run without } \\
\text { the fan. With the fan on, the fins have never encountered condensation. }\end{array}$ \\
\hline A1 & 19 & (a) Breach of surface by molten wax (b) Solid wax sinks to feed the hot base \\
\hline A1 & 20 & (a) Melting of wax in DTAC (b) Setup for data logging of test run \\
\hline A1 & 21 & Completed DTAC prototype Mark-4 \\
\hline A1 & 22 & Completed fan-only prototype \\
\hline A1 & 23 & CAD drawings and completed prototypes \\
\hline A1 & 24 & Honeycomb with claims by manufacturer to reduce turbulence and improve flow rate \\
\hline A1 & 25 & Honeycomb and spacers to enable a flushed facing when bolting on the funnel. \\
\hline A1 & 26 & Plug design for forming the profile \\
\hline A1 & 27 & (a) Purchased blower grille (b) Acrylic housing \\
\hline A1 & 28 & $\begin{array}{l}\text { (a) Initial duct design with } 2 \times 45^{\circ} \text { bends when turning from horizontal to vertical causing less turbulence and } \\
\text { lower pressure drop. (b) Fabricated design for cost economy with a } 90^{\circ} \text { elbow }\end{array}$ \\
\hline A1 & 29 & Isometric design of duct, funnel and cooling fin assembly. \\
\hline A1 & 30 & (a) Air speed measurement from blower grille (b) blower grille connection to duct \\
\hline A1 & 31 & Cooling fins and foam tape \\
\hline A1 & 32 & Mark2 with a curved funnel. \\
\hline A1 & 33 & $\begin{array}{l}\text { (a) Laser cut 3mm MDF duct being glued with PVA and coated with two coats of shellac for air-tightness, (b) } \\
\text { show here being used with Mark } 2 \text { tank. }\end{array}$ \\
\hline A1 & 34 & MDF ducts redesigned for minimal bends subsequently used for (a) Mark-3 and (b) Mark-4 \\
\hline A1 & 35 & Test of field trial (FT) units, FT1 and FT2 \\
\hline A1 & 36 & Two units of field trial DTAC, FT1 and FT2 being tested concurrently. \\
\hline A1 & 37 & Same data as above, presented as $\Delta \mathrm{T}$. \\
\hline A1 & 38 & Foam weather tape around fan to ensure a snug fit \\
\hline A1 & 39 & (a) $12.5 \mathrm{~mm}$ plywood after being cut by the CNC router (b) assembly and attachment of ironmongery. \\
\hline A1 & 40 & Application of polyurethane varnish. \\
\hline A1 & 41 & dT from initial temperature at various stages in assembly \\
\hline A1 & 42 & dT from initial temperature applying different voltages across TE modules \\
\hline A1 & 43 & Cooling fin selection and development \\
\hline A1 & 44 & Issues found with working with a vertical cooling fin design \\
\hline A1 & 45 & Merits of adopting a horizontal heat sink arrangement \\
\hline A1 & 46 & Detail of cooling fin assembly. \\
\hline
\end{tabular}




\begin{tabular}{|c|c|c|}
\hline Chapter & No. & Description \\
\hline A1 & 47 & (a) Plates being counter sunk (b) Spacers after being filed and cleaned \\
\hline A1 & 48 & Cooling fins assembled with bolts \\
\hline A1 & 49 & Setup to test efficacy of heat transfer through the spacers of the cooling fin \\
\hline A1 & 50 & Application of MX2 thermal paste between layers \\
\hline A1 & 51 & Fins were pressed wit clamps to minimise thickness of thermal interface material \\
\hline A1 & 52 & (a) Mark-3 fin press (b) Mark-4 fin press \\
\hline A1 & 53 & Hanging scale being used to determine torque applied equally to both bolts on threaded rods \\
\hline A1 & 54 & $\begin{array}{l}\text { (a) The top plate of the cooling fin assembly was masked to retain its low emissivity, and reduce radiant heat } \\
\text { gained from the underside of the tank (b) Each sweep of the spray was targeted parallel to the fins to coat as } \\
\text { far into them as possible }\end{array}$ \\
\hline A1 & 55 & $\begin{array}{l}\text { (a) Masking tape check to see that the paint had reached the } 40 \mathrm{~mm} \text { depth on either side of the spacers. (b) } \\
\text { Painted cooling fins being assembled with TE modules. }\end{array}$ \\
\hline A1 & 56 & TE modules placed in direct contact with heat sink with no effect. Without a TIM the heat transfer was minimal \\
\hline A1 & 57 & $\begin{array}{l}\text { (a)TE module on left has a blob of silver particle themal paste (b) An alternative TIM, the ArcticSilver MX2 } \\
\text { compound }\end{array}$ \\
\hline A1 & 58 & Thermal bridging as excess paste bled over the edge \\
\hline A1 & 59 & CAD of mould silicone jacket for TEM. \\
\hline A1 & 60 & $\begin{array}{l}\text { (a) Mould cut into MDF and silicone injected into mould. (b) Silicone pads breaking as they did not release } \\
\text { properly from the moulds. }\end{array}$ \\
\hline A1 & 61 & Thermal transfer tape affixed to both sides of module \\
\hline A1 & 62 & An aluminium "hot plate" positioned between TE modules and PCM tank to give a reading of T-hot \\
\hline A1 & 63 & (a) TE modules being clamped to cooling fins with an MX2 TIM (b) TE modules after pressing. \\
\hline A1 & 64 & Checking levelness of TE modules after pressing \\
\hline A1 & 65 & Tank and fins coated with 2 layers of matte black spray paint \\
\hline A1 & 66 & $\begin{array}{l}\text { Black painted tank with thermographs at normal (above) and at an angle (below) taken within seconds of each } \\
\text { other }\end{array}$ \\
\hline A1 & 67 & Thermographs showing total melting after about 5 hours \\
\hline A1 & 68 & Simplified conceptual illustrations on how the PCM was melted and regenerated. \\
\hline A1 & 69 & $\begin{array}{l}\text { An enamel container was used to melt the PCM. To enable a reading of T-hot, a } 3 \mathrm{~mm} \text { aluminium plate was } \\
\text { used with a contactless thermometer reading the infrared emission off a piece of masking tape. }\end{array}$ \\
\hline A1 & 70 & Stainless steel saucepan holding a water and a frozen bottle to simulate the refrigeration from TE modules \\
\hline A1 & 71 & $\begin{array}{l}\text { (a) Fresh wax being added to the saucepan. (b) A heat sink placed in the middle of the saucepan to allow } \\
\text { molten wax to rise. }\end{array}$ \\
\hline A1 & 72 & $\begin{array}{l}\text { (a) Observing if a highly conductive tank with a conductive strip would allow the wax to detach and sink } \\
\text { (b)Underside of tiffany tin }\end{array}$ \\
\hline A1 & 73 & Thermal images of test \\
\hline A1 & 74 & Stockpot with additional engineering done to base, being measured for variations in level with a dial gauge. \\
\hline A1 & 75 & Engineered stockpot being clamped to cooling fin assembly in duct. \\
\hline A1 & 76 & Stainless steel tank, due to poor conductivity wax cannot detach from walls to sink \\
\hline A1 & 77 & Time lapse photography at $1 \mathrm{sec}$ intervals \\
\hline A1 & 78 & $\begin{array}{l}\text { Total detachment achieved with thick walled aluminium tank but shape of solid wax, as explained by } \\
\text { Archimedes principle, remains buoyant. }\end{array}$ \\
\hline A1 & 79 & $\begin{array}{l}\text { Double-tank: an inner highly conductive and thick profiled inner wall, and a low conductive and thin profiled } \\
\text { outer wall. }\end{array}$ \\
\hline A1 & 80 & Final solution that worked: double-wall bath with a means of perforating the top. \\
\hline A1 & 81 & $\begin{array}{l}\text { (a) The inner-wall made from } 4 \mathrm{~mm} \text { folded aluminium sheets, and (b) the drum with heat sink and partially } \\
\text { melted wax. }\end{array}$ \\
\hline A1 & 82 & Stream analysis of DTAC prototype supplying warm air \\
\hline
\end{tabular}




\section{List of Tables}

\begin{tabular}{|c|c|c|}
\hline Chapter & No. & Description \\
\hline 2 & 1 & Economic Mitigation Potential in 2030 \\
\hline 2 & 2 & History of Climate Change Policy \\
\hline 2 & 3 & Examples of how to achieve a wedge \\
\hline 2 & 4 & Singapore resident employment in 2010 by occupation \\
\hline 2 & 5 & System Energy Usage Intensity of offices in Singapore \\
\hline 2 & 6 & Projected number of days over $35^{\circ} \mathrm{C}$ in Australian capital cities \\
\hline 3 & 1 & Contrast in thermal comfort approaches \\
\hline 3 & 2 & $\begin{array}{l}\text { Comparison of Fanger's laboratory experiments and how the different parameters are not possible in the really } \\
\text { world }\end{array}$ \\
\hline 3 & 3 & The missing met \\
\hline 3 & 4 & The effect of thermal environments on productivity \\
\hline 3 & 5 & Contribution of different organs to BMR \\
\hline 3 & 6 & Thermal sensation scales \\
\hline 3 & 7 & Threads in this chapter \\
\hline 4 & 1 & Overall sensation model obtained from single body \\
\hline 4 & 2 & Tolerance as a function of dose \\
\hline 4 & 3 & Adrenoreception of facial and aungularis oculi veins \\
\hline 4 & 4 & Households with air-conditioning in Singapore by age group \\
\hline 5 & 1 & Reference conditions \\
\hline 5 & 2 & Four methods analysed psychrometrically \\
\hline 5 & 3 & Cooling methods analysed in terms of energetics \\
\hline 5 & 4 & Literature on comfort in high $\mathrm{RH}$ \\
\hline 5 & 5 & Recommended $\mathrm{RH}$ in common texts \\
\hline 5 & 6 & Humidity criteria from American and Australian Standards \\
\hline 5 & 7 & Humidity control in ASHRAE 55 and preceding standards \\
\hline 5 & 8 & Alternatives to RH control in managing various microbes. \\
\hline 5 & 9 & Comfort energetics of increasing ventilation rates \\
\hline 5 & 10 & Comfort energetics of a ceiling fan \\
\hline 5 & 11 & Comfort energetics to a desk fan \\
\hline 5 & 12 & Contrast in thermal comfort approache \\
\hline 6 & 1 & Examples on the use of 'hypothesis' and 'null-hypothesis rejected' \\
\hline 6 & 2 & Lemma incorporation in the innovation process \\
\hline 6 & 3 & Similarities in schema between the heuristic and patent processes \\
\hline 7 & 1 & Characteristics of natural refrigerants \\
\hline 7 & 2 & Summary of compression cycle with a falling column of water \\
\hline 7 & 3 & Determination of pump flow rate for the Rain Tower \\
\hline 8 & 1 & Office buildings in Australia that have received high accolades for sustainability. \\
\hline 8 & 2 & $\begin{array}{l}\text { DWAHU: Outdoor air is desiccated and cooled in a double cycle before the dry air is chilled by the air } \\
\text { conditioning. }\end{array}$ \\
\hline 8 & 3 & $\begin{array}{l}\text { DWAHU: Exhaust air is used to cool the desiccated air (A-B), and part of it is heated by the heat rejected from } \\
\text { the air-conditioning }(A-C) \text {. }\end{array}$ \\
\hline 8 & 4 & Assumed air conditions \\
\hline
\end{tabular}




\begin{tabular}{|c|c|c|}
\hline Chapter & No. & Description \\
\hline 8 & 5 & Calculations on the revenue generated with a conversion of plant are \\
\hline 8 & 6 & Two possible conditions for achieving a PMV of $+0.5(P P D=10.2 \%)$ \\
\hline 8 & 7 & IDEAS business feasibility evaluation list \\
\hline 9 & 1 & Similarities between task lighting and task air-conditioning \\
\hline 9 & 2 & Reference parameters for sizing personal air-conditioning \\
\hline 9 & 3 & Key parameters for DTAC \\
\hline 9 & 4 & Properties of paraffin wax PCM, Rubitherm ${ }^{\circledast}$ RT42 \\
\hline 9 & 5 & Efficiency of TE Modules \\
\hline 9 & 6 & Personal EUI based on data from Singaporean sources \\
\hline 9 & 7 & Personal EUI based on data from ASHRAE rule-of-thumb \\
\hline 9 & 8 & Energy savings and cost recovery based on current electricity prices. \\
\hline 9 & 9 & Metric for comparing existing technologies \\
\hline 9 & 10 & DTAC in the comparison metric \\
\hline 10 & 1 & Thermal sensation scale \\
\hline 10 & 2 & General comfort sale \\
\hline 10 & 3 & Thermal comfort scale \\
\hline 10 & 4 & Differences in votes between predicted and actual with use of fan-only and DTAC units \\
\hline 10 & 5 & Current experiment (Law) compared with the sample size of similar studies. \\
\hline 10 & 6 & How T-globe can be predicted with very good accuracy from T-air \\
\hline 10 & 7 & Example design criteria for spaces in various types of buildings \\
\hline 10 & 8 & Thermal sensation scale \\
\hline 10 & 9 & Thermal comfort scale \\
\hline 10 & 10 & General comfort scale \\
\hline 10 & 11 & Karolinska Sleepiness Scale \\
\hline 10 & 12 & Fatigue scale \\
\hline 10 & 13 & Feedback on the use of DTAC and opinion of the challenge \\
\hline 10 & 14 & Key to plots \\
\hline 10 & 15 & Rationale for statistical tests used. \\
\hline 10 & 16 & Significance in change in vote after operating DTAC \\
\hline 10 & 17 & One-tail T-test results before and after using DTAC \\
\hline 10 & 18 & Thermal sensation response to use of DTAC in climate chamber \\
\hline 10 & 19 & Conditions that yield a PMV=1.1 \\
\hline 10 & 20 & Thermal sensation response to use of DTAC in climate chamber, corrected for variations in clothing \\
\hline 10 & 21 & Thermal comfort response to use of DTAC in climate chamber \\
\hline 10 & 22 & General (Bedford) comfort response to use of DTAC in climate chamber \\
\hline 10 & 23 & Sleepiness response to use of DTAC in climate chamber \\
\hline 10 & 24 & P-values of paired t-test of cognitive tests \\
\hline 10 & 25 & Summary of Stroops test \\
\hline 10 & 26 & General feedback upon completion of trial \\
\hline 10 & 27 & Evaporative cooling on an adult in conditions of $0.6 \mathrm{clo}, 23.9^{\circ} \mathrm{C}, 50 \% \mathrm{RH}$ \\
\hline 10 & 28 & Nusselt number \\
\hline A1 & 1 & Key measurements and reflection in prototypes Mark-1 to Mark-4 \\
\hline A1 & 2 & Wind velocity readings at various stages in the assembly \\
\hline A1 & 3 & Determination of cooling fin efficiency \\
\hline $\mathrm{A} 1$ & 4 & Conductivity of materials \\
\hline A1 & 5 & Conductivity and thickness of TIM \\
\hline A1 & 6 & TIMs used in the prototypes \\
\hline
\end{tabular}




\begin{tabular}{|c|c|l|}
\hline Chapter & No. & \multicolumn{1}{|c|}{ Description } \\
\hline A1 & 7 & Summary of heat loss quantities \\
\hline A1 & 8 & Conductivity of possible materials for use PCM tank \\
\hline
\end{tabular}




\section{List of Equations}

\begin{tabular}{|c|c|c|c|}
\hline Ch. & No. & Description & Formula \\
\hline 3 & 1 & $\begin{array}{l}\text { Adaptive comfort neutral temperature (Humphreys, } \\
\text { 1975) }\end{array}$ & $T_{\text {neutral }}=2.6+0.831 T_{\text {daily mean outdoor }}$ \\
\hline 3 & 2 & Cooling effect of wind (Szokolay, 2000) & $\Delta T=6 \cdot v_{e}-1.6 \cdot v_{e}^{2}$ \\
\hline 3 & 3 & Mental Effort & Mental Effort $=\left|M M-Q_{c}\right| \times \frac{f_{s}}{f_{m}}$ \\
\hline 3 & 4 & Thermic effect of food (Kinney, 1992) & $T E E=B M R+T E F+A C T$ \\
\hline 4 & 1 & Deep brain temperature (Karbowski, 2009) & $T_{\text {deep brain }} \approx T_{b l}+\frac{P_{A T P}}{\rho_{b l^{c} b l} U_{b r} C B F}$ \\
\hline 4 & 2 & Energy released by ATP (Karbowski, 2009) & $P_{A T P} \approx 31 F U_{g}\left(3 V_{N a}-2 V_{K}-V_{o}\right) C M R_{g l u}$ \\
\hline 4 & 3 & Body T in cold environments (Gisolfi, 2000) & $T_{\text {body }}=0.6 \cdot T_{\text {core }}+0.4 \cdot T_{\text {skin }}$ \\
\hline 4 & 4 & Body T in warm environments (Gisolfi, 2000) & $T_{\text {body }}=0.8 \cdot T_{\text {core }}+0.2 \cdot T_{\text {skin }}$ \\
\hline 4 & 5 & Mean skin T (Mitchell, 1969) & $T_{\text {mean skin }}=c_{1} T_{1}+c_{2} T_{2}+\ldots+c_{n} T_{n}$ \\
\hline 5 & 1 & Water activity (Kowalski, 2005) & $A w=\frac{p}{p_{0}}$ \\
\hline 5 & 2 & Operative temperature (ASHRAE 55) & $T_{\text {operative }}=A \cdot T_{\text {air }}+(1-A) \cdot M R T$ \\
\hline 5 & 3 & Draft rate (ASHRAE 55) & $D R=\left(\left(34-T_{a} \times[v-0.05]^{0.62}\right) \times(0.37 \cdot v \cdot T u+3.14)\right.$ \\
\hline 7 & 1 & Rain Tower: pump input power & $W_{\text {pump }}=\left(\dot{m}_{1}+\dot{m}_{2}\right) \cdot \Delta P E$ \\
\hline 7 & 2 & Rain Tower: heat absorbed & $Q_{\text {evaporator }}=\dot{m}_{1} \cdot\left(h_{1}-h_{4}\right)$ \\
\hline 7 & 3 & Rain Tower: theoretical COP & $C O P_{\text {theoretical }}=\frac{Q_{\text {evaporator }}}{W_{\text {pump }}}$ \\
\hline 7 & 4 & Rain Tower: net COP & $C O P_{\text {net }}=\eta_{\text {pump }} \cdot \eta_{\text {frictional head loss }} \cdot \eta_{A H U} \cdot$ C.O.P. \\
\hline 8 & 1 & DWAHU: cooling required for trickle flow $100 \%$ fresh air & $\Delta h_{5-6}=39.7 \frac{\mathrm{kJ}}{\mathrm{kg}}$ offresh air \\
\hline 8 & 2 & DWAHU: cooling required for regular flow $20 \%$ fresh air & $\Delta h_{A H U}=5 \times 22.2=111.0 \frac{\mathrm{kJ}}{\mathrm{kg}}$ offresh air \\
\hline 10 & 1 & Effective temperature (ASHRAE 55) & $T_{\text {effective }}=0.5 \cdot T_{\text {air }}+0.5 \cdot M R T$ \\
\hline 10 & 2 & PMV corrected factor & $\triangle P M V=P M V_{1}-P M V_{0}$ \\
\hline 10 & 3 & Normalied thermal sensation vote & Vote $_{\text {TS corrected for clo }}=A M V+\triangle P M V$ \\
\hline 10 & 4 & Complaint and upgrae score computation & Score $=\frac{\sum(\text { count } \times \text { score })}{\sum(\text { count } \times \text { highest score })} \times 10$ \\
\hline 10 & 5 & $\begin{array}{l}\text { Whitaker's correlation for forced convection (Incropera, } \\
\text { 2007) }\end{array}$ & $\overline{N u}=2+\left(0.4 \operatorname{Re}_{D}^{1 / 2}+0.06 \operatorname{Re}_{D}^{2 / 3}\right) \operatorname{Pr}^{0.4}\left(\frac{\mu}{\mu_{s}}\right)^{1 / 4}$ \\
\hline 10 & 6 & $\begin{array}{l}\text { Churchill's correlation for free convection (Incropera, } \\
\text { 2007) }\end{array}$ & $\overline{N u}=2+\frac{0.589 R a_{D}^{1 / 4}}{\left(1+(0.469 / P r)^{9 / 16}\right)^{4 / 9}}$ \\
\hline A1 & 1 & Press force (Laird Technologies, 2010) & $F=\frac{\tau N}{k D}$ \\
\hline A1 & 2 & Fin bypass efficiency (AIRAH DA09, 1998) & $\eta_{\text {bypass }}=1-\frac{T_{s s}-T_{a m b}}{T_{c}-T_{a m b}}$ \\
\hline
\end{tabular}




\begin{tabular}{|c|c|c|c|}
\hline Ch. & No. & Description & Formula \\
\hline A1 & 3 & Temperature difference per micron & $\Delta T / \mu m=\frac{Q}{k \cdot A \cdot 10^{6}}$ \\
\hline A1 & 4 & Heat balance of tank & $q=q_{\text {conv }}+q_{\text {rad }}$ \\
\hline A1 & 5 & Convective heat loss per unit area (Incropera, 2007) & $\frac{q_{\text {conv }}}{A}=h\left(T_{s}-T_{\infty}\right)$ \\
\hline A1 & 6 & Radiant heat loss per unit area (Incropera, 2007) & $\frac{q_{r a d}}{A}=\varepsilon \sigma\left(T_{s}^{4}-T_{s u r}^{4}\right)$ \\
\hline $\mathrm{A} 1$ & 7 & Rayleigh number for flat plate (Incropera, 2007) & $R a_{L}=\frac{g \beta\left(T_{S}-T_{\infty}\right) L^{3}}{\alpha v}$ \\
\hline A1 & 8 & Nusselt number for flat plate (Incropera, 2007) & $N u_{L}=0.68+\frac{0.670 R a_{L}^{1 / 4}}{\left[1+(0.429 / P r)^{9 / 16}\right]^{4 / 9}}$ \\
\hline A1 & 9 & Convective heat transfer coefficient (Incropera, 2007) & $h=\frac{N u_{L} \cdot k}{L}$ \\
\hline A1 & 10 & Convective heat loss per unit area (Incropera, 2007) & $\frac{q_{\text {conv }}}{A}=h\left(T_{S}-T_{\infty}\right)$ \\
\hline A1 & 11 & Radiant heat loss per unit area (Incropera, 2007) & $\frac{q_{r a d}}{A}=\varepsilon \sigma\left(T_{s}^{4}-T_{s u r}^{4}\right)$ \\
\hline
\end{tabular}




\section{Abstract}

In the context of global warming the sum of current trajectories, known as the 'business as usual' scenario, is generally compared unfavourably to alternative low-carbon scenarios. One of these trajectories sees the continuation of an unabated demand for air-conditioning with its inevitable increase in energy consumption. This thesis proposes strategies to ameliorate this problem in the difficult context of a knowledge-based economy in an equatorial climate.

It begins by retracing the emergence of thermal comfort standards in consumer societies, typified by the pursuit of individualistic interests. It identifies a gap that can explain why the scientifically valid adaptive comfort standard has not stemmed the continuous growth in air-conditioning demand, especially in knowledge-based economies. It is proposed that the nexus is brain cooling and while some studies have acknowledged, it has been too complex to quantify in existing comfort models. With the high variability of individual comfort demands, this thesis argues that future provisions of thermal comfort will be achieved by facilitating personal control over the microclimate.

A number of innovations are explored through cycles of action research, and the underlying problems are then crystallised. A successful innovation has to appeal to the business interests of key decision makers, conform to consumer interests of improved thermal comfort and address the need to conserve energy.

This has led to the development of a whole building solution (the Rain Tower), a floor-byfloor approach (a desiccant wheel AHU) and finally, cooling by means of a personal airconditioning system called the Ductless Task Air-Conditioning (DTAC) system. The DTAC technology, meeting the criteria for commercialisation, was subsequently prototyped and its performance measured. Further refinements were made before undertaking a pilot study to field trial the system in naturally ventilated offices and a climate controlled room. The results are analysed statistically to quantify its improvement to sensation and comfort.

Whilst this thesis emerges from an architectural science platform with a primary interest in thermal comfort, it draws on the disciplines of engineering, sociology, physiology and business to frame and propose viable solutions to this complex real world problem.

This thesis studies the behaviours that persist in the business-as-usual scenario and the reasons for the difficulties in changing attitudes. Technologies are then developed to reduce the environmental impact of air-conditioning whilst conforming to current and future expectations of thermal comfort. 
The results of the research demonstrate that thermal comfort, with reduced carbon emissions compared with conventional air-conditioning, can be provided for workers in knowledge-based economies in hot humid equatorial climates.

FOR Codes: 120104, 091505, 120405 


\section{Signed Statement}

This is to certify that:

This thesis contains no material which has been accepted for a degree or diploma by the University or any other institution, except by way of background information and duly acknowledged in the thesis, and to the best of the my knowledge and belief no material previously published or written by another person except where due acknowledgement is made in the text of the thesis, nor does the thesis contain any material that infringes copyright.

Teen-Onn LAW (Tim)

October 2012

\section{Copyright 2012}

This thesis is not to be made available for loan or copying for two years following the date this statement was signed. Following that time the thesis may be made available for loan and limited copying and communication in accordance with the Copyright Act 1968.

The publishers of the papers comprising Chapter 3 (ANZASCA) and Chapter 9 (ASHRAE) hold the copyright for that content, and access to the material should be sought from the respective journals. The remaining non published content of the thesis may be made available for loan and limited copying and communication in accordance with the Copyright Act 1968.

The research associated with this thesis abides by the international and Australian codes on human and animal experimentation, the guidelines by the Australian Government's Office of the Gene Technology Regulator and the rulings of the Safety, Ethics and Institutional Biosafety Committees of the University. 


\section{Acknowledgements}

I didn't fail ten thousand times. I successfully eliminated, ten thousand times, materials and combinations which wouldn't work.

Thomas Edison (1847-1931)

This work began under the label of Novel Cooling Systems. However, the term 'novel' in academia often carries a perjorative undertone, with a real likelihood that the entire candidature could be spent proving what could not possibly work, like Edison's ten thousand 'failed' attempts. In this high-risk, high-reward venture, it is of the Lord's mercies that I have emerged with some success, and a number of people need to be thankfully acknowledged for being blessings to me.

Professor Roger Fay, my primary supervisor (Architecture), for laying such a wager on me. He always had more confidence in my problem-solving abilities than I held in my own estimation, and many times it rubbed off on me and became self-fulfilling. His broad knowledge and endless curiosity made every supervisory meeting a brilliant exercise in lateral thinking.

Dr Jane Sargison, who co-supervised this project (Engineering) was mechanical engineer extraordinaire, after all she was Australian Professional Engineer of the Year 2011. Her openness to inter-disciplinary work was exceptional and crucial to the validation of the innovations.

Mr Steven Banbury, building mechanical engineering consultant, for many enlightening insights to the practice and for being my sounding board as a representative of industry.

Dr Des Fitzgerald (Maths) for his valued statistical help. Dr Catriona McLeod (Landscape Architecture), my esteemed non-technical reader, whose passion for clarity ensured that I communicated plainly.

Professor Michael Davis (Engineering), who stood in for Jane during her maternity leave, initiated me to key engineering concepts and gave a stern warning, 'If you try to violate the second law of thermodynamics, you can be sure it will resist you.' I have since steered clear of Maxwell's demon.

My fellow building technology geeks Justin Beall and Dr Mark Dewsbury, for the generous sharing of their profound knowledge, and endlessly fruitful discussions on building science. 
Special thanks to Mark my long-suffering mate for accommodating my horrific mess as I experimented in our shared office.

Professor Paddy Nixon, DVC (Research), the Graduate Research Office and the Research Office and Commercialisation Unit for generously backing the research through the Elite Research Scholarship and commercialisation efforts through the University Commercialisation Seed Fund. The notion of commercialisation would not have entered my mind without their vision. Uniquest staff David Israel, Dr Robin Fieldhouse and Mary Frey, for showing me the ropes in commercialisation and saving me from committing countless mistakes.

The Department of Innovation, Industry, Science, Research and Tertiary Education, for the Commercialisation Australia Skills and Knowledge Grant, without which the ideas could not progress beyond academia into the 'real' world.

The School of Architecture and Design, headed by Professor Stephen Loo, for funding the first prototype. This and subsequent prototypes were developed with much assistance from the workshop staff Bruce Nye, Robin Green and John Lillywhite. The staff and students from the school who volunteered for the field trials, are affectionately remembered who have hazarded their comfort in the name of science. Fifth year students Jerry Lee and Crissida Wong for their beautiful visualisation work.

Finally, and most affectionately, my lovely wife Juan who left friends and family in Singapore to be here with me so I could pursue my studies. Her tireless support and unconditional love are tokens of the Lord's daily goodness. My lovely children Earnest, Verity and Constance, for understanding why Daddy could not spend as much time with them as I would have loved to. And to Mummy, who made the many sacrifices only a mother could.

And to the many more names I have not mentioned but whose remembrance fragrance the garden of my memory palace, thank you all so very much. 


\section{Introduction}

... we need something like a $90 \%$ reduction in national consumption. Nothing remotely like this is possible within a consumer-capitalist society committed to affluent lifestyles and limitless economic growth.

Renewable Energy Cannot Sustain a Consumer Society (Trainer, 2007, p.117)

There is general recognition that the lifestyle in developed countries, typified by high levels of consumption and emissions, are not sustainable. In this multi-faceted problem, this thesis attempts to solve one part of the problem: the demand for thermal comfort in affluent tropical cities.

Admittedly, problem-solving is not a common approach for a doctoral thesis. Nevertheless we must recognise that academic research methods are integral to any viable solution, and keeps academia relevant to the challenges of our time. In the context of poverty, disease and global warming, Richard Levins, President of Yale University said, "The fate of the planet depends on our ability ... to solve society's most pressing problems." (Gallagher, 2011) For the core of these challenges to be properly understood, insights from other disciplines are always enriching, and often invaluable. Inter-disciplinary work is also necessary to validate any emergent solutions. Hence, whilst this thesis emerges from an architectural science platform with a primary interest in thermal comfort, it draws on a number of other disciplines to frame and resolve this complex problem:

1. Engineering: to validate the thermodynamic performance of innovations

2. Sociology: to describe behavioural attitudes to thermal comfort and predict future trends

3. Physiology: to understand the thermal regulation of the active brain under stressful conditions

4. Business: to identify market opportunities and business angles 
Inventiveness, is however not a discipline in its own right, but more of an attitude to a problem, an attitude underpinning many chapters in this thesis. Innovation is not a linear process, though neither is it haphazard. Many times, the innovation-critique process is run as thought experiments and I have restyled the writing as the first person, and at times as a dialectic with myself. 'Don't walk around the yard talking to yourself, the neighbour will think you're mad,' my wife often told me. Whilst this reflexive style is unconventional to a scientific thesis, it is the most honest account of the genesis of ideas, the self-dialoguing madness of the mad inventor. It is through these series of self-reflections that the research questions and hypotheses emerge as part of the narrative of this thesis, and are eventually encapsulated into a design brief.

To synthesise the disparate fields of study, a (Hegelian) dialectic approach has been found to be useful to discuss opinions and resolve contradictions. This will be presented as a series of catechetical reflections along the main narrative. For example:

\section{Q Why is there a need for Q\&A?}

A The main thread of thought is carried in the narrative of the thesis. However there are many ancillary arguments, which when entered into detail will change the trajectory of the narrative. The arguments are nonetheless necessary to complete a complex picture by taking a short and distinct digression before returning to the narrative. By keeping the main arguments separate from augmented ones the train of thought can be clearer.

\section{Q How are the Q\&As structured differently from the narrative?}

A The flow of logic in the Q\&A's is such that each question relates to the next, whilst the answers can be drawn from diverse disciplines. In contradistinction, the main narrative is like a series of arguments that lead to each other. 
Q Why not use footnotes/endnotes?

A Whilst footnotes are useful in carrying supplementary information, some of these are vital to developing the argument and need to be read alongside the main text. By allowing a conversation as a Q\&A forum, I can ensure these notes contribute to the fuller picture.

This thesis is broadly structured as theory (chapters 2-5), methodology (chapter 6), innovation (chapters 7-9) and development (chapters 10-12) as seen in figure 1.1.

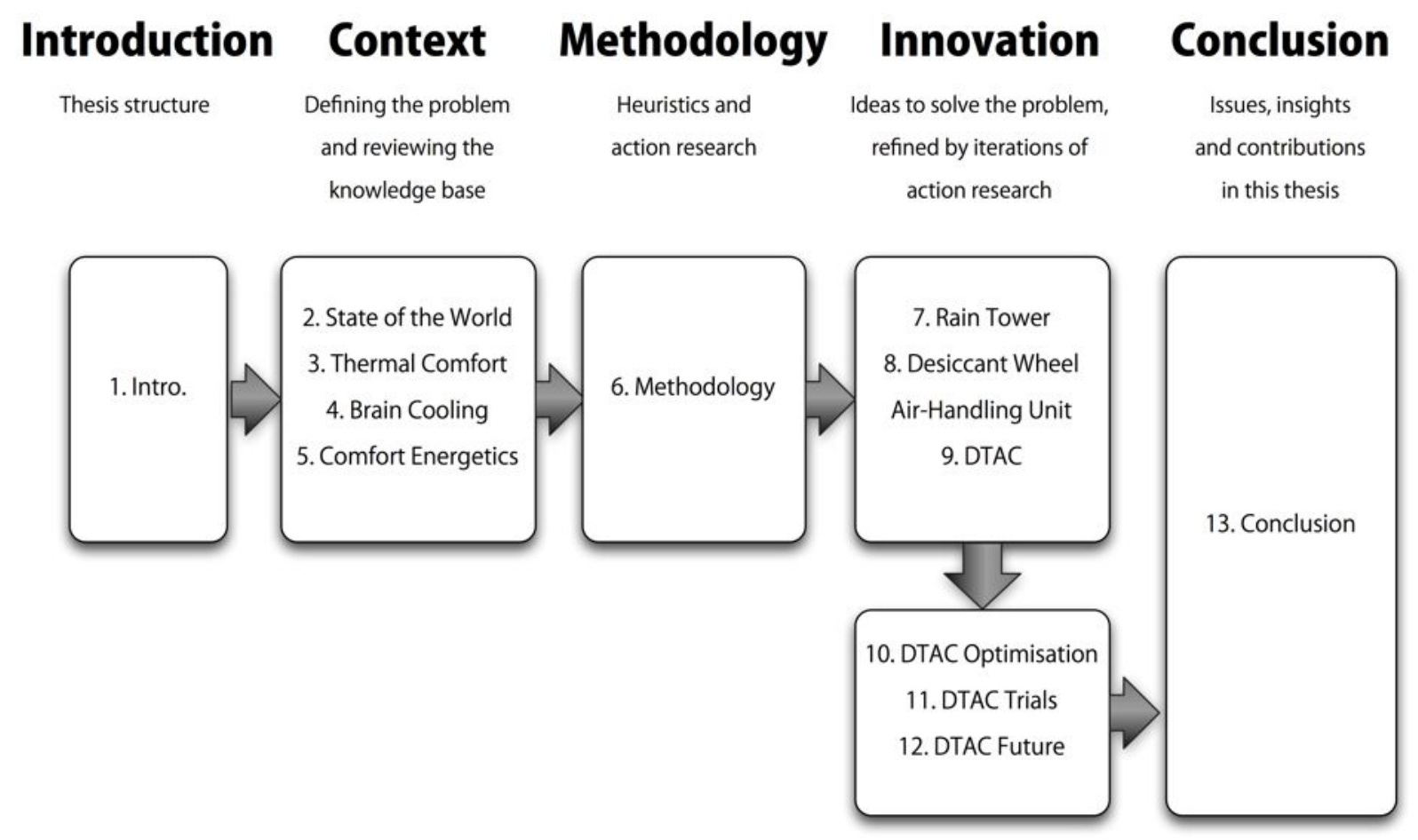

Figure 1.1: Structure of chapters in this thesis

Chapter 2 introduces the context of the problem: the majority consensus on climate change and the role of buildings in mitigating $\mathrm{CO}_{2}$ emissions. The role of air-conditioning in this problem is identified in its energy demands amidst the constraints of energy and environment.

Chapter 3 reviews the positions taken in deterministic and adaptive thermal comfort and offers a way to synthesise the apparently conflicting findings of both positions. The factors that impinge on perceptions of comfort are expanded beyond the building sciences to 
involve marketing and sociology to explain the contradictions in thermal comfort research and consumer behaviour. The definition of thermal comfort is revisited and the premise and consequence of such a definition is enjoined, giving an indication of where the future of thermal comfort will be taken.

Chapter 4 discusses the physiology of stress and brain cooling. A convergence is sought between thermal comfort, real-life work stress, sleep and other considerations that affect mental performance in an office environment. The importance of facial cooling is established here.

Chapter 5 introduces a new evaluation metric for comparing cooling efficacy with energy demands. Called comfort energetics, multiple ways of improving a thermal sensation vote are denominated by the energy required for improving votes in each process. Dehumidification shows up poorly in its comfort energetics and the need for controlling humidity is investigated at length, with a case made for ignoring the recommended optimum relative humidity range.

Chapter 6 explains why this thesis is methodologically different from the conventional. The role of heuristics, or problem-solving approach, is clarified. Criteria are set for the evaluation of the innovations which follow.

Chapter 7 begins the problem solving process through a design brief iterated through action research. The first innovation of the Rain Tower is explained and modelled, the challenges to realising such a scheme are enumerated, and the need for a solution that can be commercialised are established with case studies.

Chapter 8 introduces the business dimension into the innovation process and an early warning appraisal to decisively curb potentially futile efforts. The significance of intellectual property and its centrality to the innovation-investment relationship is established with a case study.

Chapter 9 proposes the final innovation that met all the required criteria of improved thermal comfort, energy savings and commercial potential. The Ductless Task AirConditioning (DTAC) is built on the premise of task-ambient conditioning (TAC) systems 
with an improvement in being implementable without renovations. The key operating principles and proof-of-concept experiments are explained.

Chapter 10 explains the methodology of the DTAC field trials in both naturally ventilated and climate chamber work spaces, and discusses the results of the experiment.

Chapter 11 projects the planned future of DTAC, especially in the areas of indoor air-quality improvement, and recommendations for future thermal comfort research.

Chapter 12 concludes the thesis with a short recapitulation.

The main objectives of this present work are:

1. To study how the debate between deterministic and adaptive thermal comfort models can be resolved with insights from other disciplines, particularly sociology and physiology.

2. To study how cooling comfort can be quantified by the energy efficiency and cooling efficacy.

3. To develop technologies that can reduce the energy consumption of airconditioning and be widely adopted in a consumer society.

One of the most inventive minds, Nikola Tesla, maintains in his autobiography that,

The progressive development of man is vitally dependent on invention. It is the most important product of his creative brain. Its ultimate purpose is the complete mastery of mind over the material world, the harnessing of the forces of nature to human needs. This is the difficult task of the inventor who is often misunderstood and unrewarded. But he finds ample compensation in the pleasing exercises of his powers and in the knowledge of being one of that exceptionally privileged class without whom the race would have long ago perished in the bitter struggle against pitiless elements. (Tesla, 1919, p.1)

It is the pursuit of human comfort in tropical indoor climates, accompanied by a sense of environmental stewardship, that underpins this undertaking. 
I invite you to join me on my journey, and from hence, the term we will refer to you, my reader, and $\mathrm{I}$. 


\section{The State of the World}

In the fourth assessment report of the UN Intergovernmental Panel for Climate Change (IPCC), the robust finding (defined as that which 'holds under a variety of approaches, methods, models and assumptions, and is expected to be relatively unaffected by uncertainties' (IPCC, 2007, AR4 SYR - Topic 6)) was that 'warming of the climate system is unequivocal,' and that 'most of the global average warming over the past 50 years is very likely due to anthropogenic GHG increases' (IPCC, 2007, AR4, 6.1). The IPCC also identified the building industry as the one with the most climate mitigation potential (table 2.1). When Time Magazine (Kluger, 2007) ran a special feature called The Global Warming Survival Guide, buildings accounted for the largest share of U.S. emissions, noting that:

While the power and auto industries get the bulk of the blame for the planet's carbon crisis, the business of operating office buildings and homes is responsible for $38 \%$ of U.S. CO2 emissions. In the case of offices, mid-20th century technology worked against us, as the development of low-temperature fluorescent lights and high-powered air conditioning made it possible to design sealed structures that you could drop into any climate. "It gave architects the power to design anything, then hand it over to engineers and say, 'Here, you heat and cool it,"' says Gail Brager of the Center for the Built Environment at the University of California, Berkeley.

\begin{tabular}{|l|c|}
\hline & Gt CO2-eq-yr \\
\hline Buildings & $5.3-6.7$ \\
\hline Agriculture & $2.3-6.4$ \\
\hline Industry & $2.5-5.5$ \\
\hline Energy Supply & $2.4-4.7$ \\
\hline Forestry & $1.3-4.2$ \\
\hline Transport & $1.6-2.5$ \\
\hline Waste & $0.4-1$ \\
\hline
\end{tabular}

Table 2.1: Economic Mitigation Potential in 2030 (IPCC, 2007)

Politicians on the other hand have had little will to commit to the recommended $\mathrm{CO}_{2}$ abatement measures. With the 20-year long history of UN Climate Change Conferences (table 2.2), it has become clear that an environmental imperative was not enough to demand a political response when the immediate economic costs were too high. 


\begin{tabular}{|c|l|c|l|}
\hline Year & \multicolumn{1}{|c|}{ Conference } & $\begin{array}{c}\text { Atmospheric } \\
\text { CO2 } \\
\text { concentration }\end{array}$ & Mitigation outcomes \\
\hline 1992 & Earth Summit, Rio de Janeiro & $356 \mathrm{ppm}$ & to cut CO2 to 1990 levels by 2000 \\
\hline 1995 & $\begin{array}{l}\text { 'Conference of the parties' COP1, } \\
\text { Berlin }\end{array}$ & $361 \mathrm{ppm}$ & \\
\hline 1996 & COP2, Geneva & $363 \mathrm{ppm}$ & \\
\hline 1997 & COP3, Kyoto & $364 \mathrm{ppm}$ & $\begin{array}{l}\text { Kyoto Protocol: to cut CO2 to 5.2\% below 1990 levels by } \\
2012\end{array}$ \\
\hline 1998 & COP4, Buenos Aires & $367 \mathrm{ppm}$ & \\
\hline 1999 & COP5, Bonn & $368 \mathrm{ppm}$ & \\
\hline 2000 & COP6, The Hague & $370 \mathrm{ppm}$ & \\
\hline 2001 & $\begin{array}{l}\text { COP6 (extraordinary conference), } \\
\text { Bonn }\end{array}$ & $371 \mathrm{ppm}$ & \\
\hline 2001 & COP7, Marrakesh & $371 \mathrm{ppm}$ & \\
\hline 2002 & COP8, Delhi & $373 \mathrm{ppm}$ & \\
\hline 2003 & COP9, Milan & $376 \mathrm{ppm}$ & \\
\hline 2004 & COP10, Buenos Aires & $377 \mathrm{ppm}$ & \\
\hline 2005 & COP11, Montreal & $380 \mathrm{ppm}$ & \\
\hline 2006 & COP12, Nairobi & $382 \mathrm{ppm}$ & \\
\hline 2007 & COP13, Bali & $384 \mathrm{ppm}$ & \\
\hline 2008 & COP14, Poznan & $386 \mathrm{ppm}$ & \\
\hline 2009 & COP15, Copenhagen & $390 \mathrm{ppm}$ & \\
\hline 2010 & COP16, Cancun & Copenhagen Accord had no legally binding commitments \\
\hline 2011 & COP17, South Africa & \\
\hline
\end{tabular}

Table 2.2: History of Climate Change Policy (Umashankar et. al., 2009), mitigation outcomes (Lomborg, 2010) and $\mathrm{CO}_{2}$ ppm (NOAA, 2012).

Since preindustrial times, the $\mathrm{CO}_{2}$ emissions have increased by 'about $36 \%$, with the rate of increase being about 2 ppm per year and still increasing' (Bolin, 2007, p.215). The lack of political will is even more stark when considered against the availability of technologies and plans for $\mathrm{CO}_{2}$ mitigation. Pacala \& Socolow (2004) explained the need to stabilise carbon emissions at present levels, which require substituting the business as usual (BAU) industries with existing sustainable technologies. Their multi-faceted approach is construed as an aggregate of wedges. Each wedge accounts for a reduction of 1 billion tons of carbon per year (figure 2.1 and table 2.3). In 2004 when the paper was first published, it was anticipated seven wedges would be needed for stabilisation; and in 2011, it was increased to nine wedges, and would have resulted in $\sim 0.5^{\circ} \mathrm{C}$ higher stabilisation in temperature compared to 2004 (Socolow, 2011). Further delays to act will only exacerbate an already monumental effort for transformation. 


\section{This Figure has been removed for copyright or proprietary reasons}

Figure 2.1: Stabilisation wedges (Socolow, 2004)

\begin{tabular}{|l|l|l|l|}
\hline \multicolumn{1}{|c|}{$\begin{array}{c}\text { Efficiency And } \\
\text { Conservation }\end{array}$} & \multicolumn{1}{|c|}{ Carbon Capture And Storage } & \multicolumn{1}{c|}{ Low-Carbon Fuels } & \multicolumn{1}{c|}{ Renewables and Biostorage } \\
\hline $\begin{array}{l}\text { Improve fuel economy of the } \\
\text { two billion cars expected on } \\
\text { the road by } 2057 \text { to } 60 \mathrm{mpg} \\
\text { from } 30 \mathrm{mpg} .\end{array}$ & $\begin{array}{l}\text { Introduce systems to capture CO2 } \\
\text { and store it underground at } 800 \text { large } \\
\text { coal-fired plants or 1,600 natural-gas- } \\
\text { fired plants. }\end{array}$ & $\begin{array}{l}\text { Replace 1,400 large coal- } \\
\text { fired power plants with } \\
\text { natural-gas-fired plants. }\end{array}$ & $\begin{array}{l}\text { Increase wind-generated power to 25 } \\
\text { times current capacity. }\end{array}$ \\
\hline $\begin{array}{l}\text { Reduce miles traveled annually } \\
\text { per car from 10,000 to 5,000. }\end{array}$ & $\begin{array}{l}\text { Use capture systems at coal-derived } \\
\text { hydrogen plants producing fuel for a a } \\
\text { billion cars. }\end{array}$ & $\begin{array}{l}\text { Displace coal by increasing } \\
\text { production of nuclear } \\
\text { power to three times } \\
\text { today's capacity. }\end{array}$ & $\begin{array}{l}\text { Increase solar power to 700 times } \\
\text { current capacity. }\end{array}$ \\
\hline $\begin{array}{l}\text { Increase efficiency in heating, } \\
\text { cooling, lighting, and } \\
\text { appliances by 25 percent. }\end{array}$ & $\begin{array}{l}\text { Use capture systems in coal- derived } \\
\text { synthetic fuel plants producing 30 } \\
\text { million barrels a day. }\end{array}$ & $\begin{array}{l}\text { Increase wind power to 50 times } \\
\text { current capacity to make hydrogen for } \\
\text { fuel-cell cars. }\end{array}$ \\
\hline $\begin{array}{l}\text { Improve coal-fired power plant } \\
\text { efficiency to } 60 \text { percent from } \\
40 \text { percent. }\end{array}$ & $\begin{array}{l}\text { Increase ethanol biofuel production to } \\
\text { 50 times current capacity. About one- } \\
\text { sixth of the world's cropland would be } \\
\text { needed. }\end{array}$ \\
\hline & & & \begin{tabular}{l} 
Stop all deforestation. \\
\hline cropland conservation tillage to all \\
carbon by speeding decomposition of \\
organic matter).
\end{tabular} \\
\hline
\end{tabular}

Table 2.3: Examples of how to achieve a stabilisation wedge (Socolow \&

Pacala, in National Geographic Magazine, 2007)

By looking at the whole mosaic of stabilisation solutions we see that the energy problem is twofold: a lack of economically competitive renewable energy, and a lack of distribution capacity.

At its core, the global rise in living standards demand an increasing amount of energy to power modern conveniences. As long as renewables cost more than fossil-based energy, any measure to reduce carbon emission inevitably increases the affordability of a high standard of living. Developing economies are understandably resistant to any such commitment. However, even if renewables can be cost competitive it does not automatically ensure better 
living standards. The problem of energy is not merely one of generation but of distribution as well. For example, the wholesale supply of nuclear electricity in the U.S. is $31 \%$ of the meter price, with $69 \%$ of the cost in transmission, distribution and management (Rosenfeld, 1999). Rolling blackouts in developed economies illustrate both these problems combined: limited power generation capacity and inadequate transmission infrastructure.

In this regard, energy conservation solves both problems - it frees up capacity in both power generation and transmission. To be viable it also must be done in a way that does not compromise affluence. However it must be also noted that conservation has no media appeal, no star status, no poster boy. Thus Rosenfeld goes on to say:

That makes it hard to convince most people that, for any given year in the foreseeable future, it will be cheaper and cleaner to improve efficiency by a few percent than to increase supply by the same amount. Give a congressman the choice of funding energy supply or energy efficiency, and he will go for supply almost every time. (Rosenfeld, 1999, p.57)

\subsection{Singapore as a reference city}

Singapore can be seen as the archetypal nation-city which transformed from third to first world status in a few decades. Without any natural resources for primary industries, Singapore's only recourse has been to rely on human resource. To capitalise on this resource, Singapore has always striven for a high education standard and a workforce that was industrious and productive. How did this happen in a hot and humid climate?

Writing in the May 1929 inaugural issue of Heating, Piping \& Air-Conditioning, Willis Carrier had been confident about air-conditioning's present and expressed buoyant optimism regarding its future. He imagined windowless office skyscrapers free of noise and dust and predicted air-conditioned comfort in the homes of average Americans as well as the wealthy. The air-conditioning industry could take credit, said Carrier, for the "present-day prosperity of the people of these United States." Its growth, he predicted, would be geometric. (Ackerman, 2002, p.79)

This vision became reality in the knowledge-based economy of Singapore. The founding Prime Minister, Lee Kuan Yew, named the air-conditioner as the most significant innovation of the millennium, saying: 
The humble air conditioner has changed the lives of people in the tropical regions. Before air-con, mental concentration and with it the quality of work deteriorated as the day got hotter and more humid. After lunch, business in many tropical countries stopped until the cooler hours of the late afternoon. Historically, advanced civilizations have flourished in the cooler climates. Now lifestyles have become comparable to those in temperate zones and civilization in the tropical zones need no longer lag behind. (Lee Kuan Yew, in Wall Street Journal, 1999)

Interestingly, Lee's style of governance created a climate that journalist Cherian (2000) described as politically stifling as an artificial climate, saying:

So, think of Singapore instead as the Air-conditioned Nation — a society with a unique blend of comfort and central control, where people have mastered their environment, but at the cost of individual autonomy, and at the risk of unsustainability.

Over $70 \%$ of the workforce is estimated to work in offices in Singapore (see table 2.4) and over $80 \%$ in the UK (CIBSE, 1999).

\begin{tabular}{|l|c|c|c|}
\hline \multicolumn{1}{|c|}{ Occupation } & $\begin{array}{c}2010 \text { employed } \\
\text { (thousands) }\end{array}$ & Office Utilisation (lower) & Office Utilisation (upper) \\
\hline Legislators, Senior Officials \& Managers & 335.2 & 335.2 & 335.2 \\
\hline Professionals & 312.6 & 312.6 & 312.6 \\
\hline Technicians \& Associate Professionals & 373.4 & 373.4 & 373.4 \\
\hline Clerical Workers & 240.5 & 240.5 & 240.5 \\
\hline Service \& Sales Workers & 246.4 & 123.2 & 172.48 \\
\hline Production Craftsmen \& Related Workers & 86.5 & 8.65 & 17.3 \\
\hline Plant \& Machine Operators \& Assemblers & 154.2 & 15.42 & 30.84 \\
\hline Cleaners, Labourers \& Related Workers & 145.5 & 14.55 & 29.1 \\
\hline Others & 68.7 & 0 & 13.74 \\
\hline & 1962.9 & 1423.52 & 1525.16 \\
\hline & & $72.52 \%$ & $77.70 \%$ \\
\hline
\end{tabular}

Table 2.4: Singapore resident employment in 2010 by occupation. "Office utilisation" are author's own estimates based on observation. Legislators, Senior Officials \& Managers (100\%); Professionals (100\%); Technicians \& Associate Professionals (100\%); Clerical Workers (100\%); Service \& Sales Workers (50-70\%); Production Craftsmen \& Related Workers (10-20\%); Plant \& Machine Operators \& Assemblers (10-20\%); Cleaners, Labourers \& Related Workers (10-20\%); Others (0-20\%). Employment statistics from "Statistics Singapore - Yearbook of Statistics, 2011" (Singapore Department of Statistics, 2011) (www.singstat.gov.sg/pubn/reference/yos11/statsT-labour.pdf).

For the purpose of this thesis the context for air-conditioning is confined to that for offices located in hot and humid climates. 


\section{Environmental impact of air-conditioning}

The environmental impacts of air-conditioners are two-fold: direct emissions via leakage of high global-warming potential (GWP) refrigerants, and indirect $\mathrm{CO}_{2}$ emissions via the power needed to drive the air-conditioning and mechanical ventilation (ACMV) systems derived from fossil-fuel power stations.

\section{Environmental impact of refrigerants}

The refrigerants used in air-conditioning have tremendous global warming potential (GWP). Stated in terms of carbon dioxide's GWP, or $\mathrm{CO}_{2}$-e, $\mathrm{CFC}$ (chloroflurocarbon) refrigerants have an extremely high GWP of 4,000-119,000 $\mathrm{CO}_{2}$-e. Under the Montreal Protocol, ozone depleting CFC refrigerants have already been phased out, and the less active HCFC (hydrochlorofluorocarbons) will be phased out by 2030. However, even with refrigerants that have no ozone depleting potential (also referred to as Kyoto Protocol synthetic gases), the GWP ranges between 1300 (R134a) to 3900 (R507) (Australian Fluorocarbon Council, 2001).

Globally, the various greenhouse gases responsible for radiative forcing up to 2006 are (Australian Refrigeration Council, 2011):

- $\mathrm{CO}_{2}: 61 \%$

- $\mathrm{CH} 4,22 \%$

- Montreal protocol gases (largely CFCs): $10 \%$

- $\mathrm{N} 2 \mathrm{O}, 6 \%$

- Kyoto protocol synthetic gases (largely HFCs): $<1 \%$

Refrigerants thus form a small but significant part of the global warming contribution. The successful phasing out of CFCs under the Montreal protocol bolsters a degree of confidence that the HCFCs will likely be well under control by the target dates. The remaining Kyoto protocol synthetic gases whilst insignificant now will increasingly be an issue as these refrigerants replace those that have been phased out, and as the air-conditioning market continues to grow. Australia's growth in the decade 1995-2006 was by a factor of 2.5 times (see figure 2.2. Wilkenfeld, 2006) . 
This Figure has been removed for copyright or proprietary reasons

Figure 2.2: Share of Australian households with air conditioning or evaporative cooling - historical and projected (Wilkenfeld, 2006)

\section{Environmental impact of air-conditioning power}

Air-conditioning accounts for the largest share of building operational energy. In tropical cities like Singapore, it accounts for about $50 \%$ of the system energy usage intensity in offices (table 2.5). In the Australian commercial sector it typically accounts for $30-40 \%$ of summer maximum energy demand (Wilkenfeld, 2006).

\begin{tabular}{|l|c|c|c|}
\hline & Class A & Class B & Class C \\
\hline \multicolumn{1}{|c|}{ Percentile Rating (\%) } & 25th & 50th & 75th \\
\hline Air-conditioning & $82(44 \%)$ & $132(50 \%)$ & $144(46 \%)$ \\
\hline Mechanical Ventilation & $23(12 \%)$ & $36(14 \%)$ & $51(16 \%)$ \\
\hline Lighting & $24(13 \%)$ & $28(11 \%)$ & $32(10 \%)$ \\
\hline Lift \& Escalator & $11(6 \%)$ & $16(6 \%)$ & $23(7 \%)$ \\
\hline Others & $47(25 \%)$ & $53(20 \%)$ & $61(20 \%)$ \\
\hline Total (system) kWh/sqm/yr & 187 & 265 & 311 \\
\hline
\end{tabular}

Table 2.5: System Energy Usage Intensity (SEUI, kWh/sqm/y) of offices in Singapore http://www.esu.com.sg

When the costs of abatement measures are compared to the tariffs on $\mathrm{CO}_{2}$-e emissions, upgrading to more efficient air-conditioning becomes very attractive. As an abatement measure, more efficient air-conditioning gives one of the best returns for the capital outlay, coming behind building insulation, improved efficiency in commercial vehicles and more efficienct lighting systems (figure 2.3). 
This Figure has been removed for copyright or proprietary reasons

Figure 2.3: McKinsey Curve (McKinsey and associates, 2007)

\subsection{The role of Air-conditioning in a changed climate}

With global warming, the number of hot days associated with heat related injuries will be more frequent annually, together with more record highs (right end tail of figure 2.4). CSIRO projections of the number of days in excess of $35^{\circ} \mathrm{C}$ (table 2.6) show that heat waves are likely to be longer lasting. Nicholls et. al. (2007) have discovered a trend in Melbourne's mortality rate anomaly which became substantially increased once mean temperatures exceeded $28^{\circ} \mathrm{C}$, and proposed a warning based on these criteria:

If at any time during the forecast period the average of the predicted maximum temperature on one day and the predicted minimum temperature for the following morning exceeds $30^{\circ} \mathrm{C}$, a heat alert could be issued to the public and/or local authorities, ambulance services and other health and welfare organizations. The heat alert would indicate likely increases in mortality in the 24-h period following the high temperatures. 


\title{
This Figure has been removed for copyright or proprietary reasons
}

\author{
Figure 2.4: Relationship between means and extremes, when extreme events \\ are defined as some fixed threshold related to a significant impact (e.g. \\ heatwave leading to excess deaths). (Australian Department of Climate \\ Change and Energy Efficiency, 2011)
}

\begin{tabular}{|l|c|c|c|c|}
\hline & 2008 & 2030 & 2070 & 2100 \\
\hline Melbourne & 9 & 12 & 21 & 27 \\
\hline Sydney & 3.3 & 4.4 & 9 & 14 \\
\hline Brisbane & 0.9 & 1.7 & 8 & 21 \\
\hline Adelaide & 17 & 22 & 34 & 44 \\
\hline Perth & 27 & 35 & 56 & 72 \\
\hline Canberra & 5 & 8 & 21 & 32 \\
\hline Darwin & 9 & 36 & 221 & 312 \\
\hline Hobart & 1.4 & 1.7 & 2.5 & 3.4 \\
\hline
\end{tabular}

Table 2.6: Projected number of days over $35^{\circ} \mathrm{C}$ in Australian capital cities. (Hughes \& McMichael, 2011)

Where a warmer climate will have an impact on physical and mental health, the most vulnerable, according to Lesley Hughes, co-author of Australia's Climate Commission Report, are 'the elderly, those with existing heart and kidney disease, children, people in remote communities and ... any outdoor workers.' (ABC News, 2011)

Or in other words, those who are not typically in an air-conditioned environment.

As a matter of health, or even life and death, there will be an increasing demand for airconditioning. The heatwave in France in 2006 had lower mortality levels than the previous one in 2003. A meteorologist commented this was particularly due to one aspect of the government's National Heat Wave Plan: 
It is worth mentioning here, that air conditioning can allow people to continue to work effectively in hot weather and undoubtedly lessens heat stress, thus protecting susceptible sections of the population throughout a heat wave. (Tan, 2008)

Air-conditioning will remain both a cause and arbiter of the climate change problem for the immediate future. The logical step then is to see how air-conditioning can deliver cooling with minimal impact to the environment.

\subsection{A New Paradigm of Thermal Comfort}

... the main antagonist of rooted culture is the ubiquitous air-conditioner. Wherever they occur, the fixed window and the air-conditioner are mutually indicative of domination by universal technique. (Kenneth Frampton, in Foster, 1983, p.27)

If the only problem with air-conditioning was the mindless adoption of the international style, we would have little to fear in terms of its environmental consequences. There are a select few who would take issue with air-conditioning per se, like Prins (1992) who saw airconditioning both as an evil in itself and as a tool for capitalistic domination. These are threads of research in and of themselves, and are not the focus of this thesis.

Rather, this work is concerned with the energy intensity of the over reliance on airconditioning. Air-conditioning, as we will see, contributes to workplace productivity in a way that cannot be casually dismissed. It is the excessiveness of air-conditioning and the over-reliance on it that becomes problematic. More importantly, the crux of the matter is the intensiveness of energy demanded by air-conditioning in a world that is now struggling to resource it. If air-conditioning could be supplied affordably and sustainably, it would hardly attract contempt, with too few ills to outweigh its benefits.

Thermal comfort studies have long been established and underpin mandatory building construction, operation and maintenance standards. However, today the standards for temperature and humidity control need to be interrogated in the context of energy limitations. In returning to first principles we enquire if the understanding of thermal comfort is adequately covered with the use of a sensation scale. Particular attention is given to explain the difference between the deterministic and adaptive thermal comfort models. Does comfort in a naturally ventilated office with fans have the same quality as comfort in 
an air-conditioned one? How can these differences be reconciled without disregarding the validity of decades of rigorous studies? I will postulate an explanation from disciplines that have traditionally been outside architectural science. The experimental validation of this theory is however beyond the scope of this thesis.

Any proposed solutions will be evaluated in terms of their engineering efficiency, because the primary aim is to achieve the efficiency and conservation wedge for building operational energy savings. At the same time, the approach cannot be purely academic but needs to be tampered by market realities, because after all, the uptake of an innovation is predicated on there being an improvement to the standard of living. 


\section{This chapter has been removed for copyright or proprietary reasons}

3 Literature Review: Thermal Comfort and Air-Conditioning 


\section{Brain Cooling}

"In the sweat of thy face shalt thou eat bread..."

Genesis 3:19 (King James Version)

In Genesis, the first book of the Bible, the fall of man is recorded and the consequence of labour and death is pronounced. The insights into the facility for brain cooling from eighteenth and nineteenth century commentators is remarkable:

In the sweat of thy face - Though the whole body may be thrown into a profuse sweat, if hard labor be long continued, yet the face or forehead is the first part whence this sweat begins to issue; this is occasioned by the blood being strongly propelled to the brain, partly through stooping, but principally by the strong action of the muscles; in consequence of this the blood vessels about the head become turgid through the great flux of blood, the fibres are relaxed, the pores enlarged, and the sweat or serum poured out. Thus then the very commencement of every man's labor may put him in mind of his sin and its consequences. (Adam Clarke, Commentary on the Whole Bible, 1832)

... it may have regard to all methods and means by which men get their bread, and not without sweat; and even such exercises as depend upon the brain are not excused from such an expense: so that every man, let him be in what station of life he will, is not exempt, more or less, from this sentence, and so continues till he dies. (John Gill, Exposition of the Bible, 1763)

This chapter discusses the role of the brain in productive mental work, where one can expect a high degree of work-related stress and arousal. The diversity of responses and the futility of defining a fixed perfect temperature can only be properly understood with an appreciation of the roles of cranial metabolism, autonomous stress response and braincooling.

Zhang performed extensive tests on the cooling of particular body parts. In her PhD thesis (Zhang, 2003) she wrote: 
We have showed that in general people are happy with a slightly cool head. The cool head helps to keep a cool brain. The reason that people are happy with the breathing zone air cooling and don't like breath warming might be correlated with the fact that breathing zone air is related with selective brain cooling. Cabanac (Cabanac 1997) concluded from human subject tests that upper airway convectiveevaporative heat loss does contribute to cooling the brain.

The need for a cool brain may be self-evident. This does not however explain why comfort, according to the ACS, can be achieved in temperatures much higher than the PMV model. We have earlier alluded to the possible mechanism of mental metabolism and the need for a cooled head to maintain efficient mental processes, and take a deeper look at the relationships between cognitive function, stress and temperature.

\subsection{Heat Stress}

In more extreme conditions, heat stress significantly impairs judgment and performance. Several military studies have been conducted to ascertain its relationship and limits (Manton \& Hendy, 1988, to name one). Hancock (Hancock, 1986; Hancock \& Vasmatzidis, 2003) demonstrated that shifts to deep body temperature had pronounced effects in the performance of complex tasks (vigilance, tracking and multi-tasking). However conditions that can cause perturbation to deep body temperature fall well beyond the comfort scales into thermally stressful regions not typically encountered in the office. Of interest is the region where there is sensible discomfort without disturbing deep body temperature: a region where Hancock found no performance deterioration in his laboratory-based subjects.

If in the normothermic realm (no perturbation to core temperature) there is no performance decrement, then there is good grounds to promote the ACS on the basis that it provides better energy economy for equivalent comfort as air-conditioning. On the other hand if the adaptation to warmth comes with a penalty to performance that cannot be captured in laboratory tests, than this might explain why the market continues to demand air-conditioning, and air-conditioning at a lower T setpoint then the PMV would suggest for optimal comfort.

However in thermal comfort research, the metabolism of occupants has always been based on physical activity. So the mentally active but sedentary office occupant under a mountain of work would be considered no different from a mentally inactive person watching a boring 
program on television. Is this really the case? Work stress exerts an influence on thermal response, regulation and expectation. The magnitude of this effect may be uncertain, but there appears to be a consistent effect on metabolism. We begin by considering the stress response on a person's physiology.

The term 'stress' will refer to emotional or mental strain for this chapter, unless indicated as 'thermal stress' or 'heat stress'.

\subsection{The neurophysiological stress response}

The main difference in the occupants undergoing a climate chamber trial and the field trial will be the mental exertion between a simulated and a real-world task.

What happens when we think?

Neurons have an average firing rate of $1.7 \mathrm{~Hz}$ (Karbowski, 2009) at rest and $20-30 \mathrm{~Hz}$ when stimulated (Siegfried, 2001). The active neurons demand an increased consumption of oxygen and glucose utilisation rate. Karbowski (2009) developed a model to predict brain temperature by looking at the energy released in the consumption of adenosine triphosphate (ATP, the precursor to bio-energy).

$$
T_{\text {deep brain }} \approx T_{b l}+\frac{P_{A T P}}{\rho_{b l} c_{b l} U_{b r} C B F}
$$

Where,

$$
P_{A T P} \approx 31 F U_{g}\left(3 V_{N a}-2 V_{K}-V_{o}\right) C M R_{g l u}
$$




\begin{tabular}{|c|c|c|}
\hline$T_{\text {deep brain }}$ & deep brain temperature & typically $0.1-0.2^{\circ} \mathrm{C}$ higher than $T_{b l}$ \\
\hline$T_{b l}$ & blood temperature & $309.8 K$ \\
\hline$\rho_{b l}$ & blood density & $1.06 \cdot 10^{-3} \mathrm{~kg} / \mathrm{cm}^{3}$ \\
\hline$c_{b l}$ & blood specific heat capacity & $3.8 \cdot 10^{3} \mathrm{~J} /(\mathrm{kg} \mathrm{K})$ \\
\hline$U_{b r}$ & brain volume & $U_{b r}=U_{g}+U_{w}$ \\
\hline$C B F$ & cerebral blood flow & $0.018 U_{b r}^{-0.10} l / s e c$ \\
\hline$U_{g}$ & grey matter volume & $680.0 \mathrm{~cm}^{3}$ \\
\hline$U_{w}$ & white matter volume & $U_{w}=0.166 U_{g}^{1.23} \mathrm{~cm}^{3}$ \\
\hline$F\left(3 V_{N a}-2 V_{K}-V_{o}\right)$ & work done by one mole of ATP & \\
\hline$V_{N a}$ & $\mathrm{Na}^{+}$ion potential & $0.068 \mathrm{~V}$ \\
\hline$V_{K}$ & $\mathrm{~K}^{+}$ion potential & $-0.100 \mathrm{~V}$ \\
\hline$V_{o}$ & resting potential & $-0.067 \mathrm{~V}$ \\
\hline$C M R_{g l u}$ & glucose cerebral metabolic rate & $5.7 \cdot 10^{-9} \mathrm{~mol} /\left(\mathrm{cm}^{3} \cdot \mathrm{sec}\right)$ \\
\hline$P_{A T P}$ & average power dissipated by neurons in the gray matter & $5.5 \mathrm{~W}$, and up to $7.8 \mathrm{~W}$ \\
\hline
\end{tabular}

A few key observations from Karbowski (2009) are that:

1. the brain is energy expensive and its total metabolic rate has larger scaling exponent than whole body metabolic rate (p.3)

2. metabolic rate in white matter is 3-4 times lower than in grey matter and can be neglected (p.11)

3. majority of metabolic energy in neurons goes to pumping out sodium ions (p.31)

4. the boundary temperature (and scalp cooling) becomes unimportant in the limit of deep brain temperature (p.26)

5. any local increase in the cerebral blood flow that exceeds an increase in glucose utilization rate leads to a lowering of brain temperature, and vice versa (p.26)

6. in deep brain regions cerebral blood flow plays the role of a coolant, whereas in the superficial regions it serves as a strong brain heater (p.27)

7. on the scalp, the heat transfer rate is dominated by convection/conduction, as it is twice the radiation rate $(\mathrm{p} .28)$

The firing rate of neurons does not have a linear relationship with the ATP consumption rate, and at an oxygen extraction fraction of $40 \%$ (the practical limit for the brain), blood leaves the brain at $0.4^{\circ} \mathrm{C}$ higher than it entered ( $\left.\mathrm{Zhu}, 2006\right)$. This is in agreement with Cabanac (1995): 
... the human brain also is warmer in its center than in its peripheral layer and than core temperature, and the temperature within the circle of Willis is also cooler than brain temperature. There is a temperature gradient which facilitates the flow of heat from brain to arterial blood. In turn, the venous blood warms to about $0.2-0.5^{\circ} \mathrm{C}$ above arterial blood and flushes this heat to the trunk.... The human brain is usually estimated to produce ca. $20 \mathrm{~W}$ of heat; the arterial blood flow with about $0.5 \mathrm{l} / \mathrm{min}$ can remove that heat with the actual arterial-venous temperature of only $0.5^{\circ} \mathrm{C}$.

The cranial metabolic rate thus does not produce any more heat than the body can cope with in homeostasis. However, to cope with the higher demand for blood oxygen and nutrients, an increase in cerebral blood flow (CBF) is required (Gisolfi \& Mora, 2000). This in turn is the primary cause for increased brain temperature (Zhu, 2006). How does the brain indicate this requirement to the vascular system?

\subsection{Stress and the sympathetic nervous system}

Many stressors occur at the modern workplace that can range from looming deadlines, difficult co-workers, unreasonable demands from superiors and clients, and so forth. The body undergoes a physiological reaction to what the mind perceives as a stressor in an autonomic way, hence the reference to an autonomous nervous system.

The stress response and thermoregulation both reside in the hypothalamus. More specifically, stress and thermal regulation overlap the same areas as follows (Felten \& Jozefowicz, 2003; see locations in figure 4.2):

1. Preoptic-Anterior Hypothalamus (POAH): warmth sensitive neurons, initiate heat dissipation (parasympathetic)

2. Posterior Hypothalamus Area (PHA): cold sensitive neurons, initiates heat generation (sympathetic)

Since only either one will be active at one time, stress would initiate the regions associated with heat generation, and suppress the systems that regulate heat dissipation.

The sympathetic nervous system kicks into action during emergencies, or what you think are emergencies.... Epinephrine is secreted as a result of the actions of the sympathetic nerve endings in your adrenal glands (located just above your kidneys); norepinephrine is secreted by all the other sympathetic nerve endings throughout 
the body. These are the chemical messengers that kick various organs into gear, within seconds.... The sympathetic system speeds up the heart; the parasympathetic system slows it down. The sympathetic system diverts blood flow to your muscles; the parasympathetic does the opposite. It's no surprise that it would be a disaster if both branches were very active at the same time, kind of like putting your foot on the gas and brake simultaneously. Lots of safety features exist to make sure that does not happen. For example, the parts of the brain that activate one of the two branches typically inhibit the other.... Your body reverses all of the storage steps through the release of the stress hormones glucocorticoids, glucagon, epinephrine, and norepinephrine. These cause triglycerides to be broken down in the fat cells and, as a result, free fatty acids and glycerol pour into the circulatory system. The same hormones trigger the degradation of glycogen to glucose in cells throughout the body, and the glucose is then flushed into the bloodstream. (Sapolsky, 1998, p.22-24, 56-57)

This Figure has been removed for copyright or proprietary reasons

Figure 4.1: Innervation of organs by the autonomous nervous system (Seeley, Stephens, \& Tate, 2006)

Insulin is a hormone that stores energy (Sapolsky, 2004) and cortisol (a glucocorticoid associated with stress and fear) is the "molecule of energy metabolism" (Schulkin, 2003). The sympathetic response suppresses insulin and elevates cortisol levels. Together with 
epinephrine (adrenaline) and norepinephrine (noradrenaline) the typical response due to activating the sympathetic nervous system include (Seeley, Stephens, \& Tate, 2006, p.564):

1. Increased heart rate and force of contraction potentially increases blood flow through tissues. Vasoconstriction of blood vessels in tissues not involved in exercise, such as abdominopelvic organs, reduces blood flow through them, thus making more blood available for the exercising tissues.

2. Dilation of air passageways increases air flow into and out of the lungs.

3. The availability of energy sources increases. Skeletal muscle cells and liver cells (hepatocytes) are stimulated to break down glycogen to glucose. Skeletal muscle cells use the glucose and liver cells release it into the blood for use by other tissues. Fat cells (adipocytes) break down triglycerides and release fatty acids into the blood, which are used as an energy source by skeletal and cardiac muscle.

4. As exercising muscles generate heat, body temperature increases. Vasodilation of blood vessels in the skin brings warm blood close to the surface, where heat is lost to the environment. Sweat gland activity increases, resulting in increased sweat production, and evaporation of the sweat removes additional heat.

With an increased airflow in lungs more oxygen is absorbed and with the increased heart rate and force, more oxygen enriched blood circulates throughout the body. Sapolsky (2004) says, 'If you sit and think about a major deadline looming next week, driving yourself into a hyperventilating panic, you still alter cardiovascular function to divert more blood flow to your limb muscles.' Since in a sedentary office scenario the skeletal muscles are hardly exercised, the brain is the sole benefactor of increased circulation, oxygen and glucose levels - an excellent combination to fuel the processing power of an active brain.

Glucocorticoids and the other hormones of the stress-response also act to block energy uptake into muscles and into fat tissue. Somehow the individual muscles that are exercising during the emergency have a means to override this blockade and to grab all the nutrients floating around in the circulation. No one knows what the local signal is, but the net result is that you shunt energy from fat and from nonexercising muscle to the exercising ones. (Sapolsky, 1998, p.57)

So during stress, blood pressure and overall circulation rises, but circulation to the limbs is limited unless they are exercised. This changes the thermoregulatory response of a stressed 
person. Extreme stress is associated with concepts like 'being paralysed with fear' or having 'cold feet'. The extremities of hands and feet are particularly effective at dissipating heat, so when their circulation is curtailed, blood does not cool the body as much.

In response to stress, the central nervous system is excited by vasoconstrictor agents increasing the metabolism of the liver for glycogenolysis (Cassidy, 1986). The brain derives its energy primarily from glucose but glycogen acts as an energy buffer for bursts of mental activity.

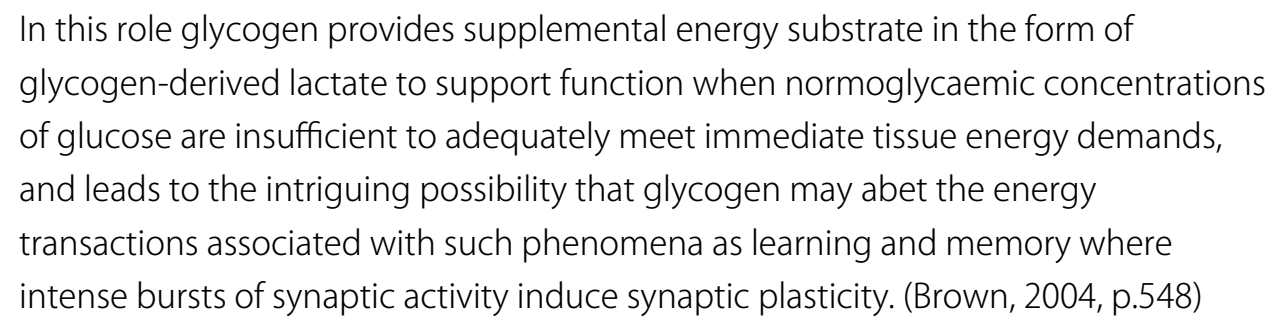

The brain and liver and respectively constitute $21 \%$ and $20 \%$ of BMR (basal metabolic rate, table 3.5 in previous chapter ). BMR is measured after a 12-hour fast which would drastically reduce blood glucose and glycogen levels and thus impede mental performance. Under ordinary conditions of office stress, the brain consumes glucose in copious amounts and the liver metabolises more glycogen for the brain under mental stimulation. The heart (9\% BMR) also works harder to cope with higher flow rates and blood pressure. The metabolism from these three organs, which alone constitute $50 \%$ of BMR, would be significantly increased under work stress.

The lack of cooling from circulation to the extremities, together with increased metabolism of brain, heart and liver would force an increase in core temperature. This increased metabolism however comes with its own penalty. Cerebral blood flow is not simply delivered from the core to the brain. At rest the brain is in homeostasis at 20W. Each increase of arterial temperatures by $1^{\circ} \mathrm{C}$ pours $45-70 \mathrm{~W}$ of heat into the head (Cabanac, 1995).

Whilst stress hormones are often associated with preparing the body for a fight or flight response, Taylor (in Sapolsky, 2004) showed that there is also a gender bias, with females often demonstrating more of a tend or befriend response. We have seen that stress hormones can elevate body temperature, but can temperature affect hormone levels? 
Anecdotally, in a discussion with a midwife at the Launceston General Hospital, I learned that cold water for drinking was given to women undergoing labour so as to intensify the contractions. Immediately after the child was born, the mother would be wrapped in a warm blanket to increase the oxytocin levels and aid the discharge of the placenta. Environmental temperature does appear to have an effect on hormones.

"... the fact that oxytocin is secreted during stress in females supports the idea that responding to stress may not just consist of preparing for a mad dash across the savanna, but may also involve feeling a pull toward sociality." (Sapolsky, 2004)

This Figure has been removed for copyright or proprietary reasons

Figure 4.2: Key areas linked to the expression of fear (Schulkin, 2003)

\subsection{The perception of temperature}

There are thousands of thermoreceptors in the skin and other organs. Johnson (1966) demonstrated that a lowered core temperature caused shivering despite the skin being kept warm, allowing us to deduce that the brain integrates all the information from all the 
sensors and decides on the appropriate thermoregulatory response: one typically does not shiver and perspire at the same time. Much like the sympathetic and parasympathetic nervous systems, only one option is activated and these functions are autonomous (Johnson, 1966; Attia, 1980). How does the brain integrate that information and decide whether it is warm or cool? Is it the simple average of all values?

The body temperature, according to Gisolfi \& Mora (2000) is taken to be as a combination of a core temperature and mean skin temperature according to environment such that:

In cold environments,

$$
T_{\text {body }}=0.6 \cdot T_{\text {core }}+0.4 \cdot T_{\text {skin }}
$$

In warm environments,

$$
T_{\text {body }}=0.8 \cdot T_{\text {core }}+0.2 \cdot T_{\text {skin }}
$$

The core temperature, being relatively stable and homogenous can be determined by one or a few measurements and assumed to be constant. Mean skin temperature on that other hand will have a large divergent range, and the integral has often been determined from weighting factors as recommended by Hardy \& DuBois (1938, in Ramanathan, 1964) with measurement made at head, hands, trunk and feet; or Ramanathan (1964) measuring chest, arms, thighs, and legs. They are similar in methodology, which is to assign a coverage surface area coefficient of a segment (c, in percent of total skin) to the temperature of that segment (T) (Mitchell, 1969), so that:

$$
T_{\text {mean skin }}=c_{1} T_{1}+c_{2} T_{2}+\ldots+c_{n} T_{n}
$$

However, the skin is not equally sensitive in all areas.

Shell temperature is frequently measured by placing temperature-measuring devices on numerous skin locations and averaging the values. However, this mean skin temperature is potentially misleading if each individual temperature is not weighted 
according to the area and sensitivity (temperature-receptor density) of the site

represented. (Gisolfi \& Mora, 2000, p.100)

Considered this way, there is a need to differentiate between the conventional weighting by skin coverage versus weighting by skin sensitivity. The notion of weighting of each skin region makes perfect sense since the amount of heat lost is not only dependent on coverage area, but also by the proximity of the blood vessels to the surface and how widely they are distributed in the region. The neck is particularly sensitive to heat and cold with the carotid arteries (located on either side of the neck, figure 4.5) carrying blood to the head. Thus wrapping a scarf on the neck will have profound effects on the retention of heat and the overall feeling of warmth, even though the area of the neck is small. We may further argue that covering the same skin area with a scarf, say in the lower leg, will hardly be as beneficial. Zhang (2003) measured regression of the sensitivity of body segments to overall sensation and proposed the weightings in table 4.1. Zhang notes the following contributions to overall sensation (p.316):

- back, chest and pelvis have dominant weights

- head, face and breathing show asymmetrical slopes, being more sensitive to warming

- hand and feet have little impact

\begin{tabular}{|l|c|c|}
\hline & Cooling weight & Warming weight \\
\hline Breathing & -0.16 & 0.19 \\
\hline Head & -0.13 & 0.21 \\
\hline Neck & -0.13 & 0.23 \\
\hline Face & -0.15 & 0.3 \\
\hline Chest & -0.23 & 0.23 \\
\hline Back & -0.23 & 0.24 \\
\hline Pelvis & -0.17 & 0.15 \\
\hline Upper arm & -0.1 & 0.14 \\
\hline Lower arm & -0.1 & 0.14 \\
\hline Hand & -0.04 & 0.04 \\
\hline Thigh & -0.13 & 0.26 \\
\hline Lower leg & -0.13 & 0.26 \\
\hline Foot (2 feet) & -0.09 & 0.24 \\
\hline Foot (1 foot) & -0.09 & 0.14 \\
\hline Upper back & -0.16 & 0.26 \\
\hline Lower back & -0.21 & 0.35 \\
\hline
\end{tabular}


The asymmetric sensation weighting of the head is consistent with our hypothesis that the brain is more sensitive to warming than to cooling. In this light, the formulation of mental effort in chapter 3 (equation 3.3) of $|(\mathrm{MM}-\mathrm{Qc})|$ should be separated into functions with different coefficients (slope) for cooling and warming.

de Dear (2009) proposes that the neurophysiological hypothesis explains why a transition to a temperature down-step is more significantly felt than an up-step due to the closer proximity of cold neurons to the surface; and proposes how draft can be welcome alliesthesia in warmth and unpleasant in cold. This agrees with Gisolfi (2000) that in coldskin the cold sensitive neurons are more innervated, and the cold response is " 2 to 3 times more effective in activating heat production" than the heat response (see figure 4.3).

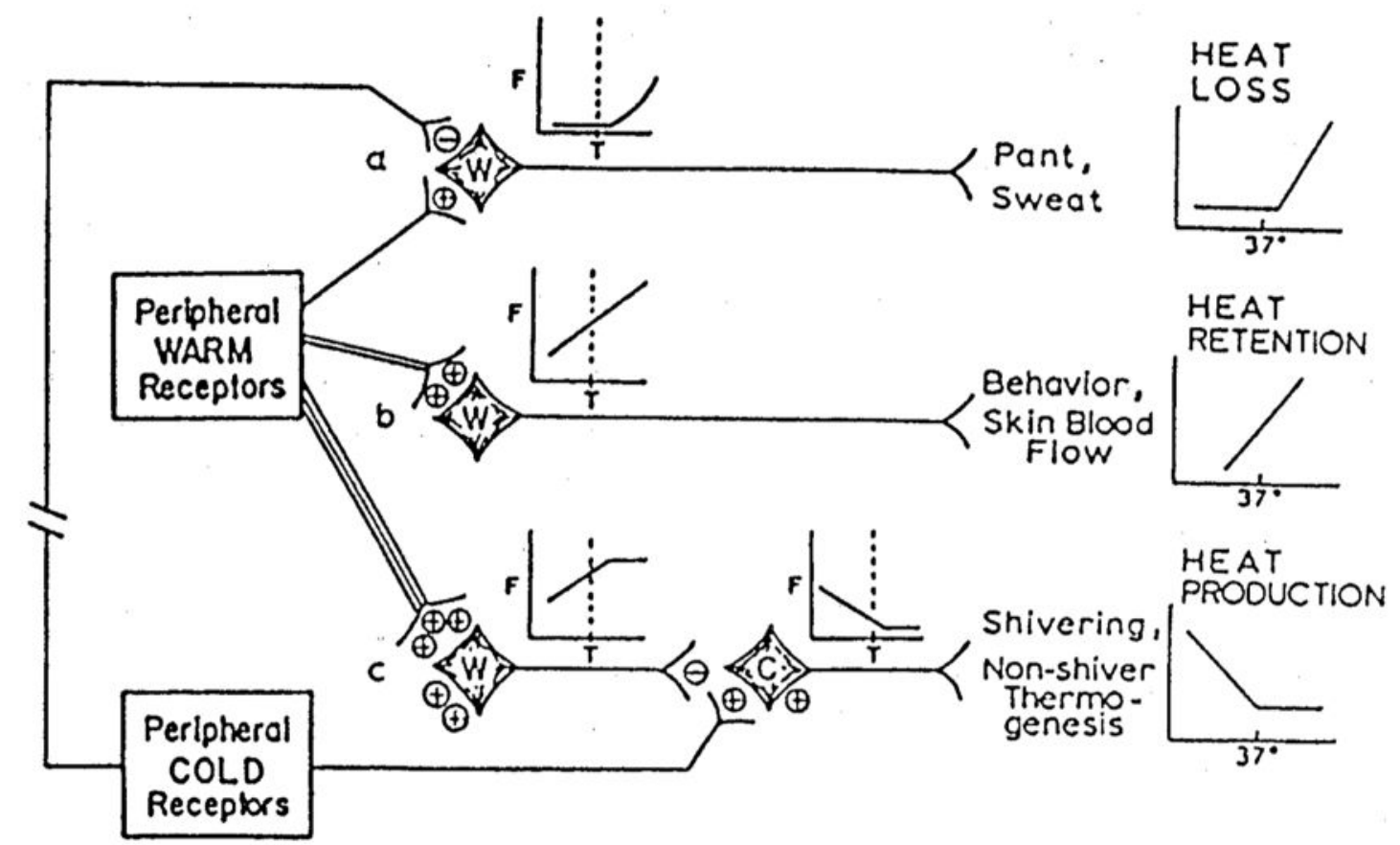

Figure 4.3: Neuronal model proposed by Boulant (1996, in Gisolfi \& Mora, 2000 ) in which 4 types of thermosensitive neurons are warm (W) neurons $(a, b$, and $c$ ) and cold (C) neurons. The cold and warm inputs to these neurons are depicted as excitatory $(+)$ and inhibltory $(-)$. The frequency $(F)$ of neuronal firing is plotted as a function of brain temperature $(T)$.

The neurophysiological approach to temperature sensing is methodologically different from isothermal heat balance approach, the latter being the premise for thermal manikins (see PhD thesis by Nilsson, 2004 for an excellent review on thermal manikins). Defining thermal perception in terms of warm-cold neuron firing rates (Ring and de Dear, 1991) translated into a thermal sensation vote (Zolfaghari, 2010) provides a more accurate accounting for 
fluctuating temperature transients, where the static heat-balance model offers no such latitude. However, is the perception of temperature necessarily the most reliable gauge for the required heat balance? Is there any danger of sending the wrong signal to the brain by cooling the most sensitive sensors, much like messing the thermostat by putting the thermistor in the supply vent?

Whilst heat-sensitive neurons are fairly equitably distributed across the skin surface, there is a prevalence of cold-sensitive neurons on the forehead (figure 4.4). If spot density determined sensitivity, then the head should not be particularly sensitive to heat, and very sensitive to cold. However experiments which showed that the head has a high sensitivity to either deviation from neutrality, led Cabanac (1995) to deduce that restoring the head to normothermia is highly effective in achieving thermal comfort not because of sensor density but due to assistance rendered to the selective brain cooling mechanism.

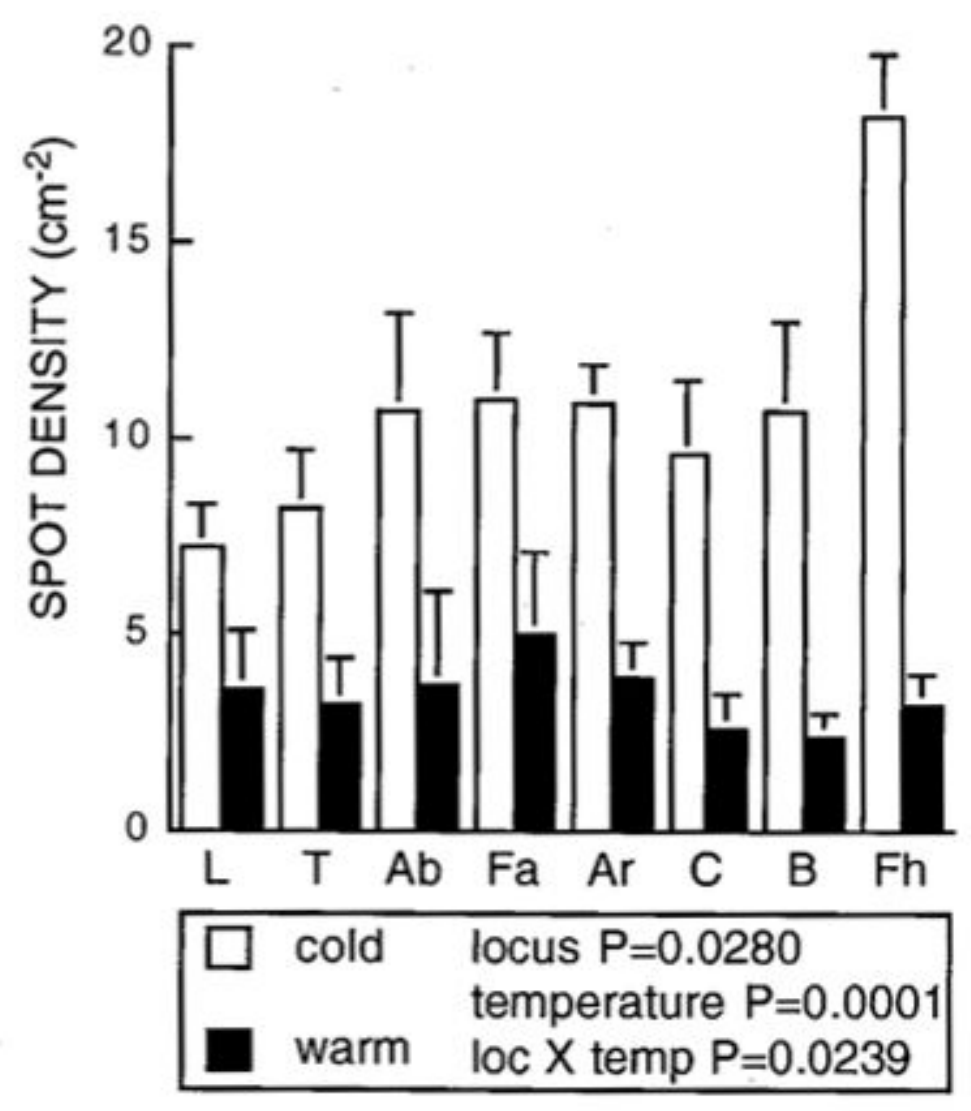

Figure 4.4: Mean density of temperature spots obtained on eight adults, four males and four females, in the various skin areas stimulated. The stimuli were given with $1.1 \mathrm{~mm}^{2}$ thermodes applied with a force of $5 \mathrm{~g}$ for $1 \mathrm{~s}\left(\mathrm{cold}, \mathrm{O}^{\circ} \mathrm{C}\right.$ )and $2 \mathrm{~s}$ (warm, $44^{\circ} \mathrm{C}$ ) duration, on a $4 \mathrm{~cm} 2$ sample of each of the skin areas tested. $\mathrm{L}$ $=$ leg, $\mathrm{T}=$ thigh, $\mathrm{Ab}=$ abdomen, $\mathrm{Fa}=$ forearm, $\mathrm{Ar}=$ upper arm, $\mathrm{C}=$ chest, $\mathrm{B}$

=back, $\mathrm{Fh}=$ forehead. (Cabanac, 1995) 
An increase in hypothalamic temperature produces marked increases in sweating and skin blood flow. Likewise, a decrease in hypothalamic temperature produces shivering and intense cutaneous vasoconstriction. Thus, it seems that it is more specifically the temperature of the brain that is being protected from marked deviations in temperature, rather than the entire core, which includes the abdommal and thoracic cavities. In support of this notion, it is brain temperature that seems to drive sweating, shivering, and skin blood flow responses. (Gisolfi \& Mora, 2000, p.102)

Thus considered, the hypothalamus is not merely an integrator of thermal sensations but is itself a key sensor. Corbit (1969, in Gisolfi \& Mora, 2000) found that rats would work to change their own hypothalamic temperature to relieve discomfort sensed from either the skin or hypothalamus. Why would the hypothalamus not only take inputs from the other parts of the body, but also from itself (see figure 4.6)? It seems crucial that the temperature of the brain is read, not by cutaneous or core sensors, but by the hypothalamus itself. The human body can be seen as a poikilothermic shell (lacking temperature regulation, like reptiles) around a homeothermic core (Gisolfi \& Mora, 2000). The core temperature is tightly regulated and operates within a much smaller margin than the shell which consists of skin, subcutaneous tissue and muscle. Within the core, consisting of abdominal, thoracic and cranial cavities, what is the priority of temperature regulation (in terms of sensitivity weighting)? It would appear that from the supremacy of the hypothalamus reading, that the cranial temperature is the most important.

If cooling the hypothalamus was like messing with the thermostat, this makes it all the more puzzling as to what advantage there could be in cooling the brain directly. It seems more logical to view the brain as the organ that would suffer the most from excessive heat gain, and thus the need to protect it from overheating. Figure 4.7 shows the proximity of the hypothalamus to the respiratory tract. It appears plausible that with the close proximity between the respiratory path and the hypothalamus, that inhaling cold air could cool the hypothalamic sensors that regulate brain temperature. 
This Figure has been removed for copyright or proprietary reasons

Figure 4.5: Arterial supply to the brain and the meninges (Felten, 2003). Note the size of the dominant carotid artery. 


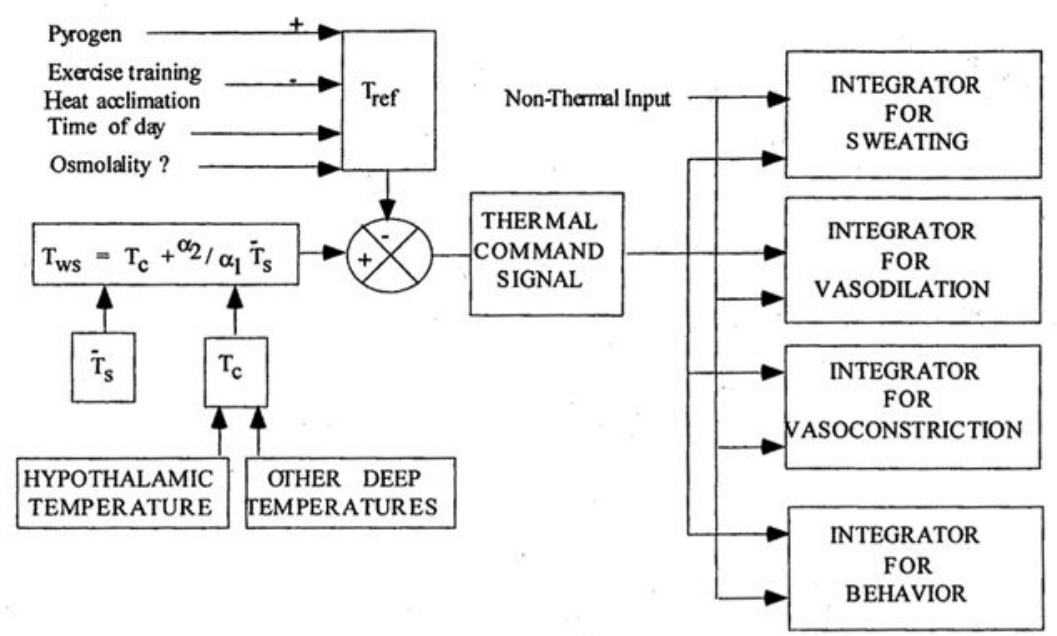

Figure 4.6: Schematic diagram illustration the elements that control the temperature regulatory effector responses. Basic thermal input is transmitted from skin (T_s) and core ( $T$ _c) thermoreceptors. This information is integrated and a "weighted sum" (T_ws) of this activity is then compared with basal neural activity (T_ref) within the regulatory circuiting to form a "command signal" that impinges on all integrators for regulating brain temperature. The ration of $\alpha_{1} / \alpha_{2}$ is $9 / 1$. (Gisolfi and Wegner, 1984 in Gisolfi \& Mora, 2000)

This Figure has been removed for copyright or proprietary reasons

Figure 4.7: Sagittal (almost median) section of the head and neck, with a portion of the brain included (O'Rahilly et. al., 2004). Note the close proximity between the hypothalamus (marked red) to the respiratory tract (marked blue).

\subsection{Selective brain cooling}

Selective Brain Cooling $(\mathrm{SBC})$ is the mechanism to cool the brain directly though special venous arrangements. Though SBC is well accepted in some animals, the existence of such a 
phenomenon in humans is still debated (see Journal of Applied Physiology, 2011; 110 (2) for a point-counterpoint series of debates on 'Humans do not demonstrate selective brain cooling during hyperthermia').

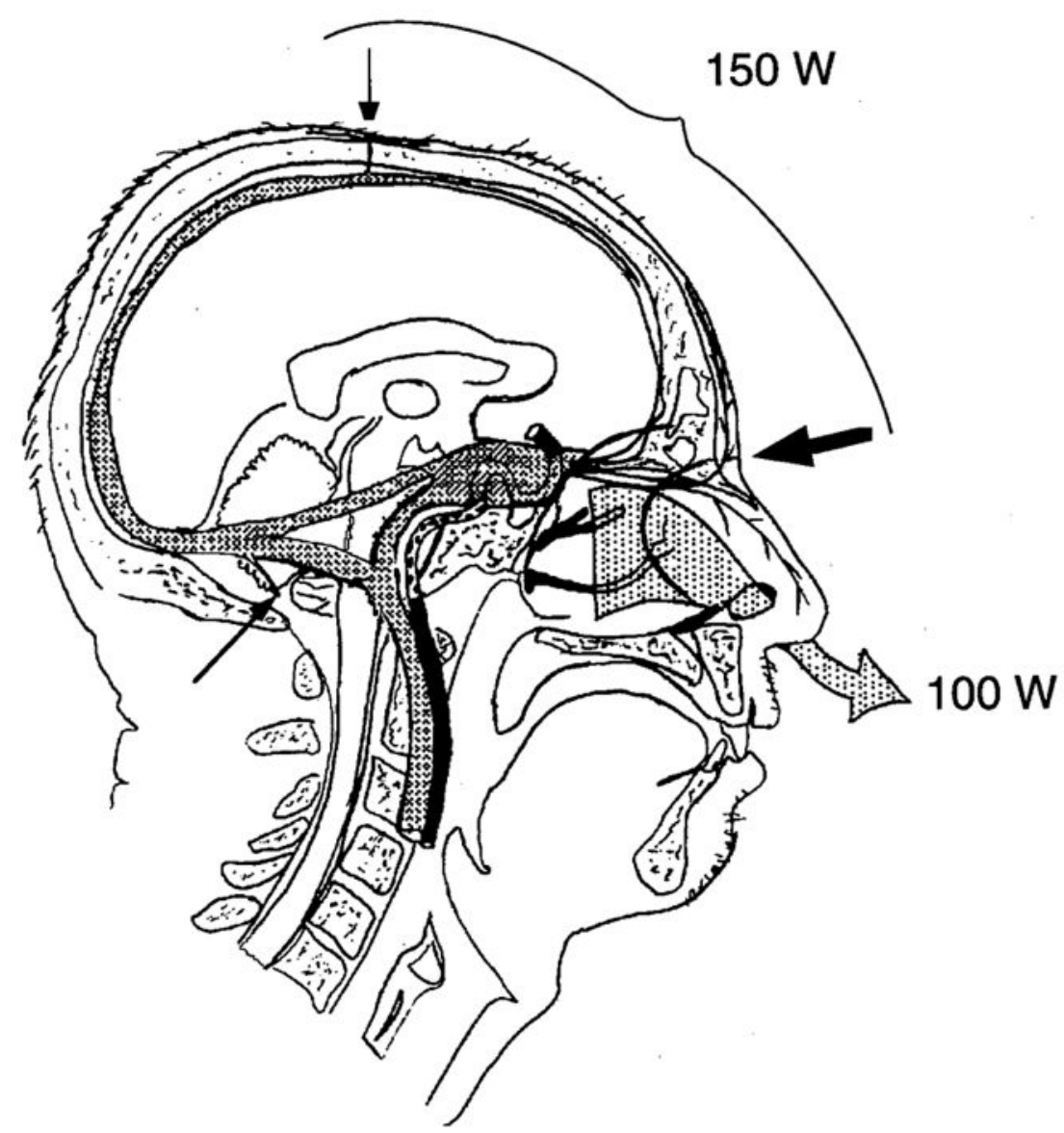

\footnotetext{
Figure 4.8: Schematic representation of some of the heat exchange mechanisms of selective brain cooling in humans. Cabanac says, 'The important heat loss areas are shown on the figure: head skin and upper airways including the conchae. The blood of the carotid artery can exchange heat with the returning venous blood in the neck (internal jugular vein), in the cranial bone (carotid sinus, spotted area), and in the sinus cavernosus. An important structure is not shown, the pterigoid sinus, an important network of veins in the cheek and pharynx communicating with the intracranial venous network. The arrows indicate the veins where blood was recorded as flowing inward during hyperthermia.' (Cabanac, 1995)
}

The brain is particularly sensitive to temperature rises. The logic behind SBC is to protect the brain against the unabated rise in temperatures brought on by hyperthermia. Beyond $42^{\circ} \mathrm{C}$ protein denatures and becomes insoluble, much like the process of boiling eggs.

Partially denatured proteins are able to recover when normal temperatures are restored (figure 4.9) but the process is complicated by other enzymes that break down partially denatured proteins (figure 4.10). Thus the impact on a subject recovering from excessive heating is not just a threshold temperature but involves the exposure time (table 4.2). 
Another reasoning for the need for brain cooling is the Salerian-Saleri Temperature Thesis which states, 'Cooler biologically compatible core body temperatures prolong lifespan and are of value to combat illness' (Salerian \& Saleri, 2006).

\begin{tabular}{|c|l|}
\hline \multicolumn{2}{|c|}{ Estimated Brain Temperature Dose } \\
\hline $42-42.5^{\circ} \mathrm{C}$ & 60 min before irreversible brain damage \\
\hline $43^{\circ} \mathrm{C}$ & $10-20$ min before irreversible brain damage \\
\hline
\end{tabular}

Table 4.2: Tolerance as a function of dose rather than absolute temperature (Cabanac, 1995)

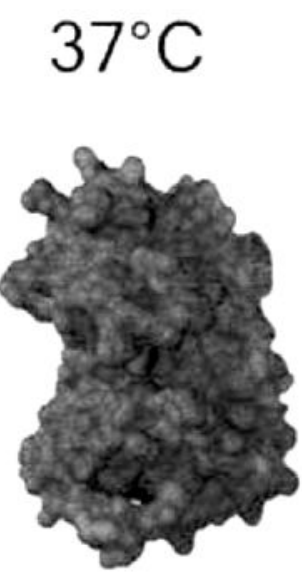

Normal protein

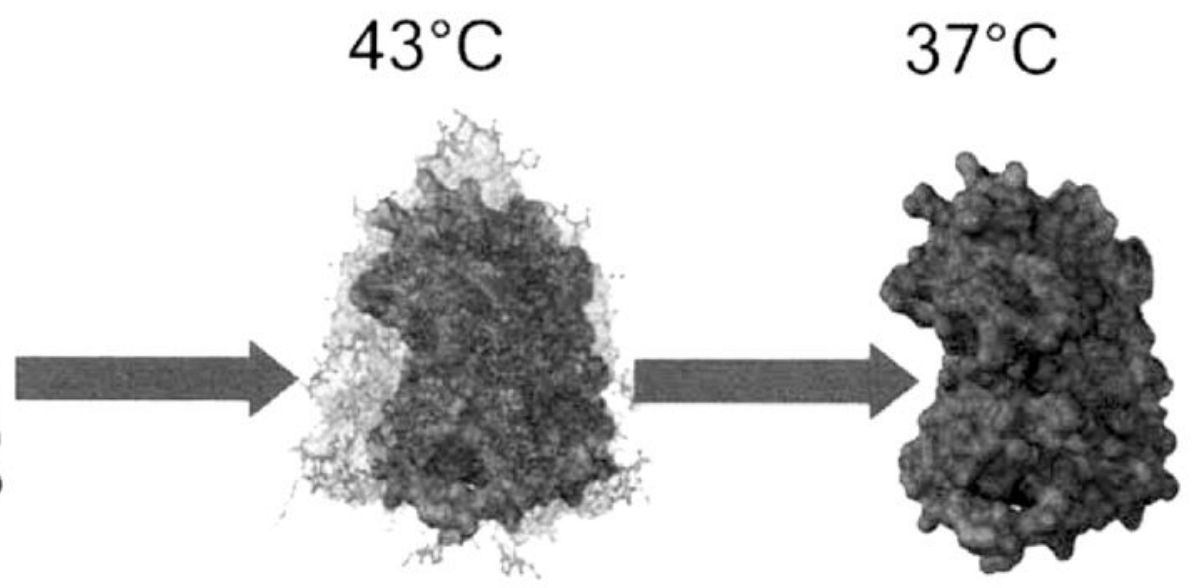

Partial denaturation
Normal protein

Figure 4.9: The process of reversible temperature disintegration of protein structure (Suvernev, 2006).

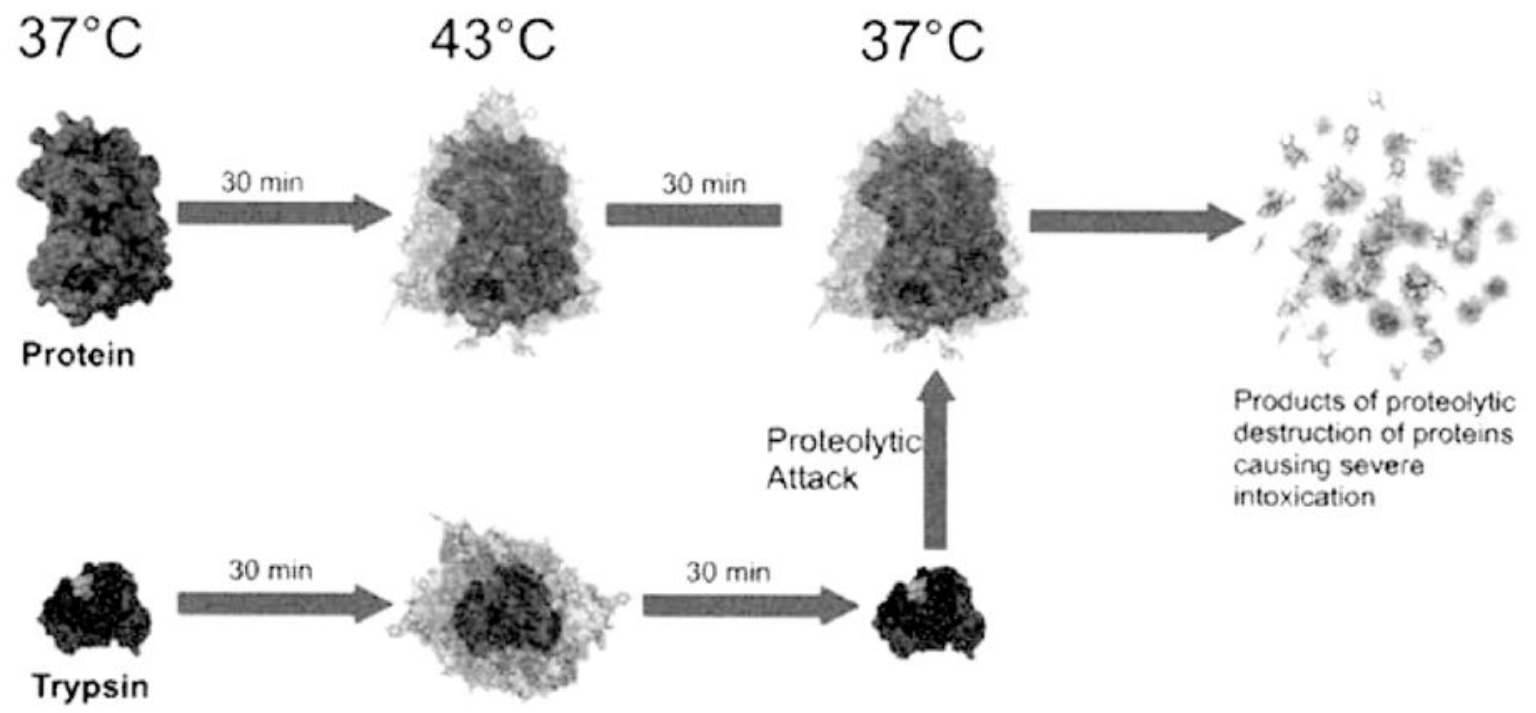

Figure 4.10: Participation of trypsin in hyperthermic proteolysis (Suvernev, 2006). 
The temperature of the brain is typically higher than the trunk. The proponents of SBC therefore judge that the unequivocal criterion for demonstrating SBC is to prove brain temperature can be decreased below trunk temperature during hyperthermia. In many human SBC experiments, hyperthermia was generated though exercise (Cabanac, 1995). When brain temperature is increased, a direct and immediate effect is seen on blood pressure (Rodbard, 1948). Whilst it is clear that a heated brain will drive a thermoregulatory response, it is less obvious if a stressed brain will be heated. With no significant muscular metabolism in the sedentary office setting, one wonders if work stress alone can elicit a SBC response. This can be further analysed along the following considerations:

1. Can stress directly trigger SBC?

2. Does a stressed brain require SBC even before there is hyperthermia?

3. Can stress raise core temperature (hyperthermia) to illicit a SBC response?

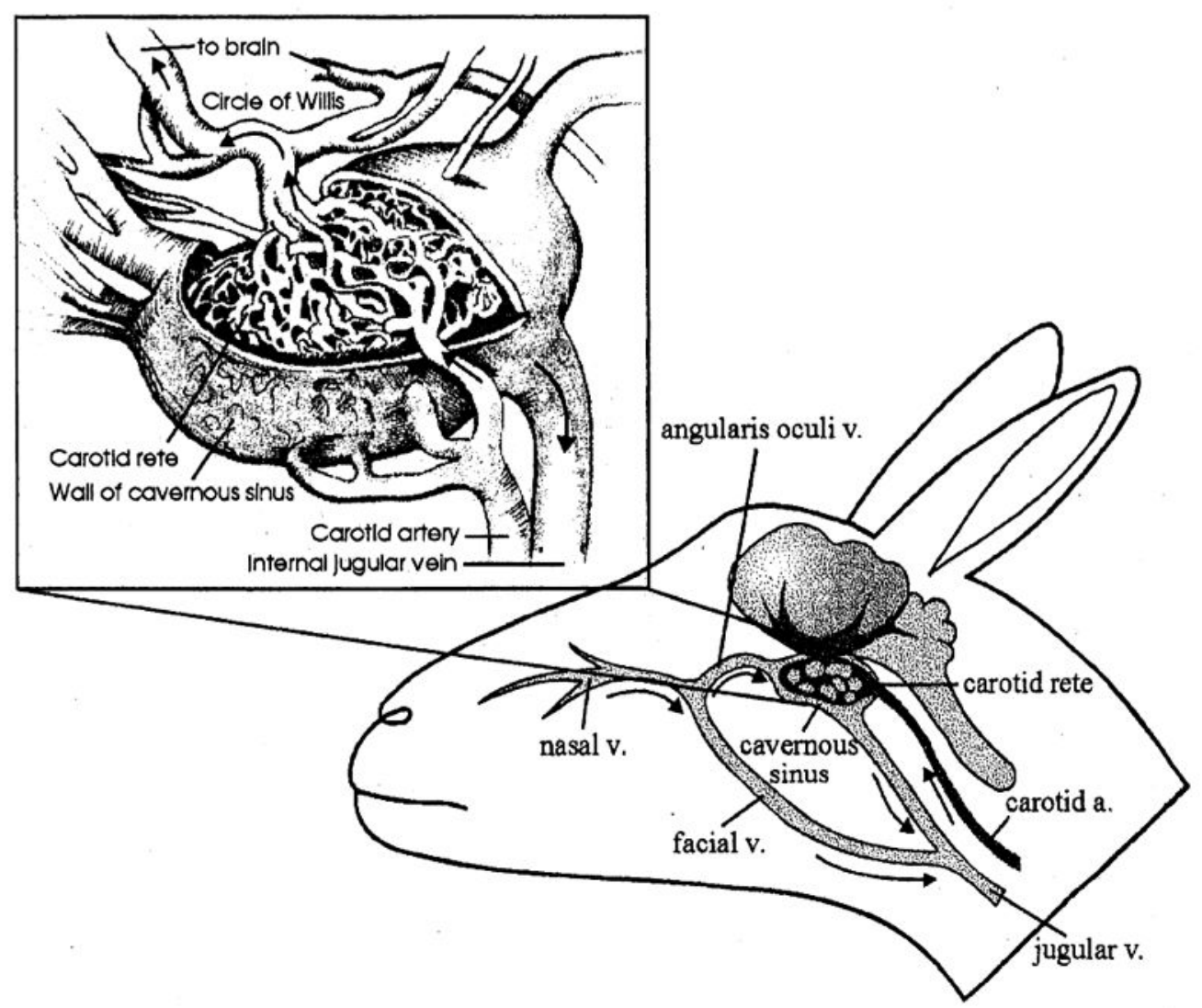

Figure 4.11: Vasculature involved in selective brain cooling (SBC) in artiodactlys. (Maloney 1997) 
Animals where SBC is not disputed possess a carotid rete (or rete mirabile) that channels blood across the stream of respired air. Maloney (1997) found evidence suggesting that in animals SBC could be adrenergically driven (responding to stress hormones), with SBC following a reduction of sympathetic activity, so that muscles which control the flow of arterial blood passively dilate the angularis oculi vein and constrict the facial vein. This means that after a stressful episode, blood flow is diverted from face to the back of nose, where the carotid rete cools the supply of blood to the brain (figure 4.11). So in animals with a carotid rete, SBC is initiated after a stressful episode.

\begin{tabular}{|l|l|l|l|}
\hline \multicolumn{1}{|c|}{ Blood vessel } & \multicolumn{1}{|c|}{$\begin{array}{c}\text { Predominant receptor } \\
\text { (Maloney, 1997) }\end{array}$} & \multicolumn{1}{c|}{ Response to epinephrine } & \multicolumn{1}{c|}{$\begin{array}{c}\text { Level for predominance } \\
\text { (Cassidy, 1986) }\end{array}$} \\
\hline Facial vein & $\beta$-adrenergic smooth muscle & vasodilation & Dominant at low levels of epinephrine \\
\hline Augularis Oculi vein & $\alpha$-adrenergic smooth muscle & vasoconstriction & Dominant at high levels of epinephrine \\
\hline
\end{tabular}

Table 4.3: Adrenoreception of facial and aungularis oculi veins

Human facial veins are supplied with both $\alpha$ - and $\beta$-adrenoreceptors which respond to transmural nerve stimulation and noradrenaline (table 4.3), these 'unusual characteristics for a vein are basically similar to the ones described for the rabbit facial vein' (Mellander, 1982, p.393), a view also supported by Bevan (1983). However in humans there is no carotid rete as heat exchanger, so the blood should ideally be cooled before entering the sinus cavernous (a big lake in the endocranial space beneath the brain), not in it. The stress response which would have dilated facial vessels and consequently made SBC less effective in animals with a carotid rete is now an essential part of the human SBC response. So under conditions of moderate stress the face flushes as the superficial facial veins carry more blood to the surface and cool it more effectively before delivering that to the brain. Under extreme stress however, vasoconstriction dominates and the face appears 'pale as a sheet'. The exact response varies across individuals depending on the "abundance of "innervated" $\alpha$ - and $\beta$-adrenoceptors in the facial vein' of which age appears to be a factor (Mellander, 1982, p.397).

Panting which facilitates heat loss from the carotid rete, is absent in both humans and horses which lack the carotid rete. Both mammals instead rely on sweating for heat loss, which is most profuse on the head (Cabanac, 1995). Doppler ultrasound measurement show strong blood flow from face (forehead and upper face) $\rightarrow$ angularis oculi veins $\rightarrow$ brain (intracranial space) during hyperthermia (Cabanac, 1995). Even in normothermia, the flow 
is similar (Cabanac and Caputa, 1979). So heat is not merely lost by surface radiation of the heat in the head which was conducted though the skull and scalp, but the act of cooling the face cools the blood that supplies into the brain.

The skin on the head is also equipped with a higher density of sweat glands than that of the rest of the body. Does the mere act of perspiring cool the body, or does perspiration need to be evaporated for it to be effective?

\begin{abstract}
There are people born without sweet glands (anhidrotc actodermal dysplasia).... A high school miler from Des Moines, lowa, who was born with anhidrotic ectodermal dysplasia, illustrates an important physiological point. The mile typically runs on a quarter-mile track, and each competitor must complete four laps. This man was able to compete because his teammates formed a bucket brigade and doused him with a bucket of water every quarter-mile of the race, to produce evaporative heat loss. This anecdotal story is extraordinarily relevant because it emphasizes a biological fact: that heat is lost by evaporation and not by the process of sweating itself. In other words, it doesn't make any difference how water reaches the surface of the skin, by sweating or by bucket; it is the process of evaporation that cools the skin, not the process of sweating. An important question is whether these individuals have a high skin blood flow, even though they have no sweat glands. (Gisolfi \& Mora, 2000, pp.104-105)
\end{abstract}

There appears to be evidence supporting the need for a cool face under times of stress. When dressed in a standard office garb of long-sleeve shirt and tie, little evaporative opportunity is provided to perspiring skin. The only viable and most effective mechanism for cooling is thus to cool the face. This explains why even when occupants are in conditions identical in thermal comfort parameters, the different levels of stress they experience account for drastically different different demands for cooling. Surgeons perspire more than nurses even though they have the same physical activity (in muscular metabolic terms, figure 4.12a); cars now feature separate climate controls to both seats even though the environment is similar (figure 4.12b); and in stressful reality TV appearances (like Millionaire Hotseat and Dragons' Den), difficult questions posed to participants cause a number to break out in sweat. So under identical conditions (of T, MRT, RH\%, vel, met and clo ) different responses emerge as a direct consequence to stress, and this is evidenced most noticeable in facial perspiration. 
This Figure has been removed for copyright or proprietary reasons

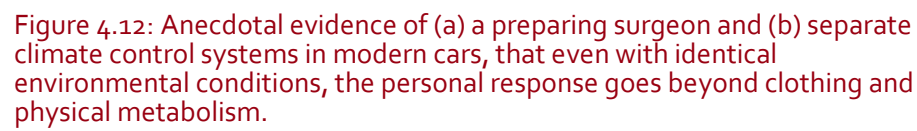

Further support is found in Magilton et. al (1984) who in human experiments discovered that the temperature of blood flowing through the angularis oculi vein was lowered during mental challenges. They state:

... the blood in the angularis oculi vein is acting as the coolant for arterial blood ascending to the brain.... The evidence presented here supports the concept that the rate of heat transfer from the superficial vessels in the face and nasal mucosa to the ambient air is regulated in responses to mental activity. Consequently, the temperature of the venous blood flowing towards the cavernous sinus via the angularis oculi vein is decreased during periods of increased heat production in the brain occasioned by an increase in the level of mental activity. (Magilton et. al., 1984, pp.3,7)

\subsection{Nasal air-conditioning}

Besides facial perspiration, nasal air-conditioning also facilitates the brain cooling process.

Irmak notes the impact of craniofacial features on the efficacy of cooling:

The size of the nasal cavity is strongly affected by climate. In hot, moist climates, it is generally broad: in cold, dry climates it is narrow. In hot climates, a broad cavity permits maximum surface area of nasal turbinates for cooling the inhaled air, while a restricted air intake under cold conditions would seem to be essential to lessen the danger of freezing the lungs. Individuals from hot climates have thick, everted lips, and those from cooler climates, have thin inverted lips. Thick, everted lips tend to radiate more heat and thus cool the brain by angular vein. Conversely, thin lips tend 
to conserve body heat and prevent their freezing in severely cold weather. (Irmak, 2004, p.977)

Whilst facial cooling of blood appears to be a primary means of cooling the brain with cooled blood, respiration also plays an important role. Mariak, White, Lewko, Lyson, \& Piekarski (1999) showed that the human brain could be cooled, at its outer frontobasal aspects, through heat loss to the upper airways. It would follow that the higher the flow rate through the nose, the more heat is loss through this passage. Since a dilated nostril reduces nasal airflow resistance and increases maximum flow rate (Cabanac, 1995), the efficacy of nasal cooling on brain temperature can be determined by nostril dilation vs temperature of ear tympana (T-ty), where White \& Cabanac (Cabanac, 1995) found a strong correlation between dilation and a reduced rate of $\mathrm{T}^{\circ} \mathrm{C} \uparrow$.

The nose plays an important part in warming and humidifying the inspired air to alveolar conditions. Based on the measurements by Lindemann et. al (2001), under ambient conditions of $22^{\circ} \mathrm{C}, 35 \% \mathrm{RH}$; healthy candidates had nasopharynx conditions of $32-34^{\circ} \mathrm{C}$ and 85-95\%RH at the end of inspiration. Elad at. al. (2008) propose a psychrometric process of determining nasal air-conditioning based on a respiration rate of 15 breaths/min and tidal volume of 0.5 litres. The nose can thus account for 1.5-1.8W of sensible cooling and 6.7-9.0W of latent cooling; in agreement with, but slightly less than, Elad et. al. who assume alveolar conditions $\left(37^{\circ} \mathrm{C}, 100 \% \mathrm{RH}\right)$ in the nasal cavity.

The magnitude of respiratory heat loss in exercising, hyperthermic humans was demonstrated by Rasch et. al (1991) to be as high as 100W. It is interesting to note that when therapeutic hyperthermia is employed in cancer treatment, the only cooling thermoregulation of the anaesthetised patient is that of high frequency artificial lung ventilation (figure 4.13). 


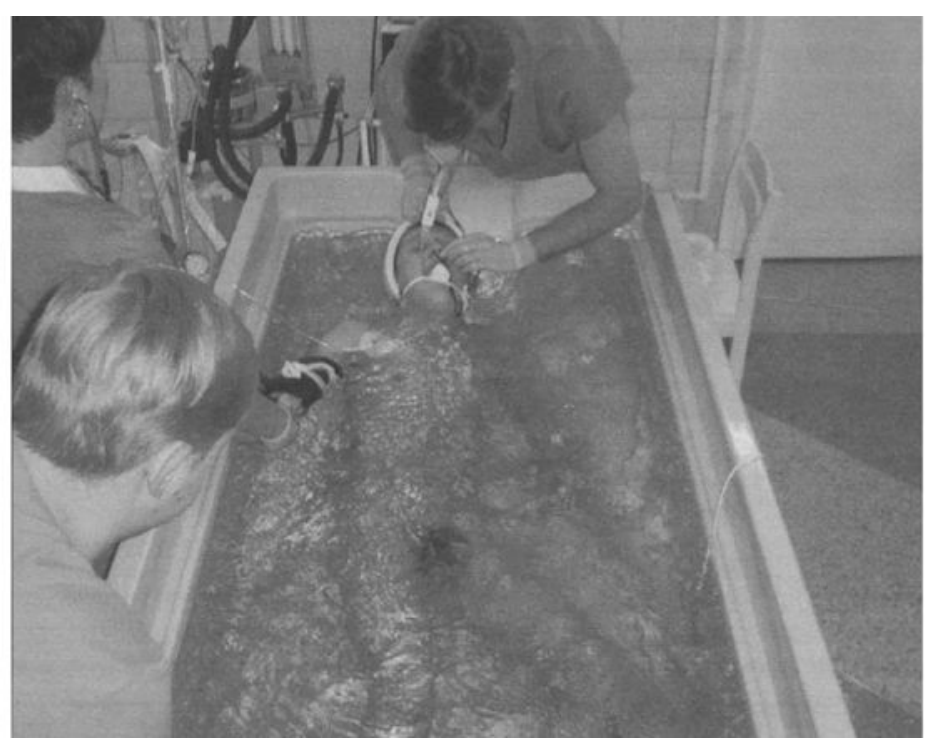

Figure 4.13: A general view of active immersion-convectional heating of the patient (Suvernev, 2006).

\subsection{Dehydration, cognitive function and temperature}

Excessive water consumption is often discouraged in thermal comfort studies in order to avoid trips to the toilets so as to maintain uniform conditions for both the environment and occupant. Where cognitive, and possibly thermoregulatory, functions are concerned, dehydration plays a larger role than acknowledged in thermal comfort studies. Batmanghelidj (2003) whose research into the effects of dehydration explains:

When there is a gradually establishing chronic dehydration in the body, the brain has to depend more on glucose as a source of energy. The brain needs more glucose for its energy value and its metabolic conversion to water. Under the urgent circumstances produced by stress, up to 85 percent of the supplemental energy requirement by the brain is provided by sugar alone. This is why stressed people resort to eating sweet food. While all the other cells need to be influenced by insulin to take up glucose through their cell walls, the brain does not depend on insulin to carry sugar across its cell membranes. (p.110)

With dehydration, the level of energy generation in the brain is decreased. The ATP pool of energy becomes gradually depleted, more at some sites of activity than others. Many silent functions of the brain that depend on hydroelectric energy become inefficient. We recognize this inadequacy of function and call it depression. To the human body, caffeine is very much like the booster system in an engine. In the same way a booster system burns fuel at a faster but inefficient rate to propel a car or plane at an exaggerated speed, so caffeine forces an increase in consumption of ATP. (p.200) 
Dehydration has well established impediments to cognitive function. Whilst the correlation is clear, the explanation behind this is still uncertain. Wilson (2003) reviews the theories behind hormonal and cellular theories and finds the evidence inconclusive. The most convincing, in Wilson's view is Barr's global workspace theory (Baar, 1993) which unifies physiological, psychological and philosophical concepts.

This is based on the concept that cognition is of limited capacity. Thus, cognitive processes perceived as working in parallel are actually functioning in competition with each other. Selected activities are presumed to dominate cognitive awareness by harnessing executive function more effectively than other competing processes. Utilizing Baar's theory, Cohen attempts to explain the effect of dehydration on cognitive function in a simplistic, albeit, rather plausible manner (Cohen, 1983). Based on the assumption that complex tasks require increased attention, Cohen proffers that acute stressors such as dehydration compete for executive attention and awareness with parallel processes occurring in other cognitive domains, thereby compromising overall cognitive performance.

Since both the stress response of office work and thermoregulatory response of the office environment will impose competing demands for attention from the hypothalamus, Baar's global workspace theory would suggest that:

1. if the hypothalamus had sufficient capacity it could respond to both streams of inputs unconsciously; or else,

2. if the hypothalamus had inadequate capacity, the streams would compete for access to a broadcasting capability, i.e. to effect a conscious change in behaviour, disposing the occupant to reduce either the stress or thermal discomfort

The adequacy of workspace capacity would be highly subjective, and this explains why different individuals differ in their tolerance to thermal discomfort. The highly motivated individual will also be able to focus on the task more and ignore the insults of the thermal conditions. Even a well-rested individual will have more capacity, and thus be able to cope better under similar conditions of stress and thermal discomfort than a participant with inadequate rest.

Sleep plays a major role in cognition, and interestingly is also closely tied to metabolism and environmental temperatures. 


\subsection{Sleep, cognitive function and temperature}

Thermoneutrality for sleep is reached for at ET $=30-32^{\circ} \mathrm{C}$ naked, or at $16-19^{\circ} \mathrm{C}$ with pyjamas and at least one sheet (Onen, 1994). The relatively stable temperature under a blanket of $30^{\circ} \mathrm{C}$ is maintained at a preferred ambient temperature of $19^{\circ} \mathrm{C}$ (Muzet, 1984). During summer in Hong Kong, a survey found that the overwhelming majority would wear sleepwear (92\%), use blankets (90\%) and switch on the air-conditioning for most of the night (68\% use the air-conditioning for 5 hours or more) (Lin, 2006). In Singapore, there is a high level of residential air-conditioning ownership (see table 4.4), primarily used for cooling through the night. This will be no surprise since Bach et. al. (2002) found sleep to be less efficient at $35^{\circ} \mathrm{C}$ than at $20^{\circ} \mathrm{C}$.

\begin{tabular}{|c|c|c|c|c|c|c|c|c|c|c|}
\hline \multicolumn{10}{|c|}{ Air-conditioner ownership } \\
\hline Age & below 25 & $25-29$ & $30-34$ & $35-39$ & $40-44$ & $45-49$ & $50-54$ & $55-59$ & $60-64$ & 65 \& over \\
\hline Percentage & 60.1 & 73.9 & 81.3 & 82.6 & 79.8 & 79.4 & 74.6 & 72.1 & 59.9 & 48.1 \\
\hline
\end{tabular}

Table 4.4: Households with air-conditioning in Singapore by age group of main income earner (Singapore Dept. of Stats, 2007)

Sleeping typically proceeds from NREM (non-rapid eye motion) to REM (rapid eye motion) stages.

During NREM sleep the body still thermoregulates and perspiration is proportionate to the ambient thermal load, whereas during REM sleep, sweating is absent (Henane et al., 1977 in Gisolfi \& Mora, 2000). During the transition from NREM to REM sleep stages, the hypothalamic temperature rises independently of ambient temperatures. During REM sleep the body does not thermoregulate (Gisolfi \& Mora, 2000).

Parmeggiani (2003) suggests that the poikilothermic state during REM sleep is produced by an inactivation of the hypothalamic thermostat. As the thermoregulatory response is switched off, sleeping outside of thermal neutrality elicits a conflict between maintenance of homeothermia and sleep pressure, where the probability of REM sleep onset depends on a successful down-regulation of core temperature' (Parmeggiani, 2003, p.564, see also figure 4.14). In a sense the hypothalamus must be satisfied that thermoregulation is not needed before it can shut down. 
Dreaming occurs during REM sleep where the increased neural activity is accompanied by higher metabolism, oxygen consumption and cerebral blood flow which cannot be attributed to muscular metabolism (Haskell, 1981). 'Reduced metabolism in animals during REM sleep can be largely attributed to muscular atonia, whereas increased metabolism in humans may depend on their large brain' (Haskell, 1981).

Gisolfi \& Mora (2000) suggests that NREM sleep is necessary to provide a homeostatic balance for brain and body cooling. He finds support for his argument in the following:

1. Elevated waking temperature in mammals and birds could not be sustained without the brain cooling provided by sleep (McGinty and Szymusiak 1990).

2. In dolphins, which basically have two brains and show unihemispheric sleep, the sleeping brain cools (Kolvalzon and Mukhametov 1982).

3. Hyperthermia induced by vigorous exercise in the day increases NREM sleep at night. Exercise in the presence of cooling, so that no hyperthermia is experienced, prevents the increase in NREM sleep.The brain appears to record how long brain temperatures have been elevated during the day and compensates for this "awake heat load" by sleep-related cooling (McGinty and Szymusiak 1990).

Deep sleep or slow wave sleep (SWS), which happened in the late stages of NREM sleep, is also the phase where energy restoration occurs, particularly stores of glycogen which is heavily consumed by an active brain or a sleep-deprived brain (Sapolsky, 2004).

... metabolically costly processes of respiration (Trinder et al. 1992), heart rate (Shinar et al. 2006), gut motility (Kumar et al. 1990) and muscle activity (Shinar et al. 2006) are reduced during sleep and some of the resulting energy saved may be redistributed to other metabolically costly processes that are proposed as sleep functions (e.g. sleep-dependent hormone synthesis and release (Sassin et al. 1969), increases in immune function (Everson, 1993; Palmblad et al. 1976; Bergmann et al. 1996), replenishment of cerebral glycogen stores (Benington \& Heller, 1995) and synaptic plasticity (Cirelli et al. 2005)). Thus, based on our findings and findings from the existing literature, we propose that one of the functions of sleep in humans is to conserve energy and that some of the energy saved is redistributed to support other critical sleep-dependent physiological processes. (Jung, 2011, p.242) 
SWS couId be stimulated by decreasing body temperature at sleep onset. The increase in SWS can be interpreted as being a thermal response which prevents hyperthermia and/or serves to down-regulate body temperature.

Behavioural thermoregulation is negatively affected by sleep since the motility related to the search for thermal comfort can only precede the onset of sleep. However, specific postures elicited by positive and negative thermal loads are static behavioural thermoregulatory responses during NREMS to maintain the balance between heat production and heat loss. In contrast, the drop in postural muscle tonus during REMS, occurring in all studied species including humans, is unrelated to ambient temperature and impairs postural thermoregulatory responses.

(Parmeggiani, 2003)

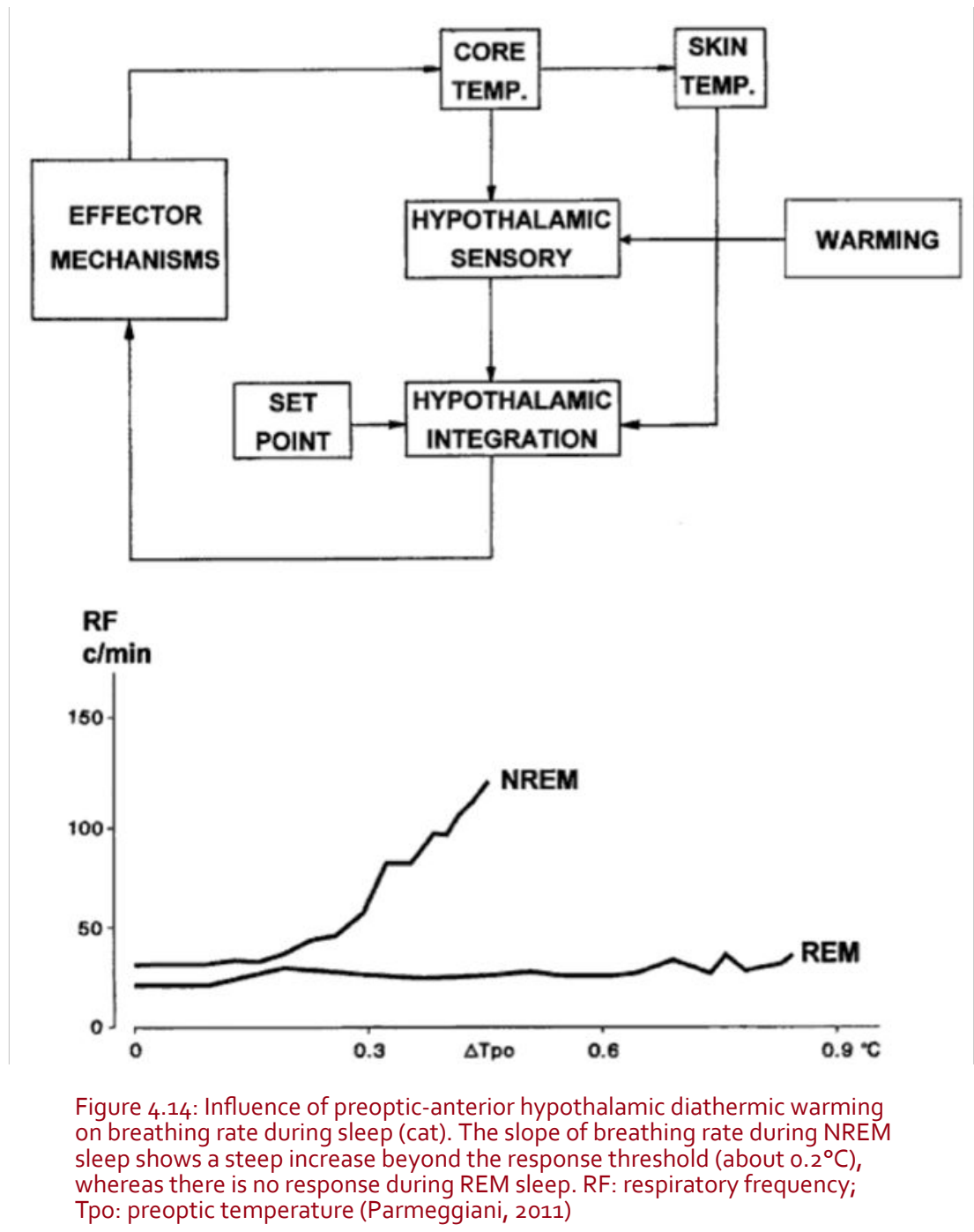

Bringing this knowledge together, the picture during REM sleep gives a good parallel to the active brain in the day: high mental activity accompanied with increased blood flow, oxygen 
consumption and elevated temperature. Despite there being no muscular metabolism, the act of dreaming elevates body temperatures and gives indication of the significance mental metabolism plays on the whole body.

The thermoregulation of NREM sleep on the other hand gives a valuable insight into why people in the tropics, or temperate summer, would sleep with blankets in an air-conditioned room instead of sleeping naked. Thermoregulation by perspiration is available during NREM sleep but shivering only occurs during wakefulness and shallow sleep. Thus cold is more disruptive to sleep than warmth (Haskell, 1981). The further temperatures depart from neutrality, the harder it is to fall asleep and maintain deep sleep. NREM sleep (and particluarly the SWS stage of NREM sleep) is also the stage where brain and sympathetic activities slow down enough for brain cooling. If one of the functions of sleep is to cool the brain, then the exposure of the head to cooling will either give a better quality of sleep or supply the required brain cooling within fewer hours of rest. The aim is therefore to achieve a stable $30^{\circ} \mathrm{C}$ under the sheets and $19^{\circ} \mathrm{C}$ on the exposed face. Thermal neutrality may prove monotonous in the day but at night, it may actually have an important role to play for quality sleep (Candas, 1982 in Bach, 2002).

\footnotetext{
As we glide down into slow wave sleep, some obvious things occur to facets of the stress-response system. For starters, the sympathetic nervous system shuts down, in favour of that calm, vegetative parasympathetic nervous system. In addition, glucocorticoid levels go down. ... Some of the hypothalamic control of pituitary hormone release consists of an accelerator and a brake-a releasing factor and an inhibiting factor.... Thus, sleep deeply, and you turn off glucocorticoid secretion. (Sapolsky, 2004)
}

If sleeping in an air-conditioned room can allow one to sleep better, it will concurrently reduce the level of stress hormones circulating in the system, which will in turn better prepare the body for the challenges of the next day. And since sleep also has a profound impact on the level of mental performance following, resting temperature also has an indirect effect on thermal comfort expectations the next day.

Take a normally rested subject, stick her in a brain imager, and ask her to solve some 'working memory' problems (holding on to some facts and manipulating them—like adding sequences of three-digit numbers). As a result, her frontal cortex lights up metabolically. Now, take someone who is sleep deprived and he's awful at the working memory task. And what's going on in his brain? What you might have 
guessed is that frontal metabolism would be inhibited, too groggy to get activated in response to the task. Instead, the opposite occurs-the frontal cortex is activated, but so are large parts of the rest of the cortex. It's as if sleep deprivation has reduced this gleaming computer of a frontal cortex to a bunch of unshaven gibbering neurons counting on their toes, having to ask the rest of their cortical buddies to help out with this tough math problem. (Sapolsky, 2004)

Since sleep deprivation requires more of the cortex to be mobilised to solve a mental problem, more energy is expanded by the brain and more cooling is demanded. The attention resource availability theorem (earlier mentioned with regard to dehydration) would explain the need to activate other regions of the brain when the cortex is exhausted.

It follows that a participant in a thermal comfort experiment should not just be healthy (a fever would drastically alter metabolism rate) but be well rested. It can further be argued that in fast-paced cities where offices operate till late, the need for air-conditioning in offices is necessitated by the chronic sleep deprivation of many workers.

This is supported by a review of research by Gallup and Hack (2011) showing a positive relationship between brain temperature and yawning. They explain the thermoregulatory role of yawning as follows:

First, yawning produces significant changes in circulation, including acceleration in heart rate and elevation of blood pressure. More specifically, powerful jaw stretching during yawning produces increases in neck, head and facial blood flow, and the deep inspiration during yawning produces significant downward flow in cerebrospinal fluid and an increase in blow flow in the internal jugular vein. Together, these processes may act like a radiator removing hyperthermic blood from brain while introducing cooler blood from the lungs and extremities, thereby cooling cortical surfaces through convection. Secondly, it is hypothesized that yawning also provides a direct heat exchange from deep inhalation of cooler ambient air. The air exchange during yawning could cool venous blood draining from the nasal and oral orifices into the cavernous sinus, which surrounds the internal carotid artery supplying blood to the rest of the brain. (Gallup, 2011, p.972)

\subsection{Stress, blood pressure and ambient temperature}

Stress is strongly linked to elevated blood pressure, but blood pressure on the other hand is significantly influenced by ambient temperatures with SBP (systolic, or maximum, blood pressure) lowered by $5 \mathrm{mmHg}$ per $10^{\circ} \mathrm{C}$ increase in ambient temperature (Kunutsor, 2010). 
The stress response has been earlier showed to deliver more resources to the brain and warmer temperatures would negate this benefit by reducing blood pressure. This could explain why when Singaporeans are expected to perform productive mental tasks, it would be an insult to not provide air-conditioning (Hitchings \& Lee, 2008).

This further explains why during a break from the stress of work, that change for a warm environment becomes particularly appealing. Much as Singaporeans may gripe about the excessive air-conditioning of their offices, this condition makes prandial thermophily (selection of a warm environmental temperature for feeding) to be particularly rewarding in terms of alliesthesia, and the return to the chilly office refreshingly welcome.

Stress would limit the circulation of blood to the extremities and elevate core temperature. This paradoxical situation sheds light into why some people experience cold sweaty palms under stress: the cold is a result of blood being shunted from the hands, and the perspiration from the elevated core temperature. Evaporating the sweat on the palms cools the hands and further constricts the circulation, making a bad situation worse. Under such a situation, taking a lunch stroll on a hot afternoon would actually have some therapeutic benefits.

The afternoon lunch break gives office workers a chance to recirculate blood flow to the limbs by strolling out for lunch. The warmth of the walk and eating destination reduces blood pressure and increases peripheral circulation. In preparation for the consumption of a meal, the parasympathetic system is activated, and encouraged by the calming effects of warmth. The previous stress response on the sympathetic system in releasing energy is now replaced by the parasympathetic system in the uptake and storage of energy. This lasts well after lunch, commonly referred to as the post-prandial snooze; an effect easily dismissed with the onset of the next stressor. Once stressed again, the sympathetic nervous system kicks in, the digestive system shuts down and energy is mobilised to tackle the next mental challenge.

\subsection{Stress Physiology and Psychology}

The physiological response to stress can be seen as an action (the stressor) causing a cascade of reactions (in the sympathetic response), which generally tend to increase the 
temperature of the head. The mechanism behind this has been discussed, but it is inadequate to understand this process mechanistically. It is not as if the magnitude of a stressor could be turned like a dial and have the resulting temperature correspond. In the context of the workplace, we mentioned stressors like looming deadlines, difficult coworkers, unreasonable demands from superiors and clients, and so forth. None of these matters present physical dangers (like war and famine) - they are only as significant as one would make them out to be.

Take public speaking for example. To some it comes naturally, and to others it takes extreme coercion. In the latter, and speaking with first-hand experience, it can be accompanied with an elevated heart rate, increased blood pressure, perspiration on the forehead, sweaty palms, cold feet, hyperventilation, etc. The psychology of a person is integral to a stress response on two levels. Firstly an event has to be perceived as a stressor, and secondly the response is limited or amplified in the mind.

An organism is subjected to a painful stimulus, and you are interested in how great a stress-response will be triggered. The bioengineers had been all over that one, mapping the relationship between the intensity and duration of the stimulus and the response. But this time, when the painful stimulus occurs, the organism under study can reach out for its Mommy and cry in her arms. And under these circumstances, this organism shows less of a stress-response.... A critical realization roared through the research community: the physiological stress-response can be modulated by psychological factors. Two identical stressors with the same extent of allostatic disruption can be perceived, can be appraised differently, and the whole show changes from there. Suddenly the stress-response could be made bigger or smaller, depending on psychological factors. (Sapolsky, 1998, p.213)

As a physiologist who has studied stress for many years, I clearly see that the physiology of the system is often no more decisive than the psychology. (Sapolsky, 1998, p.339)

Emotional and mental states, whilst not quantifiable, take as much share as the biological and physical states. And since stress is as much physiological as it is psychological, there is a valid case to be made for the self-evaluation of stress: you are as stressed as you think you are.

The phenomenal power of the mind is clearly manifest in Wim Hof, the Iceman (figure 4.15), Guinness record holder for immersing himself almost naked in ice for over an hour. Dr Ken 
Kamler who specialises in treating hypothermia believes that Hof's ability lies in the wiring of his brain. 'It's very easy to speculate that the same mind control that you use to control your heart when you're scared also can be called upon to control the other organs in the body. And maybe that's how Wim Hof does this', said Kamler. (ABC News, 2008)

This Figure has been removed for copyright or proprietary reasons

Figure 4.15: Wim Hof, the 'Iceman', running a full marathon in northern Finland in temperatures close to $-20^{\circ} \mathrm{C}$ wearing only his shorts. He claims to have prepared for the event with no physical training, but only thermal conditioning in freezing canals and a meat freezer. (Firecracker Films, 2009)

\subsection{The difficulty of an index}

Mental metabolism is missing in models, the existing ones largely cannot be applied to body segments like the head. For example, Gagge's ET* and SET* model (1986) is based on overall skin wettedness. Höppe's (1999) physiological equivalent temperature (PET) is based on the 'Munich energy-balance model for individuals' (MEMI), equations describing (1) the heat flows from body core to skin surface, (2) blood flow from body core to skin and (3) heat resistance of the clothing (Höppe, 1999). Where the heat is concentrated in the brain and dissipation through the face and respiration, it is unlikely these models can be applied accurately.

The purpose of an index is to translate measurable data into controllable conditions. The neurophysiological stress response will result in large interpersonal variations and 
fluctuations dependent on the degree of stress and a response modulated by individual psychology.

There is inadequate data to model the heat generated by the brain in conjunction with mental demands. This is related to fluctuations in core temperature and varying heat flows to the brain, the role of smooth muscles on facial veins to different concentrations of stress hormones, the location of perspiration and their different rates, the breathing rate, and many other confounding factors. Even if the data was available to model the precise heat flows, the actual response will vary through the day, depending on stress, determined by psychology. Where the resultant temperature is correlated to productivity, the cognitive performance is affected by dehydration, sleep and other factors that demand attention from the cognitive workspace.

\footnotetext{
If, say, a pianist plays a Bach fugue, I can listen to it and can watch him play and probably can adequately describe his playing. As critic, I might even be more competent to write about the concert than the pianist himself, but there remains something known only to the pianist. He plays, and he "erlebt", he experiences the playing of the fugue. To act is "unhinterfragbar", cannot be "questioned behind" or derived from something else. Any question about the quality of the experience of the pianist (1) is itself an act (and not a description of an act) and therefore presupposes that the questioner is able to act or at least "knows" what it means to act from his own experience, and (2) can finally be answered only by performing the actions of the pianist oneself, by doing something instead of talking about doing something. (Janich, 1990, p.154)
}

To borrow Janich's distinction between the unknown and the unknowable, the thermal response of humans under stress might be unknown till now but the complexity of an individual's thermal evaluation is, in my view, unknowable. The pianist in our study would be the office occupant, the performance would be the adaptive behaviour sought by an occupant. The pleasure he "erlebt" (or undergoes) is uniquely his own experience, and something that the thermal comfort researcher can observe, document and analyse. Yet the researcher will never attain the experience that underpins the expression of comfort. For the occupant, it is a satisfaction of mind known only to him.

In other words, only the occupant knows what his 'perfect' temperature is. 


\subsection{Concluding thoughts on brain cooling}

Stress arouses the the sympathetic nervous system and many of these effects require a thermoregulatory response. A number of autonomic nervous responses also parallel those needed to thermoregulate, especially in the area of SBC. The global workspace theory explains why sleep and hydration also have indirect but strong influences on cognitive performance and temperature demands.

In the office environment the most effective cooling response for productive mental work will be from facial cooling and respiration. However whilst stress can be measured by the concentration of circulating stress hormones, the stress physiology is modulated by a person's psychology.

Work stress can explain why field studies reveal a desire for colder temperatures than the climate chamber studies would determine. The confounding factors and diversity of possible responses also reveal why a common temperature cannot universally satisfy.

The practical consequence of this literature survey suggests that air-conditioning is not only needed for productive mental work in a stressful environment, but more airconditioning is needed than was predicted with the PMV model. Due to the efficacy of facially applied air-conditioning, there should be a special effort to deliver chilled air to both the face and breathing zone, instead of delivering ambient cooling. The variety of working demands require versatile and personal control: the air velocity affecting the facial skin cooling and the air temperature affecting the respiratory cooling.

Lee Kuan Yew, who made Singapore the air-conditioned nation, works in an office set at $22^{\circ} \mathrm{C}$ and sleeps at $19^{\circ} \mathrm{C}$ (McCarthy, 1999). For a person with undisputed mental performance, he may have intuitively known the impact of air-conditioning on a developing knowledgebased economy. 
Law (20I2) The Future of Thermal Comfort in an Energy-Constrained World 


\section{Comfort Energetics - Thermal Comfort Under Energy Constraints}

This chapter represents an energy-conscious approach to understanding thermal comfort. With the environmental variable of T, MRT, RH and wind $\mathrm{v}$ as its structure, it begins with a psychrometric analysis where the roles of temperature and humidity are denominated in PMV votes and the power needed to improve those votes. The role of humidity is critically reviewed with a case made for challenging the accepted norms an optimum RH range. Finally the efficacy of moving air is analysed in the different ways it can be employed.

\subsection{Case-study: The Windup Girl}

The PMV is the most popular standard for air-conditioned buildings, underpinning the ISO 7730 and ASHRAE 55 standards. It is used as a tool to assist mechanical engineers in specifying the correct plant sizes to meet the anticipated space cooling requirements. It is common that the engineering tools and rules of thumbs already have a safety margin, in addition to which engineers typically load another margin (Houghton, 1998). Assumed in this approach is that there will not be any energy constrains placed in the life of the building and its equipment. It assumes that it is acceptable to over-engineer the mechanical ventilation system for that worst case scenario with the consolation that it can always be operated at partial load, even if that requires far more power than running a correctly sized plant at full load.

In his award winning science-fiction novel The Windup Girl, Bacigalupi (2009) paints the world post global-warming, where the oil economy has collapsed and the primary sources of energy are from methane composters and food calories. Electricity is so scarce it only exists to run government-owned computers, and personal computers are pedal operated like an old-fashioned sewing machine. Energy is produced by the muscles of people or beasts of burden, then stored kinetically in either flywheels or springs to power factories, transport and weapons. What is realistic and sobering about Bacigalupi's future is the 
challenge he makes to many assumptions we take for granted: unlimited resource, continued global collaboration, genetic diversity. What if the only energy available was what we could muster from our muscles in a world with limited food?

Overhead, the towers of Bangkok's old Expansion loom, robed in vines and mold, windows long ago blown out, great bones picked clean. Without air conditioning or elevators to make them habitable, they stand and blister in the sun. (Bacigalupi, 2009, p.10)

The windup girl, the protagonist of the story, is a genetically modified woman with porcelain-perfect skin and greatly reduced pores, once a secretary for the rich who could afford air-conditioning, she has now been abandoned in hot-humid Bangkok.

Even with her augmented vision she barely spies the pores of her flesh. So small. So delicate. So optimal. But made for Nippon and a rich man's climate control, not for here. Here, she is too hot and sweats too little. She wonders if she were a different kind of animal, some mindless furry cheshire, say, if she would feel cooler. Not because her pores would be larger and more efficient and her skin not so painfully impermeable, but simply because she wouldn't have to think. She wouldn't have to know that she had been trapped in this suffocating perfect skin by some irritating scientist with his test tubes and DNA confetti mixes who made her flesh so so smooth, and her insides too too hot. (Bacigalupi, 2009, p.51) 
This Figure has been removed for copyright or proprietary reasons 


\subsection{PMV, psychrometrically analysed}

If presented with the severe energy constraints of Bacigalupi's Bangkok, how would one reapply the principles underpinning the PMV model so that our windup girl does not overheat? For argument's sake, assume she votes on the comfort scale the same way normal people do. The aim here is to provide improvement to comfort with the smallest energy input. Starting with a reference condition (table 5.1), one can determine the impact on PMV with each variable changed, and the corresponding energy needed to drive the change.

\begin{tabular}{|l|c|c|}
\hline \multicolumn{2}{|c|}{ Reference occupant } & Notes \\
\hline Ventilation rate & $10 \mathrm{I} / \mathrm{s} / \mathrm{pax}$ & Typical rate in practice (Melikov, 2002) \\
\hline T, outside & $30^{\circ} \mathrm{C}$ & \\
\hline RH, outside & $70 \%$ & \\
\hline Air speed & $0.05 \mathrm{~m} / \mathrm{s}$ & Between 0.5 and 1.0 clo \\
\hline Clothing & $0.7 \mathrm{clo}$ & used to generate comfort envelope in ASHRAE $55\{2010\}$ p.6,24 \\
\hline Metabolic Rate & $1.1 \mathrm{met}$ & As used to generate comfort envelope in ASHRAE 55 (2010) pp.6,24 \\
\hline PMV & +2.0 & \\
\hline Air-conditioning & C.O.P. $=3$ & one watt of electricity transporting 3 watts of heating/cooling \\
\hline \multicolumn{3}{|l}{} \\
Omitted items: Envelope thermal load, internal heat load, fan power
\end{tabular}

Table 5.1: Reference conditions for study in comfort energetics

The windup girl, for this exercise, will be housed in a small and heavily insulated cubicle ( $1 \mathrm{~m} \times 1 \mathrm{~m} \times 2.4 \mathrm{~m}$, see figure 5.2). Fresh air is supplied at low level by displacement ventilation at a rate of $10 \mathrm{l} / \mathrm{s}$ in a small space (c.f. Fanger, 2000), the air change will be high at 15 ach (air-changes per hour). Under steady-state conditions, air is exhausted at the same rate as it is being supplied, and there is no recirculation. It is assumed that the supply air temperature will be the same as room air temperature and MRT. 


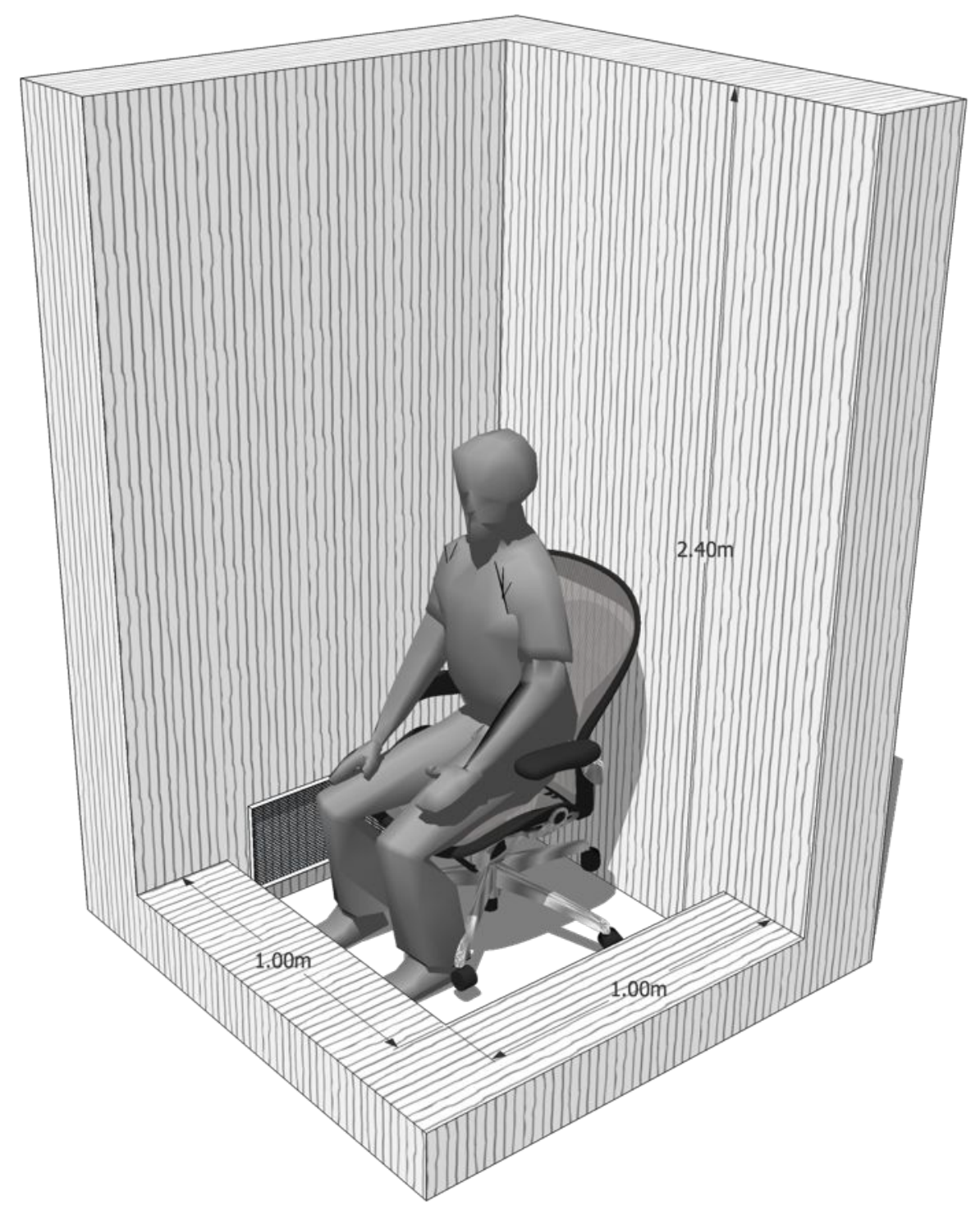

Figure 5.2: Climate booth to determine energy required to improve PMV by various cooling processes

The following calculations determine how much energy is required for each process, and the extent to which the PMV is improved. As the heat loads (external and internal) are independent of process, they have been omitted to simplify the calculations.

Four methods are plotted psychrometrically with about 7 steps in each process, in which the PMV is compared to the energy required for each step shown below and tabulated in 5.2.

1. Cooling without dehumidification: air is cooled at constant moisture ratio up to dew point $\left(30^{\circ} \mathrm{C}\right.$ to $24^{\circ} \mathrm{C}, 1^{\circ} \mathrm{C} /$ step). 
2. Cooling with dehumidification: air is cooled past dew point (70\%RH to $40 \% \mathrm{RH}$, $5 \%$ RH/step).

3. Direct evaporative cooling: air is humidified at constant enthalpy (70\%RH to $100 \% \mathrm{RH}, 5 \% \mathrm{RH} /$ step). This process is actually passive so the only energy input has been the embodied energy of water (for sourcing, conveyance, treatment, distribution, end use and water treatment, Cohen, 2004).

4. Desiccant dehumidification: air is dehumidified by desiccant (constant enthalpy) and allowed to cool to ambient (constant T) (70\%RH to 30\%RH, 5\%RH/step)

\begin{tabular}{|c|c|c|c|c|c|c|c|c|}
\hline \multicolumn{9}{|c|}{ Cooling, no dehumidification } \\
\hline $\mathrm{T}$ & $\mathrm{RH}$ & $\mathrm{PMV}$ & $\begin{array}{c}\mathrm{H} \\
(\mathrm{kJ} / \\
\mathrm{kg})\end{array}$ & $\begin{array}{c}\mathrm{dH}(\mathrm{kJ} / \\
\mathrm{kg})\end{array}$ & $\begin{array}{c}\text { Spec vol } \\
\left(\mathrm{m}^{3} / \mathrm{kg}\right)\end{array}$ & $\begin{array}{c}\text { Power } \\
(\mathrm{W})\end{array}$ & $\begin{array}{c}\text { Thermal } \\
\text { W/vote }\end{array}$ & $\begin{array}{c}\text { Electrical } \\
\text { W/vote }\end{array}$ \\
\hline $30^{\circ} \mathrm{C}$ & $70 \%$ & 1.994 & 78.37 & & & & & \\
\hline $29^{\circ} \mathrm{C}$ & $74 \%$ & 1.728 & 77.33 & 1.04 & 0.882 & 11.8 & 44.3 & 14.8 \\
\hline $28^{\circ} \mathrm{C}$ & $79 \%$ & 1.454 & 76.29 & 2.08 & 0.879 & 23.7 & 43.8 & 14.6 \\
\hline $27^{\circ} \mathrm{C}$ & $83 \%$ & 1.181 & 75.24 & 3.13 & 0.8761 & 35.7 & 43.9 & 14.6 \\
\hline $26^{\circ} \mathrm{C}$ & $88 \%$ & 0.907 & 74.2 & 4.17 & 0.8732 & 47.8 & 43.9 & 14.6 \\
\hline $25^{\circ} \mathrm{C}$ & $94 \%$ & 0.632 & 73.16 & 5.21 & 0.8703 & 59.9 & 44.0 & 14.7 \\
\hline $24{ }^{\circ} \mathrm{C}$ & $100 \%$ & 0.356 & 72.12 & 6.25 & 0.8674 & 72.1 & 44.0 & 14.7 \\
\hline
\end{tabular}

\begin{tabular}{|c|c|c|c|c|c|c|c|c|}
\hline \multicolumn{9}{|c|}{ Cooling + Dehumidification } \\
\hline $\begin{array}{c}\mathrm{RH} \\
\text { equivalent } \\
\text { (if at } 30^{\circ} \mathrm{C} \text { ) }\end{array}$ & $\begin{array}{l}\text { Dew } \\
\text { Pt }\end{array}$ & $\begin{array}{l}\text { PMV } \\
@ d p\end{array}$ & $\begin{array}{l}\mathrm{H}- \\
\mathrm{dp}\end{array}$ & $\begin{array}{c}\mathrm{dH}(\mathrm{kJ} / \\
\mathrm{kg})\end{array}$ & $\begin{array}{l}\text { Spec vol } \\
\left(\mathrm{m}^{3} / \mathrm{kg}\right)\end{array}$ & $\begin{array}{l}\text { Power } \\
\text { (W) }\end{array}$ & $\begin{array}{l}\text { Thermal } \\
\text { W/vote }\end{array}$ & $\begin{array}{l}\text { Electrical } \\
\text { W/vote }\end{array}$ \\
\hline $70 \%$ & 23.93 & 0.327 & 72.04 & & & & & \\
\hline $65 \%$ & 22.7 & -0.056 & 67.22 & 11.15 & 0.862 & 136 & 66.5 & 22.2 \\
\hline $60 \%$ & 21.39 & -0.467 & 62.36 & 16.01 & 0.856 & 194 & 78.8 & 26.3 \\
\hline $55 \%$ & 19.98 & -0.908 & 57.41 & 20.96 & 0.850 & 254 & 87.4 & 29.1 \\
\hline $50 \%$ & 18.45 & -1.376 & 52.36 & 26.01 & 0.844 & 315 & 93.5 & 31.2 \\
\hline $45 \%$ & 16.78 & -1.903 & 47.19 & 31.18 & 0.837 & 379 & 97.4 & 32.5 \\
\hline $40 \%$ & 14.94 & -2.487 & 41.86 & 36.51 & 0.830 & 447 & 99.7 & 33.2 \\
\hline
\end{tabular}

\begin{tabular}{|c|c|c|c|c|c|c|c|}
\hline \multicolumn{9}{|c|}{ Direct evaporative cooling } \\
\hline $\mathrm{RH}$ & $\begin{array}{c}\mathrm{T} \\
\left({ }^{\circ} \mathrm{C}\right)\end{array}$ & PMV & $\begin{array}{c}\mathrm{HR}(\mathrm{g} / \\
\mathrm{kg})\end{array}$ & $\begin{array}{c}\text { Vapour density } \\
\left(\mathrm{g} / \mathrm{m}^{3}\right)\end{array}$ & $\begin{array}{c}\text { Humidfication } \\
(\mathrm{g} / \mathrm{sec})\end{array}$ & $\begin{array}{c}\text { Power } \\
(\mathrm{W})\end{array}$ & $\begin{array}{c}\text { Electrical } \\
\text { W/vote }\end{array}$ \\
\hline $70 \%$ & 30 & 1.994 & 18.89 & 21.33 & & & \\
\hline $75 \%$ & 29.17 & 1.796 & 19.23 & 21.76 & 0.0043 & 0.030 & 0.154 \\
\hline $80 \%$ & 28.33 & 1.561 & 19.57 & 22.2 & 0.0087 & 0.062 & 0.142 \\
\hline $85 \%$ & 27.56 & 1.385 & 19.89 & 22.6 & 0.0127 & 0.090 & 0.148 \\
\hline $90 \%$ & 26.83 & 1.175 & 20.18 & 22.98 & 0.0165 & 0.117 & 0.143 \\
\hline $95 \%$ & 26.11 & 0.993 & 20.48 & 23.37 & 0.0204 & 0.145 & 0.145 \\
\hline $100 \%$ & 25.5 & 0.84 & 20.73 & 23.69 & 0.0236 & 0.167 & 0.145 \\
\hline
\end{tabular}




\begin{tabular}{|c|c|c|c|c|c|c|c|c|}
\hline \multicolumn{9}{|c|}{ Desiccant dehumidification } \\
\hline $\mathrm{RH}$ & $\mathrm{PMV}$ & $\begin{array}{c}\mathrm{H} \\
(\mathrm{kJ} / \\
\mathrm{kg})\end{array}$ & $\begin{array}{c}\mathrm{HR} \\
(\mathrm{g} / \\
\mathrm{kg})\end{array}$ & $\begin{array}{c}\mathrm{dH}(\mathrm{kJ} / \\
\mathrm{kg})\end{array}$ & $\begin{array}{c}\text { Spec } \\
\text { vol }\left(\mathrm{m}^{3} \mathrm{~kg}\right)\end{array}$ & $\begin{array}{c}\text { Power } \\
(\mathrm{W})\end{array}$ & $\begin{array}{c}\text { Thermal } \\
\text { W/vote }\end{array}$ & $\begin{array}{c}\text { Electrical } \\
\text { W/vote }\end{array}$ \\
\hline $70 \%$ & 1.994 & 78.37 & 18.88 & & 0.8849 & & & \\
\hline $65 \%$ & 1.943 & 74.83 & 17.49 & 3.54 & 0.883 & 40.1 & 786.1 & 262.0 \\
\hline $60 \%$ & 1.892 & 71.3 & 16.11 & 7.07 & 0.8811 & 80.2 & 786.7 & 262.2 \\
\hline $55 \%$ & 1.841 & 67.79 & 14.74 & 10.58 & 0.8792 & 120.3 & 786.5 & 262.2 \\
\hline $50 \%$ & 1.79 & 64.29 & 13.37 & 14.08 & 0.8773 & 160.5 & 786.7 & 262.2 \\
\hline $45 \%$ & 1.738 & 60.8 & 12.01 & 17.57 & 0.8754 & 200.7 & 784.0 & 261.3 \\
\hline $40 \%$ & 1.687 & 57.33 & 10.65 & 21.04 & 0.8735 & 240.9 & 784.6 & 261.5 \\
\hline $35 \%$ & 1.636 & 53.88 & 9.3 & 24.49 & 0.8717 & 280.9 & 784.8 & 261.6 \\
\hline $30 \%$ & 1.585 & 50.44 & 7.95 & 27.93 & 0.8696 & 321.2 & 785.3 & 261.8 \\
\hline
\end{tabular}

Table 5.2: Four methods analysed psychrometrically. Software: PMV

determined by PMV_Calc_V 2 Modified by Håkan Nilsson, Department of

Technology and Built Environment, Laboratory of Ventilation and Air Quality,

University of Gävle. Psychrometry based on PsyCalcg8 ver 3.1, 2008.

When the energy input for each step change is tallied with comfort outcome, it was observed that there is a good linear fit (with the exception of 'cooling with dehumidification') where each step change of equal magnitude in T or RH were matched by both 'comfort' and 'electrical W/vote'.

\subsection{Comfort Energetics}

In recognising that there can be multiple ways of achieving a better comfort vote, how do we determine which method has the most effective use of the energy input? A new unit for comfort energetics, watts per vote, is proposed to express this rating. By comparing different cooling techniques and expressing the energy needed to improve PMV by one vote we have an index to rate the efficacy of each approach to thermal comfort.

The comfort energetics, in watts/vote are summarised and the cooling technique ranked in terms of PMV efficacy (table 5.3). 


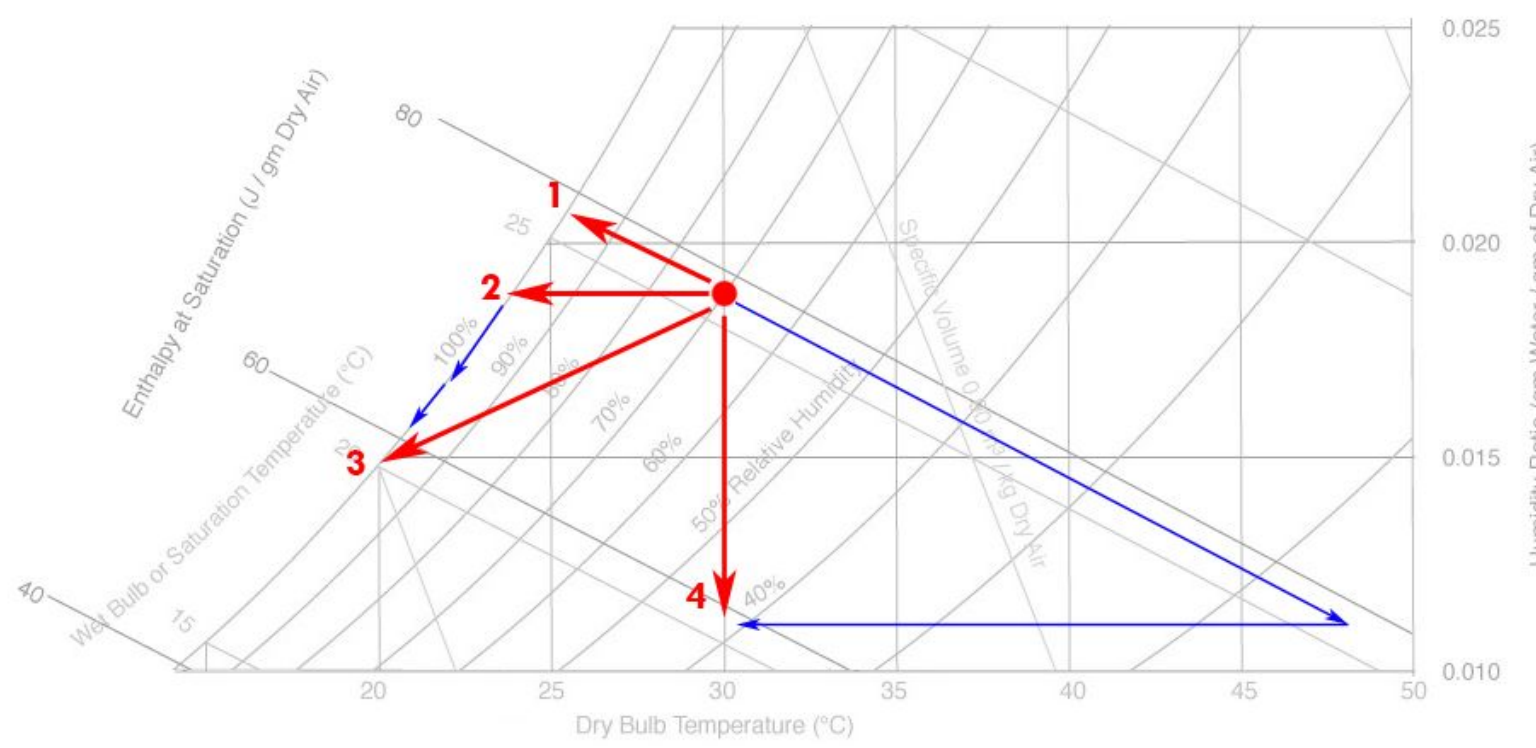

\begin{tabular}{|c|l|l|c|c|}
\hline Rank & \multicolumn{1}{|c|}{ Comfort approach } & \multicolumn{1}{c|}{ Process } & $\begin{array}{c}\text { Comfort Energetics } \\
\text { (watts/vote) }\end{array}$ & \multicolumn{1}{c|}{ S.D. } \\
\hline 1 & Direct evaporative cooling & Adiabatic humidification & 0.15 & $2.9 \%$ \\
\hline 2 & Refrigeration up to dew point & Constant humidity ratio (isodrosothermic) & 15 & $0.4 \%$ \\
\hline 3 & Refrigeration past dew point & Cooling with dehumidification & 28 & $15.7 \%$ \\
\hline 4 & Desiccant dehumidification & Adiabatic + isothermic dehumidification & 262 & $0.1 \%$ \\
\hline
\end{tabular}

Table 5.3: Cooling methods analysed in terms of energetics

With the exception of "Refrigeration Past Dew Point" the comfort energetics described in watts/vote show good linearity and minimal deviation (s.d. $<3 \%$ ), indicative that the comfort energetics are constant and independent of the starting PMV. In other words, an improvement in comfort from +3 to +2 will require the same amount of energy as +2.5 to $+1.5,+1$ to 0 and so forth.

Whilst the linear fit was unexpected it is convenient that the ordinal scale of the comfort vote could relate so well with the numerical scale of the psychrometric chart.

\subsubsection{Comfort in high humidity}

We can also see that a change in temperature has a far more profound impact on comfort than a change in humidity. This is not new, the ISO 7730 standard mentions that "typically a $10 \%$ higher relative humidity is felt to be as warm as a $0.3{ }^{\circ} \mathrm{C}$ rise in the operative temperature." There is however little meaning to compare $\% \mathrm{RH}$ to $\mathrm{T}^{\circ} \mathrm{C}$ unless it can be denominated in terms of the energy embodied to drive the change. Based on the 
psychrometric analysis of a PMV response, reducing air temperature will drive a response far more significant than the reduction in humidity. So in terms of comfort energetics we can say that reducing temperature (15W/vote) is 17 times more effective than reducing relative humidity (262W/vote), and that an evaporative cooler is 100 times more effective in achieving comfort than an air-conditioner, even if the air-conditioner does not perform any dehumidifying function.

This marginal impact of humidity is consistent with de Dear's findings that in climate chambers held at 35\%RH and 70\%RH respectively there were no significant differences in preferred temperature (de Dear, 1991).

If energy was the only constraint, and thermal comfort the only consideration, than misting fans with their saturated supply air offer unmatched comfort energetics. These are used in outdoor and semi-outdoor settings with the common notion that they are unsuitable for indoor use because they increase the moisture ratio of indoor air. From the human thermal comfort point if view, this logic is flawed. If the indoors and outdoors were at the same temperature and the misting fans were merely saturating the air surrounding an occupant, than there is no psychrometric difference. If all environmental $\left(\mathrm{T}^{\circ} \mathrm{C}, \mathrm{RH} \%, \mathrm{MRT}^{\circ} \mathrm{C}\right.$ and $\mathrm{v}$ $\mathrm{m} / \mathrm{s}$ ) and personal variables (clo and met) were made equal to both indoor and outdoor conditions, the PMV will be identical. Likewise, the adaptive model will show that if the daily, or mean monthly $\mathrm{T}$, were the same in both the in and outdoor, the ideal $\mathrm{T}$ will be the same. So strictly speaking, from the thermal comfort perspective, there should be no objection that would prejudice against the indoor operation of misting fans, an example being provided by gadget blogger Christen Costa (2012).

Low humidity is associated with higher evaporation rates of the skin. The operative parameter should be that of absolute humidity rather than relative humidity. In the earlier calculation, air at $30^{\circ} \mathrm{C}$ and $70 \% \mathrm{RH}$ had a dew point of $24^{\circ} \mathrm{C}$. It should not be assumed that skin cannot dry in air at $100 \% \mathrm{RH}$ as the saturated vapour pressure of moist skin of $5.3 \mathrm{kPa}$ (at $34^{\circ} \mathrm{C}$ ) is still significantly higher than that of the air of $3.0 \mathrm{kPa}\left(\right.$ at $\left.24^{\circ} \mathrm{C}\right)$. The vapour pressure difference will drive moisture from perspiration to evaporate and re-condense in the saturated air as steam, a phenomena similar to breathing out mist in cold weather. 
In an excellent review on the effect of high humidity levels on comfort (Fountain, 1999) research has consistently showed that the impact of humidity on comfort is minor.

\begin{tabular}{|c|c|c|c|c|}
\hline Year & $\begin{array}{l}\text { First } \\
\text { Author }\end{array}$ & T range tested & $\begin{array}{l}\mathrm{RH} \\
\text { range } \\
\text { tested }\end{array}$ & Effects noted \\
\hline 1923 & Houghten & $26.7-69.4^{\circ} \mathrm{C}$ & $\begin{array}{l}22.8^{-}-45^{\circ} \mathrm{C} \text { wet } \\
\text { bulb }\end{array}$ & $\begin{array}{l}\text { In comfort zone, comfort depends equally on wet- and dry-bulb } \\
\text { temperature }\end{array}$ \\
\hline 1950 & Glickman & Unspecified & $20-80 \% \mathrm{RH}$ & $\mathrm{ET}^{*}$ overemphasizes $\mathrm{RH}$ for long exposures \\
\hline 1960 & Koch & $20-34^{\circ} \mathrm{C}$ & $20-90 \% \mathrm{RH}$ & Small over entire range \\
\hline 1966 & Nevins & $18.9-27.8^{\circ} \mathrm{C}$ & $15-85 \% \mathrm{RH}$ & Increase of $0.3^{\circ} \mathrm{C}$ temperature $=$ decrease of $10 \%$ RH for sensation \\
\hline 1967 & McNall & $15.6-40.6^{\circ} \mathrm{C}$ & $20-90 \% \mathrm{RH}$ & No effect at low met, some effect at higher met \\
\hline 1973 & Anderson & $23^{\circ} \mathrm{C}$ & $10-70 \% \mathrm{RH}$ & None \\
\hline 1987 & Tanabe & $27.8-31.3^{\circ} \mathrm{C}$ & $50-80 \% \mathrm{RH}$ & PMV predicts TS too high \\
\hline 1989 & Berglund & $21-27.2^{\circ} \mathrm{C}$ & $20-95 \% \mathrm{RH}$ & $\begin{array}{l}\text { Temperature order of magnitude more important for determining } \\
\text { comfort }\end{array}$ \\
\hline 1989 & Hayakawa & $30-35^{\circ} \mathrm{C}$ & $30-90 \% \mathrm{RH}$ & $\begin{array}{l}\text { No effect on thermal sensation up to } 70 \% \text { - discomfort increased } \\
\text { significantly with elevated metabolism }\end{array}$ \\
\hline 1994 & Tanabe & $25-30^{\circ} \mathrm{C}$ & $30-70 \% \mathrm{RH}$ & SET* good relation with TS \\
\hline 1994 & Tanabe & $26-28^{\circ} \mathrm{C}$ & $35-75 \% \mathrm{RH}$ & TS vote at 1.2 met similar for all RH \\
\hline 1995 & Berglund & $\begin{array}{l}\text { Reananlysis of } 1989 \\
\text { data }\end{array}$ & & Increased discomfort above $18^{\circ} \mathrm{C} \mathrm{WB}$ \\
\hline 1996 & Bauman & $\begin{array}{l}26.1-26.6^{\circ} \mathrm{C} \mathrm{ET*/} \\
26.2-28.1^{\circ} \mathrm{C} \mathrm{SET*}\end{array}$ & $50-80 \% \mathrm{RH}$ & $\begin{array}{l}\text { No change in TS, no difference in acceptability except under increased } \\
\text { met }\end{array}$ \\
\hline 1999 & Fountain & $20-25^{\circ} \mathrm{C}\left(\mathrm{ET} T^{*}\right)$ & $\begin{array}{l}60-90 \% \mathrm{RH} \\
(9-15 \mathrm{~g} / \mathrm{kg})\end{array}$ & $\begin{array}{l}\text { acceptable humidity limit can be quite high when subjects are } \\
\text { sedentary }\end{array}$ \\
\hline
\end{tabular}

Table 5.4: Literature on comfort in high RH (Fountain, 1999)

Dehumidification improves comfort very marginally and comes at considerable energetic cost. Dehumidification by cooling air past its dew point involved double the comfort energetics as compared to cooling without passing passing the dew point. In typical airconditioning applications the dehumidified air is chilled so far below comfort it has to be reheated. Though this can be done with passive devices (e.g. Dinh heat pipes) it is common for the reheat cycle to be performed by electrical heaters, bringing the comfort energetics to 3 - 4 times that of cooling without dehumidification.

High humidity is not contrary to thermal comfort. The ISO 7730 (2005) standard repeatedly states that whilst humidity affects comfort, its impact is minor.

The influence of humidity on thermal sensation is small at moderate temperatures close to comfort and may usually be disregarded when determining the PMV value. (p.4) 
If humidity limits are based on the maintenance of acceptable thermal conditions based solely on comfort considerations - including thermal sensation, skin wetness, skin dryness, and eye irritation - a wide range of humidity is acceptable. (p.44)

Why then all this trouble to dehumidify?

\subsubsection{Understanding humidity}

It is a common perception that humidity affects comfort and IAQ. In ASHRAE's "Top Ten Things Consumers Should Know About Air Conditioning" (http://www.ashrae.org/ education/page/1455\#10) it is mentioned:

\footnotetext{
Humidity control was the problem that originally spurred the need for air conditioning. Lack of humidity control in hot, humid climates, in particular, can lead to mold growth and other moisture-related problems. High indoor humidities can lead to health and comfort problems. Modern air conditioners dehumidify as they cool; you can see that by the water that drains away, but this dehumidification is incidental to their main job of controlling temperature.
}

Humidity, to the technical minded, can often be used too loosely.

Humidity ratio (HR) expresses the masses of moisture to dry air, as a ratio in $\mathrm{g} / \mathrm{kg}$. Relative humidity (RH) expresses the vapour pressure in air as a percentage of the maximum it can potentially be at the same temperature. Until dew point is reached, HR is unaffected by temperature, whereas $\mathrm{RH}$ is always temperature-dependent.

Another common misconception is that when air is saturated it cannot contain more moisture. This is incorrect. At high altitudes and in the absence of condensing nuclei, air can be supersaturated to 'several hundred per cent' (Battan, 2003, p.8). Where condensing nuclei are present it will be correct to say that air cannot contain more moisture in the vapour state, yet still more moisture can still be accommodated as suspended droplets. For instance if one were to breathe outdoors on a cold morning when the air is saturated, one can observe a breath mist. In a similar condition if one were to go for a run, the profuse perspiration will evaporate, condense into suspended droplets, and appear as steam emerging from the hot skin. It is thus incorrect to think of saturated air being incapable of accommodating more moisture. The determining function is that as long as the saturated 
vapour pressure of skin was higher than the vapour pressure of air, perspiration can still evaporate.

Currently the most complete treatise on this topic will be ASHRAE 90421 Humidity Control Design Guide for Commercial and Institutional Buildings (Harriman, Brundrett, \& Kittler, 2008) which begins with a preface 'It appears to be the first time in the 101-year history of the Society that ASHRAE has focused a book on this topic.' The guide admits the uncertainty in defining a measure of RH and shows the variation over thee editions of the same standard (figure 5.3). However there is a range of HR (corresponding to dew point temperaure) that satisfies the three editions. The guide states, "What does seem consistent is the sedentary people are likely to find comfort in all seasons when the dew points between $1.7^{\circ} \mathrm{C}$ and $13.9^{\circ} \mathrm{C} \cdot(\mathrm{p} .73)$
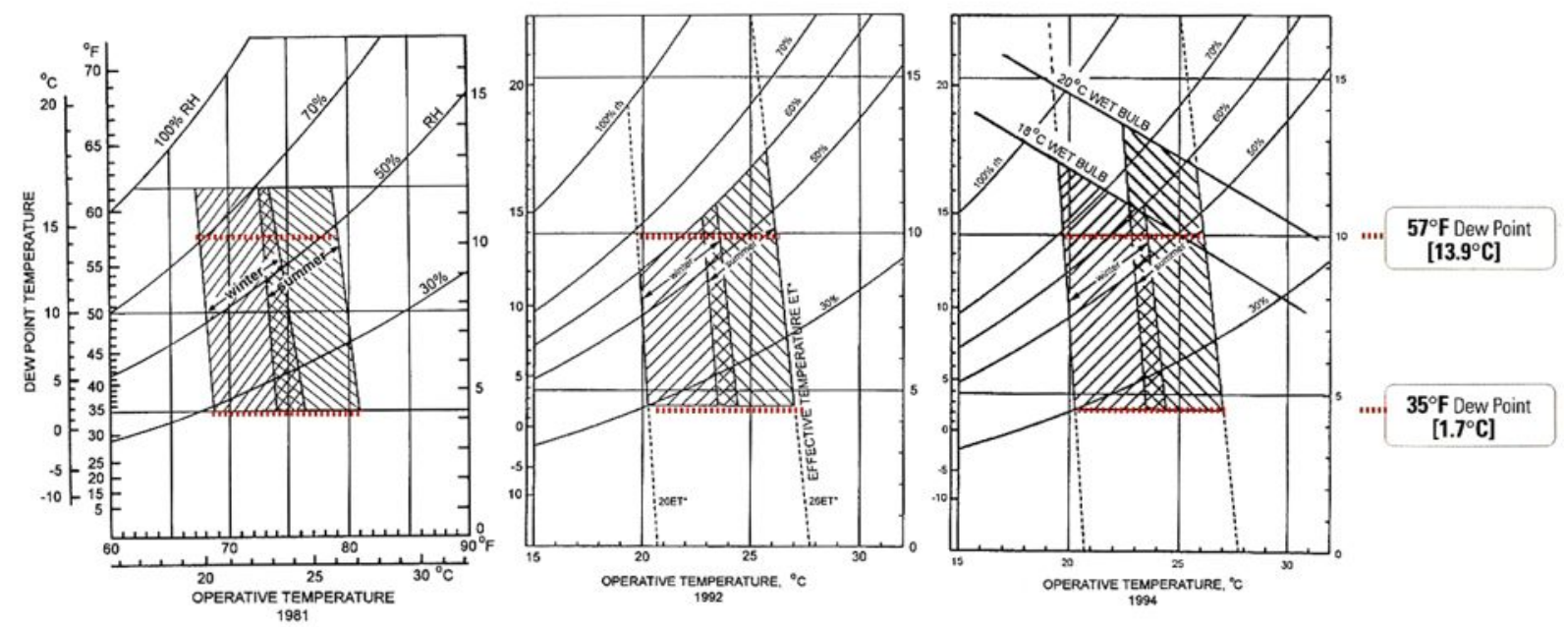

Figure 5.3: Uncertainty in the RH stipulation in the ASHRAE-55 standard in years 1981, 1992 and 1994 (Harriman, Brundrett, \& Kittler, 2008).

As this issue is of fundamental interest to the development of comfort energetics, we shall investigate it at length.

\subsubsection{Optimum RH and ASHRAE 55 misrepresented}

The ASHRAE-55 2004 revision maintained the upper $12 \mathrm{~g} / \mathrm{kg}\left(17^{\circ} \mathrm{C}\right.$ dew point) limit and removed the lower limit. The 2010 revision maintains the 2004 limits for the graphical (i.e. psychrometric) approach but also allows the software (PMV) approach, for which the RH has no stated limit. With the PMV approach, as long as the range is within \pm 0.5 
(corresponding to PPD < 10\%), the conditions are deemed to be within the comfort zone (ASHRAE, 2010, p7).

When optimum RH values are recommended, the ASHRAE 55 and other standards have been serially misquoted by major references and texts (see table 5.5). An examples is:

The earlier accepted relative humidity range, 20-80 percent, was based primarily on comfort concerns; the narrower range today, 30-60\%, incorporates health considerations. (Burroughs, 2011, p.148)

\begin{tabular}{|c|c|c|c|c|c|c|}
\hline \multicolumn{2}{|c|}{ 1st author, ref } & \multirow{2}{*}{$\begin{array}{l}\mathrm{Yr} \\
2011\end{array}$} & \multirow{2}{*}{$\begin{array}{l}\text { Recom. } \\
\mathrm{RH} \\
30-60 \% \mathrm{RH}\end{array}$} & \multicolumn{2}{|r|}{ Rationale, sources } & \multirow{2}{*}{\begin{tabular}{l}
\multicolumn{1}{|c}{ Comments } \\
Only ASHRAE and Green appear \\
in bibliography. Still cites \\
ASHRAE-55 (1992) though \\
humidity standards have been \\
superseded in 2004, and again in \\
2011.
\end{tabular}} \\
\hline Burroughs & $\begin{array}{c}\text { Managing } \\
\text { IAQ (5th ed.) }\end{array}$ & & & Health & $\begin{array}{l}\text { ASHRAE, Proetz, Andrews, Ritzel, Sale, } \\
\text { Gelperin and Green }\end{array}$ & \\
\hline Nufert & $\begin{array}{l}\text { Architect's } \\
\text { Data (3rd } \\
\text { ed.) }\end{array}$ & 2002 & $\begin{array}{l}50-60 \% \mathrm{RH} \\
40-70 \% \mathrm{RH}\end{array}$ & $\begin{array}{l}\text { Comfort } \\
\text { Health }\end{array}$ & - & \\
\hline Adler & $\begin{array}{c}\text { Metric } \\
\text { Handbook } \\
\text { (2nd ed.) }\end{array}$ & 1999 & 40-70\%RH & Comfort & - & \\
\hline Avallone & $\begin{array}{l}\text { Marks' } \\
\text { Standard } \\
\text { Handbook } \\
\quad \text { for } \\
\text { Mechanical } \\
\text { Engineers } \\
\text { (11th ed.) }\end{array}$ & 2007 & $\begin{array}{l}\min .0 .0045 \\
\text { HR, max. } \\
60 \% \text { RH }\end{array}$ & Comfort & ASHRAE Handbook (1993) & \\
\hline Kreith & $\begin{array}{c}\text { Mechanical } \\
\text { Engineering } \\
\text { Handbook }\end{array}$ & 1999 & $\begin{array}{l}<30 \% \text { or } \\
>60 \% \mathrm{RH}\end{array}$ & $\begin{array}{l}\text { Energy } \\
\text { economy }\end{array}$ & ASHRAE 90.1 (1989) & $\begin{array}{l}\text { Standard for economy to not } \\
\text { dehumidify below } 60 \% \mathrm{RH} \text { or } \\
\text { humidify above } 30 \% \mathrm{RH}\end{array}$ \\
\hline Stein & $\begin{array}{l}\text { Mechanical } \\
\text { and } \\
\text { Electrical } \\
\text { Equipment } \\
\text { for Buildings } \\
\text { (10th ed.) }\end{array}$ & 2006 & $\begin{array}{c}\text { none, } \\
\text { inconclusive }\end{array}$ & Comfort & $\begin{array}{l}\text { ASHRAE } 55 \text { (1995, 2004), ASHRAE } \\
\text { Handbook (1997, 2001), Egan (1975), } \\
\text { Givoni (1998), Heschong (1979), } \\
\text { Humphreys \& Nicol (1998), Kwok (1998), } \\
\text { Lechner (2001), Milne (1979), Olgyay } \\
\text { (1963) }\end{array}$ & $\begin{array}{l}\text { Recognises that ASHRAE } 55 \text { only } \\
\text { stipulates control of HR, not \%RH. } \\
\text { Also recognises adaptive model } \\
\text { has no } \mathrm{RH} \text { recommendations. }\end{array}$ \\
\hline Bas & $\begin{array}{l}\text { IAQ - A } \\
\text { Guide for } \\
\text { Facility } \\
\text { Managers }\end{array}$ & 2003 & $\begin{array}{l}\text { 30-60\%RH } \\
50 \% \mathrm{RH} \text { ideal }\end{array}$ & Comfort & ASHRAE 55 (1981) & \\
\hline
\end{tabular}

Table 5·5: Recommended RH in common reference and textbooks.

Once the erroneous referencing enters legislative controls, there are more serious implications. Under Australian Occupational Health and Safety (OH\&S) guidelines (Jul 2011), the recommended range is $30-60 \% \mathrm{RH}$. This range was adopted from the Canadian CSA Standard CAN/CSA Z412-00 (R2005) - "Office Ergonomics" which in turn has been sourced, it is claimed, from ASHRAE 55 (2010). 
However, a review of the most current standards (table 5.6) within my access indicate no stipulation for the control of RH.

\begin{tabular}{|l|l|l|l|}
\hline \multicolumn{1}{|c|}{ Standard } & \multicolumn{1}{|c|}{ Year } & \multicolumn{1}{c|}{ Title } & \multicolumn{1}{c|}{ Humidity criteria } \\
\hline ASHRAE 55 & 2004 & Thermal Environmental Conditions for Human Occupancy & w(i) under 0.012 \\
\hline ASHRAE 55 & 1981 & Thermal Environmental Conditions for Human Occupancy & w(i) between $0.0045-0.012$ \\
\hline ASHRAE 62 & 2010 & Ventilation for Acceptable Indoor Air Quality & RH 65\% or less \\
\hline ASHRAE 90.1 & 2004 & Energy Standard for Buildings Except Low-Rise Residential Buildings & not stipulated \\
\hline ASHRAE 160 & 2009 & Criteria for Moisture-Control Design Analysis in Buildings & w(i) $=0.004+0.4 w(0)$ \\
\hline ASHRAE 189 & 2009 & Standard for the Design of High-Performance Green Buildings & $\begin{array}{l}\text { RH under 60\% during post- } \\
\text { construction, pre-occupancy flush- } \\
\text { out }\end{array}$ \\
\hline AIRAH DA20 & 2000 & Humid Tropical Air Conditioning & $\begin{array}{l}55-60 \% \text { RH, based on upper limit of } \\
\text { Sterling (1985) }\end{array}$ \\
\hline AIRAH DA09 & 1998 & Air Conditioning Load Estimation & not stipulated \\
\hline AS 1668.2 & 1991 & $\begin{array}{l}\text { The use of mechanical ventilation and air-conditioning in buildings - } \\
\text { Mechanical ventilation for acceptable indoor-air quality }\end{array}$ & "out of scope" \\
\hline AS 4254 & 2002 & Ductwork for air-handling systems in buildings & not stipulated \\
\hline W(i) = indoor design humidity ratio, w(o) = mean coincident design outdoor humidity ratio for cooling, 1\% annual basis \\
\hline
\end{tabular}

Table 5.6: Humidity criteria from American and Australian Standards

Could it be possible that the ASHRAE 55 standard referred to have been those other than the 1981 and 2004 editions I have acquired? A summary of the standards preceding ASHRAE 55-2004 has been documented (Fountain, 1999), from where we see that this humidity ratio of 0.012 has been specified since 1974 and is here updated with the 2010 edition (table 5.7).

\begin{tabular}{|c|l|l|l|}
\hline Year & Issuer & \multicolumn{1}{|c|}{ Maximum Humidity } & \multicolumn{1}{|c|}{ Document } \\
\hline 1915 & ASHVE & $50 \%$ relative humidity (recommended) & Code of Minimum Requirements for Ventilation \\
\hline 1920 & ASHVE & $64 \%$ wet bulb $\left(17.8^{\circ} \mathrm{C}\right)$ & Synthetic Air Chart \\
\hline 1932 & ASHVE & $70 \%$ relative humidity & ASHVE Ventilation Standard \\
\hline 1938 & ASHVE & $75 \%$ relative humidity & Code of Minimum Requirements for Comfort \\
\hline $1950-1965$ & ASHRAE & No explicit limit & ASHRAE Comfort Chart \\
\hline 1966 & ASHRAE & $60 \%$ relative humidity & Standard 55-66 \\
\hline 1974 & ASHRAE & $14 \mathrm{~mm} \mathrm{Hg}(12 \mathrm{~g} / \mathrm{kg}$ humidity ratio $)$ & Standard $55-74$ \\
\hline 1981 & ASHRAE & $12 \mathrm{~g} / \mathrm{kg}$ humidity ratio & Standard 55-81 \\
\hline 1992 & ASHRAE & $60 \%$ relative humidity & Standard 55-92 \\
\hline $1992 \mathrm{a}$ & ASHRAE & $18^{\circ} \mathrm{C}\left(64.5^{\circ} \mathrm{F}\right)$ wet bulb, winter $20^{\circ} \mathrm{C}\left(68^{\circ} \mathrm{F}\right)$ wet bulb, summer & Addendum to Standard 55-92 \\
\hline 2004 & ASHRAE & $12 \mathrm{~g} / \mathrm{kg}$ humidity ratio & Standard 55-2004 \\
\hline 2010 & ASHRAE & $12 \mathrm{~g} / \mathrm{kg}$ humidity ratio, or software & Standard $55-2010$ \\
\hline
\end{tabular}

Table 5.7: Humidity control in ASHRAE 55 and preceding standards

In my investigation, the only official ASHRAE document recommending an optimum RH range is to be found in the ASHRAE Handbook, HVAC Systems and Equipment (2008), with a 
lone reference to Sterling (1985). The optimum RH chart shows a graphical indication of air quality concerns being directly correlated to RH and a sweet-spot of 40-60\%RH which can minimise all negative effects (figure 5.4).

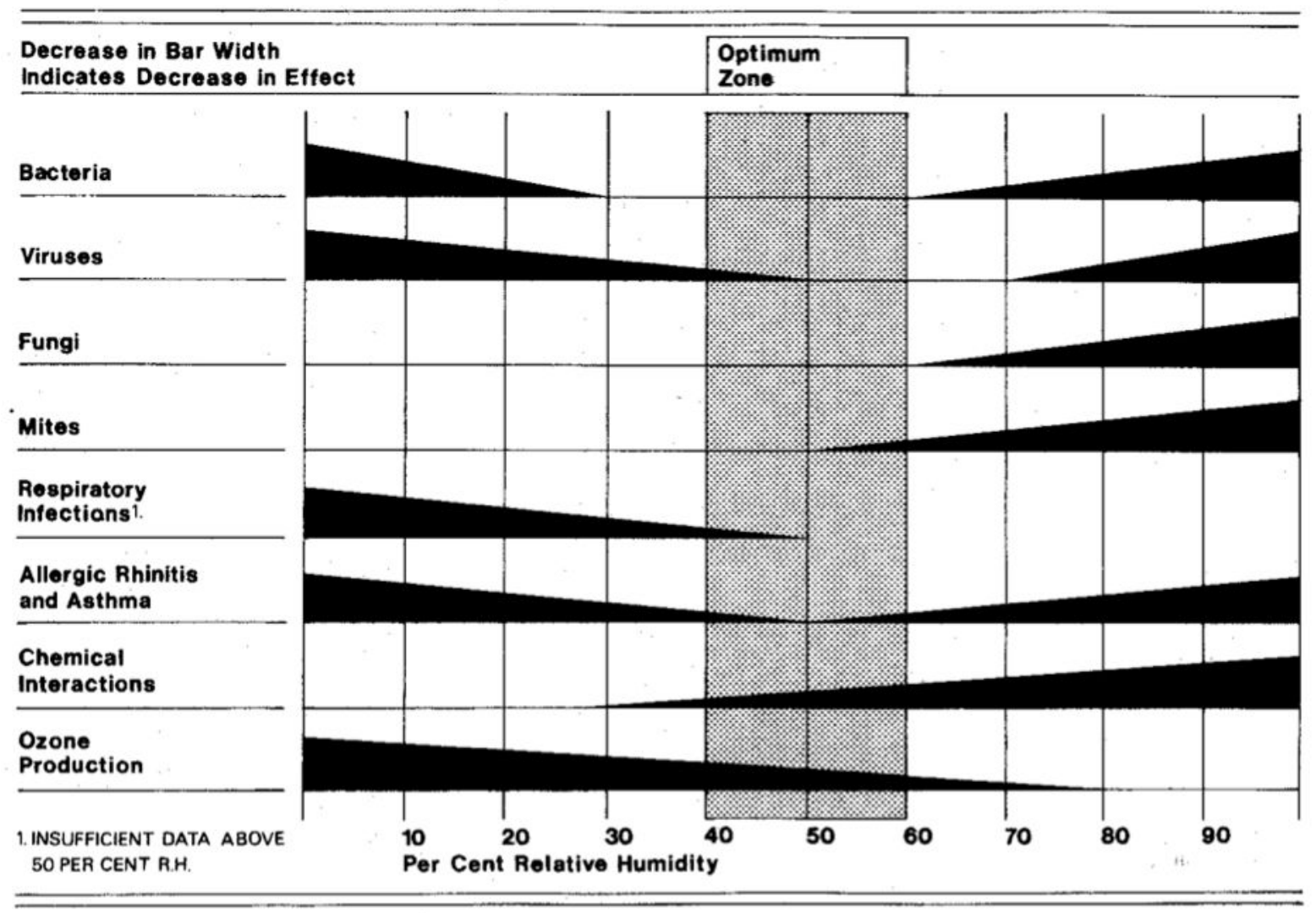

Figure 1. Optimum relative humidity ranges for health

Figure 5.4: The widely reproduced premise for recommending the optimum $\mathrm{RH}$ range, graphically presented (Sterling, 1985)

Over the years the chart has remained untouched in its basic form and is widely cited by manufacturers of humidity control equipment. This chart still underpins the section on "Humidifiers" in the current ASHRAE Handbook - HVAC Systems \& Equipment (2009) ch 21.

Extremes of humidity are the most detrimental to human comfort, productivity, and health. Figure 1 [referring to Sterling (1985)] shows that the range between 30 and $60 \%$ rh (at normal room temperatures) provides the best conditions for human occupancy (Sterling et al. 1985). In this range, both the growth of bacteria and biological organisms and the speed at which chemical interactions occur are minimized.

In the most recent and extensive study commissioned by ASHRAE into humidity control, Brundrett (Chapter 9 in "Humidity Control Design Guide" (Harriman, 2008)) reviewed the 
behaviour of three viruses (Influenza A, Vaccinia, Poliomyelitis) and ten bacteria (Escherichia coli, Legionella pneumphilia, pneumococcus, Serratia marcescens, Staphylococcus aureus, streptococci, pseudomonas vulgaris, proteus morgani, Salmonella derby, Ps aeruginosa), based on old papers, stating that such research was "rare and valuable". This literature reviewed averaged $1966 \pm 12 y$ (s.d.), of which 5 of the 20 references could be found in Sterling (1985). Brundett also recommends the same $30-60 \%$ RH range even though 2 viruses and 5 bacteria in the review could be most limited by high $\mathrm{RH}$.

After a half-century one wonders if new microbes have become more commonplace, or if these old strains of microbes have not long mutated to behave differently since they were tested. The dated research is also indicative that there is no modern evidence (in the last 20 years, based on the most recent of Brundrett's references) for RH as control mechanism for bacteria and viruses. It appears that the whole premise for the optimum RH range has not changed from trying to limit "the life span of the broadest variety of bacteria and viruses" (Brundrett, 2008), an approach first proposed by Sterling.

This paper (Sterling, 1985) is here investigated in greater detail, not as a young researcher trying to be captious, but because it stands as such a significant document, and the only one offering a rationale behind the optimum $\mathrm{RH}$ range.

\subsubsection{A Critique of Sterling}

Sterling's (1985) paper “Criteria for Human Exposure to Humidity in Occupied Buildings" was a starting point to recommend a narrower range of $40-60 \% \mathrm{RH}$. The then current ASHRAE Standard 55 (1981) did not actually stipulate an acceptable range of 20-90\%RH as Sterling suggested, but a 4.25-12 g/kg ratio, which within the limits of acceptable operative temperature could potentially vary from 20-90\%RH (figure 5.5). Graphically, the acceptable range is bound by two (horizontal) limits in terms of humidity ratio lines of 4.25 and $12 \mathrm{~g} / \mathrm{kg}$, and so it is erroneous to interpret the standard as thinking the acceptable range is bound by (the curved) relative humidity lines of $20 \%$ and $90 \%$. The failure to distinguish the humidity units has, in my opinion, cascaded in a series of potentially flawed analyses. 


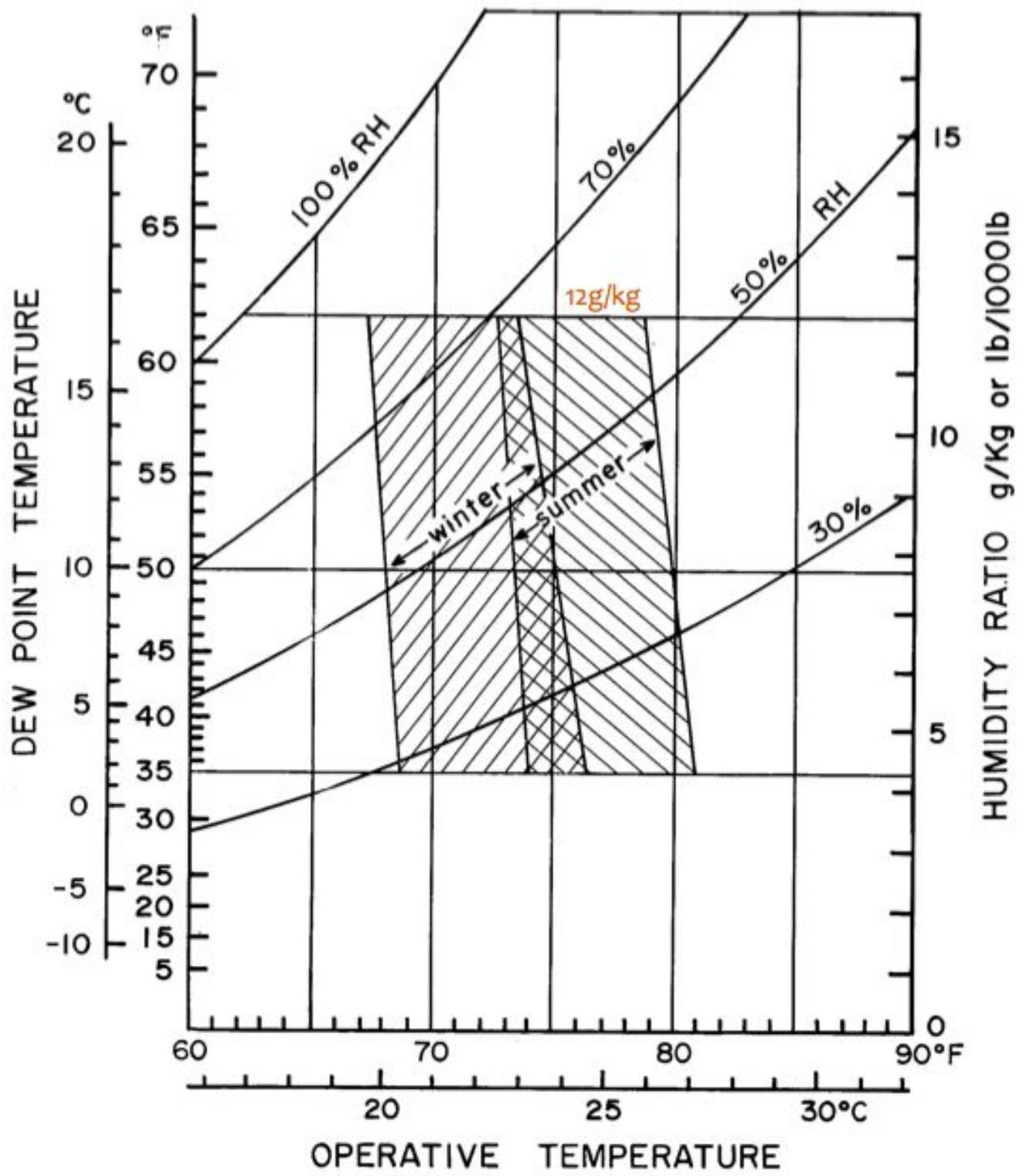

Figure 5.5: Acceptable T and humidity range (ASHRAE-55, 1981)

Sterling's paper is not based on original experiments but a "review of the relevant health literature", a total of 75 separate studies, manuals and literature reviews with a mean date $1975 \pm 7.8$ years (s.d.).

The paper looks at the premise for recommending 40-60\%RH as optimum "at normal room temperature" (p.615). However, instead of indoor temperatures, it begins with the introduction: 
High relative humidity prevents effective evaporative cooling of the body during exposure to high temperatures and may lead to heat exhaustion or heat stroke and possible death.

Evaporation rate is affected by absolute humidity (or humidity ratio, HR) not relative humidity (RH). To impede evaporative cooling takes the combination of both high RH and, more importantly, high T, a T that well exceeds normal room temperatures. We labour this point again because this paper presents a common misconception: that high $\mathrm{RH}$ is a health hazard. The condition that causes heat related injuries is primarily that of high temperatures. Whilst high RH can exacerbate the condition, it is not the primary cause of these injuries, and one can as easily, if not more easily, succumb to heat stroke in the hotarid desert as in a hot-humid forest. It is temperature, radiant temperature in particular, that is the key factor in "heat exhaustion or heat stroke and possible death" and not RH.

On closer inspection of Sterling's (1985) graphical presentation, a number of concerns can be raised:

1. The term "humidity" is used very loosely. Of interest to the issue of RH should be that of gaseous atmospheric humidity. However references are made to "humidifying equipment" where it is water in liquid state that becomes a breeding site for bacteria. Control of RH is immaterial to the subsequent delivery of these contaminants in the misting aerosol.

2. The literature review is based on work done with airborne pathogens but the selection does not necessarily reflect a representative sample of the most common variants in the indoor environment. Salmonella and rhinovirus are, respectively, the most striking bacterium and virus missing. Uncommon viruses like polio and cowpox are included in the mix and their relevance is somewhat stretched.

3. It is unclear what is meant by "effect" which for microbes could possibly refer to the increase in colony forming units per cubic metre of air (ie. $\mathrm{cfu} / \mathrm{m}^{3}$ ). Alternatively, it could even refer to absenteeism, occupants who complain of at least two SBS symptoms, perceived air quality, and an unending list of criteria. Without understanding the actual mechanics of each parameter it is impossible to plot wedges to indicate linear relationships between effect and RH\%.

4. In many instances the relationships are non-linear to RH\%. Different species of viruses also behave differently: influenza and vaccinia decrease in viability at 
increasing RH whereas results for poliomyelitis and Venezuelan equine encephalitis showed the opposite tendency (Harper, 1961 in Kowalski, 2005). One can as easily argue that $50 \% \mathrm{RH}$ is the ideal condition for limiting, as it is for promoting, respective strains of virus.

5. The graphical presentation gives the impression that at certain point in the RH scale, there are no deleterious effects. A casual observer will not realise that the author of the paper admits, '... there is probably no level of humidity at which some biological or chemical factor that affects health negatively does not flourish.' (p.615)

6. Many other parameters come into play to influence the 'effect'. For example the death of microbes from desiccation is impacted by the initial moisture content, growth phase, rate of drying, relative humidity or composition of the surrounding medium, temperature, the coincident presence of sunlight, and other factors (Henis, 1987 in Kowalski, 2005). No mention has been made if these conditions have been kept constant to isolate RH\% as the determining factor in the review of literature.

7. An impression is given that all the listed contaminants should be controlled for good IAQ. However, whilst viruses are almost exclusively communicable (Murray, 1999; Fields and Knipe, 1991; both in Kowalski, 2005), fungal spores, on the other hand, are almost exclusively noncommunicable (Bosche et al., 1993; Burge, 1989; both in Kowalski, 2005) and come mainly from the outdoor environment (Howard and Howard, 1983; Muilenberg and Burge, 1996; both in Kowalski, 2005).

Thus the optimum RH chart remains an oversimplified approach for controlling air contaminants by limiting RH to a range, though this is not to say RH does not have any effect on air quality.

What is needed is to ascertain firstly, if RH has a direct correlation to contaminant proliferation and human susceptibility; and secondly, if regulating RH is the most effective way of controlling contamination. In a hot-humid context, the discussion is focussed on the following areas of concern:

1. Bacteria

2. Viruses 
3. Moulds

4. Mites

\subsubsection{Effects of RH on bacteria and viruses}

Airborne Legionella survive over greater distances when the relative humidity is $65 \%$ or greater (Kowalski, 2005, p.60). Viruses may not behave the same as bacteria in terms of their susceptibility to variations in relative humidity. Low humidities appear to have a limited effect on virus viability while high humidities appear to decrease viability. Figure 5.6 shows a graph of the survival of influenza versus relative humidity at several sample times. The pattern is clearly a decrease in viability at increasing relative humidity. (Kowalski, 2005, p.113)

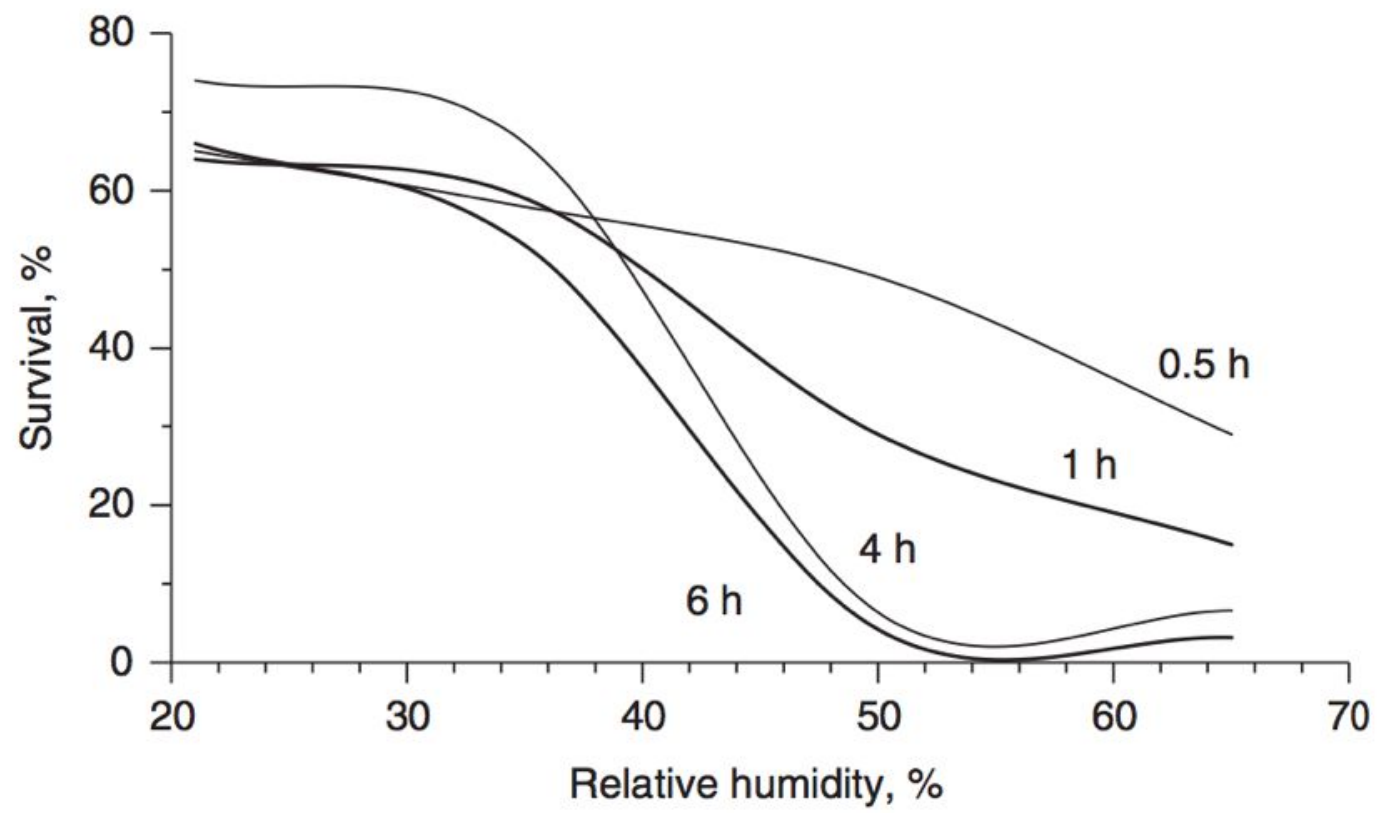

Figure 5.6: Influenza viability under different exposure of $\mathrm{RH} \%$ and exposure (Clarke, 1998, in Kowalski, 2005)

Besides direct contact, the main mode of transmission of communicable diseases is through large droplets $>10 \mu \mathrm{m}$ and droplet nuclei $<10 \mu \mathrm{m}$ (ASHRAE 2009). 'The residue of the droplet after evaporation, which contains any organism originally present, is called a droplet nucleus. It is typically $5 \mu \mathrm{m}$ or smaller in size' (Rural Infection Control Practice Group, 2008, Section 2.1). At $50 \% \mathrm{RH}$, a droplet of distilled water of $3 \mu \mathrm{m}$ can be reduced to a tenth of its original size in a fraction of a second (Dunklin \& Puck, 1948). Figure 5.7 shows that RH has an impact on the initial evaporation rates, with droplets evaporating about four times faster at $0 \% \mathrm{RH}$ than at $70 \% \mathrm{RH}$. However, droplets which contain bacteria do not evaporate 
completely, and despite similar initial evaporation rates, droplets with bacteria retain the nuclei for much longer that those without. The authors of this graph observed:

the graph shows how droplet-contained bacteria might not appreciably affect droplet evaporation until almost all of the droplet water had evaporated and the agglomerated bacteria or droplet nuclei were left. At this point the survival of the agglomerated bacteria might depend on such unknowns as the water evaporation rate, the position in the agglomerate, and the life-sustaining water content of the bacteria. (Lighthart \& Kim, 1989, p.2351)

They suggest that the following mechanisms are involved with this phenomena:

... it is hypothesized that as droplet water evaporates, cells, which are thought to have a lower water vapor pressure (e.g., due to lipid-containing cell membranes), may be present in the droplet air-water film, lowering the overall droplet evaporation rate. Carrying the argument further, it is hypothesized that as the cells agglomerate or form a protective shell configuration during evaporation, the outermost cells would dry to a critical (life-sustaining) water content before those cells deeper in the agglomerate do. From this, it might be expected that those relatively large droplets that originate with the most microbes would contain at least one deeply embedded viable microorganism for the longest period of transport time downwind. Thus, the larger droplet nuclei presumably will have more surviving microbes over a longer time. (Lighthart \& Kim, 1989, p.2354) 


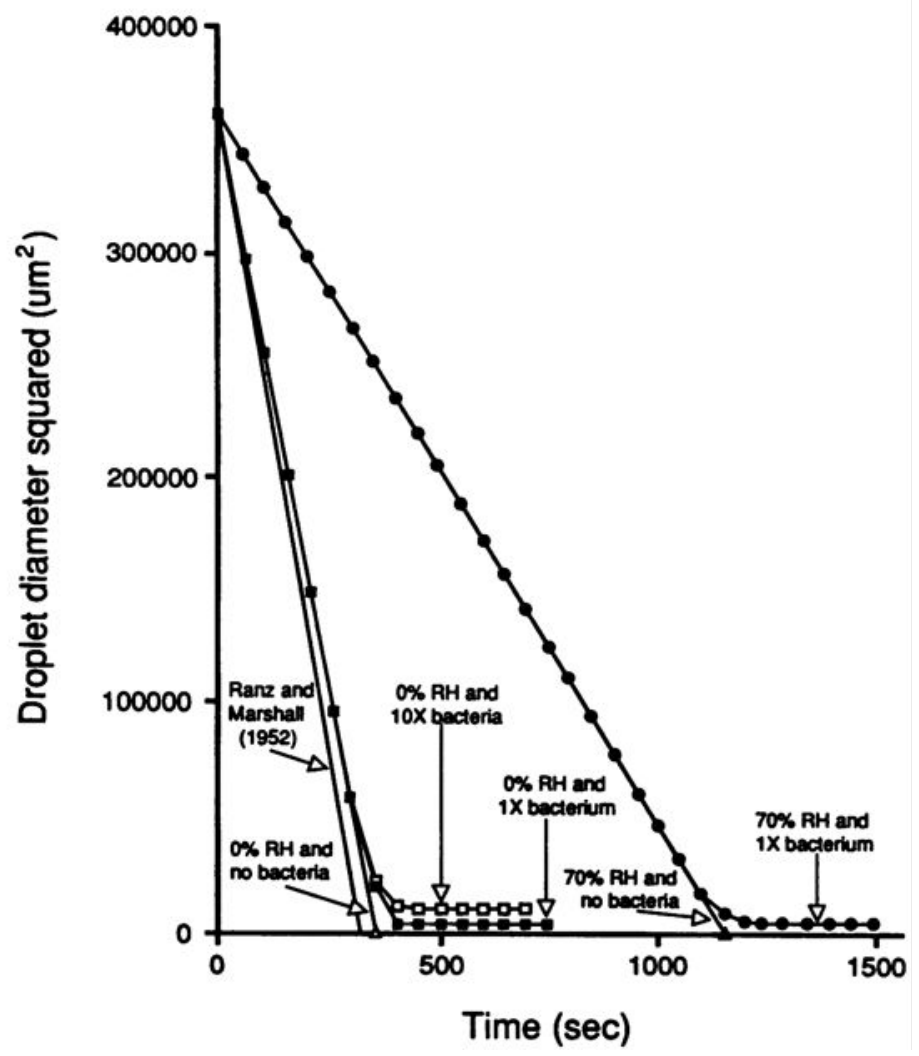

Figure 5.7: Simulated water evaporation from bacteria containing 600- $\mu \mathrm{m}$ diameter water droplets in an atmosphere of $\% \% \mathrm{RH}$ or $70 \% \mathrm{RH}$ and $25^{\circ} \mathrm{C}$ (Lighthart \& Kim, 1989).

Evaporation of these agglomerated droplets under typical room conditions is not immediate enough to control disease spread and the most effective way of removing these droplets or droplet nuclei is by filtration. Filtration, however, is significantly affected by RH. Below $80 \%$ $\mathrm{RH}$, air filters led to a marked reduction of airborne bacteria concentrations by approximately $70 \%$. Above $80 \% \mathrm{RH}$, a proliferation of bacteria on air filters resulted in a subsequent release back into the filtered air (Kowalski, 2005, p.225). Hence where air filters are used, care must be exercised to control the subsequent re-entry of bacteria into the air stream at $>80 \%$ RH.

For bacteria and viruses, air sanitisation has been the most reliable control. For instance, Langmuir (1948, in Fisk, 1999) reported 23\% decrease in respiratory illness with UV irradiation during an epidemic in U.S. Army barracks. 


\subsubsection{Effects of RH on moulds}

Though moulds are non-communicable, the spores of some species, in high concentrations, can be toxic to humans. Mould growth occurs at the confluence of humidity, temperature and the availability of nutrients (figure 5.8).

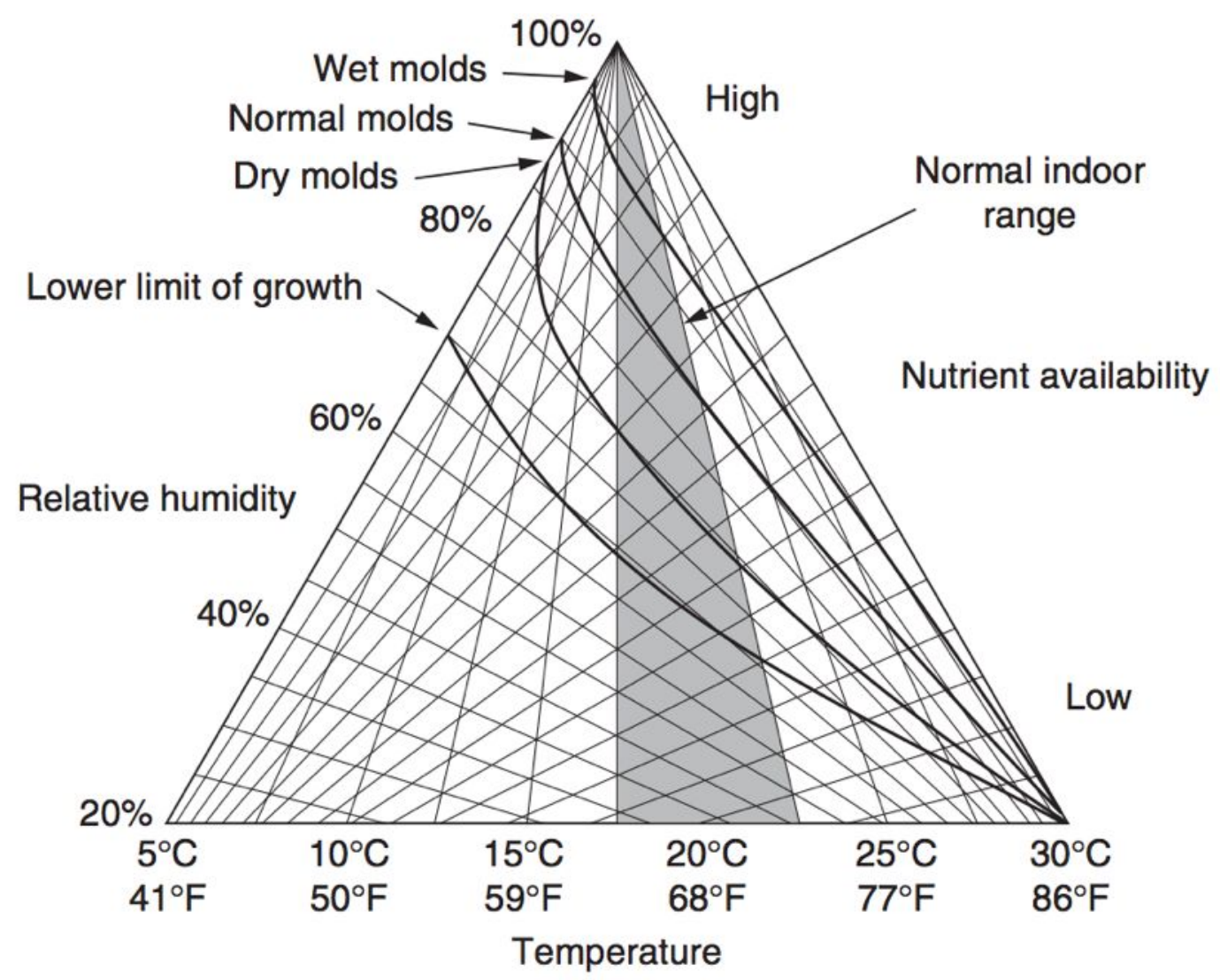

Figure 5.8: Growth conditions for mould (Clark, 1998, in Kowalski, 2005, p.176)

Evidence exists to suggest that many of the building materials like gypsum and wallpaper that favor the growth of fungi also influence the generation of potentially hazardous mycotoxins (Nielsen et al., 1999). Bacteria can influence the growth of fungi. Environmental bacteria can grow biofilms, and thereby provide fungal spores a nutrient base. Biofilms generally grow where there is excessive moisture or where water collects, such as drain pans, dehumidification cooling coils, and sump type humidifiers (Morey, 2001).

The indoor relative humidity itself is less an indicator of mould growth than is the water activity (Aw) of the building materials (Kowalski, 2005, p.174), determined as follows:

$$
A w=\frac{p}{p_{0}}
$$




\begin{tabular}{|c|l|}
\hline \multicolumn{2}{|c|}{ Equation notes } \\
\hline $\boldsymbol{p}$ & vapour pressure of water in the substance \\
\hline $\boldsymbol{p}_{\mathbf{0}}$ & vapour pressure of pure water at the same temperature. \\
\hline
\end{tabular}

Fungal growth is likely if the water activity exceeds 0.76 to 0.96 , depending on fungal species, temperature, time, and composition of the material (Pasanen et al., 1992). The way to control mould growth is by selecting the least hygroscopic materials and finishing them with hydrophilic paints. Alternatively, mould can be controlled by air filters, where it was found that the lack of available nutrients on clean filters generally precluded most mould growth even under high RH (Kowalski, 2005, p.223).

\subsubsection{Effects of RH on mites}

Higher humidities provide conditions suitable for mite population survival and growth. It also results in greater faecal production per mite, resulting in higher allergen levels (Arlian, 1992). However low temperatures have been shown to drastically impede mite population growth rate (Cunningham, 1996) at a rate far more significant than RH. Moreover the humidity of the microclimate where mites are typically found (e.g. pillows, carpets) is significantly different from the ambient microclimate (Yellen, 1995). It would thus be ineffective to regulate ambient $\mathrm{T}$, and even less effective to regulate ambient $\mathrm{RH}$, in order to control mite populations and their allergenic effects.

To control mites it would be far more effective to deal with them in their habitats by vacuuming, chemical sanitisation, extreme heat or cold, or simply regular replacement of items like pillows.

\subsubsection{Summary of findings compared to Sterling (1985)}

Sterling's work was for its time a significant contribution, and the optimum RH recommendation was based on tenable ideas. We must however recognise that this was a literature review and not basic research involving testing the contaminants, particularly the biological ones, with the specific intent of determining their viability under varying ambient RH conditions. After a quarter of a century, huge advancements have been made in microbiology, with potential epidemics like SARS and avian flu fuelling very active research into the area. It is needful that this work be updated, if possible. As the sole reference in the ASHRAE Handbook and AIRAH Guide, and on which other standards and legal requirements 
are based, the limitations to our knowledge of such an optimum RH should be openly acknowledged.

The problem is that microbiologists themselves recognise that 'the effects of relative humidity on airborne microbes are complex and involve phase changes at the molecular level' (Kowalski, 2005, p.157). With so many aspects of aerobiological behaviour not fully understood it is no wonder that in the ASHRAE Position Document on Airborne Infectious Diseases , the only mention of humidity is that

humidity affects survival of the infectious agent although not always in predictable ways. (ASHRAE, 2009, p.5)

Controlling RH\% in today's context is, without doubt, a blunt and energetically costly way of controlling microbes, and for some viruses it is of questionable efficacy. There can be many other ways of controlling each factor that affects IAQ as tabulated in 5.8.

\begin{tabular}{|c|l|}
\hline $\begin{array}{l}\text { Virus \& } \\
\text { Bacteria }\end{array}$ & $\begin{array}{l}\text { Air filtration \{Fisk, 1999\} and sanitisation (UV, ozone), control RH of filter (can be achieved by heating air passing } \\
\text { through filter) }\end{array}$ \\
\hline Mould & $\begin{array}{l}\text { Select building materials with low water activity and low nutrient content, maintain clean filters, control bacteria } \\
\text { biofilms }\end{array}$ \\
\hline Mites & $\begin{array}{l}\text { Control amount and type of soft finishes, reducing temperature, change pillows, steam cleaning, vacuuming with fine } \\
\text { filter }\end{array}$ \\
\hline
\end{tabular}

Table 5.8: Alternatives to $\mathrm{RH}$ control in managing various microbes.

If indoor air quality (IAQ) were the real issue, than there are other approaches to improving IAQ without dehumidification. Instead of controlling humidity, designers could look at paints and finishes that inhibited microbial growth on walls and ceilings. They could also minimise the amount of soft finishes (carpets, drapery, fabric, etc.) used in interiors. The key is to look at materials with low water activity and low nutrient content for moulds. As an air quality issue, filtration and sanitisation devices could be employed to reduce, remove or destroy microscopic organisms. All these could be done, with less operational energy than to dehumidify air, an energy demand particularly strenuous in tropical cities.

However, when humidity is made a thermal comfort issue, the need for compliance does not leave designers any room to explore alternative solutions. In an energy-constrained world we need to evaluate the issues separately: lowering of temperatures for improved comfort 
which is distinct from removing of microbes for improved air quality — of which lowering humidity is but one of many viable strategies.

In as much as we can demonstrate energy efficient alternatives to improving IAQ, one reason why the control of indoor climates is so energetically inefficient is from the inclusion of humidity control as a comfort issue. Other than instances where air quality is crucial (like in hospitals), the inclusion of humidity control as a comfort consideration nullifies the need to adopt any of these alternative strategies.

\subsubsection{Humidity and Disease}

I am New People. Your sicknesses do not frighten me. (Bacigalupi, 2009, p.488)

If microbes had no pathogenic effects on the windup girl, there would be no necessity for humidity control. Adopting a purist approach to thermal comfort, the most efficient route would be firstly by evaporative cooling and, if necessary, further refrigeration to reach thermal neutrality. There will be no need to dehumidify (to a humidity ratio of $12 \mathrm{~g} / \mathrm{kg}$ ) and reheat (till RH is at 65\%). Designing an energy efficient climate chamber for the windup girl has uncovered a new index for evaluating the effectiveness of climate control processes: comfort energetics. This hypothetical client, with her genetically engineered resistance to disease, also helps to distil the thermal comfort considerations from indoor air quality ones.

Nevertheless, we are not "New People", and high RH is a potential sick building syndrome (SBS) problem. Besides SBS, there are also other ways in which RH affects perceived air quality, odours and eye irritation, though these are not covered here as they have not been cited in the standards as reasons for controlling humidity. Recognising that the standards cannot be easily amended, compliance will still be obligatory for the immediate future. If we intended to improve thermal comfort with less energy and without increasing the RH of a space, what viable options remain?

\subsection{Energetics of fans}

Yellow card coolies crank at wide-bore fans, driving air through the club. Sweat drips from their faces and runs in gleaming rivulets down their backs. They burn calories as quickly as they consume them and yet still the club bakes with the memory of the afternoon sun. (Bacigalupi, 2009, pp.55-56) 
The cooling effect of moving air can be analysed in three methods:

1. Altering the wind speed parameter in the PMV

2. Determining the effective $\mathrm{dT}$ of moving air and adjusting the operative $\mathrm{T}$ in PMV to account for this effect.

3. Determining the wind chill index (WCI) through wind velocity and air temperature ASHRAE Handbook: Fundamentals (ASHRAE, 2005, 8.21). The methods discussed for methods 1 and 2 could also be applied to WCI, using the energy required to increase $v$ to evaluate the lower vote from WCI. However, as the wind chill index has been developed for outdoor use, it is not considered in our discussion on comfort energetics.

\subsubsection{Wind velocity in the PMV model}

Under this setup, the flow rate can be assumed to have a linear relationship with power consumption: a ventilation fan is installed in the ceiling with a fixed maximum power (5W) and exhaust rate $(10 \mathrm{l} / \mathrm{s})$. Additional fans are installed, up to 10 units, all running at the same speed and power, giving a linear relationship between power and exhaust rates. The fan-only cooling under this calculation averages $148 \mathrm{~W} /$ vote (s.d. $=11 \%$, refer to table 5.9 ) and does not improve comfort by much.

\begin{tabular}{|c|c|c|c|c|}
\hline \multicolumn{5}{|c|}{ Increased Ventilation } \\
\hline Ventilation (I/s) & Velocity $(\mathrm{m} / \mathrm{s})$ & PMV & Power $(\mathrm{W})$ & W/vote \\
\hline 10 & 0.05 & 1.994 & 5 & \\
\hline 20 & 0.1 & 1.937 & 10 & 175.4 \\
\hline 30 & 0.15 & 1.873 & 15 & 124.0 \\
\hline 40 & 0.2 & 1.835 & 20 & 125.8 \\
\hline 50 & 0.25 & 1.804 & 25 & 131.6 \\
\hline 60 & 0.3 & 1.778 & 30 & 138.9 \\
\hline 70 & 0.35 & 1.755 & 35 & 146.4 \\
\hline 80 & 0.4 & 1.735 & 40 & 154.4 \\
\hline 90 & 0.45 & 1.718 & 45 & 163.0 \\
\hline 100 & 0.5 & 1.702 & 50 & 171.2 \\
\hline
\end{tabular}

Table 5.9: Comfort energetics of increasing ventilation rates

\subsection{2 $\mathrm{dT}$ as a result of increased cooling with higher wind speed}

Instead of looking at the fans as performing exhaust ventilation, we can see them as circulating the air, as in the case of ceiling fans. In this scenario it is assumed that the 
occupants will sit in the region where the fan speed is about $1 \mathrm{~m} / \mathrm{s}$ (Rohles, 1983, figure). The moving air across a lightly clothed occupant will cause a difference in temperature (dT) from the forced convection. Various models exist (Emmanuel, 2005, p. 69) to determine the magnitude of the dT. At $1 \mathrm{~m} / \mathrm{s}$ the average of these eight models is $\mathrm{dT}=-3.89^{\circ} \mathrm{C}(\mathrm{s} . \mathrm{d} .=1.69 \mathrm{~m} / \mathrm{s})$ in agreement with the difference in equivalent temperature of $3.3^{\circ} \mathrm{C}$ when ceiling fans are compared to still air (Rohles, 1983). This difference is applied to determine the operative T for the PMV model (ASHRAE55, 2004).

$$
T_{\text {operative }}=A \cdot T_{\text {air }}+(1-A) \cdot M R T
$$

\begin{tabular}{|c|l|l|}
\hline \multicolumn{3}{|c|}{ Equation notes } \\
\hline $\boldsymbol{A}$ & Ratio of air temperature & 0.7 (at vel=1m/s) \\
\hline $\boldsymbol{T}_{\boldsymbol{a i r}}$ & Air temperature, corrected for wind at $1 \mathrm{~m} / \mathrm{s}$ & $(30-3.89)^{\circ} \mathrm{C}$ \\
\hline $\boldsymbol{M R T}$ & Mean Radiant Temperature & $30^{\circ} \mathrm{C}$ \\
\hline
\end{tabular}

Based on a $69 \mathrm{~W}$ ceiling fan (table 5.10), the comfort energetics works out as $83 \mathrm{~W} /$ vote for a single occupant. However, recognising that a ceiling fan can support a whole room (see figure 5.9), the comfort energetics could be as low as $21 \mathrm{~W} /$ vote if 4 occupants could be positioned within the $1 \mathrm{~m} / \mathrm{s}$ range of the ceiling fan. 


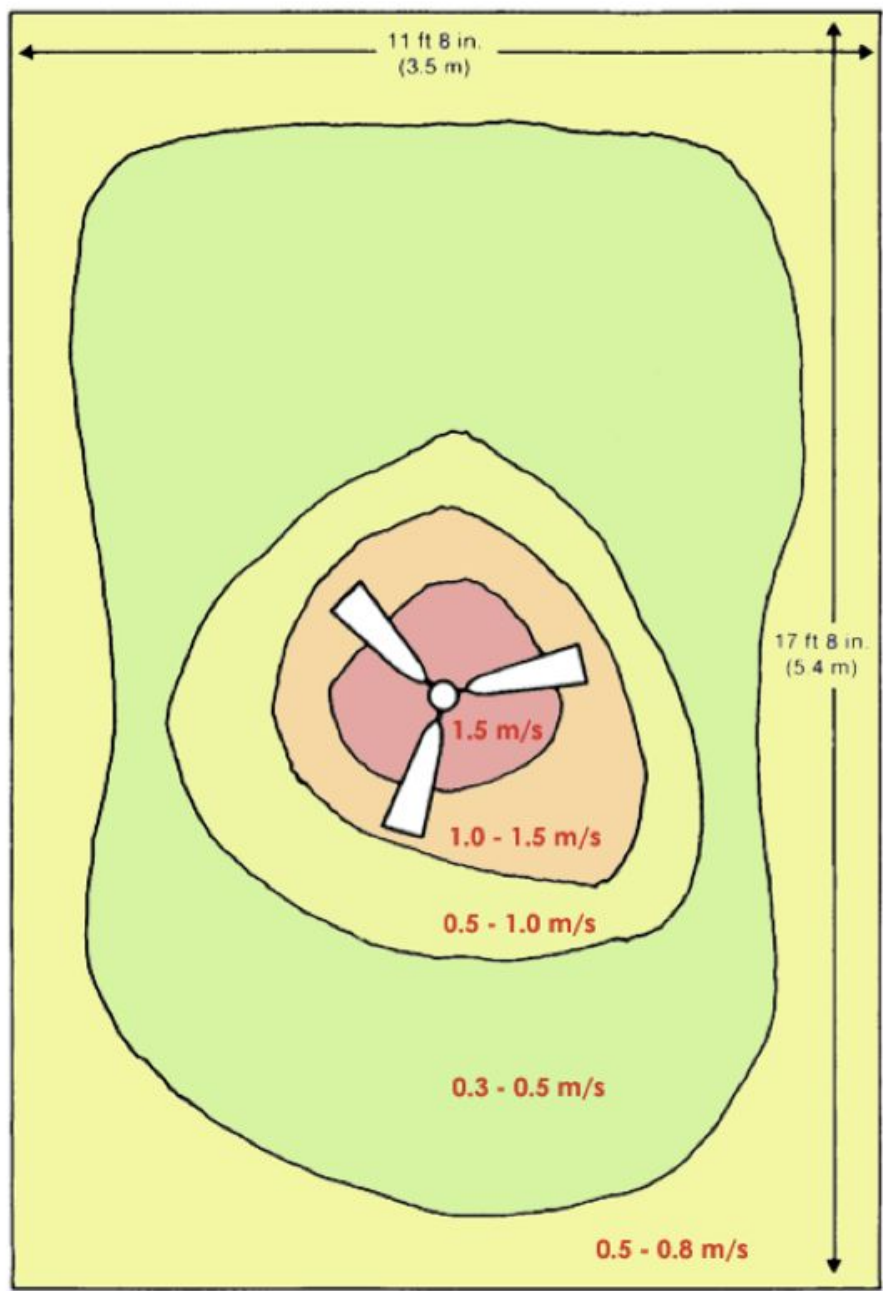

Figure 5.9: Wind speeds under a ceiling fan (Cook,1989, p.46)

\begin{tabular}{|l|c|}
\hline \multicolumn{2}{|c|}{ Ceiling fan reference } \\
\hline Motor power (Martec 1.3m) & $69 \mathrm{~W}$ \\
\hline Free air displacement & $3,770 \mathrm{I} / \mathrm{s}$ \\
\hline Assumed wind velocity & $1.0 \mathrm{~m} / \mathrm{s}$ \\
\hline T (operative) & $27.28^{\circ} \mathrm{C}$ \\
\hline Reference PMV & 1.994 \\
\hline PMV with wind cooling & 1.159 \\
\hline Comfort energetics for 1 pax & 83 W/vote \\
\hline Comfort energetics for 4 pax & 21 W/vote \\
\hline
\end{tabular}

Table 5.10: Comfort energetics of a ceiling fan

In the ASHRAE standards, draft rates (DR) are used to predict the percentage of people dissatisfied with a draft condition based on the work of Fanger and Christensen (1986) and Fanger (1988) with the following expression: 


$$
D R=\left(34-T_{a} \times[v-0.05]^{0.62}\right) \times(0.37 \cdot v \cdot T u+3.14)(\mathrm{Eq} .
$$

$5.3)$

\begin{tabular}{|c|l|}
\hline \multicolumn{2}{|c|}{ Equation notes } \\
\hline$v$ & mean velocity \\
\hline $\mathrm{t}$ & air temperature \\
\hline $\mathrm{Tu}$ & turbulence intensity \\
\hline
\end{tabular}

The turbulence intensity $(\mathrm{Tu})$ for ceiling fans were measured to be $7.1 \%$ under the middle of blades and 3.5\% at 300mm from the outer edge of blades (Chiang, Pan, Wu, \& Yang, 2007). Based on a DR $<20 \%$ stipulated under ASHRAE 55, the air speed cannot exceed $0.9 \mathrm{~m} / \mathrm{s}$. However other researchers (Zhang, 2007) present a case to raise the draft limit. It was found that even when the draft standard had been exceeded, $41 \%$ of occupants feeling neutral and $68 \%$ for occupants feeling warm still wanted more air motion.

\subsubsection{How much air movement is considered a draft?}

The maximum permissible air speed has varied at different times between researchers:

1. ' $0.2 \mathrm{~m} / \mathrm{s}$ is the de facto draft limit in the current ASHRAE and ISO thermal environment standards' (Zhang 2007, when referring to ASHRAE 55-2004).

2. The ASHRAE Standard also states that 'loose paper, hair and other light objects may start to be blown about at air movements of $160 \mathrm{fpm}(0.8 \mathrm{~m} / \mathrm{s})$.' (Rohles, 1983 when referring to ASHRAE 55, 1981)

It should be emphasized that the $1.0 \mathrm{~m} / \mathrm{s}$ (200-ft/min) air speed was not demonstrated to be a maximum allowed speed. ASHRAE defines $0.8 \mathrm{~m} / \mathrm{s}(160 \mathrm{ft} / \mathrm{min})$ as an upper limit on uniform air speed in occupied spaces based on motion of hair, paper, and other light objects. Such annoyance was not observed at $1.0 \mathrm{~m} / \mathrm{s}$ (200 ft/ $\mathrm{min}$ ) in the Kansas State experiments. In an earlier experiment with ceiling fans mounted above a flow straightening louver, Mclntyre concluded that $2 \mathrm{~m} / \mathrm{s}$ (400 ft/ min) was the upper limit on acceptable air speed (McIntyre, 1976).... However, because the rate of convective heat removal increases as only the square root of the air speed, higher air speeds provide diminishing comfort returns at increased power requirements (McIntyre, 1976).

Clark, "Passive Cooling Systems "in Cook (1989), p.366

High air velocities of up to $1.6 \mathrm{~m} / \mathrm{s}$ were preferred by Japanese subjects exposed to a modified temperature of $31^{\circ} \mathrm{C}$ (Tanabe et al., 1987). Modified temperature was defined as the 
ambient temperature connected to the equivalent condition at $50 \% \mathrm{RH}$ and $0.1 \mathrm{~m} / \mathrm{s}$ air velocity, according to the PMV-model, that would be felt equally warm by a subject wearing 0.6 clo.

Toftum (2004) when referring to the highest category (in terms of measuring instrumentation and rigour) in the ASHRAE RP884 Project "The World Database of Thermal Comfort Field Experiments" commented:

The distribution of air velocities measured during these field studies was skewed towards rather low values. Thus, out of a total number of 5653 observations, only $8 \%$ resulted in air velocities higher than $0.2 \mathrm{~m} / \mathrm{s}, 3 \%$ higher than $0.25 \mathrm{~m} / \mathrm{s}$ and $2 \%$ higher than $0.3 \mathrm{~m} / \mathrm{s}$. This alone may explain why occupants under warm conditions frequently expressed a desire for more air movement rather than complained of draught.

The latest ASHRAE 55 (2010) standard recognises this research and has increased the maximum permissible operative temperatures dramatically from traditional still-air comfort zones (Turner, 2011) as seen in figure 5.10.

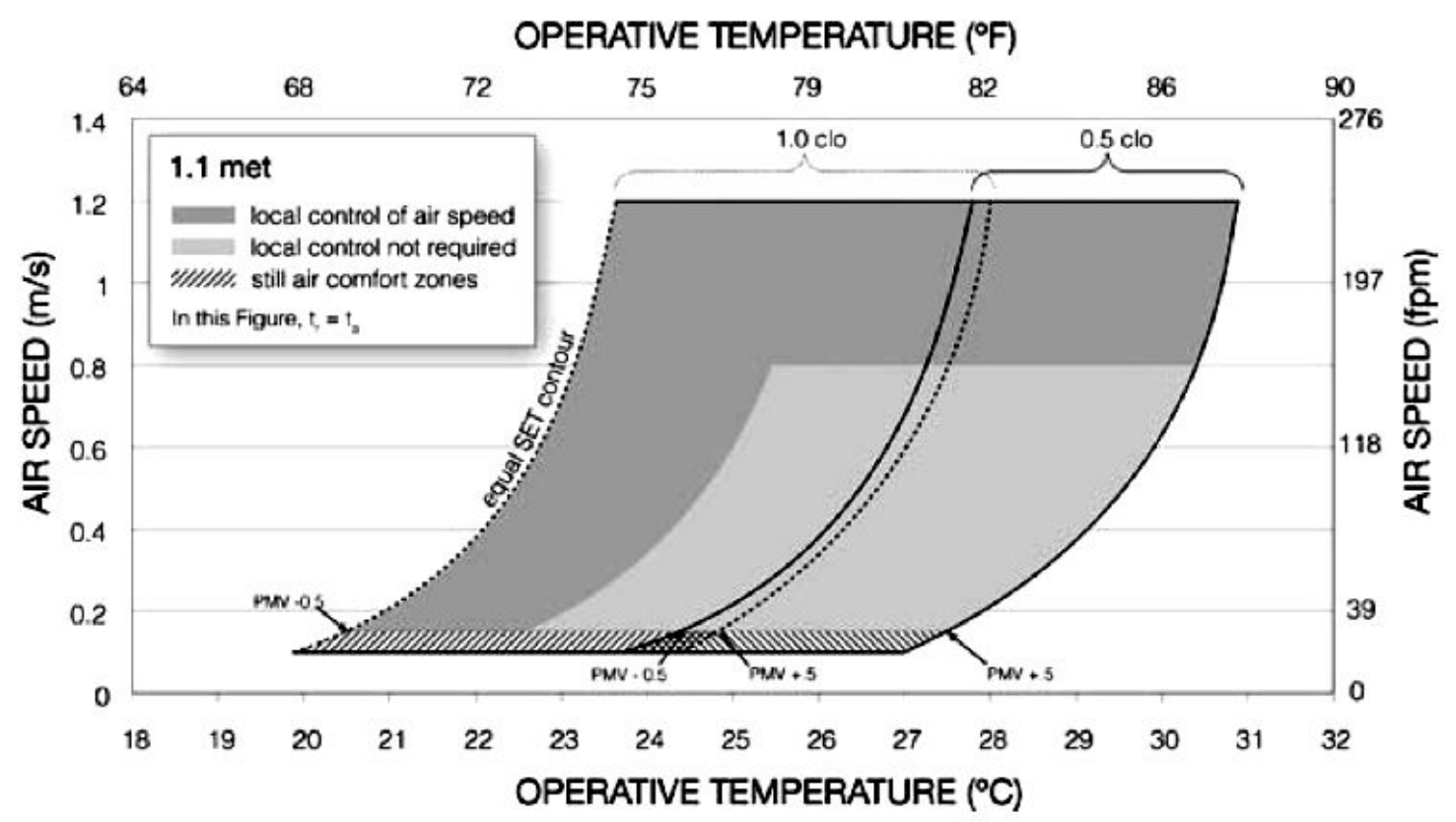

Figure 5.10: Acceptable operative temperature and air speeds for the comfort zone at humidity ratio of 0.010 (ASHRAE55, 2010, in Turner, 2011) 


\subsubsection{Air movement summarised}

Relating air movement to PMV is heavily dependent on the method in which airflow is generated. In an air-conditioned office, the increased air speed is achieved by increased supply-air flow rate, and in a naturally ventilated office by the recirculation with a ceiling fan. With the acceptance of higher air velocities in the ASHRAE-55 standard, it might even be possible to have a hybrid system of fans within an air-conditioned office space. These methods are concerned with general flow rates across an occupant and do not consider the different sensitivities of body parts to air movement. To understand this, we turn our discussion to a specialised form of air movement known as personalised ventilation.

\subsection{Personalised Ventilation}

An alternative approach to air movement would be to apply personalised ventilation (PV). PV works on the principle each occupant should have direct control over the immediate thermal environment in order to adjust it to their personal preference. PV is delivered locally at each workstation through air terminal devices (ATDs) that typically cool the upper part of a seated occupant.

10l/s is negligible flow rate under PMV model. In the reference climate booth the air speed would average $0.01 \mathrm{~m} / \mathrm{s}$ and could potentially reach $0.05 \mathrm{~m} / \mathrm{s}$ in the constricted areas where the body is close to the wall. In a $120 \mathrm{~mm}$ diameter fan this same flow rate will produce a face velocity of $0.7 \mathrm{~m} / \mathrm{s}$. When applied frontally to the face, air speeds of up to $0.9 \mathrm{~m} / \mathrm{s}$ (Gong, 2006) were found to be acceptable and $96 \%$ of occupants at an ambient and task air supply temperature of $26^{\circ} \mathrm{C}$. This gives another indicator of the energetics of personal ventilation. The PMV at the experiment conditions would be +0.596 without air movement, and the actual vote is assumed as 0 with air flow directed to the face (96\% satisfaction will surpass the 5\% PPD at PMV=0).

To achieve $0.9 \mathrm{~m} / \mathrm{s}$ air speed, a flow rate exceeding $231 / \mathrm{s}(49 \mathrm{cfm})$ is required and this be easily achieved by a $120 \mathrm{~mm}$ axial fan (used in computer cases, see figure 5.11 for a sample specification) running at $7 \mathrm{~W}$, yielding $11.7 \mathrm{~W} /$ vote in comfort energetics. 


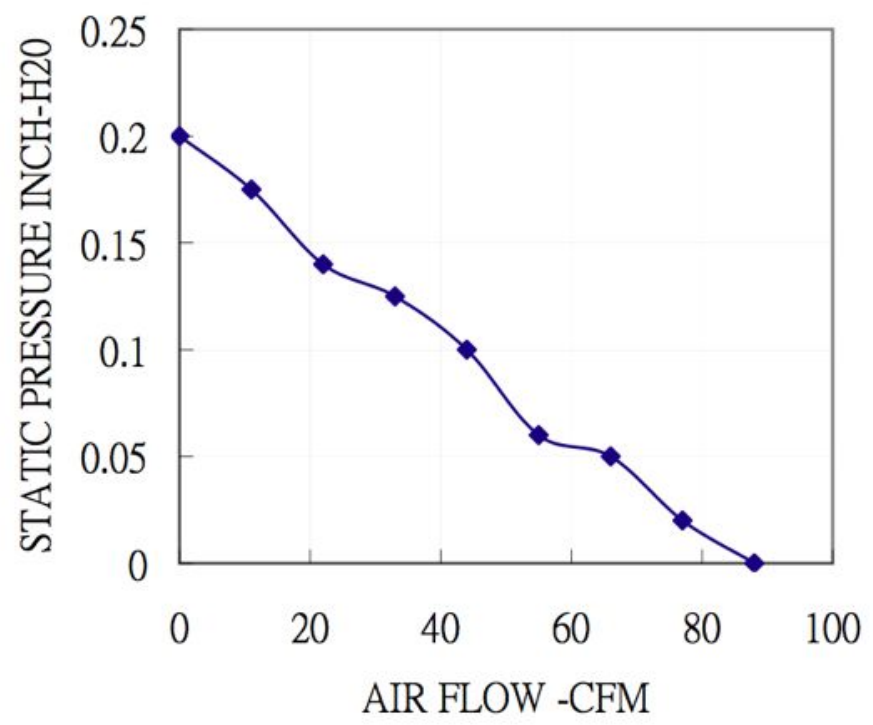

Figure 5.11: Flow rate of $120 \mathrm{~mm}$ diameter fan at $3000 \mathrm{rpm}$ (Specifications from manufacturer: Commonwealth Industrial Corporation)

Schiavon (2009) developed a cooling fan efficiency (CFE) index comparing the $\Delta \mathrm{T}$ equivalent of whole body cooling effect with the power input for the fan, expressed in ${ }^{\circ} \mathrm{C} / \mathrm{W}$. He determined that the most effective cooling device was the desk fan (16-20W) with an efficiency of $0.123^{\circ} \mathrm{C} / \mathrm{W}$. We also see from figure 5.12 the $\Delta \mathrm{T}$ has a practical limit of $-3^{\circ} \mathrm{C}$. Within this range, personal ventilation yields $26.3 \mathrm{~W} /$ vote (table 5.11). Most significant to the difference between the comfort energetics of desk fans (26W/vote) and computer fans $(12 \mathrm{~W} /$ vote) is the power input. At a fan power of $10 \mathrm{~W}$, the CFE is double that at $20 \mathrm{~W}$ and places the earlier estimation in the same ball-park as Schiavon's detailed model.

... the required power input of the fan is a critical factor for achieving energy saving at elevated room temperature ... The power of a fan used to cool people by increasing air movement should be in general less than $20 \mathrm{~W}$.... Computer fans can be used as cooling fans because their power input is extremely low while the generated flow rate is quite high. (Schiavon, 2009, p.43-45) 


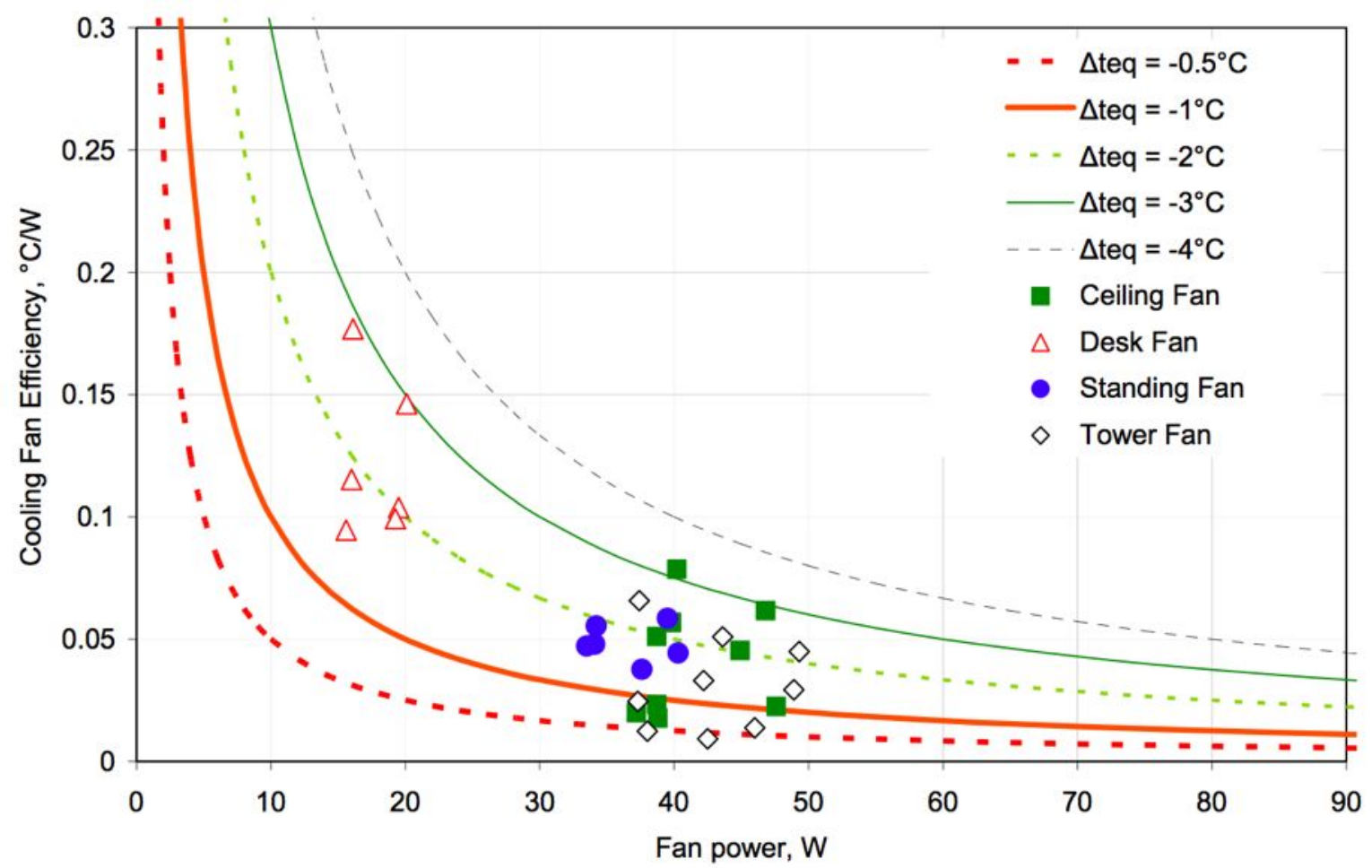

Figure 5.12: Fan power versus cooling fan efficiency index for the ceiling fan (CF) the desk fan (DF), the standing fan (SF), and the tower fan (TF). Lines with constant cooling effect ( $\Delta T \cdot$ eq) are plotted. (Schiavon, 2009)

\begin{tabular}{|c|c|c|c|c|}
\hline \multicolumn{5}{|c|}{ Cooling Fan Efficiency } \\
\hline$T$ & $\begin{array}{c}\text { Fan Power (W) } \\
\text { CFE=0.123ㄷ/W }\end{array}$ & PMV & dPMV & Elect W/vote \\
\hline 30.0 & & 1.994 & & \\
\hline 29.5 & 4.1 & 1.840 & -0.154 & 26.4 \\
\hline 29.0 & 8.1 & 1.685 & -0.309 & 26.3 \\
\hline 28.5 & 12.2 & 1.530 & -0.464 & 26.3 \\
\hline 28.0 & 16.3 & 1.375 & -0.619 & 26.3 \\
\hline 27.5 & 20.3 & 1.221 & -0.773 & 26.3 \\
\hline 27.0 & 24.4 & 1.066 & -0.928 & 26.3 \\
\hline
\end{tabular}

Table 5.11: Comfort energetics of a desk fan based on Schiavon's CFE index

\subsection{Comfort energetics, in summary}

In summary, the various processes can be ranked in the power each process consumes to effect an improvement of one vote. A fan power consumption of $7 \mathrm{~W}$ is here added to the computation where it had been earlier omitted to give a common baseline against fan-based cooling and tabulated in 5.12. 


\begin{tabular}{|c|l|l|c|}
\hline & \multicolumn{1}{|c|}{ Comfort approach } & \multicolumn{1}{|c|}{ Process } & Comfort Energetics (watts/vote) \\
\hline 1 & Computer fan & Wind directed only on face & 12 \\
\hline 2 & Direct evaporative cooling & Adiabatic humidification & 14 \\
\hline 3 & Refrigeration up to dew point & Constant humidity ratio (isodrosothermic) & 18 \\
\hline 4 & Ceiling fan & Recirculation (shared 4 pax) & 21 \\
\hline 5 & Desk fan & Wind directed to upper body & 26 \\
\hline 6 & Refrigeration past dew point & Cooling with dehumidification & 83 \\
\hline 7 & Ceiling fan & Recirculation (1 pax) & $76-124$ \\
\hline 8 & Refrigeration past dew point & To ASHRAE standards & 148 \\
\hline 9 & Extraction fan & Exhaust ventilation & 277 \\
\hline 10 & Desiccant dehumidification & Adiabatic + isothermic dehumidification & (depending on reheat efficiency) \\
\hline
\end{tabular}

Table 5.12: Summary of comfort energetics for cooling

\subsection{The Limit of Comfort Energetics}

Comfort energetics offers a basis to compare the efficiency of different approaches to comfort. As a theoretical exercise it separates peripheral issues like RH, which is more an air quality issue, from the central components of thermal comfort: air temperature and air movement. Whilst the human sensitivity to MRT is acknowledged, it is often not significantly different from air temperature for office occupants sitting away from the windows.

It needs to be noted that these tabulations are based on PMV scenarios. Even for processes that show linearity it may not be feasible to use one process alone to improve comfort by 2 to 3 votes. Based on the science of thermal comfort, for the best comfort energetics in a hothumid climate, it is noted that:

1. PMV is most effectively improved by reducing temperature

2. increased air movement is generally welcome

3. high RH not a comfort issue, and arguably not even an IAQ issue

4. IAQ is better improved with filtration and sanitisation than with dehumidification

\subsection{Conclusion to Comfort Energetics}

With the wet season, Emiko's life becomes bearable. The flooded metropolis means that there is always water nearby, even if it is a stagnant bathtub stinking with the refuse of millions.... She eats well and sleeps easily, and with water all around, she 
does not so greatly fear the heat that burns within her. If it is not the place for New

People that she once imagined, it is still a niche. (Bacigalupi, 2009, p.501)

In the tropics the options for cooling are greatly limited with high humidity. The difficulty with cooling in the tropics is that the air is already near saturation, limiting the options for evaporative cooling. The high humidity and cloud cover also limit the availability of radiant cooling to the night sky. Passive cooling in the tropics is often limited simply to increased cross-ventilation, which requires adequate spacing between blocks to encourage airflow.

In developing tropical cities confronted with poor air quality, massive demand for prime commercial real estate and the need for a productive workforce, the ubiquity of offices that are fully-glazed, deep-planned and air-conditioned is inevitable. Where increasing the humidity ratio is not an option, the best improvements in terms of comfort energetics will be, in order:

1. Low-power computer fan blowing at the face

2. Refrigeration of air, up to and not below dew point

3. Ceiling fan covering multiple occupants

However, the long-term acceptance of air-conditioning marketing, the acclimatised addiction to air-conditioning standards and the social expectations for air-conditioning all indicate that there will be massive resistance from the general public to accept the proposition that moving air will give them just as much comfort as air-conditioning. Whilst low-power fans can use far less energy than air-conditioning to ASHRAE standards, it is unlikely, at this stage, to provide an acceptable solution in Singaporean office buildings. It is acknowledged that this may be a disheartening conclusion unless there are mechanisms to change behaviour, an endeavour not within the scope of this thesis.

It would appear that to solve the problem of over reliance on energy-intensive airconditioning, the solution is not to avoid air-conditioning altogether, but rather to make it less energy-intensive. To do this we ask the following questions:

1. Without resorting to evaporative cooling, increased air movement or radiant sky cooling, can cooling still be achieved passively? 
2. If it cannot be done passively, what are the limits to which the energy inputs for cooling can be minimised? 


\section{Research Methodology}

This is not a conventional research thesis.

The thesis is concerned with solving a problem (hereafter referred to as The Problem) thus stated:

How can we solve the problem of over-reliance on energy-intensive airconditioning in knowledge-based economies located in tropical climates?

If methodology serves to appraise 'already formulated pieces of knowledge, such as theories or steps in a research program' (Kiss, 2006, p.315), this chapter is, strictly speaking, not about methodology in the deductivist sense.

[The] deductivist style tears the proof-generated definitions off their 'proofancestors', presents them out of the blue, in an artificial and authoritarian way. It hides the global counterexamples which led to their discovery. Heuristic style on the contrary highlights these factors. It emphasises the problem-situation: it emphasises the 'logic' which gave birth to the new concept. (Lakatos, 1976, p.144)

In this chapter, which also serves as an interlude between Context and Innovation (see figure 1.1, at start of thesis), I will explain why the rules for proof (methodology) do not apply as the rules for improvement (heuristics). I must also emphasise that the methods derived for innovation have not been shaped by the ideas covered in this chapter. Instead, this chapter has been written retrospectively, a guide produced after the adventure into innovation had been completed. Thus I am not suggesting that innovations proceed from this chapter in an a priori sense.

Whilst the method of inventing and improving inventions are my original work, it is not to say the methods developed are all-together novel. I have found the work of Imre Lakatos (Lakatos, Worrall, \& Zahar, 1976; Lakatos, 1980; Lakatos, Worrall, \& Currie, 1980) particularly helpful in elucidating the thoughts I have struggled to articulate. The format for 
emancipatory action research (Zuber-Skerritt, 1996) has also been a useful framework to structure the reflexive process. Lakatos' philosophical papers and the theory behind actionresearch were not an influence in the innovation process, though they greatly influenced how I now describe the process. Like allies for a common cause, arrived at from different angles, they explain my reasons for breaking from the conventional thesis structure, such as the one described by Evans \& Gruba (2007) in their book 'How to Write a Better Thesis'. Instead I have opted for the system of Lakatos:

In writing a historical case study, one should, I think, adopt the following procedure:

(1) one gives a rational reconstruction; (2) one tries to compare this rational reconstruction with actual history and to criticize both one's rational reconstruction for lack of historicity and the actual history for lack of rationality. Thus any historical study must be preceded by a heuristic study: history of science without philosophy of science is blind. (Lakatos, Worrall, \& Currie, 1980, pp.52-53)

Before proceeding to the history of innovations, it is precisely for the important role of heuristics, rather than of methodology, that this chapter has been written.

\subsection{Apologetics against a falsifiable hypothesis}

In a scientific thesis it is common to state a hypothesis that endeavours 'to explain, predict, and explore the phenomenon of interest' (Marczyk, DeMatteo, \& Festinger, 2010, p.37). In an academic argument, the rejection of a hypothesis (or its null hypothesis) features as a central endeavour.

First, all hypotheses must be falsifiable. That is, hypotheses must be capable of being refuted based on the results of the study (Christensen, 2001). This point cannot be emphasized enough. Put simply, if a researcher's hypothesis cannot be refuted, then the researcher is not conducting a scientific investigation. Articulating hypotheses that are not falsifiable is one sure way to ruin what could have otherwise been a wellconducted and important research study. (Marczyk, DeMatteo, \& Festinger, 2010, p.37)

In the earlier chapters ( 3 to 5, see table 6.1) the key concepts, for instance, can each be loosely constructed as a hypothesis. Here, the causal connection postulated and a 'null hypothesis rejected' have have based on the literature reviewed. Accordingly, to be 'dogmatic' the null hypothesis should only be properly rejected with experimental data. 


\begin{tabular}{|l|l|l|}
\hline \multicolumn{1}{|c|}{ Chapter Titles } & \multicolumn{1}{|c|}{ Hypothesis } & \multicolumn{1}{|c|}{ Null-hypothesis rejected } \\
\hline $\begin{array}{l}\text { Ch.3: Thermal Comfort } \\
\text { and Air-conditioning }\end{array}$ & $\begin{array}{l}\text { Thermal comfort will become more personal in the } \\
\text { future }\end{array}$ & $\begin{array}{l}\text { Thermal comfort will continue to be achieved by whole } \\
\text { body cooling at a shared thermostat setting }\end{array}$ \\
\hline Ch.4: Brain Cooling & $\begin{array}{l}\text { Stress can affect the brain in such way as to affect } \\
\text { preferred temperature }\end{array}$ & Stress has no effect on preferred temperature \\
\hline Ch.5: Comfort Energetics & $\begin{array}{l}\text { For a particular cooling technique, comfort can be } \\
\text { correlated to energy consumption }\end{array}$ & Comfort is independent of the energy needed to drive it \\
\hline
\end{tabular}

Table 6.1: Examples on the use of 'hypothesis' and 'null-hypothesis rejected' in the earlier chapters of this thesis

However, as we proceed to the innovation chapters, any hypothesis of this nature fails to account for the near-unlimited number of variables in the real world, nor does it have the flexibility to accommodate the development of lateral-thought. The scientific method of a falsifiable hypothesis ensures accuracy and consistency in inquiry, but offers little help, and can even be counter-productive, to discovery. This brand of justificationism is termed dogmatic falsificationism by Lakatos (1980):

The hallmark of dogmatic falsificationism is then the recognition that all theories are equally conjectural. Science cannot prove any theory. But although science cannot prove, it can disprove: it 'can perform with complete logical certainty [the act of] repudiation of what is false', (Medawar, 1967, p.144) that is, there is an absolutely firm empirical basis of facts which can be used to disprove theories. (p.12)

Lakatos then proceeds to show how this approach is untenable because it assumes a demarcation between theory and observation. Using arguments from psychology, logic and methodological judgment, Lakatos rejects this demarcation as non-existent and undefinable (pp.14-16). This approach, which he also terms naive falsificationism, should be superseded with sophisticated falsificationism (also referred to as Popper's methodological falsificationism), with a defining feature being the distinction between false and 'false' (to be elaborated in a later section).

Besides the problematic rationale behind falsifiabiility (in the dogmatic sense), a further problem with the conventional approach is its singularity: a hypothesis. Since this thesis is concerned with The Problem, it cannot be constructed in a (singular) hypothetical statement on which the modus tollens is directed. Instead with heuristics 'we must use our ingenuity to articulate or even invent 'auxiliary hypotheses', which form a protective belt around this core, and we must redirect the modus tollens to these' (Lakatos, 1980, p.48). 
Where The Problem is concerned, this thesis therefore cannot be presented as a hypothesis that can be tested and, if successful, not rejected. It is rather a program based on a core about the theory of comfort and a belt of theories about brain cooling and comfort energetics. I proposed that on this structure we build additional layers of engineering innovation. The criterion for success is a demonstration of a progressive problemshift. Lakatos (1980) explains the role of heuristics in a program as such:

First, I claim that the typical descriptive unit of great scientific achievements is not an isolated hypothesis but rather a research programme. Science is not simply trial and error, a series of conjectures and refutations.... Newtonian science, for instance, is not simply a set of four conjectures - the three laws of mechanics and the law of gravitation. These four laws constitute only the 'hard core' of the Newtonian programme. But this hard core is tenaciously protected from refutation by a vast 'protective belt' of auxiliary hypotheses. And, even more importantly, the research programme also has a 'heuristic', that is, a powerful problem-solving machinery, which, with the help of sophisticated mathematical techniques, digests anomalies and even turns them into positive evidence. (p.4)

From the earlier background, how can we construct this core? I may say:

There exists a non-static perfect temperature for which an individual will express as 'very comfortable' the state of mind being satisfied with the thermal environment.

Around this core I can build auxiliary hypotheses, for example:

This perfect temperature (1) varies across individuals, and (2) varies within an individual at different times. This perfect temperature can be (3) perturbed in an office occupant significantly by the (4) autonomic response to stress, and insignificantly by (5) the level of relative humidity.

In the dogmatic falsificationist position, a hypothesis can process facts until it encounters an anomaly. Since a hypothesis has been made falsifiable (the conditions for its refutation), an anomaly destroys the hypothesis. The methodological falsification differs in that it adopts a 'problem-solving machinery' to process both facts and anomalies. 
In heuristics, the research program, "this product of human activity, "alienates itself" from the human activity which has been producing it. It becomes a living, growing organism, that acquires a certain autonomy from the activity which has produced it; it develops its own autonomous laws of growth, its own dialectic.' (Lakatos, 1976, p.145) I may further this analogy in a pathological sense. The research program (organism) periodically encounters criticisms (viruses) which reveals a lack of response (no immunity), it is ill (pun intended) equipped to deflect the anomaly. But the program does not die: an antithesis is not its nemesis. The program accepts the challenge and adapts over a period (illness) with a synthesis (metabolising an antibody) of its original thesis and the challenging anti-thesis. It is this process of internalising the criticism that the program acquires limited protection (limited immunity) from similar future attacks (infection). I say limited because 'even the most rapidly and consistently progressive research programmes can digest their "counterevidence" only piecemeal: anomalies are never completely exhausted' (Lakatos, 1980, p.49).

Lakatos' description of 'digesting anomalies' which he elsewhere refers to as 'monstrous counterexamples' (Lakatos, 1976, p.22) has inspired me to illustrate both falsificationists' positions in figure 6.1; trusting that my humour is not entirely incongruous to the wit of his Proofs and Refutations: The Logic of Mathematical Discovery (Lakatos, 1976).

Thus, insofar as we are concerned with The Problem, it is the heuristics of a research program that offer the more appropriate framework to make and evaluate progress, rather than the methodology of a falsifiable hypothesis. 


\section{Dogmatic Falsificationist}

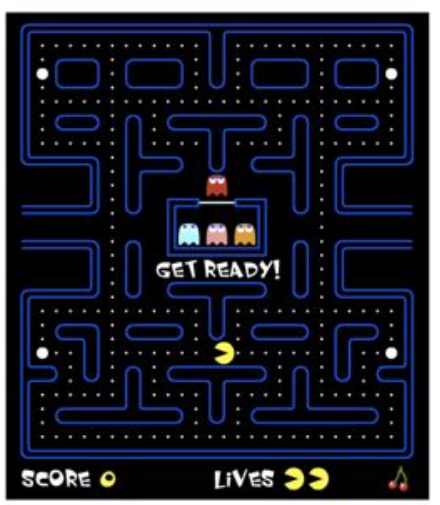

Hypothesis

- Fact

$\therefore$ Anomaly (fatal to hypothesis)

\section{Methodological Falsificationist}

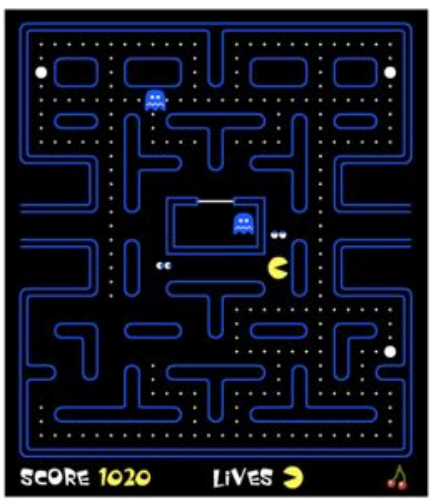

Negative Heuristic

(inner core)

- Fact

Positive Heuristic

(protective belt of partially articulated suggestions)

in (digested by positive heuristic)

.. but anomalies are never completely exhausted

Figure 6.1: Illustrating the dogmatic and methodological falsificationist reaction to anomalies. Screenshot of PACMAN game from www.thepcmanwebsite.com/media/pacman_flash/, characters from www.softicons.com

\subsection{Appreciating the difference between false and 'false'}

Lakatos (1980) asserted,

Methodological 'falsification' is very different from dogmatic falsification. If a theory is falsified, it is proven false; if it is 'falsified', it may still be true. If we follow up this sort of 'falsification' by the actual 'elimination' of a theory, we may well end up by eliminating a true, and accepting a false, theory (a possibility which is thoroughly abhorrent to the old-fashioned justificationist)." (p.24) 
Particular to the debate between deterministic and adaptive thermal comfort, I have strenuously avoided making a judgment as to whether there was a true and false theory. My starting point has been one of respecting both arguments, and seeking to understand if there existed assumptions and limits (spatio-temporal) to which the theorems could be applied (ceteris paribus) and under what conditions the theorem failed to explain or predict (anomalies). This was not difficult to uncover, for there were distinct methods for acquiring the data on which the two models were developed (previously discussed in table 3.1). The challenge was to harmonise the two theorems, and then with a third hybrid: the field studies (adaptive approach) in air-conditioned offices (deterministic approach) by Schiller (1990).

The problem is then shifted from the old problem of replacing a theory refuted by 'facts' to the new problem of how to resolve inconsistencies between closely associated theories. Which of the mutually inconsistent theories should be eliminated? The sophisticated falsificationist can answer that question easily: one has to try to replace first one, then the other, then possibly both, and opt for that new set-up which provides the biggest increase in corroborated content, which provides the most progressive problemshift. (Lakatos, 1980, p.45)

In Chapter 3, I attempted to frame the issue of over-reliance on energy-intensive airconditioning usage from sociology, marketing psychology and the various positions taken by thermal comfort researchers, who in turn emerge from a myriad of disciplines including architecture, mechanical engineering, physics and anthropology, to name just a few. The plurality of opinions shed crucial insight and allow the problem to be framed more comprehensively. Similar to the Indian fable of The Blind Men and an Elephant (figure 6.2), each opinion is valid within a specified context, and the challenge is to integrate the information that is, seemingly, both accurate and contradictory.

So oft in theologic wars,

The disputants, I ween,

Rail on in utter ignorance

Of what each other mean,

And prate about an Elephant

Not one of them has seen

(Saxe, 1865, p.64) 


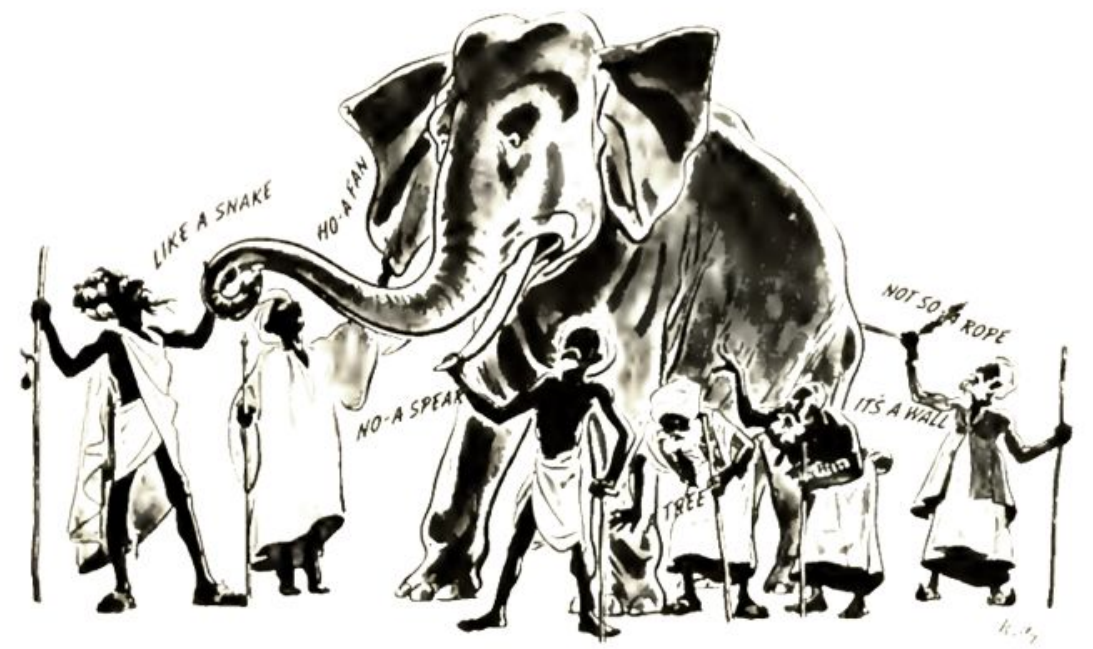

It was six men of Indostan

To learning much inclined,

Who went to see the Elephant

(Though all of them were blind.)

That each by observation

Might satisfy his mind.

The First (side) "Is very like a wall!"

The Second (tusk) "Is very like a spear!"

The Third (trunk) "Is very like a snake!"
The Fourth (knee) "Is very like a tree!"

The Fifth (ear) "Is mighty like a fan!"

The Sixth (tail) "Is very like a rope!"

And so these men of Indostan

Disputed loud and long.

Each in his own opinion

Excceding stiff and strong

Though each was partly in the right, And all were in the wrong!

From John Godfrey Saxe. "The Blind Men and the Elephant". Clever Stoties of Many Nations Rundered in Rhime, 1865.

Figure 6.2: The Blind Men and an Elephant (Saxe,1865)

The hermeneutic world view recognises multiple interpretations ... Each individual has their own construction of the world and creates their own reality and their own learning pathway through it. There is no objectively 'correct answer' to any educational research question and it is therefore not necessary, or even desirable, to begin with a definite hypothesis about an educational situation. (Zuber-Skerritt, 1996, pp.50-51)

Whilst written from the perspective of one from the discipline of Education, ZuberSkerritt's comment is wholly valid for research-based innovations. Like a lens, each academic discipline brings about a unique set of hermeneutics, procedures and criteria to analyse a given problem, but each lens focusses on particular aspects in such a way it becomes myopic to other ways of viewing it. These lenses can only deliver a consistent picture if an underlying theory can unite them: the theory is tested on how consistent it can hold up to scrutiny. As Lakatos explains, 'It is not that we propose a theory and Nature may 
shout NO; rather, we propose a maze of theories, and Nature may shout INCONSISTENT.' $(1980$, p.45)

How do I propose my theories of personalised comfort, brain cooling and comfort energetics be evaluated? I think the criteria will be an 'increased corroborated content' and 'progressive problemshift' that is consistent from a multi-disciplinary angle. I propose that this would be more appropriate than a binary judgment of false or not false based on dogmatic falsificationism.

\section{Q What is the nature of a theoretically progressive problemshift?}

A LAKATOS (1980, p.34): Progress is measured by the degree to which a problemshift is progressive, by the degree to which the series of theories leads us to the discovery of novel facts.

\section{Q How is a theory 'falsified'?}

A LAKATOS (1980, p.34): We regard a theory in the series 'falsified' when it is superseded by a theory with higher corroborated content.

Q What is the difference between rejection and disproof?

A To the dogmatic falsificationist, the two are conflated (Lakatos, 1980, p.25) in that a falsifiable hypothesis can be disproven and thus rejected. To the methodological falsificationist, theories have to be distinguished between the 'critical stance' and any number of 'non-observational propositions' (p.25) . Elsewhere Lakatos refers to them respectively as the negative and positive heuristics. He explains, 'The negative heuristic specifies the "hard core" of the programme which is "irrefutable" by the methodological decision of its proponents; the positive heuristic consists of a partially articulated set of suggestions or hints on how to change, develop the "refutable variants" of the research-programme, how to modify, sophisticate, the "refutable" protective belt.' (p.50) On these definitions, the 
positive heuristic can be repeatedly rejected without the negative heuristic disproven.

\subsubsection{The Role of Criticism}

In Proofs and Refutations, Lakatos uses the dialogue between a maths teacher and his students (named after Greek letters) as a scene to debate theories and their proof. Here, 'students do not represent particular mathematicians, but rather customs and typical behaviours of scientists faced with the coexistence of alternative proofs and refutations to the same theorem: Which one is wrong, and what is the problem with it?' (Kiss, 2006, p.303).

In this lively scene where students hurl objections in the most unrestrained way, Epsilon proceeds to give his proof with special attention to definitions, when Kappa launches an oblique attack. Keen to return to the main argument, the teacher intervenes:

TEACHER: Epsilon, do not listen to Kappa. Refutations, inconsistencies, criticism in general are very important, but only if they lead to improvement. A mere refutation is no victory. If mere criticism, even though correct, had authority, Berkeley would have stopped the development of mathematics and Dirac could not have found an editor for his papers.(Lakatos, 1976, p.112)

In the same spirit, Nathan Myhrvold (in Lomborg, 2010; see figure 6.3 ) describes his response to criticism for his work in geoengineering, for example delivering sulphur dioxide to the upper atmosphere:

There are some folks who will say, 'Look, this technology got us here [global warming] in the first place. You guys are only going to screw things up worse.' And I think the appropriate answer is to say, 'Okay... what's your solution? [pause] Don't stop me if you don't have a solution of your own.' 


\section{This Figure has been removed for copyright or proprietary reasons}

No theory is irrefutable, no discovery is ultimate, no effort is final, no construction of truth is guaranteed. Consequently all theories are subject to criticism, but it is the heuristic attitude to sweep aside criticism that offers no improvement. A theory is never abandoned because of criticism, it can only be superseded by a superior theory.

Contrary to naive falsificationism, no experiment, experimental report, observation statement or well-corroborated low-level falsifying hypothesis alone can lead to falsification. There is no falsification before the emergence of a better theory. But then the distinctively negative character of naive falsificationism vanishes; criticism becomes more difficult, and also positive, constructive. (p.35)

I now make a short digression from criticism of theories in the academic realm to criticism of ideas (in the widest possible sense to include all creative output, intellectual and material) in the real world. In contradistinction from theories, ideas are not merely produced but are also consumed, and many consumers have no involvement in the production of ideas, and are hence unable to offer any improvements. Should their opinion matter?

To illustrate this, the chef and connoisseur play distinct roles: one to create food and one to critique it (often in a deprecatory sense). Say the critic offers no (constructive) basis for her conclusion, 'I will not dine here again.' Should the connoisseur's opinion matter, seeing she cannot reproduce the food, let alone improve it? Should the critic defer to the technically superior knowledge of other chefs, for only they can improve the food by replacing it with a better version? 
Here I make a qualified departure from the safety of Lakatos' shadow. Firstly, the critics' opinions do matter. Whilst criticisms of an unconstructive nature do not improve an idea, they can diminish its popularity. A scientific statement retains its validity whoever says it. Yet even in academia, the weight of a scientific statement differs with the esteem given to the one declaring it. In the broad context of society, differences in opinions are resolved, to an extent, on the popularity of the opinion. Hence we do not find scientists to be the ones endorsing air-conditioners but media celebrities appearing beside them in advertisements, providing the illusion of endorsement (figure 6.4).

\title{
This Figure has been removed for copyright or proprietary reasons
}

\author{
Figure 6.4: Movie celebrities as air-conditioning ambassadors: (a) Hong Kong \\ action star Jackie Chan and (b) Singaporean comedian Jack Neo. From \\ advertisements produced by manufacturers Gree Electric and Mitsubishi \\ Electric respectively. Retrieved from YouTube.
}

Secondly, a mere opinion is still a real opinion. In the context of a scientific research program, evaluations are made though intellectual rigour. To a consumer, evaluation is based on personal gratification, with a large emotional component. It is pointless to convince a consumer that a critic's scathing review was irrational - opinions do not have to be rationally made or rationally accepted. Consumers can likewise make (scientifically) irrational statements like 'I feel more comfortable in high heels,' or, 'I feel important by putting on a designer jacket.' There is no empirical value in these statements, yet they are no less factual to the ones believing so.

Thirdly, an unconstructive criticism is not a useless criticism. In Lakatos' heuristic, unconstructive criticisms are not given consideration. However if a large portion of the consumer market agrees with the criticism, however unconstructive, it should still be considered. Again, it is the creative force of an inventive mind that provides the positive heuristic to assimilate these opinions and invent a new solution. Thus the Hegelian dialectic needs to accept an antithesis even in the form of mere opinion on account of its popularity, not its validity. 
I propose therefore, that criticisms have to be distinguished by their sources. Academic criticism of the rational sort will be subject to Lakatos' heuristic process. Market criticisms (from business, industry and consumer) need not fulfil any criteria of (scientific) rationality, but are considered in priority of their representativeness: a function of (1) the weightage of the opinion-giver and (2) the frequency to which the opinion is commonly held. These irrational criticisms have no bearing on the theory on the inner core, only affecting the invention at the outermost layer. The assimilation of these criticisms, more commonly called critiques in the design circle, is by way of integration into the design brief. I will explain this using the structure from Lakatos.

Under the heuristic model, there are two concentric circles with the non-negotiable negative heuristic as the inner, and the responsive positive heuristic on the outer. I suggest that with research innovation, the positive heuristic have two further coats: a double-layer atmosphere that distinguishes between the conditions for an innovation (foundational layer) and the innovation itself (superstructural layer) - or, the brief and the design respectively. Thus we have four concentric circles: the core is heuristically unresponsive; the belt is responsive only to rational debate; and the creative atmosphere (comprising layers of foundation and superstructure) are responsive to opinions, even irrational ones. This demarcation is necessary because there is no direct causal relationship between theory and invention, and thus no clear criteria on which to judge an invention. A design is deemed successful if it fulfils the brief, but fulfilling a brief does not equate to problem-solving. The Problem may remain unchanged, but with new understanding of its complexities, more conditions are introduced into the brief, making existing designs irrelevant and inadequate. The condition of acceptance should therefore be consistency on two terms: the design must be consistent with the brief; and the brief must be consistent with The Problem.

The design critique is crucial to the incremental complexity of the brief. Lakatos explains a similar process of proof as lemma incorporation.

\subsection{Lemma Incorporation}

The heuristic, or problem-solving, approach, made conjectures more rigorous by proving. In Proofs and Reputations the term 'proof' was more commonly used in the sense of to demonstrate by argument, rather than to demonstrate to be true. The proving process thus 
subjected conjectures to the debate of counterexamples and criticisms - or more commonly expressed, 'the theory must be made to stick its neck out' (Lakatos, 1980, p.26). The heuristic method 'improves by proving. This intrinsic unity between the "logic of discovery" and the "logic of justification" is the most important aspect of the method of lemma-incorporation.' (1976, p.37)

According to Lakatos the human problem-solving process happens in three distinct stages, which he called monster barring, exception-barring and lemmaincorporation. In the first stage, monster barring, one attempts to negate a new problem by treating it as a monster, insoluble. If the problem persists, we reach the second stage, in which the problem is acknowledged, but incorporated into our knowledge as an exception to the established rule. Only in the third stage, the lemma-incorporation, will we accept the problem as such and modify our knowledge to incorporate a solution. (Mayer-Schönberger, 2000, p.2)

In the subsequent innovation chapters it is not necessary to distinguish which of these three stages each improvement represented. There are, however, three major innovations that were developed by the gradual expansion of the invention brief, incorporating the lemmas that the previous invention could no longer accommodate. How did one innovation lead to another? I am tempted to say I gained new insights through cycles of action research. But Lakatos puts it better:

TEACHER: I abhor your pretentious 'insight'. I respect conscious guessing, because it comes from the best human qualities: courage and modesty. (1976, p.30)

The innovation process in table 6.2 shows the horizontal sequence from innovation $I_{1} \rightarrow I_{2} \rightarrow I_{3}$ being Rain Tower $\rightarrow$ Desiccant Wheel Air Handling Unit $\rightarrow$ Ductless Task AirConditioning. The chronology of this sequence reveals no logic, each invention was, well and truly, guesswork. However, the rationalisation of the process, also true to the history, is in the expanding lemma incorporation in the vertical sequence of the table. $I_{1}$ fulfilled the criteria of $L_{1}, L_{2}$ that was initially thought requisite to solve The Problem. Further research uncovered criteria from outside the scientific process, starting with $L_{3}$. If accepted, both the idea and premise of $I_{1}$ were conjunctively rejected: it was 'proven' to not solve The Problem. Similarly, with the realisation of $L_{4}$ and $L_{5}, I_{2}$ had to, in turn, be superseded by $I_{3}$. 
Will we discover yet more monsters in the future? Certainly! Thus I do not promise finality, only more (lemma incorporating) depth with each innovation (rephrased, Lakatos, 1976, p.120).

\begin{tabular}{|c|l|c|c|c|}
\hline \multicolumn{2}{|c|}{ Lemmas } & \multicolumn{3}{|c|}{ Innovation, in response to lemma } \\
\hline \multicolumn{2}{|c|}{} & \multicolumn{1}{|c|}{$\boldsymbol{I}_{\mathbf{1}}$} & \multicolumn{1}{|c|}{$\boldsymbol{I}_{\mathbf{2}}$} & $\boldsymbol{I}_{\mathbf{3}}$ \\
\hline $\boldsymbol{L}_{\mathbf{1}}$ & $\begin{array}{l}\text { Energy consumption } \\
\text { (compared to conventional systems) }\end{array}$ & More efficient & More efficient & More efficient \\
\hline $\boldsymbol{L}_{\mathbf{2}}$ & $\begin{array}{l}\text { Impact on } \\
\text { global warming potential }\end{array}$ & No synthetic refrigerants & Reduced synthetic refrigerants & No refrigerants \\
\hline $\boldsymbol{L}_{\mathbf{3}}$ & $\begin{array}{l}\text { Commercialisability 1: } \\
\text { selling advantage to property developer }\end{array}$ & Reduced AHU room size & Reduced AHU room size \\
\hline $\boldsymbol{L}_{\mathbf{4}}$ & $\begin{array}{l}\text { Commercialisability 2: } \\
\text { selling advantage to customer }\end{array}$ & & Direct individual control \\
\hline $\boldsymbol{L}_{\mathbf{5}}$ & $\begin{array}{l}\text { Commercialisability 3: } \\
\text { applicability within existing building stock }\end{array}$ & & No installation \\
\hline
\end{tabular}

Table 6.2: Lemma incorporation in the innovation process

The integration of lemmas into the design brief can be a trying process, because each additional lemma restarts the design process. When the foundation is redefined, the superstructure is demolished and rebuilt. It is here that the innovator must remember that a problem that has long persisted is not solved easily. Thus the conventional thinking:

Except under special circumstances, we think it ill-advised to try to get university researchers to work on specific practical problems of industry, or on particular product or process development efforts. In general, university researchers are poorly equipped for judging what is likely to be an acceptable solution to a problem and what is not. University researchers are almost always insufficiently versed in the particulars of specific product markets to make good decisions about appropriate tradeoffs. Equally important, such work provides few results that are respected or rewarded in academic circles, unlike research that pushes forward conceptual knowledge in an applied science or engineering discipline. (Rosenberg \& Nelson, 1994, pp.346-7)

I would thus recommend care in selecting what problem the heuristic researcher decides to solve. The problem should be so worthy it provides the inspiration to persist solving with tenacity and creativity, for if either virtue is depleted, so is the heuristic momentum. Daniel Koshland (in Schiavon, 2009) puts it aptly, 'It's probably equally difficult to solve an unimportant problem as it is to solve an important problem, so you might as well pick an important problem.' 


\subsection{The Commercialisation Test}

Lakatos viewed research programs as degenerative 'when the positive heuristic ran out of steam' (1980, p.52), where heuristic power is 'a technical term to characterise the power of a research programme to anticipate theoretically novel facts in its growth' (p.69). The innovation must therefore both be novel, and a source for novel findings. In this aspect, heuristics and patenting have some similarities shown in table 6.3.

\begin{tabular}{|c|l|l|}
\hline & \multicolumn{1}{|c|}{ Heuristic Process } & \multicolumn{1}{c|}{ Patent Process } \\
\hline $\begin{array}{c}\text { Progressive } \\
\text { problemshift }\end{array}$ & discovery of novel facts & invention of novel product or process \\
\hline $\begin{array}{c}\text { Time to } \\
\text { ascertain factual } \\
\text { novelty }\end{array}$ & 'the novelty of a factual proposition can frequently be seen only after a \\
long period has elapsed.' (Lakatos, 1980, p.69) & $\begin{array}{l}\text { open to challenges throughout the } \\
\text { patent lifespan (typically 20 years) }\end{array}$ \\
\hline Corroboration & 'acceptability' evaluated by anyone with relevant technique & $\begin{array}{l}\text { understood and confirmed by 'one skilled } \\
\text { in the art' }\end{array}$ \\
\hline
\end{tabular}

Table 6.3: Similarities in schema between the heuristic and patent processes

It is not requisite for research-based innovations to have a patent, and in fact there are dangerous pitfalls going down the commercialisation path (Nicholls, 2011). Nevertheless the commercialisation pathway has a method for proving on two key criteria: novelty (patent test) and marketability (pitch test).

The process of filing a patent through the university is very different from doing it privately and the two need to be distinguished. In a private submission, no checks are undertaken by the patent office at the time of filing a provisional patent. One need only pay a relatively small administration fee to submit the application. The application, not reviewed at this stage, is deposited in the patent office for safe-keeping. Only upon a subsequent filing of the full patent (typically within a year) is the invention reviewed by a patent officer. Thus it is possible for one to hold a provisional patent for an invention that was entirely precedented on prior art - an unthinkable disregard for novelty.

\section{Q What is 'prior art'?}

A 'Prior art is any body of knowledge relating to your research that exists prior to the completion of the research or the filing of a patent application. It may include patents filed in Australia or overseas; printed publications such as 
books, theses, journals and technical reports; public discussions; or public use of the research anywhere in the world.' (www.ipaustralia.gov.au)

The technology transfer (TT) office of universities have a more onerous system to ensure prior art cannot exist in their submissions. The TT front office (usually located on campus) requires a background to the invention, akin to a literature review. This forms the premise on which the invention is seen to have taken the inventive step beyond the knowledge-base. Satisfied, the TT officer submits the invention to the back office, typically off-campus. Here a patent researcher does a search to confirm that no prior art exists. Following which a patent review committee is convened by the TT office comprising entrepreneurs, patent attorneys, and, when necessary, field experts. The inventor is typically not present, and the invention has to 'sell itself'. Only after the committee deems the invention commercialiseable is a recommendation made to the university to pursue a patent. Even though the patent office does not require patents to be drafted by attorneys, universities routinely engage them to ensure all documents will hold up to scrutiny if the patent is disputed in court. The attorneys double-check that the invention fulfil the legal criteria for inventiveness and novelty before lodging the application.

'In general, the process of commercializing intellectual property is very complex, highly risky, takes a long time, cost much more than you think it will, and usually fails. (US Congress, Committee on Science and Technology, 1985, p. 12; in Bozeman, 2000). It is against these risks that the university patent process imposes such rigorous tests for novelty and commercial value.

One peculiar challenge is that the invention should need to 'sell itself'. This imposes another criteria on the innovation cycle. Besides increased lemma incorporation, successive inventions had to be increasingly elegant in their solution to The Problem. To the patent review committee, even though the decision is made prima facie, the more unknowns they had to accept tentatively, the less likely they were to recommend it for a provisional patent. But how can one make an invention simple in its novelty, or if you like, novel in its simplicity? The autonomy of the human product from human activity (Lakatos, 1976, p.145), requires that the invention, by design, be imbued with enough meaning to justify its 
purpose. Products should be 'so strong and convincing in their own right, that they so to say carry the validation with them, such as a strong piece of art' (Kvale, 1994, p.12). An invention receives the best review if it can convey the 'classical ideal of a unity of truth, good[ness] and beauty' (Kvale, 1994, p.12), or - to borrow the maxim from a science-fiction utopian city - 'Functional simplicity, structural complexity: the best life for all.' (Appleseed, Shirow, 1985)

In commercialiseable innovations, the recommendation of the TT office to proceed is proof of an invention's novelty. The converse need not necessarily be taken to be a refutation of novelty, as there can be many other reasons to decline commercialisation, particularly when there is no clear path to market. It is here that the inventor is at the mercy of the intuition of the reviewers.

\footnotetext{
Entrepreneurs with strong entrepreneurial cognition may be more likely to quickly develop new hunches about how a new piece of information such as that relating to a technological breakthrough will impact a specific project idea long before it can be methodically and rationally explained. ... The creation of significant scientific breakthroughs by university researchers may require leaps of intuition rather than deterministic logic. (Wright, Birley, \& Mosey, 2004, p.241)
}

I will explain my position on intuition and its role in marketability concurrently, which can also be understood heuristically.

\subsection{The Role of Intuition}

In Proofs and Refutations, Epsilon describes his intuitions as the 'nondubious apprehensions of a pure and attentive mind which are born in the sole light of reason'. (p.107) He further explains,

EPSILON: I get my definitions. just as I get my axioms, by intuition. They are really of equal standing: you can take my definitions as additional axioms or you can take my axioms as implicit definitions. They give the essence of the terms in questions.

TEACHER: Enough of philosophy! Let us see the proof. I do not like your philosophy, but I still may like your proof.

(Lakatos, 1976, p.108-109)

Intuition has two uses: it may be used to justify knowledge epistemologically, or used to account for a decision that canot be rationalised. In the former it is the master of 
knowledge, in the latter the servant of heuristics. Hegel and Lakatos reject intuition of the first kind.

As a kind of philosophical knowledge given to those fortunate to be born with it, it is, for Hegel, entirely unrelated to ordinary modes of knowing, a special kind of cognition altogether. Consequently, certain types of knowledge are effectively unlearnable. Another result is that the world becomes divided between those who have the inarticulate feeling or intuition to grasp the absolute and those who inexplicably lack that capacity. Schelling, as Lukacs remarks, created in Hegel's eyes an "aristocratic theory of knowledge" in which authentic knowledge may be accessible only by a chosen few. In his lectures, Hegel made this aristocratism clear: 'As the science of reason, philosophy is of its very nature ... available for all. Not all can attain to it, but that is not in question, any more than that few people become princes. That some men are placed higher than others is a scandal only if it is claimed that they are creatures of another kind and that nature had created them so.' (Imre Lakatos and the Guises of Reason, Kadvany, 2001, p.41)

Intuition of the second nature has its particular use, as we can see again from Epsilon's acknowledgement after being alerted to an inconsistency. He says, 'I was wrong. That "definition" was a stupid anticipation. I jumped to my judgment in a silly rush. True intuition, true interpretation, ripens slowly, and purging one's soul of conjectures takes time.' (p.109) Thus understood, this intuition is fallible, in contrast to the the earlier form. For example, Tversky \& Kahneman (1974, p.1130) show how even though 'the statistically sophisticated avoid elementary errors, such as the gambler's fallacy, their intuitive judgments are liable to similar fallacies in more intricate and less transparent problems.' It is for this precise weakness that intuition should not be used when a problem can be better solved rationally. However intuition is often relied upon when a complex situation requires a snap decision, a situation commonly encountered in the business world.

Businessmen hone their intuition by doing business. It is the product of apprenticeship, self-teaching, experimentation and reflection. In this sense, the proof pedagogy of business can be described as a Lakatosian heuristic process. How can an academic acquire business acumen without doing business? I suggest that the next best alternative is to role play the business encounter of a pitch. I have watched almost every episode of Dragons Den (UK), Dragons Den (Canada) and Shark Tank (U.S.). This was not intended for entertainment, for at the back of my mind was the action research format: plan $\rightarrow$ act $\rightarrow$ observe $\rightarrow$ reflect. I imagined myself in the role of the pitcher and attempted to understand the product or 
concept to be pitched (plan). I would then draft an elevator-style pitch, articulating in ninety seconds the unique selling points and market opportunities (act). Then I compared my approach with the pitcher's (observe) and rationalised the reaction of the investors (reflect). I accept that this approach is non-academic in that it cannot be theorised and its results cannot be peer validated; although it is an experimental technique which can be used by anyone.

The aim here is to develop sufficient business intuition so that a stage reminiscent of Proofs and Refutations can be recreated in the mind. I have composed a short specimen, casting an innovator with investors, who are designated after currencies.

INNOVATOR: Air-conditioning accounts for the majority of the energy used in tropical cities. I have invented a new way of delivering cooling with lower power consumption than that used by conventional systems, and which uses no synthetic refrigerants. I call this the Rain Tower. It uses a column of water as a piston to compress and condense vapour in a single stroke, thereby achieving better thermodynamic efficiency...

YEN: Show me your prototype.

INNOVATOR: At this stage I have only calculated the thermodynamic properties...

YEN: What? You haven't built anything yet?

INNOVATOR: No, not yet. I am here to ask for funding to prove that the engineering concept is viable and...

POUND: [interrupts him] You have twenty seconds to explain, in plain English, how this thing works.

INNOVATOR: [perspiring and speaking quickly] The engine of air-conditioning is the compressor. All compressors need to have a clearance because you can't have the piston striking against the walls. But like pumping a bicycle, if you don't squeeze it to the end you lose the valuable part of compression. I've eliminated that with my invention using a falling column of water to regenerate steam. No clearance equals better efficiency. [breathes] 
DOLLAR: Cut out the science, I'm not interested. How do we make money?

INNOVATOR: We haven't got there yet. At this stage we need to confirm the technology is viable.

DOLLAR: [irritated] Let's assume that the science works, how do we turn a profit?

INNOVATOR: Electricity will continue to get more costly and the carbon price introduces an additional charge for refrigerant leakage, which has a high global warming potential.

DOLLAR: Is there a dollar value in there somewhere?

INNOVATOR: Yes at the proposed carbon price, the total emissions from refrigerant leakage and refilling in Australia will be about $\$ 96$ million.

DOLLAR: And how much is this Rain Tower going to cost?

INNOVATOR: I'm afraid I don't ...

DOLLAR: [throws his hands up] You don't know? How can you not know? That is the only number that matters! I am an investor, you want my money and you have no clue what it will cost, what it will sell for and if I'll ever see my money again?

INNOVATOR: I'm very sorry...

DOLLAR: You should be! You're wasting my time. I'm out.

EURO: [aside to Dollar]Cut the poor fella some slack. [turning to Innovator]I'm intrigued, I think with the carbon price the market is ready for some innovation. How long before we can roll out a manufactured version?

INNOVATOR: We will need about three months to build a test rig, about as long to test and tune. Then we should, ideally, build it to full scale and that will take about nine months, and about as long to collect data. We will then be able to approach industry to manufacture to our specifications.

YEN: By which time my children will have received their inheritance. [shaking his head] You should have built a 
prototype before asking for a share of my children's inheritance.

I'm out.

EURO: Why do you need so much time? How big is it?

INNOVATOR: For a 40-storey office block of average size, it would be a continuous section with a cross-section of four parking lots on the side of a building.

EURO: Did you say on the side of a building?

INNOVATOR: Yes, it has to be in thermal communication with the ambient. So the side of a building is best.

EURO: That's a bad idea. Not the water thing, the side of building thing. Don't like that. And it can't be installed in existing buildings?

INNOVATOR: I'm afraid not, the building has to be designed around the cooling apparatus.

POUND: I haven't said much but I've heard enough. You obviously don't have a clue how things work in the rea/world. Get out of university and get a rea/job selling something. Until then I'm not trusting you with my money. I'm out.

EURO: I like you but I don't like your idea. Work on something else, this idea isn't going to be the one. And for that reason, I'm out.

DOLLAR: [to Euro] It's a bad idea. Why are you still encouraging him? [turning to Innovator] You are dead to me. Now get off my carpet.

If an innovation cannot meet marketability criteria, regardless of novelty, it will not be funded, manufactured, distributed and retailed. The ability to role-play the pitch in the mind allows research ideas - this embodiment of academic knowledge - to be tested against business intuition. It is the fastest and cheapest way to refute an idea. It is also far easier to be self-deprecating than to be ripped apart and scorched by a panel of impatient investors: there is a reason why they are called dragons and sharks. 


\subsection{Concluding thoughts on heuristics}

The significant problems we face cannot be solved at the same level of thinking we were at when we created them.

Albert Einstein (1879-1955)

The conventions of a methodology chapter and a falsifiable hypothesis do not offer the appropriate structure to solve problems. Being concerned with The Problem, this chapter has shown a better way in the heuristic style of Imre Lakatos. However his approach was intended for the academic realm and I have proposed modifications to extend the heuristic method so that research can be realised in the world of commerce. For this particular Problem the commercialisation route was chosen and served well to validate novelty and marketability. Recognising my own inadequacy to intuit business, I have devised a method to simulate a pitch, analogous to Lakatos' classroom scene.

Having explained why I made a break with convention, we may proceed, tabula rasa, to solve The Problem. 


\section{The Rain Tower}

Rather than tinkering with small incremental improvements in the efficiency of air conditioning systems, we need a step change to new paradigms for cooling buildings. Just as with the cars, we need super-low-consumption, dual fuel, ecobuildings that are naturally ventilated in spring, winter and autumn, and in summer are run on solar air conditioning when the sun is out topped up by small amounts of grid electricity when it is not. This is the way forward. (Roaf, 2005, p.233)

The problem of energy-intensive air-conditioning has been very persistent. Incremental steps in improving energy economy may be too modest an approach to tackle the imminent risk of anthropological climate change. To accommodate the need for non-linear creative thinking, the following approach was taken as an adapted model for action research:

1. Framing the research problem as a design brief

2. Disruptive creativity: proposing solutions through lateral thinking, a process that is not necessarily linear or sequential

3. Action research: evaluating the solutions against its intents and ascertaining its implementability

The inventive process is often non-linear, with the most significant breakthroughs often having little resemblance to earlier ideas. The valuable insights gained in the earlier stages however frame the issues with greater clarity and facilitate reprioritisation so that the brief can be revisited with more knowledge and detail.

\subsection{The Brief}

In 9 April 2007, TIME magazine (2007) ran a special article on global warming. In that article, buildings were highlighted as key contributors to warming, with offices and homes said to account for $38 \%$ of U.S. $\mathrm{CO}_{2}$ emissions. All the green buildings mentioned in the article featured novel approaches to thermal control, such as the Federal Building (San Francisco), Bank of America Building (New York) and Pearl River Tower (Guanzhou, China). In 
Singapore $34 \%$ of the nation's annual 35.9GWh energy consumption is attributed to buildings (both commercial and residential), of which 33\% is for air-conditioning and another $25 \%$ for refrigeration (NCCC, 2006).

Office workers are responsible for approximately $50 \%$ of the US annual gross national product (Traynor, 1993 in Fisk, 1999). In the foreseeable future, offices will continue to be the central power house for the economy. Until there is a large critical mass of lessees who will pay higher premiums for energy efficient buildings, these offices will continue to be developed as deep plan, fully-glazed offices. In areas with poor air quality or noisy external environments, in both cases necessitating closed windows, the reliance on air-conditioning is understandable, but even when air does not have to be filtered or conditioned there are prestige factors (Tselepidaki \& Santamouris, 1991), social norms (Wilhite, 1996) and building standards (Shove, 2003) that lead us to predict that air-conditioning is here to stay - at least until circumstances force change.

For buildings to be sustainable, it is becoming increasingly important that they have high performance while consuming minimal resources. The area of research innovation here can be constructed as a brief:

\section{Design a system that can provide air-conditioning to high-rise offices in the} tropics with little or no demand on grid power

Being in the tropics the enthalpy of air is already high (hot-humid), and has limited capacity as a heat sink by further evaporative cooling. Being equatorial, the solar angles are high and limit the prospect for photovoltaics or solar-thermal collection to only the roof. Being multi-storey, the one roof needs to supply enough converted solar power for all floors. Being in a densely populated city, there is minimal availability for cross-ventilation due to the tight urban planning and deep office plans.

To tackle the issue of climate change at its root, incremental steps are not adequate. So instead of looking at marginal improvements to efficiency, the theoretical limits are considered. Similarly whilst the use of high global-warming potential (GWP) refrigerants is discouraged, the ultimate intent is to avoid these refrigerants altogether, and this intent is assumed in the brief. 
The properties of natural refrigerants are tabulated in 7.1 and show the challenges of working with these refrigerants. Studied thermodynamically, Kilicarslan and Muller (2004) found that at a temperature lift ( $\triangle \mathrm{T}$, or $T D$ in figure 7.1 ) of $30 \mathrm{~K}$, water is equivalent in COP to $\mathrm{R} 134 \mathrm{a}$ at an evaporator temperature, $\mathrm{Te}=12^{\circ} \mathrm{C}$ and superior to all the other refrigerants modelled (R12, R22, R134A, R290, R152A and R717) at $\mathrm{Te}=34^{\circ} \mathrm{C}$.

With a high COP (coefficient of performance), no ODP (ozone depleting potential) and neutral GWP, water appeared a natural choice around which to design a cooling system.

\begin{tabular}{|c|c|c|c|c|c|c|}
\hline \multicolumn{2}{|c|}{ Refrigerant } & $\mathrm{CO}_{2}$ & Hydrocarbon & Ammonia & Water & Air \\
\hline \multirow{3}{*}{ Chemical properties } & Toxicity/flammability & O & $\Delta$ & $\Delta$ & $\mathrm{O}$ & $\mathrm{O}$ \\
\hline & Material deterioration & $\mathrm{O}$ & $\mathrm{O}$ & $\Delta$ & $\mathrm{O}$ & O \\
\hline & Chemical stability & O & O & $\Delta$ & $\mathrm{O}$ & $\mathrm{O}$ \\
\hline \multirow{4}{*}{ Thermophysical properties } & Moderate boiling point & $\Delta$ & $\mathrm{O}$ & $\mathrm{O}$ & $\Delta / O^{* *}$ & $\Delta$ \\
\hline & Capacity per unit volume & O & O & $\mathrm{O}$ & $\Delta / O^{* *}$ & O \\
\hline & Theoretical COP & $\Delta / O^{*}$ & O & $\mathrm{O}$ & $\mathrm{O}$ & $\Delta$ \\
\hline & Moderate discharge temperature & O & O & $\mathrm{O}$ & $\mathrm{O}$ & O \\
\hline \multirow{2}{*}{$\begin{array}{c}\text { Global environmental } \\
\text { property }\end{array}$} & Ozone layer & O & O & O & $\mathrm{O}$ & 0 \\
\hline & Warming & O & O & $\mathrm{O}$ & $\mathrm{O}$ & O \\
\hline \multicolumn{2}{|c|}{$\begin{array}{l}\text { * Evaluated with air-conditioners/water heaters. } \\
{ }^{* *} \text { Evaluated for source-of-heat temperature at low/high }\end{array}$} & $\begin{array}{l}\text { : Accep } \\
\text { Unacc }\end{array}$ & $E$ & & & \\
\hline
\end{tabular}

Table 7.1: Characteristics of natural refrigerants (Tanaka, 2007)

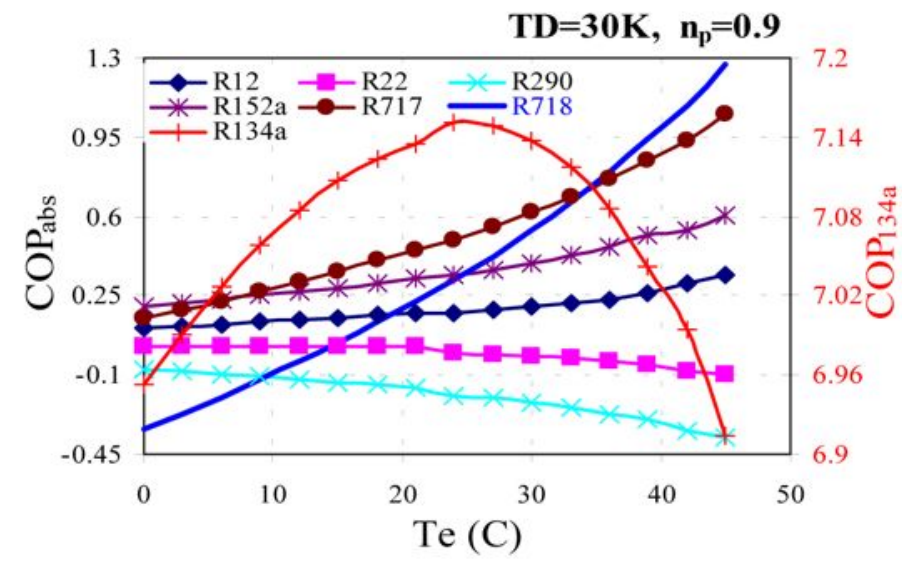

Figure 7.1: Water (R718) compared to natural refrigerant ammonia (R717) and other synthetic refrigerants. (Kilicarslan, 2004)

\subsection{Innovation 1: Water as refrigerant}

Conventional air-conditioning systems use mechanical compression to restore a refrigerant from gaseous to liquid state, a process that invariably generates more heat through 
inherent inefficiencies of the machinery. The proposed alternative to the air-conditioning system begins by rethinking how a gaseous refrigerant could be readily recondensed, and perhaps the passive cooling solution might be in selecting a refrigerant that was less volatile.

This Figure has been removed for copyright or proprietary reasons

Figure 7.2: Cloud seeding (Battan, 2003)

\section{Cloud seeding}

The inspiration came from the notion of cloud seeding (figure 7.2). When suspended cloud droplets and supersaturated water vapour were sprayed with a suitable seed (dry ice or silver iodide), the ice crystal would grow till it became sufficiently heavy to fall, and passed through the warmer lower atmosphere as raindrops (Ball, 2002 ; Battan, 2003). What if we could have a tower filled with saturated vapour and seed it from the top? Or better, what if the top of the tower was so high that it was cold enough for the vapour to condense?

\section{Adiabatic lapse rate}

The higher we go, the thinner the atmosphere gets, and correspondingly, the colder it becomes. The phenomenon is known as the adiabatic lapse rate (see figure 7.3a) and meteorologists have computed a range of values corresponding to dry and moist air of $10^{\circ} \mathrm{C} /$ $\mathrm{km}$ and $5^{\circ} \mathrm{C} / \mathrm{km}$ respectively (Lutgens \& Tarbuck, 1995; Allaby, 1992). Water vapour condenses naturally into clouds at about $3 \mathrm{~km}$. If we could increase the humidity inside a column, could a tower $200 \mathrm{~m}$ tall have sufficient coolness to drive condensation with a $2^{\circ} \mathrm{C}$ drop in temperature, for example in $7.3 b$ ? 

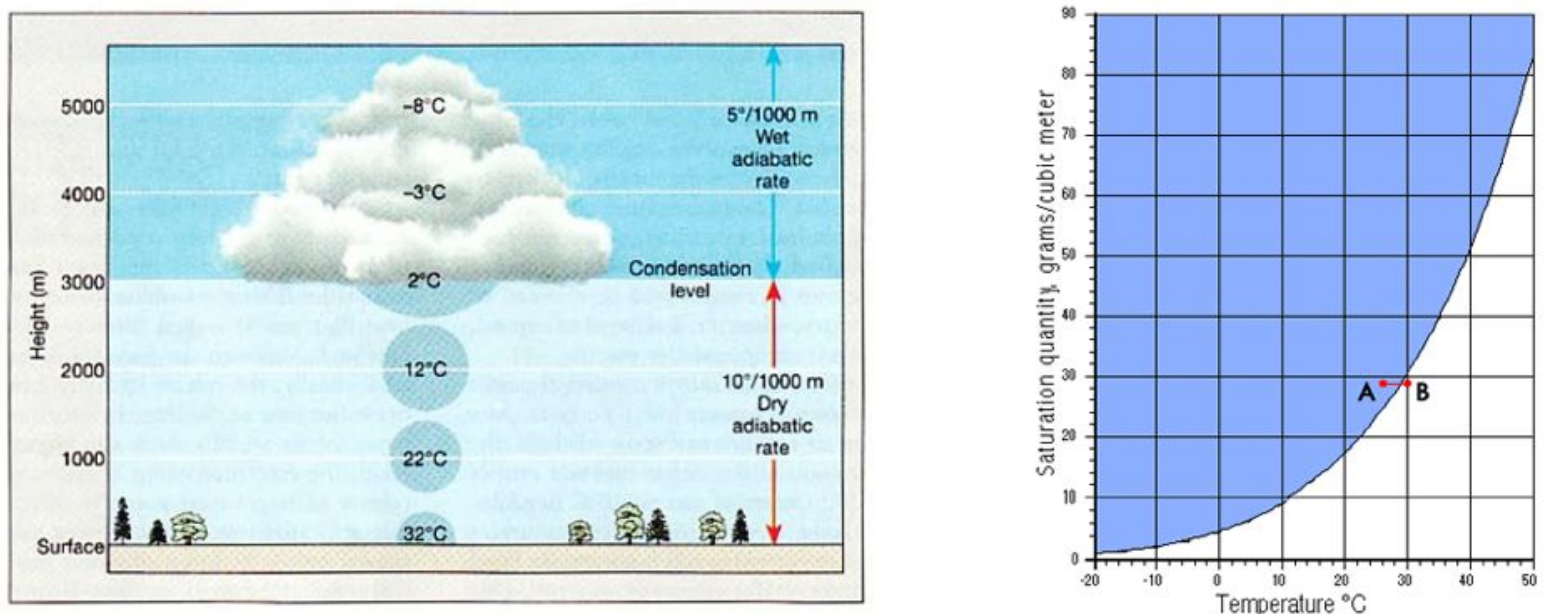

Figure 7.3: (a) Adiabatic lapse rates (Lutgens \& Tarbuck 1995) (b) Water vapour saturation curve, redrawn from Loubere (2012)

If a column of air could be saturated to a humidity of $28 \mathrm{~g} / \mathrm{m}^{3}$ then a $2^{\circ} \mathrm{C}$ drop in temperature between base of this tower and its summit (figure 7.4) would be sufficient to cause vapour to condense.

Operating on a similar premise to evacuated heat pipes, the rain tower essentially uses the temperature differential from altitude to drive a evaporation-condensation cycle, and, through the processes of evaporating the water at low altitudes and condensing at high ones, allows ground level spaces to approach the temperature of high altitudes.

However a $2^{\circ} \mathrm{C}$ temperature drop would hardly be adequate for the tropics. With an ambient temperature of $30-35^{\circ} \mathrm{C}$ in the tropics, a drop of about $\sim 10^{\circ} \mathrm{C}$ was needed for comfort, and a further $10^{\circ} \mathrm{C}$ necessary for dehumidification. For buildings that were already tall (Burj Khalifa, AC Towers), the adiabatic lapse rate could be a means of supplementing the cooling load. However for the majority of buildings, simply building taller was clearly not the solution.

Some form of energy input is therefore essential to supplement the cooling with altitude. 


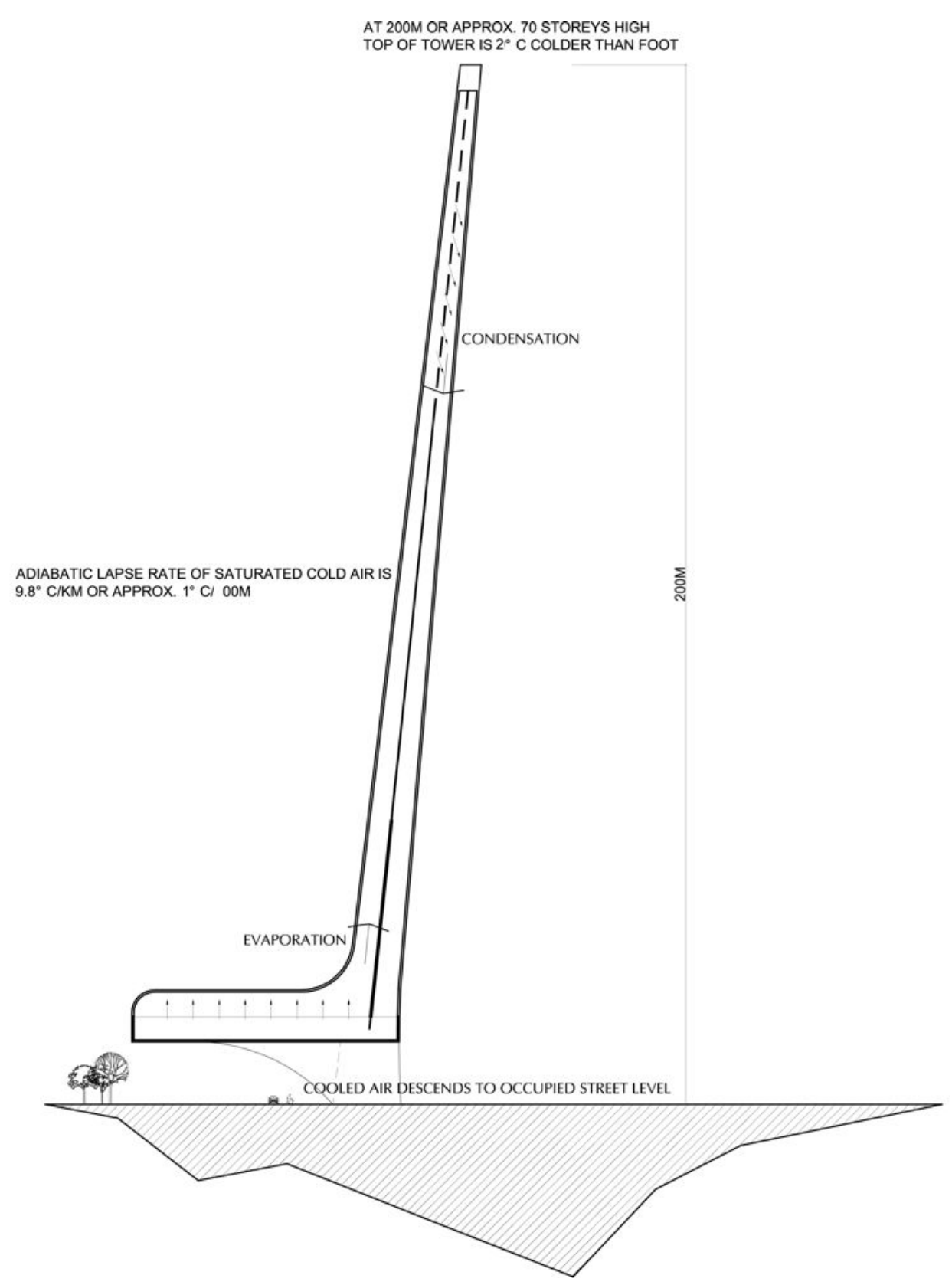

Figure 7.4: Rain tower using altitude cooling

\section{Solar-thermal absorption chiller}

Pairing the power supply to the chiller to a solar source has the advantage of delivering more power when the outdoor radiant heat was high, and thus demand for air-conditioning was also at its highest. There are two passive ways of driving chillers, both with comparable efficiencies:

1. Photovoltaics (10-15\% solar-electric efficiency) to drive a vapour compressor ( $C O P=$ 3 to 4$)$ 
2. Concentrated solar on evacuated heat pipes (80-90\% solar-thermal efficiency) to drive absorption chillers ( $\mathrm{COP}=0.5$ to 0.7$)$

Once again, to avoid synthetic refrigerants, the use of vapour compression chillers is not considered. Instead water is heated by evacuated tubes or concentrated parabolic troughs, then passed through an absorption chiller (e.g. lithim bromide - water). The chiller condenses some of the vapour into liquid state and sprays a chilled mist into the tower where the rest of the water vapour is fed (see figure 7.5). The mist acts as condensing nuclei, causing the vapour to coalesce and precipitate to the base. The system would now be able to achieve more cooling without having to build higher, though height will still be an advantage, allowing droplets more growth time. 


\section{Absorbtion chiller}

Rising vapour is bifurcated to condensing tower and absorbtion chiller. The absorbtion chiller condenses the vapour and sprays the condensate into the tower where the chilled droplets become condensing nuclei for droplet growth.

\section{Solar thermal collectors}

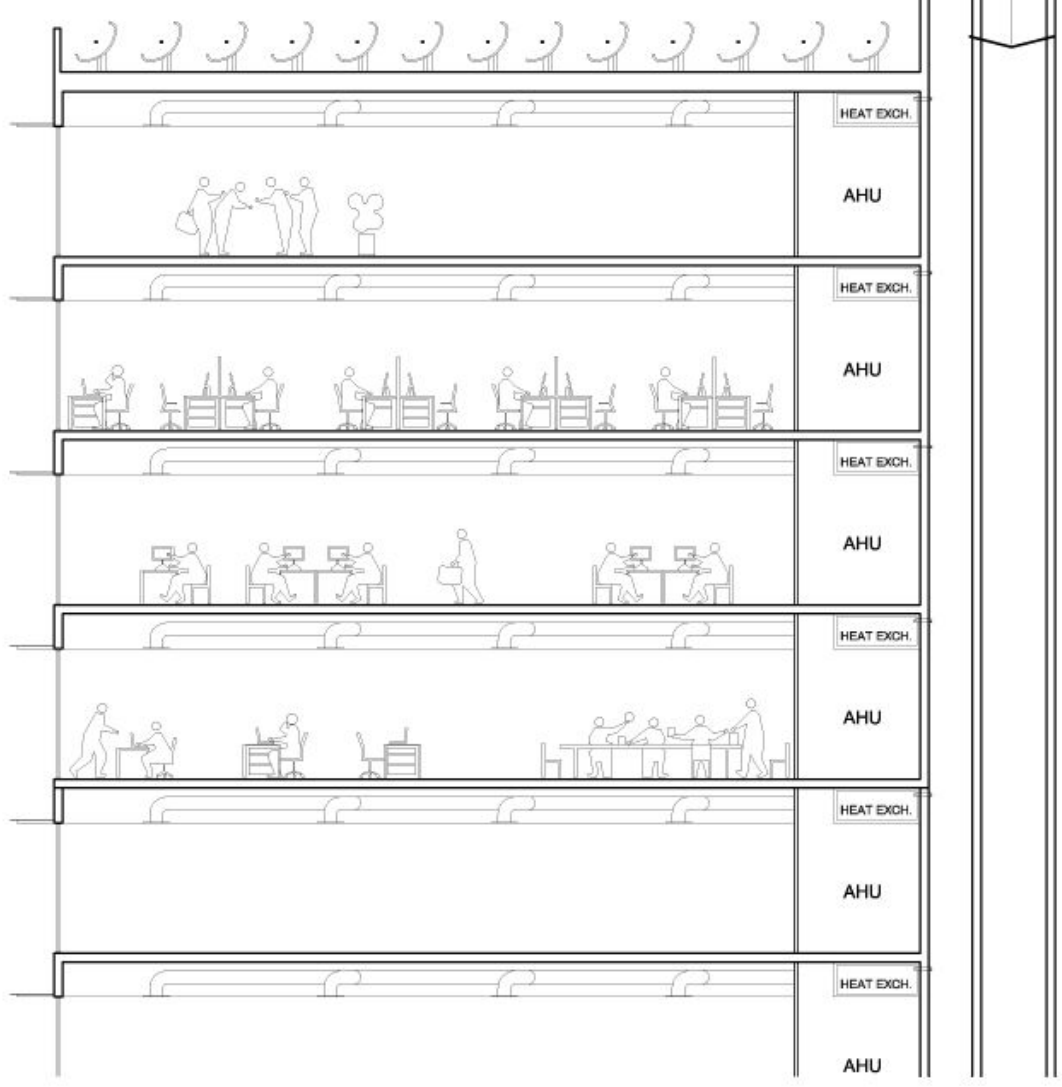

Figure 7.5: Rain Tower using solar thermal driven absorption chiller 


\section{Reflections}

The early attempt to create an artificial water cycle utilising the height of a tower gave limited cooling of $2^{\circ} \mathrm{C}$. This was the limit to a passive mode of cooling. Further cooling required the use of a chiller, which could be run with solar power. To avoid the use of synthetic refrigerants, an absorption chiller coupled with concentrated solar-power can provide further cooling. However the chiller capacity is limited to the size of the rooftop collectors, and cannot scale up for a large number of floors. When there are too many storeys to cool, each floor may not receive adequate cooling.

The limits to passive cooling were clear. Without the heat sinks of dry air and the night sky in the tropics, the only option of heat rejection to the upper atmosphere was not adequate for a $200 \mathrm{~m}$ high tower. At the same time, a multi-storey building had a very small roof-floor ratio and limited the possibility of using the roof as a solar collector.

If cooling could not be achieved passively, what was the theoretical minimum energy needed?

\subsection{Innovation 2: Water as a Plug to compress R718}

There are technical difficulties working with water in conventional compressors which include:

- the need to work and maintain very low pressures to evaporate water

- when compared to synthetic refrigerants, water has a higher chance of condensing in the compressor (leading to compressor malfunction), thus requiring that the vapour to be superheated. However every degrees celsius of superheat decreases COP by approximately 0.05 (Lachner, 2007).

Whereas the previous idea dealt with using chilled droplets to condense water vapour and coalesce suspended droplets to fall as rain, this idea deals with using water as a piston to compress vapour to liquid. 


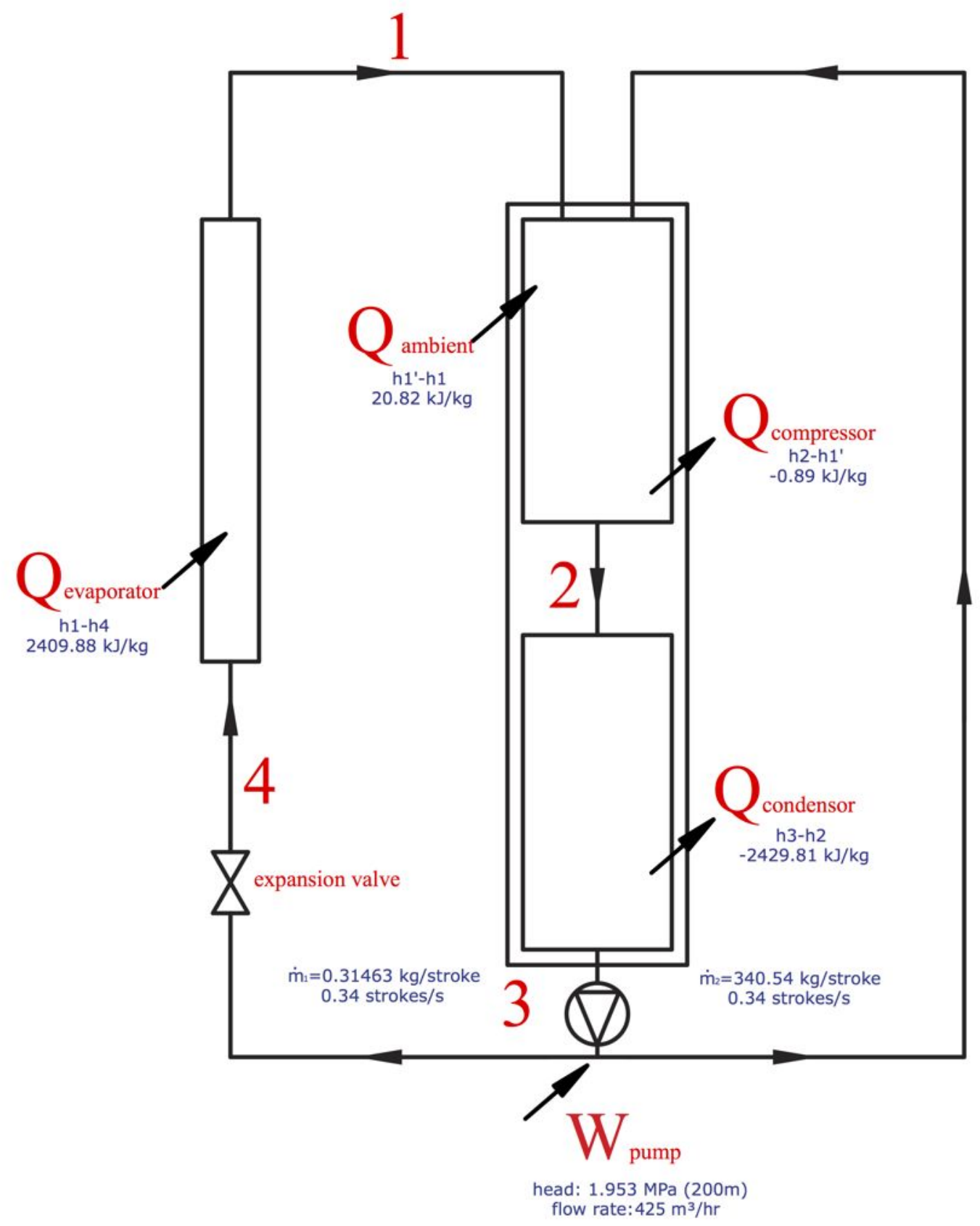

Figure 7.6: System Diagram for the Rain Tower

\subsubsection{System concept}

The Rain Tower uses water as a natural refrigerant in a hermetically sealed cycle to create cooling from an ambient condition of $30^{\circ} \mathrm{C}$ to an indoor one of $19^{\circ} \mathrm{C}$. Its mode of operation is similar to a vapour-compression air-conditioning cycle with the main exception being that the compressor is replaced by a falling column of water acting by gravity to compress and condense steam in one stroke (figure 7.6). 
Water is passed across an expansion valve (3-4) to a mean pressure of $0.022 \mathrm{bar}$. The vapour is passed to the condensing tower, a $20 \mathrm{~m}$ high (variable as needed) thin-walled aluminium cylinder where it is allowed to warm to ambient conditions $\left(30^{\circ} \mathrm{C}\right.$, stage $\left.1-1^{\prime}\right)$.

A column of water exerting 0.034 bars is released on the steam and the falling column, acting as a plug, compresses the vapour adiabatically up to $35^{\circ} \mathrm{C}$. Assuming the cylinder walls are thin enough to maintain the $\mathrm{T}$ of steam (mixture of vapour and droplets) close to $30^{\circ} \mathrm{C}$, the compression can be taken to occur isothermally (1'-2). The internal pressure of the steam eventually reaches equilibrium with the net pressure exerted $(0.022+0.034=0.056 \mathrm{bar})$. As the steam fraction decreases, the volume corresponds and the steam is condensed isothermally (2-3). Table 7.2 and figures 7.7, 7.8 and 7.9 give further details to the thermodynamic process.

\begin{tabular}{|c|l|}
\hline $1-1^{\prime}$ & Warming of steam (constant-volume) from evaporator to ambient temperature \\
\hline $1^{\prime}-2$ & Isothermal compression \\
\hline $2-3$ & Isothermal condensation \\
\hline $3-4$ & Isenthalpic expansion \\
\hline
\end{tabular}

Table 7.2: Summary of compression cycle with a falling column of water

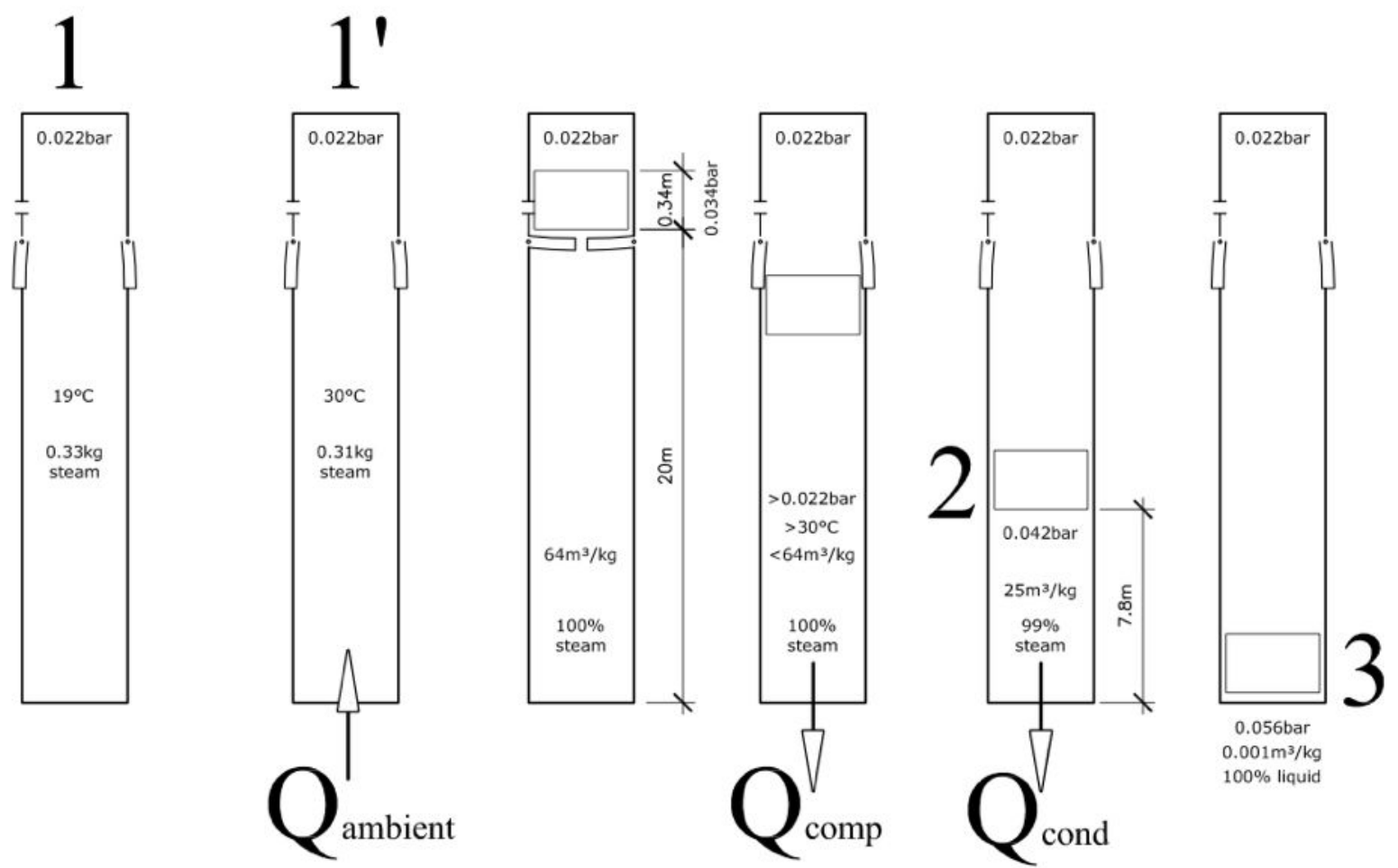




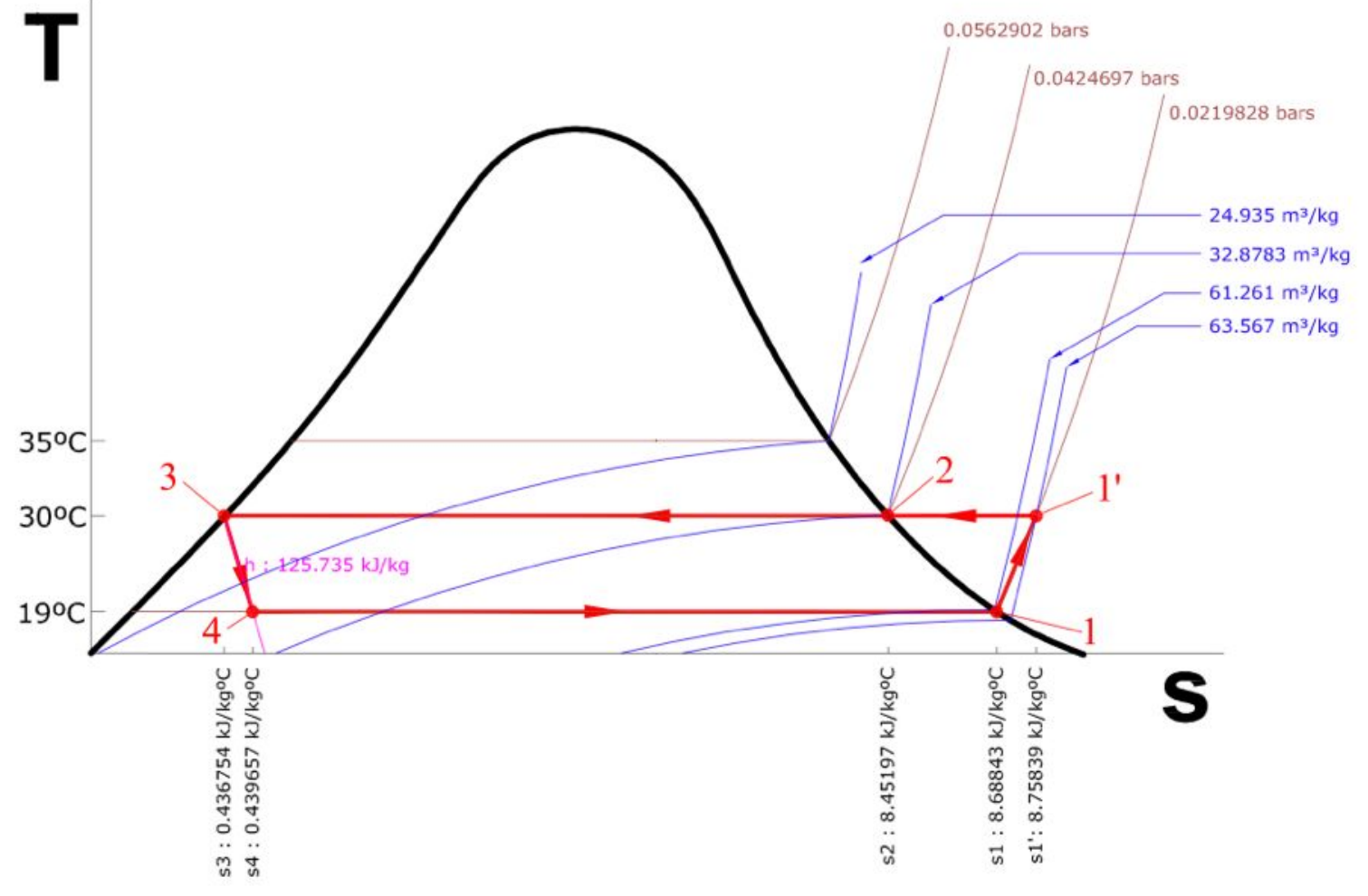

Figure 7.8: Temperature-Entropy Diagram 


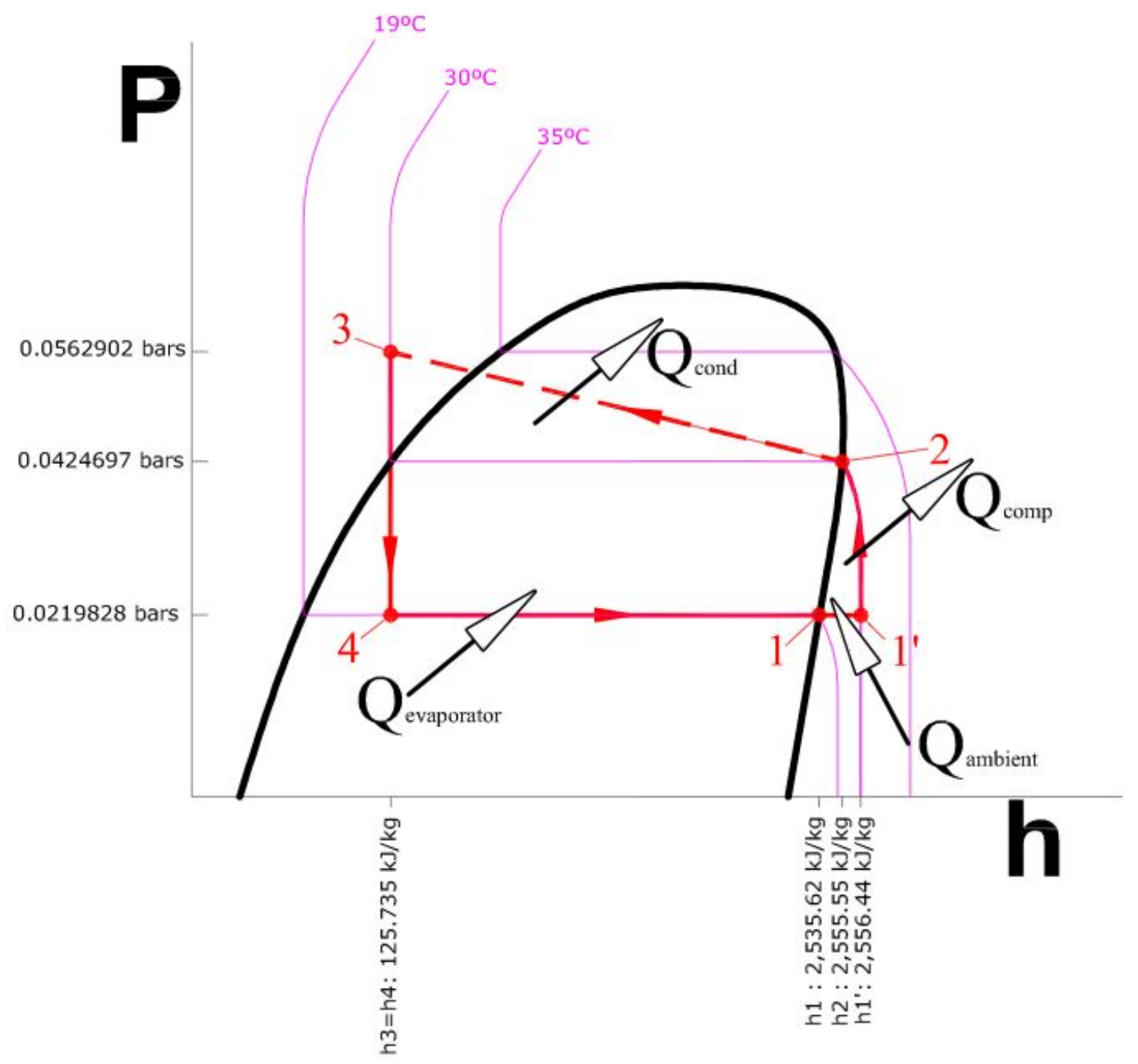

Figure 7.9: Pressure-Enthalpy Diagram

Considering one stroke of the cycle:

$$
\begin{aligned}
& W_{\text {pump }}=\left(\dot{m}_{1}+\dot{m}_{2}\right) \cdot \Delta P E=67.93 \mathrm{~kJ} \\
& Q_{\text {evaporator }}=\dot{m}_{1} \cdot\left(h_{1}-h_{4}\right)=758.22 \mathrm{~kJ} \\
& C O P_{\text {theoretical }}=\frac{758.22}{67.93}=11.16
\end{aligned}
$$




\begin{tabular}{|c|l|}
\hline $\boldsymbol{W}_{\boldsymbol{p u m p}}$ & mechanical work of pump \\
\hline$\dot{\boldsymbol{m}} \mathbf{1}$ & mass flow rate through evaporator \\
\hline$\dot{\boldsymbol{m}} \mathbf{2}$ & mass flow rate to create water plug \\
\hline $\boldsymbol{\Delta} \boldsymbol{P E}$ & potential energy difference \\
\hline $\boldsymbol{Q}_{\text {evaporator }}$ & energy absorbed in evaporator \\
\hline$\dot{\boldsymbol{m}} \mathbf{1}$ & mass flow rate through evaporator \\
\hline $\boldsymbol{h}_{\mathbf{1}}-\boldsymbol{h}_{\mathbf{4}}$ & enthalpy of evaporation \\
\hline
\end{tabular}

In order to determine the pump efficiency, the flow rate had to be determined. This in turn is determined from the heat load of the building and covered in greater detail in the next section. From the flow rate, it can be estimated that:

$$
C O P_{n e t}=\eta_{\text {pump }} \cdot \eta_{f h l} \cdot \eta_{A H U} \cdot \text { C.O.P. }
$$

\begin{tabular}{|c|l|l|}
\hline $\boldsymbol{\eta}_{\boldsymbol{p u m p}}$ & 0.84 & from pump efficiency table (www.lightmypump.com) at flow rate of $946 \mathrm{~m}^{3} / \mathrm{hr}$ \\
\hline $\boldsymbol{\eta}_{\boldsymbol{f h l}}$ & 0.9888 & frictional head loss, from pipe table (DN400), at $12.22 \mathrm{~m} / \mathrm{km}$ \\
\hline $\boldsymbol{\eta}_{\boldsymbol{A H U}}$ & 0.94 & highest typical fan efficiency, Nilsson $\{1995\}$ \\
\hline $\boldsymbol{C O P}$ & 11.16 & \\
\hline $\boldsymbol{C O P} \boldsymbol{P}_{\boldsymbol{n e t}}$ & 8.7 & \\
\hline
\end{tabular}

Even with the foreseeable penalties on perfect efficiency considered, the net C.O.P. (coefficient of performance) is still high, at 8.7. Whilst this is still far below the maximum theoretical limit of a Carnot cycle (26.6 for the equivalent temperature difference), this is a marked increase in the C.O.P. of residential systems (3 to 3.5) and commercial (4 to 5). The central innovation is the use of a liquid plug to drive the isobaric compression, a technique that can also be extended to other natural refrigerants operating in low pressure (like ammonia and $\mathrm{CO}_{2}$ ).

\section{Calculations}

To size the Rain Tower, a reference building was based on an office tower of 40 storeys ( $5 \mathrm{~m} \mathrm{f-}$ $\mathrm{f}$ height) with a floor plate of $30.5 \times 30.5 \mathrm{~m}^{2}$ and a non-AC space of $9.1 \times 9.1 \mathrm{~m}^{2}$. Four different methods (Adapt-Inc, 2002; Ansari, Mokhtar, Abbas, \& Adam, 2005; Bobenhausen, 1994; Ding, McCulley, Pederson, \& Rao, 1983) were used to determine the cooling requirement and the highest value was used. This was confirmed to also be higher than empirical values (Sekhar et al., 2003). 
From the calculations shown in table 7.3, a total of 9 ducts, each $1 \mathrm{~m}^{2}$ in cross-section, will be required to continuously operate the Rain Tower. 


\begin{tabular}{|c|c|c|c|c|c|}
\hline & Parameters & & Notes & Units & Value \\
\hline 1 & Height of rain tower & A & & $\mathrm{m}$ & 200 \\
\hline 2 & Cross sectional area of duct & A & & $\mathrm{m}^{2}$ & 1 \\
\hline 3 & Height of piston & $=$ & (34) & $\mathrm{m}$ & 0.341 \\
\hline 4 & Specific Mass & S & & $\mathrm{kg} / \mathrm{m}^{3}$ & 999.34 \\
\hline 5 & Mass of piston & $=$ & (2) X (3) X (4) & $\mathrm{kg}$ & 340.90 \\
\hline 6 & Gravitational P.E. of piston at roof & $=$ & (5) X (1) x 9.80665 & kJ & 668.62 \\
\hline \multirow[t]{2}{*}{7} & External Temp. & A & & ${ }^{\circ} \mathrm{C}$ & 38.50 \\
\hline & & $=$ & & oF & 101.30 \\
\hline \multirow[t]{2}{*}{8} & Target Temp. & $\mathrm{L}$ & & ${ }^{\circ} \mathrm{C}$ & 19.00 \\
\hline & & $=$ & & oF & 66.20 \\
\hline 9 & External humidity ratio & A & & Ib H2O/lb air & 0.020 \\
\hline 10 & Target humidity ratio & $\mathrm{L}$ & & Ib H2O/lb air & 0.009 \\
\hline 11 & Total floor plate & A & $30.5 \times 30.5$ & $m^{2}$ & 930.25 \\
\hline 12 & Non-airconditioned core & A & $9.1 \times 9.1$ & $\mathrm{~m}^{2}$ & 82.81 \\
\hline 13 & Air conditioned space & $=$ & $(11)-(12)$ & $m^{2}$ & 847.44 \\
\hline 14 & Number of floors & A & & storeys & 40 \\
\hline \multirow[t]{2}{*}{15} & Total a/c office space & $=$ & $(13) \times(14)$ & $\mathrm{m}^{2}$ & 33,898 \\
\hline & & & & $\mathrm{sq} \mathrm{ft}$ & 364,871 \\
\hline 16 & Cooling Load Factor & R1 & & $\mathrm{cfm} / \mathrm{sq} \mathrm{ft}$ & 1.2 \\
\hline \multirow[t]{2}{*}{17} & Cooling Load & $=$ & $(15) \times(16)$ & cfm & 437,845 \\
\hline & & $=$ & (17) / 400 & ton & $1,094.61$ \\
\hline 18 & Occupancy & A & & pax/floor & 90 \\
\hline 19 & Ventilation Factor & R1 & & cfm/pax & 20 \\
\hline 20 & Ventilation Load & $=$ & $(14) \times(18) \times(19)$ & $\mathrm{cfm}$ & 72,000 \\
\hline 21 & Required cfm & $=$ & $(17)+(20)$ & $\mathrm{cfm}$ & 509,845 \\
\hline 22 & Q (sensible) & $=$ & $1.10 \times(21) \times[(7)-(8) \circ F]$ & btu/hr & $2,779,920$ \\
\hline 23 & Q (latent) & $=$ & $4840 \times(21) \times(9)-(10)$ & btu/hr & $3,833,280$ \\
\hline \multirow[t]{2}{*}{24} & Q (total ventilation) & $=$ & $(22)+(23)$ & btu/hr & $6,613,200$ \\
\hline & & & $(24) / 12,000$ & ton & 551.10 \\
\hline \multirow[t]{2}{*}{25} & Total cooling load & $=$ & $(17)+(24)$ ton & ton & $1,645.71$ \\
\hline & & $=$ & $(25) \times 3.517$ & $\mathrm{~kW}$ & $5,787.97$ \\
\hline 26 & Energy (heat) to be extracted in one hour & $=$ & $(25) \times 3,600$ & $\mathrm{~kJ} / \mathrm{hr}$ & $20,836,691$ \\
\hline 27 & Mean pressure of duct & S & (steam prop. at $19^{\circ} \mathrm{C}$ ) & bars & 0.0219828 \\
\hline 28 & Density of steam & S & & $\mathrm{kg} / \mathrm{m}^{3}$ & 0.0163249 \\
\hline 29 & Mass of water vapour in duct & $=$ & $200 \times(28) @ 19^{\circ} \mathrm{C}$ & $\mathrm{kg}$ & 3.2650 \\
\hline 30 & & $=$ & (29) X (292.15/303.15 @30 C & $\mathrm{kg}$ & 3.1465 \\
\hline 31 & Specific volume of steam & $=$ & $200 /(30)$ & $\mathrm{m}^{3} / \mathrm{kg}$ & 63.5625 \\
\hline 32 & Requisite specific volume for condensation to occur & S & (steam prop. at $35^{\circ} \mathrm{C}$ ) & $\mathrm{m}^{3} / \mathrm{kg}$ & 25.2053 \\
\hline 33 & Compression factor required & $=$ & $(31) /(32)$ & dimensionless & 2.5218 \\
\hline \multirow[t]{2}{*}{34} & Pressure from piston required to deliver compression & $=$ & {$[(33) \times(27)]-(27)$} & bars & 0.0335 \\
\hline & & $=$ & (34) X 10.197162 & $\mathrm{~m} \mathrm{H} 20$ & 0.3411 \\
\hline 35 & $\Delta$ Specific enthalpy of vapourisation in flash chamber & S & $\mathrm{H}$-steam $\left(19^{\circ} \mathrm{C}\right)-\mathrm{H}$-water $\left(30^{\circ} \mathrm{C}\right)$ & $\mathrm{kJ} / \mathrm{kg}$ & $2,409.89$ \\
\hline 36 & $\Delta$ Enthalpy of vapour in duct & $=$ & $(30) \times(35)$ & kJ & $7,582.73$ \\
\hline
\end{tabular}




\begin{tabular}{|c|c|c|c|c|c|}
\hline \multirow[b]{2}{*}{37} & \multirow{2}{*}{$\begin{array}{c}\text { Parameters } \\
\text { Strokes of piston to achieve required } \mathrm{a} / \mathrm{c} \text { load }\end{array}$} & \multicolumn{2}{|r|}{ Notes } & \multirow{2}{*}{$\begin{array}{c}\text { Units } \\
\text { strokes/hr }\end{array}$} & \multirow{2}{*}{\begin{tabular}{|r|} 
Value \\
2,748
\end{tabular}} \\
\hline & & $=$ & $(26) /(36)$ & & \\
\hline 38 & Energy to pump to roof for one hour & $=$ & $(37) \times[(6)+(30) \times 9.80665]$ & $\mathrm{kJ} / \mathrm{hr}$ & $1,922,112$ \\
\hline 39 & C.O.P & $=$ & $(26) /(38)$ & & 10.84 \\
\hline \multirow[t]{3}{*}{40} & Number of ducts required & $=$ & $3+7 \times(37) / 3600$ & & 8.3 \\
\hline & & & \multicolumn{3}{|c|}{$7 \mathrm{sec}$ for piston to free fall down $200 \mathrm{~m}$} \\
\hline & & & \multicolumn{3}{|l|}{3 sec to refill } \\
\hline \multirow[t]{7}{*}{41} & Pump flow rate & $=$ & $(37) \times(5)+(30) /(4)$ & $\mathrm{m}^{3} / \mathrm{hr}$ & 946 \\
\hline & Notes & & & & \\
\hline & Assumed & A & & & \\
\hline & Steam Table & $S$ & & & \\
\hline & Locked Parameter & L & & & \\
\hline & Calculated & $=$ & & & \\
\hline & Bobenhausen and William (1994) & R1 & & & \\
\hline
\end{tabular}

Table 7.3: Determination of pump flow rate for the Rain Tower

\subsubsection{Testing the Water Plug, the Rain Rod}

Water as a refrigerant, R718, could be an alternative to synthetic refrigerants if the falling water plug could be realised as an alternative to the compression piston. The water plug needs no lubrication and requires no piston-wall clearance. With a liquid plug, the work input was through the pump, which typically had higher efficiencies than compressors. The presence of droplets in the compressor also poses no threat to a fluid piston and obviates the requirement for superheating, thus maintaining the high C.O.P.

But does a column of water retain its integrity as a body, or does it break up into droplets?

To empirically determine if a falling column of water can be used as a plug to compress steam, a rig was designed (figure 7.10). Sealed and evacuated, the tower (right) would be fed water from the mains. On reaching the requisite volume, the valve will release a column of water, causing a drop in pressure in its wake. The lower pressure causes the water in the evaporator (left) to boil and balance the pressure. 


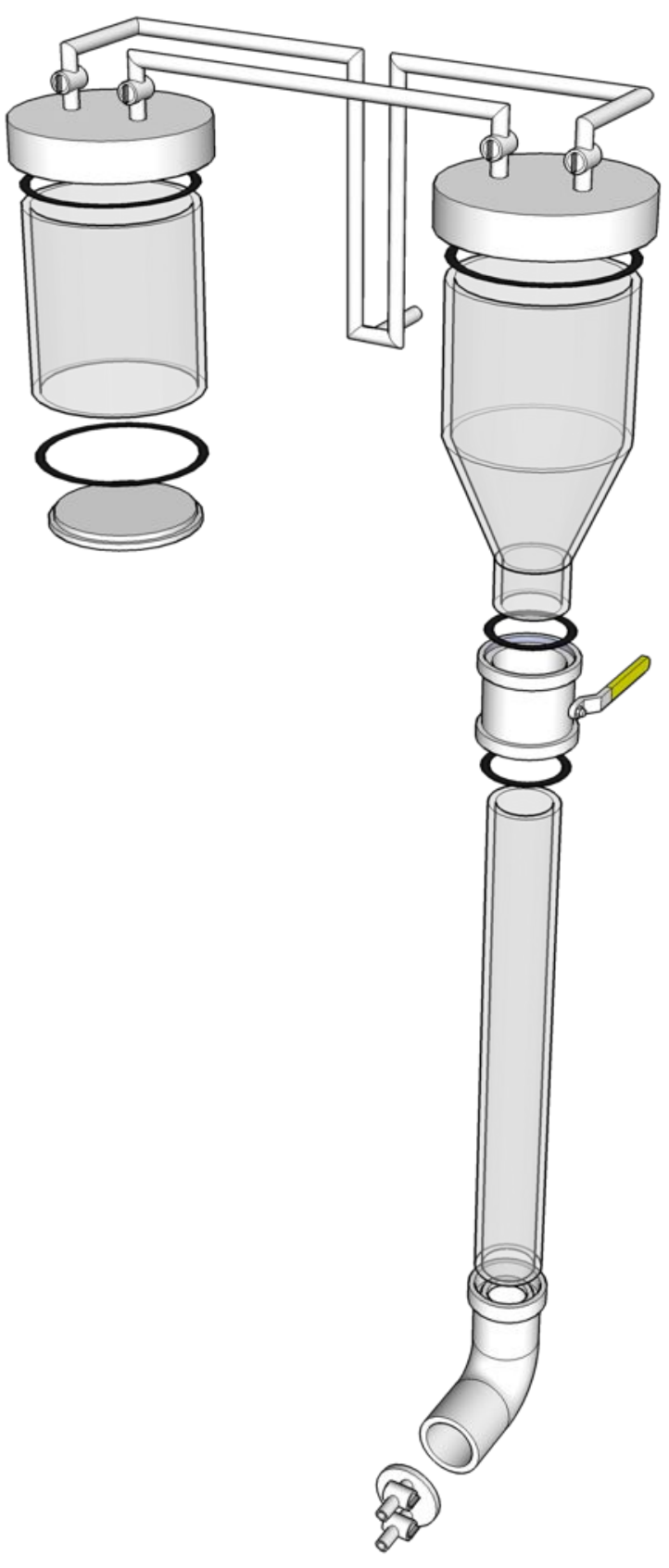

Figure 7.10: Sketch design to test the integrity of a falling column of water

Quotations returned at $\$ 3,000$ for fabrication and deemed as too costly. A low cost version had to be contrived. Consisting of three segments of copper pipe and two stop-valves, a column of water was retained whilst the rod was evacuated. To create a vacuum, the rod was filled with water, heated to steam to displace the water and allowed to cool. The condensed steam was expected to create a near-vacuum in its wake corresponding to its saturated 
pressure at ambient temperature. Setup and preparation is illustrated in figures 7.11 and 7.12 . 


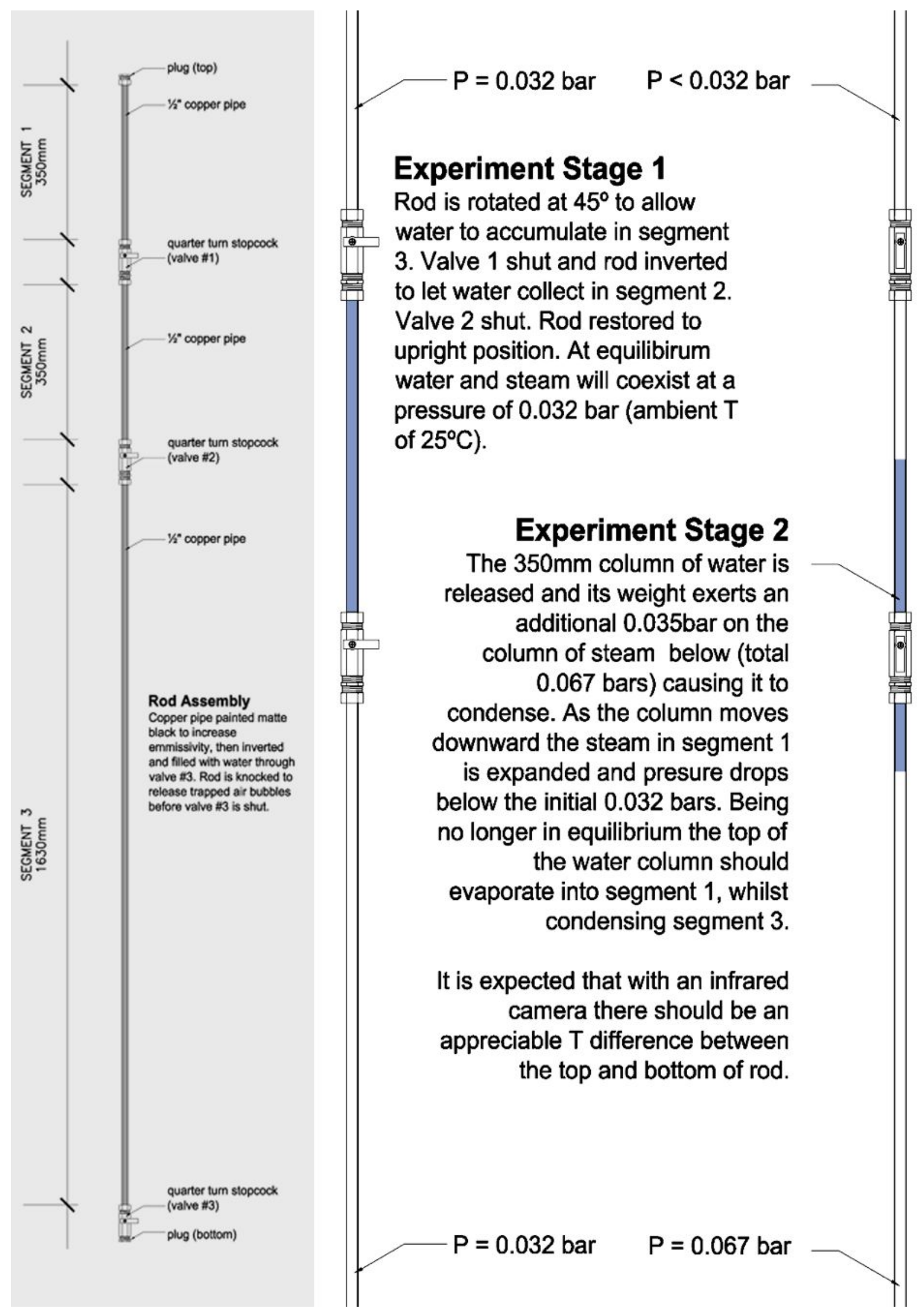

Figure 7.11: The premise for using a rod to ascertain the plug integrity 


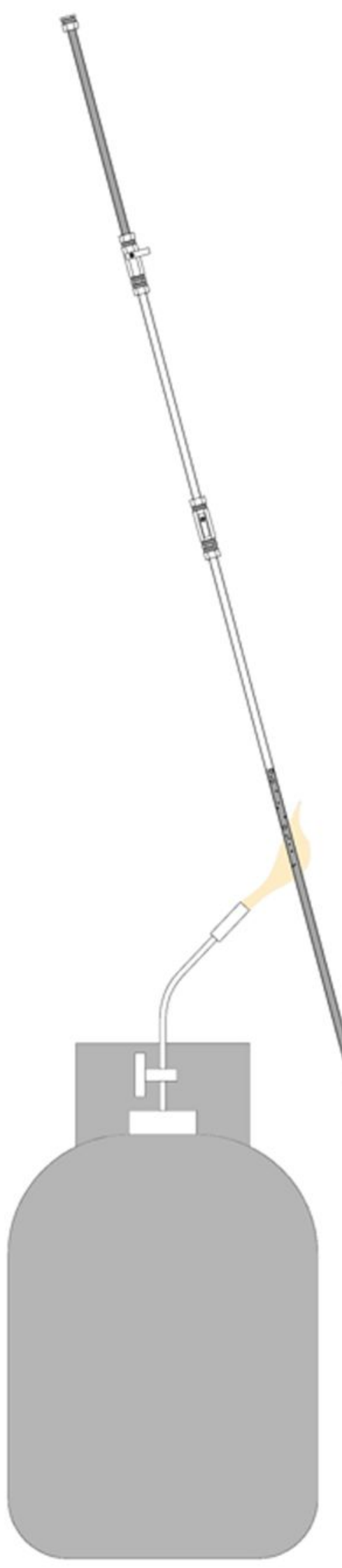

\section{Vacuum Preparation}

Segment 1 is sealed whilst the pipe is heated by a butane torch. Valve 3 is opened at $30 \mathrm{sec}$ intervals to release the pressure build-up. Bubbles were noticed in initial release, likely from air trapped below valve 3 .

Rod is raised vertically and knocked at $2 \mathrm{~min}$ intervals after $15 \mathrm{~min}$ to avoid water being trapped at the top end. total preparation time $20+$ min before no noticeable warm water ejected. thermal imager show generally high temperatures $\left(60^{\circ} \mathrm{C}-120^{\circ} \mathrm{C}\right)$ in segment $2-3$, and $25^{\circ} \mathrm{C}$ in segment 1 .

Bottom plug is fastened whilst rod is immersed in basin of water.

Apparatus is left to cool, during which time steam is assumed to reach ambient temperature of $25^{\circ} \mathrm{C}$ at a pressure of 0.032 bar

Figure 7.12: Extraction of air and creating of an exclusive water-steam internal condition. 
When the column of water was allowed to fall it was expected that as it fell, the column of vapour above would be expanded adiabatically to show cooling, while the vapour below was compressed and eventually condensed to show some heat rejection. The saturated pressure of steam $\left(0.032 \mathrm{bar} @ 25^{\circ} \mathrm{C}\right)$ with the pressure from the plug $(0.035 \mathrm{bar}$ from $350 \mathrm{~mm}$ water: $997 \mathrm{~kg} / \mathrm{m}^{3} @ 25^{\circ} \mathrm{C}$ ) would, upon release, compress the steam and condense it to water as long as the temperature $\operatorname{did}$ not exceed $38^{\circ} \mathrm{C}$. With this it was expected that the piston should demonstrate discernible temperature difference between the top and bottom. A thermal imaging camera was used to measure the difference and showed an average $4^{\circ} \mathrm{C}$ difference in the 2 temperatures.

Aware that the disparity could be a consequence of reading the background thermal radiation, and to avoid the likelihood of reading a reflection on a metallic surface, the surface of the copper pipes had already been painted matte black (2 coats figure 7.14). Despite that it might still be possible that the emissivity of the surface was low enough to catch reflections (figure 7.15).
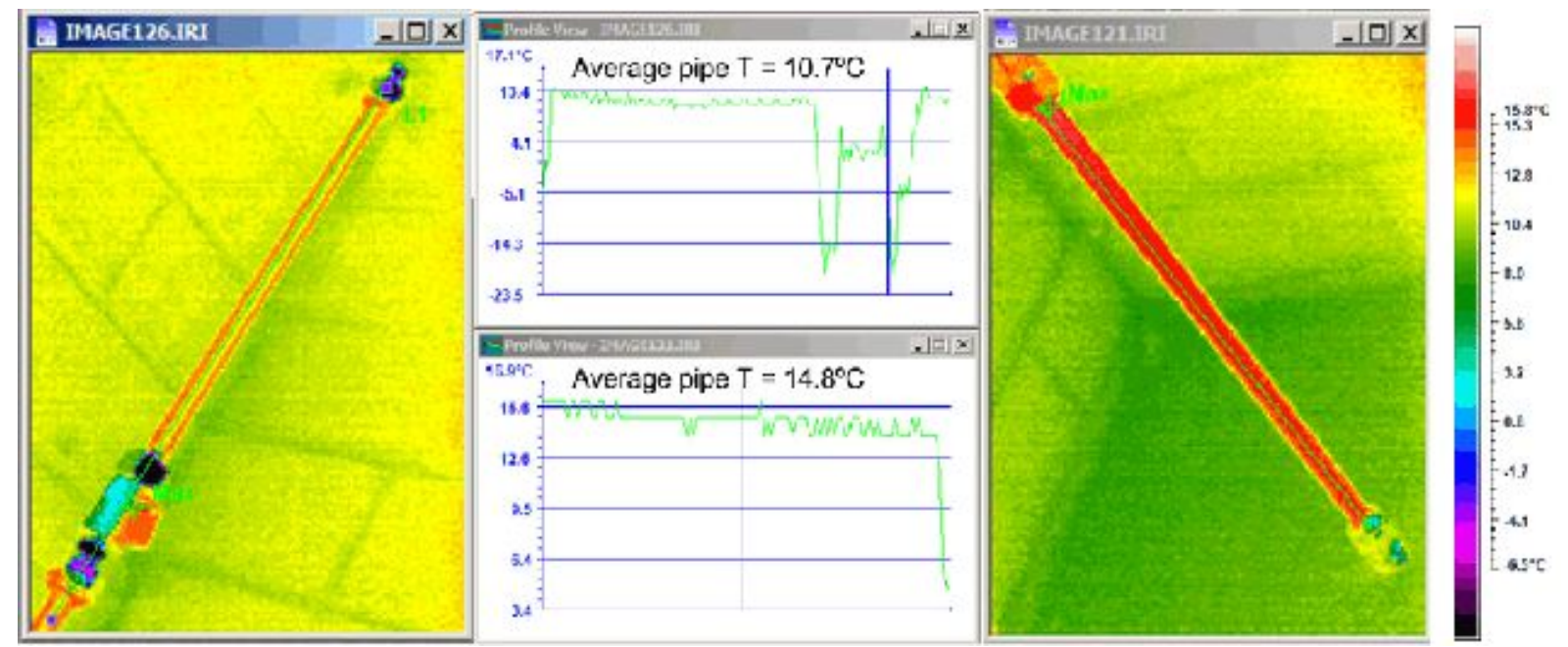

Figure 7.13: Thermal imagery of top and bottom of rod. 

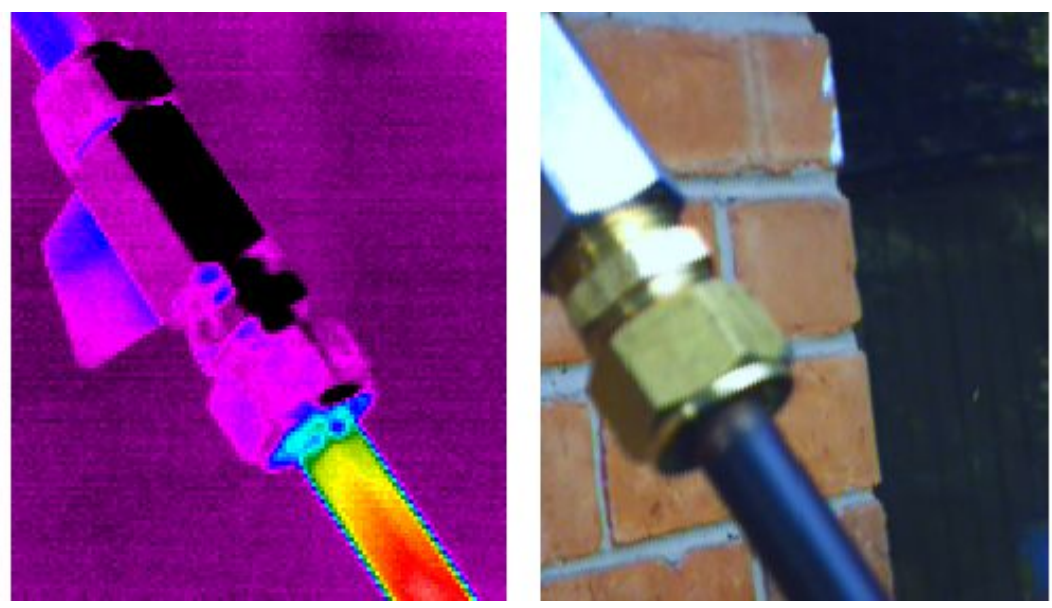

Figure 7.14: Non-uniformity in IR temperature of chrome valve as contrasted to black pipe.

Reflection from sky $\left(-20^{\circ} \mathrm{C}\right)$

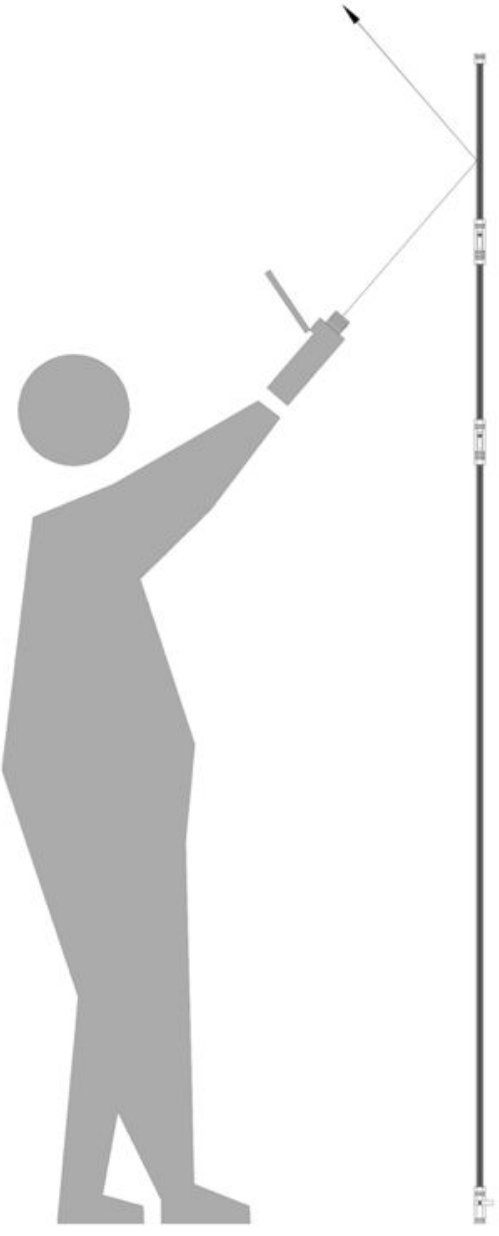

\section{Emissivity}

Copper pipes were coated with a

matte black enamel paint (2

coats) to increase emissivity.

However the same spot

measured from different angles

yielded different values.

igure 7.15: How the geometry of the rod and its reflectance affected thermal

imaging accuracy. 
To complete the experiment the valves were released to atmosphere to see if the vacuum had been contained. It was ascertained that the procedure/apparatus did not successfully create or contain a vacuum. To exclude the possibility of off-gassing of non-water gases into the vacuum, the preparation was repeated with water filtered through a domestic filter (to remove chlorine) and double-boiled (to remove oxygen and other gases). Within 30min of removing from flame, the valves were open to atmosphere. The creation of a vacuum had again been unsuccessful.

A few possibilities could explain the leakage:

1. Valve seals may have melted in extreme heat as steam $\mathrm{T}$ approach LPG flame $\mathrm{T} \approx 2000^{\circ} \mathrm{C}$

2. Rubber washers (2 no.s) deteriorated with extreme heat

3. Water fixtures may not be suitable for vacuum operations; though this is unlikely since plumbing fixtures are rated to 10 bars.

Due to the difficulty in achieving a vacuum without a vacuum pump, the integrity of a falling column of water was inconclusive. Can a column of falling water retain enough integrity to be a pressure plug? The plumbing practise to ventilate waste stacks suggest that when water falls under gravity it does not break up into droplets. 'The introduction of air near the fixture ... breaks the possible siphonage of water out of the trap.' (Stein, Reynolds, Grondzik, \& Kwok, 2006, p.989) When water is flushed down a waste stack it can potentially falls as a plug, capable of suction, otherwise there is no risk of siphonage. On hindsight the experiment was unnecessary though it provided insight into the challenges in creating and maintaining a near vacuum of 0.02 bar.

\subsection{Reflections on the Rain Tower}

This Rain Tower system should surpass the typical vapour-compression system adopted for most air-conditioning systems for the following reasons:

- Superior thermal transport properties of steam over synthetic refrigerants (Kilicarslan \& Muller, 2004) 
- Use of water as a natural refrigerant avoids problems of ozone depletion and greenhouse gas emissions confronting synthetic refrigerants (Tanaka \& Kotoh, 2007)

- Non-reciprocating nature of piston (no need for clearance) avoids technical limitation of reciprocating compressors

- Ability of compression cycle to handle liquid droplets results in better matching of work input without fear of compressor malfunction

- Work input for compression is via the pump, with higher efficiency than reciprocating/centrifugal compressors

- Heat rejection is passive over large surface, without use of cooling tower or fans

The known issues to implementing such a system are:

- Technical difficulties creating and maintaining a vacuum

- The water column can lose effective height (and hence pressure) as wall resistance causes it to shape into a vortex

- The cylinder walls must be highly conductive yet be able to resist atmospheric pressure against a vacuum.

- Refrigerant-grade water is an aggressive solvent

- Due to the narrow optimum temperature lift, the air needs to be dehumidified by a separate process.

The issues can be resolved with existing technology and do not pose insurmountable obstacles. For example, thin-walled detector tubes in particle accelerators are made from self-organising vault structures in alumnium pipes 'designed to be as thin as possible. These tubes are maintained under high internal vacuum. The thin-walled tubes must be very rigid to avoid collapsing under atmospheric pressure' (Altan, 2006). With the correct pipe geometry (like having a honeycomb inside the main pipe), the vortex effect can also be minimised. Dehumidification, on the other hand, would need to be tackled with desiccants.

Technical proof in hand, it appears all that was needed was to find the right investor. Assuming I could miniaturise the proof of concept to a tenth of the scale, where can I install a $20 \mathrm{~m}$ high aluminium structure on to the side of a building? It seems that this was the 
defining issue, not so much the technicalities of some novel energy-saving air-conditioning system.

Most people innovate backward. They develop a product to solve a problem that bothers them personally without first confirming that it bothers the market universally. They dream up a product without first identifying who will use it, how, and why. They conjure up a clever idea-thinking, Man, this is going to be mindblowing! Nothing like it out there! Then they build a prototype, file a patent, and start making and marketing it — without first identifying the market, qualifying the market, or even knowing whether there is a market for it. Not surprisingly, most of those ideas fail. In fact, most patents never make more money than the cost of the patent itself. Why? Primarily because the designer innovated for the sake of innovation rather than for the benefit of the market. (Key 2011, p.37)

Consequently, the angle of approach from the technical, and not from the market viewpoint, described the Rain Tower innovation as a backward innovation. In fact it can also explain why good ideas, technically speaking, were excruciatingly slow to be implemented. Two of these ideas are here briefly studied to discover where the crux of the matter lies: the Solar Tower and Zero Carbon Australia Stationary Energy Plan.

\subsection{Lessons from the Solar Tower}

The Solar Tower (figures 7.16 and 7.17), alternatively and originally referred to as the Solar Chimney (Schlaich, 1995), was designed in 1980 as a renewable energy plant using sunlight to warm air under a canopy (glass or polyester), channelled to a tall stack where the rising convection currents turn wind turbines. A prototype was constructed in Spain starting in 1981 and commissioned in 1982. 


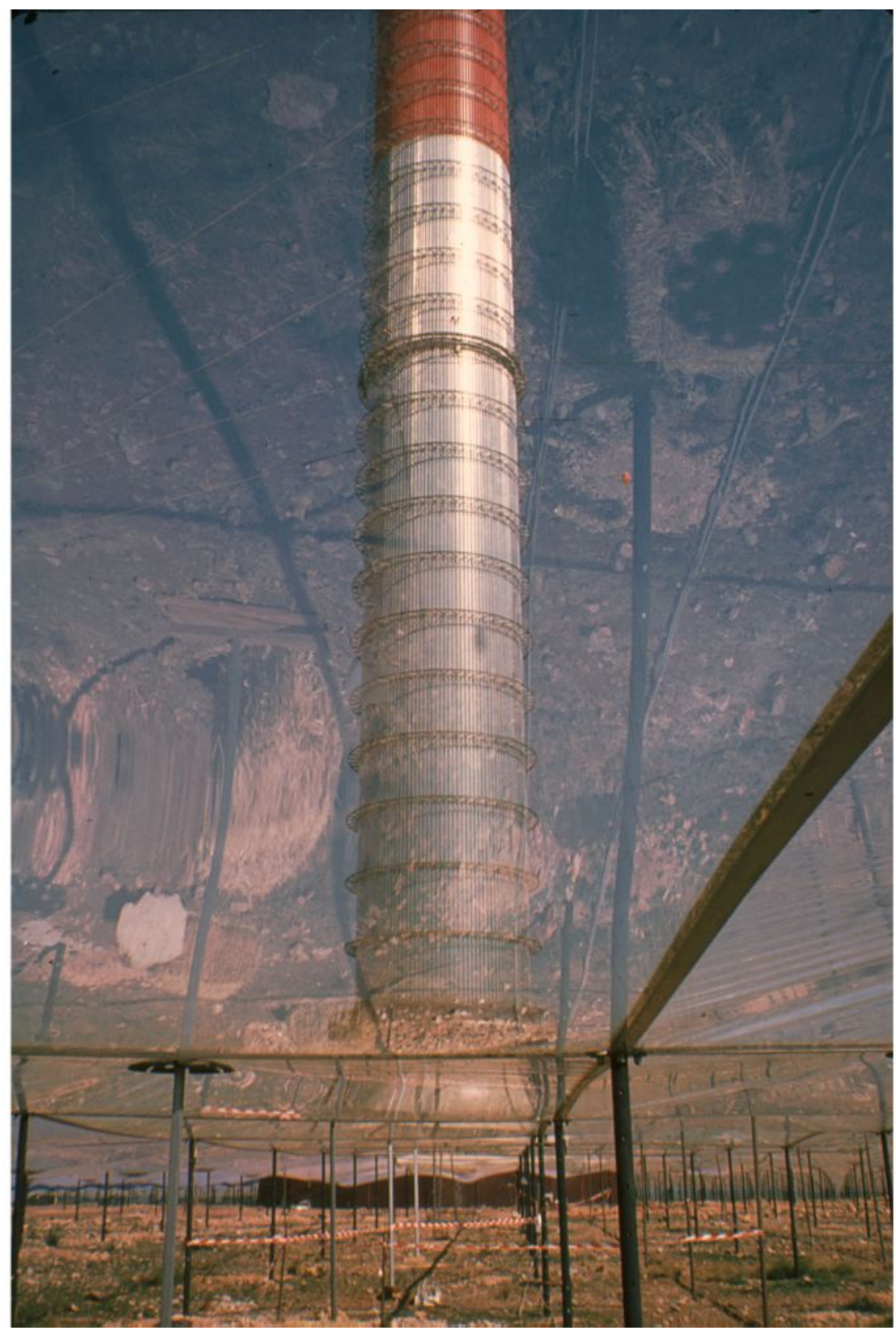

Figure 7.16: Solar chimney in Spain, viewed trough the polyester collector roof. (Widakora, 2011)

The Solar Tower could supply renewable energy from the sun and overcome the major obstacles of photovoltaic technologies in cost and night time production (using the heated thermal mass of the earth below the canopy). Moreover it offered a use for unproductive desert land. It had been built as a proof-of-concept and proven its ability to deliver renewable energy as claimed. Numerous studies have been performed around this technology (Petela, 2009; more references in Thirugnanasambandam 2010) with the 
consensus that it was an elegant source of clean energy economically competitive to fossilbased electricity.
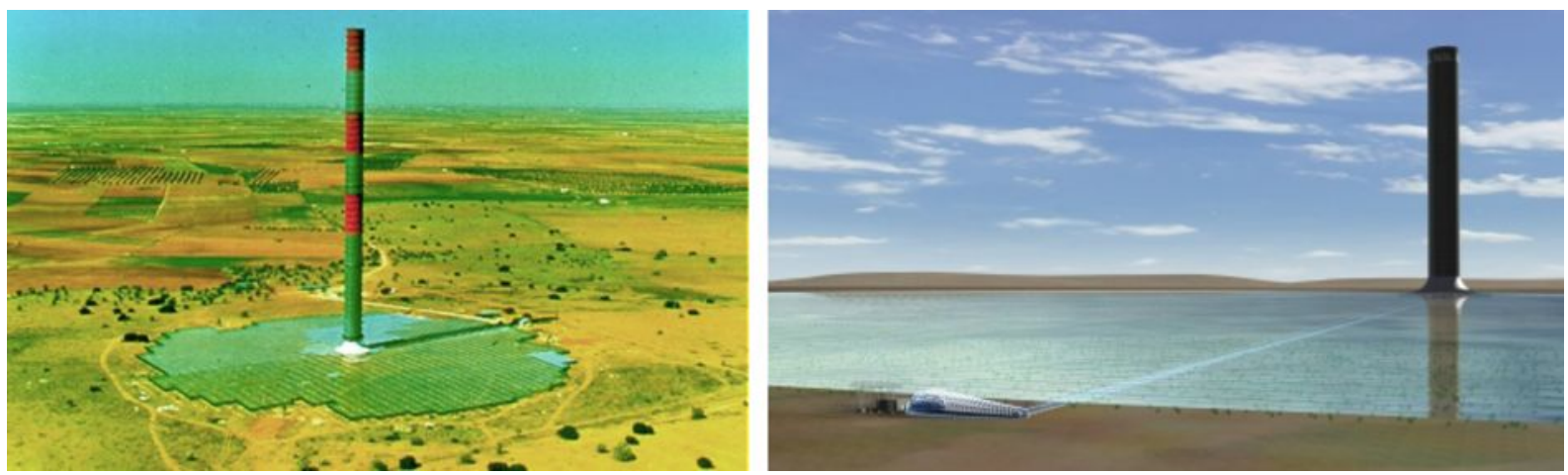

Figure 7.17: (a) The Manzanares 50kW Solar Tower, 195m high (Thomas \&

Davey, 2004), (b) Solar Tower Power Station conceptualisation, 1000m high

(Thomas \& Davey, 2004)

The Australian firm EnviroMissions acquired the technology in 1998. Since 2001 it has championed this technology with no success in Australia, and has only in 2011 secured investment to develop it in Arizona, ready to go online in 2015 (Blain, 2011). Roger Davey, the CEO of EnviroMissions attributes this to the contrasting support for renewable technology between the two governments. Speaking of the incentives in the U.S., he says,

\footnotetext{
There's input tax credits, there's an amount of money you can recoup on the capital cost once it's built and that comes to somewhere around 30 per cent so that reduces your capital costs which obviously therefore would increase your internal rate of return and perhaps provide some equity base and provide greater surety for those investors.
}

Roger Davey, CEO, EnviroMissions (McDonald, 2011)

With these incentives the proposed $\$ 750$ million plant, designed to operate for 80 years, can have a pay-back within eleven years (Blain, 2011). Assuming no future delays, it would have taken a total 35 years for the concept to eventually reach commercial reality. During this period it was the investment climate, rather than the science, that proved the decisive obstacle.

\subsection{Lessons from Zero Carbon Australia 2020 Stationary Energy Plan}

In 2010, the Melbourne Energy Institute of the University of Melbourne, published the 'Australian Sustainable Energy Zero Carbon Australia (ZCA) Stationary Energy Plan', a ‘ten-year 
roadmap for $100 \%$ renewable energy' using only existent and proven renewable generation technologies, primarily, concentrated solar thermal (CST) towers (figure 7.18). A sea of heliostats (mirrors) receive and concentrate solar radiation to the top of a tower which heats molten salt. The salt is passed between 'hot' and 'cold' tanks through a heat exchanger that flashes water into steam through a conventional turbine similar to those found in coal stations. This arrangement allows electrical generation through the night and ensures transferability of jobs from coal power to the clean alternative.

The ZCA plan expresses its environmental and political imperatives for the ten-year time frame:
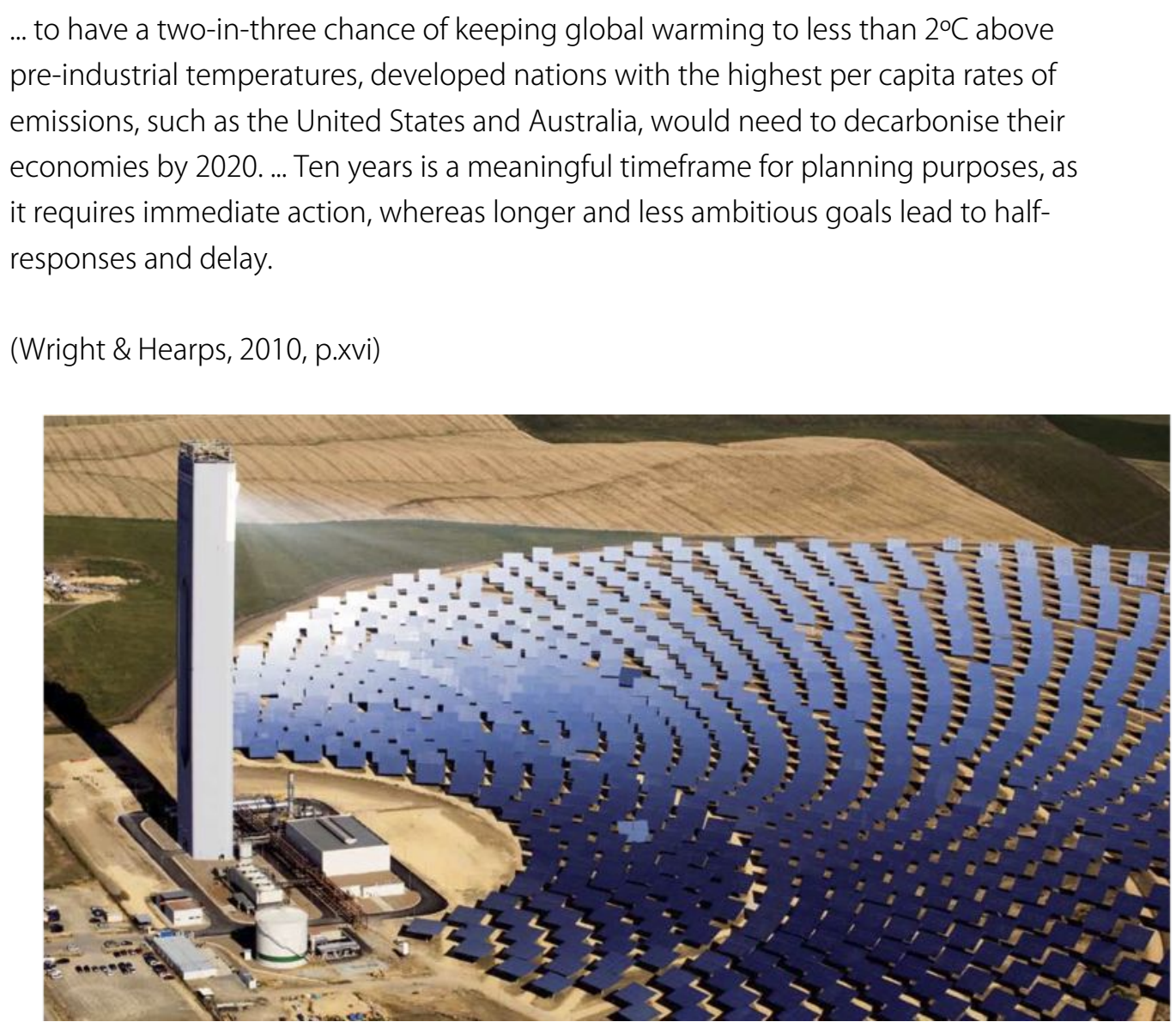

Figure 7.18: CST plant (Redondo, in ZCA Stationary Energy Plan, 2010)

Long delays are evidence to the lack of political will to implement the actions proposed by the IPCC in Chapter 2. Lomborg, the skeptical environmentalist (with a book of the same title first published in 1998), says, 'Kyoto was negotiated in 1997, but the restrictions will first hit 
between 2008 and 2012. The politicians who could claim victory in 1997 will generally not be the same ones to bear the costs of abiding by the restrictions.' (Lomborg, 2007, p.146)

The ZCA blueprint showed how an ambitious target could be achieved in a relatively short time. With mature CST and wind turbine technology, there were no technological barriers. With detailed economic modelling, the cost of mitigation was not high, and could be more than compensated for with increased energy security. The whole plan was viable, but contingent on the force of political will. The transition required bold leadership to make hard decisions that terminated existing technologies and reintroduced new ones. This potential backlash in making such a definitive move could not be measured. Adger (2008) proposes that individual and social characteristics, in particular risk perception, interact with underlying values to form subjective and mutable limits to adaptation that currently hinder society's ability to act.' (p.339) Hence, instead of aiming for the bold 100\% carbon reduction by 2020, the Australian government has only committed to a $5 \%$ reduction by this date (Department of Climate Change and Energy Efficiency, 2012).

Once again it is not the scientific premise of ZCA that was called in question. Two years into the ten-year plan, still no CST plant construction of the kind proposed under ZCA has been envisioned. The main obstacle is that the ZCA is entirely reliant on government initiative, which in a complex society marked by divergent values and an intricate landscape of governance (Adger, 2008), is predominantly risk-averse.

\subsection{Power conservation is far more important than power generation}

The carbon output from power generation can be mitigated by demand-side management and supply-side transformation, each with intricate socio-economical implications described by Biggart \& Lutzenhiser (2007). Rosenfeld argues that even if energy could be produced for free, there is still the distribution requirement which poses the more significant cost.

... for end-use efficiency (versus additional central power plants) is that an efficient appliance saves electricity at your meter, priced at $\$ 0.08 / \mathrm{kWh}$, whereas $1 \mathrm{kWh}$ of new wholesale supply is worth only $\$ 0.02-\$ 0.03$ at the bus-bar. Thus even if electricity from some future wonderful new central power plant is "too cheap to meter," it still 
must be transmitted, distributed, and managed, for $\$ 0.05-\$ 0.06 / \mathrm{kWh}$. (Rosenfeld, 1999, p.49)

This cost is particularly significant in Australia, where outside the few major cities, the population is characterised by low density suburbs. The magnitude of this cost was evident in an episode of a popular Australian television forum ABC Q\&A:

BARNABY JOYCE: It is something wrong that the people in Singapore deliver cheaper power to their people - 30 per cent cheaper to their people with our coal than what we [Australians] can deliver to our people with our coal. ... As you know, Premier, they actually have to move the coal 6,300 kilometres before it gets to the power station.... That is kind of a bit of a journey as opposed to the power station which is actually in the coal field.

ANNA BLIGH: You know as well as I do it's the distribution network that costs the money. It's pumping it out there to people's homes.

ABC Q\&A (21 February, 2011, 51:15 of clip) http://www.abc.net.au/tv/qanda/txt/ s3138582.htm

Put in another way, if energy conservation could halve the average household's electricity demands, it would both halve their power bills and double the capacity of the grid. If on the other hand, assuming there were no improvements in efficiency, and the grid was supplemented by renewables to double the output, the average cost of every household would be drastically increased (assuming present costs for renewables). Concurrently, existing infrastructure would also have to be upgraded, and further cost passed on to consumers.

Eventually it is cost that determines the price signal which affects behaviour. Thus, Rosenfeld ends his monograph with this thought:

In conclusion, energy efficiency is an enduring challenge. Inefficient use of energy and hence waste of money and resources will merit our attention for the foreseeable future, and I believe the same can be said of the threat of climate change. Energy efficiency has been a rewarding discipline because it simultaneously saves money and protects the environment. I'm proud to be working in this field. (Rosenfeld, 1999, p.80) 


\subsection{Lessons for the future}

There are many promising ideas, like the ZCA 2020 Stationary Energy Plan and the Solar Tower, which could do tremendous social and environmental good. These can be termed as good ideas that are based on detailed simulations, experimental proof-of-concepts and economic modelling. These ideas have been researched by academics with no conflict of interest, published in international peer-reviewed journals, and widely accepted as sound, robust and tenable. If good scientific ideas were all that were needed to drive a change, they do already exist. Yet the resistance to taking up these ideas has been disconcerting, leading one to be doubtful if purely technocratic measures were practicable. Even when armed with a 'good idea', one still needed to navigate the lack of government funding, the social fears of the unexpected, and the unexciting appearance of energy-efficiency.

The Rain Tower was theoretically feasible. And if a massless, frictionless disc could be conceived one might even argue that it was technically possible to use a liquid plug to replace the chiller compressor for better efficiency. But how was one to avoid the fate of potentially good ideas not being implemented?

Nikola Tesla (1856-1943), inventor, mechanical and electrical engineer, would be the archetype of the learned inventor. He gave the world (literally, with minimal royalties) multiphase alternating current, the induction motor, the fluorescent light, radio wave technology and a myriad of modern conveniences. When describing Thomas Edison's approach to inventing, Tesla said:

His method was inefficient in the extreme, for an immense ground had to be covered to get anything at all unless blind chance intervened and, at first, I was almost a sorry witness of his doings, knowing that just a little theory and calculation would have saved him 90 percent of the labor. But he had a veritable contempt for book learning and mathematical knowledge, trusting himself entirely to his inventor's instinct and practical American sense.

Nikola Tesla, referring to Thomas Edison in his obituary (New York Times, 1931, in Morgan, 1939)

However Tesla had a difficult career and died in poverty (Cheney, 1981). The Rain Tower seemed destined to take its inventor on a similar route. It was hard for an inventor to sustain continuous innovation without commercial backing. Inventors need their patrons, 
and good ideas need investment. It appeared that ideas cannot merely be technically good, they need to be commercialisable and made attractive to investors seeking a monetary return.

In this regard, Edison puts it most compellingly,

Anything that won't sell, I don't want to invent. Its sale is proof of utility, and utility is success. Thomas Edison (1847-1931)

For ideas to initiate socially beneficial market transformations, they have to be transferred from the inventor's mind to the consumer's hand using investor dollars. In a capitalistic society, problem resolution is dependent to a great extent on product acquisition.

Enter the world of research, innovation and commercialisation. 


\section{Finding a market-oriented solution}

In the previous chapter, a design methodology had emerged for the innovation process:

- Using a design brief instead of an academic research question.

- Adopting an action research cycle to improve the ideas: plan $\rightarrow$ act $\rightarrow$ observe $\rightarrow$ reflect $\rightarrow$ plan ...

- Utilising the architectural studio model of the critique as reflection, which involved:

- self-critique, and

- supervisors' critique.

A technical approach alone might succeed in a technocracy, but in an economy more typified by capitalism, the brief needed to be expanded to accommodate a value-proposition. It was understood that an idea had to be implemented in order for it to be successful, and that many ideas, despite being technologically sound, did not impel a consumer across the purchasing threshold. The reflection stage in action research needed an additional business dimension of feedback from an investment pitch. There is little academic reference to the contents of a business pitch. However, based on a video review of reality shows on venturecapitalism comprising Dragons' Den UK (8 series, British Broadcasting Corporation), Dragons' Den Canada (6 series, Canadian Broadcasting Corporation) and Shark Tank (3 series, American Broadcasting Corporation), the key aspects of a pitch are:

- establishing the value proposition

- presenting a business model

- declare the unique selling point

- describe the care taken with intellectual property

- immediacy of understanding the new concept

- virulence in transferring the concept behind the innovation 
Intellectual Ventures is an innovation firm that is a 'hybrid of think tank, private equity firm, venture-capitalist investor, research and development lab and law firm' (Watts, 2011, p.110). Founded by former Microsoft executives Nathan Myhrvold and Edward Jung, the firm manages $\$ 5$ billion in investments (Watts, 2011) and files five hundred patents a year (Gladwell, 2008).

The challenge isn't necessarily to find the golden nugget. The challenge is: don't spend too much money on the ones that aren't. You want to take the mentality of the venture capitalist: fail fast and fail cheap."

Geoff Deane (VP Engineering, Intellectual Ventures), in Watts (2011, p.114)

We see in this chapter how another idea was developed with a business slant, and how, through a quick evaluation process, the decision was made to proceed no further.

Mumford did see real dangers in the heedless application of powerful machinery to human problems and processes. Technology, he argued, tends to overpower common sense and undercut traditional practices, actually encouraging social inefficiency. New tools like telephones supplant equally effective if somewhat slower methods of communication. Commercially canned foods make eating fresh produce in the country in the summertime seem provincial and outmoded. "One is faced here with a magnified form of danger common to all inventions: a tendency to use them whether or not the occasion demands," Mumford wrote.

The habit of dependence on new technologies and the machines that implement them, Mumford argued, loosens the contingencies of time and season, ultimately causing the atrophy of the human function. A "purposeless materialism" develops, placing a "disproportionate emphasis on the physical means of living." Comfort seems to be modern man's greatest achievement, but it multiplies his desire for goods and dangerously increases his reliance on living conditions that are no longer produced by his own exertions.

(Ackerman, 2002, p.142-143)

The over-reliance on air-conditioning is symptomatic of the processes described by Mumford. But how did this problem arise in systemic terms for the business players and their interaction? How can we move from energy efficiency being its own goal, and seeing inefficiency as endemic to the 'business as usual' (BAU) scenario? Who is the key decision 
maker that drives and defines the process? What motivates each profession, and how did each party acting in its self-interest contribute to the current problem?

To gain useful insights, the drivers of business investment, particularly in relation to property development, are investigated.

\subsection{Property developers}

The emphasis is now on selfishness and separation rather than contact and community. In the new kinds of urban development, the activities that traditionally overlapped are organised for the purpose of maximising profit for developers or retailers. (Richard Rogers, in Heng \& Law, 2002).

Real estate imperatives are predominantly determined by property developers. The professional consultants (architect, civil engineer, mechanical and electrical engineers, quantity surveyors, among others), being engaged by the developer, fulfil their roles according to the brief. In countries (like Singapore) where a handful of major developers dominate the real estate scene, even the planning authorities very much take into consideration the feedback from developers, understanding that without the support of private property developers, urban planning cannot come to fruition.

In short, property developers exert executive control on the professionals under them, and considerable influence on the authorities over them.

As a private business entity, the priority of property development is singular: profit. Robert Vale (2009, p.10) states categorically, 'Developers nearly always prefer to make personal profit rather than to do good for the community.' The motive of maximising revenue has led to the down-town office typology of tight urban blocks, high-rise offices, deep floor plans and fully glazed facades. Where the typical business model is arranged such that developers absorb capital cost and tenants the operational costs, there is little incentive for developers to adopt energy saving mechanisms beyond what is required by code.

This is all the more apparent when we consider that the most efficient office buildings, in Australia for example, have typically been been built and occupied by either a property developer or an owner-occupier, as seen in table 8.1. 


\begin{tabular}{|c|c|l|l|}
\hline Building & Year Compleeted & \multicolumn{1}{|c|}{ Accreditation } & \multicolumn{1}{|c|}{ Developer/Owner } \\
\hline Bond & 2004 & First in Australia, GBCA 5 Star - Office As Built & Lend Lease \\
\hline CH2 & 2006 & First in Australia, GBCA 6 Star - Office Design & Melbourne City Council \\
\hline The Gauge & 2008 & First in Australia, GBCA 6 Star - Office As Built & Lend Lease \\
\hline ANZ HQ & 2009 & GBCA 6-star office design & ANZ Banking Group \\
\hline Pixel & 2010 & $100 \%$ Green Star Score & Grocon \\
\hline
\end{tabular}

Table 8.1: Office buildings in Australia that have received high accolades for sustainability.

Take 5 star Green Star as the base, the incremental cost increase to achieving the carbon neutrality outcome at Pixel is in the order of 14 per cent.

David Waldren, GM Carlton Brewery project, Grocon (McGowan, 2010)

In the competitive property market, a $14 \%$ increase in construction cost is a very hard case for any project manager to propose to the owner. On top of this construction cost are the higher premiums charged by the architects and engineers for the extra work needed to design with sustainability which requires specific skills in modelling and resolving very sitespecific issues. Unless the developers drive this process, or unless there is an anchor tenant who is committed to supporting it, there is very little likelihood that new multi-tenanted offices can meet or exceed the highest national or international energy standards.

The reduction in air-conditioning energy consumption is not a quest that can be driven by building professionals. It can only happen if there are attractive incentives to property developers, in accordance with their value metrics. This does not however absolve architects and engineers from any responsibility since these professionals are also contributors to the BAU scenario.

A symposium on "Thermal Discomfort in the Name of Energy Conservation" was held during ASHRAE's 1979 annual meeting in Detroit. "From all sides we are told that we can no longer enjoy the luxury of being comfortable. ... Must we sacrifice comfort to conserve energy? No!" declared Michigan architect Joseph B. Olivieri. He went on to recommend that glass be used less and insulation more, and that sections of houses, such as bedrooms, be placed underground because "we don't need large windows when we're asleep. "Stressing winter comfort needs, Olivieri considered but seemed to reject such options as changing thermostat settings or wearing more or heavier clothing indoors. Such low-tech solutions would not require the expertise of an engineer or architect. (Ackerman, 2002, p.167b) 


\title{
8.2 Architects and Engineers
}

Extensive glazing has however been a major culprit in the need for heating and airconditioning, increasing the heat loss when heating is required, and heat gain when cooling is required.

You want to save serious energy and serious money? Easy, use less glass. Windows and curtain walls are the most expensive component in a building and provide the worst energy performance. The more you use the more energy and money you burn. Limit the glazing area to approximately 30 percent — and use really good glass and frames. (Lstiburek, 2008, p.2)

Since offices with a view fetch better premiums than those without, the typical office is designed with a central service core and offices around the periphery. The need for glazing is evident from the financial point, but there is also a strong aesthetic consideration: a modern office needs to look streamlined.

\begin{abstract}
As Jeffrey Meikle explains, streamlining, acclaimed by the thirties public as "modernistic," was the visual representation of "frictionlessness," the achievement of social and physical control sought by leading designers and industrialists with a Depression-driven sense of urgency. "Streamlined" was short hand for unimpeded progress and smooth forward movement. It connoted control of air movement in the same way that air-conditioning signified control of air temperature. Both airconditioning and streamlining obligated the very atmosphere to conform to a human plan.
\end{abstract}

(Ackerman, 2002, p.81)

Furthermore the energy performance of buildings has been a recognised area of weakness amongst architects and purposeful neglect amongst engineers. Lstiburek, when referring to the myths of superior performance of a double-skin facade, says, 'If we taught architects more physics and less philosophy they wouldn't fall for this garbage - and while I'm at it shame on you engineers for using bad physics to deceive gullible architects.' (Lstiburek, 2008, p.7)

Bay and Ong (2006) identify two approaches in which tropical architects apply building science to respond to the environment: the thermal comfort checklist to design typified by Fanger, and the bioclimatic response typified by Olgyay. Both approaches result from the 
common need for simplified tools for architects to solve the environmental responses concurrently with a broad range of design and legislative issues. They further observe:

Architects tend to avoid applying building science directly in their design process, preferring where feasible to work with a building scientist as a consultant. (Bay \& Ong, 2006, p.6)

The typical architect prefers to work with broad principles and strategies (Hyde, 2000). A survey on the use of environmental design software among architects showed that almost none of the architects surveyed employed such tools in their practice, and that consultations with building scientists are rare (Wong et al., 1999).

This behaviour is confirmed in the following personal discussions. Dewsbury (2011), who observed that architects are becoming increasingly reliant on energy accessors to advise them on how their buildings can be improved. The environmental impact of architecture has been treated as a matter of personal rather than professional ethic. 'An architect could be taken to court for leaking rain (of which Frank Gehry's Stata Centre at MIT comes to mind) but rarely for leaking heat; said Geard (2011) because the regulations only control the submission of building plans, not the actual thermal performance. 'Engineers interested in hyper-efficiency are a lonely bunch. There are so few of us in the world we probably all know each other, said Wilton, (2010) an engineer who works with a chiller OEM.

Engineers, whilst in a position to optimise M\&E systems, are presented with two perverse motivators: a professional penalty for undersizing air-conditioners, and a financial incentive for oversizing them.

Houghton (1998) has observed compounded safety factors resulting in cooling systems 'over designed by $100 \%$ or more.' Lee Eng Lock, an engineer known for notably improving building energy efficiency (Berger, 1998) says :

In engineering, you have to do things elegantly, which sometimes conflicts with doing it for the fees. In a fee, you are driven to jack up capital costs. If you make it elegant and cheap and better, you're working against your own financial interests. (p.262) 
Lee's experience with increasing air-conditioning efficiency is not for the lack of technological advancements, but that 'most of the problems in going to factor two or factor four reduction in energy are institutional barriers, consultants and architects and project managers and owner's representatives stick to the tried and true (truly wasteful and inefficient) and resist any kind of change' (Lee, 2009). There is a systemic problem with the way professional fees are pegged as a percentage of project costs. Amory Lovins says it well (Berger, 1998):

As long as we reward design professionals for what they spend, not what they save, we can expect to get nutty results.

\subsection{Consumers}

How can one describe consumer society?

The silly marketing that America falls for has resulted in this: we buy things we don't need with money we don't have in order to impress people we don't like. (Ramsey, 2003, p.31)

Consumerism is a large and complex field in socio-economics. This short section is an acknowledgedly inadequate treatise, and the reader is referred to the the BBC (2002) documentary 'The Century of the Self' for a primer and the critical works of nobel laureate (Economics) Joseph Stiglitz (for example Toward a General Theory of Consumerism, in Pecchi \& Piga, 2008).

Over the last hundred years, the two most significant economic catastrophes, the Great Depression and the Global Financial Crisis, were preceded by the Hoover and Bush Administrations respectively. Both administrations were (amongst other factors) strong advocates for deregulation, free-market and consumerism as the central motto of American life. And both, in Stiglitz's view (2007), were contenders for 'worst president' due to their poor stewardship of the American economy. Lynd (1934) remarked of commerce policy under Hoover, 'Never before had the Nation's business been so completely the business of the National Government.' (p.3) A month after the September-11 terrorist attack, President Bush gave a press conference which was particularly revealing of his view - that the good consumer was the good citizen: 
Now, the American people have got to go about their business. We cannot let the terrorists achieve the objective of frightening our nation to the point where we don't - where we don't conduct business, where people don't shop. That's their intention.

(11 October 2001, http://www.johnstonsarchive.net/terrorism/bush911e.html)

The engineering of consumer society originates from Freudian theory of the unconscious mind being the dominant force that directs behaviour. His theories were further developed by his nephew, Edward Bernays the 'Father of Public Relations' (New York Times, 1995) who 'showed corporations how to make people want things they didn't need by linking massproduced goods to their unconscious desires' (BBC, 2002). Whilst the prognosis of consumerism was unclear in the early days of mass advertising, Lynd (1934) expressed this concern:

It seems probable that under the pressures of modern business development, the consumer is becoming confused and illiterate as a buyer more rapidly than the combined positive factors of education, standardization, and so on are succeeding in making him literate as a buyer. (p.4)

In the consumerist culture, purchasing is motivated not by the rational but the emotive. Similarly, the choice to consume air-conditioning was rarely made on the premise of informed rationalism. As early as in the 1930s, it had been understood that air-conditioning should not be marketed in technical terms, but under abstract concepts. It was not intended to address the rational and conscious intellect, but the irrational and unconscious emotions. A 1939 article Selling Seats with Modern Air-Conditioning was categorical:

Never, never, never refer to air-conditioning in the terms of refrigeration and coldness. Adherence to the "comfort zone" devised in 1923 by professional engineers would satisfy 97-98 percent of the audience. (in Ackermann, 2002, p.49)

The overconsumption of air-conditioning can thus be linked to general overconsumption in society, which stems from successful corporate marketing to manipulate society into becoming become docile consumers. We saw in Chapter 3 examples of the lifestyle marketing that transformed air-conditioning from a luxury to a present day necessity: indispensable and routinely expected. Consumer society is neither environmentally nor economically sustainable, marked by a 'strong value orientation that puts unrestrained freedom to the forefront' (O'Shaughnessy \& O'Shaughnessy, 2002, p.544). 
More than any other single factor, consumeristic behaviour has resulted in the status quo of big business and entrenched political interest that the BAU scenario epitomises.

\title{
8.4 The angle of the pitch
}

\author{
Businesses will increasingly be judged on their 'triple bottom line' which takes into \\ account their economic, social and environmental performance. There is huge \\ interest in issues such as intergenerational equity, which means we try to leave the \\ planet for future generations in as good or better shape than it is today, sustainable \\ development, which is economic development that is in harmony with the natural \\ environment, and eco-footprinting, which means we use only our fair share of \\ limited. resources. The growing concern about these issues is driving new \\ environmental legislation and regulation. (English, 2009, p.89)
}

Solving the energy demands of air-conditioning was an academic interest, and the benefit of it seemed obvious enough to myself as the inventor, but was inadequate in itself to prompt society to switch technology. To convince an investor that the innovation was worth pursuing, one had to demonstrate how a proposal was not only on trend for the near and medium future, it needed to be lucrative.

When evaluating the selection of air-conditioning systems, I found the following to be decisive in my professional experience as architectural project manager:

1. The key decision maker is the property developer(s), and his/their interest was in generating revenue. A more energy efficient air-conditioning and mechanical ventilation (ACMV) system was only worth installing if the lease charge could be increased.

2. ACMV systems were selected primarily on a cost basis as long as the system met specifications from the mechanical engineer.

3. Specifications typically state refrigeration and ventilation rate requirements, and rarely stipulate the COP of the system.

4. Minimum COP of chillers (not the entire ACMV system) is controlled by regulatory standards (e.g. SS530:2006 in Singapore; ASNZ3823 in Australia). Unless pursuing an energy certification (e.g Green Star, LEED, BREEAM, etc) there was no incentive for developers to exceed the minimum requirement. 
Based on preliminary sizing rules of thumb (Allen \& Iano, 2002, p.190) the plant room size for an air-handling unit (AHU) occupies about $5 \%$ of the gross floor area in a typical office block. Freeing up this area into tenable space would pose an attractive proposition to developers. A business case could thus be made to the developer:

1. There is a way to reduce the size of the AHU plant room.

2. This will increase the net leasable area and pay for itself within the short term and generate extra revenue in the medium-long term.

3. The efficiency of the system will be improved and cost the tenants less in power bills, giving the developer a competitive advantage.

4. The higher efficiency can complement other green initiatives to get publicity from energy certification.

For the benefits to be real to a developer, the following values needed to be quantified:

1. Area saved $\left(\mathrm{m}^{2}\right)$ and revenue generated (dollars per $\mathrm{m}^{2}$ per year)

2. Energy saved (kWh per year) and cost avoided for tenants (aggregated as dollars per floor per year)

3. $\mathrm{CO}_{2}$ emissions avoided from reduced power load demands $\left(\mathrm{tCO}_{2}-\mathrm{e}\right.$, depending on energy source) and GWP avoided through refrigerant selection $\left(\mathrm{tCO}_{2}-\mathrm{e}\right.$, depending on refrigerant). This is of further relevance with the Australian carbon price (starting at $\$ 23 / \mathrm{tCO}_{2}-\mathrm{e}$ ) to be introduced in July 2012, making $\mathrm{CO}_{2}$ emissions reductions a real currency.

So how do we dispense with the AHU room? My proposal is to separately handle the latent and sensible loads, using lightweight equipment that can be ceiling mounted. 
8.5 Using desiccant wheels and radiant cooling

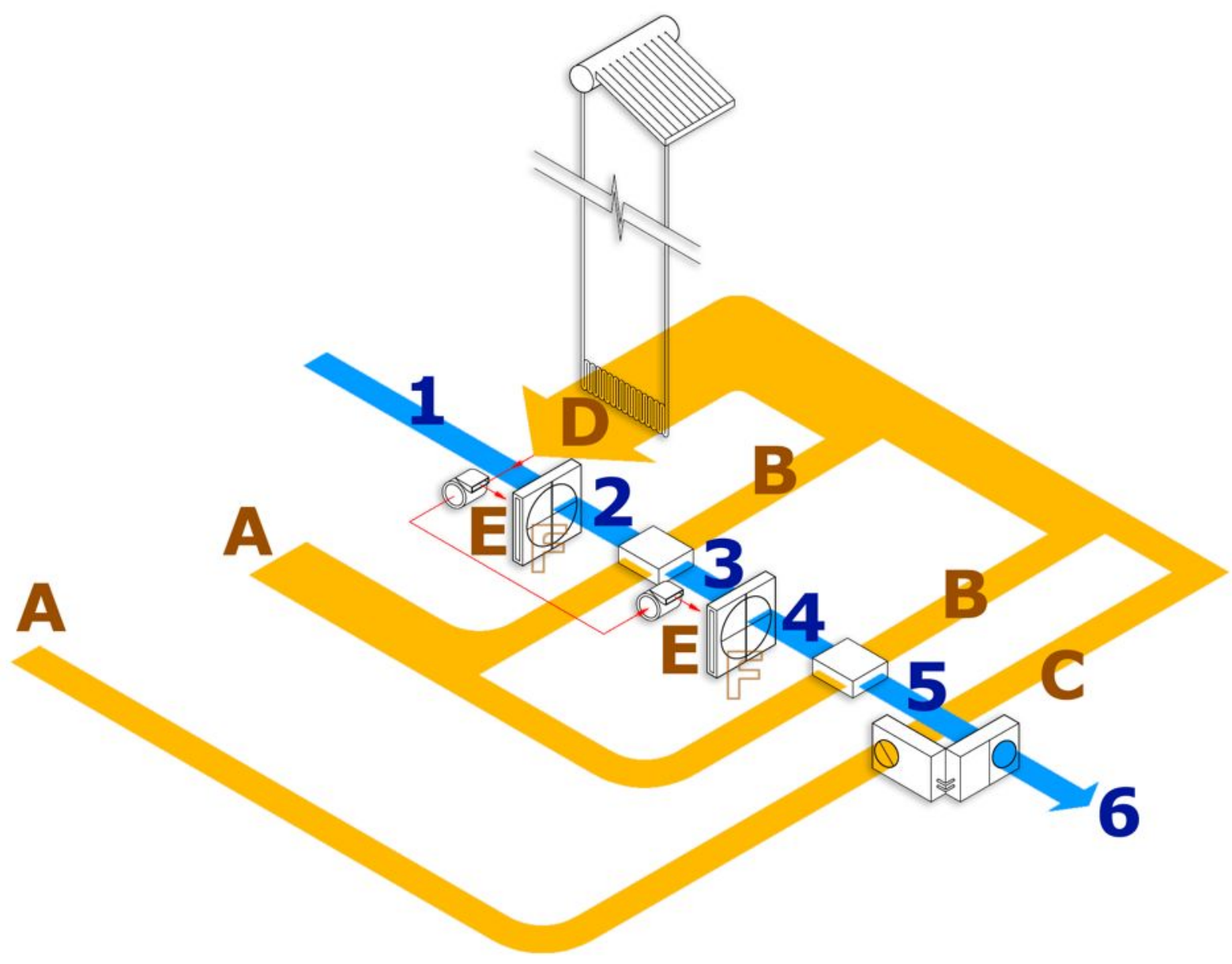

Figure 8.1: Schematic of air flow. Processes 1-6 illustrate outdoor air $\rightarrow$ supply air. Proceses A-E illustrate extract/exhaust air $\rightarrow$ outdoor air

To eliminate the spatial requirement of the AHU room, the following changes are proposed, as illustrated in the schematic figure 8.1 and processes explained in tables 8.2 and 8.3.

1. Utilise desiccant wheels to handle the latent load of air-conditioning, making the resulting air chiller responsible only for sensory load

2. Use a $100 \%$ fresh air supply to the ventilation rate for the occupancy required by code

3. Mount all plant equipment within a $1.5 \mathrm{~m}$ ceiling of the lift lobby

4. Introduce a radiant chilled aluminium ceiling that copes with the reduced air velocity by providing a lower mean radiant temperature

5. Introduce a displacement ventilation system that does not depend on high air velocity for mixing and pollutant extraction 
The final point deserves particular elaboration. The most conventional delivery of conditioned air is by ducting to ceiling registers. Known as mixing ventilation, the supply air (comprising a mixture of roughly 20\% fresh air and $80 \%$ return air) leaves these registers (also called diffusers) at fairly high velocity to enable mixing. Displacement ventilation demonstrates the engineering adage 'the solution to pollution is not dilution.' Instead of mixing the air, supply air is delivered at low speed and low temperature (thus higher density) near the floor, effectively pushing the room air up into the ceiling return. In this scheme supply air is $100 \%$ fresh outdoor air, and 'return' air is completely exhausted. Displacement ventilation systems require less flow rate and no recycled air, making the AHU much simpler.

\begin{tabular}{|c|c|}
\hline Supply Air Process & \\
\hline \multirow[t]{2}{*}{1} & Outdoor air @33º, $57 \% R H$ \\
\hline & (Humidity ratio $18.3 \mathrm{~g} / \mathrm{kg}$ ) \\
\hline $1-2$ & Desiccant wheel dehumidification \\
\hline 2 & Air @ 45ㄷ, 14g/kg \\
\hline $2-3$ & Heat exchanger \\
\hline 3 & Air @ 30, $14 \mathrm{~g} / \mathrm{kg}$ \\
\hline $3-4$ & Desiccant wheel dehumidification \\
\hline 4 & Air @ 45ㄷ, 10g/kg \\
\hline $4-5$ & Heat exchanger \\
\hline 5 & Air @ 30, 10g/kg \\
\hline $5-6$ & Air-conditioning (sensible only) \\
\hline 6 & Air @ 15ㄷ, 10g/kg \\
\hline \multirow[t]{2}{*}{7} & Office air @ 25ㄷ, 50\%RH \\
\hline & (Humidity ratio $10 \mathrm{~g} / \mathrm{kg}$ ) \\
\hline
\end{tabular}

Table 8.2: Outdoor air is desiccated and cooled in a double cycle before the dry air is chilled by the air conditioning.

\begin{tabular}{|c|l|}
\hline Exhaust Air & \\
\hline A & Office air @ $25^{\circ} \mathrm{C}$ \\
\hline A-B & Heat exchanger \\
\hline B & Air @ $40^{\circ} \mathrm{C}$ \\
\hline A-C & Reverse a/c cycle (heat pump) \\
\hline C & Air @ 50 $\mathrm{C}$ \\
\hline B-D \& C-D & Air heated by solar-thermal collectors \\
\hline & (with electrical boost) \\
\hline D-E & Air @ 80 $\mathrm{C}$ \\
\hline E-F & Desiccant regeneration \\
\hline
\end{tabular}

Table 8.3: Exhaust air is used to cool the desiccated air (A-B), and part of it is heated by the heat rejected from the air-conditioning (A-C). Depending on availability it can be heated by solar thermal or an electrical circuit to regenerate the desiccants before being exhausted to the outdoors. 


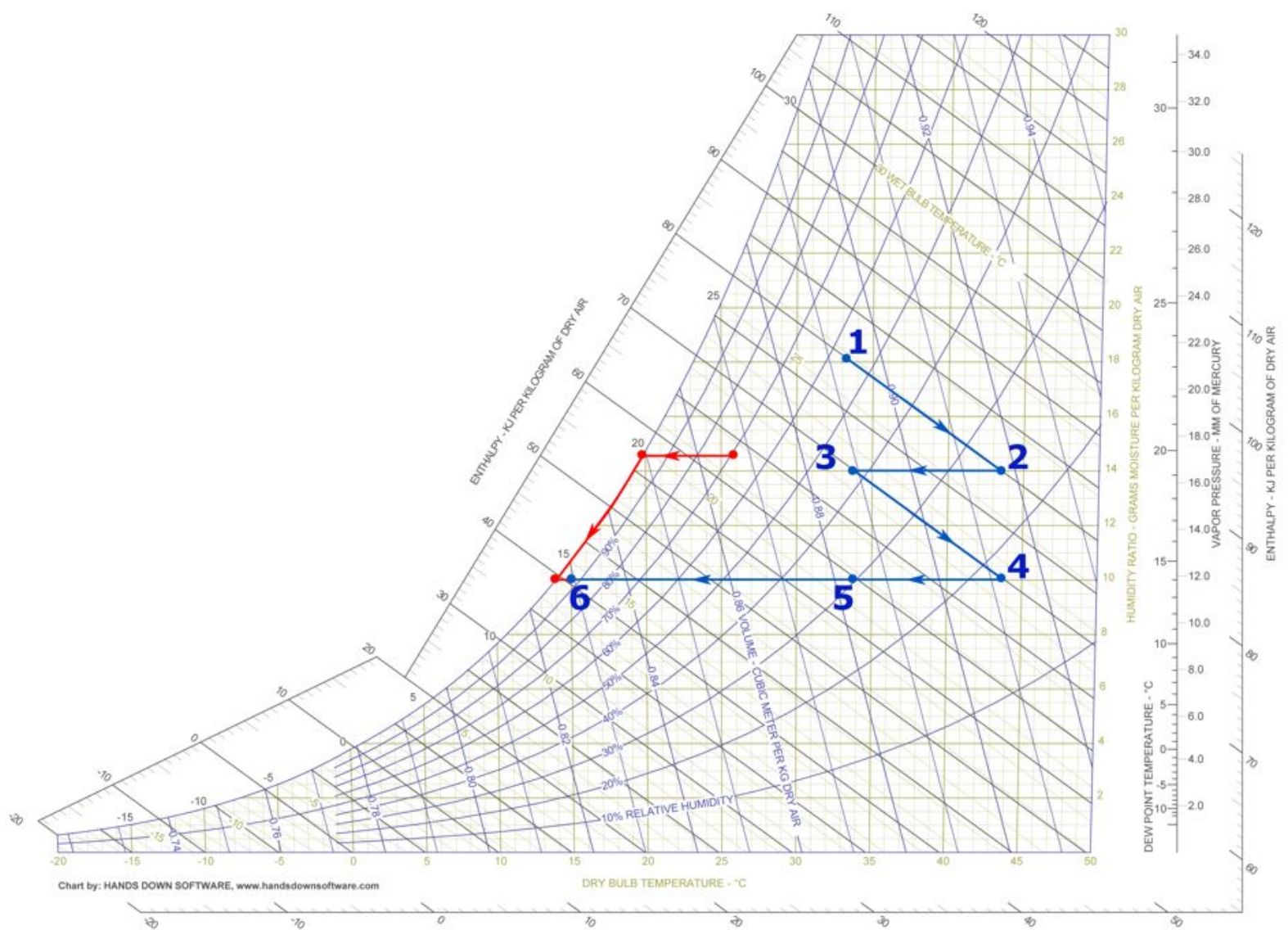

Figure 8.2: Processes on psychromtric chart

\begin{tabular}{|r|c|c|c|}
\hline & $\mathrm{T}\left({ }^{\circ} \mathrm{C}\right)$ & $\mathrm{HR}(\mathrm{g} / \mathrm{kg})$ & $\mathrm{h}(\mathrm{kJ} / \mathrm{kg})$ \\
\hline Outdoor air & 33.0 & 18.33 & 80.11 \\
\hline Supply air & 15.0 & 10.00 & 40.28 \\
\hline Return air & 25.0 & 12.96 & 58.08 \\
\hline Mixed air & 26.6 & 14.04 & 62.48 \\
\hline
\end{tabular}

Table 8.4: Assumed air conditions

To determine the efficiency, I use the psychrometric processes of 8.2 and conditions shown in table 8.4. Since processes 1-5 are passive (except for fan power), the power required, psychrometrically speaking is:

$$
\Delta h_{5-6}=39.7 \frac{\mathrm{kJ}}{\mathrm{kg}} \text { of fresh air }
$$

By reducing the intake to $100 \%$ fresh air at a fifth the flow rate (figure 8.3), this compares very favourably against an AHU taking $20 \%$ fresh air $\left(33^{\circ} \mathrm{C}, 57.3 \% \mathrm{RH}\right)$ and $80 \%$ recycled air (25 $\left.{ }^{\circ} \mathrm{C}, 65 \% \mathrm{RH}\right)$ : 


$$
\Delta h_{A H U}=5 \times 22.2=111.0 \frac{\mathrm{kJ}}{\mathrm{kg}} \text { of fresh air }
$$

Desiccant wheels are fairly light devices, requiring two $50 \mathrm{~kg}$ wheels $(1.2 \mathrm{X} 1.2 \mathrm{X} 0.2 \mathrm{~m})$ to provide the requisite dehumidification for an office floor of 90 occupants. The chiller load, being a third of the typical AHU and having eliminated the return air controls and dehumidification requirement, could amount to simply a single (or double) row cooling coil attachment to the VAV box.

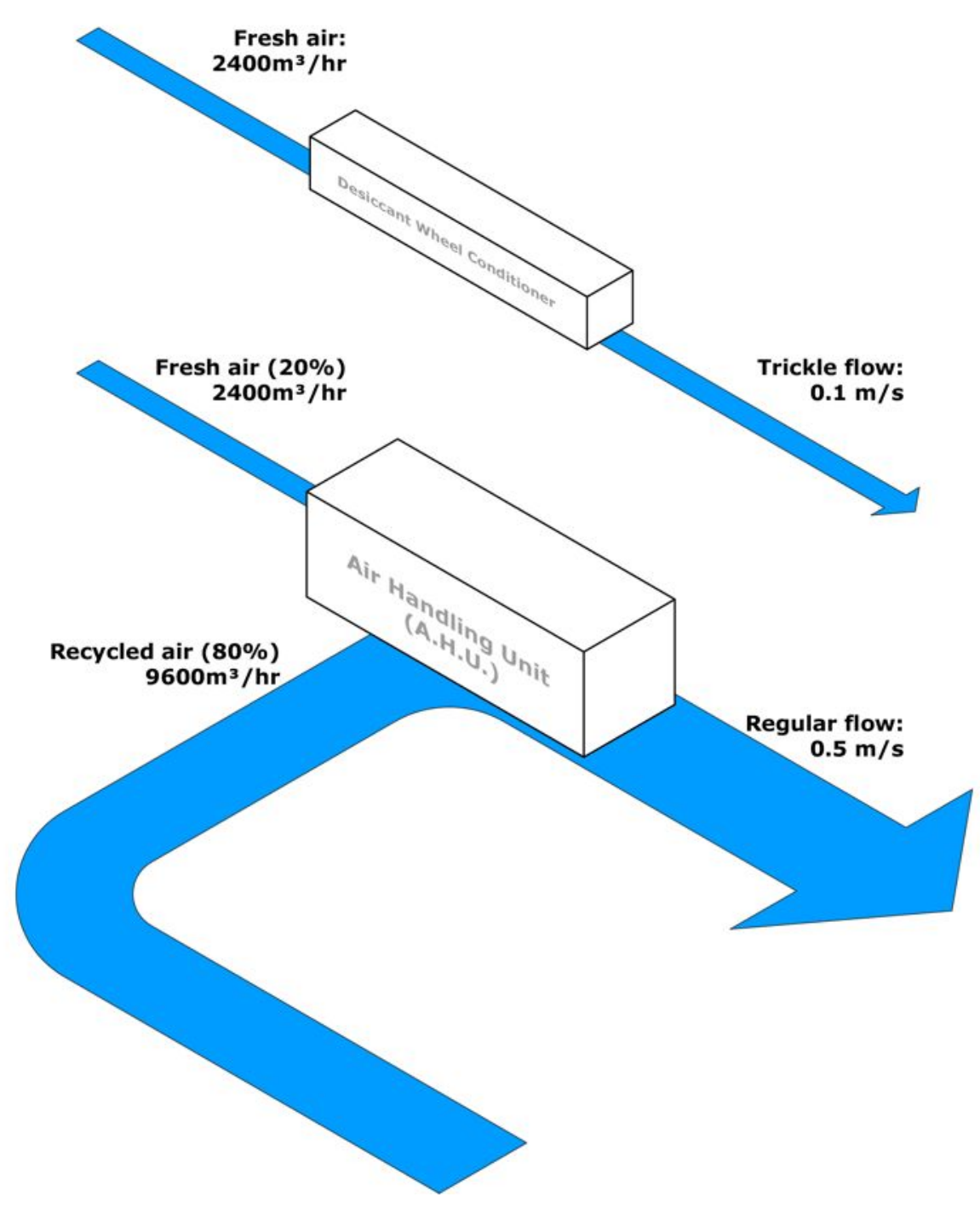

Figure 8.3: Economy and better air quality by avoiding air recycling

Table 8.5 shows the potential savings and revenue from the AHU plant space liberated. Whilst the electrical savings benefits the tenant, it is the space savings from eliminating the AHU room that is more likely to convince the developers to adopt the technology as it represents revenue of concern to them. 


\begin{tabular}{|c|l|l|}
\hline Annual electrical savings & $\$ 334,000$ & 205 tons $\mathrm{CO} 2$ \\
\hline Space liberated for annual revenue & $\$ 500,000$ & at $\$ 7.50$ per sq foot/month in a premium location \\
\hline
\end{tabular}

Table 8.5: Calculations on the revenue generated with a conversion of plant area to leasable area (from project on file planned for Dubai)

By reducing the air-flow to a trickle of conventional quantities, better economy is achieved and symptoms of sick building syndrome minimised as these are commonly found by systems utilising recycled air. This however results in the following issues: (1) reduced air velocity for thermal comfort, and (2) ineffective mixing when adopting conventional ceiling air diffusers. I will now attempt to solve these with the same imperative of saving energy.

\subsection{Radiant Cooling from the Ceiling}

\begin{tabular}{|l|c|c|}
\hline \multicolumn{2}{|c|}{ Two possible conditions for achieving a PMV of +0.5} \\
\hline Air Temp & \multicolumn{2}{|c|}{$25.0^{\circ} \mathrm{C}$} \\
\hline Radiant Temp & $25.0^{\circ} \mathrm{C}$ & $22.6^{\circ} \mathrm{C}$ \\
\hline Relative Humidity & \multicolumn{3}{|c|}{$50 \%$} \\
\hline Air Velocity & $0.5 \mathrm{~m} / \mathrm{s}$ & $0.1 \mathrm{~m} / \mathrm{s}$ \\
\hline Activity Rate & \multicolumn{3}{|c|}{$1.2 \mathrm{met}$} \\
\hline Clothing level & \multicolumn{3}{|c|}{$1 \mathrm{clo}$} \\
\hline
\end{tabular}

Table 8.6: Two possible conditions for achieving a PMV of $+0.5(P P D=10.2 \%)$

For an equivalent thermal comfort condition to a room with wind speed, $v=0.5 \mathrm{~m} / \mathrm{s}$, the office space can alternatively provide $\mathrm{v}=0.1 \mathrm{~m} / \mathrm{s}$ with mean radiant temperature (MRT) at $22.6^{\circ} \mathrm{C}$. This is equivalent to having $70 \%$ of the ceiling at $19^{\circ} \mathrm{C}$ whilst the rest of the surfaces are at air temperature of $25^{\circ} \mathrm{C}$.

Chilled beams provide a small amount of radiant cooling but their coverage is often limited to a small part of whole ceiling coverage. Thus to rely on chilled beams to provide radiant cooling as the primary means of comfort would require temperatures that would risk falling below the dewpoint of the supply air, creating the risk of condensation.

A more effective was of providing radiant cooling would be to adopt chilled ceilings that cover most of the ceiling surface. This approach has been utilised in the following innovations, to which the proposed ceiling mounted air handler can dovetail:

1. a perforated ceiling; or 
2. an evaporatively cooled ceiling

\section{Perforated Ceiling}

Carat passive chilled beams developed by Fregner Systems Limited, UK (figure 8.4), features a ceiling plenum where air is cooled by chilled water, transferring the 'coolth' to the perforated aluminum ceiling as it descends into the occupied space. The Carat chilled ceiling relies on a supply of preconditioned air to avoid condensation on the chilled coils in the ceiling plenum. With the proposed desiccant wheels, dry air can be supplied to the ceiling space to be chilled.

This Figure has been removed for copyright or proprietary reasons

Cooling unit by Loughborough University, UK

These ceiling tile replacements (figure 8.5) pass the return air over a wicking surface that cools the panels by evaporative cooling. The wicked ceiling panel operates with exhaust air that is not readmitted into the AHU, otherwise the excess latent load will burden the dehumidification cycle. The ceiling mounted air handler can take advantage of lower air temperatures to cool desiccated air though the heat exchanger (process A-B). 


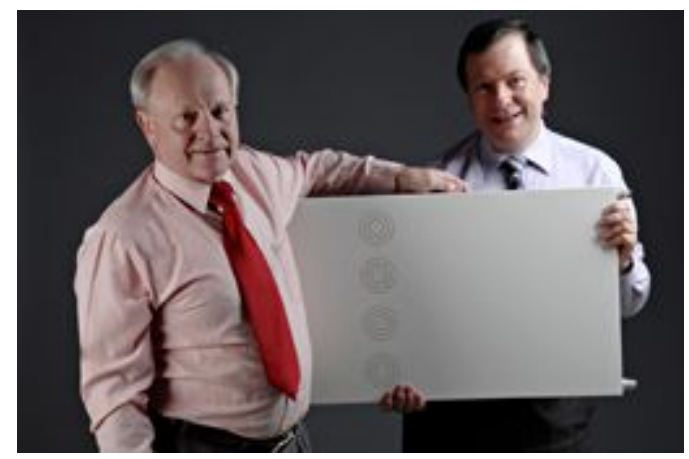

Figure 8.5: Loughborough University's ceiling tile cooling unit, U.S. patent no. 7047752

Of these two options, the second would be better suited to interface with the desiccant wheel AHU as it can be readily implemented with displacement ventilation: $100 \%$ fresh conditioned air is introduced at low speed and low level, pushing the more buoyant, warm and polluted air to the ceiling where it is extracted over the ceiling tile cooling unit. Since the ceiling is not dependent on the supply air as the medium of heat transfer (in the instance of a perforated ceiling), the conditioned air can be supplied at a temperature much closer to comfort $\left(\sim 25^{\circ} \mathrm{C}\right)$, the smaller $\Delta \mathrm{T}$ corresponding to a higher COP.

The desiccant wheel \& radiant ceiling system provides a commercially viable means of eliminating the AHU room, transforming what typically amounts for $5 \%$ of the office floor plate to leasable area, a tangible benefit to property developers.

\subsection{Reflections on the Desiccant Wheel AHU (DWAHU)}

John English (2009) developed the Innovation Development Early Assessment System (IDEAS), a comprehensive risk evaluation plotted on a radar graph to identify areas of weakness in an innovation and business proposal, and assess how possible it was to improve on these areas. Forty criteria (see table 8.7) are assessed in the system where each is scored on a five-point scale, totalled and expressed as a percentage of total possible score. A green light has a score of 80-100, yellow 60-79, and red below 60 .

\begin{tabular}{|l|l|l|l|}
\hline \multicolumn{1}{|c|}{$\begin{array}{c}\text { POTENTIAL } \\
\text { DEMAND }\end{array}$} & \multicolumn{1}{c|}{$\begin{array}{c}\text { MARKET } \\
\text { APPROVAL }\end{array}$} & \multicolumn{1}{c|}{$\begin{array}{c}\text { COMPETITIVE } \\
\text { STRENGTH }\end{array}$} & \multicolumn{1}{c|}{$\begin{array}{c}\text { BOUNDARY } \\
\text { RISKS }\end{array}$} \\
\hline 1. Market size & 6. Need & 11. Differentiation & 16. Regulatory risk \\
\hline 2. Market growth & 7. Recognition & 12. Value & 17. Technology risk \\
\hline 3. Market stability & 8. Compatibility & 13. Customer leverage & 18. Environmental risk \\
\hline 4. Sustainability & 9. Complexity & 14. Supplier leverage & 19. Socio-economic risk \\
\hline 5. Extensions & 10. Distribution & 15. Competitors & 20. Dependence risk \\
\hline
\end{tabular}




\begin{tabular}{|l|l|l|l|}
\hline \multicolumn{1}{|c|}{$\begin{array}{c}\text { ESTABLISHMENT } \\
\text { RISKS }\end{array}$} & \multicolumn{1}{|c|}{$\begin{array}{c}\text { SKILLS AND } \\
\text { EXPERIENCE }\end{array}$} & \multicolumn{1}{|c|}{ RESOURCES } & \multicolumn{1}{c|}{$\begin{array}{c}\text { DOLLARS } \\
\text { AND SENSE }\end{array}$} \\
\hline 21. Planning risk & 26. Marketing expertise & 31. Financial resources & 36. Sales forecast \\
\hline 22. Marketing risk & 27. Technical expertise & 32. Physical resources & 37. Profitability \\
\hline 23. Deliverables risk & 28. Financial expertise & 33. Human resources & 38. Cost structure \\
\hline 24. Liquidity risk & 29. Operational expertise & 34. Intellectual resources & 39. Financial structure \\
\hline 25. Personal risk & 30. Managerial expertise & 35. Network resources & 40. Cash flow \\
\hline
\end{tabular}

Table 8.7: IDEAS business feasibility evaluation list (English, 2009)

The business concept of the desiccant wheel AHU (DWAHU) was evaluated under IDEAS with a score of 72, which indicated 'satisfactory market viability but there are typically some concerns about risk and/or problems with the business model that need to be resolved.' (English, 2009, p.181) The greatest weaknesses were the supplier leverage, technology and dependence risks. The viability of DWAHU was contingent on the availability of desiccant with low regeneration temperature, of which 'only the last generation of adsorption desiccants achieve regeneration temperatures between $40^{\circ} \mathrm{C}$ and $80^{\circ} \mathrm{C}$.' (Mazzei, 2005, p.698)

The proposal was presented at the university business competition, and as one of the winners, subsequently recommended to the Patent Review Committee (PRC) of Uniquest, the university's commercialisation service provider. In technology innovation, patents protect investors' interest by offering litigative resolutions if an idea was copied. Since desiccant wheels already existed and were used in conjunction with air-handlers, the PRC had reservations if mounting a desiccant wheel in the ceiling constituted an inventive step. Working with desiccant wheel manufacturers was also a challenge as they kept the formulation of the low regeneration temperature desiccants a trade secret and were not willing to co-develop the technology with the university. None of the manufacturers approached were willing to supply the desiccants separately from the entire air-handling system, which indicated that the desiccants could not be distributed at a high enough profit; and also indicated a fear that the desiccants could be reverse engineered.

The inability to follow though with a patent was more than a stumbling block, it conclusively terminated further development of DWAHU and radiant ceiling concepts. The centrality of patents to the inventing-commercialising efforts can be illustrated in the following case study of the skytherm roof. 


\subsection{Case study: The Skytherm Roof}

Building scientists have, for a long time, been pursuing the quest for totally passive buildings. The Skytherm roofing system designed by Harold Hay (1967) was in its time reported as the the only passive solution that could provide heating and cooling to most of United States (Cook, 1989; Santamouris, 1996). The main feature was thermal storage by water contained in plastic bladders sandwiched between two roofs, an insulated upper roof and metal lower roof (figure 8.6). By selectively exposing the water bags for night cooling in summer, and day heating in winter, it was able to achieve all day, all year passive comfort.

This Figure has been removed for copyright or proprietary reasons

In the 1970s, extensive validation was initially undertaken by the Trinity University (Cook, 1989) and largely neglected for a period. It has most recently been studied for application in 
Iran where the effectiveness of the system was modelled for a $141 \mathrm{~m}^{2}$ single-storey house in Shiraz, Iran, reducing heating demands by $86 \%$ and cooling loads by $52 \%$ (Raeissi, 2000). Research is currently undertaken by Cal Poly to bring the original Skytherm house located at Atascadero up to current building codes (Evelyn and Harold Hay Fund website, http://51.calpoly.edu/sites/ehhf/index.html undated webpage).

The main criticism for the Skytherm house has not been a matter of its performance but the reliability of a mechanism that moves insulated panels over the water bags (Givoni, 1991). In a day when we can rotate entire floors of a skyscraper (like the Rotating Tower in Dubai), surely this should no longer be a valid reason for ignoring this idea. Or are there forces at play?

To solve a universal problem, a far-reaching solution was required. Godin in discussing how ideas became viral, said:

The goal, of course, is to have an ideavirus so smooth that once someone is exposed to it, they are instantly hooked. A virus so powerful that all it takes is one guitar lick on the radio, one phrase in a book review, one glimpse of a website and you completely and totally "get it." And not only do you get it, but you want it. Now and forever.

(Godin, 2001, p.98)

Skytherm cooling exemplified a revolutionary idea that was scientifically sound: the use of the night sky to provide radiant cooling to a roof thermal mass at night, which in turn provided radiant cooling to the space it covered in the day. Neither concept of radiant heat exchange could be easily grasped by the average layperson. Yet both needed to be understood, one being the human skin sensitivity to radiant cooling, and the other that the night sky could function as a radiant heat sink.

Speaking from personal experience teaching architectural science, I have appreciated how foreign the concept of radiation appeared to first year students when encountering related topics like MRT, low-emissivity glass coatings, sarking and so forth. To communicate this concept I have employed common analogies of radiant heat (like bathroom lights, pop-up toasters and fire pots) and performed demonstrations with infrared spot thermometers and thermal imaging (figure 8.7). Despite my best efforts, the concept had only been vaguely understood and after a semester students typically cannot explain how frost could form on 
grass when both the air and soil temperatures were above freezing. Evidently, it was not smooth (in Godin's definition) to convey concepts surrounding radiation. It would therefore not be easy to educate the target market to understand skytherm cooling.
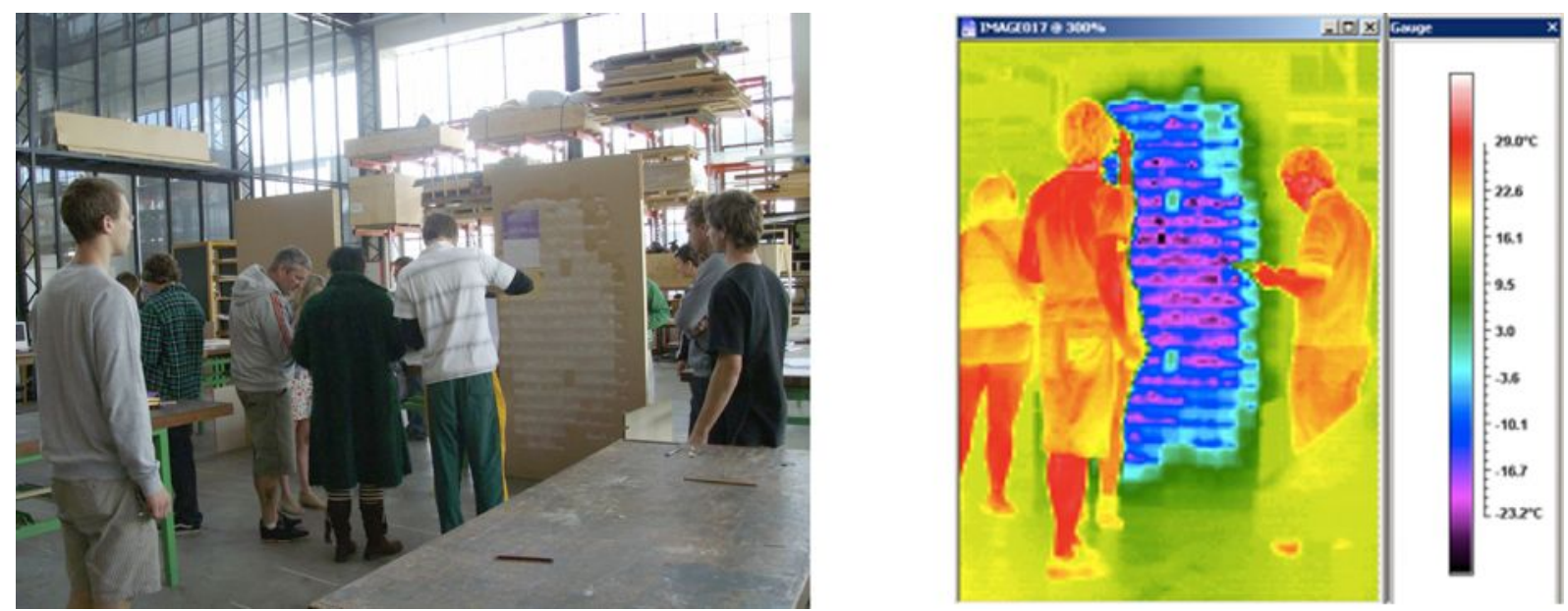

Figure 8.7: Experiment to teach first year Building Technology \& Design students the concepts of radiant heating and cooling: MRT, emissivity and the inverse-square law.

This does not necessarily suggest that the target market can never be cognisant with Skytherm, it just meant it would eventually be a costly affair. It would involve large scale marketing and endorsement in order for the general public to understand and begin demanding it. Any investor will have to factor into his costs a marketing campaign for home buyers and the training of builders and electricians to install the proprietary roof system. The first to market investor (roofing manufacturer or property developer) will have to bear this public relations campaign in the hope of recovering it subsequently. However, patents are typically valid for twenty years, so the original Skytherm patent has now become public domain material. With the twin deterrents of high education cost and no protection from copycats, it is unlikely that Skytherm will ever gain traction in the market.

Another important factor for the failure of Skytherm was personality. The complexity of the commercialisation process involves working with multiple parties (commercialisation managers, business mentors, venture capitalists, patent attorneys, etc.) and numerous bureaucratic layers (university, state and federal government, and the various compartmentalised departments in each organisation). A close associate of Hay commented:

'Over time, people lost patience with Hay and then lost interest in his creation. Hay's combative personality and reluctance to let others join his mission scotched one 
potential deal and may have turned others off,' says Ken Haggard, who met Hay in 1972 when the architect was a young professor at Cal Poly San Luis Obispo. 'He's a caricature of the mad inventor. He's a genius. But he's also impossible. And he has not mellowed one iota.' (Douglass, 2007)

\title{
8.9 The Commercial and Scientific Imperatives
}

\author{
In 1997 the Administration, with the backing of the solar industry, introduced a \\ "Million Solar Roofs" initiative to install solar systems (mainly domestic hot water and \\ PVs) on buildings. To my great (but predicted) disappointment, it fails to address the \\ most obvious "solar" option of switching roof color (an almost free measure at the \\ time of the next roof replacement, which accordingly has little backing from \\ manufacturers—cheap solutions are not popular). (Rosenfeld, 1999, p.65)
}

For a solution to work, it had to be implemented. Whilst scientific merit is a key starting point, an idea based on good science does not in itself warrant success. Many obstacles impede the transition between research and reality. The commercial considerations can be surmised in the following insights:

1. In a capitalistic society, you needed people to buy your solution for you to solve their problems. The saleability of an idea had to be considered at the very conception of an invention.

2. If the idea was not 'smooth', it will be more costly for it to catch on. Marketing can consume a massive budget so an idea powerful enough to self-propagate as an ideavirus would greatly increase profit margins.

3. Investors expected you to protect their interests. The patentability of an idea was vital, so was the zeal manifested in ensuring good laboratory records, confidentiality agreements and patent rights enforcement.

For the innovation to have market sustainability, it could not be merely a marketing play, a technological breakthrough was vital. Industrial designer James Dyson puts it well in his advertising:

Solve the obvious problems others seem to ignore.

The proverbial elephant in the room was the existing stock of buildings, a typical office building having a lifespan of 40 years (CIBSE, 1999). An air-conditioning system that was 
more efficient could not be adopted unless it could be installed without inconvenience. As an improvement over current systems, it also had to attain 0\% PPD where each occupant decided on their own perfect temperature. Furthermore, with the Australian Carbon Price introduced in July 2012, the new system should not require refrigerants.

To embed the commercial and scientific imperatives, the brief was refined as follows:

Design a system that can provide air-conditioning to high-rise offices in the tropics that is more energy efficient, more space efficient, offers personalised control, requires no refrigerants and, above all, requires no installation.

Now, we are ready to solve what Dyson refered to as the 'obvious' problem. 
This chapter has been removed for copyright or proprietary reasons

9 Personal air-conditioning 


\section{Field Testing DTAC, Methodology \& Results}

\subsection{Background to the field trial}

The Ductless Task Air-Conditioning (DTAC) system was developed for supplementary personal cooling to office occupants. DTAC utilised thermoelectric (peltier) modules for heat exchange into a phase change material (PCM) as heat sink, allowing workspaces to be air-conditioned with no installation. The process of prototyping and optimising this unit is covered at length and in detail in Appendix 1. The final DTAC Mark-4 prototype was capable of supplying air at $4-10^{\circ} \mathrm{C}$ below ambient, depending on the external ambient temperatures and the fan speed. To test if this amount of cooling was sufficient for human comfort, a field trial was organised.

\subsection{Field trials in NV offices}

\subsubsection{Purpose of field study}

The field study was designed to ascertain the degree to which ambient air-conditioning setpoint can be raised with the use of supplementary air-conditioning. This may overlap with existing research with existing studies on TAC (task-ambient conditioning), PEM (Personal Environmental Modules) and PV (personal ventilation). It was very possible that if DTAC's cooling capacity (flow rate and supply temperature) were comparable to TAC, then the thermal comfort outcome would also be similar.

\subsubsection{Methodology}

Eight participants in the field trials were divided into two groups: one group to field test the DTAC system while the other control group will concurrently use a fan-only unit. After one week (5 working days), the groups had a swop of appliance and repeated the test. Invitations were sent to all staff at the School of Architecture and Design, and of the 10 who responded the first 8 respondents were selected for the trials (figure 11.1). 

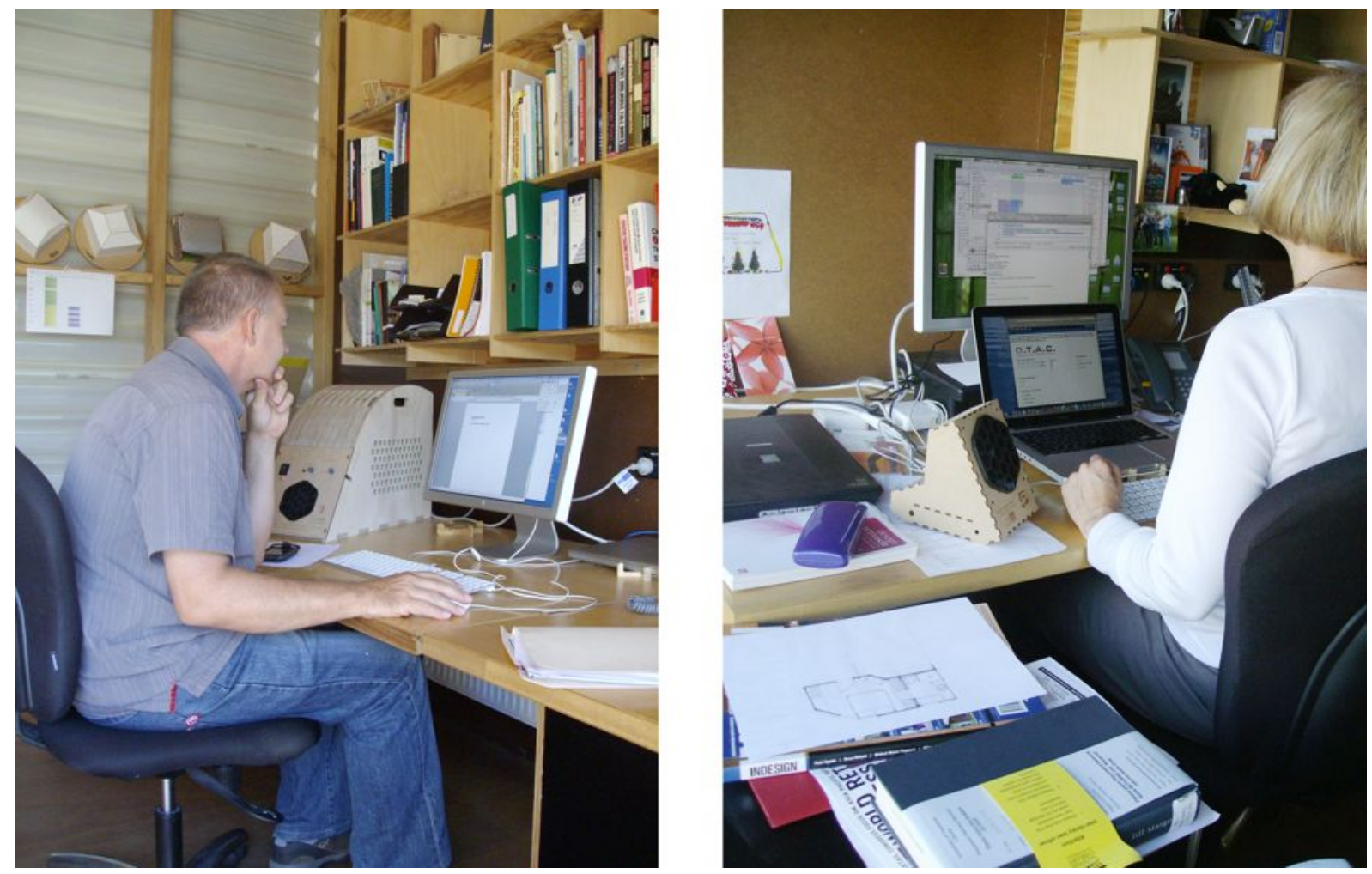

Figure 10.1: (a) Participant using DTAC unit (b) Participant using fan-only uniy

Trials were run from 15 Feb 2011-1Mar 2011. Participant were required to fill up online survey forms comprising:

1. Start of the day comfort questionnaire

2. Comfort questionnaire to be filled every hour on the hour.

3. End of day

Questionnaires indicated clothing, metabolism and stress level. Feedback on the efficacy of DTAC or fan-only units was collected in the following areas: thermal comfort, air quality, office productivity, general well-being and background noise. The questionnaires were based on the following references:

1. Appendix E: Thermal Environment Survey of ASHRAE 55 (2004): Thermal Environmental Conditions for Human Occupancy

2. ISO 7730 (2005): Ergonomics of the thermal environment - Analytical determination and interpretation of thermal comfort using calculation of the PMV and PPD indices and local thermal comfort criteria 
3. Bedford, T. (1936): The Warmth Factor in Comfort at Work. Rep. Industr. Hith. Res. Bd., No. 76, London.

The surveys were based on two theories of thermal comfort. Deterministic thermal comfort theory underlies the bulk of air-conditioning research and is based on laboratory work by volunteers (often students) in climate chambers doing simulated work for 2-3 hours. Adaptive thermal comfort underlies natural ventilation research and is based on field studies by office workers (typically in the tropics) performing their actual occupation through the day. The two schools differ in approach, application and method. As the DTAC field trial was performed in a naturally ventilated building, both scales were used.

The first was Predicted Mean Vote (PMV) from the deterministic thermal comfort theory which relates six variables (clothing, metabolism, T, RH, MRT, wind velocity) to a vote (table 11.1).

\begin{tabular}{|c|l|}
\hline \multicolumn{2}{|c|}{ Describe your thermal sensation: } \\
\hline 1 & Cold \\
\hline 2 & Cool \\
\hline 3 & Slightly Cool \\
\hline 4 & Neutral \\
\hline 5 & llightly Warm \\
\hline 6 & Warm \\
\hline 7 & Hot \\
\hline
\end{tabular}

Table 10.1: Thermal sensation scale

By comparing the Actual Mean Vote (AMV) to the PMV, I expected to see an improvement with the fan-only unit and a further improvement with DTAC.

The other indicator was to use a combination of a 6-point comfort scale (table 11.2). 


\begin{tabular}{|l|l|}
\hline \multicolumn{2}{|c|}{$\begin{array}{l}\text { How comfortable are you feeling } \\
\text { with regard to temperature? }\end{array}$} \\
\hline 1 & Very uncomfortable \\
\hline 2 & Moderately uncomfortable \\
\hline 3 & Slightly uncomfortable \\
\hline 4 & Slightly comfortable \\
\hline 5 & Moderately comfortable \\
\hline 6 & Very comfortable \\
\hline
\end{tabular}

Table 10.2: General comfort sale

A third scale is based on the Bedford scale (Bedford, 1936) commonly used in England (table 11.3).

\begin{tabular}{|r|l|}
\hline \multicolumn{2}{|c|}{ Which best describes your thermal comfort? } \\
\hline-3 & Much too cool \\
\hline-2 & Too cool \\
\hline-1 & Comfortably cool \\
\hline 0 & Comfortable and neither cool/warm \\
\hline+1 & Comfortably warm \\
\hline+2 & Too warm \\
\hline+3 & Much too warm \\
\hline
\end{tabular}

Table 10.3: Thermal comfort scale

\subsubsection{Temperature $(\mathrm{T})$ and Relative Humidity $(\mathrm{RH})$ logging}

Outdoor T \& RH were taken at my office above an open window. Indoor T was taken inside my office at three levels (as stipulated by ASHRAE55): $0.1 \mathrm{~m}, 0.6 \mathrm{~m}$ and $1.1 \mathrm{~m}$ from floor. Globe T was taken at $1.1 \mathrm{~m}$ (instead of $0.6 \mathrm{~m}$ stipulated by ASHRAE55) as a more accurate representation of radiant heat on the head, especially that which was contributed by computer monitors. A $38 \mathrm{~mm}$ table tennis ball was used instead of the $150 \mathrm{~mm}$ copper globe in favour of its faster response and equivalent accuracy (Humphreys, 1977). Air velocity was taken at $1.1 \mathrm{~m}$, to correspond with globe $\mathrm{T}$ in order to calculate mean radiant temperature (MRT). Indoor RH was taken at $1.1 \mathrm{~m}$. The measurements within my office would be similar to the other offices as all offices had the same facing and were of the same size.

$\mathrm{T}$ and RH were logged on Hobo U12 data loggers with built in sensors. Air velocity was read by Kimo CTV100 hot wire anemometer and logged on Hobo U12. Logging was set to $1 \mathrm{~min}$ intervals. 
10.2.4 Response Rate

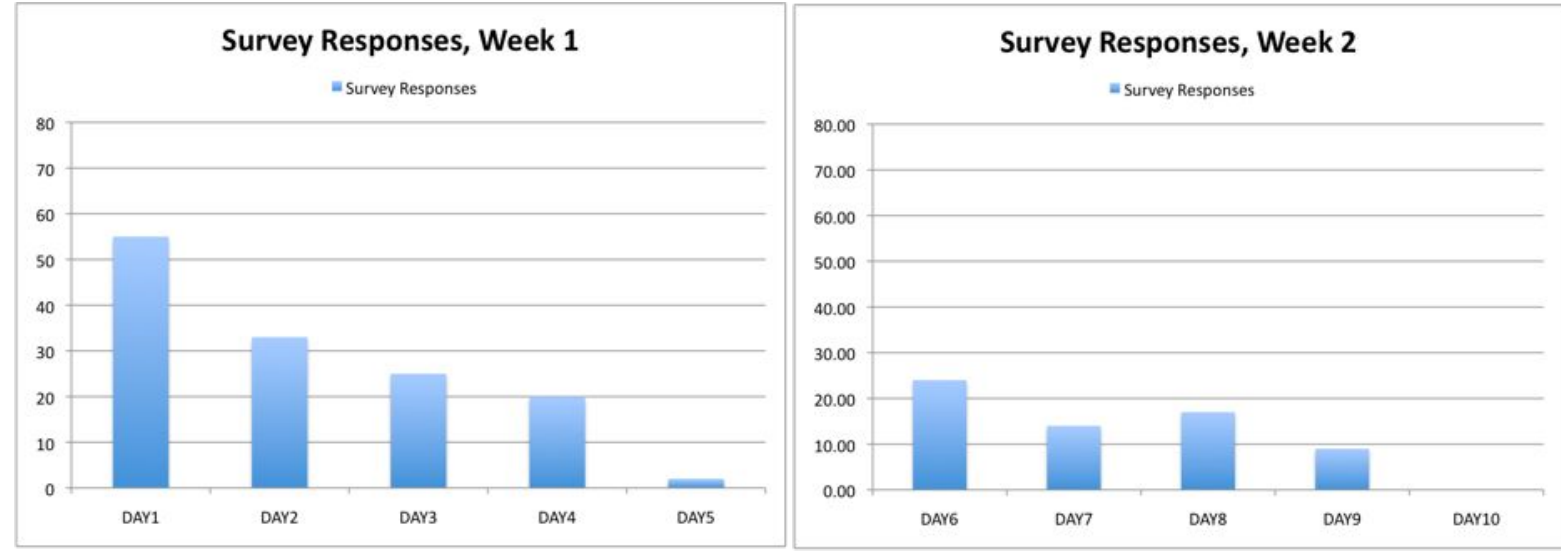

Figure 10.2: Number of responses received for thermal comfort survey in (a) week 1 (b) week 2

The participation rate for the first week was rather low. After speaking to the participants the consensus was to switch to a paper survey in place of online survey forms. The time taken to fill up each online survey had been about $90 \mathrm{sec}$, and we expected the paper surveys to substantially reduce that time, making it quicker and more convenient. The other advantage of a tabulated survey form was that it imposed a subconscious pressure to be more conscientious if a participant had left too many blanks in the responses. A further advantage was that if one was sensitive enough and so inclined, one could reflect a degree of comfort to a decimal placing. Majority (7 of 8) preferred the paper survey immediately. Despite this, the response rate in figure 11.2 was rather disappointing. 
10.2.5 PMV and AMV Results

FT Day 1 (15 Feb 2010)

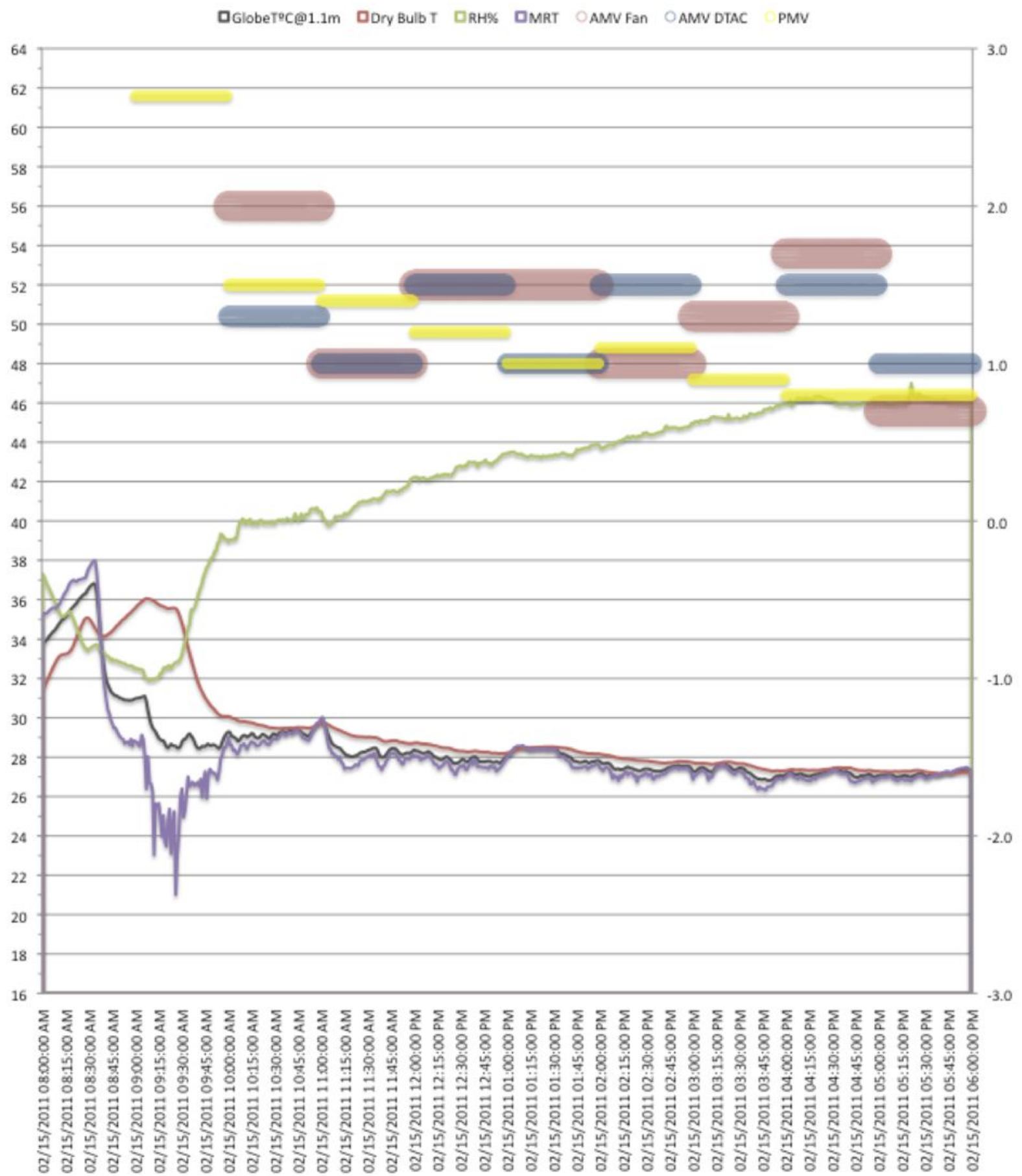

Figure 10.3: Plots of environmental thermal factors on left vertical axis: dry bulb T, globe T, relative humidity, MRT. Votes (PMV, AMV-Fan and AMV-DTAC) are the thick horizontal bars read to the right vertical axis.

Whilst not the most representative of natural ventilated buildings, it was expected that the PMV could still be a baseline reference in an office had there been no supplementary personal cooling. The improvement from using a fan could be seen from the difference 
between AMV (fan only) and PMV, and a further improvement could be expected between AMV (DTAC) and AMV (fan only).

The results for the first day was the most complete and yielded no conclusive evidence if either the DTAC or fan-only units improved the actual vote against what would have been predicted (figure 11.3 and table 11.4).

\begin{tabular}{|c|c|c|c|c|c|}
\hline Time & PMV & AMV FAN & AMV DTAC & $\Delta$ Vote (Fan) & $\Delta$ Vote (DTAC) \\
\hline $10 \mathrm{am}$ & 1.5 & 2.0 & 1.3 & 0.5 & -0.2 \\
\hline $11 \mathrm{am}$ & 1.4 & 1.0 & 1.0 & -0.4 & -0.4 \\
\hline $12 \mathrm{pm}$ & 1.2 & 1.5 & 1.5 & 0.3 & 0.3 \\
\hline $1 \mathrm{pm}$ & 1.0 & 1.5 & 1.0 & 0.5 & 0.0 \\
\hline $2 \mathrm{pm}$ & 1.1 & 1.0 & 1.5 & -0.1 & 0.4 \\
\hline $3 \mathrm{pm}$ & 0.8 & 1.7 & 1.5 & 0.9 & 0.7 \\
\hline $4 \mathrm{pm}$ & 0.8 & 0.7 & 1.0 & -0.1 & 0.2 \\
\hline \multicolumn{7}{|c|}{ Average difference in vote } & 0.2 & 0.1 \\
\hline
\end{tabular}

Table 10.4: Differences in votes between predicted and actual with use of fanonly and DTAC units

10.2.6 Thermal sensation results (based on adaptive thermal comfort studies)

The thermal sensation votes were plotted against the average effective temperature of the hour prior to the vote taken, i.e. the sensation vote as filled out at 10am was plotted against the average effective temperature from 9.01am to 10.00 a.m. Where:

$$
T_{\text {effective }}=0.5 \cdot T_{\text {air }}+0.5 \cdot M R T
$$

The decision to use effective indoor temperatures instead of outdoor air temperatures was due to the large amount of glazing found in the offices where the experiment was conducted. All offices were fully glazed on one side $(3 \mathrm{~m} \times 1.8 \mathrm{~m})$ and would account for a substantial amount of radiant heat.

The aim was to determine a linear function between thermal sensation vote and T(effective) which could then determine the neutral sensation temperature, $T$ (neutral), when vote $=0$. Due to the additional cooling that each device offered, it was expected that the fan only regression would have a higher $\mathrm{T}$ (neutral) than the adaptive thermal comfort models would 
predict, and the DTAC regression an even higher T(neutral) value, showed in the plot of figure 11.4 .

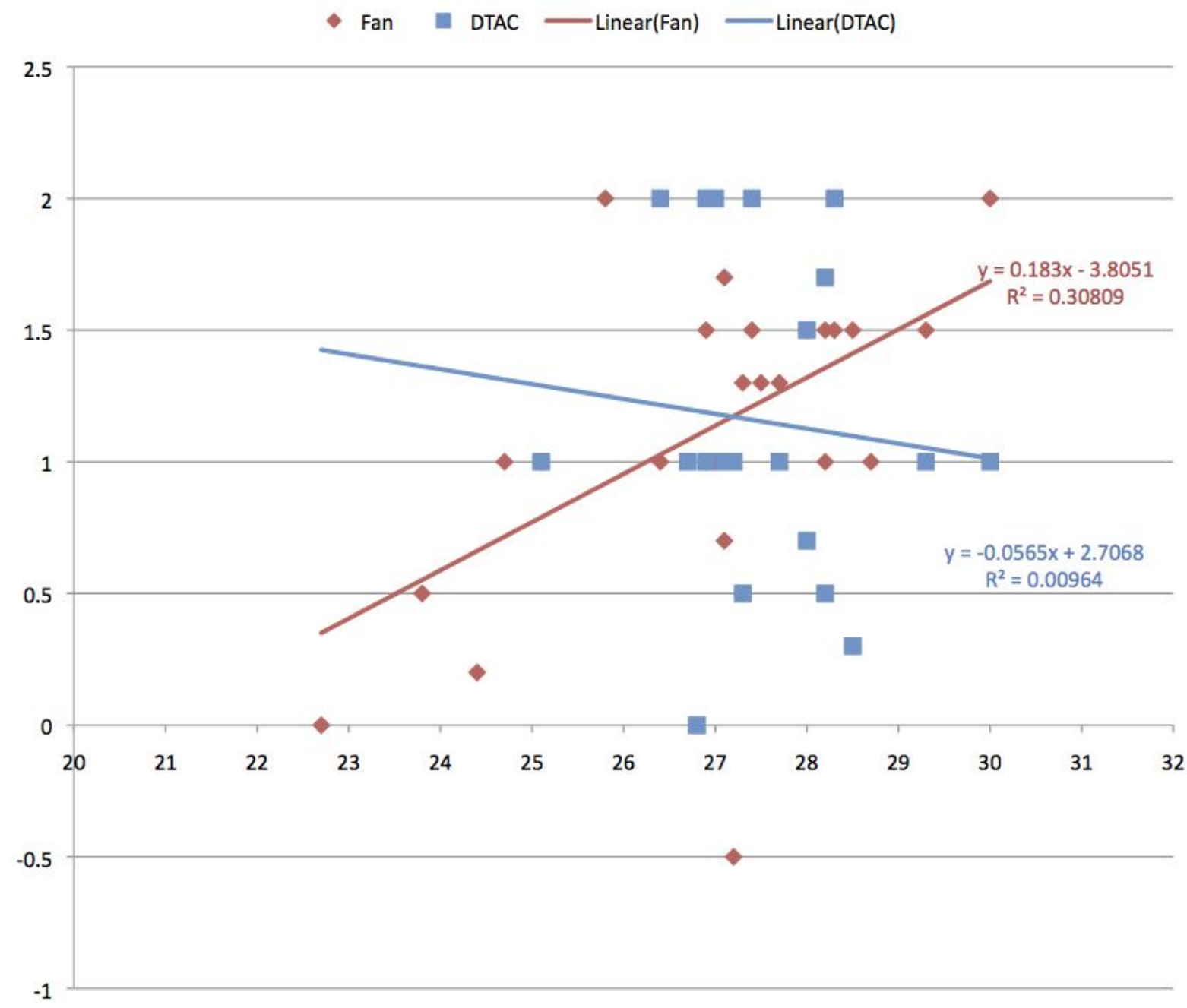

Figure 10.4: All data points of actual votes, and the corresponding effective T plotted for fan-only (red) and DTAC (blue). Fan votes show a weak correlation $\left(r^{2}=0.3\right)$ and DTAC votes show no correlation with $T\left(r^{2}=0.0\right)$

With the fan only units, $\mathrm{T}$ (neutral) worked out to be $20.8^{\circ} \mathrm{C}$. Based on a weak correlation $\left(r^{2}=0.3\right)$ the data suggests that occupants would have a neutral sensation with a small fan at an effective indoor temperature of $20.8^{\circ} \mathrm{C}$. The DTAC regression would suggest a T(neutral) of $47.9^{\circ} \mathrm{C}$. However the DTAC correlation was so weak $\left(r^{2}=0.01\right)$ I cannot say with any degree of certainty that $48^{\circ} \mathrm{C}$ would be the optimum indoor temperature with DTAC. In fact, with the weak correlation, it would be more accurate to infer that indoor $\mathrm{T}$ ( $\mathrm{x}$-axis) and the thermal sensation vote when using DTAC (y-axis) had little correlation. This would support the position that DTAC can be an effective personal cooling unit, such that actual thermal sensation could not be accounted for in terms of ambient temperature fluctuations. 


\subsubsection{Concerns}

Climate

Late February was typically the hottest period in Tasmania. However in this particular year (2011) the summer was unusually cool, with very few days requiring any supplementary cooling.

\section{Sample size}

The amount of funds and the time required to fabricate each DTAC unit limited the number of participants to four in the DTAC group and four in the fan-only control group. Whilst the outcome of 162 actual data points was comparable to many similar studies (table 11.5), I felt a need for more thorough field testing. The table shows a summary of similar recent studies, none of which had been done in naturally ventilated buildings:

\begin{tabular}{|c|c|}
\hline Law & $\begin{array}{l}162 \text { (actual) of } 640 \text { (planned) data points } \\
8 \text { participants ( } 4 \text { DTAC, } 4 \text { control) } \text { X } 8 \text { surveys/day } \text { X } 10 \text { days }\end{array}$ \\
\hline Zhang (2010) & $\begin{array}{l}270 \text { data points } \\
18 \text { participants }(9 \mathrm{M}, 9 \mathrm{~F}) \times 5 \text { conditions } \\
\left(\mathrm{ET} 18^{\circ} \mathrm{C}, 19.9^{\circ} \mathrm{C}, 24.2^{\circ} \mathrm{C}, 27.5^{\circ} \mathrm{C}, 29^{\circ} \mathrm{C}\right) \times 3 \text { surveys }(1 \mathrm{per} \text { hr) }\end{array}$ \\
\hline Kaczmarczyk (2004) & 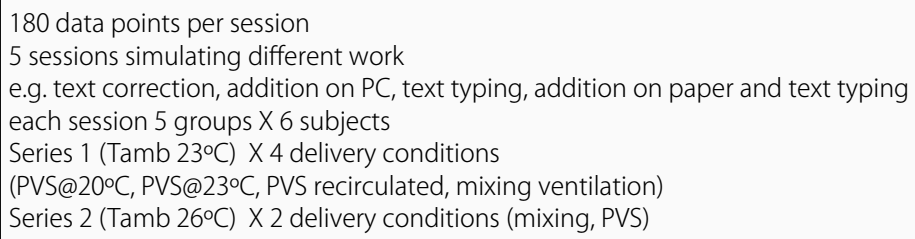 \\
\hline Kaczmarcyk (2010) & $\begin{array}{l}180 \text { data points } \\
3 \text { survey (every } 5 \text { min) } \times 4 \times 15 \text { min exposures (50\% with PV, 50\% control } \\
8 \text { desk (4 PV, } 4 \text { none) }\end{array}$ \\
\hline Akimoto (2010) & $\begin{array}{l}96 \text { data points (2005) and } 240 \text { data points (2006) } \\
8 \text { participants (2005: } 6 \text { M 2F) } 20 \text { participants (2006: 12M 8F) } \\
3 \text { days (TAC off, TAC full open, TAC controllable), } 4 \text { surveys daily }\end{array}$ \\
\hline Amai (2007) & $\begin{array}{l}96 \text { data points for each TAC (standard, 3DU, PEM, RCU, RCU+meshchair, TU) } \\
24 \text { participants (12M 12F) X } 4 \text { surveys ( } 25 \text { min from start then every } 60 \text { min) }\end{array}$ \\
\hline Bauman (1997) & $\begin{array}{l}212 \text { data points } \\
53 \text { participants, } 1 \text { survey X } 4 \text { periods } \\
\text { original } 42 \text { PEMs (total of } 3 \text { buildings) }+36 \text { control ( } 10 \text { to } 12 \text { per building) } \\
4 \text { measuring periods ( Baseline Mar, Post PEM normal 10-11 July } \\
\text { Post-PEM set-up } 24-25 \text { July, Post PEM set-down } 31 \text { July) } \\
\text { post: } 28 \text { PEM + } 25 \text { control = } 53 \text { participants }\end{array}$ \\
\hline Post (1993) [in Baunman (1997)] & $\begin{array}{l}200 \text { data points } \\
100 \text { participants ( } 27 \text { weeks before, } 24 \text { weeks after), of } 370 \text { units in WBM building }\end{array}$ \\
\hline
\end{tabular}

Table 10.5: Current experiment (Law) compared with the sample size of similar studies. 


\section{Response rate}

The response rate was fairly low. For some days there was virtually no response. The participants were predominantly lecturers who could not fill up the surveys when they were holding classes or meetings. Out of a total of 640 expected responses there was only a quarter of actual responses.

\section{Wax capacity}

The quantity of wax in the DTAC units allowed typically 2.5 hours of use at maximum cooling. Whilst this coincided with the morning when the offices were hottest due to a north-eastern facade, this meant that no supplementary cooling could be offered in the afternoon.

\subsubsection{Next Steps}

Without conclusive data, I had to plan another round of field trials. With the unreliability of the initial sample group to fill out the comfort surveys, one could either conduct an objective study or another round of field trials with paid participants voting on sensation and comfort (subjective study).

To conduct thermal comfort studies with objective measurements, four regimes existed:

1. Use of human subjects with surface and core temperatures measurements

2. Use of thermal mannequins and either measure changes to surface temperature, or measure energy needed to maintain constant surface temperatures

3. Use of heated sensors according to guidelines of ISO 14505-2 (2006) 'Ergonomics of the thermal environment - Evaluation of thermal environments in vehicles - Part 2: Determination of equivalent temperature'

4. Use of environmental measurements (MRT, air T, wind vel, RH) and relate these to the ISO 7730 'Ergonomics of the thermal environment - Analytical determination and interpretation of thermal comfort using calculation of the PMV and PPD indices and local thermal comfort criteria'

The use of human subjects would require monitoring of skin and core temperatures of subjects. Core temperatures were traditionally measured with rectal thermometers. 
Alternatively task-ambient air conditioning studies done at the Lawrence Berkeley National Laboratory (Zhang, 2010) used transducer pills to monitor body core temperature. For an 8-participant, 10-day trial, the ingestible pills and data recorders would cost a total of $\$ 34,000$ and was deemed too costly. Moreover the pills were designed for studies of heat/ cold stress and may not accurate indicate thermal comfort as the range of temperatures in the office was unlikely to perturb core temperatures. It was also uncertain if the readings could be significantly altered by the consumption of hot/cold food and beverages. In Zhang's study (Zhang, 2010), the pills were mentioned in the methodology but no results were presented. She did not respond to a private enquiry on the matter.

The use of a thermal mannequin was deemed to be financially prohibitive at this stage. A quote from one supplier (Kanomax, U.S.) came to $\$ 300,000$. Moreover, since there were more than one thermal mannequin supplier, there would be a need to validate the accuracy of thermal mannequins to real life examples.

A modification from the heated mannequin would be to use heated sensors mounted on a rig exemplified in figure 11.5 from the ISO 14505 Standard. Vehicular comfort standards are, at this time, the only ones that acknowledge the effects of localised cooling. The shortcoming in this approach was the uncertainty regarding the transferability of vehicular thermal standards to the office. In Chapter 4 we also expressed concern that mannequins could not simulate the mechanisms of SBC, and that the summation of skin temperatures weighted by area did not express the sensitivity of particular areas, especially of the face, to cooling. 


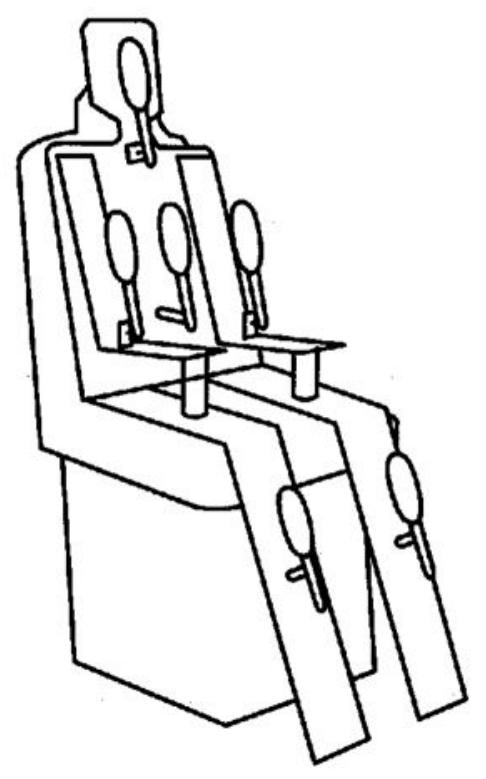

Figure 10.5: Example of measuring set-up with several ellipsoid sensors mounted on rig simulating a seated person (ISO14505:2, 2006)

The PMV is an accepted standard under ISO 7730 and ASHRAE 55. The ASHRAE standard recommends that dry bulb temperature be taken as the average of three heights $(0.1 \mathrm{~m}, 0.6 \mathrm{~m}$ and $1.1 \mathrm{~m}$ ) with MRT and RH measured at $0.6 \mathrm{~m}$ for seated occupants. DTAC focussed on cooling the upper body and the face in particular. Since only the topmost sensor would be exposed to the cooled stream, would the cooling effect only be a third of the overall sensation? Other than air temperature, all measurements were taken at only one level as representative of that experienced across a whole person. It was therefore difficult to determine how net wind velocity was to be aggregated, for example with a fan velocity of $1 \mathrm{~m} / \mathrm{s}$ on the face and $0.2 \mathrm{~m} / \mathrm{s}$ background air speed.

The efficacy of DTAC thus had to be experimentally determined in two steps:

1. The occupant, with estimated clo and met values and controlled environmental variables, would answer the thermal comfort questionnaire to ascertain a match between his/her sensation to PMV.

2. The occupant will subsequently switch on the DTAC, and the efficacy of it determined by any significant changes from feedback through the questionnaire. 


\subsection{Climate chamber setup}

The aim was to control the air and mean radiant temperatures of the Climate Chamber (CC), together with humidity and air speed. Volunteers were given a task that simulated work which took three hours to complete, the first hour without DTAC and the next two hours with the DTAC switched on and controlled to make themselves as comfortable as possible.

\subsubsection{Room setup}

A room within the School of Architecture and Design of the University of Tasmania was designated as the $\mathrm{CC}$. The room was equipped with a centrally controlled panel heater and had no windows. T-air and T-globe was logged at the position where the participant would be seated at three heights $(0.1 \mathrm{~m}, 0.6 \mathrm{~m}$ and $1.1 \mathrm{~m}$, according to ASHRAE 55). The logging was done over a few days at each stage as the room was set up:

1. Panel heater (under central automated hydronic control) only

2. Panel heater + humidifier (cool mist)

3. Panel heater + humidifier (warm mist)

4. Panel heater + humidifier (warm mist) $+1 \mathrm{~kW}$ oil-fin heater on electronic thermostat.

\subsubsection{Room Environment with Panel Heater Only}

The room has proven to be an excellent choice as a climate chamber, with the air and globe temperatures having a near-pefect correlation $\left(r^{2}=0.998\right.$, figure 11.6). When applied in the operating range of $25^{\circ} \mathrm{C}-30^{\circ} \mathrm{C}$ and the target temperature of $28^{\circ} \mathrm{C}$, the difference between air and globe temperatures were negligible.

This eliminates the entire argument of what ratio of air temp vs MRT we should adopt to determine effective temperature. As a countercheck, the Hobo loggers were verified against high accuracy digital loggers $\left( \pm 0.2^{\circ} \mathrm{C}\right)$, labelled "EL2Tair" below with excellent correlations (also figure 11.6). 


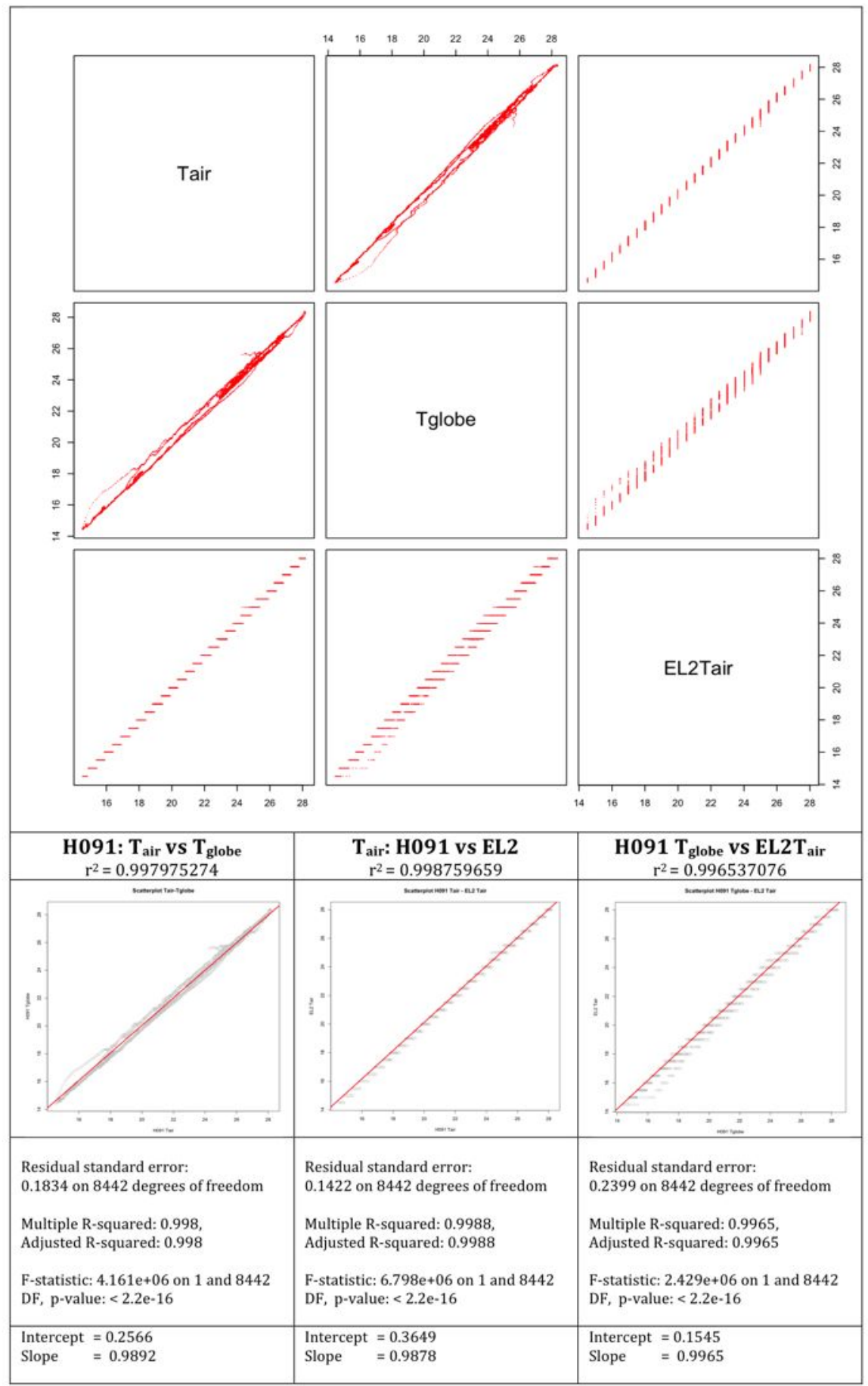

Figure 10.6: Correlation of air temperature (Tair) and globe temperature (Tglobe), verified against a new high accuracy digital logger (EL2Tair)

\begin{tabular}{|c|c|c|}
\hline Tair & Tglobe & dT \\
\hline 25.000 & 24.987 & 0.013 \\
\hline 28.000 & 27.954 & 0.046 \\
\hline 30.000 & 29.933 & 0.067 \\
\hline
\end{tabular}

Table 10.6: Using linear correlations, the T-globe can be predicted with very good accuracy from T-air, and shown that difference between the two values is negligible. 


\subsubsection{Why $28^{\circ} \mathrm{C}$ ?}

The ISO7730 (2005) standard acknowledges the difficulty in determining the PMV without accurate instruments, and allows that 'the verification may be based on the equivalent operative temperature range' (see table 11.7). Assuming summer conditions for offices in category $\mathrm{C}$, the highest acceptable temperature is $\mathrm{T}$ (ambient) $=24.5+2.5=27.0^{\circ} \mathrm{C}$, on which another $1^{\circ} \mathrm{C}$ was added to move it just out of the acceptable range.

\begin{tabular}{|c|c|c|c|c|c|c|}
\hline \multirow[t]{2}{*}{$\begin{array}{c}\text { Type of } \\
\text { building/space }\end{array}$} & \multirow[t]{2}{*}{$\begin{array}{l}\text { Activity } \\
\mathrm{W} / \mathrm{m}^{2}\end{array}$} & \multirow[t]{2}{*}{ Category } & \multicolumn{2}{|c|}{$\begin{array}{l}\text { Operative temperature } \\
{ }^{\circ} \mathrm{C}\end{array}$} & \multicolumn{2}{|c|}{$\begin{array}{c}\text { Maximum mean air velocity }{ }^{a} \\
\mathrm{~m} / \mathrm{s}\end{array}$} \\
\hline & & & $\begin{array}{c}\text { Summer } \\
\text { (cooling season) }\end{array}$ & \begin{tabular}{|c|} 
Winter \\
(heating season)
\end{tabular} & \begin{tabular}{c|}
$\begin{array}{c}\text { Summer } \\
\text { (cooling season) }\end{array}$ \\
\end{tabular} & $\begin{array}{c}\text { Winter } \\
\text { (heating season) }\end{array}$ \\
\hline \multirow{3}{*}{$\begin{array}{l}\text { Single office } \\
\text { Landscape office } \\
\text { Conference room } \\
\text { Auditorium } \\
\text { Cafeteria/restaurant } \\
\text { Classroom }\end{array}$} & \multirow{3}{*}{70} & A & $24,5 \pm 1,0$ & $22,0 \pm 1,0$ & 0,12 & 0,10 \\
\hline & & B & $24,5 \pm 1,5$ & $22,0 \pm 2,0$ & 0,19 & 0,16 \\
\hline & & C & $24,5 \pm 2,5$ & $22,0 \pm 3,0$ & 0,24 & $0,21^{\mathrm{b}}$ \\
\hline \multirow[t]{3}{*}{ Kindergarten } & \multirow[t]{3}{*}{81} & A & $23,5 \pm 1,0$ & $20,0 \pm 1,0$ & 0,11 & $0,10^{b}$ \\
\hline & & B & $23,5 \pm 2,0$ & $22,0 \pm 2,5$ & 0,18 & $0,15^{b}$ \\
\hline & & $\mathrm{C}$ & $23,5 \pm 2,5$ & $22,0 \pm 3,5$ & 0,23 & $0,19^{b}$ \\
\hline \multirow[t]{3}{*}{ Department store } & \multirow[t]{3}{*}{93} & A & $23,0 \pm 1,0$ & $19,0 \pm 1,5$ & 0,16 & $0,13^{b}$ \\
\hline & & B & $23,0 \pm 2,0$ & $19,0 \pm 3,0$ & 0,20 & $0,15^{b}$ \\
\hline & & $\mathrm{C}$ & $23,0 \pm 3,0$ & $19,0 \pm 4,0$ & 0,23 & $0,18^{b}$ \\
\hline \multicolumn{7}{|c|}{$\begin{array}{l}\text { The maximum mean air velocity is based on a turbulence intensity of } 40 \% \text { and air temperature equal to the operative temperature } \\
\text { according to } 6.2 \text { and Figure A.2. A relative humidity of } 60 \% \text { and } 40 \% \text { is used for summer and winter, respectively. For both summer } \\
\text { and winter a lower temperature in the range is used to determine the maximum mean air velocity. } \\
\text { b Below } 20{ }^{\circ} \mathrm{C} \text { limit (see Figure A.2). }\end{array}$} \\
\hline
\end{tabular}

Table 10.7: Example design criteria for spaces in various types of buildings ISO-7730 (ISO, 2005)

\subsubsection{Oil-fin Heater and Humidifier}

An ultrasonic humidifier was installed and run. Ultrasonic humidifiers work by agitating the water that sat over a $\sim 1 \mathrm{MHz}$ piezo-electric speaker. The droplets formed were small and light enough to suspend in air and vaporised by absorbing ambient heat. This cold steam, and consequently an evaporative cooling effect, resulted in air temperatures dropping significantly whenever it was operated. When run in "ultrasound + heat" mode, the excellent correlation prior to the operation of the humidifier was restored (figure 11.7). 


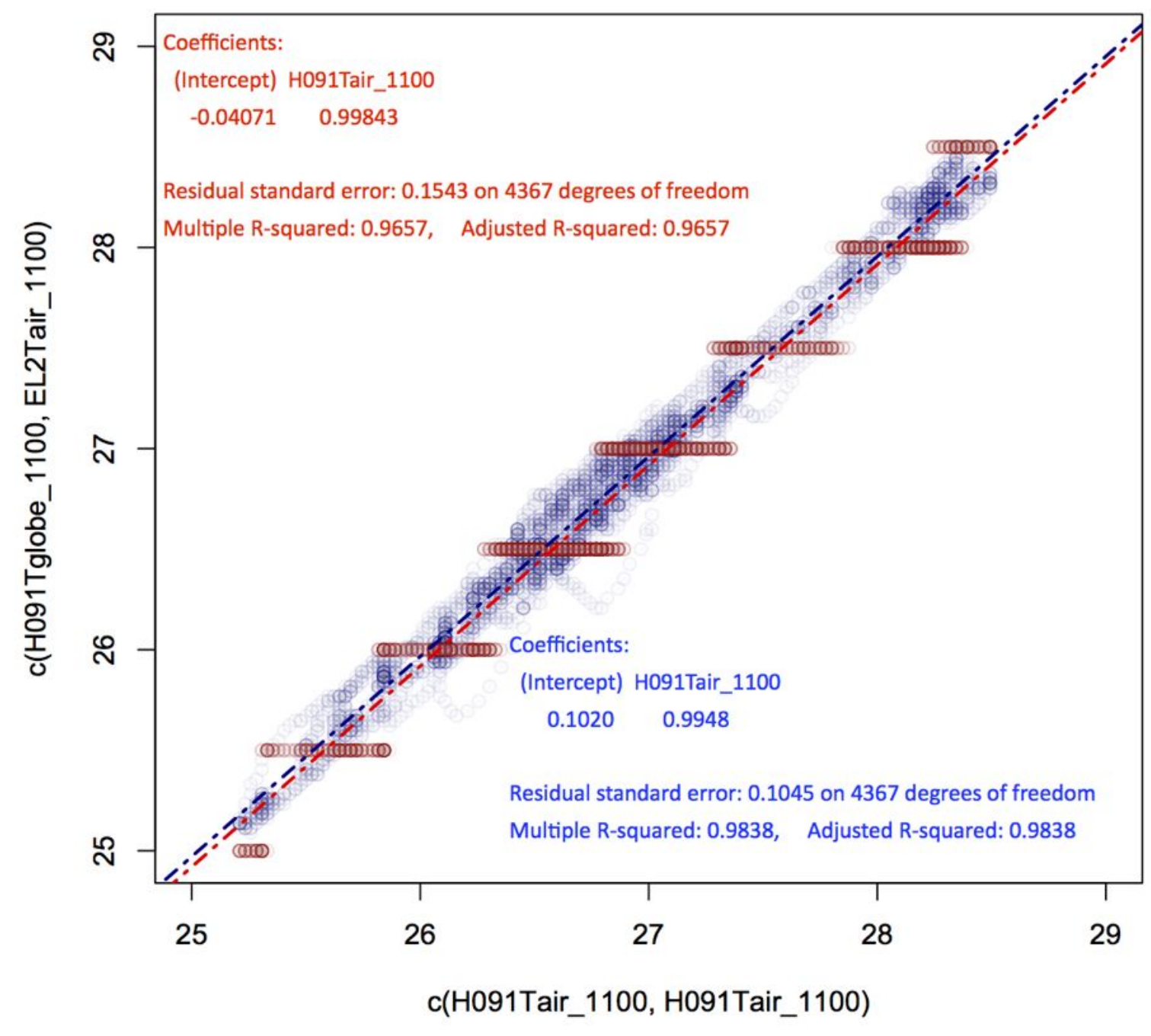

Figure 10.7: Scatterplot after humidifier installed and run at "ultrasound + heat" mode. Correlation of T-air vs T-globe (blue) and T-air vs EL2Tair (red) show a near perfect linear correlation and negligible difference in intercept and slope. For all practical purposes, the measurements of air temperature and globe temperature were interchangeable.

Having earlier established the close interchangeability of air and globe temperatures, the aim was for a smaller fluctuation of temperatures. The panel heater did not keep the temperature of the occupied area stable enough, so an oil-fin heater controlled by a digital thermostat was added. The loggers were placed at 1100mm from floor level at the precise location where participants would sit. Measurements were taken at table top (750mm) to determine if it would be a suitable proxy for the conditions experienced by the occupant and the correlation was good, $r^{2}=0.86$, intercept $=0.77$, slope $=0.98$ (figure 11.8). The weaker $r^{2}$ was due to a more compressed range of $25-28^{\circ} \mathrm{C}$ measured by digital loggers which resolved 
to $0.5^{\circ} \mathrm{C}$. Also the switching on and off of the oil-fin heater did result in time lags between the different measurements. Stratification was also observed with air T at 1100mm having a $1^{\circ} \mathrm{C}$ variance with that at $600 \mathrm{~mm}$ (figure 11.9). Air velocity was logged consistently at $0.02 \mathrm{~m} /$ s. As temperatures were maintained at $28^{\circ} \mathrm{C}$, it became less important to strive for a tight correlation.

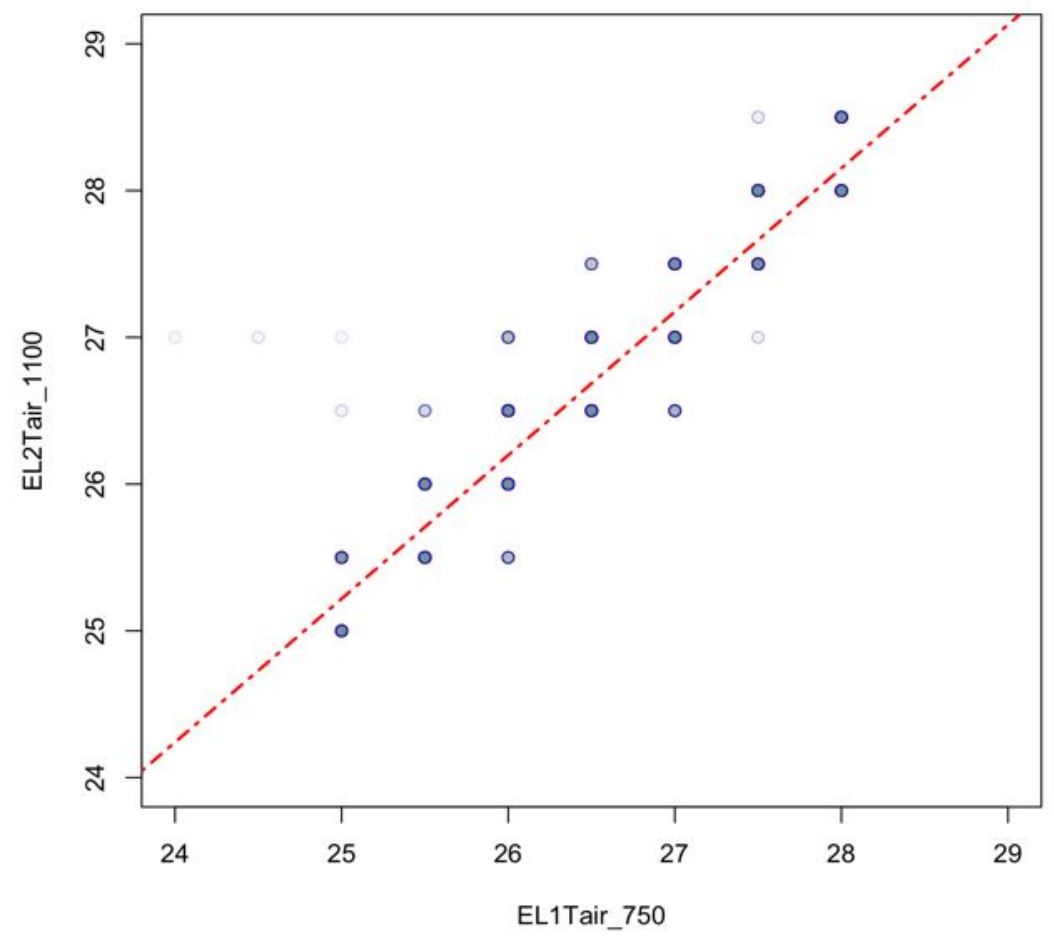

Figure 10.8: Scatterplot of high accuracy $\left( \pm 0.2^{\circ} \mathrm{C}\right)$ digital loggers at table top height $(750 \mathrm{~mm})$ and at ASHRAE recommended $1100 \mathrm{~mm}$. 


\section{Air Temperatures @1100 and @600mm}

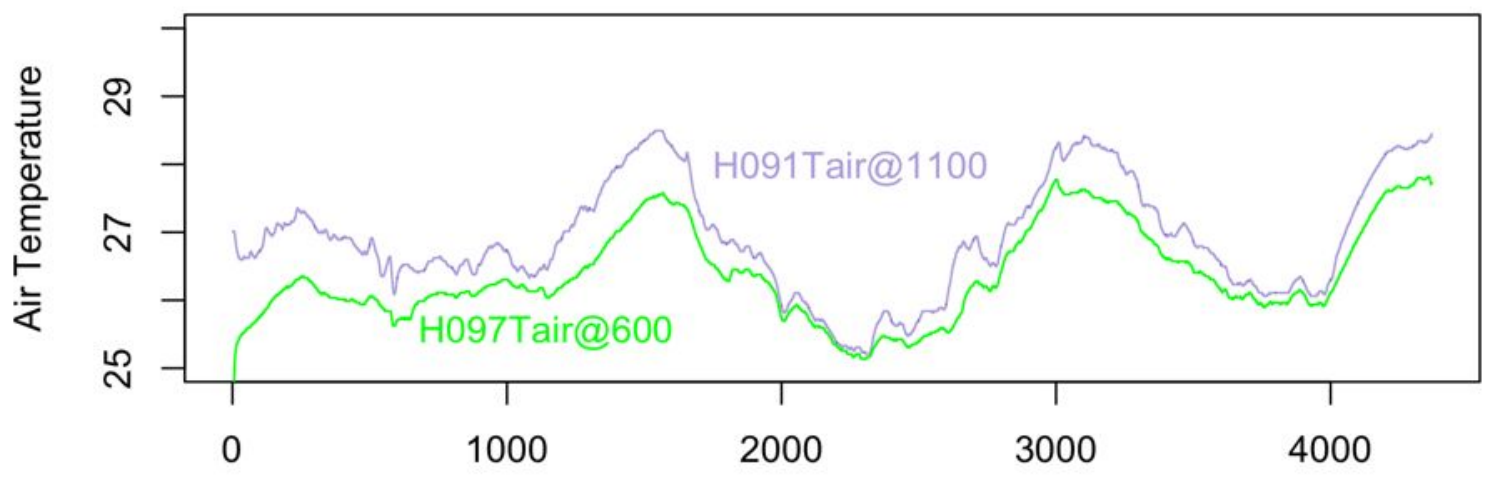

dT Air Temperatures

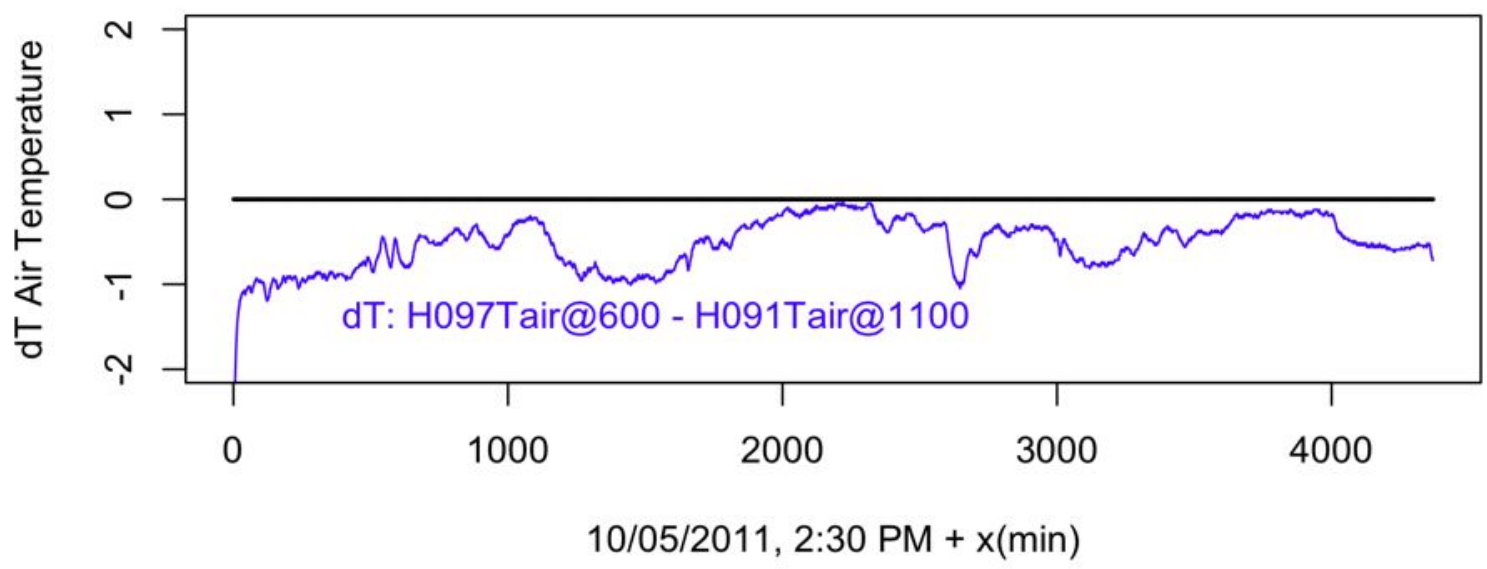

Figure 10.9: Temperature of air at different levels. The greatest $\mathrm{dT}$ corresponds to the highest temperature, indicative that air was not mixed but stratified.

\subsubsection{Selection of a suitable proxy}

A tower was used to mount the loggers at the heights $0.1 \mathrm{~m} 0.6 \mathrm{~m}$ and $1.1 \mathrm{~m}$. Placed at the location where participants were expected to sit it was set to log over a few days with heaters, humidifiers and oil-fin heater on. 


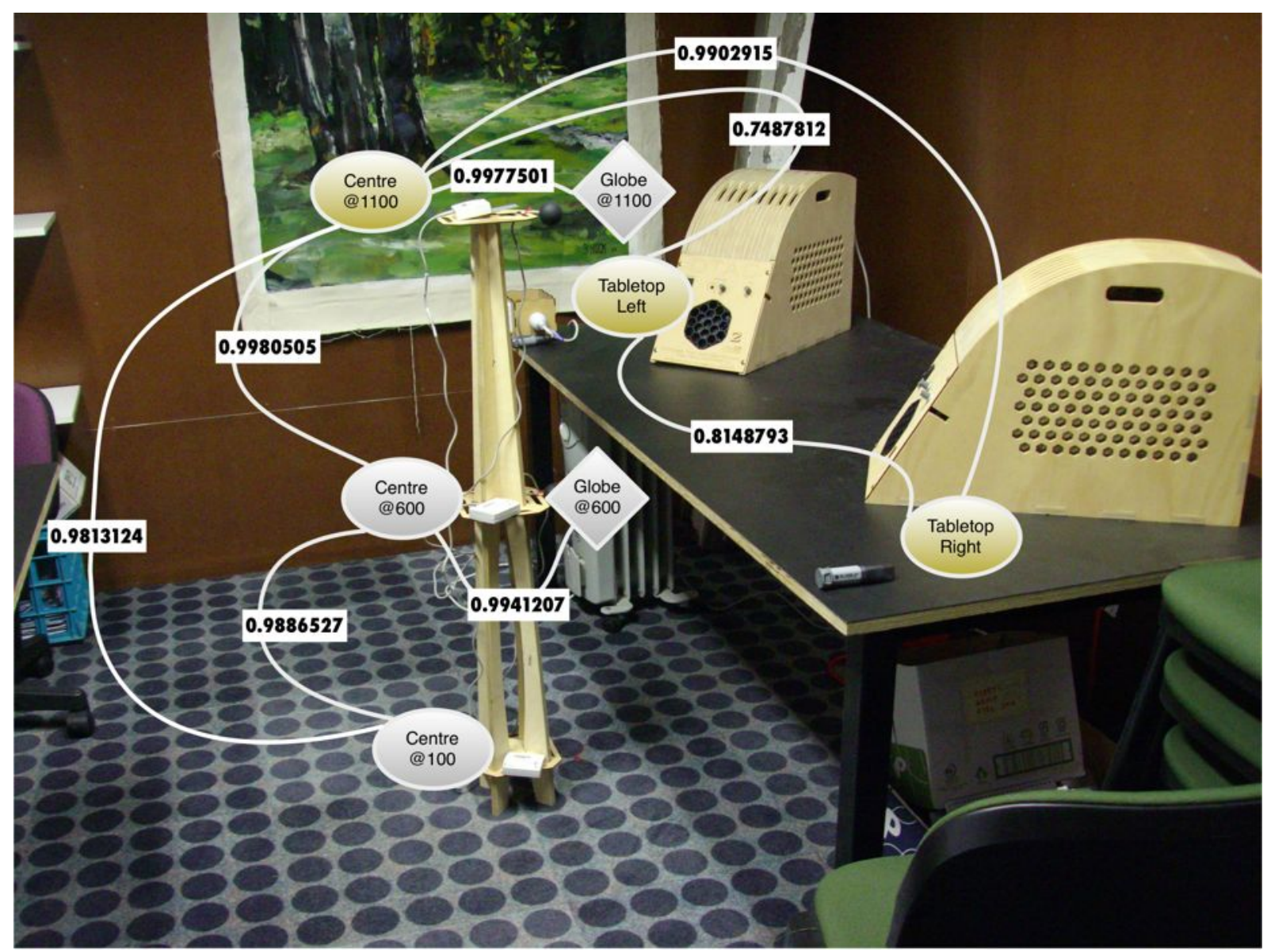

Figure 10.10: $\mathrm{r}^{2}$ of different positions compared primarily with centre of table air $\mathrm{T}$ at $1100 \mathrm{~mm}$.

By comparing the linear correlations of the temperature logs, it was found that the readings on the tower, including air and globe temperatures, all had a very strong correlation ( $\mathrm{r}$-sq > 0.98). Making it possible to extrapolate the other readings with a single record of temperature, proposed to be the air temperature at $1.1 \mathrm{~m}$ being the most representative of the occupant's head. 


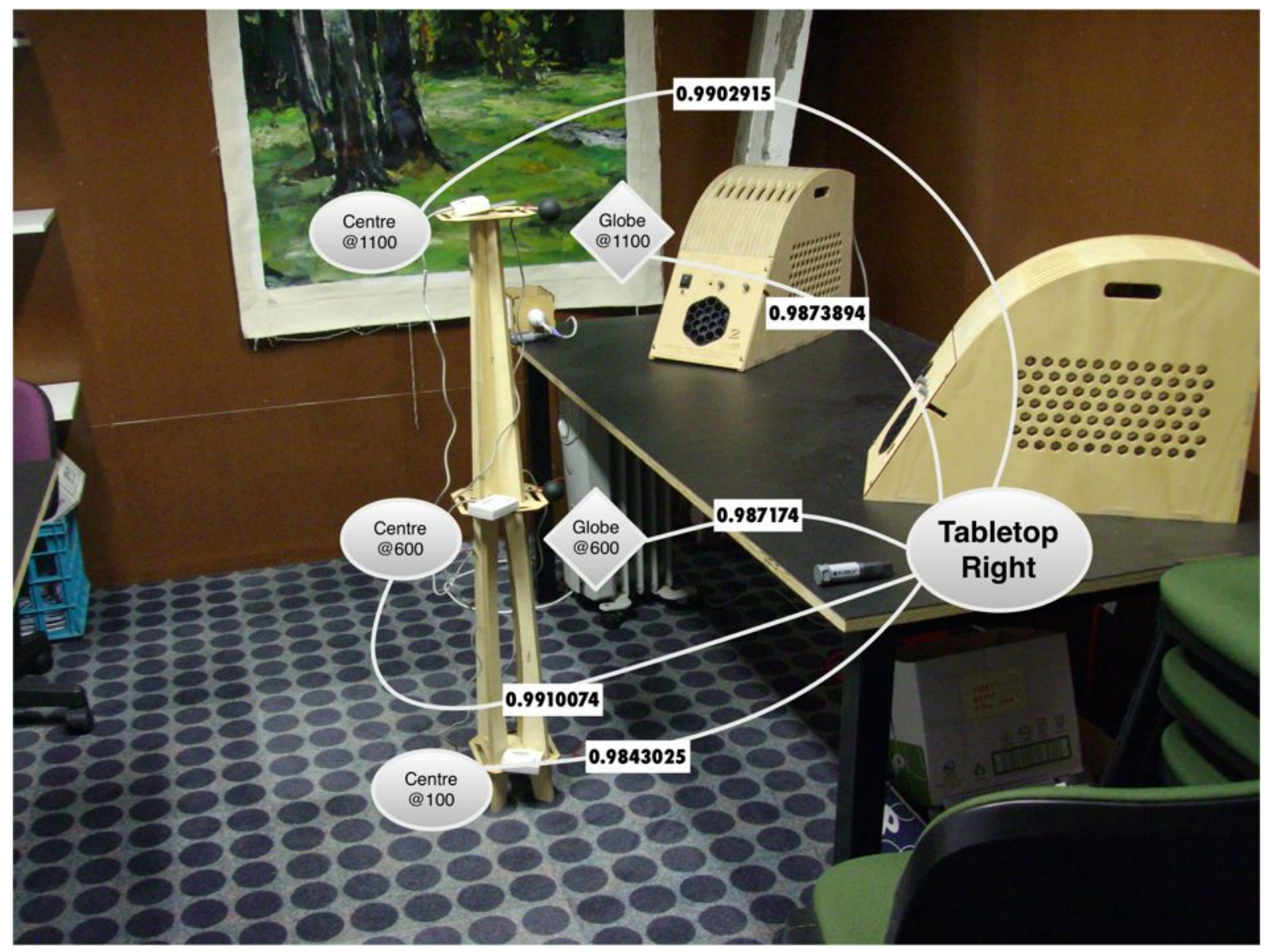

Figure 10.11: $\mathrm{r}^{2}$ of different positions compared to tabletop right

At the same time loggers placed on either side of the table were also run to determine which would be a suitable proxy. The left side of the table top was nearer the oil-fin heater and naturally had a weaker correlation with the rest (figure 11.10). Having found that the one on the tabletop right had a much closer relationship with T(air@1.1m), a check was done with all readings on the tower to verify that the linear correlation was very strong ( $r$ sq $>0.98$, figure 11.11). With the linear relationships established, we could extrapolate all the temperatures with one measurement if needed.

\subsubsection{Sample size}

12 volunteer students were deemed to be sufficient for the CC trial. A total of 17 volunteers signed up. With more than the required number, after the first 12 had completed the trial, subsequent volunteers were not informed (single-blind) that the power supply unit had been disconnected from the TE modules, making the DTAC effectively a fan-only system. However a total of only 14 eventually participated (12 using DTAC, 2 fan-only) as a number of students had taken ill and were advised not to participate. 


\subsubsection{Productivity indexing}

In Chapter 3 (thread 8) we saw how the means of measuring productivity remained highly disputed. In studies with objective measures of productivity, a battery of test include a mix of typing, arithmetic (or Sudoku), learning and memory. However, in the case of students at the School of Architecture and Design, it was deemed that these tests would not be reflective of their strengths or inclinations. Instead, they were put through a design challenge for a task I felt was achievable within the three-hour period planned. The assessment rubric was available to participants so that they knew the largest portion of marks went into the design resolution which typically was the most time-consuming process. This would encourage those that finished early to keep working for the whole duration. They were also told that the winner of the design challenge, as determined by staff judges of the School, would receive a new Apple iPad2.

Being a design challenge, the aim was not to measure productivity directly but to make a reasoned assumption that participants were both highly challenged and highly motivated. This was predicated on providing the participants with an achievable task, a pressure to complete it on time (neither early nor late) and an attractive incentive.

\subsubsection{Time of experiment}

The experiment was conducted at the same time each day, from $1 \mathrm{pm}$ to $4 \mathrm{pm}$. This would minimise variations in the room temperature, which was connected to the central heater and, from earlier climate chamber measurements, had shown a climb from 7am-9am and drop from 6pm-7am. The effect of circadian rhythm, known to cause metabolism to fluctuate through a 24-hour cycle (Ladou, 1982; Zhang, 2003) would also be minimised.

\subsubsection{Participants}

Participants were volunteers from the first year cohort of the Building Technology and Design course for which I was a tutor. They had recently completed their first semester which introduced them to the concept of climate responsiveness in buildings, heat balance and thermal comfort. Having themselves completed graded assignments on evaluating thermal comfort of buildings they were deemed to be relatively astute to the parameters used to evaluate thermal comfort. 
Participants were told to abstain from the field trial if they were not feeling well. Running a fever, for example, would have greatly increased their metabolism (Sapolsky, 1990). They were also discouraged from listening to music or consuming caffeinated drinks during the experiment. After each survey, scheduled every 30 minutes, they were to have a stretch break and walk around the room for 1-2 minutes. A 3-axis accelerometer was strapped to their waist and logged at $0.1 \mathrm{sec}$ intervals.

To keep the conditions of the room constant they were encouraged to use the washroom prior to the experiment and not leave the climate chamber during the experiment.

\subsubsection{The Design Challenge}

Participants were each provided an A3 sheet with complete instructions and space for their design (figure 11.12). Unlimited rough paper was provided for sketches which were not judged.

As first year students, they could possess a large deviation in graphical abilities and the design challenge had to underrate this aspect so that they were focussed on the intellectual part of the challenge: to think laterally and cyclically. No internet research was allowed during the challenge. A parental filter was installed on the web browser to limit access to only the websites associated with the experiment.

Reference numbers (CC-01 to CC-14) were used as pseudonyms instead of names so as not to bias the judging process. Only the researcher knew the identities and was not involved in judging.

Participants were briefed that penalties will be imposed for any failure to fill up their thermal survey vote completely and punctually as this would have undermined the purpose of the experiment. 


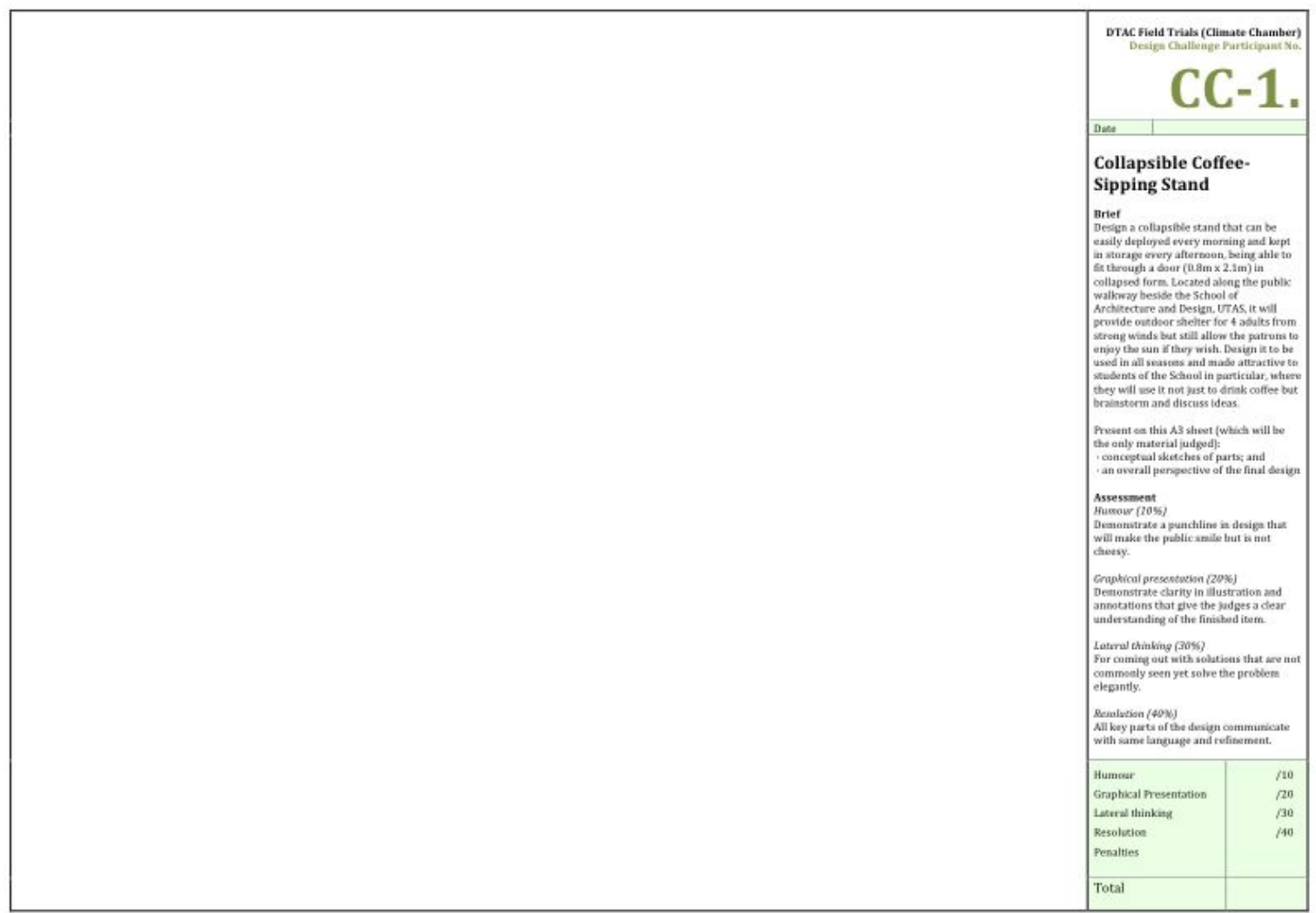

Figure 10.12: Design challenge $A_{3}$ sheet with reference number, brief and rubric.

\section{The following brief was provided:}

Design a collapsible stand that can be easily deployed every morning and kept in storage every afternoon, being able to fit through a door $(0.8 \mathrm{~m} \times 2.1 \mathrm{~m})$ in collapsed form. Located along the public walkway beside the School of Architecture and Design, UTAS, it will provide outdoor shelter for 4 adults from strong winds but still allow the patrons to enjoy the sun if they wish. Design it to be used in all seasons and made attractive to students of the School in particular, where they will use it not just to drink coffee but to brainstorm and discuss ideas.

Present on this A3 sheet (which will be the only material judged):

- conceptual sketches of parts; and

- an overall perspective of the final design

\section{The challenge was scored on the following rubric:}

Humour (10\%) Demonstrate a punchline in design that will make the public smile but is not cheesy.

Graphical presentation (20\%) Demonstrate clarity in illustration and annotations that give the judges a clear understanding of the finished item. 
Lateral thinking (30\%) For coming out with solutions that are not commonly seen yet solve the problem elegantly.

Resolution (40\%) All key parts of the design communicate with same language and refinement.

10.3.11 Schedule

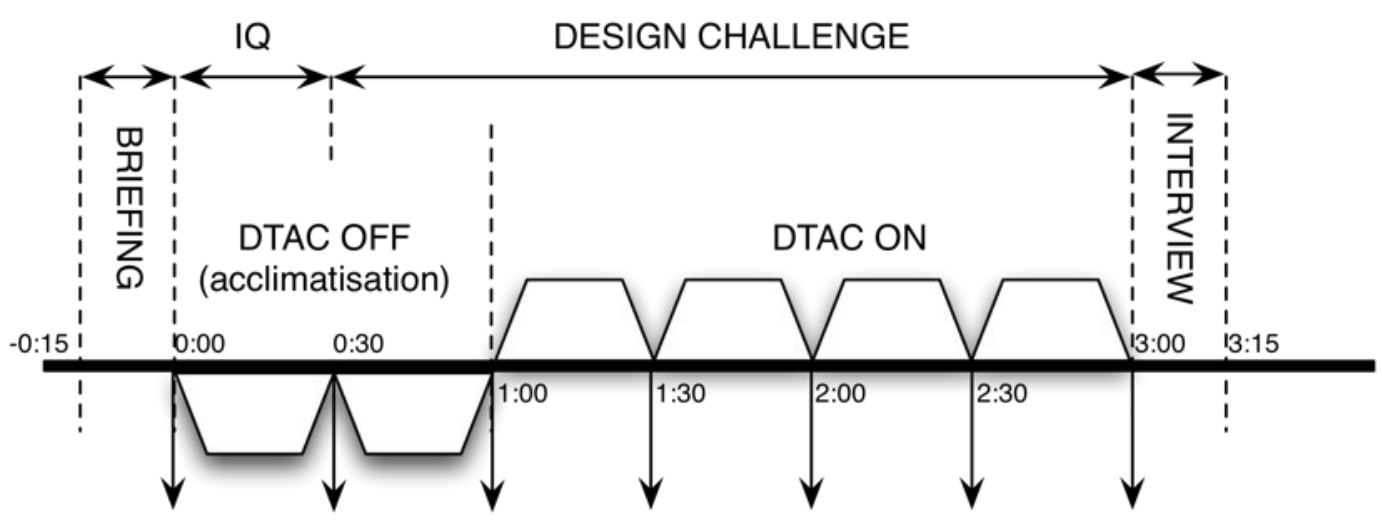

HALF-HOURLY SURVEY: THERMAL COMFORT, FATIGUE, SLEEPINESS, VIGILANCE TEST

Figure 10.13: Structure of three-hour climate controlled field trial

The experiment (figure 11.13) consisted of an initial briefing to check their state of health, and ensure that their meals were taken and that they had visited the washroom. The design challenge was left on the table face down.

The researcher would guide them through the first survey and answer any questions. He would then leave the room and they would commence on the IQ test for about 20-25min. After another survey they would commence on the design challenge. An announcement on the computer would remind them to fill up the survey every 30 minutes.

\subsubsection{IQ/Memory Test}

Participants would spend about 20-25min in a memory and intelligence test designed by Robert Lodgie from the University of Edinburgh (BBC, web page no longer available, figure 11.14). The test was engaging and would initiate the participants into an aroused mental state for the design challenge. Expecting that some participants might have come for the challenge all psyched up (as they would for an examination), the test was also intended to take their minds off from the design challenge as a stressful and examination-like procedure, and more like an activity that would be representative of a creative workplace. 


\section{$B|B| C_{\text {Home }}$}

13 October 2011 Accessibility help Text only

BBC Homepage

Science \& Nature Homepage

In Human Body \& Mind:

The mind

Psychology - an

overview

Personality and

individuality

Emotions and

instincts

Brain

Intelligence and

memory

Mental disorders

The body

Brain Sex

Sleep

Contact Us

Like this page?

Send it to a friend!

\section{Science: Human Body \& Mind}

\begin{tabular}{|c|c|c|c|c|}
\hline Nature & Wildilfe Finder & Science & Prehistoric Life & Human Body \& Mind \\
\hline
\end{tabular}

\section{Explore your memory}

Stretch your memory with fun challenges designed by experts. Your answers will help University of Edinburgh experimental psychologists with their research.

Most people will not be able to get everything right. People with normal memories can have low scores.

Duration: about 20 minutes

\section{Click here to start the test}

Professor Robert Logie of the University of Edinburgh helped design this test.

Please note, you will need Flash 7. See below for more details. Explore your Memory gives you feedback which is for demonstration purposes only and cannot diagnose memory disorders.

\begin{tabular}{|l|}
\hline Related Links \\
\hline BBC Science \\
Related articles \\
Explore your Memory \\
Sniffing the Decades \\
What Thinker are You? \\
Q\&A: Memory \\
Power of Omega Oils \\
Diary of a Memory \\
Champion \\
Nostalgic smells \\
The Human Mind \\
Psychology \\
Personality \& Individuality \\
Brain \\
Intelligence \& Memory \\
Mental disorders \\
The Human Body \\
Organs \\
Muscles \\
Skeleton \\
Nervous System \\
Puhertv
\end{tabular}

Figure 10.14: Memory challenge (webpage no longer available, previously http://www.bbc.co.uk/science/humanbody/mind/surveys/memory)

\subsubsection{Survey questions}

Thermal Sensation : 7-point scale based on studies in deterministic thermal comfort from Fanger's PMV as adopted by ISO 7730 (ISO, 2005) and ASHRAE 55 Standard (ASHRAE, 2004, table 11.8)

\begin{tabular}{|c|l|}
\hline \multicolumn{2}{|c|}{ Thermal sensation scale } \\
\hline 3 & Hot \\
\hline 2 & Warm \\
\hline 1 & Slightly Warm \\
\hline 0 & Neutral \\
\hline-1 & Slightly Cool \\
\hline-2 & Cool \\
\hline-3 & Cold \\
\hline
\end{tabular}

Table 10.8: Thermal sensation scale

Thermal Comfort: 6-point scale based on Schiller's work (Schiller ,1990, table 11.9). An important contribution of her work was the observation that a neutral sensation did not 
necessarily equate to being the most comfortable. She measured an optimum temperature which was $2.3^{\circ} \mathrm{C}$ cooler than the predicted neutral temperature (at PPD $=5 \%$ ).

\begin{tabular}{|c|l|}
\hline \multicolumn{2}{|c|}{ Thermal comfort scale } \\
\hline 6 & Very comfortable \\
\hline 5 & moderately comfortable \\
\hline 4 & slightly comfortable \\
\hline 3 & slightly uncomfortable \\
\hline 2 & moderately uncomfortable \\
\hline 1 & very uncomfortable \\
\hline
\end{tabular}

Table 10.9: Thermal comfort scale

General Comfort: 7-point scale based on Bedford Scale (Bedford, 1936, table 11.10) which is adopted in a number of adaptive thermal comfort studies.

\begin{tabular}{|c|l|}
\hline \multicolumn{2}{|c|}{ General comfort scale } \\
\hline 7 & Much too warm \\
\hline 6 & Too warm \\
\hline 5 & Comfortably warm \\
\hline 4 & Comfortable and neither cool nor warm \\
\hline 3 & Comfortably cool \\
\hline 2 & Too cool \\
\hline 1 & Much too cool \\
\hline
\end{tabular}

Table 10.10: General comfort scale

Karolinska Sleepiness Scale (KSS): 9-point scale in table 11.11.

\begin{tabular}{|c|l|}
\hline \multicolumn{2}{|l|}{ Karolinska Sleepiness Scale } \\
\hline 1 & extremely alert \\
\hline 2 & very alert \\
\hline 3 & alert \\
\hline 4 & rather alert \\
\hline 5 & neither alert nor sleepy \\
\hline 6 & some signs of sleepiness \\
\hline 7 & sleepy, but no effort to keep awake \\
\hline 8 & sleepy, some effort to keep awake \\
\hline 9 & extremely sleepy-fighting sleep \\
\hline
\end{tabular}

Table 10.11: Karolinska Sleepiness Scale 
Fatigue scale: 30-point scale (table 11.12) covering three categories of subjective symptoms with a pattern of fatigue suggested by Yoshitake (1973) (in Tanabe, 2004). With the following patterns of classification:

- General pattern of fatigue: $1>3>2$

- Typical pattern of fatigue for mental work and overnight duty: $1>2>3$

- Typical pattern of physical work: $3>1>2$

\begin{tabular}{|l|l|l|}
\hline \multicolumn{3}{|c|}{ Three categories of subjective symptoms of fatigue } \\
\hline \multicolumn{1}{|c|}{ Category 1 } & \multicolumn{1}{|c|}{ Category 2 } & \multicolumn{1}{c|}{ Category 3 } \\
\hline My head is drooping & I can't think clearly & I have a headache \\
\hline My whole body is getting tired & Talking would take some effort & My shoulder muscles are tense \\
\hline My legs are getting tired & I am starting to feel nervous & My back hurts \\
\hline I can't stop yawning & I can't concentrate & Breathing takes an effort \\
\hline My mind is blank & I am losing interest in my work & I feel thirsty \\
\hline I am starting to feel drowsy & I am starting to forget things & My voice is probably hoarse \\
\hline My eyes are getting tired & I am uncertain & I feel giddy \\
\hline I feel stiff and clumsy & I am worried & The small muscles around my eyes are twitching \\
\hline I would be unsteady on my feet & I am sitting badly & My limbs are shaking \\
\hline I feel like lying down & I feel impatient & I feel unwell \\
\hline
\end{tabular}

Table 10.12: Fatigue scale

\subsection{Field trial results}

Due to the large number of results, the discussion is not presented as a separate section but follows immediately after each test result. 


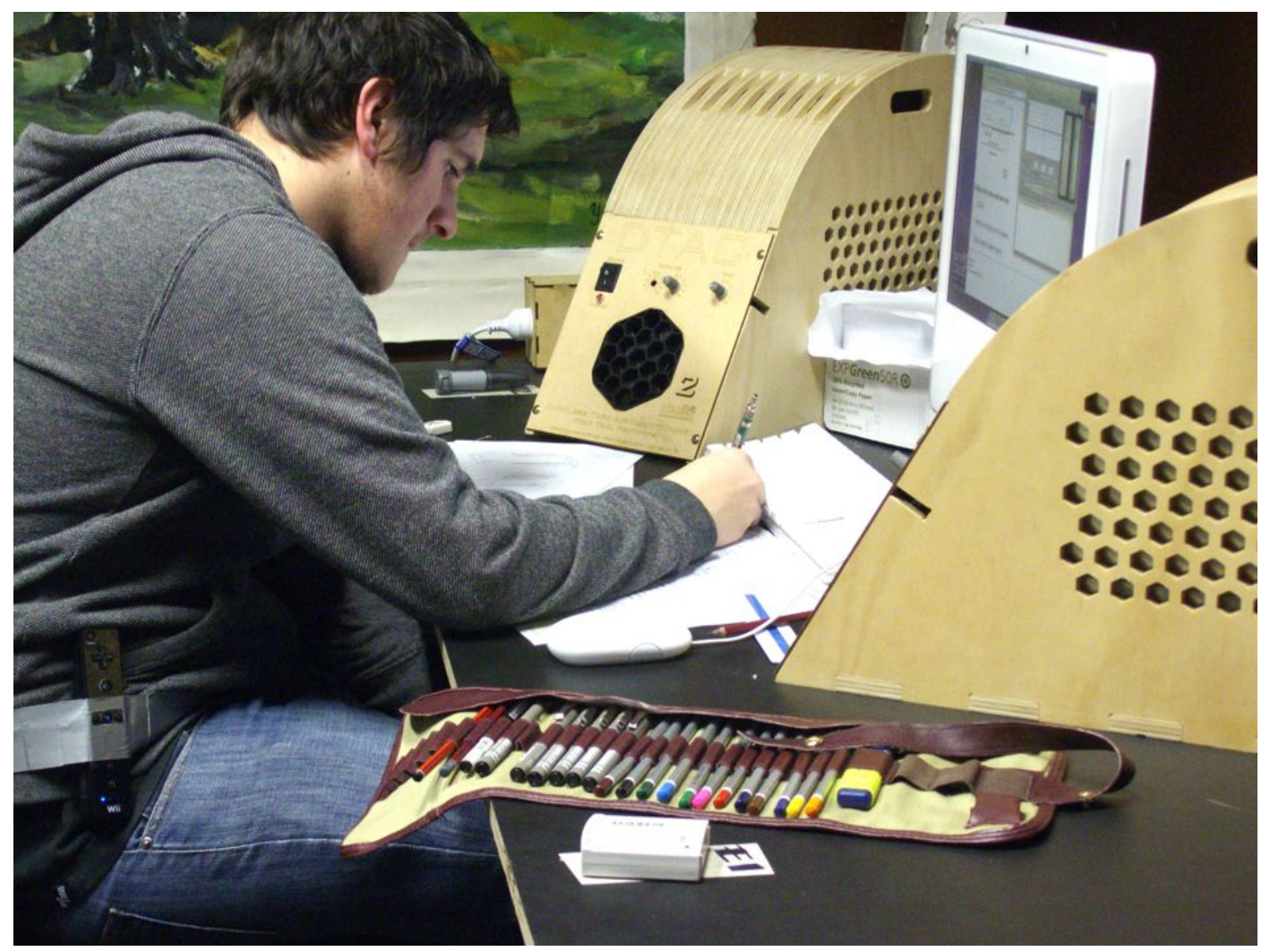

Figure 10.15: One of the field trial participants during the design challenge.

Of the 12 volunteers that tested the DTAC, one responded as "hot", "very uncomfortable" and "much too warm" for all entries. As his responses were markedly distinct even from the outliers in the data pool, he was excluded after I consulted with a statistician from the School of Mathematics \& Physics. The remaining 11 participants ( 7 male, 4 female, average age 23.5 $\pm 7.3 y r$ ) were asked, at the end of the trial, what settings they ran DTAC on and how they found the design challenge (table 11.8). 


\begin{tabular}{|l|c|c|}
\hline \multicolumn{1}{|c|}{ Enquiry } & $\begin{array}{c}\text { Mean } \\
\text { (on scale of 0 to 10) }\end{array}$ & s.d. \\
\hline \multicolumn{2}{|c|}{ Typical DTAC setting } & \pm 4.1 \\
\hline Left fan & 4.7 & \pm 3.8 \\
\hline Left cooling & 5.6 & \pm 3.6 \\
\hline Right fan & 4.2 & \pm 3.8 \\
\hline Right cooling & 7.3 & \pm 1.4 \\
\hline \multicolumn{3}{|c|}{} \\
\hline How challenging did you find the task, where 5=typical day \\
\hline Mental load & 5.9 & \pm 1.4 \\
\hline Stress level & 2.5 & \pm 1.6 \\
\hline Difficulties of task & 6.1 & \pm 1.8 \\
\hline Motivational level & 7.8 & \pm 1.5 \\
\hline Enjoyability of task & 8.4 & \\
\hline
\end{tabular}

Table 10.13: Feedback on the use of DTAC and opinion of the challenge

On a subjective level there was little difference in attitude to the design challenge amongst participants. The general sentiment was that the challenge was engaging, set at the appropriate difficulty and within a reasonable time frame. Participants thus found themselves highly motivated and the task very enjoyable (possibly even too enjoyable). The design challenge however did not adequately replicate the stressfulness of a working environment with a low self-evaluated stress score, this is something worth improving in future experiments.

In contrast, the operational settings showed high variability in preferred setting. The fan speed was typically operated in the middle range and support the applicability of computer fans for task cooling in Schivaon's (2009) thesis. The high cooling setting of the units, particularly the one on the right, is indicative that participants found the units underpowered. There was a general preference to control the unit on the right side possibly due to all participants being right-handed, but one wonders if it could also relate to the task being concentrated on right-brain creativity.

The thermal comfort and sleepiness responses have been summarised in the following plots (generated in the statistical software R) with the following symbols (table 11.14). 


\begin{tabular}{|c|l|l|}
\hline Box-plot & median & bold blue line \\
\hline & 25th and 75th percentile & boxed \\
\hline Line-plot & mean & red dot \\
\hline & \pm standard deviation (s.d.) & dotted red line \\
\hline
\end{tabular}

Table 10.14: Key to plots

\section{Thermal Sensation}

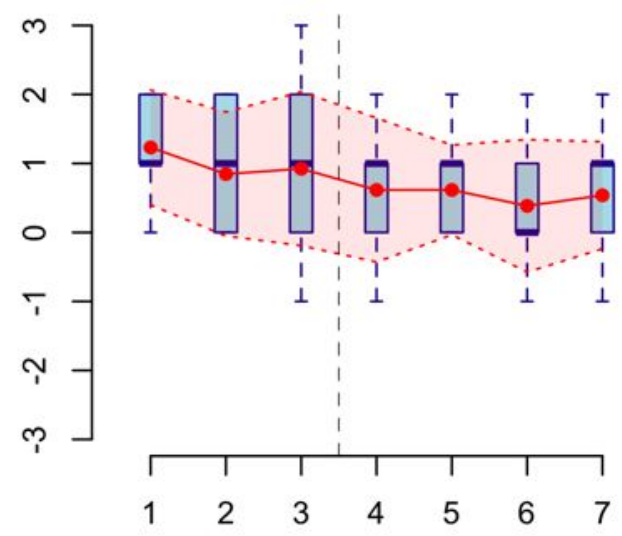

General Comfort

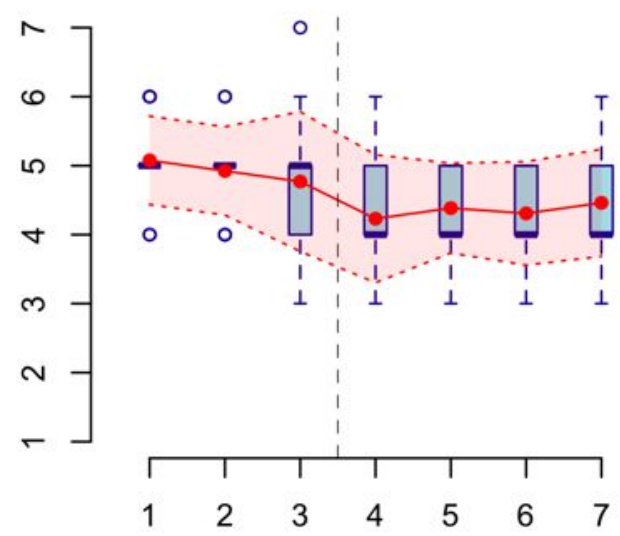

Thermal Comfort

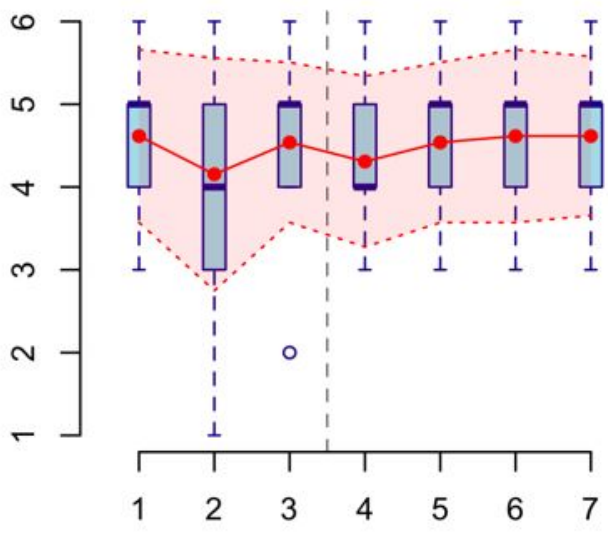

KSS

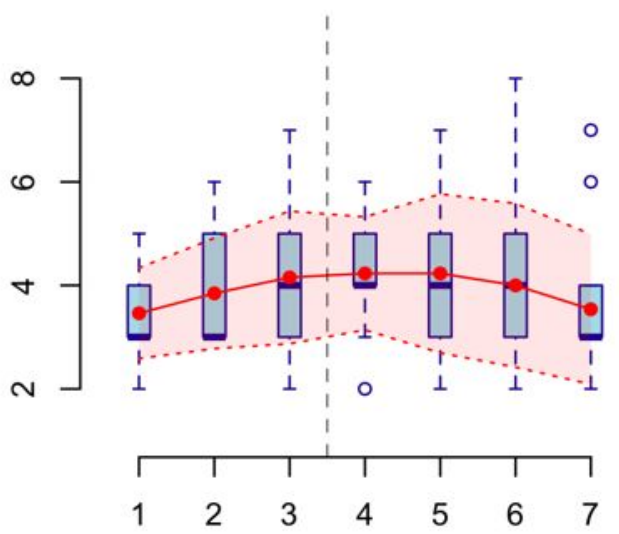

Figure 10.16: Overview of survey responses $(n=11)$. Vertical scale are cumulative responses, horizontal scale are feedback rounds every 30 minutes.

Each of the responses are studied statistically in further detail with the rationale shown in table 11.15. 


\begin{tabular}{|c|l|}
\hline \multicolumn{2}{|c|}{ Analysis } \\
\hline $\begin{array}{c}\text { mean before } \\
\text { DTAC }\end{array}$ & mean of all votes before DTAC used (feedback rounds 1 to 3) \\
\hline $\begin{array}{c}\text { mean after } \\
\text { DTAC }\end{array}$ & mean of all votes after DTAC used (feedback rounds 4 to 7) \\
\hline Delta AMV & difference = after - before \\
\hline $\begin{array}{c}\text { just before } \\
\text { DTAC }\end{array}$ & mean of votes in feedback round 3 \\
\hline $\begin{array}{c}\text { just after } \\
\text { DTAC }\end{array}$ & mean of votes in feedback round 4 \\
\hline delta & difference = just after - just before \\
\hline s.d. & standard deviation of all rounds \\
\hline$\sigma$ & standard deviation of the sample means (all rounds) \\
\hline p (rd 3:5) & $\begin{array}{l}\text { p-value of t-test between feedback of round 3 and round 5, where occupant has acclimatised 1 hr to chamber, and 1 } \\
\text { hr to DTAC respectively }\end{array}$ \\
\hline
\end{tabular}

Table 10.15: Rationale for statistical tests used.

\subsection{Statistical significance}

The results of the climate chamber trials were analysed statistically to answer the following considerations:

1. Determine if the $\delta$, the change in vote (before and after DTAC usage), is of significant magnitude compared to the $\sigma$, the standard deviation of the sample means.

2. Determine if the change in vote is indicative of a trend by a paired t-test with a $\mathrm{p}<0.05$.

3. Quantify the improvements by determining a threshold criteria and the percentages that fell within the criteria before and after DTAC usage.

The first two considerations are summarised in this section. The third is expanded with details of each survey.

The $\sigma$ helps ascertains if the movement has any significance above the 'noise' level. A $\delta$ value greater in magnitude than $\sigma$-vlaue would be indicative of a statistically significant movement (table 11.16). 


\begin{tabular}{|c|c|c|c|l|l|}
\hline Test & $\sigma$ & $\begin{array}{c}\delta \\
(m e a n)\end{array}$ & $\begin{array}{c}\delta \\
\text { (just) }\end{array}$ & \multicolumn{1}{|c|}{ Significance } & \multicolumn{1}{|c|}{ Change in vote after DTAC use } \\
\hline $\begin{array}{c}\text { Thermal } \\
\text { sensation }\end{array}$ & 0.30 & -0.50 & -0.27 & Significant & From feeling slightly warm toward feeling neutral \\
\hline Thermal comfort & 0.35 & -0.05 & -0.27 & Almost significant & Less comfortable \\
\hline General comfort & 0.24 & -0.61 & -0.45 & Significant & $\begin{array}{l}\text { From comfortably warm towards comfortably } \\
\text { neutral }\end{array}$ \\
\hline KSS & 0.37 & 0.00 & 0.09 & Not significant & More sleepy \\
\hline
\end{tabular}

Table 10.16: Significance in change in vote after operating DTAC

Where:

\begin{tabular}{|c|l|}
\hline$\sigma$ & standard deviation of the sample means, $\sigma=\mathrm{SD} / \sqrt{\mathrm{n}}$ \\
\hline$\delta$ (mean) & difference in vote between average before and average after DTAC switched on \\
\hline$\delta$ (just) & difference in vote between just before and just after DTAC switched on \\
\hline
\end{tabular}

Using a criteria of $\mathrm{p}<0.05$, the paired T-test showed that the results had little statistical significance (table 11.17), except for the General Comfort when participants were exposed to either condition for $0.5 \mathrm{hr}(\mathrm{p}=0.05)$. The population sample is an acknowledged weakness in this study and a p-value $<0.05$ was difficult to achieve with 11 participants.

\begin{tabular}{|c|c|c|}
\hline Test & $p(r d 2: 4)$ & $p(r d ~ 3: 5)$ \\
\hline Thermal sensation & 0.62 & 0.21 \\
\hline Thermal comfort & 1.00 & 0.85 \\
\hline General comfort & 0.05 & 0.14 \\
\hline KSS & 0.56 & 0.89 \\
\hline
\end{tabular}

Table 10.17: One-tail T-test results before and after using DTAC

Where:

\begin{tabular}{|c|l|}
\hline$P$ & P-value \\
\hline rd & feedback round in survey \\
\hline 2 & survey at 0.5hr (DTAC off) \\
\hline 3 & survey at 1.0hr (DTAC off) \\
\hline 4 & survey at 1.5hr (DTAC on for 0.5hr) \\
\hline 5 & survey at 2.0hr (DTAC on for 1.0hr) \\
\hline rd 2:4 & comparing 0.5hr in climate chamber vs 0.5hr use of DTAC \\
\hline rd 3:5 & comparing $1 \mathrm{hr}$ in climate chamber vs 1.0hr use of DTAC \\
\hline
\end{tabular}




\subsubsection{Thermal Sensation (ASHRAE Scale)}

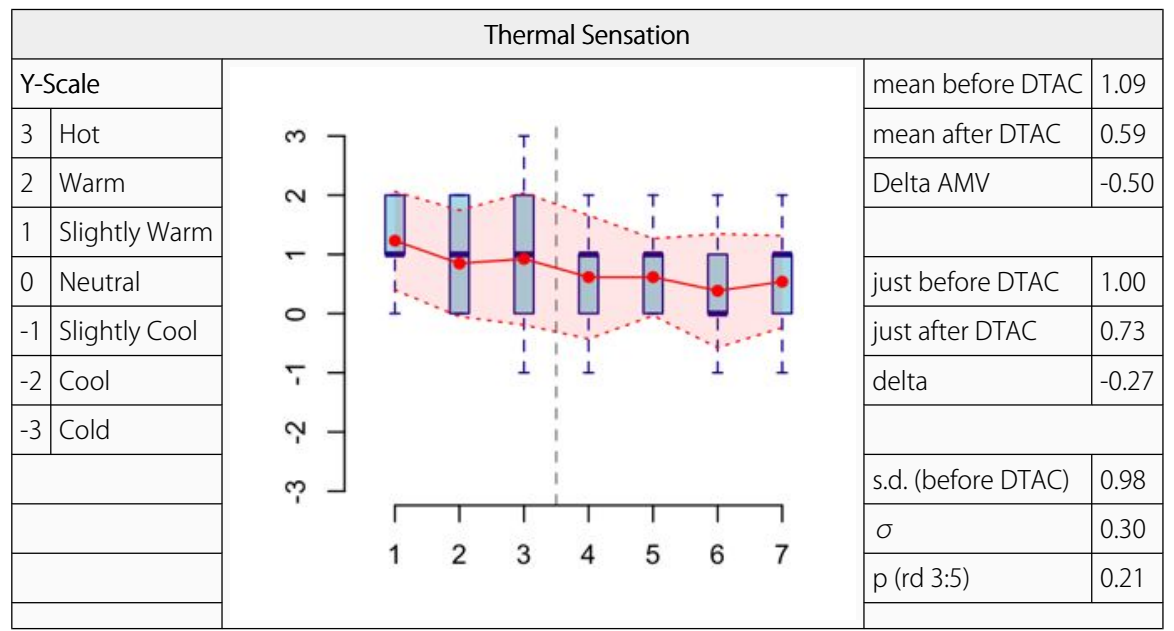

Table 10.18: Thermal sensation response to use of DTAC in climate chamber

After DTAC was switched on there was an overall move of 0.5 vote towards a sensation of thermal neutrality (0-value). Based on an acceptable threshold of \pm 1 (slightly warm, neutral, slightly cool) the thermal acceptability by $58 \%$ of the participants before DTAC was improved to $84 \%$ after that.

\subsubsection{Thermal Sensation, Normalised}

The data was further refined by accounting for variations in clothing insulation. At the end of the experiment, participants had been interviewed on their clothing at the start and end, and at which point they had made the change. The clothing ensemble was converted to clo insulation values using the ASHRAE 55 standard, with the average determined to be 0.694 clo. Based on the following variables (table 11.19), the PMV was determined to be 1.1.

\begin{tabular}{|l|l|}
\hline Clothing (clo) & 0.7 \\
\hline Air temp. $\left({ }^{\circ} \mathrm{C}\right)$ & 28 \\
\hline Mean radiant temp. $\left({ }^{\circ} \mathrm{C}\right)$ & 28 \\
\hline Activity (met) & 1.1 \\
\hline Air speed $(\mathrm{m} / \mathrm{s})$ & 0.05 \\
\hline Relative humidity $(\%)$ & 40 \\
\hline
\end{tabular}

Table 10.19: Conditions that yield a $P M V=1.1$

With PMV=1.1 as a baseline $\left(P M V_{0}\right)$, and a PMV based on actual observed clothing $\left(P M V_{1}\right)$ a correction factor was determined as follows: 


$$
\triangle P M V=P M V_{1}-P M V_{0}
$$

The actual votes were passed through this correction factor to yield a normalised thermal sensation vote, plotted in figure 11.17.

$$
\text { Vote }_{T S \text { corrected for clo }}=A M V+\triangle P M V
$$

\section{Thermal Sensation}

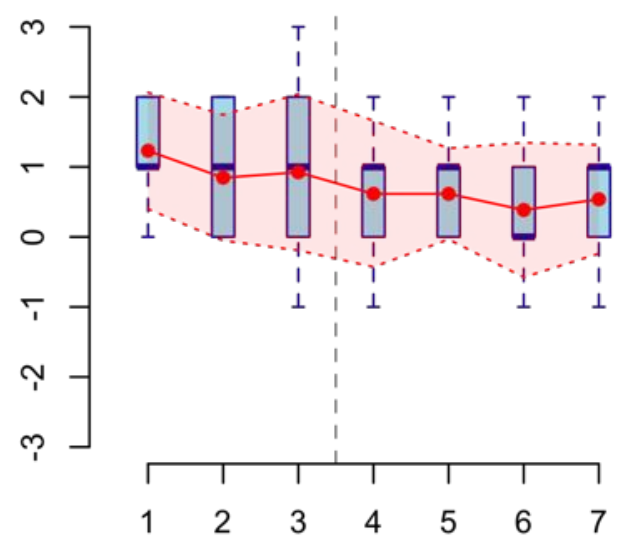

Thermal Sensation, corrected for clo

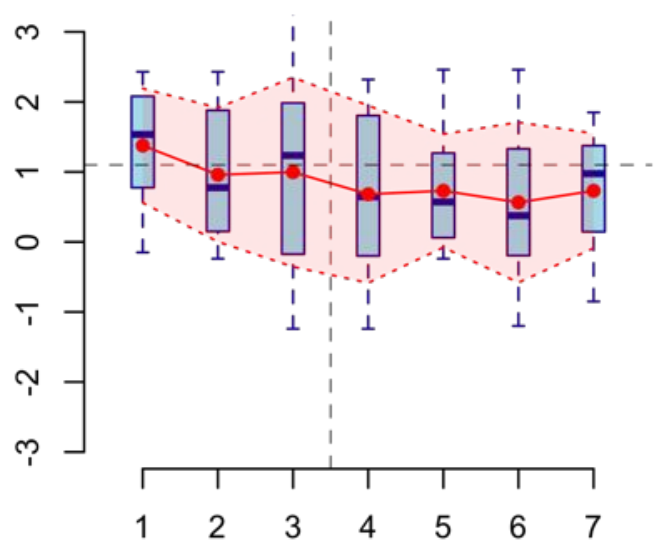

Figure 10.17: Thermal sensation before and after correction for clo variation

Before DTAC was switched on, the AMV of 1.17 (average of first hour) and 1.11 (just prior to DTAC use), which was in excellent agreement with what was predicted by Fanger's model of $\mathrm{PMV}=1.1$. This provides further evidence of the viability of the selected room as a climate chamber and accuracy of the experiment. Furthermore, it was also reasonable to assume that one hour was sufficient for the participants to acclimatise to the climate chamber conditions even though the experiment was conducted during winter. 


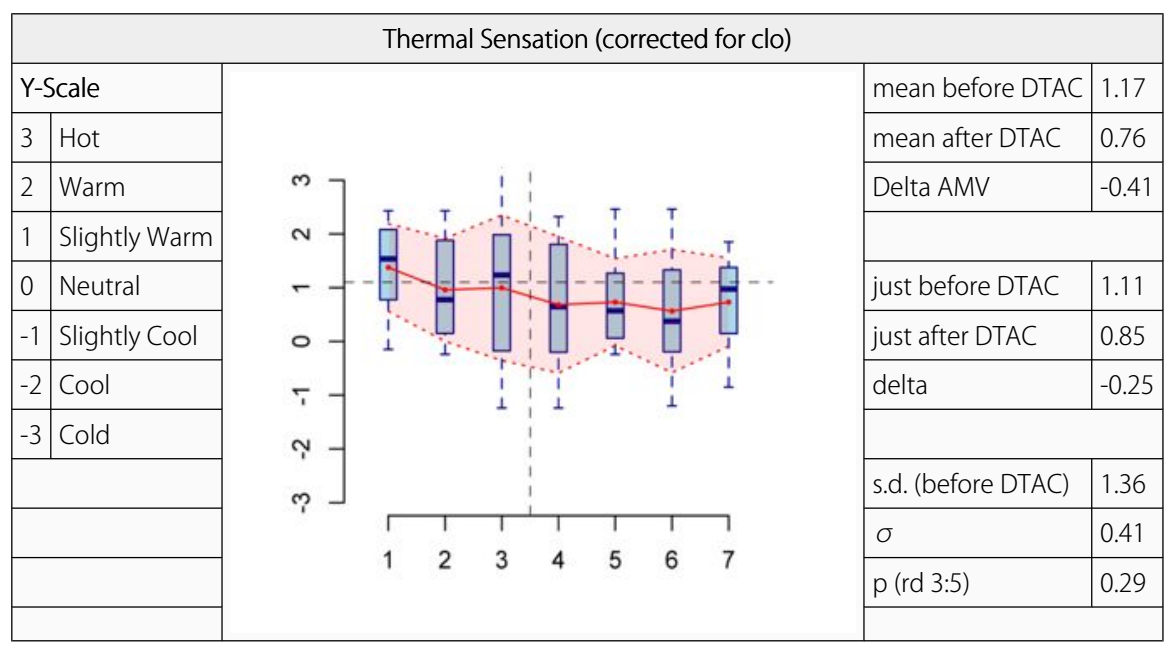

Table 10.20: Thermal sensation response to use of DTAC in climate chamber, corrected for variations in clothing

After correcting for clothing variation, we note an overall move of 0.4 vote towards a sensation of thermal neutrality (table 11.20). Based on an acceptable threshold of \pm 1 (slightly warm, neutral, slightly cool) the thermal acceptability by $16 \%$ of the participant before DTAC was improved to $29 \%$ after that. Compared to the previous result before correcting for clothing we see a substantial drop in the number of participants to be found within the acceptable range. Clothing variation could account for a correction of -0.25 to +0.46 of AMV which was sufficient to move a large number of marginal cases beyond the threshold of acceptable thermal comfort. In other words, had the occupants not been allowed to seek their own adaptation by a change of clothes, and all made to wear 1.1 clo worth of dressing, only $16 \%$ would have found it acceptable without DTAC and $29 \%$ with DTAC. 


\subsubsection{Thermal Comfort}

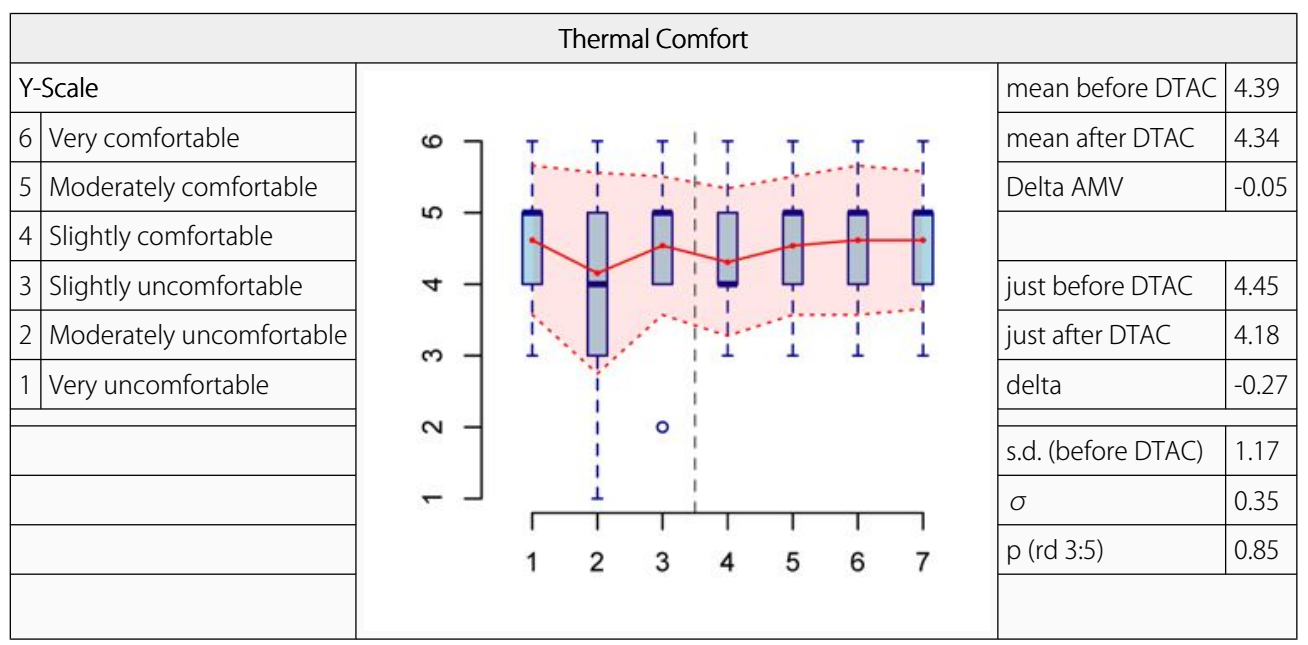

Table 10.21: Thermal comfort response to use of DTAC in climate chamber

After DTAC was switched on there was no discernible change in thermal comfort (table 11.21). In the PEM field study (Bauman, 1997) only those who indicated they were either very uncomfortable or moderately uncomfortable ( 1 to 2 on the scale) were deemed as uncomfortable. Based on this threshold, thermal discomfort of $6 \%$ before DTAC usage was decreased to $0 \%$ after that.

Majority of the votes (82\%) were in the comfort range (4 to 6) before and during DTAC and indicate that even though the sensation was different, there was no discernible impact on comfort. 15\% delivered a vote of 'very comfortable' before DTAC (mostly on the first survey) compared to $9 \%$ during DTAC. This suggests that upon entering the heated climate chamber from the cold outdoors many found the (alliesthesia) change pleasing. 
10.5.4 General comfort (Bedford Scale)

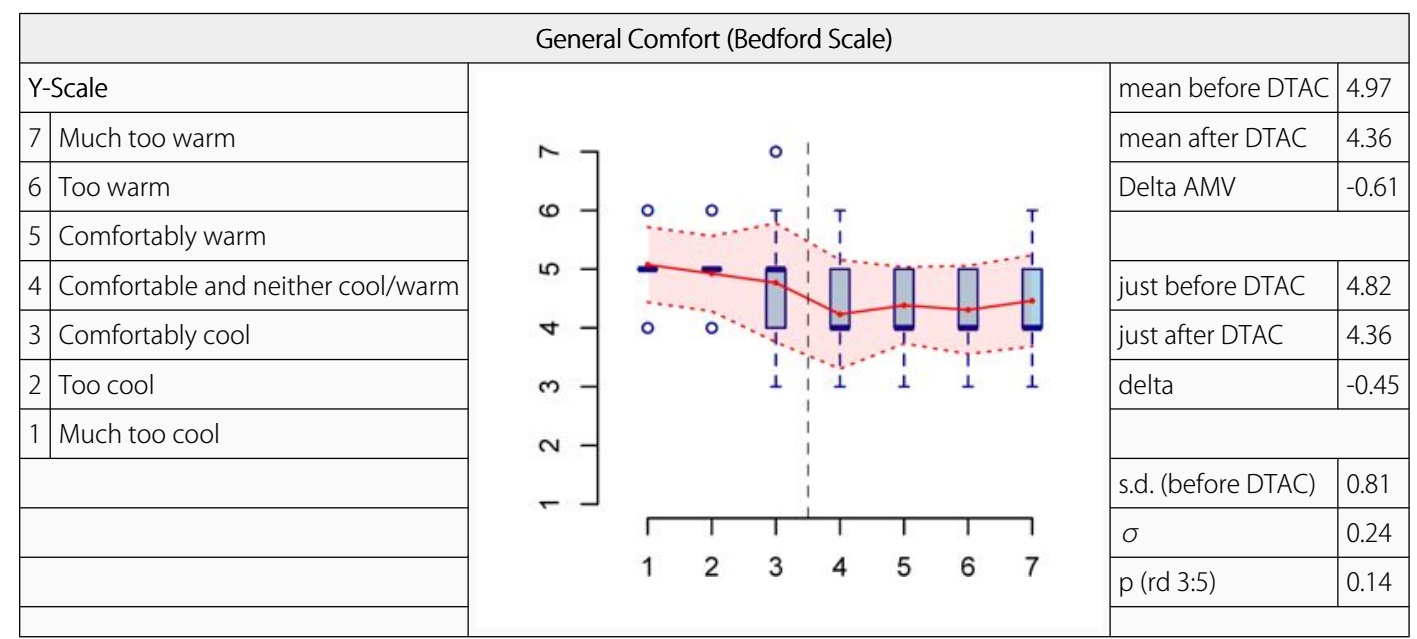

Table 10.22: General (Bedford) comfort response to use of DTAC in climate chamber

After DTAC was switched on there was a notable 0.61 vote overall improvement towards being "comfortable and neither warm nor cool", with a 0.45 improvement occurring at the interval immediately following the switching on of DTAC (table 11.22). Based on a threshold of 3 to 5 (comfortably warm, comfortable and neither cool nor warm, comfortably cool) the general comfort of $79 \%$ of participants before DTAC was increased to $98 \%$ after that.

10.5.5 Karolinska Sleepiness Scale

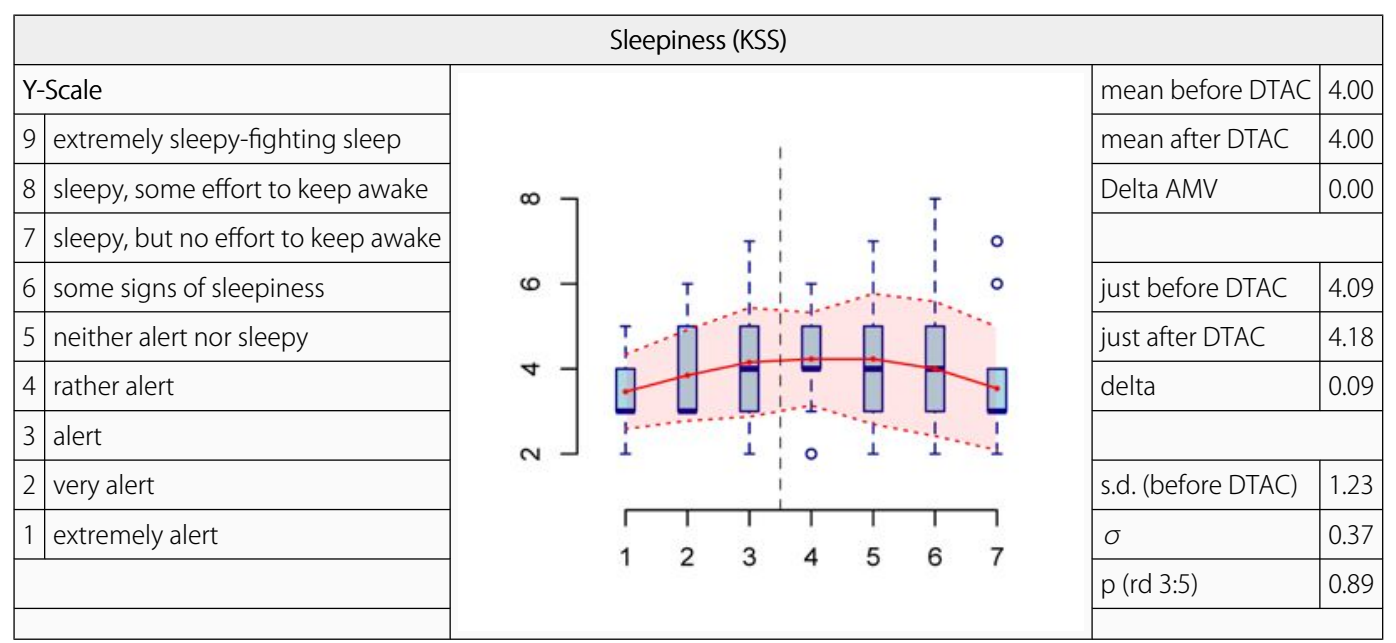

Table 10.23: Sleepiness response to use of DTAC in climate chamber

Referring to table 11.23 At the start and end of the trial, the task itself would largely account for the participants alertness and override the environmental drivers. As such the first and last interval (feedback round 1 and 7) have been omitted. It can be said there was no change 
in sleepiness according to the KSS, or that alertness or wakefulness was maintained with the use of DTAC. This is bolstered by the trend of increasing sleepiness observed from intervals 1-3, for which it could have been extrapolated to 5 (green dashed line. see figure ) instead of being maintained at 4 (figure 11.18).

\section{KSS}

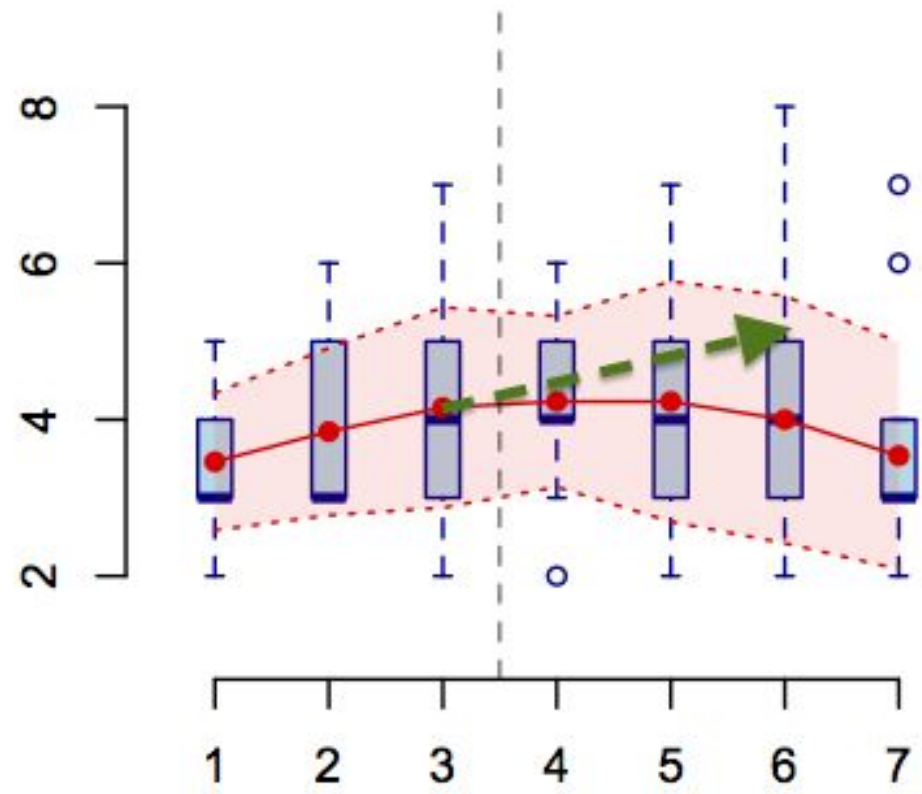

Figure 10.18: Projection of sleepiness based on trend before DTAC being switched on.

10.5.6 Comparison with fan-only control

After the initial 12 participants had completed the trial, the power supply to the TE modules was disconnected, making the 'cooling' control a dummy. The 'fan only DTAC' was tested on the last two participants who were not notified of the changes (single-blind), and the results overlaid in figure 11.19 to compare with the rest of the group. 
Thermal Sensation

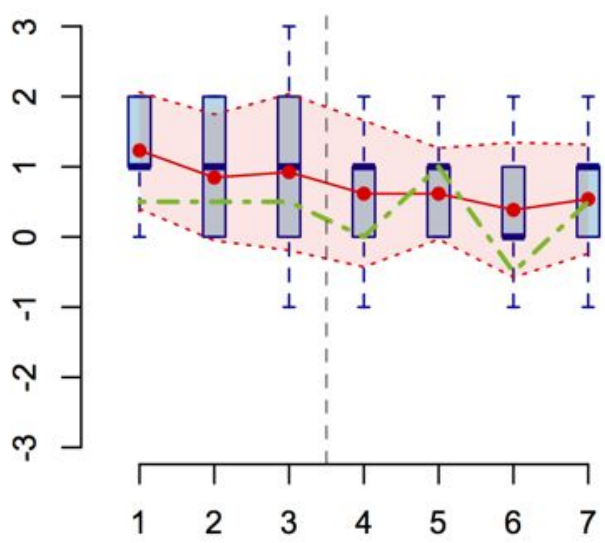

General Comfort

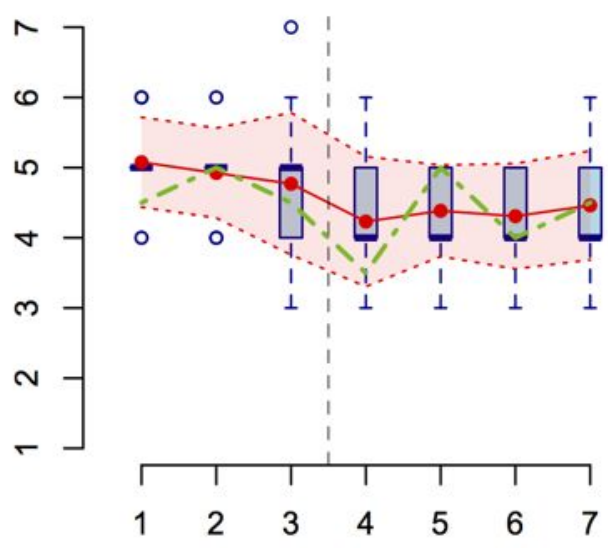

Thermal Comfort

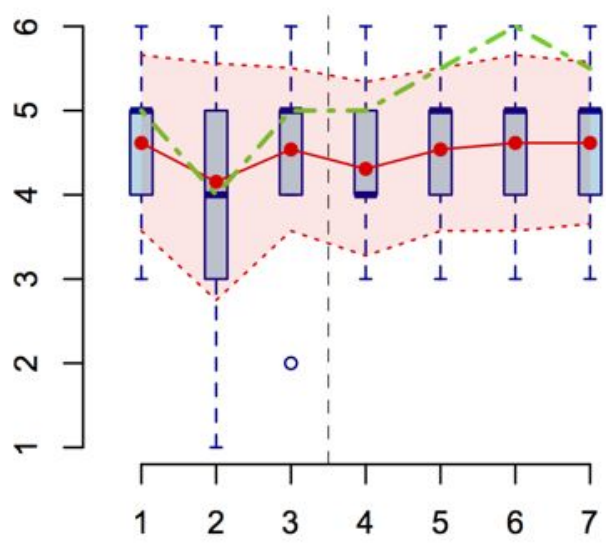

KSS

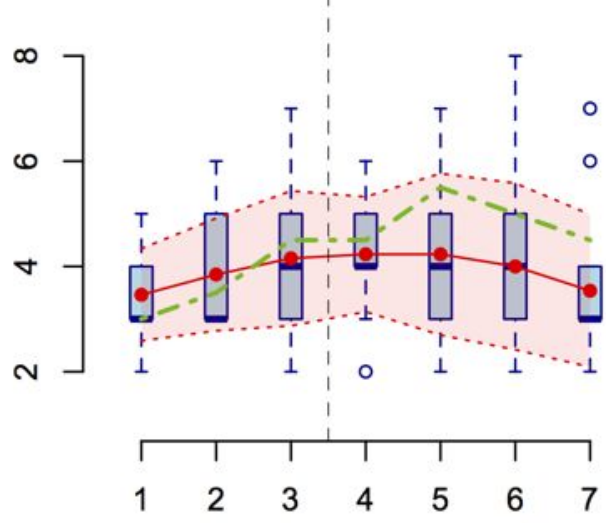

Figure 10.19: Mean sensation, comfort and sleepiness votes of 'fan-only' participants control group ( $n=2$, green dotted line) overlaid on DTAC group $(n=11)$

Due to the small sample size, the results from the blind trial can only be tentative. Most of the responses fall within one standard deviation, suggesting that the fan-only group responded as well to the fan as the DTAC group with the whole cooling system. The engineering rationale is explained in a later section on Target Cooling.

10.5.7 Cognitive Tests $(n=11)$

As an objective indicator of the fatigue expressed by participants, the cognitive tests have been established as indicator of performance under varying thermal environments. 
Transient heat fatigue causing decreased productivity, alertness, coordination and vigilance (Kroemer, 2010 p214).

In shooting competitions (Broad, 1997) ambient temperatures were found to impede psychomotor performance (including vigilance and cognitive capability) well before physiological performance.

\subsubsection{Visual Reaction Test}

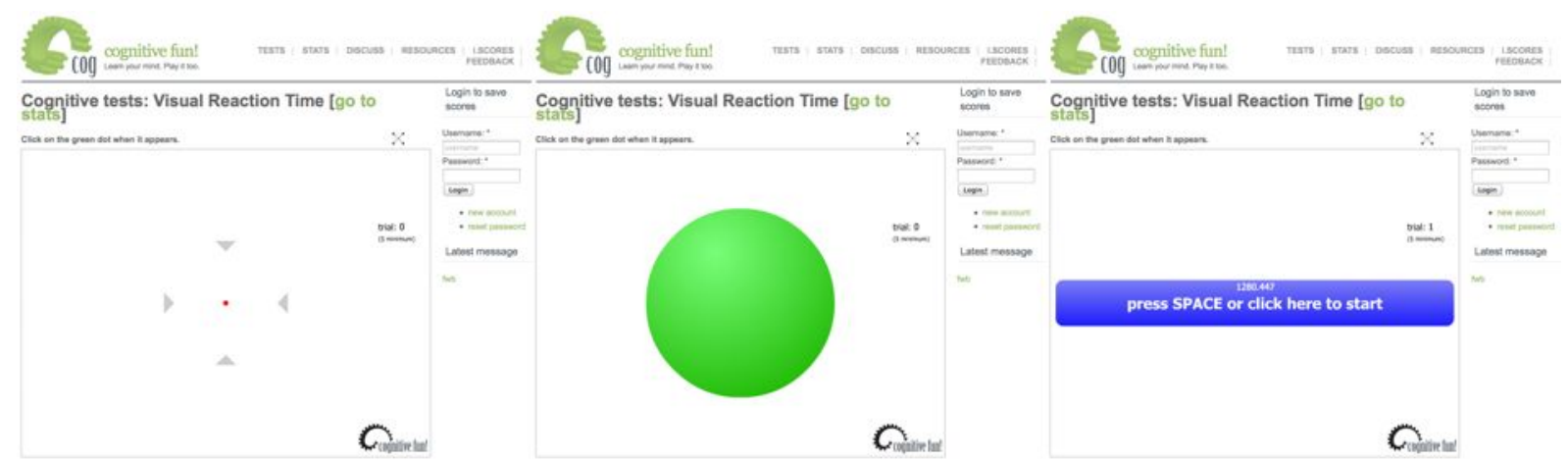

Figure 10.20: Webshots of the online visual reaction test (http://cognitivefun.net/)

The visual react test (figure 11.20) measures the mental alertness of the participant. Participants are required to stare at a small red dot till it turns green after a random duration and either click the mouse or hit the space bar. After 5 rounds the average reaction time is calculated.

Variations of this visual reaction test experiments have been used to index the following: 1 . Heat and thermal stress (Hancock, 1986; Manton, 1988) 2. Air ions and performance (Charry, 1987) 3. Sleep deprivation (van Hoof, 2008) 4. Self assessed productivity in offices

(Humphreys, 2000) 5. Sick building syndrome (Wargocki, 1999) 

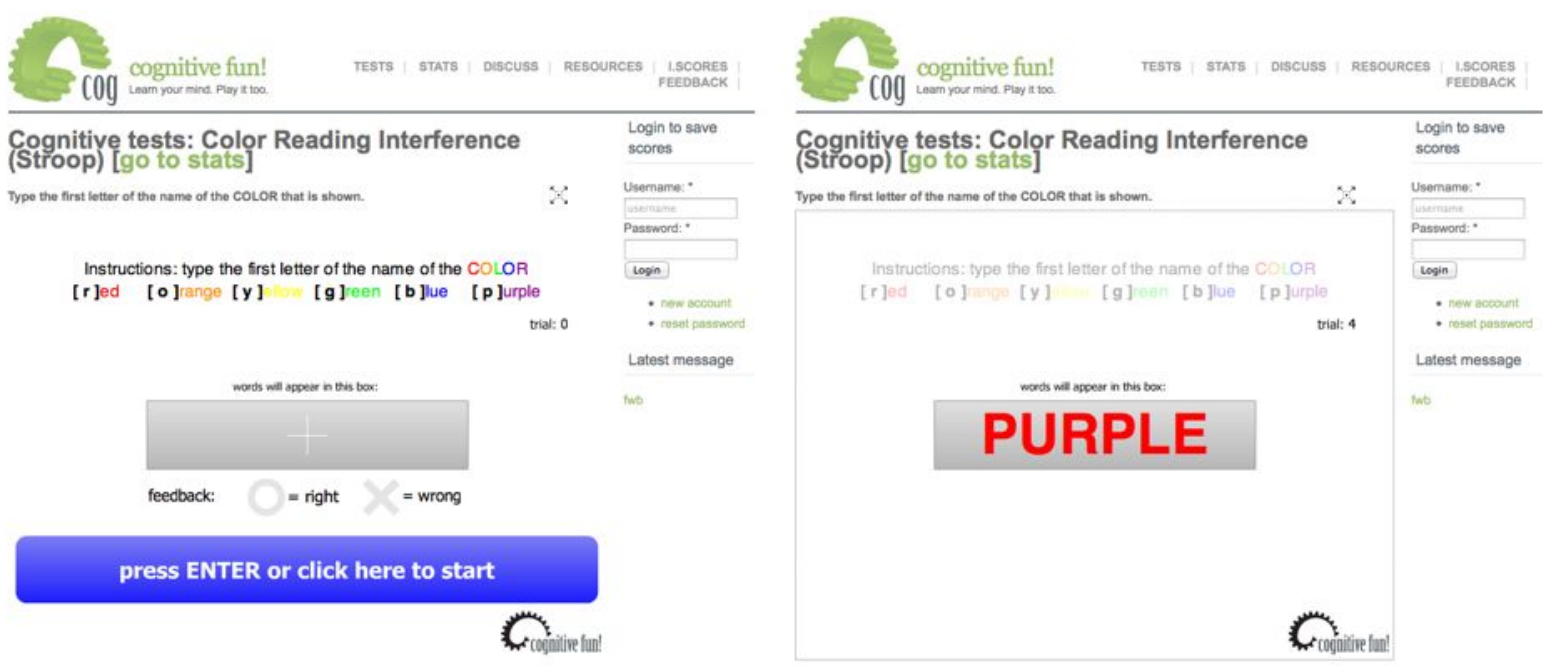

Figure 10.21: Webshots of the online visual Stroop colour test (http://cognitivefun.net/)

The Stroop Colour Test (figure 11.21) measures the mental effort required to correctly identify words that contradicted the colours they were displayed (interference) against words stating the same colour (normal). The interval between these two cases was known to increase with increasing fatigue. This test has also been adopted in a few preceding studies with Sick Building Syndrome (Wargocki 1999), negative ions (Hedge, 1987) and metabolism (Fairclough, 2004).

\subsubsection{Cognitive Test Results}

All improvements at the first interval (between the first and second tests) showed a marked improvement (see table 11.24) and were statistically significant (paired t-test, $p<0.05$ ) indicating that this improvement was not the outcome of natural variation. At the next interval, between tests 2 and 3, we observe the improvements are marginal and statistically insignificant, with the exception of the Stroops intereference test. There is strong suggestion that there was a learning and familiarisation phase in the cognitive tests which was overcome after the first run. The counterintuitive nature of the Stroops interference test however required a longer familiarisation period.

During the conduct of the experiment, the researcher would guide them through the first round of tests and would then leave the climate chamber, returning only minutes before the last test. He observed that some participants had become so acquainted with the Stroops test they would position their fingers on selected keys to achieve a better score. 


\begin{tabular}{|l|l|l|l|}
\hline \multicolumn{1}{|c|}{ Test } & \multicolumn{3}{c|}{ Improvement over interval } \\
\hline & $1-2$ & $2-3$ & $6-7$ \\
\hline Visual reaction time & $12.8 \%$ & $-3.3 \%$ & $-14.3 \%$ \\
\hline$p$-value & $(0.046)$ & $(0.537)$ & $(0.004)$ \\
\hline Stroops, normal time & $20.7 \%$ & $-3.8 \%$ & \\
\hline$p$-value & $(0.047)$ & $(0.384)$ & \\
\hline Stroops, interference time & $18.9 \%$ & $9.6 \%$ & \\
\hline$p$-value & $(0.040)$ & $(0.026)$ & \\
\hline Stroops, percentage correct & $2.5 \%$ & $2.3 \%$ & \\
\hline$p$-value & $(0.215)$ & $(0.022)$ & \\
\hline positive percentage values indicate improvement \\
\hline
\end{tabular}

Table 10.24: P-values of paired t-test of cognitive tests

In recognising that there was a familiarisation period,the first return of cognitive test results has been omitted in comparing the pre-DTAC and post-DTAC results. In both the visual reaction and stroops tests the result show little variation after the first interval, suggestive that there is no significant improvement in the use of DTAC. In the visual reaction test we do however observe a $14.3 \%$ downswing (p-value < 0.005 ) in the last interval, indicative that sustained vigilance had been associated with a period of mental exertion right up to, but not beyond, the completion of the design challenge.

There was no significant improvement in vigilance (as reflected in the visual reaction results, $p>0.5$ ). Directed attention (as reflected by the Stroops test) did show a slight improvement, indicative of a decrease in attentional fatigue with the use of DTAC. However we cannot rule out the possibility that there was already a trend towards shorter reaction times with greater familiarity to the regime. If there was a familiarisation pattern, it should affect both the normal reaction time and interference reaction time. By observing the interval between these two times we can see if the intervals were shortened with the use of DTAC (table 11.25).

\begin{tabular}{|c|l|l|}
\hline & Improvement & P-value \\
\hline Visual reaction time & $2.05 \%$ & 0.512 \\
\hline Stroops normal reaction time & $15.23 \%$ & 0.001 \\
\hline Stroops interference reaction time & $8.55 \%$ & 0.035 \\
\hline Stroops percentage correct & $0.35 \%$ & 0.326 \\
\hline
\end{tabular}




$$
t_{\text {interference interval }}=t_{\text {interference }}-t_{\text {normal }}(m s) \quad(\text { Eq. 10.4) }
$$

\section{Stroops Interference Interval (ms)}

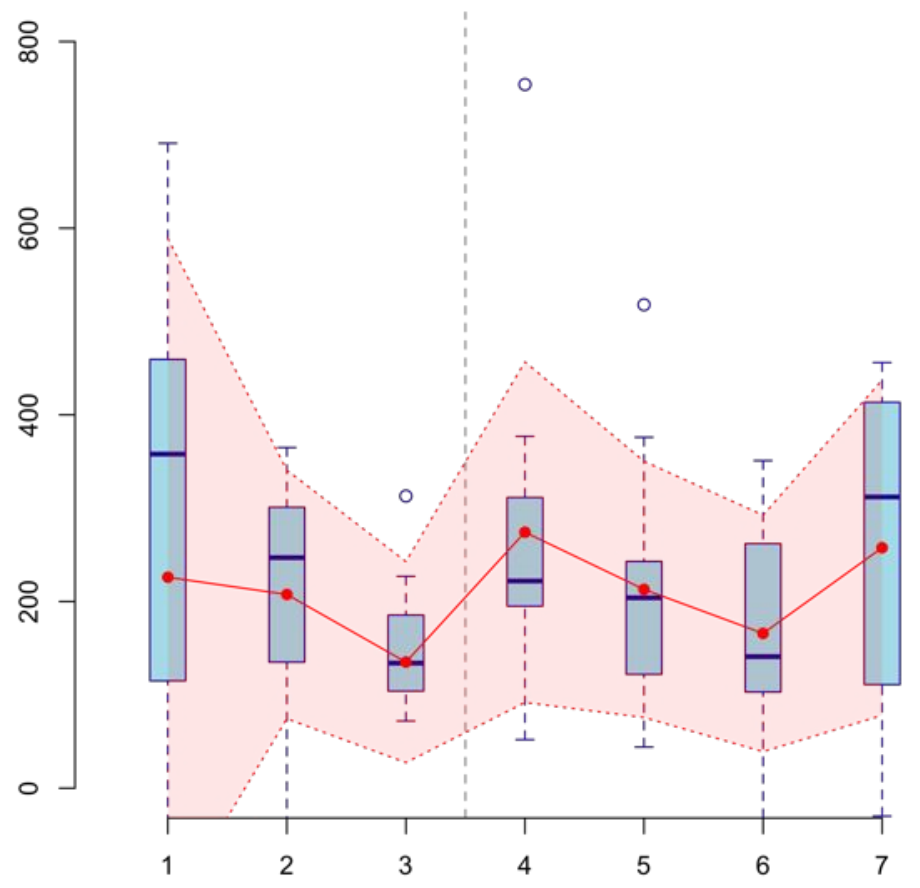

Figure 10.22: Stroop interference interval for participants in climate chamber.

In plotting the Stroop interference interval (figure 11.22), there appears to be neither an improvement nor indication of a trend There is thus a strong case that it was the familiarisation process and not the DTAC that had led to the improved reaction times in the Stroops tests. It is noteworthy that the Stroop tests performed in air-quality experiments (Wargocki, 1999) also showed little statistical difference (3.1\% effect, $p$-value $=0.10)$ to different pollution loads.

Whilst there has been no improvement to the cognitive performance of the DTAC it is also true that there has been no deterioration in psychomotor performance, which would have been an indication of fatigue, with the continued use of DTAC 
10.5.11 General and Marketing Feedback

At the end of the trial, each participant gave general feedback on how they felt the DTAC performed and how they felt the improvements should be prioritised, see figure 11.23. 
CC - General feedback

1. End of DTAC Trial General Feedback

General and marketing feedback after the completion of trials.

1. Has the performance of DTAC in the following areas met your initial expectation of a personal air-conditioner:

$\begin{array}{lcccc}\text { Thermal comfort } & \text { Exceeds expectation } & \text { Meets expectation } & \text { Neutral } & \text { Dissatisfied } \\ \text { General comfort } & 0 & 0 & 0 & 0 \\ \text { Ease of use } & 0 & 0 & 0 & 0 \\ \text { Reliability } & 0 & 0 & 0 & 0\end{array}$

Other (please specify)

*2. What is the maximum price (AUS) you will pay for a DTAC unit?

No more than $\$ 100$

No more than $\$ 200$

No more than $\$ 300$

No more than $\$ 400$

No more than $\$ 500$

Other maximum:

*3. Rank the following complaints as they apply to you in the last few hours of use:

Difficult to regulate coldness
Unit takes up too much desk
space
Difficult to regulate fan speed
Noise annoyance

Other (please specify)

*4. For the next version of the DTAC, rank the following upgrades you would wish to see.

\begin{tabular}{|c|c|c|c|c|c|c|c|}
\hline & Highest Priority & & & & & & est priority \\
\hline Quieter operation & $\mathrm{O}$ & 0 & 0 & $\mathrm{O}$ & 0 & 0 & 0 \\
\hline Colder air & O & $\mathrm{O}$ & $\mathrm{O}$ & $\mathrm{O}$ & 0 & $\mathrm{O}$ & 0 \\
\hline Dehumidifying capability & $\mathrm{O}$ & $\mathrm{O}$ & 0 & $\mathrm{O}$ & 0 & 0 & $\mathrm{O}$ \\
\hline More powerful fan & 0 & 0 & 0 & 0 & 0 & 0 & 0 \\
\hline Air filtering capability & 0 & 0 & 0 & 0 & 0 & 0 & 0 \\
\hline Automatic sweeping louvers & O & $\mathrm{O}$ & 0 & $\mathrm{O}$ & 0 & 0 & 0 \\
\hline
\end{tabular}

Your dream list:

*5. If we implement your top two choices, how much more are you willing to pay for an upgraded DTAC unit?

another $\$ 20$

another $\$ 50$

another $\$ 100$

Other sum:

6. Please leave your general imperessions

Figure 10.23: End of trial general feedback survey web page. 


\subsubsection{Expectations $(n=14)$}

On a five-point Likert scale participants expressed their expectations (figure 11.24).

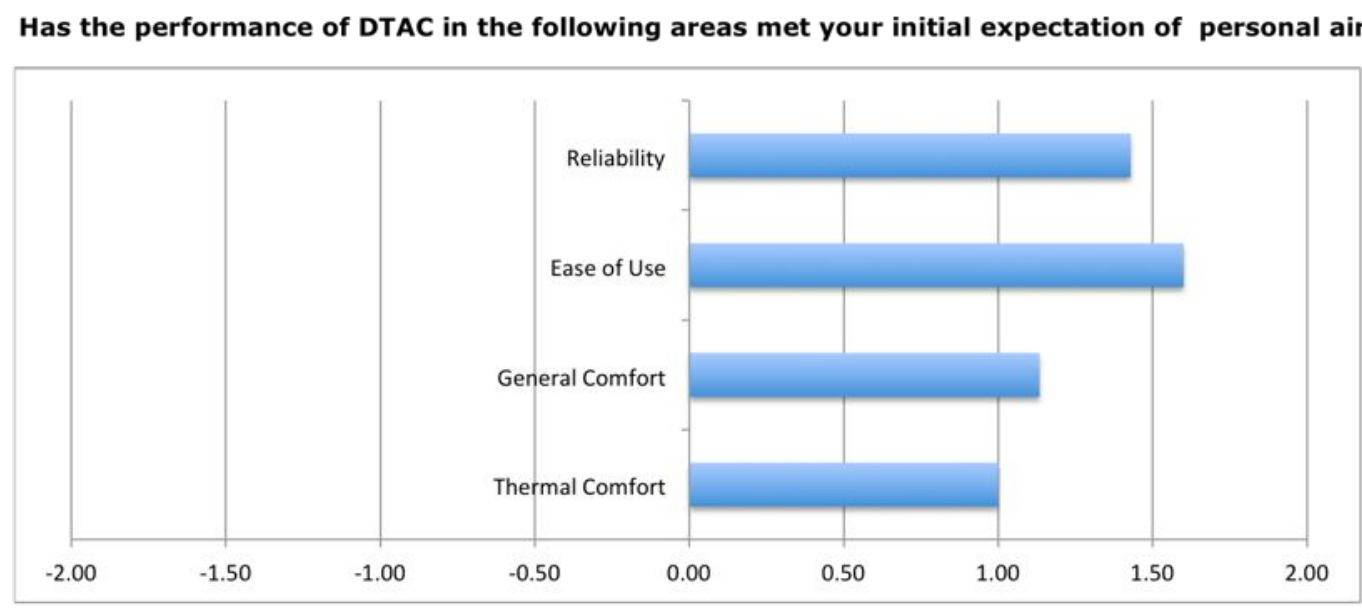

$$
\begin{aligned}
& 2 \text { Exceeds expectation } \\
& 1 \text { Meets expectation } \\
& 0 \text { Neutral } \\
& -1 \text { Dissatisfied } \\
& \text {-2 } \text { Very dissatisfied }
\end{aligned}
$$

Figure 10.24: Satisfaction with DTAC in meeting expectations for the criteria of reliability, wase of use, general comfort and thermal comfort

Ease of use (score $\left.=1.6, s_{.} d_{0}=0.51\right)$

The DTAC had a main switch and two controls for fan speed and cooling power. The familiarity of this method of control and ease in which it could be operated gave this a high score in exceeding expectations.

Reliability (score $=1.43$ s.d. $=0.76)$

Within the two hours where DTAC was in operation for each participant there was no instance of malfunction.

General comfort (score $\left.=1.13, s_{.} d_{0}=0.74\right)$

The difficulty of attaining a vote of 'very comfortable' remains a big challenge, and is reinforced with the general comfort being marginally better than meeting expectation. 
Thermal comfort $\left(\right.$ score $\left.=1.0, s_{.} d_{0}=0.76\right)$

The thermal comfort score was that of just meeting expectation. This would be the area where users would have the most demanding expectations. This was evident in this category, where it obtained the lowest satisfaction score and largest diversity in opinion.

Whilst the optimum comfort is a subjective issue, we have established that this is typically lower in temperature than a neutral vote. The supply air temperature of the DTAC was clearly not able to bring the conditions within the optimal comfort range. The supply air temperature should be further lowered so that a comfort vote in the range of $-1<\mathrm{PMV}<-0.5$ could be achieved.

It is also likely that the issue of noise, which should have been an issue with general comfort rather than thermal comfort, was confused by some participants. Where participants felt a constant annoyance with the acoustic environment, they mentioned that they could have also been more demanding on their thermal environment.

\subsubsection{Future Upgrades $(n=14)$}

Having tested the DTAC for a reasonable period of two hours, participants gave feedback on what they considered to be their most important complaint. These were weighted from a score of least concern of 0 , to most concerned of 5 (figure 11.25 and table 11.26).

The number of participants who voted in each category were tallied and assigned a complaint score as follows:

$$
\text { Score }=\frac{\sum(\text { count } \times \text { score })}{\sum(\text { count } \times \text { highest score })} \times 10
$$



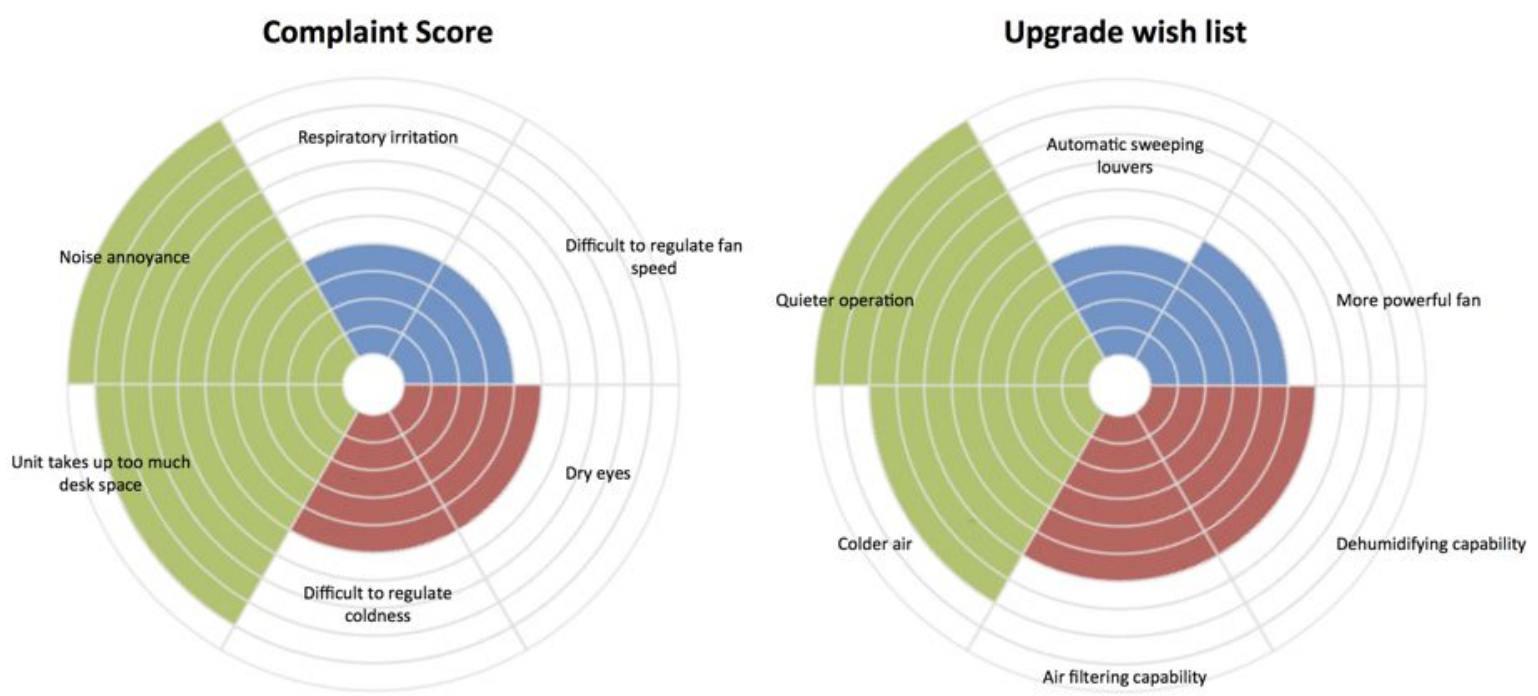

Figure 10.25: General feedback upon completion of trial

\begin{tabular}{|l|l|l|l|c|}
\hline \multicolumn{2}{|c|}{ Complaint score } & & \multicolumn{2}{c|}{ Upgrade Wish List } \\
\hline \multicolumn{2}{|c|}{ (higher = more dissatisfied) } & & \multicolumn{2}{c|}{ (higher = higher priority) } \\
\hline Noise annoyance & 10.00 & & Quieter operation & 10.00 \\
\hline Unit takes up too much desk space & 9.55 & & Colder air & 8.13 \\
\hline Difficult to regulate coldness & 5.97 & & Air filtering capability & 6.26 \\
\hline Dry eyes & 5.67 & & Dehumidifying capability & 6.04 \\
\hline Difficult to regulate fan speed & 4.78 & & More powerful fan & 5.49 \\
\hline Respiratory irritation & 4.03 & & Automatic sweeping louvers & 4.73 \\
\hline
\end{tabular}

Table 10.26: General feedback upon completion of trial

Noise

Noise ranked as the most unacceptable complaint. The only sounds coming from the DTAC unit would have been primarily from the fan, with a very small contribution from the buzzing in the iron core transformers of the power supply units. After the field trial, the noise level was measured with a sound level meter, Digitech QM-1589 (accuracy $\pm 1.5 \mathrm{~dB}$, time weighted to $1 \mathrm{sec}$ ). The noise from both DTAC units were measured at different settings on the fan controller and measured at the seated head level. This was found to be up to 22.4dBA higher than the ambient background level (table 11.26). For a mentally productive environment like the office this level of noise would be unacceptable. Since the noise annoyance featured highly in the complaint score it is not surprising that this was also ranked the highest priority for future upgrades. 
For a sample of how significant $22.4 \mathrm{~dB}$ is, it will be roughly equivalent to the difference between the first and last steps in this audio clip:

http://www.animations.physics.unsw.edu.au/waves-sound/quantifying/downloads/ quantifying_1dBnoise.swf

Even thought the fan noise was significant, I personally felt that it was not as drastic as measured and suspect the wind could have generated more crackle on the sound level meter than was audible, like someone blowing into a microphone.

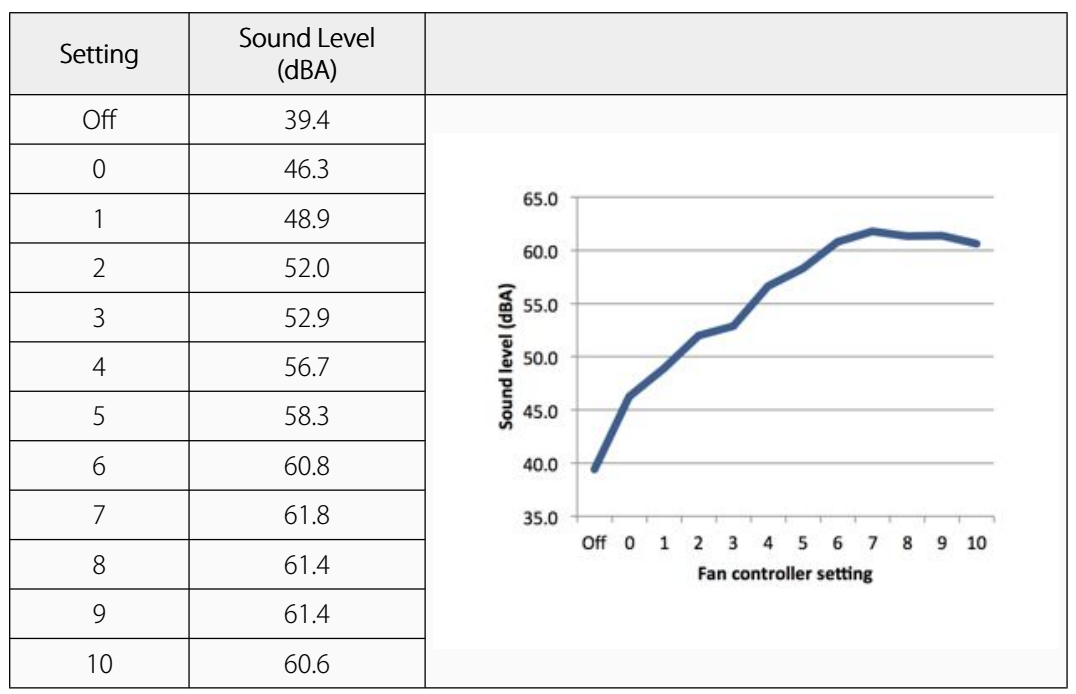

Figure 10.26: Sound level measured with Digitech QM1589 set to 'Slow', 'A' Rated (dBA). Recorded at 1.1m height between two DTAC units both with fans on. Average of readings values taken increasing fan controller (o to 10) and decreasing (10 to o).

\section{Cooling}

Even though DTAC improved thermal comfort to a mean of 0.76 , within the neutral band \pm 1 in the ASHRAE Scale, it is evident from the wish list that this needs to be further improved. Thus even thought the use of DTAC approaches the neutral point on both ASHRAE and Bedford scales, users expressed more could be achieved for them to feel 'very comfortable'. Taking into account the earlier discussion on the preference to be slightly cool in chapters 3 and 4 , the thermal comfort scale underestimates the preferred coldness due to the concentration of heat in the head from mental metabolism, the ideal would be to see that occupants would have a system that rated -1 (slightly cool) on the ASHRAE scale or 3 (comfortably cool) on the Bedford scale. The 'right' temperature for mentally productive work would always be slight cool for the rest of the body. 


\section{Desktop Space Usage}

The DTAC prototypes had been built as desktop units to avoid the need for drilling holes into the tables and the use of long ducts which would incur a higher static pressure and refrigeration loss. The prototypes used in the climate chamber were originally designed to be used in different offices and were thus fabricated as desktop units. It is clearly understandable that users prefer to have as much real estate as possible on their desks.

\section{Cooling Control}

In order to achieve this, the feedback indicated that more powerful TE modules (ranked 2nd priority) should be used instead of more powerful fans (ranked 5th priority).

\section{Future upgrades}

The use of axial fans on the faceplate had clearly been the main factor in the noise annoyance to users. Whilst this configuration provided a reasonable flow rate with low power consumption (max. 7W) it did not attenuate any of the noise generated. Moreover the refrigerated air was passing over the fan motor which would invariably overheat with extended use. A scroll fan would be a more efficient alternative, being able to handle larger static pressures and flow rates, and a motor can be located external from the impeller and air stream. A more effective cooling fin and a lower melting point PCM would result in more cooling without needing to increase the TE cooling effect with more modules or running them at a higher voltage.

\section{Pricing}

The modal group comprising $46 \%$ of the participants indicated that they were willing to pay up to $\$ 300$ for a unit, i.e. $\$ 600$ for the two unit set-up for the experiment (figure 11.27). This price point indicated a readiness to adopt DTAC as a direct consumer purchase, rather than a building or engineering component. If treated as an accessory, the visual presentation of the item becomes significant, requiring the employment of industrial designers to imbue the device with a contemporary presence. Further thought also needed to be given into how DTAC can be customised to the various tastes of consumers. 


\section{What is the maximum price (AU\$) you will pay for a DTAC unit?}

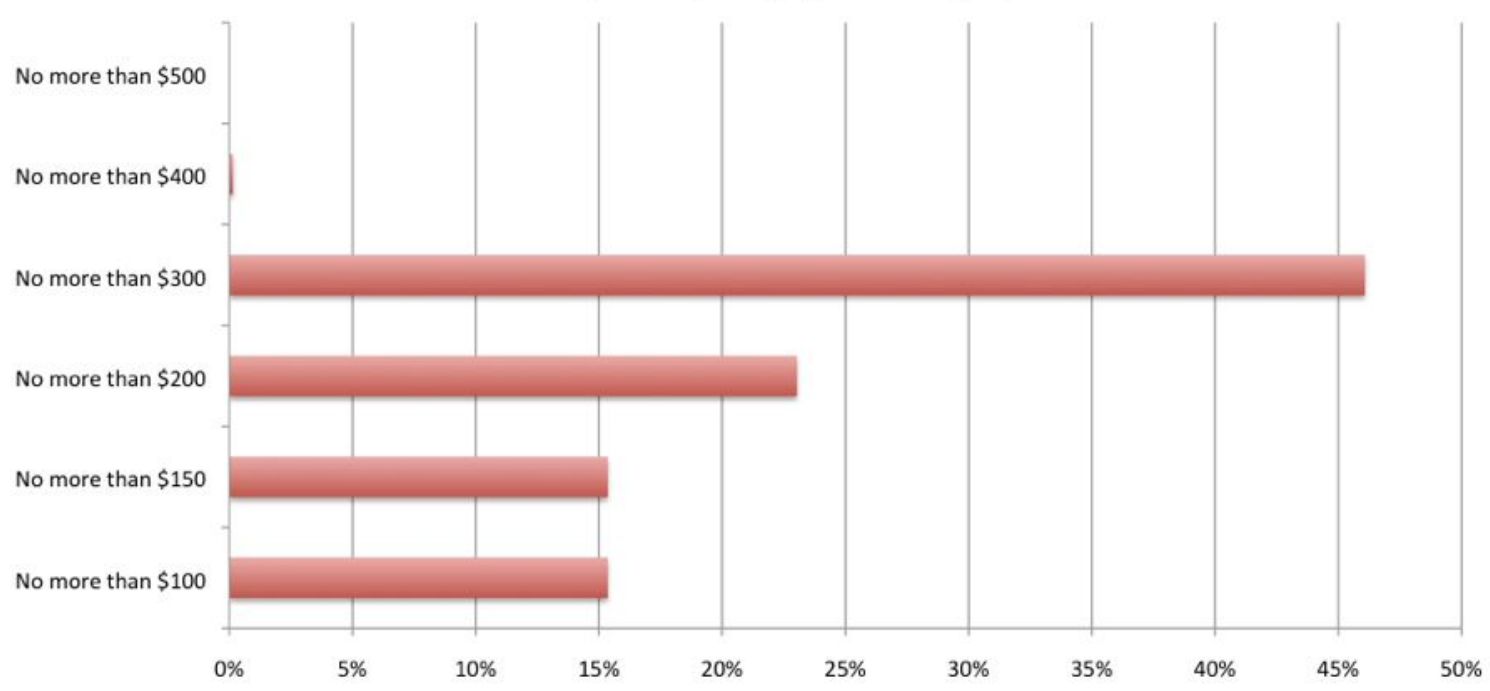

How much more are you willing to pay for an upgraded DTAC unit?

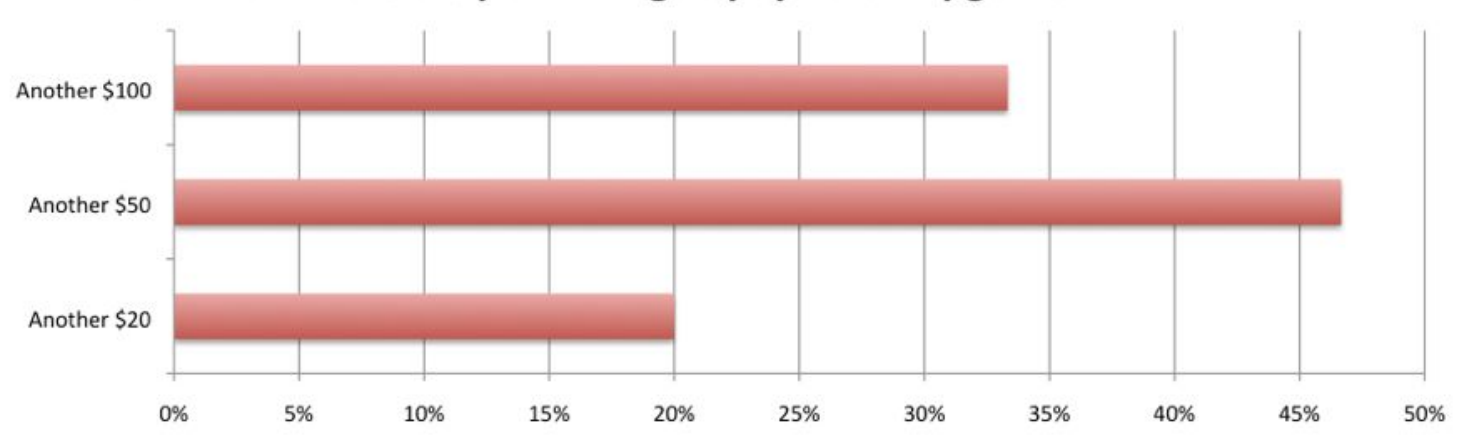

Figure 10.27: Percentage of participants nominating recommended retail value and upgrades.

\section{General feedback}

Participants were free to leave feedback, the following were collected and reproduced in full with minor language editing:

very easy to use and efficient at cooling. if noise was less would be perfect

noise only disrupts when one needs [quiet] to generate idea, but when one is doing work like drawing, noise fades out.

very impressed with the dtac unit overall. performs well and produces a lot less noise than anticipated

incredibly easy to use; great design; styling, materials, simple appearance good air pressure with a range of speeds and temperature 
i think that the dtac system is great. personally it really satisfies my needs for a cooling method in a confined space. i would happily purchase one for a desk top situation.

it functions great for cooling. and controls great. looking forward for the new prototype

it looks great and functions great too. looking forward for the next prototype. cheers

really alleviated any uncomfortableness of being too warm and is easy to use. it is only slightly noisy but you get used to it pretty quickly.

over all it works well. the size and noise are the only issues.

works great but the noise can be distracting especially when on high fan speed which was needed to cool me. cooler air may help this

quite noisy, [not effective] ... in adjusting the maximum cool temperature ...

\subsection{Target cooling}

DTAC predominantly cools the head and upper body. Whilst the psychrometric relationships are well understood (between temperature, humidity and enthalpy), the relationship between $\mathrm{T}$ and wind velocity is not.

To better understand the thermodynamic relationship, the head is simplified to a sphere $150 \mathrm{~mm}$ diameter at $34^{\circ} \mathrm{C}$. Only the dry heat loss is considered in this model as the restorative moisture loss will be equivalent with or without fan movement, and the perspiration rate is negligible for (Gagge, 1986, table 11.27)

\begin{tabular}{|c|c|c|c|}
\hline Activity & Respiratory moisture loss (heat loss) & Perspiration rate (heat loss) & Skin moisture loss (heat loss) \\
\hline Resting 1met (105W) & $12 \mathrm{~g} / \mathrm{h} \mathrm{(21W)}$ & No perspiration & $20 \mathrm{~g} / \mathrm{h}(84 \mathrm{~W})$ \\
\hline Walking 3met (315W) & $37 \mathrm{~g} / \mathrm{h}(65 \mathrm{~W})$ & $241 \mathrm{~g} / \mathrm{h}$ & $38 \mathrm{~g} / \mathrm{h}(161 \mathrm{~W})$ \\
\hline
\end{tabular}

Table 10.27: Evaporative cooling on an adult in conditions of $0.6 \mathrm{clo}, 23.9^{\circ} \mathrm{C}$, 50\%RH (Cagge, 1986)

Using Whitaker's correlation (Whitaker, 1972) in (Incropera, 2007) the forced convection can be determined from the relationships: 


$$
\overline{N u}=2+\left(0.4 R e_{D}^{1 / 2}+0.06 \operatorname{Re}_{D}^{2 / 3}\right) \operatorname{Pr}^{0.4}\left(\frac{\mu}{\mu_{s}}\right)^{1 / 4}
$$

\begin{tabular}{|c|c|}
\hline$N u=\frac{h D}{k_{\infty}}$ & Nusselt number \\
\hline$h=\frac{Q}{4 \pi D^{2}\left(T_{0}-T_{\infty}\right)}$ & Convective heat transfer coefficient for sphere \\
\hline
\end{tabular}

Note that Whitaker uses a convective coefficient with area of sphere as $4 \pi \mathrm{D}^{2}$ instead of $4 \pi \mathrm{r}^{2}$. It is unclear if Whitaker's correlation can be used to determine free convection when vel = $0 \mathrm{~m} / \mathrm{s}$. In the temperature range $20-34^{\circ} \mathrm{C}$, the velocity where the Archimedes number was 1 (where $\mathrm{Ar}=\mathrm{Gr} / \mathrm{Re}^{2}$ ) was at vel=0.2m/s. Since $\mathrm{Ar}=1$ indicates the condition where forced of free convection rates would be comparable, this vel would represent the lower limit of forced convection. Figure 11.28 shows how this was found to be in close agreement with Churchill's correlation free convection of a sphere (in Incropera, 2007):

$$
\overline{N u}=2+\frac{0.589 R a_{D}^{1 / 4}}{\left(1+(0.469 / P r)^{9 / 16}\right)^{4 / 9}}
$$




\section{Convective heat loss (dry)}

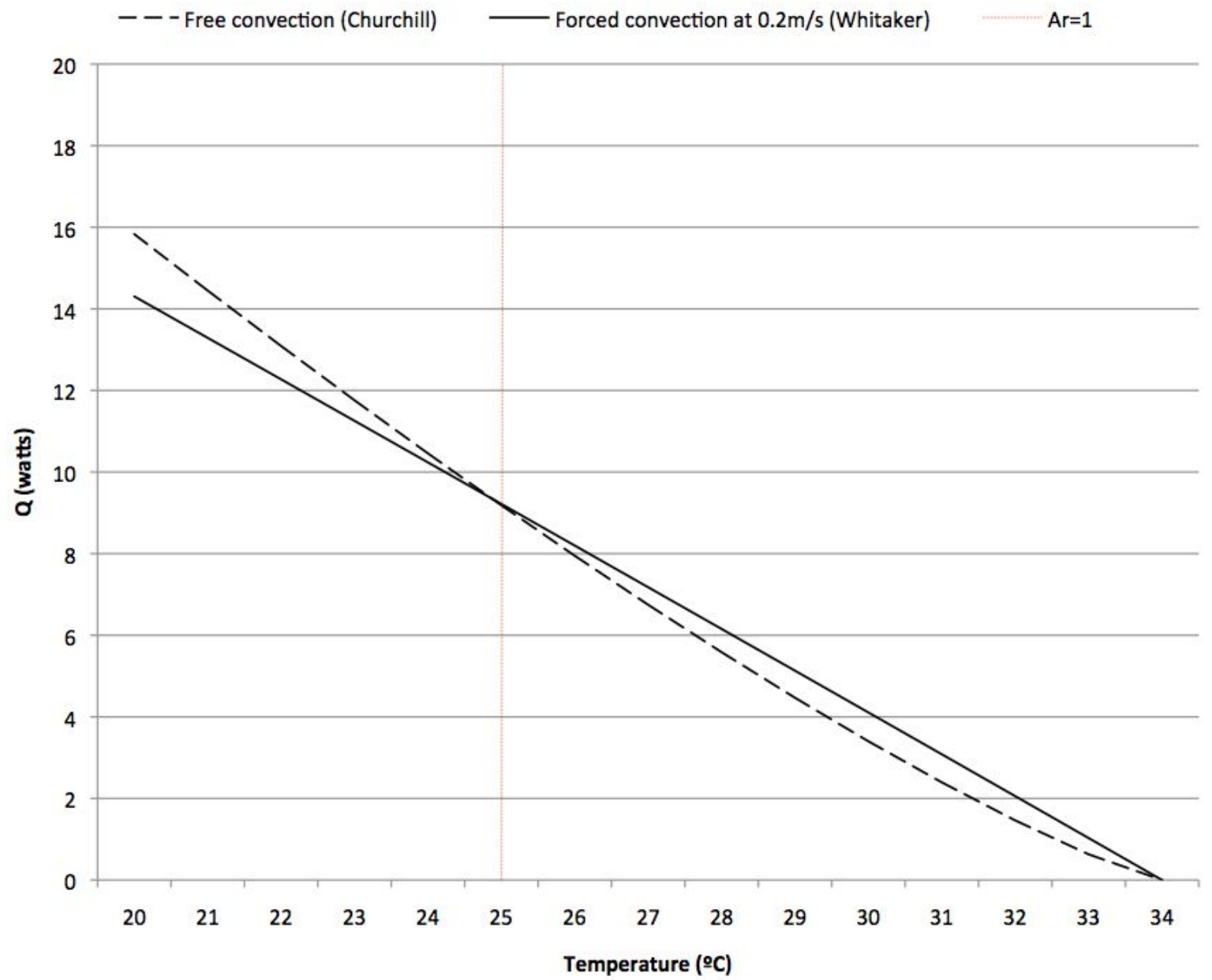

Figure 10.28: Plots of free convection (Churchill) and forced convection at $0.2 \mathrm{~m} / \mathrm{s}$ (Whitaker)

Q-conv (heat loss from forced convection) demonstrates a linear relationship with temperaure in the target range studied $\left(20-34^{\circ} \mathrm{C}\right)$ when velocity is fixed (figure 11.29). 


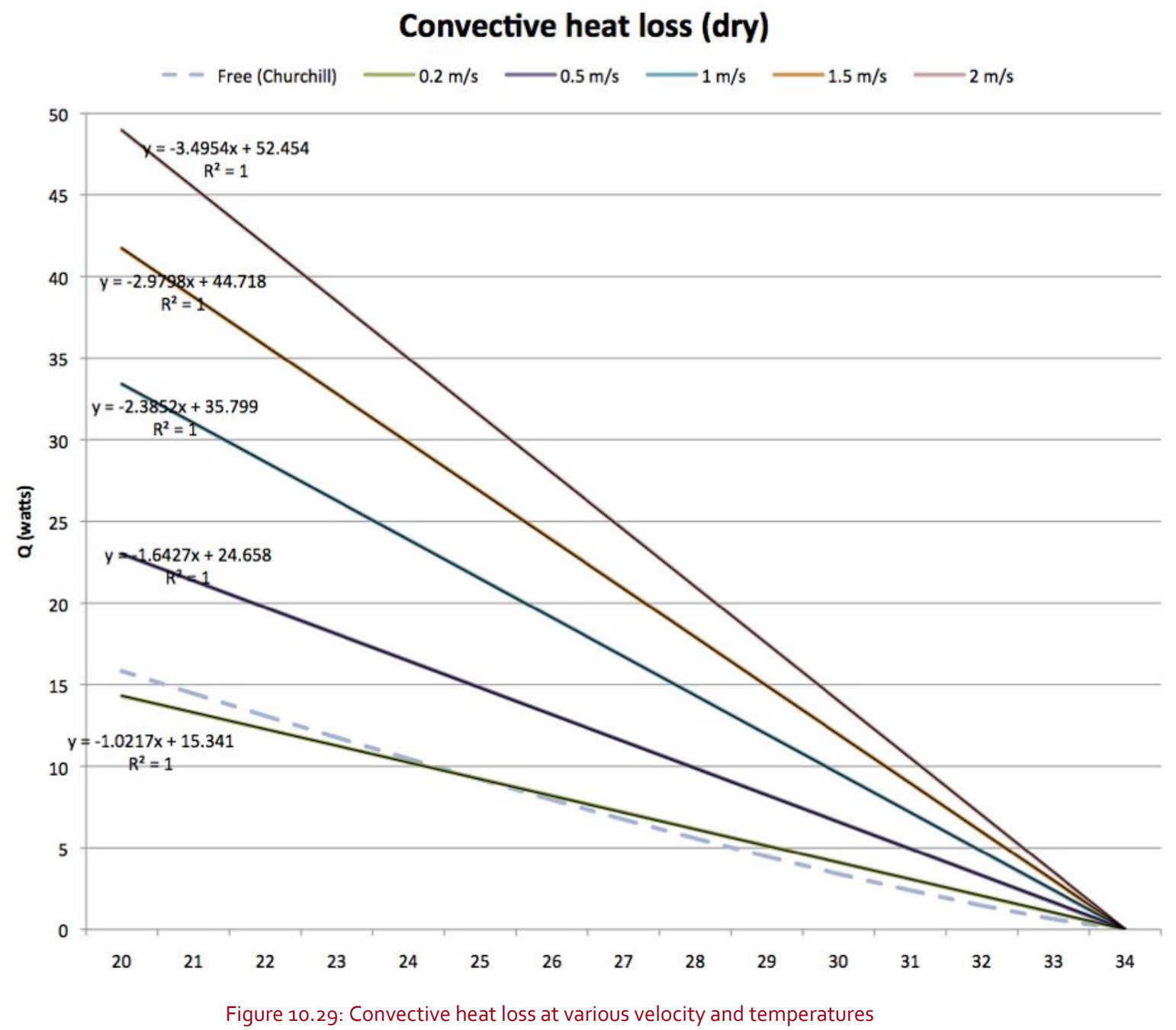

This model allows us to look at each velocity as removing a multiple of heat beyond natural convection (table 11.28). So at $0.5 \mathrm{~m} / \mathrm{s}$, forced convection cools 1.61 times (or $61 \%$ more) than free convection. We can see from this the efficacy of even a small amount of air movement, and this relationship continues way beyond the $2 \mathrm{~m} / \mathrm{s}$ practical limit for wind directed on the face.

\begin{tabular}{|c|c|c|}
\hline $\begin{array}{c}\text { Wind } v \\
(\mathrm{~m} / \mathrm{s})\end{array}$ & $\mathrm{Nu}$ & Cooling multiple \\
\hline 0.2 & 21.06 & 1.00 \\
\hline 0.5 & 33.86 & 1.61 \\
\hline 1.0 & 49.16 & 2.33 \\
\hline 1.5 & 61.42 & 2.92 \\
\hline 2.0 & 72.05 & 3.42 \\
\hline 2.5 & 81.61 & 3.88 \\
\hline 3.0 & 90.42 & 4.29 \\
\hline
\end{tabular}


Forced convective loss as multiple of natural convection (or $\mathrm{Nu}$ at $\mathbf{2 0}$-C) vs wind velocity

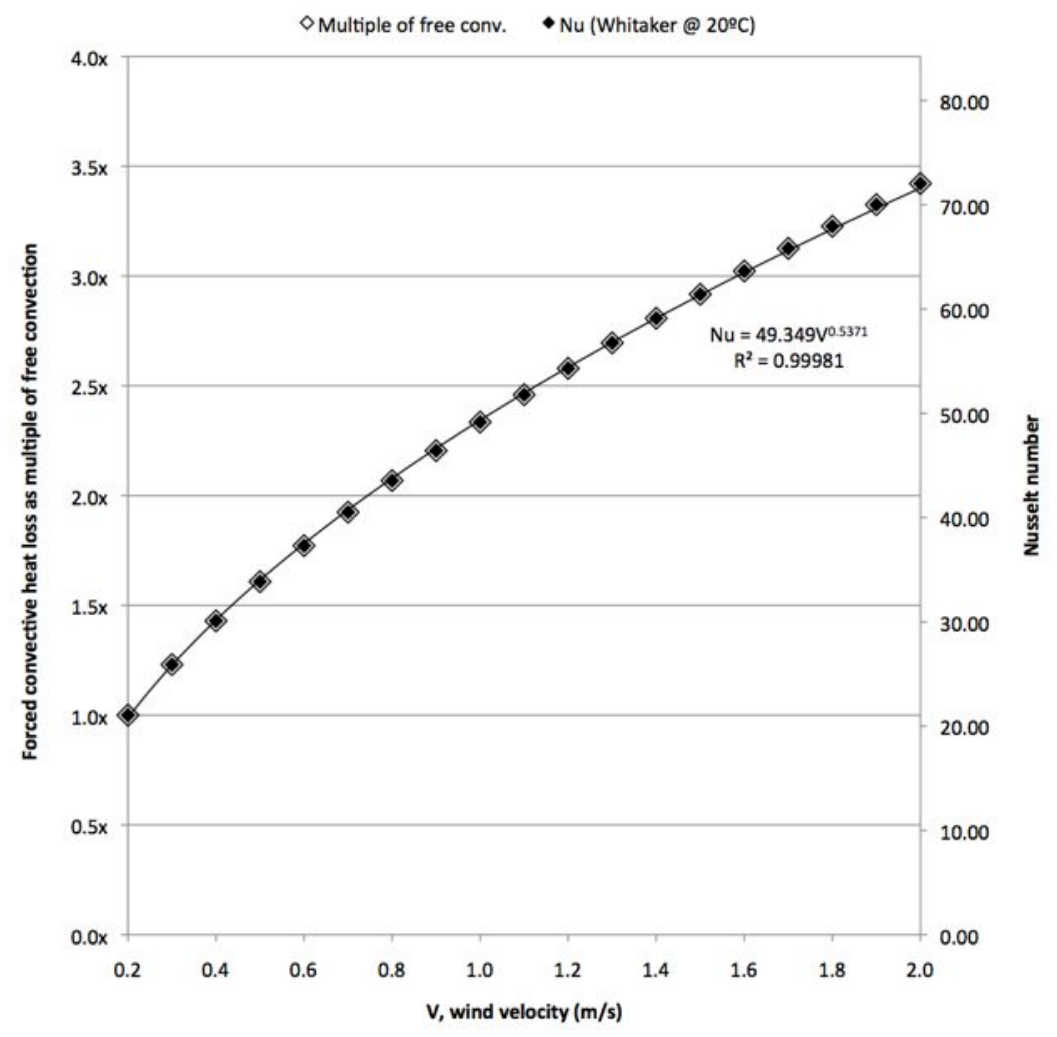

Figure 10.30: Forced convective heat loss (as a multiple of natural convection) at various wind velocities

Finally, assuming the heat produced by the head is 20W under no physical exertion

(Cabanac, 1995) we can plot the dT and V combinations to extract that amount of heat from the head (figure 11.30). 
dT and $V$ combination to effect 20W cooling

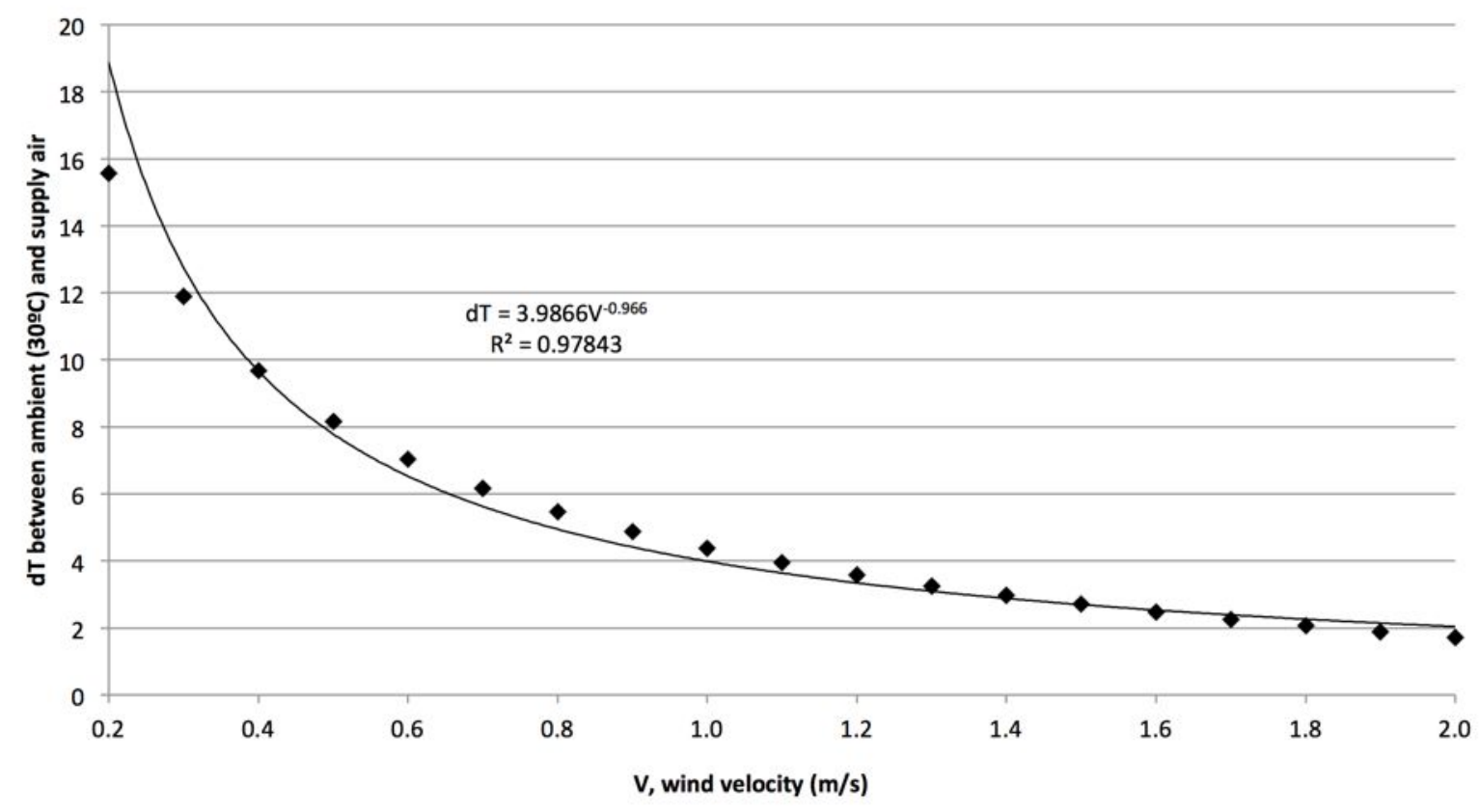

Figure 10.31: Combined relationship between $d T$ and $v$ to effect $20 \mathrm{~W}$ of cooling.

The room $\mathrm{T}$ is here assumed as $30^{\circ} \mathrm{C}$ (to fit the regression analysis where the power function cannot accept 0 or negative dT values). In the climate chamber where ambient $\mathrm{T}$ was $28^{\circ} \mathrm{C}$ and typical fan speed was about $1 \mathrm{~m} / \mathrm{s}$, where only $2^{\circ} \mathrm{C}$ cooling was required. At a velocity of $1 \mathrm{~m} / \mathrm{s}$, this model approximates well with the experimental findings for a target $\mathrm{T} \approx 26^{\circ} \mathrm{C}$. On top of this model it is recommended to have an extra margin to cater for mental metabolism of an active mind and for the transient demand for extra cooling after having lunch in warm eateries. Whilst increasing wind velocity is the energetically efficient mode of improving convective cooling, from the field trials with staff it was found that user satisfaction was rapidly lost if strong winds were deemed to mess the hair, dry contact lenses or dehydrate skin. $1 \mathrm{~m} / \mathrm{s}$ will be the preferred upper limit for prolonged air movement across the face. Further cooling will have to be delivered by lowering air temperaure.

\subsection{Concluding thoughts on the experiment}

Field trials were held with DTAC and a fan-only control in naturally ventilated offices with staff volunteers but the lack of diligence in filling up the questionnaire yielded no meaningful results. Even so there were intriguing outcomes from the experiment. 
1. Through discussion with the staff involved in the trial, the tedium of filling out survey forms was clear, and this task was found to be an intrusion into the routine and focus for work, committed as they would have liked to have been for the experiment. Under these circumstances, one was less likely to contemplate the state mind which expresses satisfaction with the thermal environment, and more inclined to get through the task of filling the survey and returning to work. Under work pressure it was apparent that the most convenient response was to pick a vote in the midrange.

2. Some staff were also particularly pedantic about the semantics of the survey, which brings to mind the differences in attitudes between students (typical of climate chamber experiments) and academics or other mature thinkers, who were as concerned with the connotation of words as they are with its denotation. For example, would a vote of 'very uncomfortable' be taken as an imprecation on fellow architects who designed an environmentally sensitive building making assumptions for greater adaptive opportunities?

3. With older participants, the demand on the environment tended to be more onerous. A number of participants could not isolate thermal comfort from other aspects of comfort and felt that the entire environment (including the seating, lighting, acoustics and air quality) had to be taken into account of their state of mind for them to be 'thermally comfortable'.

4. Making an experiment successful, even amongst academics, was secondary to their core work. Better results could be obtained by working with students, who are not distracted with other priorities.

Hence subsequently, a climate chamber was set up for a trial using students working towards a prize. The experimental method showed that occupants in an otherwise uncomfortable condition could be cooled to (only just) comfortable conditions with DTAC. The acceptability of the conditions match the design parameters for personalised ventilation (see table 9.2) from other researchers. Calculations showed that the primary 
cooling effect was that from air movement, and this was confirmed by the similar results of the 'fan only' blind test.

DTAC however, did not deliver as expected in bringing sensation to 'slightly cool' and comfort to 'very comfortable'. As fan speeds were approaching the acceptable draft limits, it appears that the cooling power should be increased in a manufactured version to cater to more demanding occupants and conditions.

Fan noise was expressed to be a major annoyance in the use of DTAC. Participants gave feedback that if the fan was quiet they would have been more inclined to turn up the fan and not rely so much on TE cooling. The drone of the fan actually made some participants more sleepy. The air movement was also found to be the most responsive to control and achieving the desired comfort.

Greater cooling and quieter operation are the priorities for future development of DTAC. We will consider a few others in the next chapter. 


\section{Future Research}

\subsection{The future of DTAC}

Up to the end of this thesis the DTAC has been developed solely to improve personal thermal comfort by providing a stream of air that has been chilled a few degrees below ambient conditions. As a complete personal climate control solution it will have to address indoor air quality as well. Preliminary thoughts for the future design is illustrated in figure 12.1. with suggested IAQ improvement in figure 12.2. A two-stage IAQ improvement is proposed:

1. removal of particulate matter and gaseous pollutants

2. sanitisation of cool air

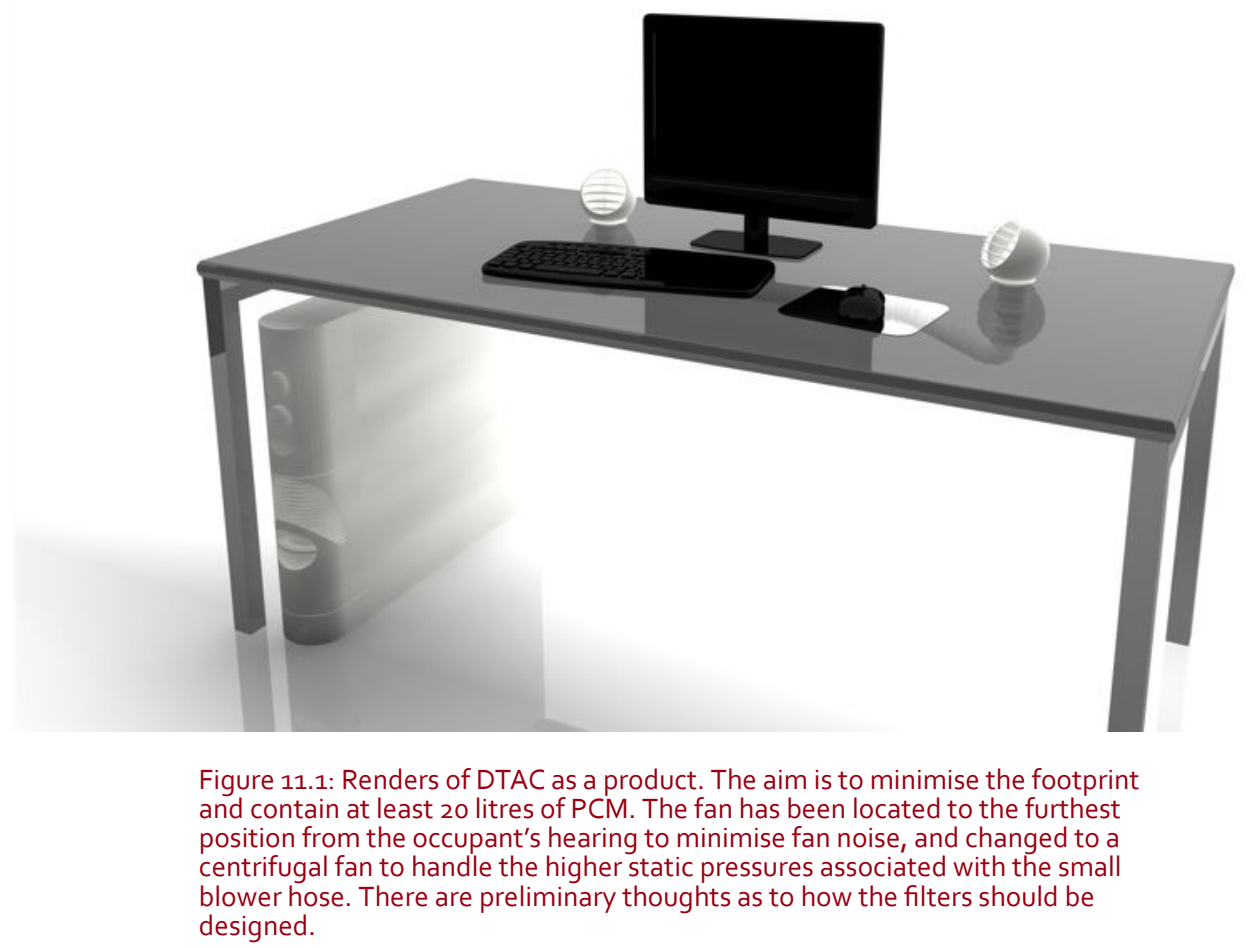




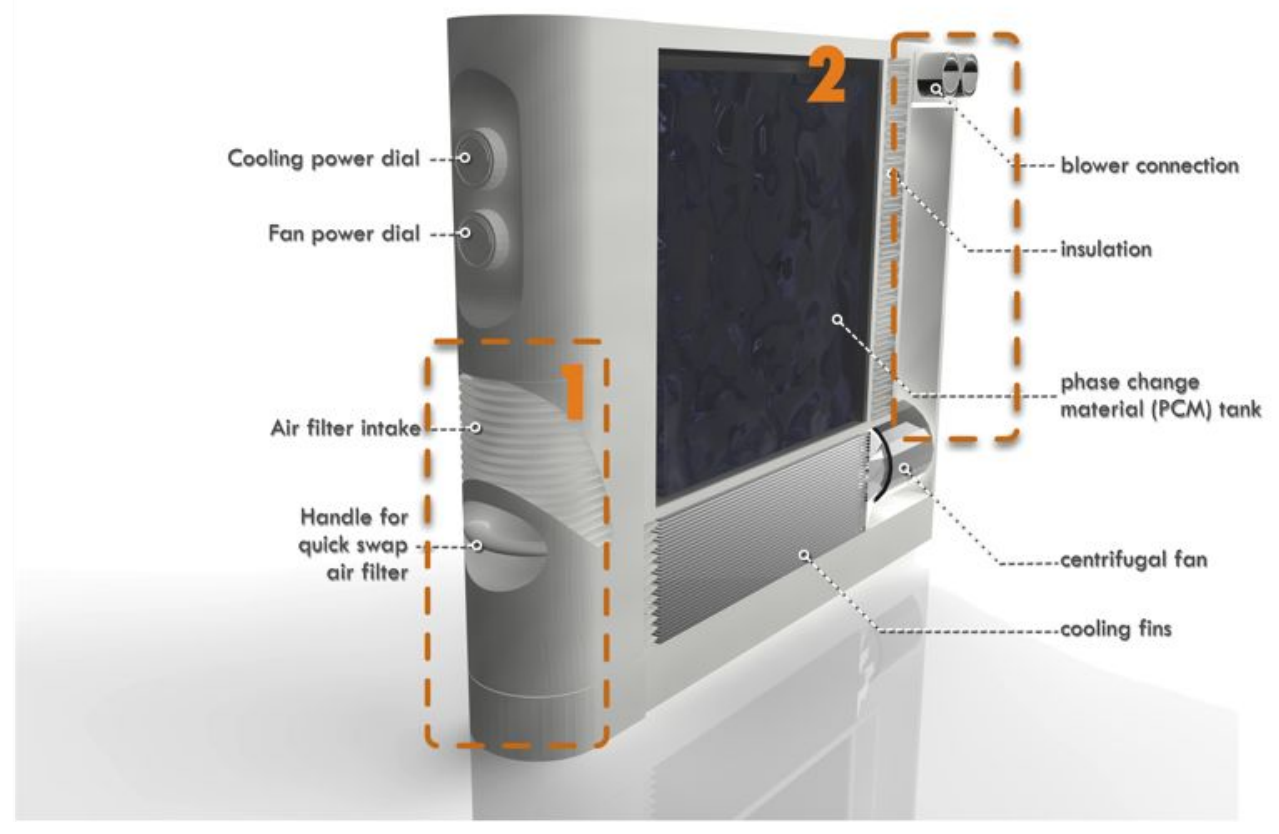

Figure 11.2: Two main areas of improvement to IAQ. The quick swap filter in region 1 provides dehumidification, particulate filtration and gas filtrationand is user-operated. Sanitisation occurs at region 2 and because of safety concerns, should only be maintained by specialist.

\section{Air Filtration}

Air filtration is one of the most effective and affordable method of improving air quality. Fisk (1999) estimates the maintenance of filter at $\$ 23 / \mathrm{pax} / \mathrm{yr}$ for high efficiency $(0.3 \mu \mathrm{m})$ filter replacement. Since DTAC only filters the air that is delivered directly to the occupant, the cost of maintaining air filters will be even lower than this. At the same time it must be appreciated that the occupants are unlikely to replace the filters unless it is easily accessible and the improvements to air quality is perceivable. The production version of DTAC will need to feature a front-access filter that can be easily swopped without tools and without dust balls falling around. This "quick swop air filter" can even be maintained by contractors that periodically replace all the DTAC filters in the office floor.

Particulate matter can be removed by a number of established means like particulate filters, electrostatic filters or High Efficiency Particulate Air (HEPA) filters. Where DTAC is used as a supplementary air-filter and air-conditioner, the assumption is that the ambient air will already be regulated in humidity and particular matter. Only a MERV 13 or finer filter is required to remove the small particles and improve air quality. Electrostatic and HEPA filters also work better where particulate loads are not high. 
In some rapidly developing cities pedestrians and motorcyclists often travel with masks and give some indication to the degree of pollution. If DTAC was used in a naturally ventilated application in a polluted city then it may warrant a two-stage filter, suh as a MERV 8 prefilter followed by a MERV 13 final filter. With the higher static drop a more powerful fan will be needed. Though this will result in higher fan noise, it can be assumed that will be less of a concern in naturally ventilated buildings along busy roads.

\section{Dehumidification}

DTAC was intended to be operated only above dew point. As such the cooling fins have not been designed to be self-draining, and no condensate collection or discharge has been built in. The energy needed to dehumidify air through the TE modules at present efficiencies are not attractive.

If dehumidification was necessary, such as in tropical natural ventilation, a desiccant should be employed to strip moisture from the air stream. The desiccant can be placed in a microwave oven at the end of the day to regenerate it, and left to cool, as the heat from the freshly microwaved desiccant will increase the cooling load. Furthermore, as the enthalpy of dehumidification will increase sensible heat, it is best when the desiccant is cooled before it is used. When the DTAC is switched off, the cartridge should automatically seal itself to reduce exposure of the desiccant to ambient moisture whilst it is cooling down.

As filtrating, disinfecting and gas removing processes are enhanced by dehumidification, the desiccant pack/honeycomb should be located upstream of the other processes.

\section{Removal of gaseous pollutants}

It needs to be clarified that $\mathrm{CO}_{2}$ is not associated with SBS under concentrations of $5000 \mathrm{ppm}$ (Wyon, 2000). In the office environment, the monitoring of $\mathrm{CO}_{2}$ is not so much a matter of concern in itself, but as a proxy for ventilation rates, Batterman \& Peng (1995) intimate, 'Probably the most important use of $\mathrm{CO}_{2}$ is as a crude indicator of ventilation efficiency, showing whether the supply of outdoor air is sufficient to dilute air contaminants.' (unpaginated, ' $\mathrm{CO}_{2} \& T V O C$ '?1) 
One of the benefits of personal ventilation is that it brings freshly filtered air, together with a proportion of outdoor air, into the breathing zone. DTAC on the other hand is limited to the air that is already in the room which is mixed with materials and equipments that are off-gassing. There is an engineering adage, 'The solution to pollution is not dilution.' Hence, gaseous pollutant sources are best stemmed at source. Failing which, the option for DTAC is to have gas filtration.

To have ductless improvement of IAQ, two methods exist:

1. Use of organisms to absorb and/or break down the compounds

2. Use of solid filters that trap the compounds

One way of dealing with the excessive pollution in New Delhi, India, is to utilise areca palms (oxygen production) and money plants (VOC absorption), as recommended by Meattle (2009) who implemented a roof floor of indoor plants as the "outdoor air supply" for the ACMV system at the Paharpur Business Centre and Software Technology Incubator Park. Figure 12.3 shows a photograph of the green house and the ACMV schematic. The main disadvantage of this system is the increased latent load from the water sprays and plant transpiration.
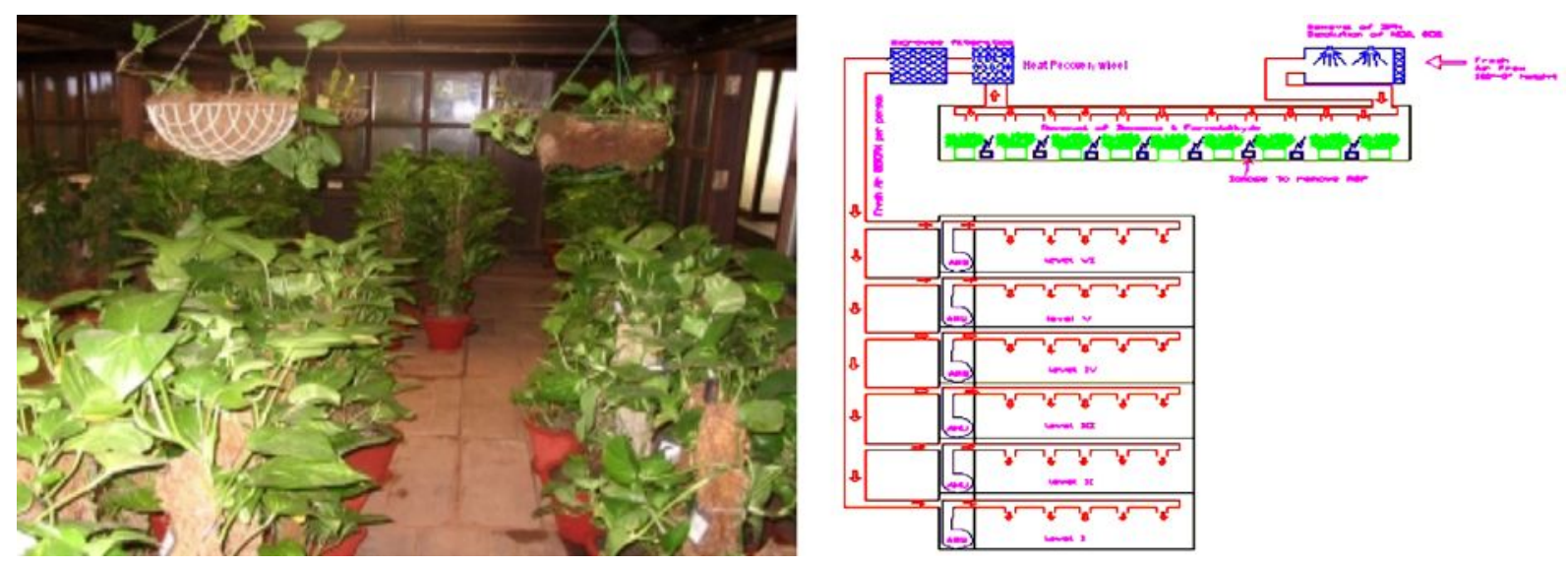

Figure 11.3: (a) Rooftop green house and (b) ACMV system schematic of Paharpur Business Centre and Software Technology Incubator Park (www.pbcnet.com)

Alternatively a NASA report (Wolverton,1989) explicated relationship of indoor plants and air quality, especially when air was passed through the root system (see figure 12.4) as the 
soil microorganisms are 'capable of biodegrading toxic chemicals when activated by plant root growth.' (p.15)

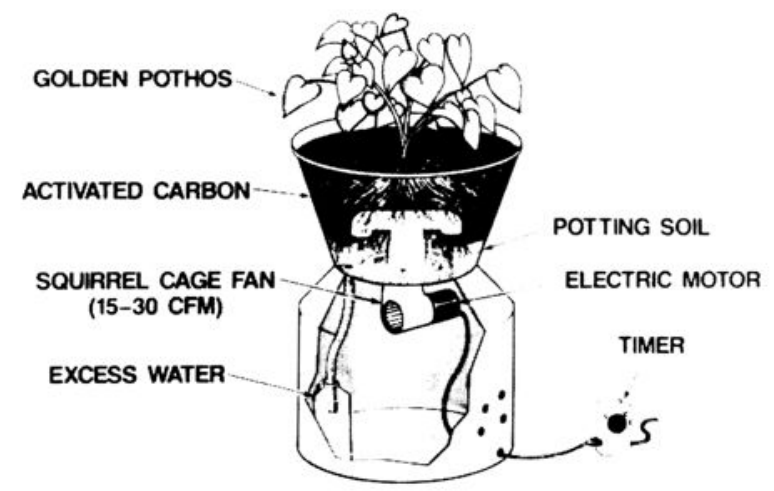

Figure 11.4: Indoor air purification system combining houseplants and activated carbon. (Wolverton, 1989)

The use of indoor plants is possible in offices with abundant natural light and will work for the perimeter of fully-glazed offices. For non-organic pollutant removal, molecular sieves can be employed. Predominantly used for gas purification, molecular sieves can strip vapour molecules by trapping them in the crystalline lattice sized for a particular kinetic diameter. Alternatively an activated carbon honeycomb can remove odours, beside VOCs.

\section{Disinfection with UV and photocatalyst}

A recent study undertaken in a university classroom found that the human microbial taxa unique to the human skin (Propionibacterineae, Staphylococcus, Enterobacteriaceae, and Corynebacterineae) were enriched by 3.5 times relative to outdoor airborne bacteria (Qian et. al., 2012).

In hospitals UV-C arrays are installed in ducts to sanitise the supply air. These are characterised by high intensity tubes as the flow rates are high and consequently the exposure time short. To maximise the exposure time in the DTAC, UV-C tubes will be best installed not with air filters but at the risers after the fan. To further improve on sanitisation, $\mathrm{TiO}_{2}$ photocatalysts can be employed in conjunction with UV-C (Hashimoto, Irie, \& Fujishima, 2005; Chuaybamroong et al., 2010). 


\section{Thermal variation}

A Toyota patent (Taniguchi, 1993) expresses the need to solve the problem of thermal monotony in the car when the target temperature is reached and suggests that comfort, after acclimatisation to, eventually becomes discomfort. Thermal variation can be achieved by changing the blower velocities or supply temperature. Taniguchi's patent suggest that velocity variations, whilst technically easier to implement, result in noise disturbance. Variable refrigerant flow and variable refrigerant volume are technically complex processes with vapour-compression cycles, but varying refrigerant loads are straightforward with TE modules. It only requires a PSU with variable regulated output voltage (and the accompanying current draw). Automatic thermal variation can be created with a wave generator in line with the voltage selector (potentiometer). The wave amplitude and interval will need future testing to be determined, my preliminary estimate is between $\pm 0.5 \mathrm{~V}$ and $\pm 2 \mathrm{~V}$ of the selected voltage, and over a wave period of 2 to 15 minutes.

\section{Industrial design}

To bring the product to market funds were raised through the Commercialisation Australia Skills and Knowledge Grant for the purposes of engineering optimisation of the cooling fin design and the industrial design.

Industrial design plays a major part in making the sale. It is the crucial last step where research ideas are prepared for a pitch to likely investors and manufacturers. A render by Sydney-based industrial designer Tiller Design is illustrated in figure 12.5 and 12.6. A particular point made to the industrial designers was that it was not solely a matter of appearance, but noise generated from devices could also influence the perception of quality (Fenko, Schifferstein, \& Hekkert, 2011). 


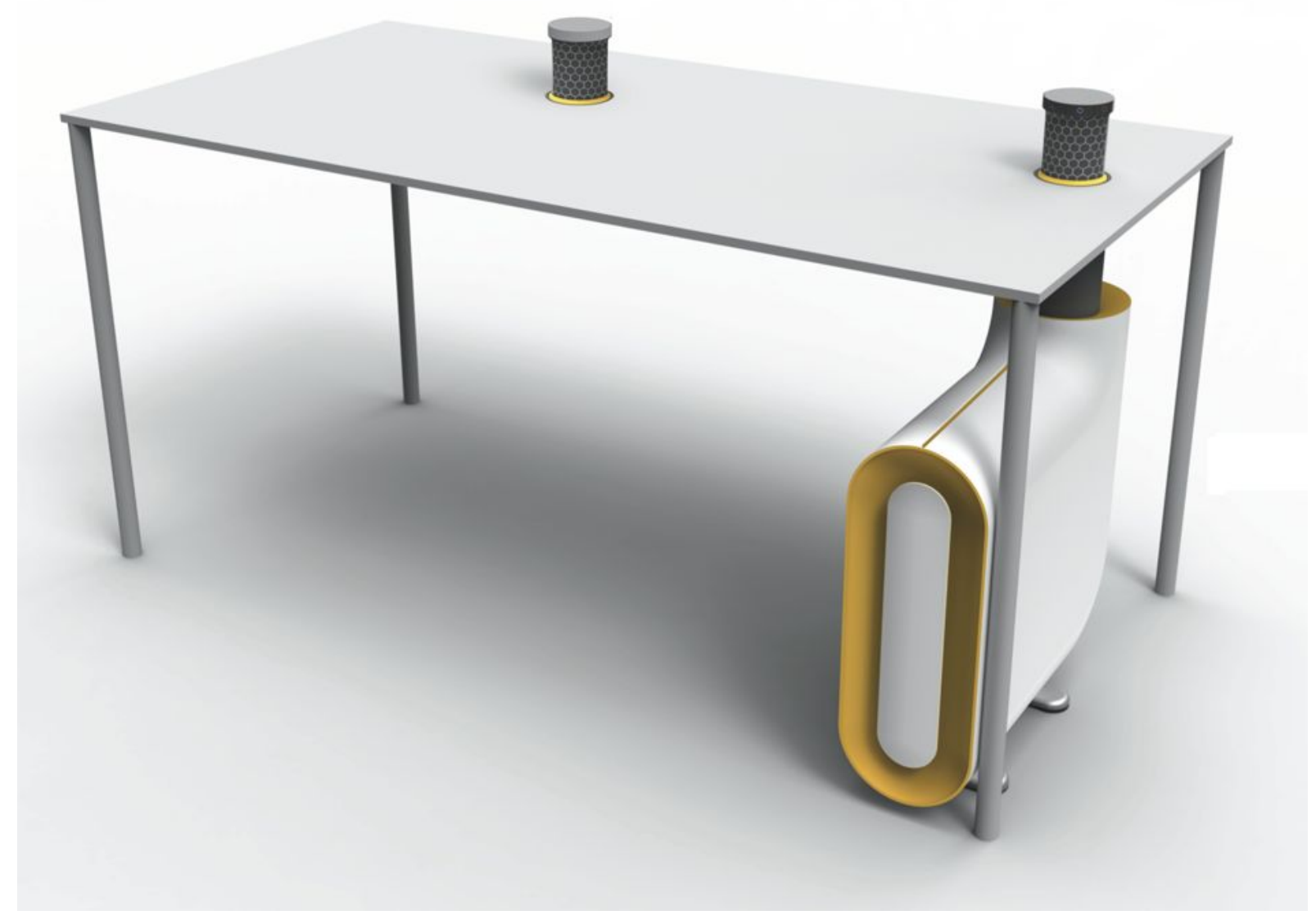

Figure 11.5: Industrial designer's artist impression (Tiller Design)

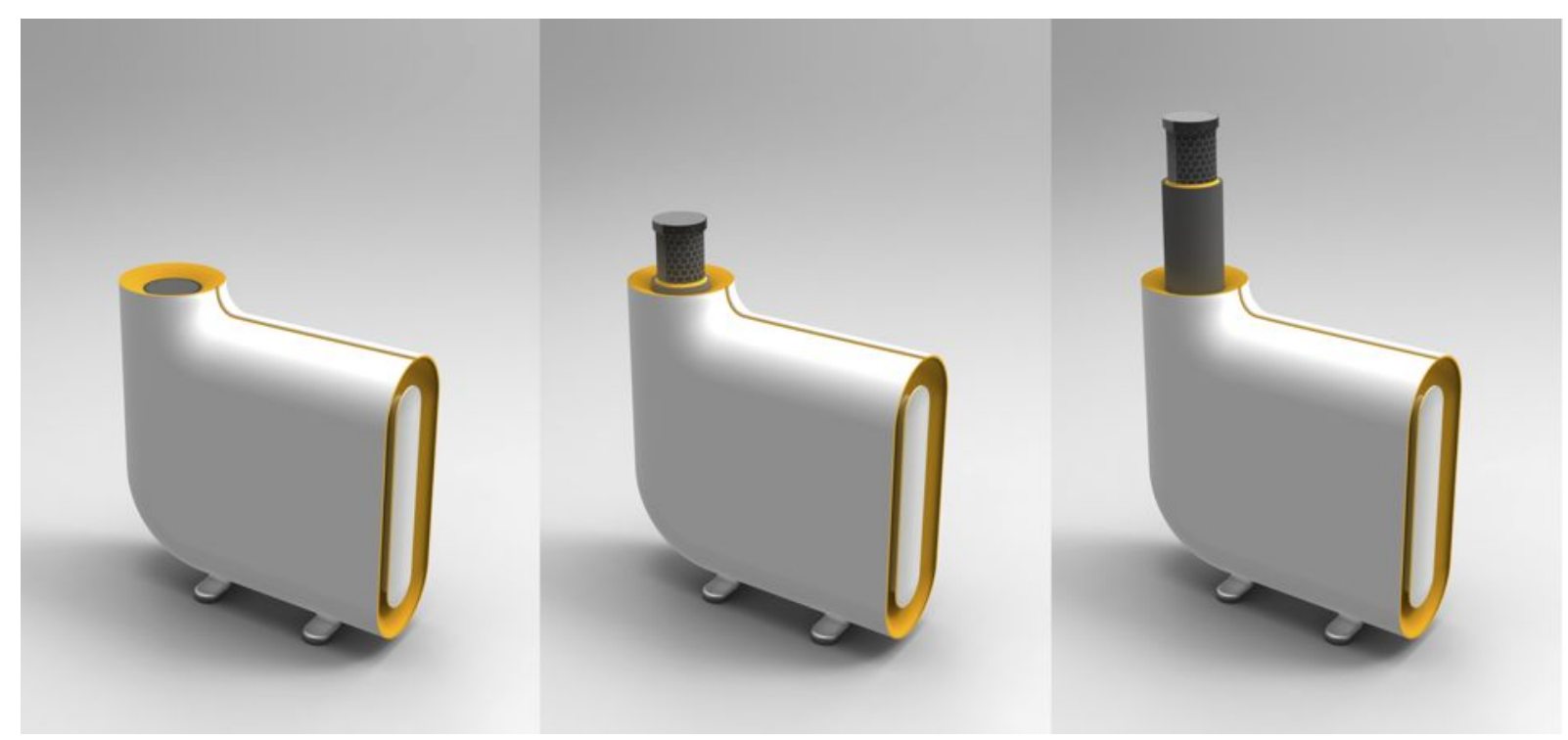

Figure 11.6: DTAC in various applications: (a) with blower grille fully retracted, (b) to be used beside a sofa or bed as a standalone unit, and (c) with the turret raised to meet the table surface so that the grille can be retracted and made flush with tabletop (Tiller Design) 


\section{Usage by the elderly}

The elderly can be especially at risk because perception of ambient temperature is poorer, so they do not always recognise that they are over heating (Kovats 2006 in (Nicholls, 2007)).

Whilst the elderly are highly prone to heat injury in a heat wave, they are also the most resistant to having air-conditioning installed for reasons of cost and inconvenience. DTAC circumvents these issues, and as a personal device it can offer the added functionality of alerting the user of the need to switch it on under high ambient temperature.

Or, as a classic example, normal body temperature, 98.6 degrees, does not change with age. Nevertheless, aged bodies are impaired in mounting a thermoregulatory stress-response, and thus it takes the bodies of the elderly longer to restore a normal temperature after being warmed or chilled. (Sapolsky, 2004)

If a cellular mobile service can be integrated in the DTAC it can receive weather forecasts over SMS (Short Message Service), together with heat wave alerts of the type proposed by Nicholls, Skinner, Loughnan, \& Tapper (2007) discussed in Chapter 2. A warning light on the DTAC unit will be illuminated when extra cooling is recommended for the current weather conditions.

\subsection{A possible future for thermal comfort research: research-innovate- commercialise}

Thermal comfort is a complex problem. There are many theories, each attempting to explain the desire for comfort and how it is achieved. Yet each theory is fraught with limitations. To make this problem worse, everyone is, in a sense, an authority on thermal comfort. This is because the variables that affect comfort have to be aggregated into a perception, and one is after all the best judge to his own perception of comfort. So one can only know for oneself whether one is comfortable. If we agree that the occupant knows best, then there is clear indication that the thrust for the future is in a more customisable microclimate. However whilst personal ventilation already exists, it cannot be readily implemented in existing offices.

Thermal comfort researchers may need to go beyond describing the conditions of comfort, and embark on designing the implements that achieve those conditions. The call of the 
future is to go beyond data analysis, and to design, engineer and manufacture. If we agree with Richard Levin that 'the fate of the planet depends on our ability ... to solve society's most pressing problems' (Gallagher, 2011), then the call of the future is for solutions, which means researchers also have to invent. 


\section{2 conclusion}

I have written this thesis not only as a document for examination, but as an account of a four-year long research program. Thus even though DTAC was the culmination of this program, this thesis is not about DTAC as a technology in itself. Instead I have looked at the state of the world and the role that air-conditioning has played in it, especially in knowledge-based economies located in the tropics, for which I have used my homeland Singapore as a case in point. I have presented my understanding of how the airconditioning problem came to be and how it has persisted despite the research behind adaptive comfort standards that evidence the possibility of comfort without airconditioning even in challenging climates.

In Chapter 2 we set the context of the problem, presenting the immoderate adoption of airconditioning as a significant contributor to the global warming phenomenon.

In Chapter 3, I have made the distinction between temperature that is comfortable for work as opposed to being comfortable for relaxation. Whilst self-evident, I have laboured the need to distinguish between muscular and mental metabolism, showing how under realworld work scenarios the physiological stress response has been one that generally increases core temperatures, especially the brain temperature, even though office occupants are typically seen to be as sedentary as a relaxed person in terms of physical metabolism.

I have argued that it is the quality of comfort that differs between the adaptive comfort standard and the deterministic one. The adaptive model works on the premise that occupants in an equatorial climate tolerate much higher temperatures by adaptation. However, I theorised that this tolerance comes with relinquishing the speed of mental performance, a sacrifice that is deemed to costly in a knowledge-based economy like Singapore. Thus we find that in Singapore, and other tropical cities where occupants have been routinely exposed to air-conditioning, the preferred indoor temperatures are much closer to PMV standards. This acclimatised addiction is not merely physiological but 
psychological as well. Decades of marketing where air-conditioning was presented as a the enabler of greater productivity has been imbibed by consumer society today, transforming a luxury good into a present day necessity.

Mental metabolism explained why an occupant would choose air-conditioning over natural ventilation. It further explained the preference for colder temperatures in the field compared to the climate chambers on which PMV was derived. However, how credible was this theory? In chapter 4, we looked at the evidence for the heating of the brain under stress, and the need for the brain cooling mechanism to protect this vital organ.

From here we could have jumped to Chapter 9 where the solution to an overheated brain was provided by means of an invention for facial cooling, but I have chosen not to make this leap. In Lakatos' words, this would have stripped the proof from the proof-ancestors and presented it in a pretentious and peremptory manner.

Hence in chapter 5 I explained how different methods of cooling could be determined and ranked by comfort energetics. With $\frac{\text { Watts }}{V o t e}$ as a common unit to compare cooling techniques, dehumidification was clearly an energetically inefficient approach and was investigated at length to challenge the accepted norm of an optimum RH range. In the tally, the two most efficient cooling methods were refrigeration of air and moving it with low-power computer fans. Both of these were later adopted in DTAC.

In chapter 6 I explained why the research program, and consequently this thesis, have been structured on heuristic principles. I have retained much of the method of Lakatos and included a few more considerations to facilitate the technology transfer from academia to the world of commerce.

In chapters 7 and 8 I detailed the inventions preceding DTAC and why, even though failing to solve the problem, they have nevertheless enriched the final solution. My failings, together with those of other sound scientific ideas discussed in case studies, can be accounted for by their lack of commercial consideration. In these chapters I demonstrated the integral role of commercialisation in a problem-solving program. 
Finally, it was the invention of DTAC (chapter 9) that satisfied the commercialisation test. The invention was subject to experimentation firstly to prove it could cool air and regenerate the PCM overnight, and secondly to prove that it could improve the thermal comfort of occupants. Through a series of optimisation efforts (appendix 1), the first criteria was satisfied. The second however, had not been unequivocally determined in the field trials (chapter 11), though there were indications that it could have been achieved had the cooling fins been more efficient. Falling beyond the scope of the present study and budget, I left that as one of many things to be improved on in future versions of DTAC, as proposed in chapter 12.

During my candidature I have had, on occasions, to justify:

1. why inventing should be considered as a legitimate part of academic research,

2. why commercialisation should be considered in research,

3. why problem-solving should be considered an acceptable method.

To this I respond, it is a matter of being relevant.

Firstly, when scientists are liberated from preconceived limitations, many important discoveries and inventions emerged (New Scientist, 2009). Often the distinction between weird and wonderful is a question of an invention's relevance to humanity - we dismiss as incredulous an invention with no practical worth. It is the academic moorings that keeps innovation on a purposeful path. In this sense, an invention is the outcome and embodiment of academic knowledge. Inventing is a form of applied research that keeps basic research relevant to society at large. It makes theory practical, and thus relevant.

Secondly, being scientifically sound has also been demonstrably inadequate to solve problems, as seen in the case studies of the Solar Chimney, Australian 2020 Stationary Energy Plan and Skytherm Roof. Scientists need to consider the commercialisation of their research in order to have a path to market in a capitalistic society. We need to steer from the mentality that scientists are only concerned with producing the bitter-pill and an imaginary someone else will convince the politicians and citizenry to swallow it. As illustrated in the imaginary (Socratic) dialogue with mock investors (chapter 6), the 
solutions from research need to be relevant to the business interest of investors, and this must happen at the very inception of any innovation-based research program. This alternative mind-set sits uneasily with many academics, but is central if an idea is to survive outside the university.

Thirdly, thermal comfort is an architectural problem because it involves an appreciation for architectural science that is antecedent to architectural design. Failure to view comfort as a design consideration is precisely one of the causes for the business as usual scenario in instances where architects have abdicated this responsibility to other professionals who have no direct influence on design. Hence, thermal comfort should be fundamental to building design and operation, with the expectation of consuming as few resources as practical.

Additionally, the design-critique process distinct to Architecture among academic disciplines, is the accepted pedagogy of design instruction, and a system that lends itself well to problem solving. We have seen that research-based problem solving requires researchers to navigate very complex issues involving an interdisciplinary understanding. In my case, it has been the following:

1. Engineering: calculations and optimisation. Ability to use physics to model, simulate and predict outcomes.

2. Medical physiology: understanding the stress response, thermal regulation and brain cooling.

3. Sociology: the role of marketing, mass-consciousness and consumer society.

4. Philosophy: an epistemological approach to sensation, using alliesthesia and hedonism to explain comfort and behaviour. Cognitive performance in the global workspace theory.

5. Professional exposure: understanding motivational drivers behind architects, engineers and property developers.

6. Commercialisation: sensitivity to price signals, market positioning. Being able to pitch, to take commercial considerations into the design process. Understanding the real-world impediments to implementation. 
These disciplines had to be understood and their implications consolidated into a comprehensible and actionable proposition. My training in architecture has helped me appreciate complex problems and to handle multiple considerations concurrently. Particularly relevant was the use of design thinking where the search for an answer was not directed to a research question, but to a design brief.

Throughout this thesis spanning wide-ranging disciplines, one of the challenges was finding the most appropriate and telling illustrations. In my case (and true to my Singaporean identity) I have used food in many analogies; talking of sushi, Pepsis, coffee and connoisseurs (to name a few). If you will indulge another note on food, I would leave you with a concluding observation from Singaporean engineer Lee Eng Lock (Hawken, Lovins, \& Lovins, 1999, p.123):

\footnotetext{
To save land (very costly in Singapore), he [the engineer] untangles and compacts plant layouts so they take up less space, yet are easier to maintain. Space, money, metal, energy, time, words - he uses just the right amount of every resource, in the right place and time and manner. Every input and result is measured, nothing is guessed. Energy is used frugally, then recaptured and reused until almost nothing is left. When he was once congratulated on devising an especially clever way to use a building's outgoing air to pre-dry its incoming fresh air, using no energy and no moving parts, Mr. Lee replied: 'Like Chinese cooking. Use everything. Eat the feet.'
}

In a world with diminishing energy sources and alarmingly dwindling environmental sinks, the approach that we take towards attaining thermal comfort will play a huge role in its future. 


\section{References}

ABC News. (2008). 10 Baffling Medical Conditions. ABC News. Retrieved March 30, 2012, from http://abcnews.go.com/Health/ ColdandFluNews/ story?id=6378009\&page=1\#.T3Ulto6Ggao

ABC News. (2011). Report warns of deadly climate change - ABC News (Australian Broadcasting Corporation)

Ackermann, M. (2002). Cool Comfort: America's Romance with Air-Conditioning. Smithsonian.

Adams, J. L. (2001). Conceptual Blockbusting: A Guide to Better ldeas (4th ed.). Basic Books.

Adger, W. N., Dessai, S., Goulden, M., Hulme, M., Lorenzoni, I., Nelson, D. R., Naess, L. O., et al. (2008). Are there social limits to adaptation to climate change? Climatic Change, 93(3-4), 335-354.

Alfano, G., \& d' Ambrosio, F. R. (1991). Clothing: An essential individual adjustment factor for obtaining general thermal comfort. Environment International, 17(4), 205-209.

Ali, Z., Tatlah, I. A., \& Saeed, M. (2011). Motivation and Student's Behavior: A Tertiary Level Study. International Journal of Psychology and Counseling, 3(2), 29-32.

Allen, E., \& lano, J. (2002). The Architect's Studio Companion, 3rd Edition (3rd ed.). Wiley.

Andamon, M. M. (2005). Building climatology and thermal comfort: themal environments and occupant (comfort) responses in Philippine office buildings (PhD). University of Adelaide.

Ansari, F. A., Mokhtar, A. S., Abbas, K. A., \& Adam, N. M. (2005). A Simple Approach for Building Cooling Load Estimation. American Journal of Environmental Sciences, 1(3), 209-212.

ASHRAE. (2005). 2005 ASHRAE handbook: fundamentals. American Society of Heating, Refrigerating \& Air Conditioning Engineers, Incorporated.

ASHRAE. (2009). ASHRAE Position Document on Airborne Infectious Diseases.

ASHRAE. (2010). Standard 55: Thermal Environmental Conditions for Human Occupancy.

Attia, M., Engel, P., \& Hildebrandt, G. (1980). Thermal comfort during work. International Archives of Occupational and Environmental Health, 45(3), 205-215.

Auliciems, A. (1981). Towards a psycho-physiological model of thermal perception. International Journal of Biometeorology, 25(2), 109-122.

Australian Institute of Refrigeration, Air Conditioning and Heating. (1995). Handbook/The Australian Institute of Refrigeration, Air Conditioning and Heating. [Adelaide, S. Australia]
Austrlian Flurocarbon Council. (2001). The Australian Refrigeration and Air-conditioning Code of Good Practice. HB 40.1.

Baars, B. J. (1993). How does a serial, integrated and very limited stream of consciousness emerge from a nervous system that is mostly unconscious, distributed, parallel and of enormous capacity? Ciba Foundation symposium, 174, 282-290; discussion 291-303.

Baker, N. (1996). The Irritable Occupant: Recent Developments in Thermal Comfort Theory. Architectural Research Quarterly, 2(02), 84-90.

Baskin, E., \& Vineyard, E. A. (2003). Thermal Comfort Assessment of Conventional and HighVelocity Distribution Systems for Cooling Season. ASHRAE Transactions, 109(1).

Battan, L. J. (2003). Cloud Physics: A Popular Introduction to Applied Meteorology. Dover Publications.

Batterman, S., \& Peng, C. (1995). TVOC and CO2 concentrations as indicators in indoor air quality studies. American Industrial Hygiene Association Journal, 56(1), 55.

Bauman, F., Baughman, A., Carter, G., \& Arens, E. (1997). A Field Study of PEM (Personal Environmental Module) Performance in Bank of America's San Francisco Office Buildings. UC Berkeley report submitted to Johnson Controls World Services, Inc.

BBC. (2002). The Century of the Self. Documentary.

Bedford, T. (1936). The warmth factor in comfort at work: a physiological study of heating and ventilation. H. M. Stationery off.

Berger, J. J. (1998). Charging Ahead: The Business of Renewable Energy and What It Means for America (1st ed.). University of California Press.

Bevan, J. A. (1983). The human adrenergic neurovascular mechanism. General Pharmacology: The Vascular System, 14(1), 21-26.

Biggart, N. W., \& Lutzenhiser, L. (2007). Economic Sociology and the Social Problem of Energy Inefficiency. American Behavioral Scientist, 50(8), 1070-1087.

Blain, L. (2011). Twice the height of the Empire State EnviroMission plans massive solar tower for Arizona. Retrieved June 1, 2012, from http://www.gizmag.com/enviromission-solartower-arizona-clean-energy-renewable/ 19287/

Bobenhausen, W. (1994). Simplified design of HVAC systems. Parker-Ambrose series of simplified design guides. New York: Wiley.

Brager, G. S., \& Dear, R. de. (2001). Climate, Comfort, \& Natural Ventilation: A new adaptive comfort 
standard for ASHRAE Standard 55. Moving Thermal Comfort Standards into the 21st Century. Windsor, UK.

Brill, M. (1984). Using Office Design to Increase Productivity. Bosti Studies.

Brown, A. M. (2004). Brain glycogen re - awakened. Journal of Neurochemistry, 89(3), 537-552.

Cabanac, M, \& Caputa, M. (1979). Open loop increase in trunk temperature produced by face cooling in working humans. The Journal of Physiology, 289, 163-174.

Cabanac, Michel. (1995). Human Selective Brain Cooling. R G Landes Co.

Calvino, F., La Gennusa, M., Rizzo, G., \& Scaccianoce, G. (2004). The control of indoor thermal comfort conditions: introducing a fuzzy adaptive controller. Energy and Buildings, 36(2), 97-102.

Cassidy, J. P., Phero, J. C., \& Grau, W. H. (1986). Epinephrine: Systemic Effects and Varying Concentrations in Local Anesthesia. Anesthesia Progress, 33(6), 289-297.

Charles, K. E. (2003). Fanger's Thermal Comfort and Draught Models. Institute for Research in Construction National Research Council of Canada, Ottawa, K1A 0R6, Canada.

Cheney, M. (1989). Tesla, man out of time. Dorset Press.

Cherian, G. (2000). Singapore: The air-conditioned nation: essays on the politics of comfort and control, 1990-2000. Landmark Books.

Chiang, H.-C., Pan, C., Wu, H.-S., \& Yang, B.-C. (2007). Measurement of Flow Characteristics of a Ceiling Fan with Varying Rotational Speed. Proceedings of Clima 2007 WellBeing Indoors. Presented at the Clima 2007 Wellbeing Indoors: REHVA World Congress, Helsinki, Finland.

Chuaybamroong, P., Chotigawin, R., Supothina, S., Sribenjalux, P., Larpkiattaworn, S., \& Wu, C.-Y. (2010). Efficacy of photocatalytic HEPA filter on microorganism removal. Indoor Air, 20(3), 246-254.

CIBSE. (1999). CIBSE Technical Memorandum Environmental Factors Affecting Office Worker Performance. London: Chartered Institution of Building Services Engineers.

Clean Energy Council. (2011). Clean Energy Australia 2010.

Cook, J. (1989). Passive Cooling. The MIT Press.

Costa, C. (2012). Evaporative Mist Indoor Fan Cools Like AC | GadgetReview. Retrieved October 19, 2012, from http://www.gadgetreview.com/ 2012/06/evaporative-mist-indoor-fan.html

de Dear, R. (2010). Past and Future of Thermal Comfort and the HVAC Industry. Presented at the AIRAH's 90th Anniversary Conference: HVAC\&R in the 21st Century, Sydney.

de Dear, R. J. (1998). A global database of thermal comfort field experiments. ASHRAE Transactions.

de Dear, R. J., Brager, G., \& Cooper, D. (1997). Developing an Adaptive Model of Thermal Comfort and Preference ( No. ASHRAE RP-
884). American Society of Heating, Refrigerating and Air Conditioning Engineers, Inc.

de Dear, R. J., \& Brager, G. S. (2002). Thermal comfort in naturally ventilated buildings: revisions to ASHRAE Standard 55. Energy and Buildings, 34(6), 549-561.

Department of Climate Change and Energy Efficiency. (2012). National targets. Retrieved April 26, 2012, from http://www.climatechange.gov.au/ government/reduce/national-targets.aspx

Dieckmann, J., Cooperman, A., \& Brodrick, J. (2011). Solid-State Cooling, Part 2. ASHRAE Jornal, 53(4), 66-68

Douglass, E. (2007). A pioneer refuses to fade away His passion for solar still burns. Los Angeles Times.

Dunklin, E. W., \& Puck, T. T. (1948). The Lethal Effect of Relative Humidity on Air-borne Bacteria. The Journal of Experimental Medicine, 87(2), 87-101.

Emmanuel, M. R. (2005). An Urban Approach to Climate-Sensitive Design. Oxon: Spon Press.

English, J. W., \& Moate, B. (2009). Discovering New Business Opportunities. Allen \& Unwin.

Fanger, P. O. (1970). Thermal Comfort. Copenhagen, Danish Technical Press.

Fanger, P. Ole, \& Toftum, J. (2002). Extension of the PMV model to non-air-conditioned buildings in warm climates. Energy and Buildings, 34(6), 533-536.

Federspiel, C. C., Bridges, B., \& Langkilde, G. (1998). Statistical analysis of unsolicited thermal sensation complaints in commercial buildings. ASHRAE Transactions, 104, 912.

Felten, D. L., \& Jozefowicz, R. (2003). Netter's Atlas of Human Neuroscience, 1e (1st ed.). Saunders.

Fenko, A., Schifferstein, H. N. J., \& Hekkert, P. (2011). Noisy Products: Does Appearance Matter? International Journal of Design, 5(3), 77-87.

Firecracker Films. (2009). Daredevils: The Ice Man.

Fishman, D. S., \& Pimbert, S. L. (1982). The thermal environment in offices. Energy and Buildings, 5(2), 109-116.

Fisk, W. J. (1999). Estimates Of Potential Nationwide Productivity And Health Benefits From Better Indoor Environments: An Update. Indoor Air Quality Handbook. McGraw Hill.

Food and Agriculture Organization of the United Nations. (2006). The State of Food Insecurity in the World.

Foster, H. (1983). The Anti-aesthetic: essays on postmodern culture. Bay Press.

Fountain, M., Arens, E. A., Xu, T., Bauman, F., \& Oguru, M. (1999). An Investigation of Thermal Comfort at High Humidities. ASHRAE Transactions, 105(2), 94-103.

Frank, R. H. (1999). 258136 Luxury Fever (New ed.). Princeton University Press.

Gallagher, S. (2011). Rankings can't measure this century's research. The Australian, p. 36. Australia.

Gallup, A. C., \& Hack, G. D. (2011). Human paranasal sinuses and selective brain cooling: A 
ventilation system activated by yawning? Medical Hypotheses, 77(6), 970-973.

Gisolfi, C. V., \& Mora, M. T. (2000). The hot brain: survival, temperature, and the human body. MIT Press.

Gladwell, M. (2004). The Ketchup Conundrum. The New Yorker, $6 \mathrm{Sep}$.

Gladwell, M. (2008). In the air: Who says big ideas are rare? The New Yorker, Annals of Innovation.

Hancock, P. A. (1986). Sustained attention under thermal stress. Psychological Bulletin, 99(2), 263-281.

Hancock, P. A., \& Vasmatzidis, I. (2003). Effects of heat stress on cognitive performance: the current state of knowledge. International Journal of Hyperthermia, 19(3), 355-372.

Halvoňová, Barbora, \& Melikov, A. K. (2008). Displacement ventilation in conjunction with personalized ventilation. Proceedings of the 11th International conference on Indoor Air Quality and Climate. Presented at the Indoor Air 2008, Copenhagen.

Halvoňová, Barbora, \& Melikov, A. K. (2010). Performance of "ductless" personalized ventilation in conjunction with displacement ventilation: Impact of disturbances due to walking person(s). Building and Environment, 45(2), 427-436.

Harriman, L., Brundrett, G., \& Kittler, R. (2008). Humidity Control Design Guide for Commercial and Institutional Buildings. American Society of Heating, Refrigerating and Air-Conditioning Engineers.

Hashimoto, K., Irie, H., \& Fujishima, A. (2005). TiO2 Photocatalysis: A Historical Overview and Future Prospects. Japanese Journal of Applied Physics, 44, 8269.

Haskell, E. H., Palca, J. W., Walker, J. M., Berger, R. J., \& Heller, H. C. (1981). Metabolism and thermoregulation during stages of sleep in humans exposed to heat and cold. Journal of Applied Physiology, 51(4), 948-954.

Hawken, P., Lovins, A. B., \& Lovins, L. H. (1999). Natural Capitalism: The Next Industrial Revolution. Earthscan.

Hay, H. R. (1967, January 24). Apparatus for Modulating the Temperature Within Enclosures.

Heath, C., \& Heath, D. (2007). Made to Stick: Why Some Ideas Survive and Others Die. Random House.

Hensel, H. (1981). ILL (Science) Thermoreception and Temperature Regulation. Monographs of the Physiological Society. London: Academic Press.

Heschong, L. (1979). Thermal Delight in Architecture (4th ed.). Cambridge: The MIT Press.

Hitchings, R., \& Lee, S. J. (2008). Air Conditioning and the Material Culture of Routine Human Encasement: The Case of Young People in Contemporary Singapore. Journal of Material Culture, 13(3), 251-265.
Hoof, J. van. (2008). Forty years of Fanger's model of thermal comfort: comfort for all? Indoor Air, 18(3), 182-201.

Höppe, P. (1999). The physiological equivalent temperature - a universal index for the biometeorological assessment of the thermal environment. International Journal of Biometeorology, 43(2), 71-75.

Houghton, D. (1998). Building Comfort with Less HVAC. Retrieved March 2, 2009, from http://archrecord.construction.com/ resources/conteduc/archives/research/ 12_98_1.asp

Hughes, L., \& McMichael, T. (2011). The Critical Decade: Climate Change and Health.

Humphreys, M. A. (1995). Thermal Comfort Temperatures and the Habits of Hobbits. Standards for Thermal Comfort (pp. 3-13). Windsor, UK: E \& FN Spon.

Humphreys, M. A. (1977). The optimum diameter for a globe thermometer for use indoors. Annals of Occupational Hygiene, 20(2), $135-140$

Humphreys, Michael A, \& Nicol, J. F. (1998). Understanding the adaptive approach to thermal comfort. ASHRAE Transactions, 104, 991-1004.

Humphreys, Michael A, \& Nicol, J. F. (2004). Do People Like to Feel "Neutral"? Response to the ASHRAE Scale of Subjective Warmth in Relation to Thermal Preference, Indoor and Outdoor Temperature/DISCUSSION. ASHRAE Transactions.

Humphreys, Michael A, \& Nicol, J. F. (2007). SelfAssessed Productivity and the Office Environment: Monthly Surveys in Five European Countries. ASHRAE Transactions, 113, 606-616

Incropera, F. P., \& DeWitt, D. P. (2007). Fundamentals of heat and mass transfer. John Wiley.

Irmak, M. K., Korkmaz, A., \& Erogul, O. (2004). Selective brain cooling seems to be a mechanism leading to human craniofacial diversity observed in different geographical regions. Medical Hypotheses, 63(6), 974-979.

ISO. (2005). ISO 7730 Ergonomics of the thermal environment -- Analytical determination and interpretation of thermal comfort using calculation of the PMV and PPD indices and local thermal comfort criteria.

Janich, P. (1990). Physiology and Language. Epistemological Questions About Scientific Theories of Perception. Thermoreception and Temperature Regulation (pp. 151-159). Berlin, Heidelberg: Springer-Verlag.

Johnson, R. H. (1966). The autonomic nervous system and body temperature. Proceedings of the Royal Society of Medicine, 59(5), 463-466.

Jones, S. R. G. (1992). Was There a Hawthorne Effect? American Journal of Sociology, 98(3), 451-468.

Jung, C. M., Melanson, E. L., Frydendall, E. J., Perreault, L., Eckel, R. H., \& Wright, K. P. (2011). Energy expenditure during sleep, sleep deprivation and sleep following sleep deprivation in adult 
humans. The Journal of Physiology, 589(1), 235-244.

Kamal Meattle on how to grow fresh air / Video on TED.com. (2009).

Karbowski, J. (2009). Thermodynamic constraints on neural dimensions, firing rates, brain temperature and size. Journal of Computational Neuroscience, (in press).

Key, S. (2011). One Simple Idea: Turn Your Dreams into a Licensing Goldmine While Letting Others Do the Work (1st ed.). McGraw-Hill.

Kilicarslan, A., \& Muller, N. (2004). COPs of R718 in Comparison with Other Modern Refrigerants. Proceedings of the First Cappadocia International Mechanical Engineering Symposium (pp. 317-323). Presented at the CMES '04, Cappadocia, Turkey.

Kinney, J. (1992). Introduction (to conference proceedings). Energy Metabolism - Tissue Determinants and Cellular Corollaries. Presented at the Clintec International Horizons Conference, Amsterdam: Raven Press.

Kishnani, N. (2002). Climate, buildings and occupant expectations: a comfort-based model for the design and operation of office buildings in hot-humid conditions. Curtin University of Technology.

Kluger, J. (2007). What Now For Our Feverish Planet? Time.

Kosonen, R., \& Tan, F. (2004). The effect of perceived indoor air quality on productivity loss. Energy and Buildings, 36(10), 981-986.

Kowalski, W. (2005). Aerobiological Engineering Handbook: Airborne Disease and Control Technologies (1st ed.). McGraw-Hill Professional.

Kunutsor, S. K., \& Powles, J. W. (2010). The effect of ambient temperature on blood pressure in a rural West African adult population: a crosssectional study. Cardiovascular Journal of Africa, 21(1), 17-20.

Lachner, J., Nellis, G. F., \& Reindl, D. T. (2007). The commercial feasibility of the use of water vapor as a refrigerant. International Journal of Refrigeration, 30(4), 699-708.

Laird Technologies. (2010). Thermoelectric Handbook.

Lakatos, I. (1980). Mathematics, Science and Epistemology: Volume 2, Philosophical Papers. (J. Worrall \& G. Currie, Eds.). Cambridge University Press.

Lakatos, I., Worrall, J., \& Currie, G. (1980). The Methodology of Scientific Research Programmes. Cambridge University Press.

Law, T. O., \& Fay, R. (2009). Thermal Comfort, Productivity and Energy Consumption in the Tropical Office Environment: A Critical Overview. Performative Ecologies in the Built Environment: Sustainability Research Across Disciplines. Presented at the 42nd International Architectural Science Association (ANZAScA) Conference, Launceston, Australia.

Lee, E. L. (2009). Private correspondence (Research in Air-conditioning Efficiency).
Lee, S. E. (2001). Energy Efficiency Of Office Buildings In Singapore. Presented at the Seminar on Energy Efficiency in Building Design.

Lighthart, B., \& Kim, J. (1989). Simulation of Airborne Microbial Droplet Transport. Applied and Environmental Microbiology, 55(9), 2349-2355.

Lin, Z., \& Deng, S. (2006). A questionnaire survey on sleeping thermal environment and bedroom air conditioning in high-rise residences in Hong Kong. Energy and Buildings, 38(11), 1302-1307.

Lomborg, B. (2007). COOL IT: The Skeptical Environmentalist's Guide to Global Warming. ALOUND, presented by the Library Foundation of Los Angeles. Los Angeles.

Lomborg, B. (2010). Smart Solutions to Climate Change: Comparing Costs and Benefits. Cambridge University Press.

Lord, R. (2008). Designing personnal micro-climates with workstation based air conditionoing. Ecolibrium, (Oct), 24-31.

Loubere, P. (2012). The Global Climate System. Retrieved June 1, 2012, from http://www.nature.com/scitable/knowledge/ library/the-global-climate-system-46362636

Lstiburek, J. (2008). Prioritizing Green-It's the Energy Stupid. Building Science Insight, 007.

Lutgens, F. K., \& Tarbuck, E. J. (1995). The Atmosphere (6th ed.). New Jersey: Prentice-Hall, Inc.

Maloney, S. K., \& Mitchell, G. (1997). Selective brain cooling: role of angularis oculi vein and nasal thermoreception. American Journal of Physiology - Regulatory, Integrative and Comparative Physiology, 273(3), R1108-R1116.

Marczyk, G. R., DeMatteo, D., \& Festinger, D. (2010). Essentials of Research Design and Methodology. John Wiley \& Sons.

Mariak, Z., White, M. D., Lewko, J., Lyson, T., \& Piekarski, P. (1999). Direct cooling of the human brain by heat loss from the upper respiratory tract. Journal of Applied Physiology, 87(5), 1609-1613.

Mazzei, P., Minichiello, F., \& Palma, D. (2005). HVAC dehumidification systems for thermal comfort: a critical review. Applied Thermal Engineering, 25(5-6), 677-707.

McCarthy, T. (1999). Lee Kuan Yew. Time.

McDonald, T. (2011). Solar snub for Australia. Retrieved June 1, 2012, from http://www.abc.net.au/pm/content/2011/ s3281405.htm

McGowan, S. (2010). Lowering the ceiling on heat loads. HVAC\&R Nation, May, 10-12.

McIntyre, D. A. (1976). Thermal sensation. A comparison of rating scales and cross modality matching. International Journal of Biometeorology, 20(4), 295-303.

Mclntyre, D. A. (1980). Indoor Climate. London: Applied Science Publishers.

Melikov, A. K., Cermak, R., \& Majer, M. (2002). Personalized ventilation: evaluation of 
different air terminal devices. Energy and Buildings, 34(8), 829-836.

Melikov, A. K. (2004). Personalized ventilation. Indoor Air, 14(s7), 157-167.

Melikov, Arsen K. (2011). Advanced Air Distribution. ASHRAE Journal, 53(11), 73-77.

Mellander, S., Andersson, P., Afzelius, L., \& Hellstrand, P. (1982). Neural beta - adrenergic dilatation of the facial vein in man Possible mechanism in emotional blushing. Acta Physiologica Scandinavica, 114(3), 393-399.

Mitchell, D., \& Wyndham, C. H. (1969). Comparison of Weighting Formulas for Calculating Mean Skin Temperature. Journal of Applied Physiology, 26(5), 616-622.

Muzet, A., Libert, J.-P., \& Candas, V. (1984). Ambient temperature and human sleep. Cellular and Molecular Life Sciences, 40(5), 425-429.

NCCC. (2006). Inter-Agency Committee on Energy Efficiency (IACEE) Report.

New Scientist. (2009). How to Make a Tornado: The strange and wonderful things that happen when scientists break free. Profile Books.

Nicholls, N., Skinner, C., Loughnan, M., \& Tapper, N. (2007). A simple heat alert system for Melbourne, Australia. International Journal of Biometeorology, 52(5), 375-384.

Nicol, F., Humphreys, M., Sykes, O., \& Roaf, S. (1995). Standards for Thermal Comfort. London: Chapman \& Hall.

Nicol, F., \& Pagliano, L. (2007). Allowing for thermal comfort in free-running buildings in the new European Standard EN15251 (pp. 708-711). Presented at the 2nd PALENC Conference, Crete.

Nicol, J. F., \& Humphreys, M. A. (2009). New standards for comfort and energy use in buildings. Building Research \& Information, 37(1), 68 73.

Nilsson, L. J. (1995). Air-handling energy efficiency and design practices. Energy and Buildings, 22(1), $1-13$.

NOAA. (2012). CO2 expressed as a mole fraction in dry air, micromol $/ \mathrm{mol}$, abbreviated as ppm. Retrieved May 3, 2012, from $\mathrm{ftp}: / / \mathrm{ftp} . c \mathrm{cmdl}$.noaa.gov/ccg/co2/trends/ co2_annmean_mlo.txt

O'Shaughnessy, J., \& O'Shaughnessy, N. J. (2002). Marketing, the consumer society and hedonism. European Journal of Marketing, 36(5/6), 524-547.

Ohashi, Y., Genchi, Y., Kondo, H., Kikegawa, Y., Yoshikado, H., \& Hirano, Y. (2007). Influence of Air-Conditioning Waste Heat on Air Temperature in Tokyo during Summer: Numerical Experiments Using an Urban Canopy Model Coupled with a Building Energy Model. Journal of Applied Meteorology and Climatology, 46(1), 66-81.

Onen, S. H., Onen, F., Bailly, D., \& Parquet, P. (1994). Prevention and treatment of sleep disorders through regulation of sleeping habits. Presse Médicale (Paris, France: 1983), 23(10), 485-489.
Pacala, S., \& Socolow, R. (2004). Stabilization Wedges: Solving the Climate Problem for the Next 50 Years with Current Technologies. Science, 305(5686), 968-972.

Parmeggiani, P. L. (2003). Thermoregulation and sleep. Frontiers in Bioscience, 8(1-3), s557.

Parmeggiani, P. L. (2011). Systemic Homeostasis and Poikilostasis in Sleep: Is REM Sleep a Physiological Paradox? World Scientific.

Peeters, L., Dear, R. de, Hensen, J., \& D'haeseleer, W. (2009). Thermal comfort in residential buildings: Comfort values and scales for building energy simulation. Applied Energy, $86(5), 772-780$.

Postaer, S. (2012). Lessons in Creativity from Google Forbes. Forbes.

Prins, G. (1992). On condis and coolth. Energy and Buildings, 18(3-4), 251-258.

Raeissi, S., \& Taheri, M. (2000). Skytherm: an approach to year-round thermal energy sufficient houses. Renewable Energy, 19(4), 527-543.

Ramanathan, N. L. (1964). A New Weighting System for Mean Surface Temperature of the Human Body. Journal of Applied Physiology, 19(3), 531-533.

Ramsey, D. (2003). The Total Money Makeover: A Proven Plan for Financial Fitness. Thomas Nelson.

Riffat, S. B., \& Ma, X. (2004). Improving the coefficient of performance of thermoelectric cooling systems: a review. International Journal of Energy Research, 28(9), 753-768.

Ring, J. W., \& Dear, R. (1991). 256106 Temperature Transients: A Model for Heat Diffusion through the Skin, Thermoreceptor Response and Thermal Sensation. Indoor Air, 1(4), 448-456.

Roaf, S., Crichton, D., \& Nicol, F. (2005). Adapting Buildings and Cities for Climate Change.

Rodbard, S. (1948). Body Temperature, Blood Pressure, and Hypothalamus. Science, 108(2807), 413-415.

Rohles, F. H. (2007). Temperature and temperament: A Psychologist Looks at Comfort. ASHRAE Jornal, 14-22.

Rosenfeld, A. H. (1999). The Art of Energy Efficincy: Protecting the Environment with Better Technology. Annual Review of Energy and the Environment, 24(1), 33-82.

Rural Infection Control Practice Group. (2008). Infection Prevention and Control Manual(3rd ed.).

Salerian, A. J., \& Saleri, N. G. (2007). Cooling Core Body Temperature May Slow Down Neurodegeneration. CNS Spectrums, 13(3), 227-229.

Salerian, A., \& Saleri, N. (2006). Cooler biologically compatible core body temperatures may prolong longevity and combat neurodegenerative disorders. Medical Hypotheses, 66(3), 636-642.

Santamouris, M., \& Asimakopoulos, D. (1996). Passive Cooling of Buildings. Earthscan.

Sapolsky, R. M. (1998). Why Zebras Don't Get Ulcers: An Updated Guide to Stress, Stress Related 
Diseases, and Coping (2nd ed.). W. H. Freeman.

Sapolsky, R. M. (2004). Why Zebras Don't Get Ulcers, Third Edition (3rd ed.). Holt Paperbacks.

Schiavon, S. (2009). Energy Saving With Personalized Ventilation And Cooling Fan. University of Padua, Italy.

Schiller, G. E. (1990). A comparison of measured and predicted comfort in office buildings. ASHRAE Transactions, 96(1), 609-622.

Schulkin, J. (2003). Rethinking homeostasis: allostatic regulation in physiology and pathophysiology. MIT Press.

Seeley, R. R., Stephens, T. D., \& Tate, P. (2006). Essentials of Anatomy \& Physiology (6th ed.). McGraw-Hill Science/Engineering/Math.

Seppänen, O., Fisk, W. J., \& Faulkner, D. (2005). Control of Temperature for Health and Productivity in Offices. ASHRAE Transactions.

Seppanen, O., Fisk, W. J., \& Lei, Q. H. (2006). Room temperature and productivity in office work.

Shove, E. (2003). Comfort, cleanliness and convenience: the social organization of normality. Berg Publishers.

Siegfried, T. (2001). A face that rings a bell ... and fires a neuron. The Dallas Morning News.

Simmonds, P. (1993). Thermal Comfort and Optimal Energy Use. ASHRAE Transactions, 99(1), 1037-48.

Singapore Department of Statistics Singapore. (2011). Yearbook of Statistics Singapore.

Socolow, R. (2011). Wedges Reaffirmed / Climate Central. Retrieved May 3, 2012, from http://www.climatecentral.org/blogs/wedgesreaffirmed

Stein, B., Reynolds, J. S., Grondzik, W. T., \& Kwok, A. G. (2006). Mechanical and Electrical Equipment for Buildings, 10th Edition (10th ed.). Wiley.

Sterling, E. M., Arundel, A., \& Sterling, T. D. (1985). Criteria for human exposure to humidity in occupied buildings. ASHRAE transactions, 91(1), 611-622.

Suvernev, A. V., Ivanov, G. V., Efremov, A. V., \& Tchervov, R. (2006). Whole Body Hypothermia at 43.5-44 C. Hyperthermia in Cancer Treatment: A Primer (pp. 227-236). Boston, MA: Springer US.

Szokolay, S. (2000). Dilemmas of warm-humid climate house design: heavy vs. lightweight + cooling effect of air movement. Architecture, city, environment (pp. 144-149). Presented at the PLEA, Cambridge, U.K.: James \& James (Science Publishers) Ltd.

Szokolay, S. (2008). Introduction to architectural science. Architectural Press.

Tan, J. (2008). Commentary: People's Vulnerability to Heat Wave. International Journal of Epidemiology, 37(2), 318-320.

Tanabe, S., \& Nishihara, N. (2004). Productivity and fatigue. Indoor Air, 14(s7), 126-133.

Tanaka, N., \& Kotoh, S. (2007). The Current Status of and Future Trends in Heat Pump Technologies with Natural Refrigerants. Mitsubishi Electric ADVANCE, (December 2007), 2-5.
Taniguchi, Y., \& Aoki, H. (1993). Car air conditioning equipment with temperature variation system to avoid ...

Toftum, J. (2004). Air movement - good or bad? Indoor Air, 14(s7), 40-45.

Trainer, T. (2007). Renewable Energy Cannot Sustain a Consumer Society.

Tse, W. L., So, A. T. P., Chan, W. L., \& Mak, I. K. Y. (2005). The validity of predicted mean vote for airconditioned offices. Facilities, 23, 558-569.

Tselepidaki, I., \& Santamouris, M. (1991). Statistical and persistence analysis of high summer ambient temperatures in Athens for cooling purposes. Energy and Buildings, 17(3), 243-251.

Turner, S. C. (2011). What's New in ASHRAE's Standard on Comfort. ASHRAE Journal, 53(6), 42-48.

Vale, R., \& Vale, B. (2009). Time to Eat the Dog?: The Real Guide to Sustainable Living. Thames \& Hudson.

Walitzki, H. J. (2009). Thermal tunneling gap diode with integrated spacers and vacuum seal.

Wargocki, P., Seppänen, O., Andersson, J., \& ClementsCroome, D. J. (2006). Indoor Climate and Productivity in Offices. REHVA Guide Book. Federation of European Heating and Airconditioning Associations.

Watts, M. (2011). The Intellectual Venturer. Wired UK, $108-117$.

Whitaker, S. (1972). Forced convection heat transfer correlations for flow in pipes, past flat plates, single cylinders, single spheres, and for flow in packed beds and tube bundles. A/ChE Journal, 18(2), 361-371.

Wilhite, H., Nakagami, H., Masuda, T., Yamaga, Y., \& Haneda, H. (1996). A cross-cultural analysis of household energy use behaviour in Japan and Norway. Energy Policy, 24(9), 795-803.

Wilkenfeld, G. (2006). Demand Response: A National Strategy to address Air Conditioner Peak Load. Equipment Energy Efficiency Committee (E3).

Wilson, M.-M. G., \& Morley, J. E. (2003). Impaired cognitive function and mental performance in mild dehydration. European Journal of Clinical Nutrition, 57, S24-S29.

Wilson, T. E., Cui, J., Zhang, R., Witkowski, S., \& Crandall, C. G. (2002). Skin cooling maintains cerebral blood flow velocity and orthostatic tolerance during tilting in heated humans. Journal of Applied Physiology, 93(1), 85-91.

Wolverton, B. C., Johnson, A., \& Bounds, K. (1989). Interior Landscape Plants for Indoor Air Pollution Abatement (Final Report). Plants for Clean Air Council. Davidsonville, Maryland: NASA/ALCA.

Wong, N. H., \& Khoo, S. S. (2003). Thermal comfort in classrooms in the tropics. Energy and Buildings, 35(4), 337-351.

Wright, M., \& Hearps, P. (2010). Zero Carbon Australia Stationary Energy Plan (Synopsis). Melbourne Energy Institute.

WWF. (2011). WWF - Earth Hour Poll: Nearly Half of Singaporeans Give Thumbs Down to Strong Air-Conditioning. Retrieved February 24, 2012, from http://wwf.panda.org/who_we_are/ 
wwf_offices/singapore/?199561/Earth-HourPoll-Nearly-Half-of-Singaporeans-GiveThumbs-Down-to-Strong-Air-Conditioning

Wyon, D. P. (2000). Enhancing Productivity While Reducing Energy Use in Buildings. Proceedings of the E-Vision 2000 Conference, 11-13 Oct 2000 (pp. 233-257). Washington, DC: RAND Corporation, Arlington, VA.

Yang, B. (2009). Thermal comfort and indoor air quality evaluation of a ceiling mounted personalized ventilation system integrated with an ambient mixing ventilation system (Thesis). National University of Singapore, Singapore.

Zhang, H., Arens, E. A., Fard, S. A., Huizenga, C., Paliaga, G., Brager, G., \& Zagreus, L. (2007). Air Movement Preferences Observed in Office Buildings. International Journal of Biometeorology, 51(5), 349-360.

Zhang, Hui. (2003). 145086 Human thermal sensation and comfort in transient and non-uniform thermal environments. University of California, Berkeley.

Zhang, Hui, Arens, E., Huizenga, C., \& Han, T. (2010). Thermal sensation and comfort models for non-uniform and transient environments: Part I: Local sensation of individual body parts. Building and Environment, 45(2), 380-388.

Zhu, M., Ackerman, J. J. H., Sukstanskii, A. L., \& Yablonskiy, D. A. (2006). How the body controls brain temperature: the temperature shielding effect of cerebral blood flow. Journal of Applied Physiology, 101(5), 1481-1488.

Zolfaghari, A., \& Maerefat, M. (2010). Thermal response of cutaneous thermoreceptors: A new criterion for the human body thermal sensation. 2010 17th Iranian Conference of Biomedical Engineering (ICBME) (pp. 1-4). Presented at the 2010 17th Iranian Conference of Biomedical Engineering (ICBME), IEEE. 


\section{Appendices}

1. Building and Optimising the Ductless Task Air-Conditioning Unit

\section{ANZAScA Paper}

Law, T. O., \& Fay, R. (2009). Thermal Comfort, Productivity and Energy Consumption in the Tropical Office Environment: A Critical Overview. Performative Ecologies in the Built Environment: Sustainability Research Across Disciplines. Presented at the 42nd International Architectural Science Association (ANZAScA) Conference, Launceston, Australia.

\section{ASHRAE Paper}

Law, T. O., Sargison, J., Fay, R., \& Banbury, S. (2012). Ductless Task Air-Conditioning. ASHRAE Transactions, 118(1), 367-374. 



\section{A 1 Building and optimising the DTAC}

This appendix explains how the DTAC was developed and optimised in a step-wise process. The advances have been categorised by the components (instead of chronologically) for clarity. The following aspects of DTAC were analysed:

1. Overall design changes in four generation of prototypes

2. Fan selection and positions

3. Airflow

4. Air handling

5. Cooling fin heat exchange

6. Thermal interface materials

7. Thermal storage tank: the wax bath

\section{A1.1 Overview of Prototypes}

\section{A1.1.1 DTAC Mark-1}

As the general parameters were not established at this point, an oversized pedestal was designed to give flexibility in terms of housing the apparatus and the gamut of sensors. Of particular consideration was the size of the PCM tank and it was designed to house a 20-litre paint drum as the PCM container. The cooling fin assembly could take up to four TE modules. The initial double- $45^{\circ}$ bends in the duct were intended to reduce drag but were subsequently simplified to a $90^{\circ}$ elbow for ease of fabrication (figure A1.1). 


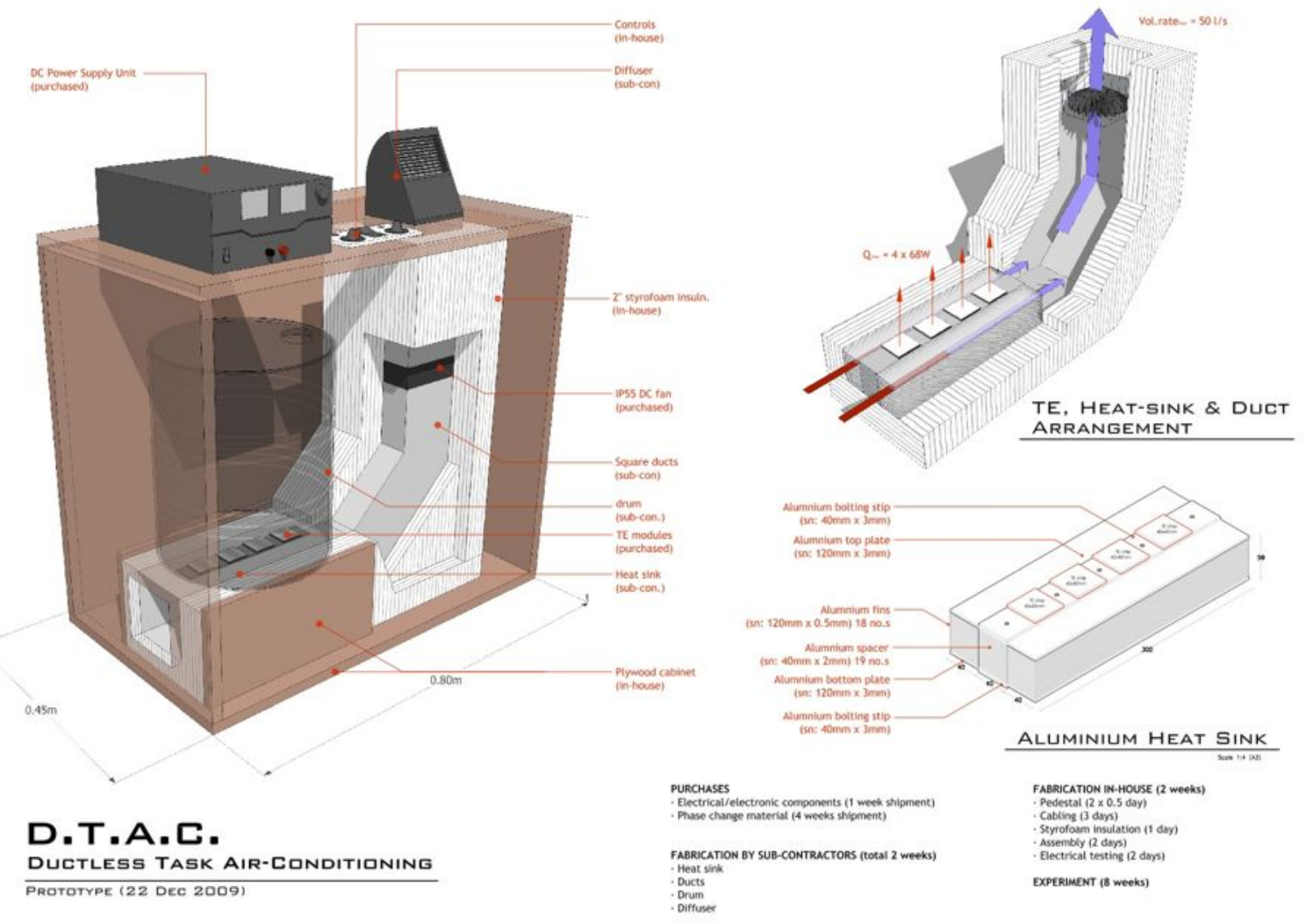

Figure A1.1: DTAC Mark 1 prototype design

The original intent was to develop DTAC simultaneously with DWAHU (for the ceilingmounted Desiccant Wheel Air Handling Unit) in the following configuration (figure A1.2):

1. Climate box equipped with heater and humidifier to supply warm-humid air

2. DWAHU box equipped with rotating desiccant wheel to dehumidify the air-stream, supplying warm-dry air (figure A1.3)

3. DTAC box equipped with TE modules and PCM to cool air-stream thus supplying cool-dry air 


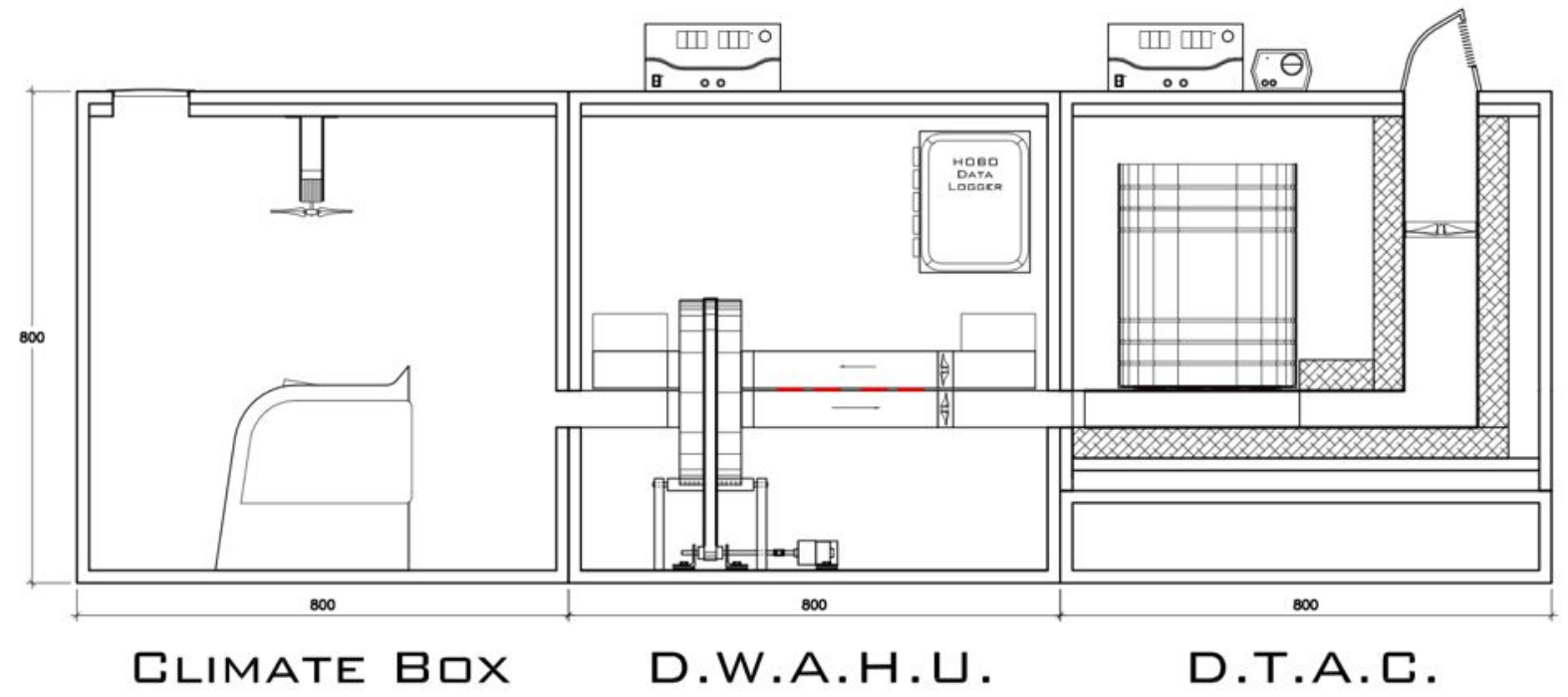

Figure A1.2: Experiment setup to test (1) supply of hot-humid air simulating outdoor tropical air (2) desiccant dehumidification and pre-cooling simulating DWAHU ambient air-conditioning, and (3) personal air-conditioning of cooled air, simulating DTAC

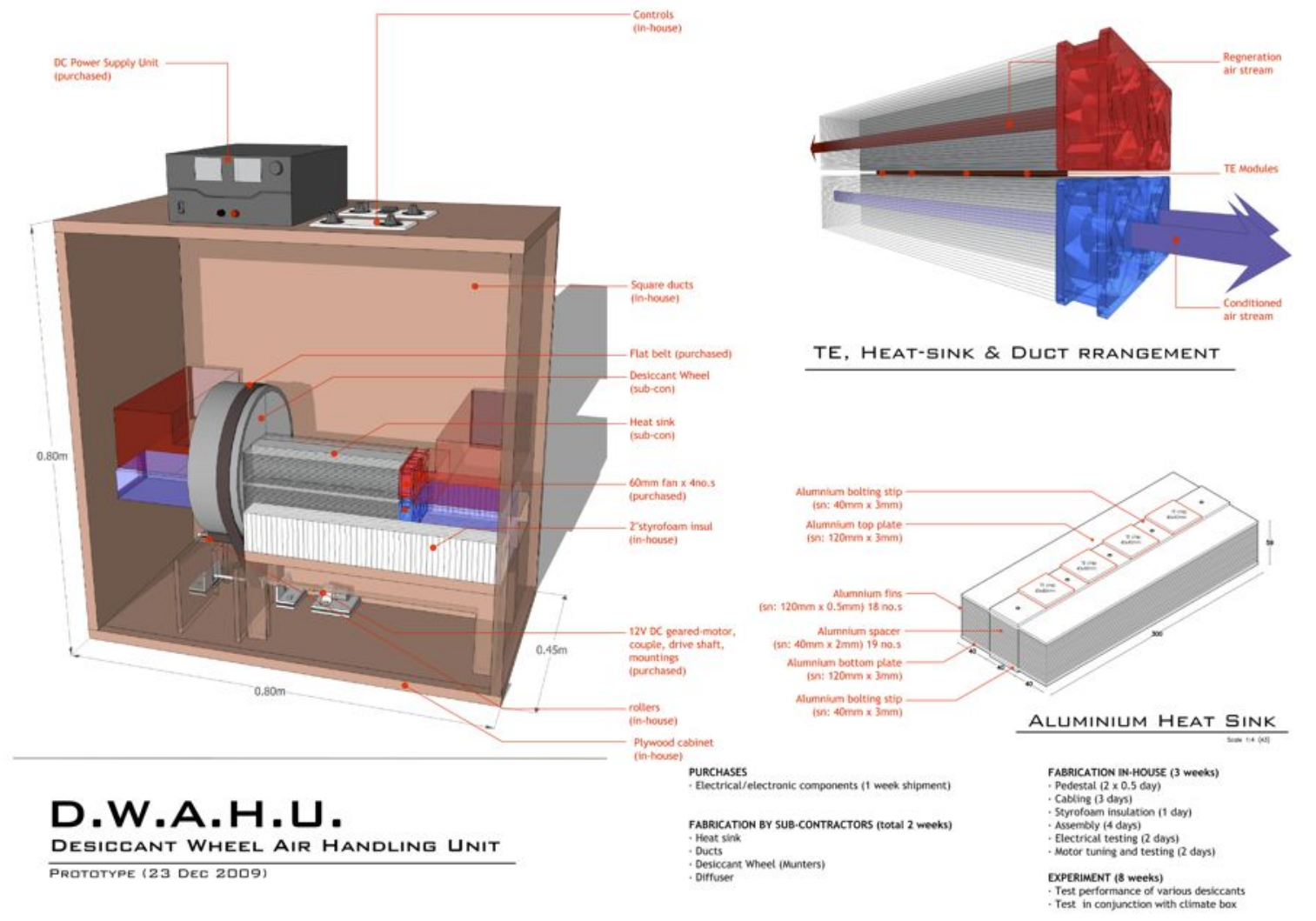

Figure A1.3: DWAHU design. A desiccant wheel is rotated by a step-motor and hot-humid air is passed through it. The air emerges from the wheel dry and warmer. The air is chilled by TE modules, with the rejected heat passed to the exhaust air stream that regenerates the desiccant. 
The DWAHU concept was not prototyped due to the lack of commercialisation potential as determined by the university's technology transfer office. Existing desiccants with low regeneration temperature are commercially used in proprietary systems but I could not find a manufacturer willing to supply the desiccants separately from the system. This raised suspicion on the extent to which these desiccants could be regenerated with exhaust heat from air-conditioning condensers. There were also technical issues, which were at that time not resolved:

1. Development of suitable seals to allow rotation of drums without leakage. The initial plan was to design a desiccant wheel that rotated $90^{\circ}$ at timed intervals. An inflatable seal would deflate to allow a quarter-turn rotation, then reseal and the fans resumed. It was uncertain if such a seal would work.

2. The potential desiccants were silica gel, 13X molecular sieve and coconut pith. All desiccants can regenerate partially even with mild heat but it was uncertain if adequate regeneration could be achieved with TE modules.

Mark-1 enabled the determination of the melting characteristics of wax and gave the empirical knowledge to develop the wax-bath in Mark-2. The cooling fin design has remained unchanged in further prototypes other than in altering its length.

\section{A1.1.2 DTAC Mark-2}

Mark-2 was designed as a demonstrable portable prototype to fit in a Pelicase suitcase. In order for it to be able to demonstrate the technology at business competitions and to prospective investors, one side of the box was left exposed so that the contents and processes could be visible (figure A1.4). 


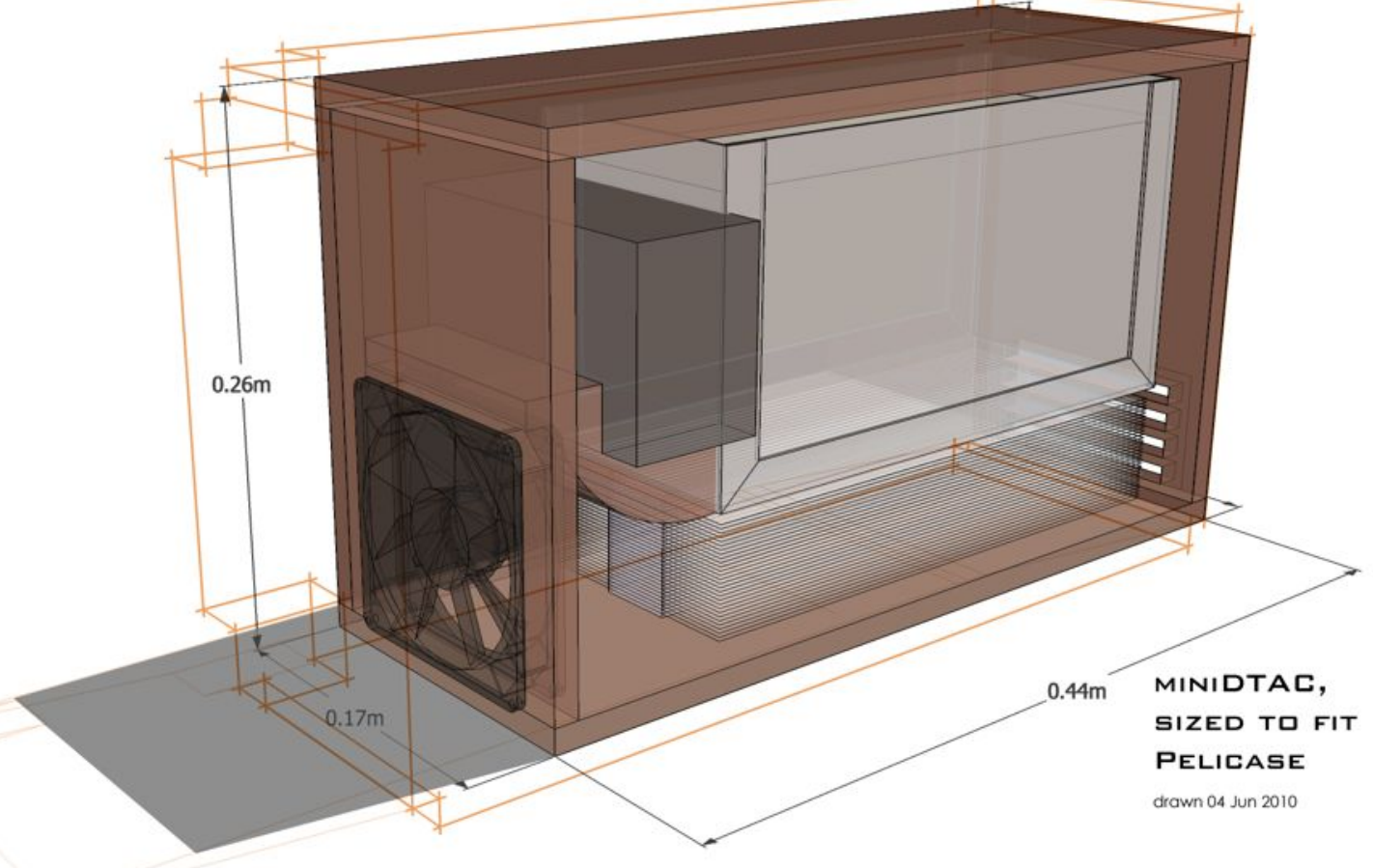

Figure A1.4: Design of Mark-2

To simplify the airflow there were no flexible hoses or funnels, the casing and acrylic cover would contain the airstream. By creating a circuit with a switch each to 2 modules and 4 modules, there could be the option, at fixed voltage, to select low (2 modules), medium (4 modules) and high ( $2+4$ modules). The prototype carried a 12V, 9Ah sealed-lead acid (SLA) battery and an external PSU could either power the modules or recharge the battery with the circuity sketched in figure A1.5. 


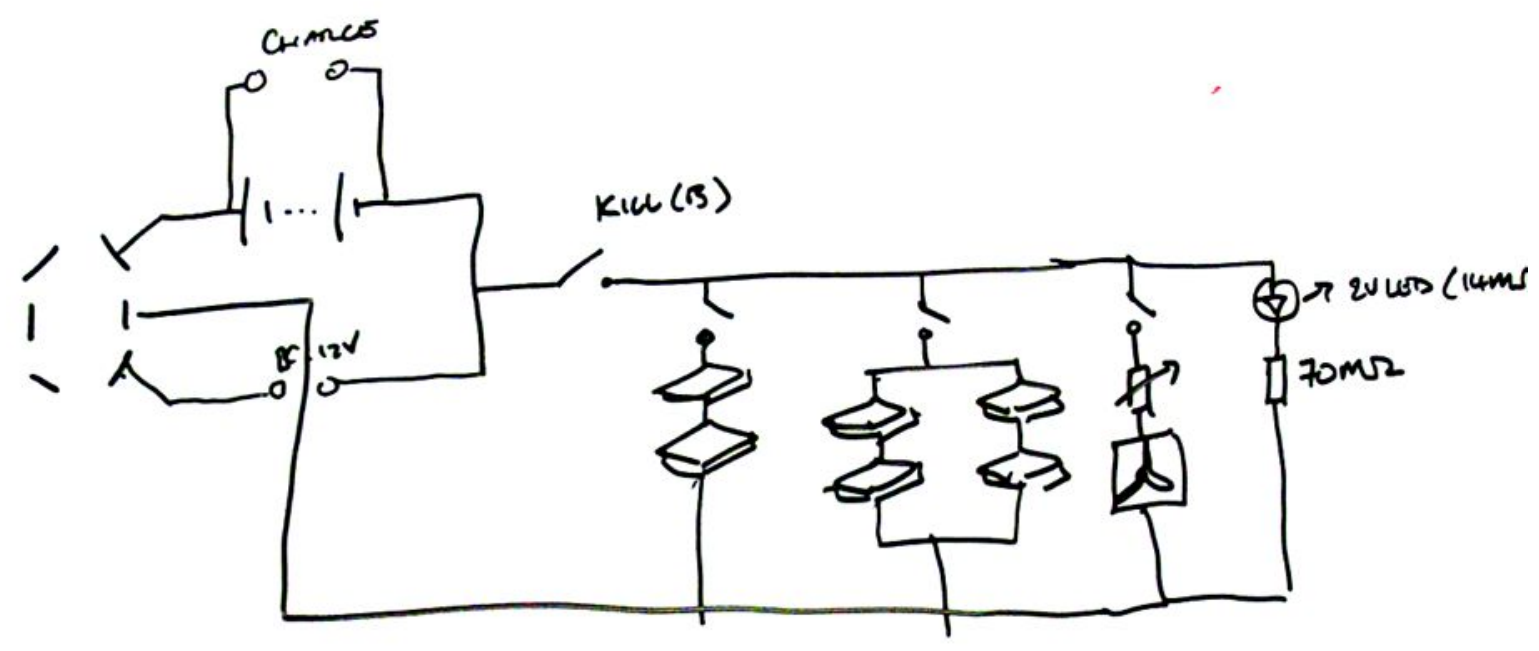

Figure A1.5: Circuit diagram to enable selection between battery and PSU operation, and between 2-, 4- or 6-module operation

On reflection, the modules that were switched off would have become thermal bridges to return heat back from tank to cooling fins. All modules needed to be on, and preferably at the same voltage. Airflow was very poor without a honeycomb or proper duct. It was likely that the supply side of the fan was highly turbulent, and exacerbated by the funnelling into the fins. Consequently the flow was indiscernible. The internal battery also turned out to be a constant issue with weight and airport security. Overall views are shown in figures A1.6, A1.7 and A1.8.

Whilst Mark 2 was not a successful prototype, a number of manufacturing and testing protocols were determined in this stage:

1. Wax bath designed with double-tank and method to allow molten wax to breach surface

2. The leeward side of the fan was highly turbulent and unsuitable for funnelling. The air stream should be "pulled" though the fins and not "pushed" through them. A honeycomb on the leeward side would be advantageous.

3. Tank cannot be painted

4. Clamps and vices could minimise the air gaps that would otherwise jeopardise heat transfer (figure A1.9) 

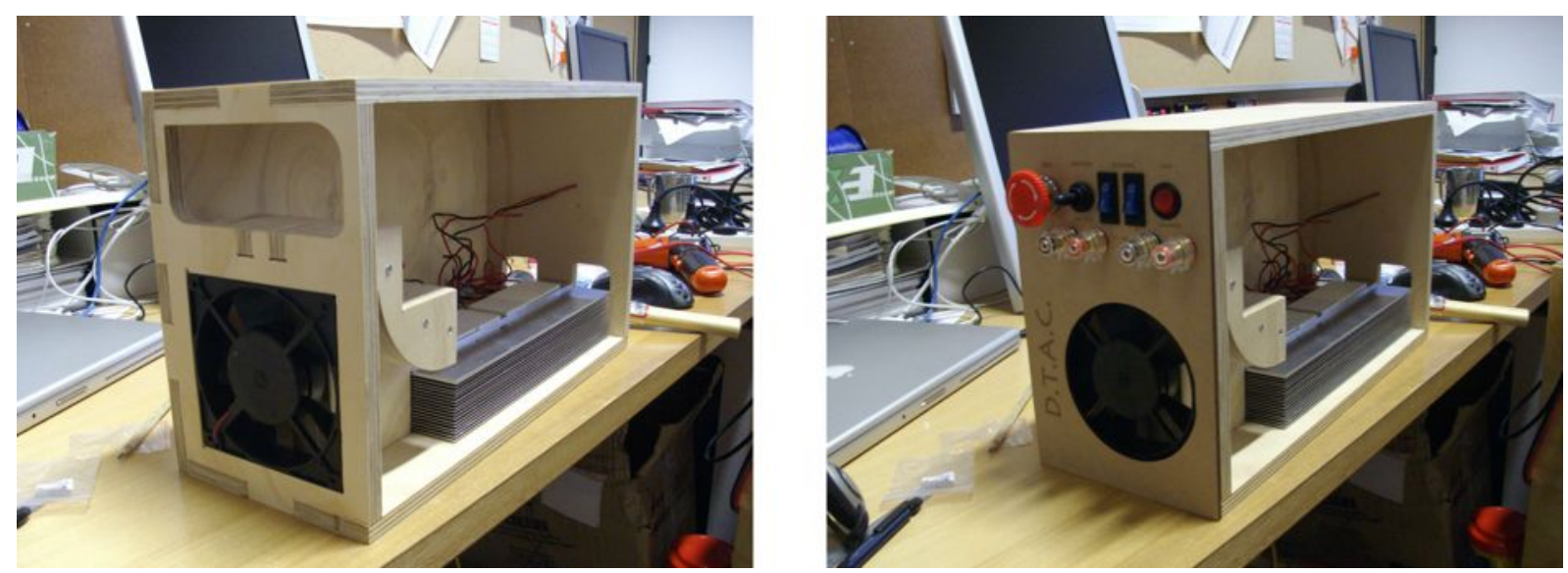

Figure A1.6: Mark 2 with cooling fins and faceplate
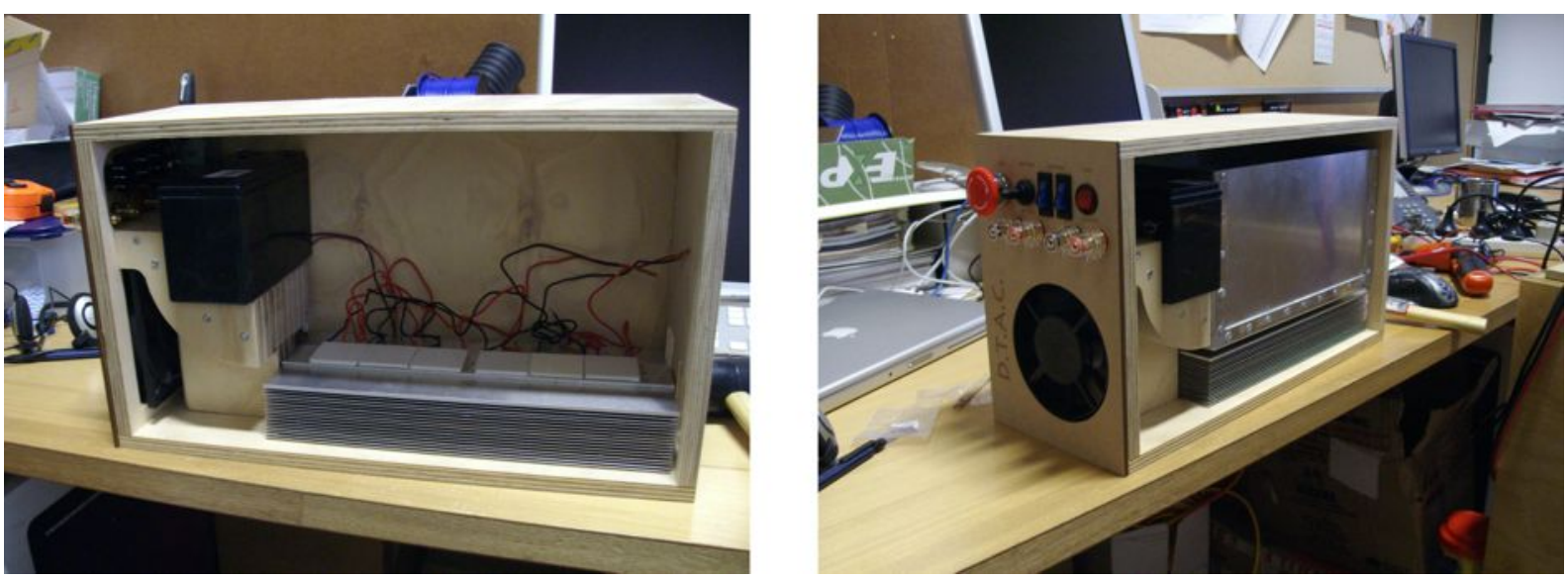

Figure A1.7: Mark 2 with battery and PCM tank

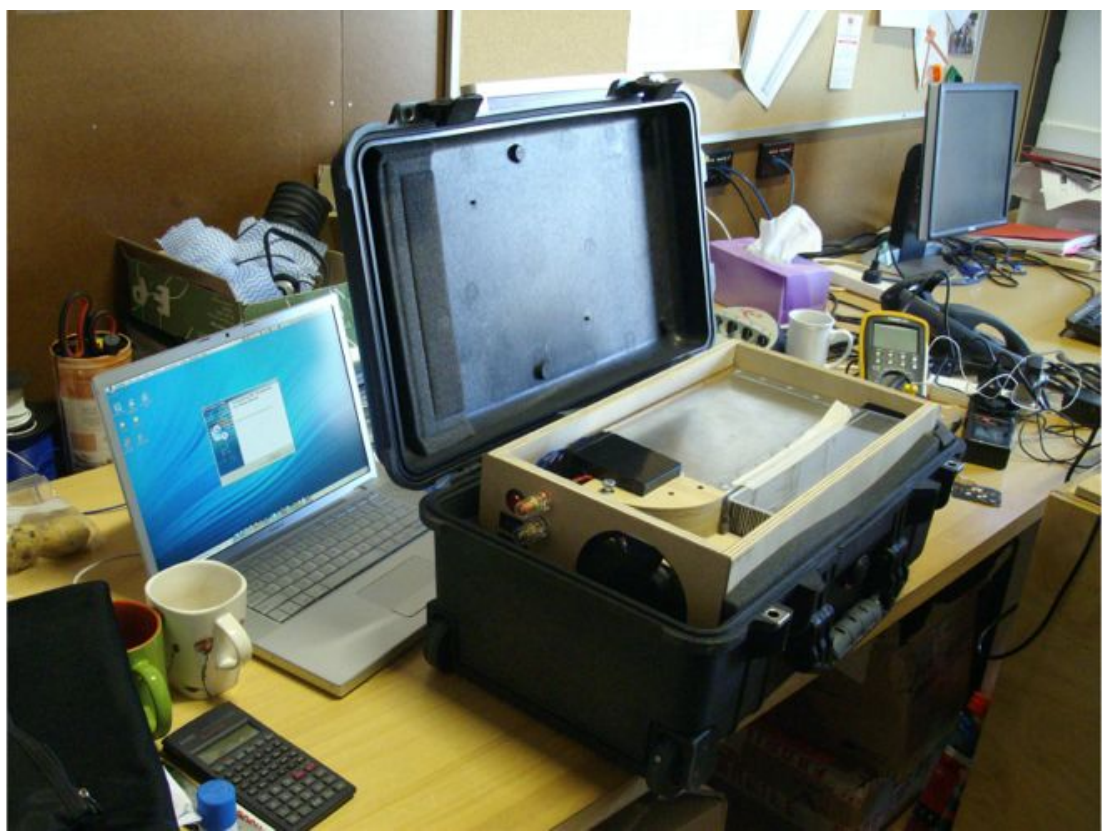

Figure A1.8: Mark 2 in the pelicase 


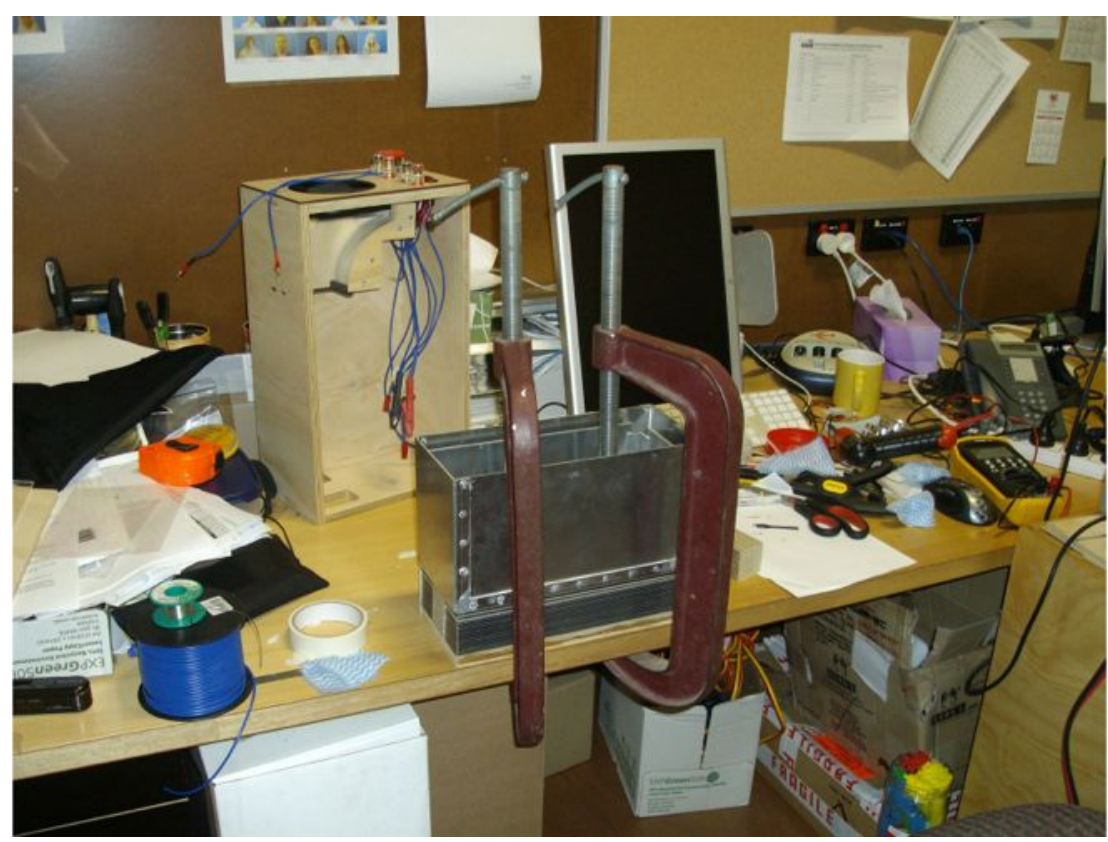

Figure A1.9: Use of clamps to minimise TIM thickness was effective and routinely adopted in future prototypes

\section{A1.1.3 DTAC Mark-3}

A lighter unit was needed for ease of transport. Mark-3 was designed to use less material, with a truss structure to make contents visible. A honeycomb pattern was cut where material mass could be further reduced. The battery pack and power supply was separated from the unit. Fan was moved to the faceplate to improve flow (less turbulent flow when pulling air through the fins instead of pushing it). A small fan controller was included and concealed within the cabling space. This allowed a preselection of what speed the fans would spin at when switched on. The faceplate was simplified to just have 2 switches: one for the TE modules to cool the fin so that viewers could touch and feel them get cold, and one for the fan to drive the cooled air. Cooling fins were contained in a 3mm-thick MDF duct, which could be cut and glued with better economy, higher accuracy and tighter tolerance than an aluminium one, which had to be cut, folded and riveted. PCM tank was designed to contain 1 litre which would could be operated for about 30 mins, just sufficient for a demonstration, and with less PCM it solidified faster and was ready for transport sooner after the demonstration. Preparation of the tank is shown in figure A1.10, the cooling fins in A1.11 and A1.12. figure A1.13 shows the completed prototype.

The engagement of a specialist supplier of TE modules instead of general electronic supplier, enabled the specification of close height matching of $\pm 0.025 \mathrm{~mm}$. The axial fan was 
relocated to the face plate, and used in conjunction with honeycomb. This gave a much higher face velocity.
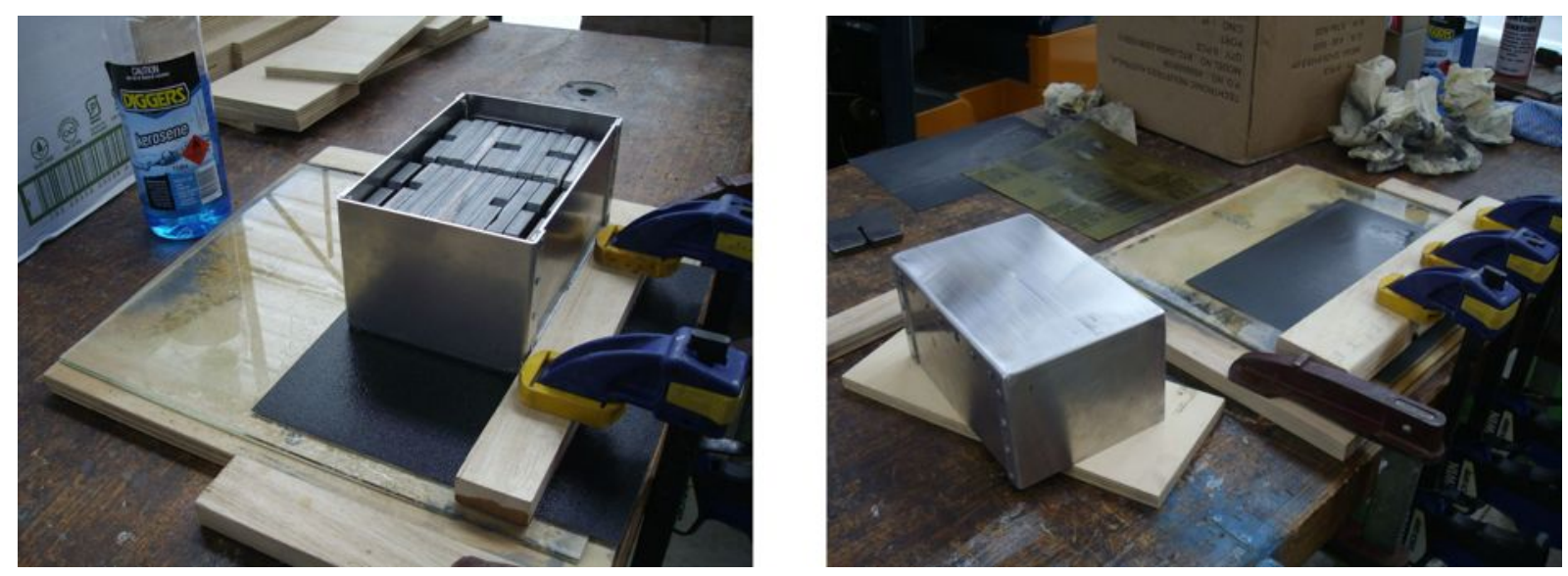

Figure A1.10: Weights in tank for better consistency in lapping process.
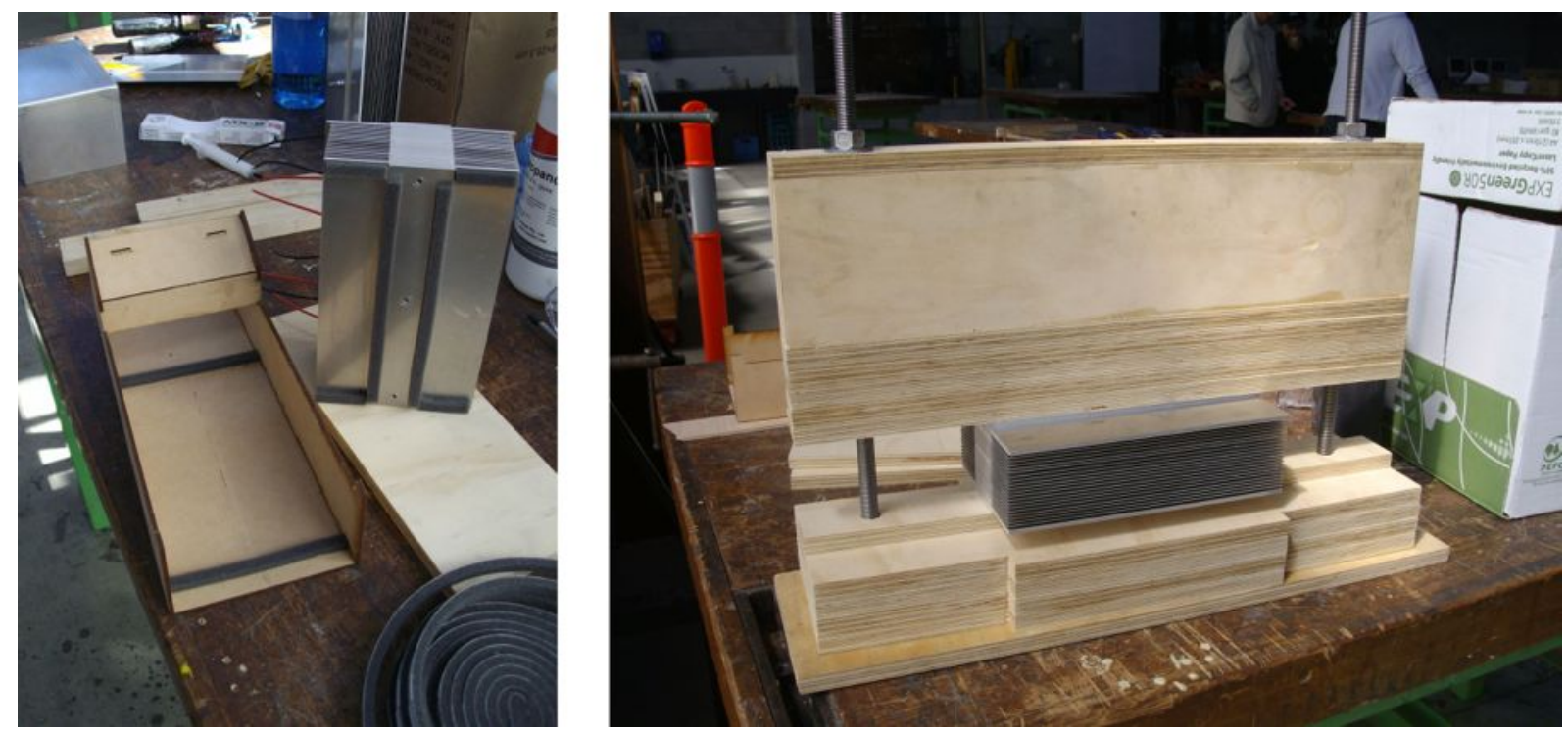

Figure A1.11: (a) Duct made of MDF, laser cut and glued (b) A rig was designed to apply pressure evenly on the cooling fin assembly 

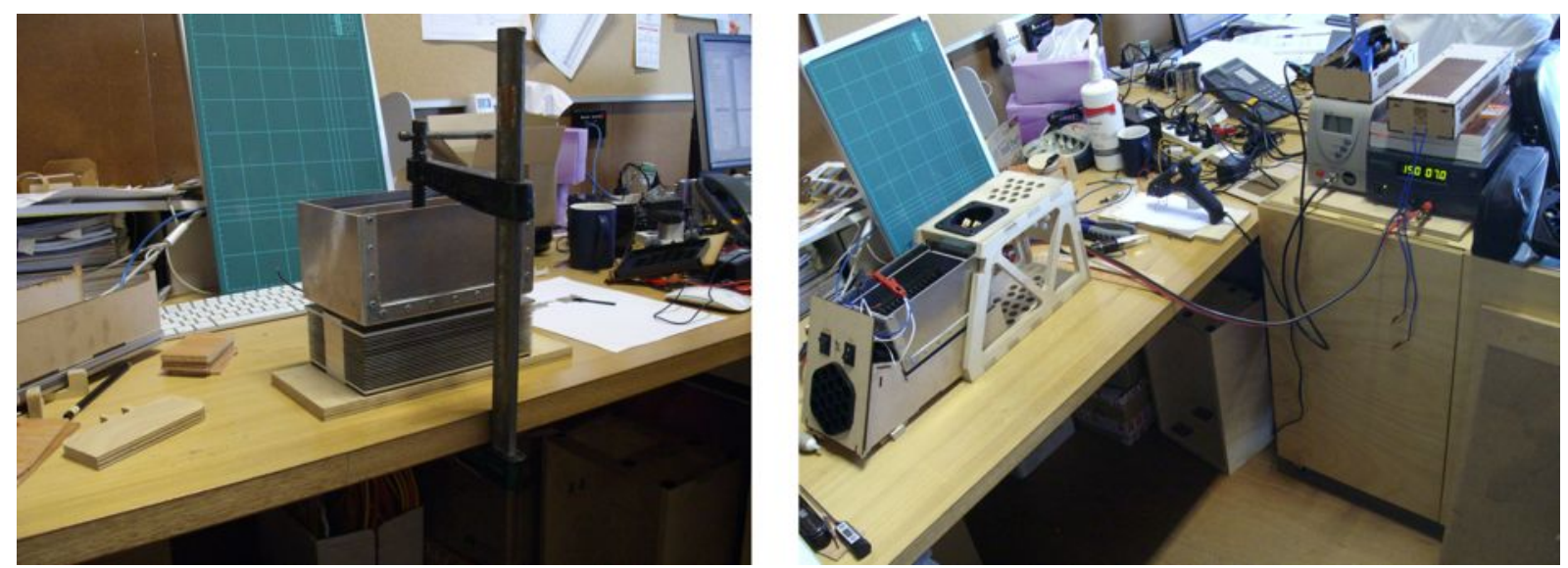

Figure A1.12: (a)Tank being clamped to cooling fins. (b) Testing and melting of PCM
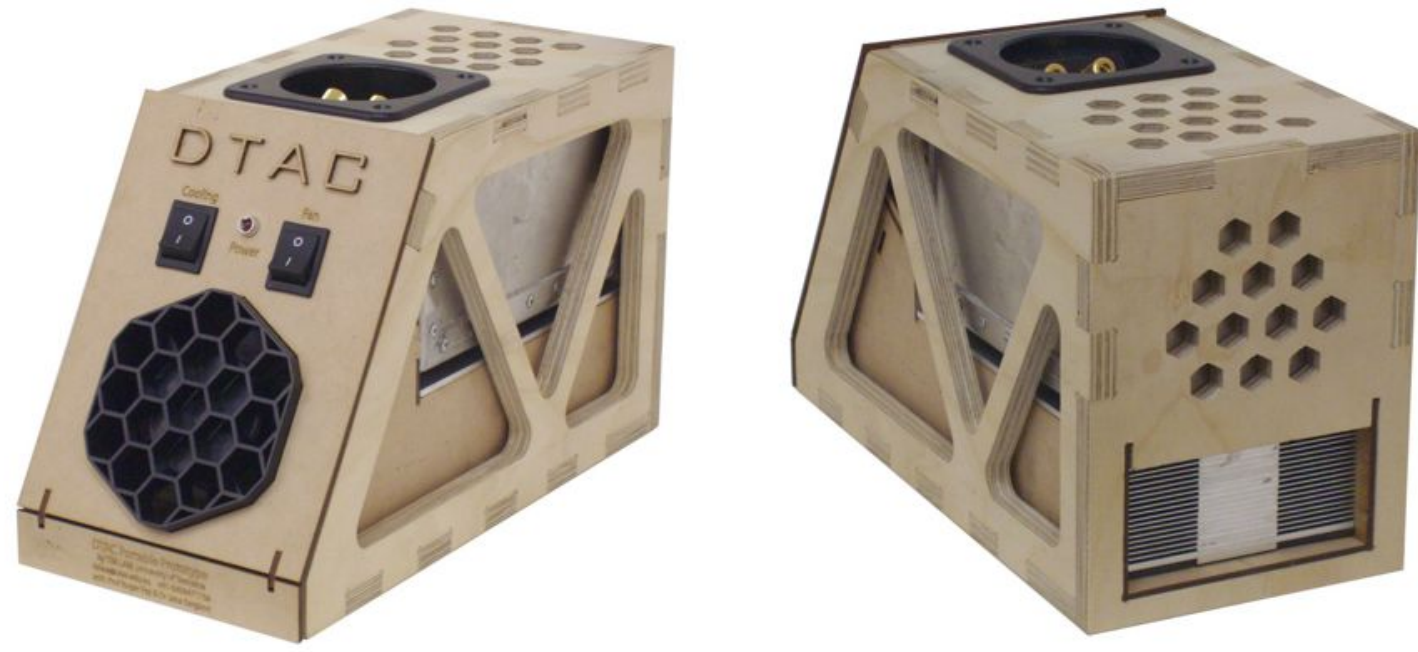

Figure A1.13: Completed Mark-3 prototype

\section{A1.1.4 DTAC Mark-4}

As part of the field trial, Mark-4 (figure A1.14 to A1.20) was designed for pilot production of 4 units (figure A1.21). The control group would be using 4 fan-only units (figure A1.22) which were essentially fans paired with the honeycomb and equipped with a controller. As multiple units of Mark- 4 were to be made by hand, the main considerations were:

- Buildability. Parts were CNC routed with minimal time spent assembling. No varnish was used to reduce off-gassing during the trial. Rigs were built to facilitate assembly of parts that required more attention to detail and consistency.

- Consistency. The following parameters were kept constant: press forces, sanding weights and number of repetitions, PCM weight and power supply output voltage. 
Finally, each DTAC unit was measured to have similar performance. Specialist suppliers were sought for TE modules (Tellurex) and paraffin wax (Rubitherm) to ensure repeatability.

- Safety. As a prototype to be used by general participants, safety issues were a concern. A thermostat circuit breaker (opening $\mathrm{T}=60^{\circ} \mathrm{C}$, reclosing $\mathrm{T}=40^{\circ} \mathrm{C}$ ) would switch off the unit and prevent it from overheating. To avoid the vents being covered (by books and files), it was designed as a curved top to discourage placement of objects. Extra vents were made in the sides and rear of the casing. Each units was also installed with a fast-blow fuse (2.5A) at the IEC connection. Earthing links were made to the tank and cooling fins. The casing was made of plywood and MDF with no exposed metal parts to minimise risk of electric shock. High voltage (240V) cables were double-insulated. Connections were soldered and double shrink-wrapped. Low voltage $(24 \mathrm{~V})$ cables were specified to carry current with at least $25 \%$ margin. Power cords were all tested and tagged by the School technical officer. The electrical circuit and prototype was presented to a technical officer conversant with electrical work. Briefing sessions and user manuals were provided to all participants.
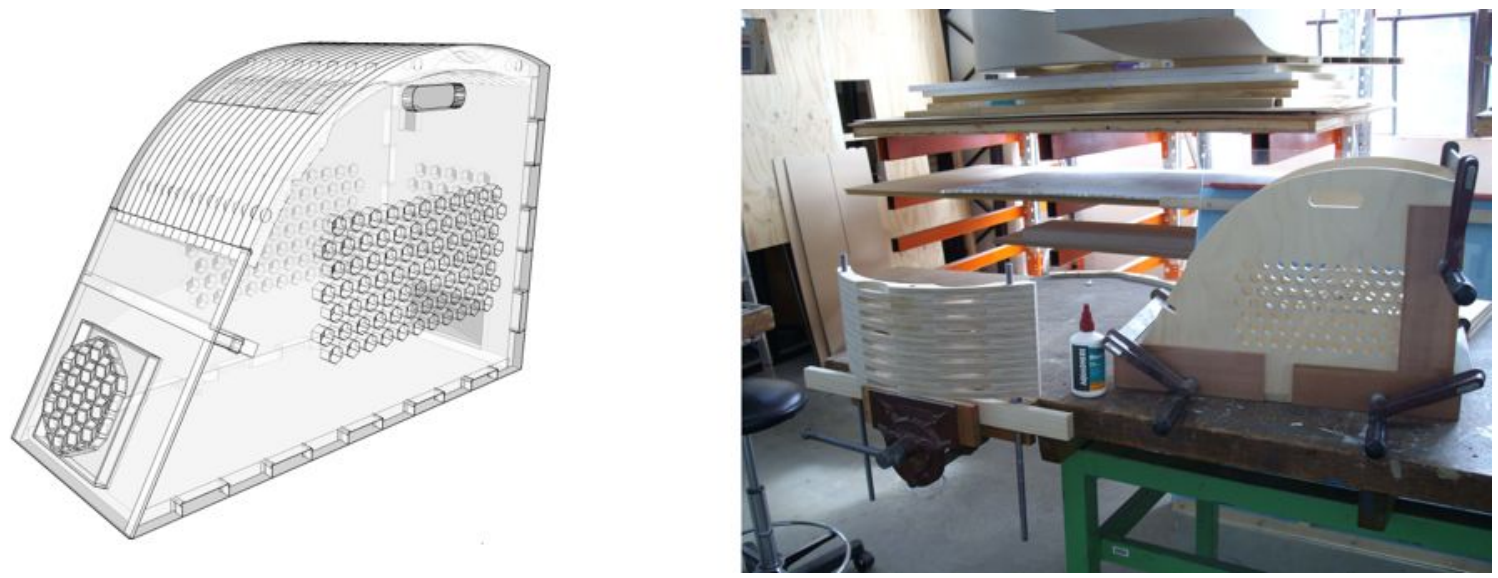

Figure A1.14: (a) Design of field trial prototype, and (b) assembly of top-shell and casing 


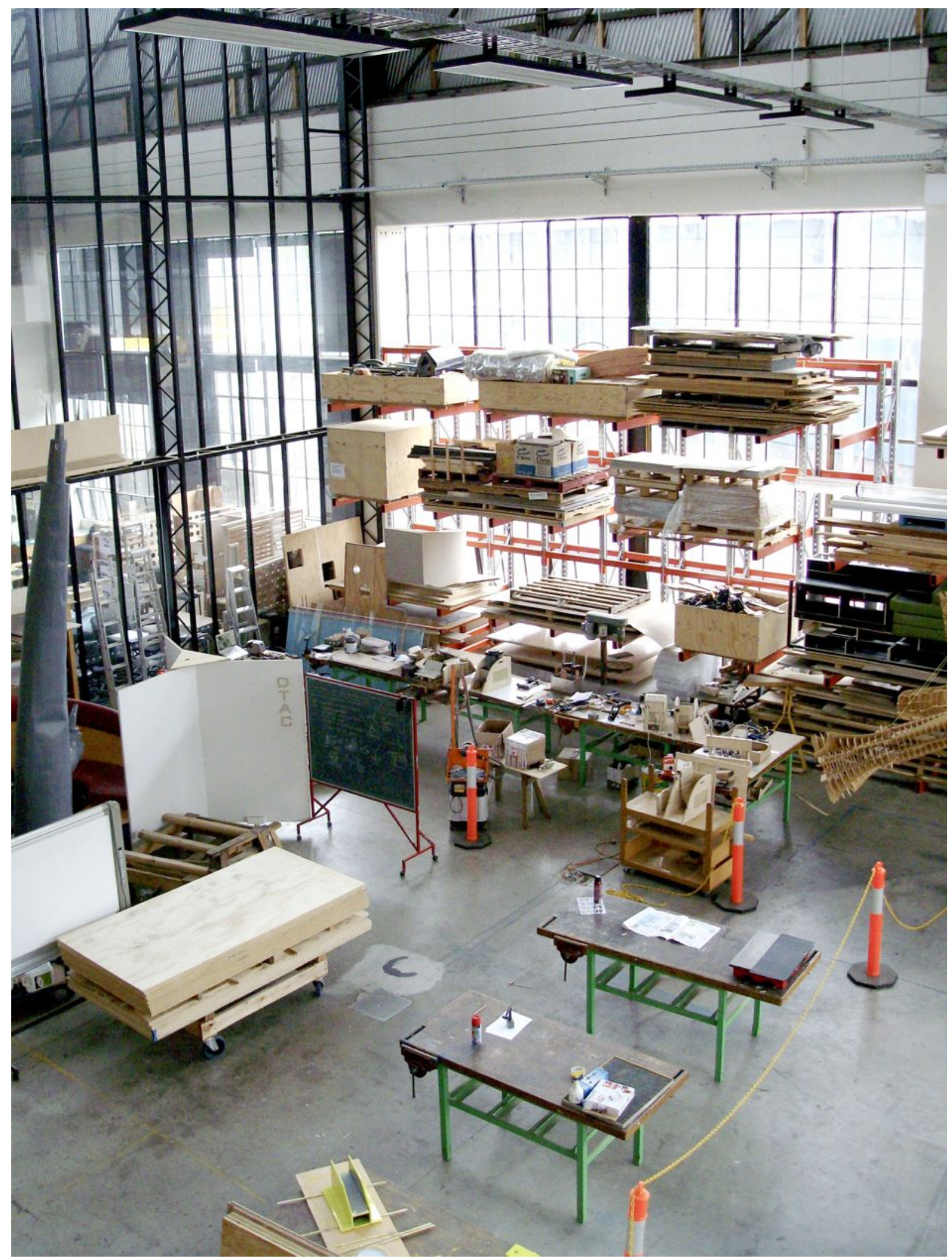

Figure A1.15: Overview of production at the workshop

The PSU was initially a switch mode PSU ( $25 \mathrm{~V}$ with control to trim $\pm 3 \mathrm{~V})$. The degree of control was found to be inadequate to regulate the temperature of modules. The limited 
power output required 2 no.s PSUs (with separate controllers). Later, a 0-24V power supply was reselected ( $8 \mathrm{~V}$ each to $3 \mathrm{x}$ TE modules) which allowed selection from the full range.
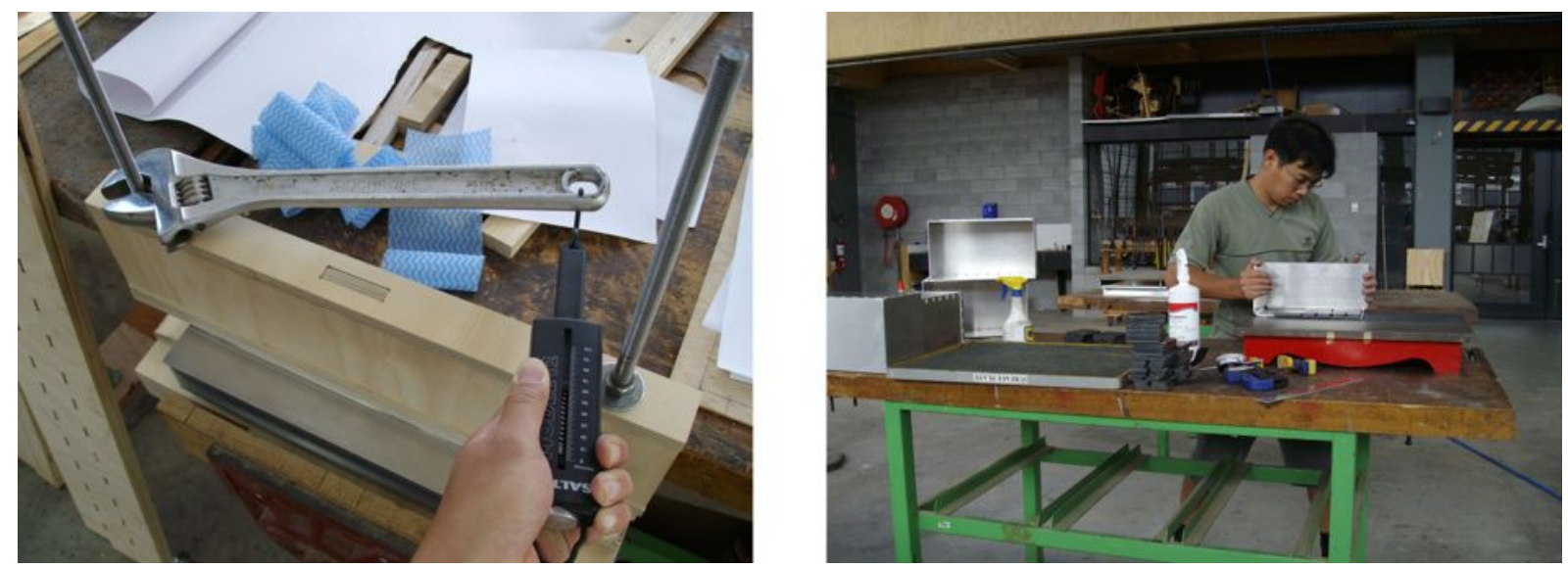

Figure A1.16: To ensure consistency, (a) the torque applied to the nuts was measured, and (b) weights applied, number of strokes and angle of strokes in sanding were kept consistent
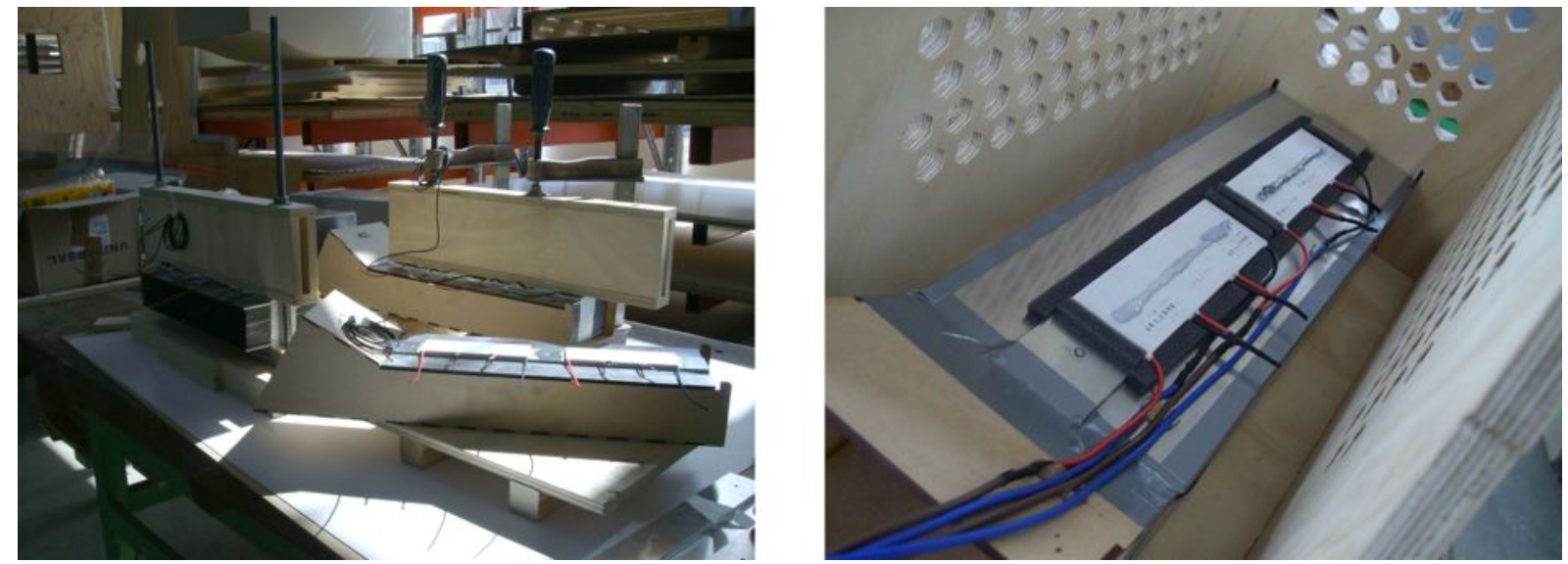

Figure A1.17: (a-left) Cooling fin assembly being pressed, (a-rear) TE modules being fixed onto cooling fin assembly and (a-foreground) complete fin and TE modules, (b) TE modules with thermal paste, ready to receive tank
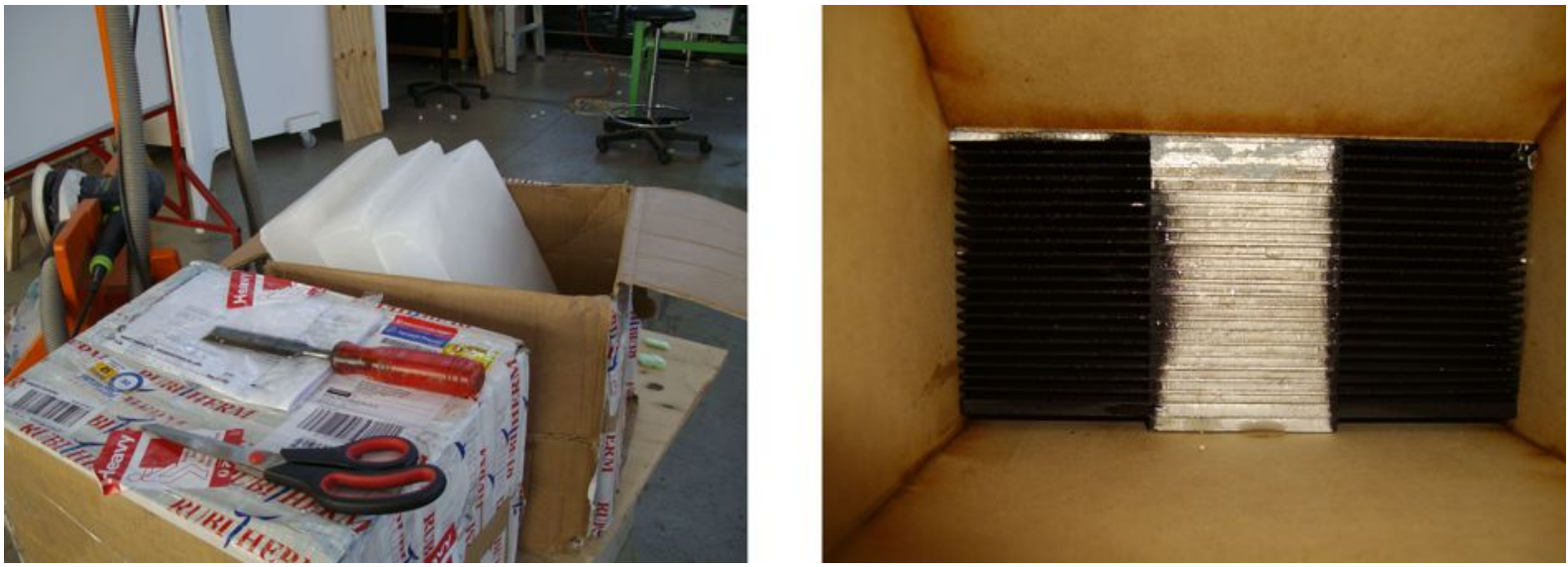

Figure A1.18: (a)PCM as delivered (b) On a particularly humid day, the cooling fins were below dew point when run without the fan. With the fan on, the fins have never encountered condensation. 

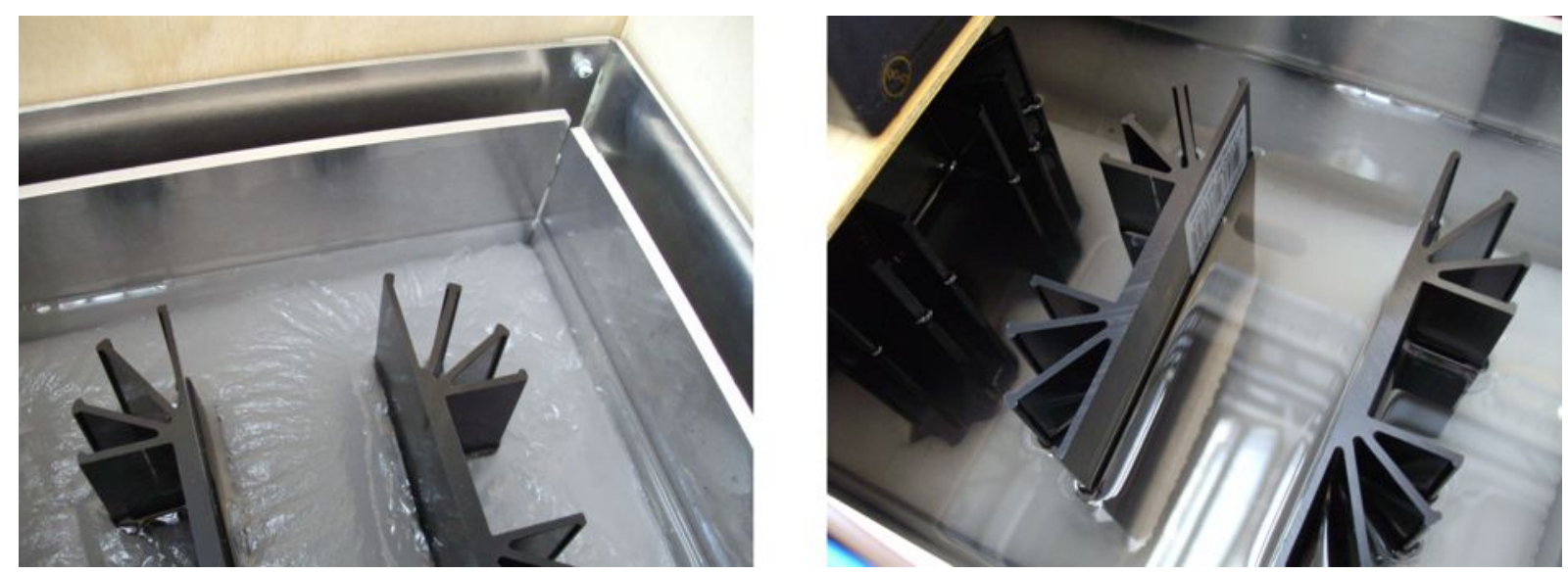

Figure A1.19: (a) Breach of surface by molten wax (b) Solid wax sinks to feed the hot base
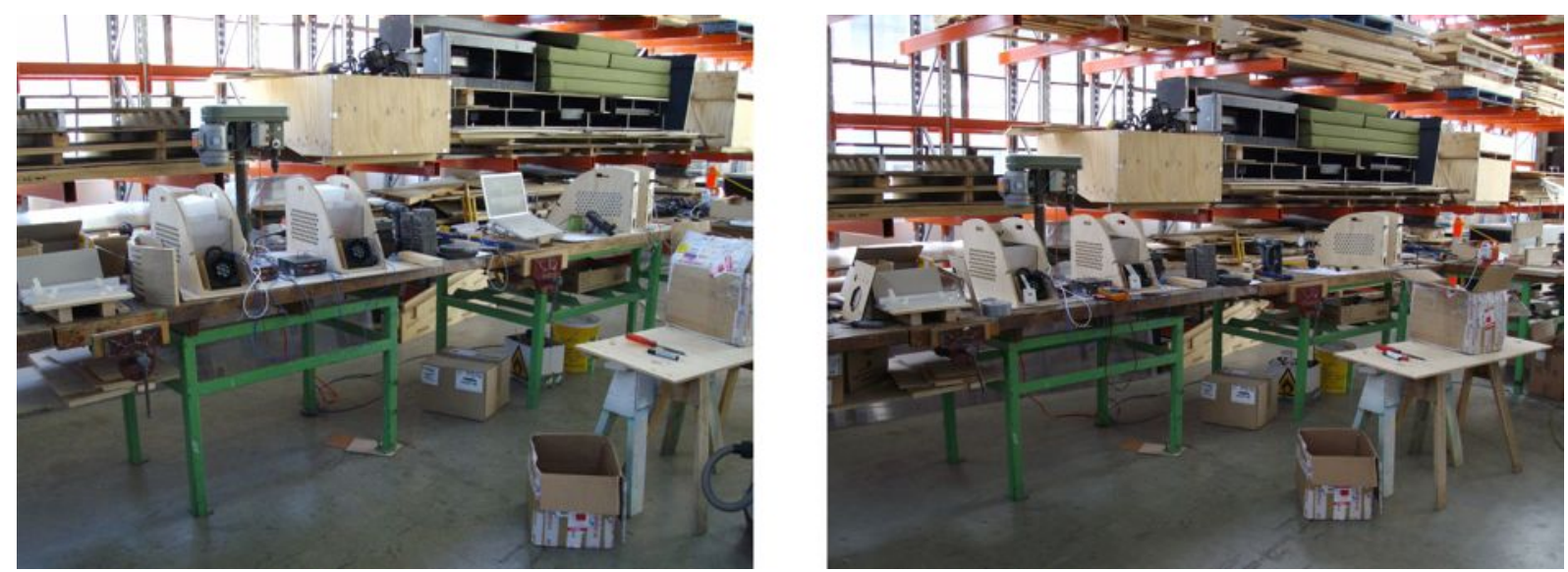

Figure A1.20: (a) Melting of wax in DTAC (b) Setup for data logging of test run 


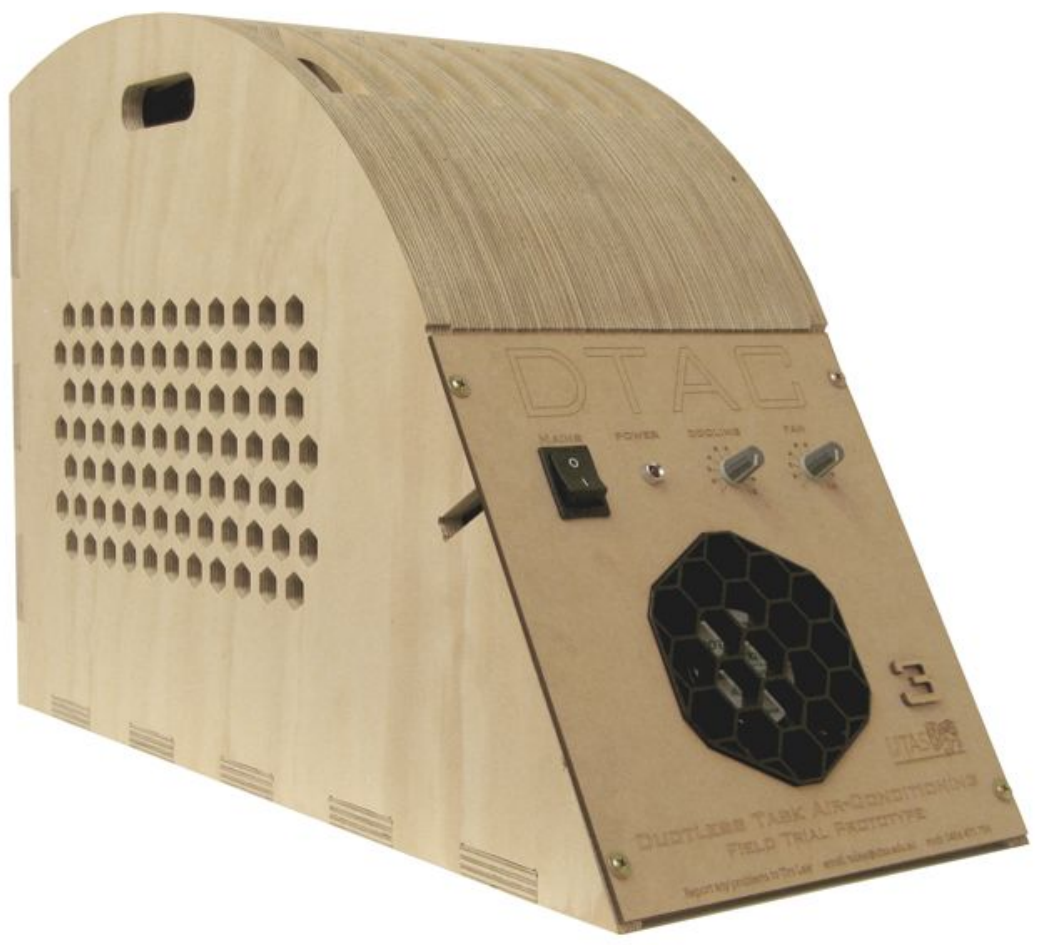

Figure A1.21: Completed DTAC prototype Mark-4

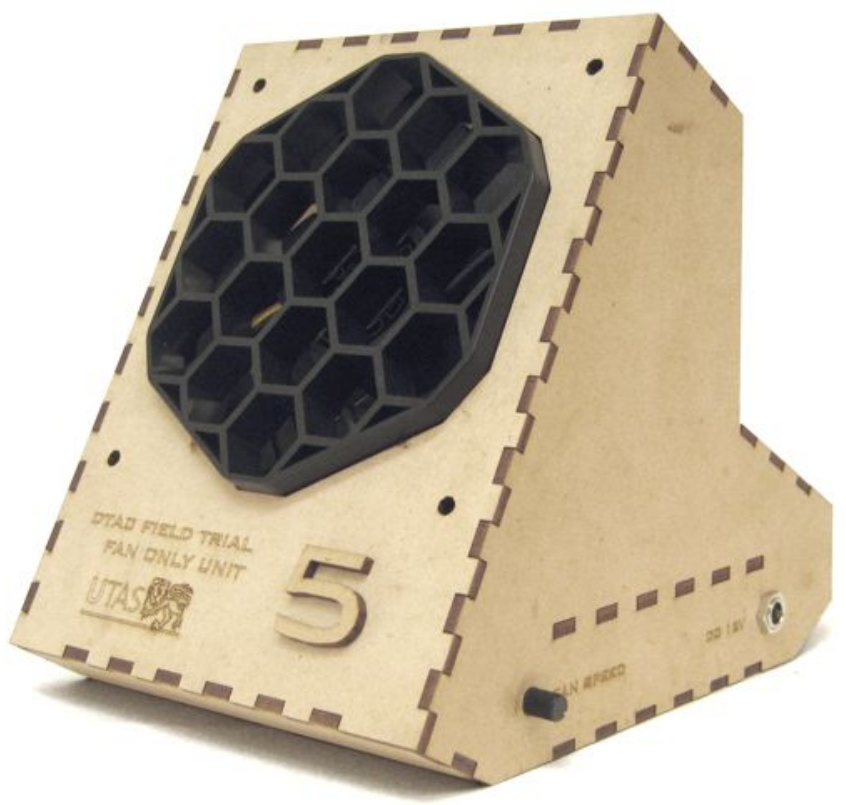

Figure A1.22: Completed fan-only prototype 


\section{A1.1.5 Prototype Summary}

In summary the prototype performance, established methods and recommended upgrades are tabulated in A1.1 and illustrated in figure A1.23.

\begin{tabular}{|l|l|l|l|l|l|}
\hline Prototype & \multicolumn{2}{|c|}{$\begin{array}{c}\text { dT(ini), dT(ss) } \\
\text { cooling } \\
\text { duration }\end{array}$} & \multicolumn{1}{c|}{$\begin{array}{c}\text { Methods/applications } \\
\text { established }\end{array}$} & \multicolumn{1}{c|}{ Recommended upgrades } \\
\hline Mark 1 & $-4.1^{\circ} \mathrm{C}$ & $-2.0^{\circ} \mathrm{C}$ & $\begin{array}{l}3 \mathrm{~h} \\
45 \mathrm{~min}\end{array}$ & $\begin{array}{l}\text { method of getting wax to sink, fan } \\
\text { selection, cooling fin assembly and } \\
\text { dimensions }\end{array}$ & $\begin{array}{l}\text { remove funnel (increases static pressure substantially } \\
\text { thus lowering flow rate) }\end{array}$ \\
\hline Mark 2 & $-2.0^{\circ} \mathrm{C}$ & n.d. & $5 \mathrm{~h}+$ & $\begin{array}{l}\text { double-tank design, clamping of all } \\
\text { thermally conductive elements to } \\
\text { reduce space }\end{array}$ & $\begin{array}{l}\text { fan needs to be relocated for better flow, omit selective } \\
\text { switching of modules, alternative to using clamps on } \\
\text { cooling to ensure even distribution of pressure, need for } \\
\text { internal ducting }\end{array}$ \\
\hline Mark 3 & $-12.0^{\circ} \mathrm{C}$ & $-3.5^{\circ} \mathrm{C}$ & $20 \mathrm{~min}$ & $\begin{array}{l}\text { heat sink included within double tank, } \\
\text { rig for pressing fins, fan controller, } \\
\text { sanding of tank and plates with } \\
\text { weights on glass }\end{array}$ & $\begin{array}{l}\text { larger PCM tank, longer cooling fin assembly, bolting of } \\
\text { assembly needed on top of clamping with TIM }\end{array}$ \\
\hline Mark 4 & $-16.0^{\circ} \mathrm{C}$ & $-8.0^{\circ} \mathrm{C}$ & $3 \mathrm{~h}$ & $\begin{array}{l}\text { measured torque on rig for } \\
\text { momin } \\
\text { consistency, use of engineered cast } \\
\text { iron flat for sanding, }\end{array}$ & $\begin{array}{l}\text { heating of cooling fin to improve TIM conductivity, } \\
\text { topple switch, lower melting point PCM }\end{array}$ \\
\hline
\end{tabular}

Table A1.1: Key measurements and reflection in prototypes Mark-1 to Mark-4. $\mathrm{dT}($ ini) $=$ initial $\mathrm{T}$ of cooling fin - lowest $\mathrm{T}$ of cooling fin. $\mathrm{dT}(\mathrm{ss})=$ ambient $\mathrm{T}$ lowest supply T. "n.d." not determined as flow rate was too low. 


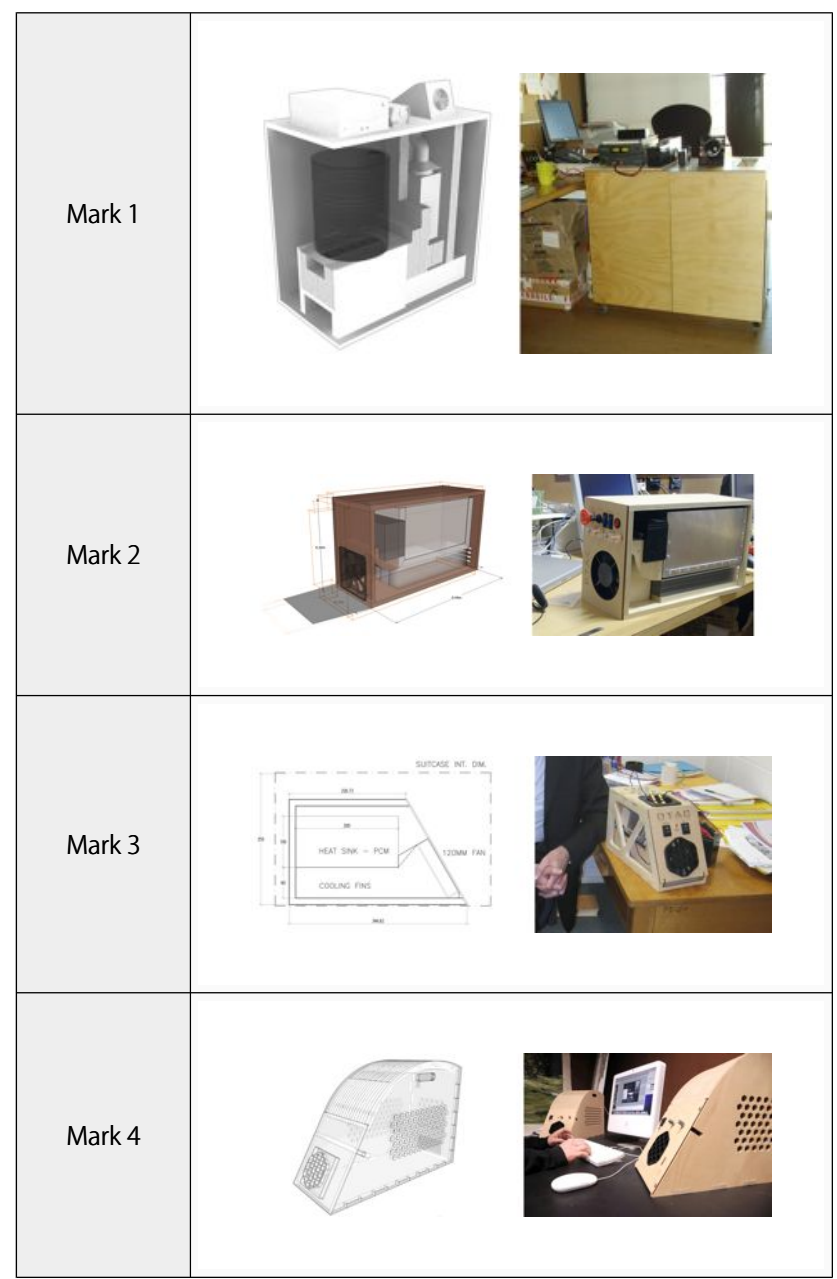

Figure A1.23: CAD drawings and completed prototypes

\section{A1.2 Airflow, fan position}

12V DC (direct current) 120mm axial fans were selected for high volumetric flow rate and large selection range. Typically used in PC cooling applications they were easily accessible and could be selected based on fan speed (RPM), flow rate $\left(\mathrm{m}^{3} / \mathrm{hr}\right.$ or $\left.\mathrm{l} / \mathrm{s}\right)$, and sound rating $(\mathrm{dB})$. and the ease of coupling with $12 \mathrm{~V}$ fan controllers.

Recognising the moderately dusty environments of the workshop in which the DTAC would be fabricated, fans with IP55 rating were used. This gave greater confidence that the fan performance would not change substantially from the manufacturer's specifications over extended use. 


\section{Q What is IP55?}

A IP stands for Ingress Protection. The digits rate solid and liquid ingress respectively. IP55 has limited ingress protection against dust, and protection against low pressure jets of water. (http://www.sensorsone.co.uk/ip-ratingchecker.html)

The following positions for fan placement were tested with similar results of $\sim 4 \mathrm{~m} / \mathrm{s}$ :

1. Axial fan placed immediately after bend in duct

2. Axial fan placed at supply end of duct

3. Axial fan placed at ambient end of duct

In all cases it was found that when coupled with a honeycomb, the flow rate could be improved by about $50 \%$.

The shortcomings of axial fans were that:

- Axial fans typically handled lower static pressures than centrifugal fans. Particular attention had to be paid to minimising flow turbulence in the wake of the fan.

- Axial fans in the $120 \mathrm{~mm}$ range were designed for cooling computers by extracting heat from case. As such it did not matter that the motors were inside the fan. Since the DTAC was working with fairly low refrigeration loads $(\sim 60 \mathrm{~W})$, the heat from the fan motors (7W) could significantly negate the cooling output

\section{A1.3 Airflow}

The cooling fins required the duct to have a rectangular cross-section, whereas the blower grille had a circular connector. A funnel was fabricated to mate the different sections and designed to fit over the circular opening of the (square) fan. When the funnel was used directly with the fan the exit flow rate was $<0.5 \mathrm{~m} / \mathrm{s}$. The angle of the funnel was deemed too steep for this flow. A honeycomb (Nexus Beamair) positioned in the wake of the fan substantially improved flow (figure A1.24 and A1.25). Even so there were substantial losses with the funnel (see table A1.2). 
This Figure has been removed for copyright or proprietary reasons

Figure A1.24: Honeycomb with claims by manufacturer to reduce turbulence and improve flow rate (Source: manufacturer, http://www.nexustek.nl/NXSnexus-beamair-airguider.htm)
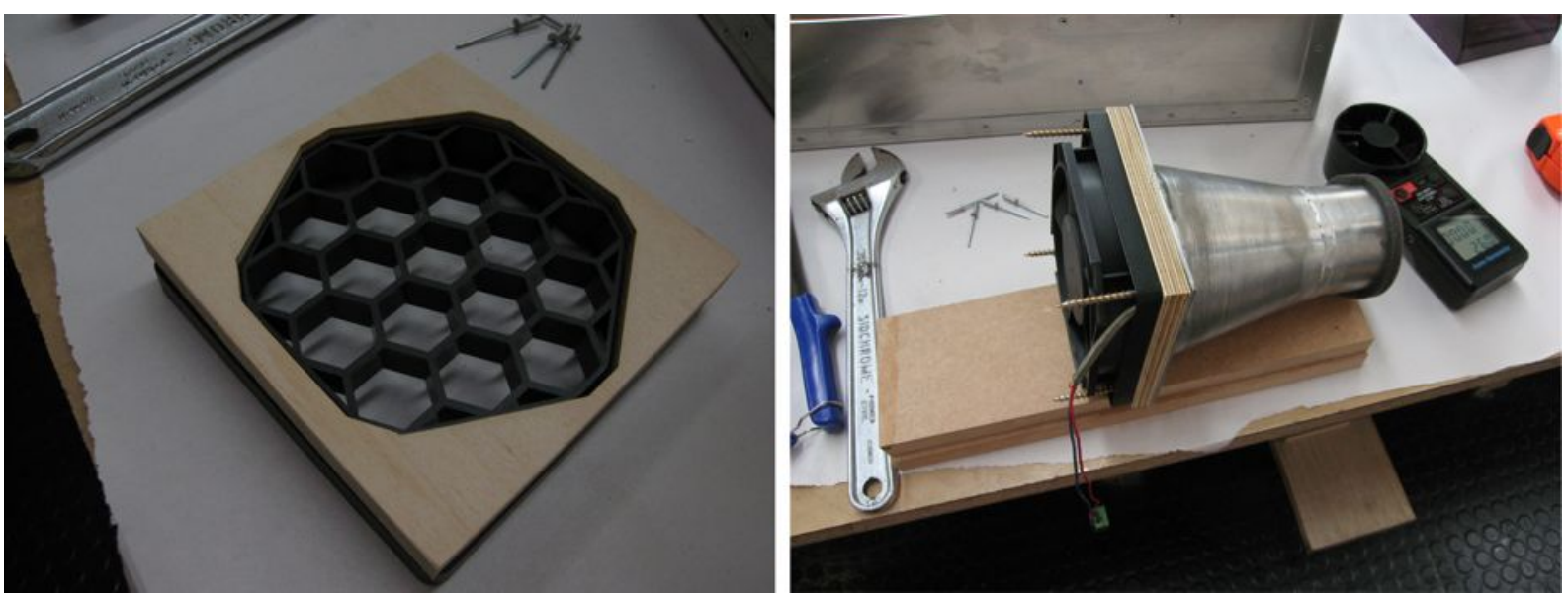

Figure A1.25: Honeycomb and spacers to enable a flushed facing when bolting on the funnel. 


\begin{tabular}{|l|c|c|}
\hline \multicolumn{1}{|c|}{$\begin{array}{c}\text { Setup: } \\
\text { fan at 12V in duct at supply end) }\end{array}$} & $\begin{array}{c}\text { Anemometer reading } \\
(\mathrm{m} / \mathrm{s})\end{array}$ & $\begin{array}{c}\text { Section width } \\
\varnothing(\mathrm{mm})\end{array}$ \\
\hline Fan alone (calculated) & 3.7 & 120 \\
\hline Fan alone & $\sim 4$ & 120 \\
\hline Fan + honeycomb & $\sim 6$ & 70 \\
\hline Fan with funnel (calculated, no loss) & 10.8 & 70 \\
\hline Fan with funnel & $<1$ & 70 \\
\hline Fan + honeycomb with funnel & 6.9 & 70 \\
\hline Fan + honeycomb with funnel and hose & 5.8 & 70 \\
\hline Fan + honeycomb with funnel and cooling fins & 3.3 & 70 \\
\hline $\begin{array}{l}\text { Fan + honeycomb with funnel, } \\
\text { with hose connector, blower grille }\end{array}$ & 3.9 & 70 \\
\hline $\begin{array}{l}\text { Fan + honeycomb with funnel, } \\
\text { with hose connector, blower grille and cooling fins }\end{array}$ & 2.3 & 70 \\
\hline
\end{tabular}

Table A1.2: Wind velocity readings at various stages in the assembly. Measured values, unless indicted as derived from calculations

\section{A1.4 Blower housing}

A manufactured blower grille was purchased through the Mazda 3 vehicle dealership carrying spare parts. The housing was fabricated to drawings and specification (figure A1.26 and A1.27) by a plastic specialist with the following steps:

- acrylic laser cutting according to drawings

- heat folding

- side walls (with offset) fused to the folded profile using chloroform

- offset removed by router to give a seamless finish. 


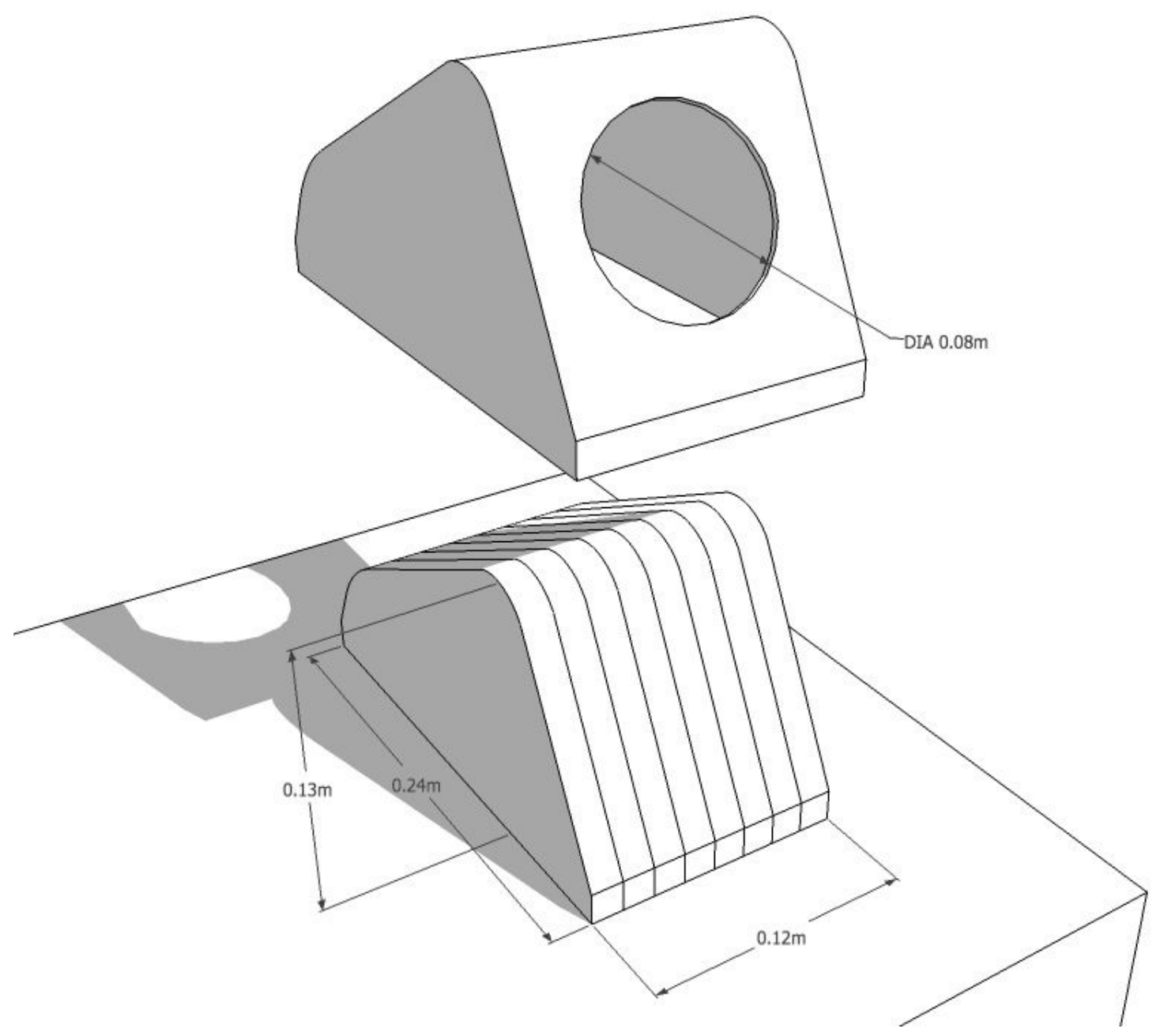

Figure A1.26: Plug design for forming the profile
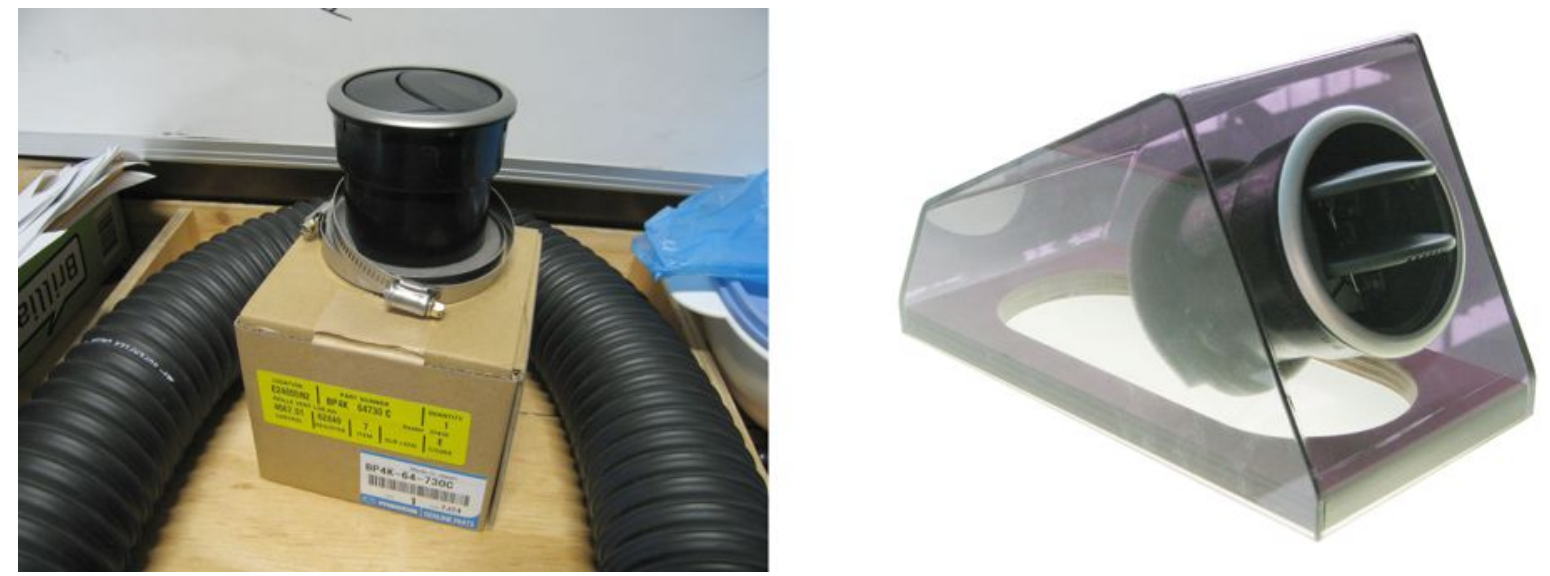

Figure A1.27: (a) Purchased blower grille (b) Acrylic housing

\section{A1.5 Internal ducts}

Internal ducts were fabricated from $2 \mathrm{~mm}$ sheet aluminium and insulated in $50 \mathrm{~mm}$ thick polystyrene. Joints were further covered in duct tape to minimise leakage. A foam draft tape 
was used to seal gaps internally and still allow for parts to be removed and adjusted. Due to the high cost of fabricating the aluminium ducts, they were changed to MDF subsequently, which could be made in the School workshop.

As an under-table pedestal, the Mark-1 ducts had a $90^{\circ}$ elbow (figure A1.28 to A1.31) which connected to a flexible conduit. It was designed as a straight path in Mark-2 (figure A1.32) with no discernible airflow so the heat exchangers were salvaged and used in a MDF duct (figure A1.33) for further testing. Having found the MDF duct viable, subsequent Mark-3 and Mark-4 versions were redesigned to have a $30^{\circ}$ bend after the cooling fins that connected to the fan (figure A1.34). This proved to be a far more efficient, with a Loss Coefficient correction of 0.13 ; compared to 1.0 for a $90^{\circ}$ bend (Australian Institute of Refrigeration, Air Conditioning and Heating, 1995, p.4.05).
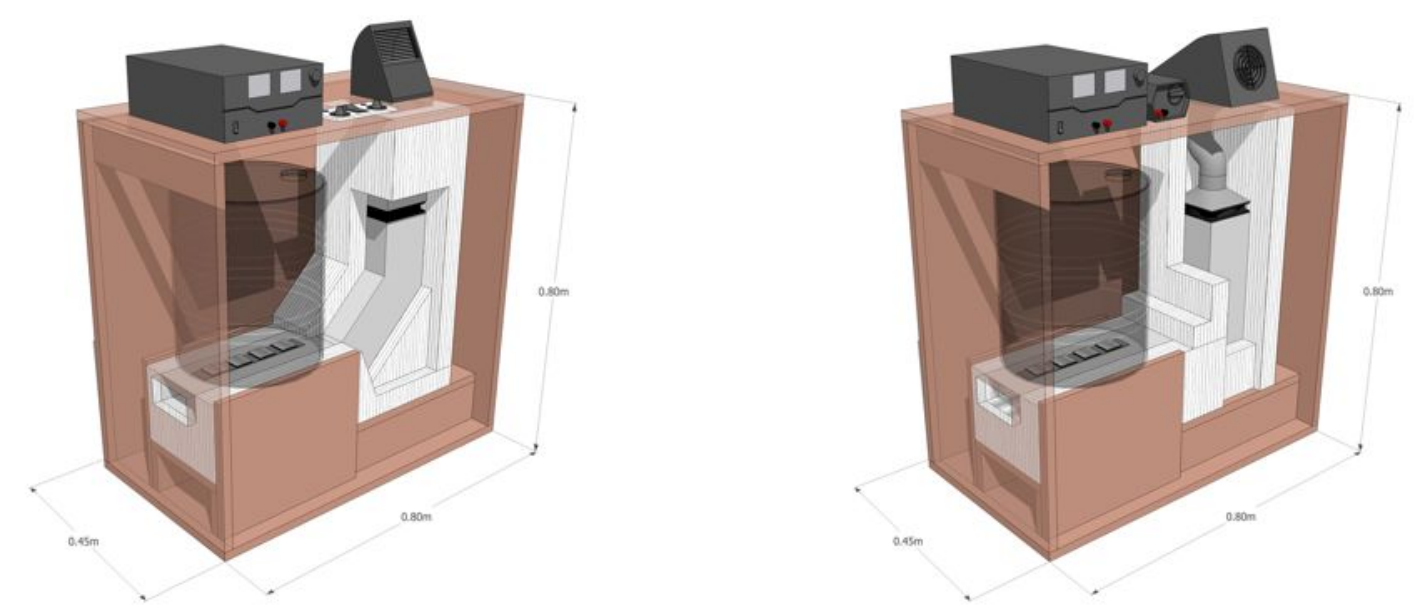

Figure A1.28: (a) Initial duct design with $2 \times 45^{\circ}$ bends when turning from horizontal to vertical causing less turbulence and lower pressure drop. (b) Fabricated design for cost economy with a $90^{\circ}$ elbow 


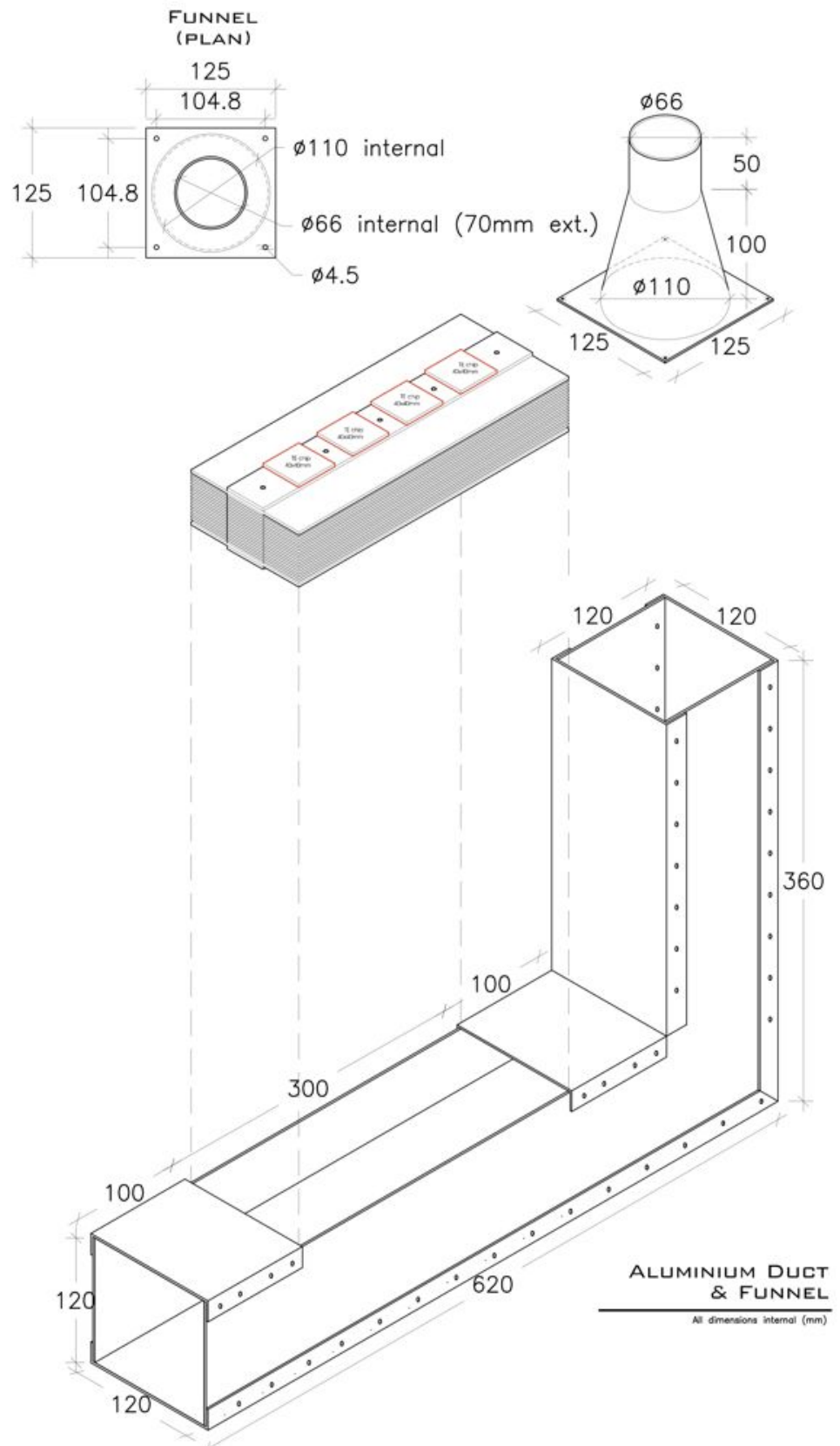

Figure A1.29: Isometric design of duct, funnel and cooling fin assembly. 

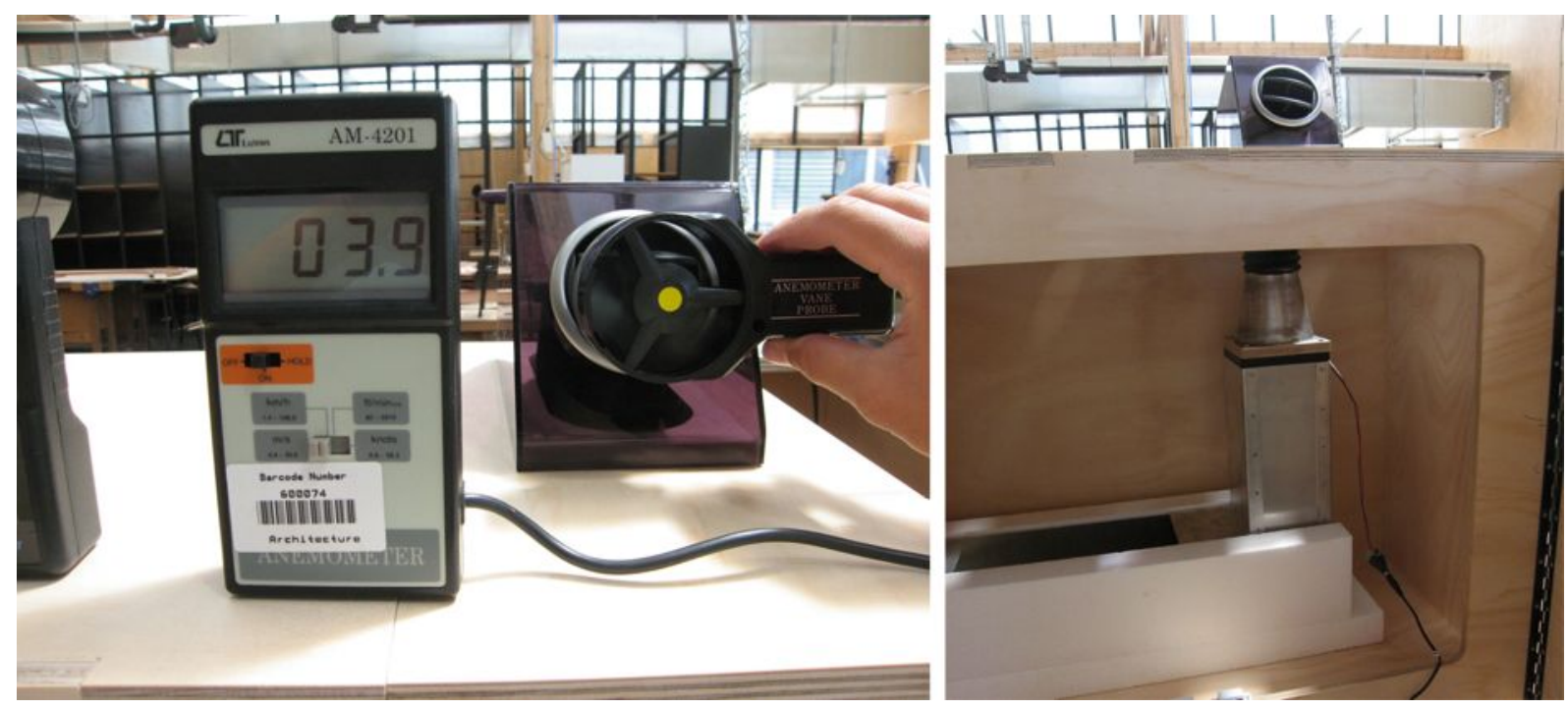

Figure A1.30: (a) Air speed measurement from blower grille (b) blower grille connection to duct
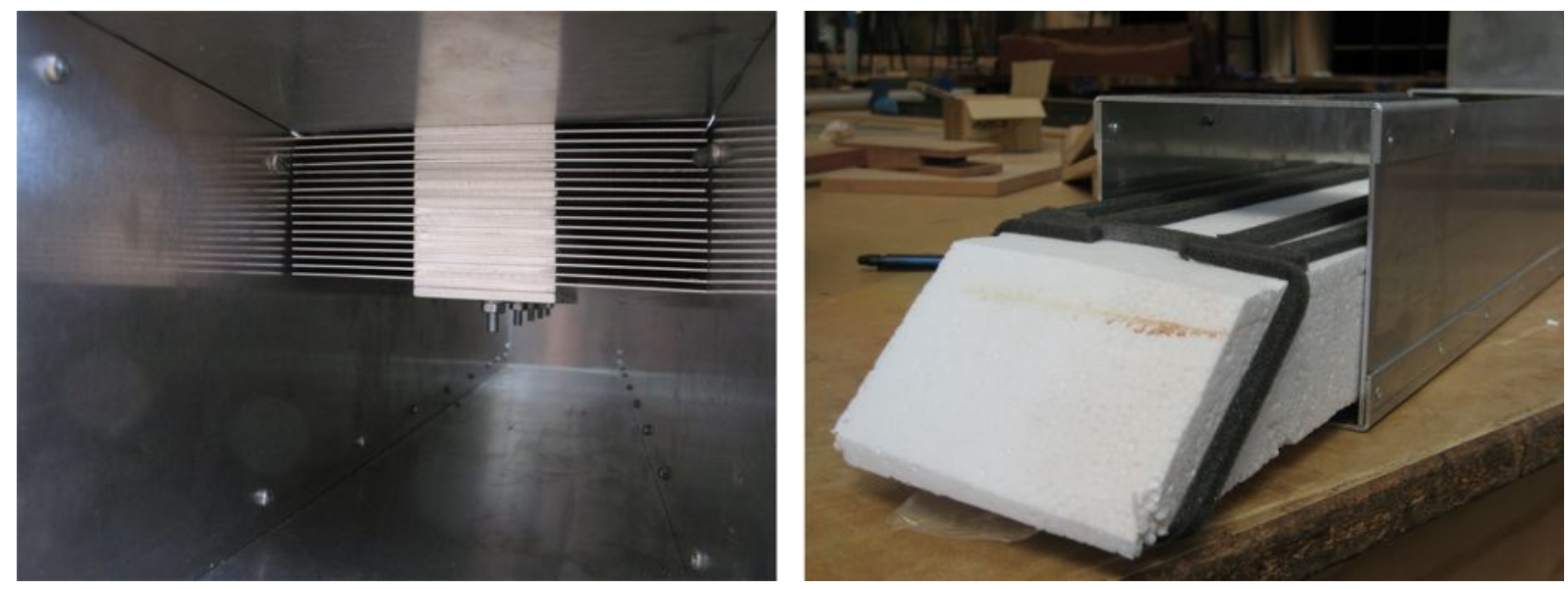

Figure A1.31: Cooling fins to half the duct height with lower half blocked with polystyrene. Foam tape around the polystyrene block prevented air flow from bypassing the cooling fins. 


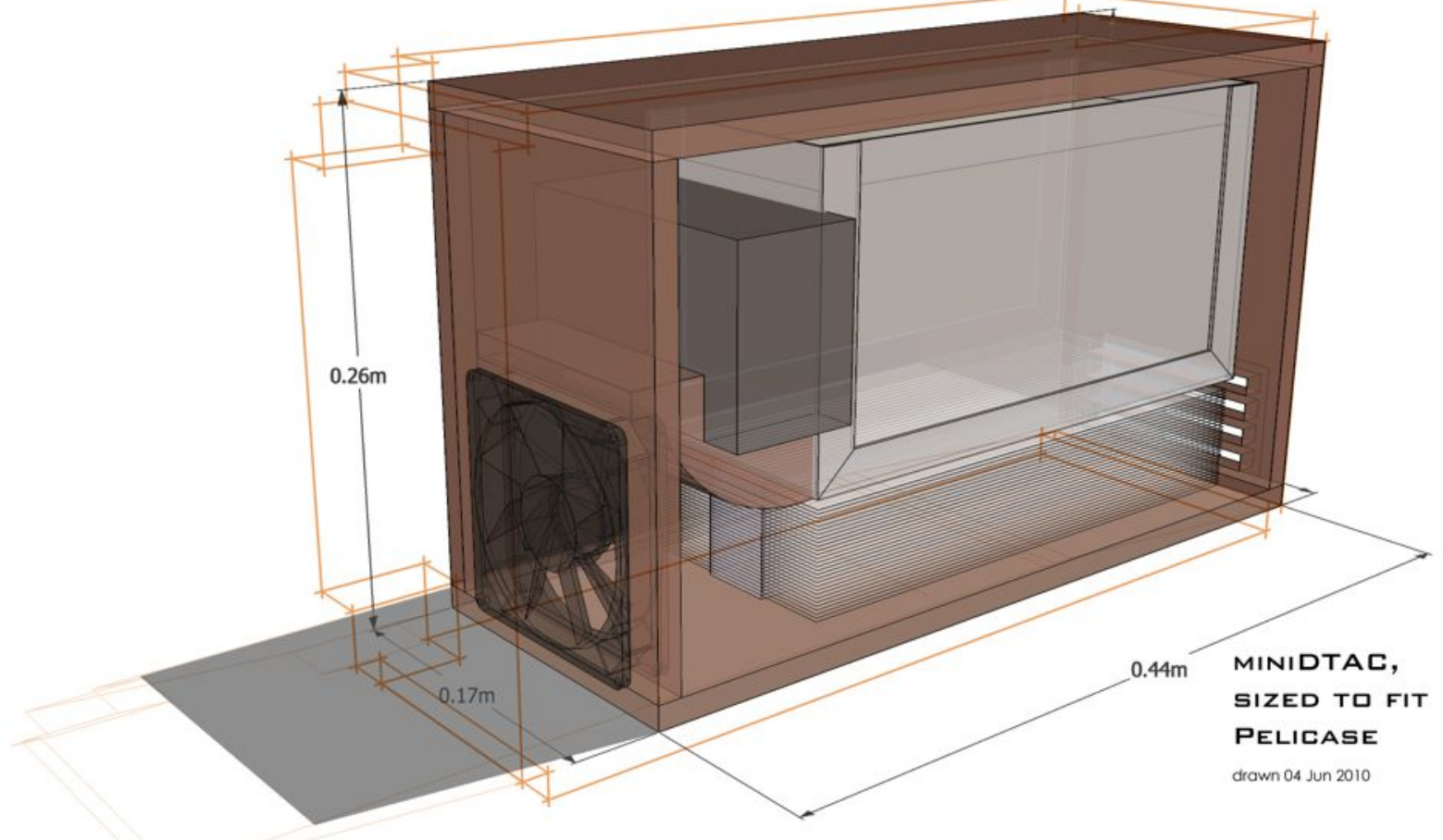

Figure A1.32: Mark2 with a curved funnel. This prototype showed too much turbulence and a honeycomb was deemed necessary. In addition the cooling fins were repositioned at the windward side of the fan in subsequent prototypes.
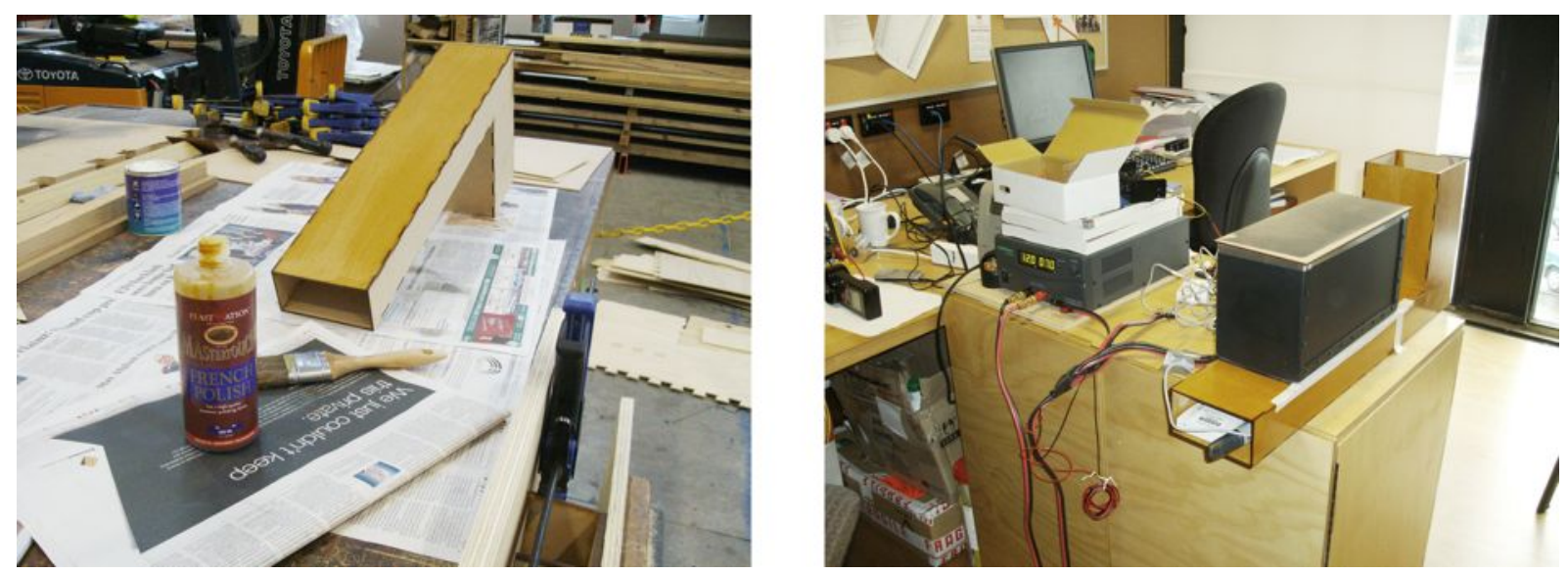

Figure A1.33: (a) Laser cut 3mm MDF duct being glued with PVA and coated with two coats of shellac for air-tightness, (b) show here being used with Mark 2 tank. 

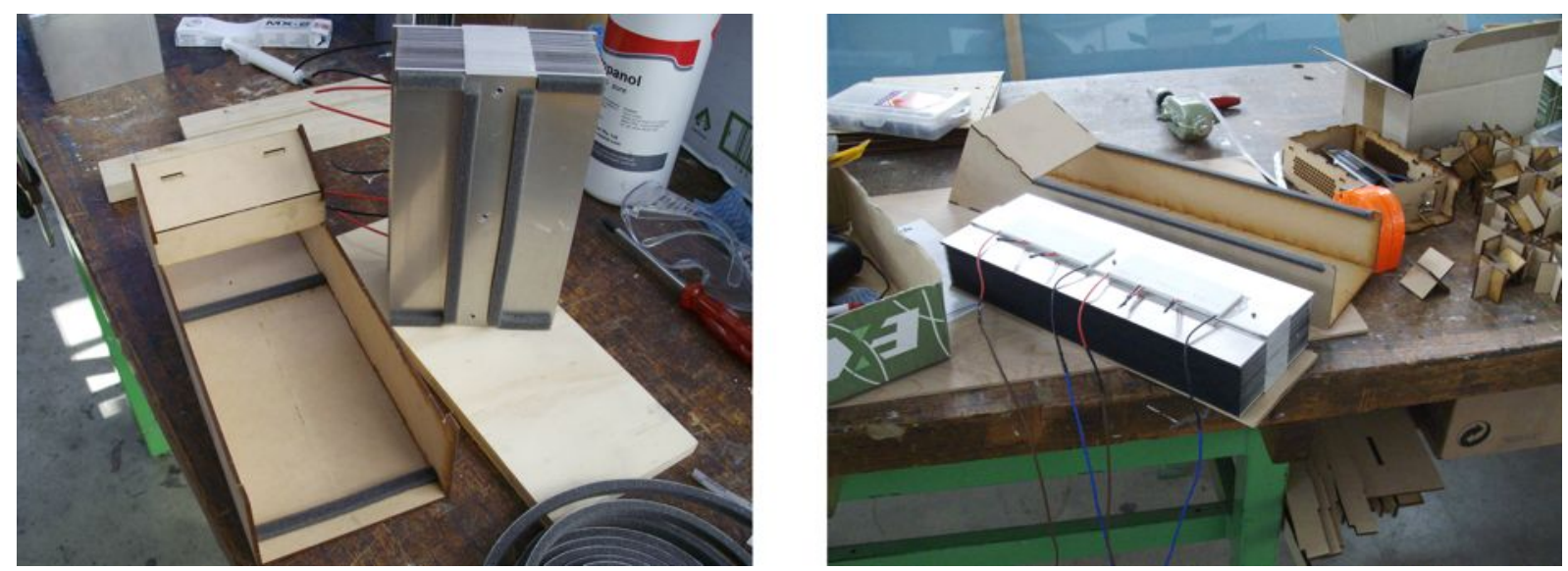

Figure A1.34: MDF ducts redesigned for minimal bends subsequently used for (a) Mark-3 and (b) Mark-4

During one of the preliminary test for the field trial prototype (figure A1.35), one of the units (FT1) had a supply air temperature close to ambient even though the cooling fins were about $4^{\circ} \mathrm{C}$ below ambient (figure A1.36 and A1.37), indicative of a leak in the system. The most likely cause of the leak was the gap between the straight edges of the fan enclosure and the MDF duct. This region was patched with a foam tape (figure A1.38) which eliminated the problem.
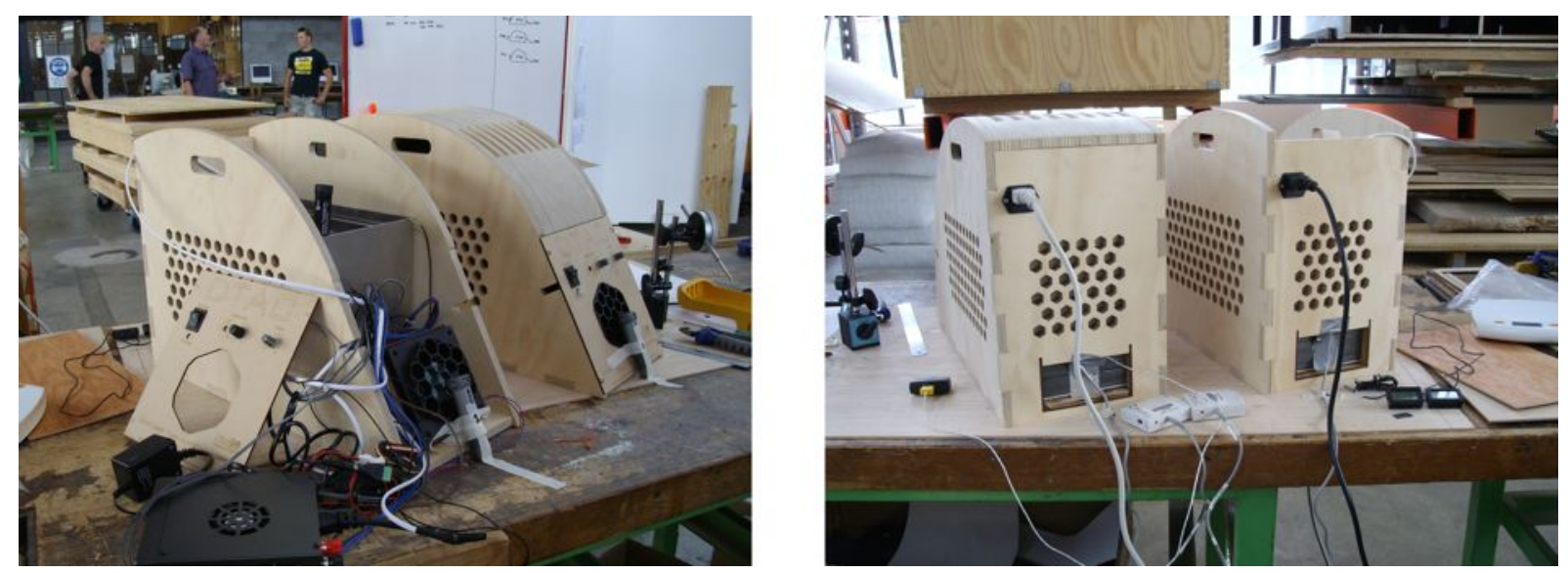

Figure A1.35: Test of field trial (FT) units, $\mathrm{FT}_{1}$ and $\mathrm{FT}_{2}$ 


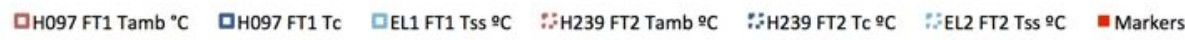

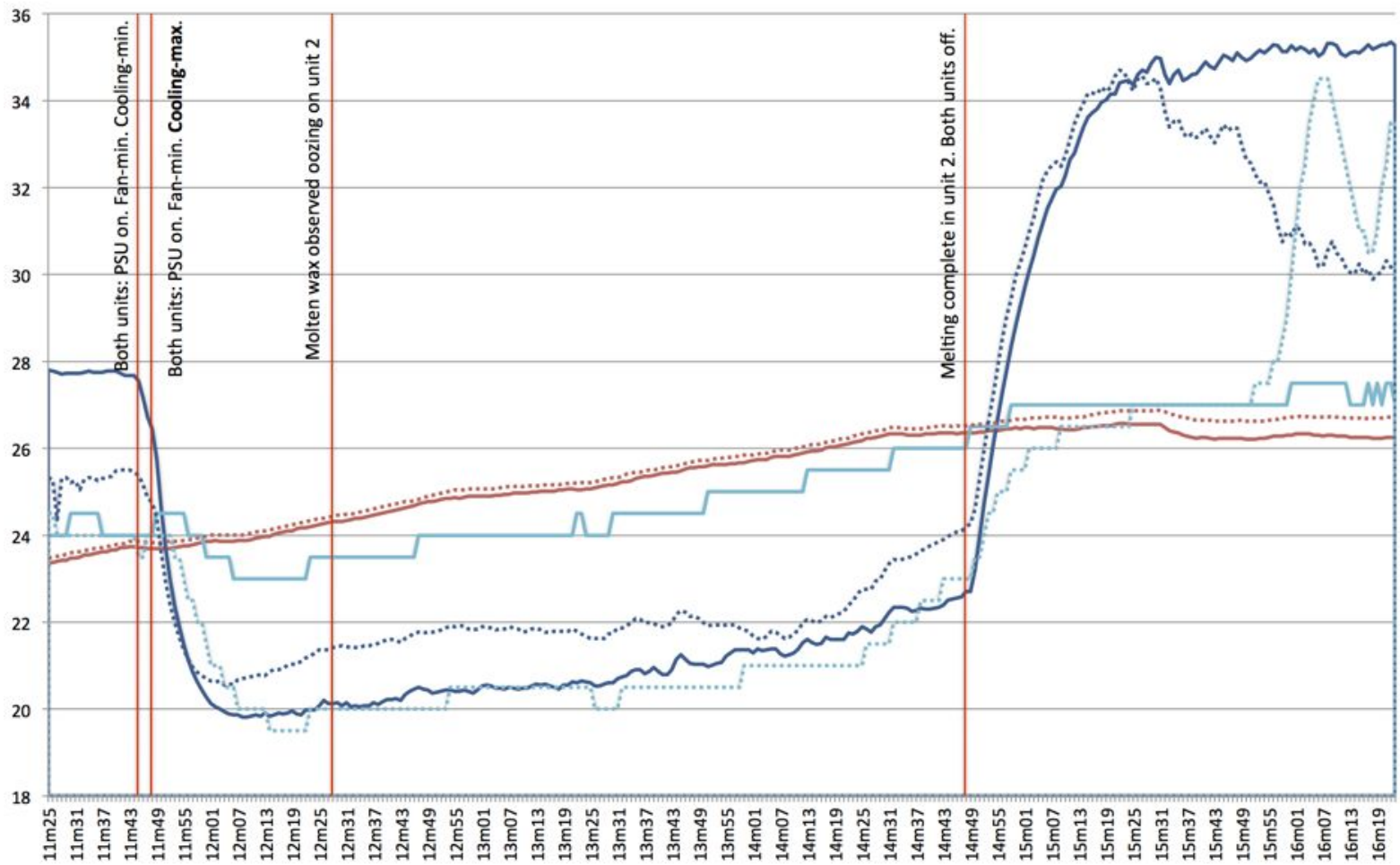

Figure A1.36: Two units of field trial DTAC, FT1 and FT2 being tested concurrently. Readings from placements are colour coded, with solid line for $\mathrm{FT}_{1}$ and dotted for FT2. T-ambient (reds) shows a close match of conditions. Tcold side (dark blues) show a match of about $1^{\circ} \mathrm{C}$.

T-supply air (cyans) indicate that $\mathrm{FT}_{1}$ (solid line) is supplying air that is only very slightly cooled. This cannot be due to a malfunctioning heat exchanger as the cold sides are showing significant lower than ambient temperatures. This is most likely due to a leaky system so that the fan is not drawing air through the cooling fins but predominantly from the ambient. FT2 (dotted) is supplying air colder than the cold side. This is certainly not the case in reality. The method of adhering the Hobo sensors to the cooling fins will read a higher than actual temperature, and is an acknowledged weakness in this measuring procedure. 


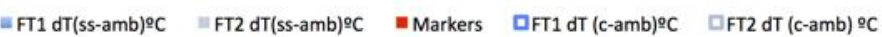

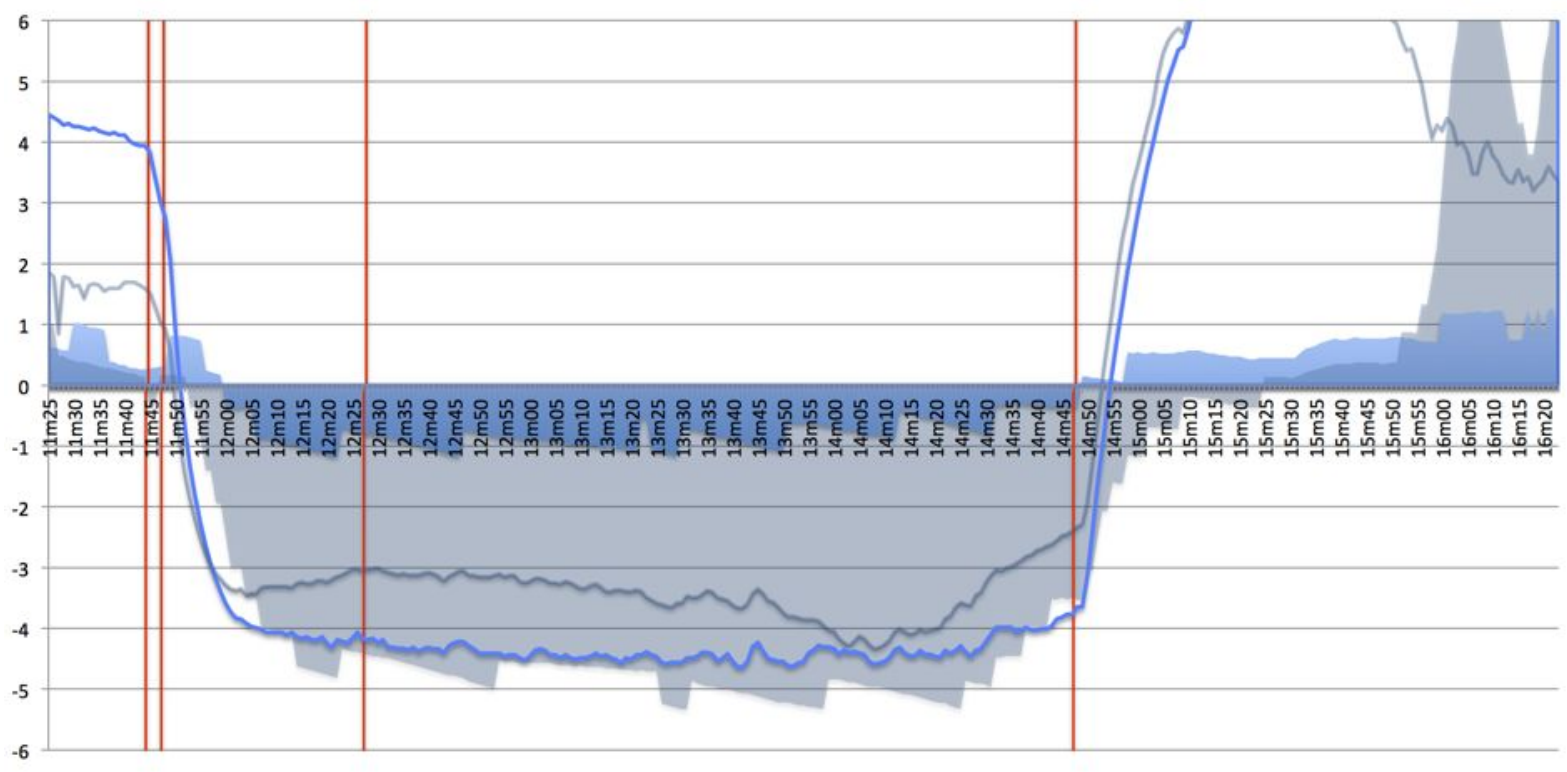

Figure A1.37: Same data as above presented as $\Delta T$. Shaded areas show $\Delta T$ (supply $T$ - ambient $\mathrm{T}$ ), and lines show $\Delta \mathrm{T}$ (cold $\mathrm{T}$ - ambient $\mathrm{T}$ )

$\mathrm{FT}_{1}$ is being cooled (blue line) by $4-5^{\circ} \mathrm{C}$ but supply air is only slightly below ambient (blue area).

$\mathrm{FT} 2$ is cooled (grey line) by $3-4^{\circ} \mathrm{C}$ but supply air is colder than cooling fin (grey area.)

This confirms the earlier suspicion that $\mathrm{FT}_{1}$ is leaky and the cooling fin temperatue of $\mathrm{FT}_{2}$ is inaccurately read.
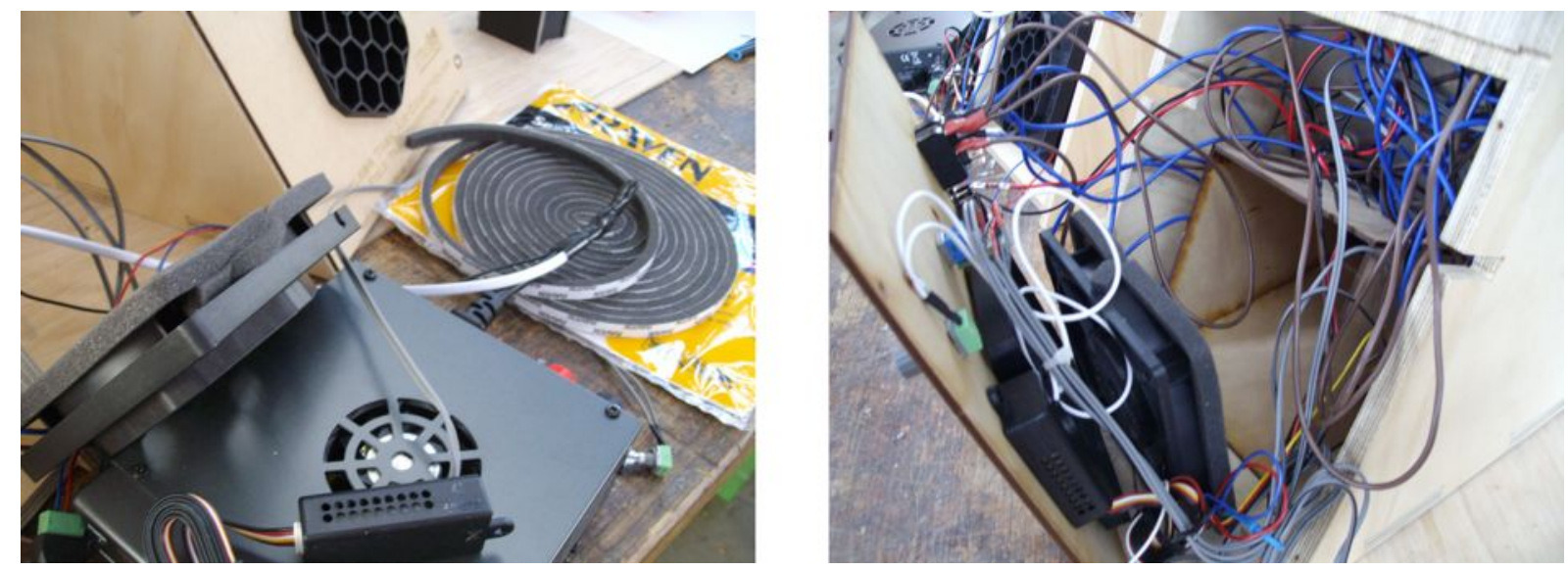

Figure A1.38: Foam weather tape around fan to ensure a snug fit

\section{A1.6 Manufacture}

After cutting on a CNC router (figure A1.39a), assembly and installation of hinges, castors and piston stays (figure A1.39b), the pedestal was varnished with two coats of polyurethane (figure A1.40). Despite being left to dry for a week, it was still off-gassing an odour for months after application and a distinct smell of the solvent was noticeable upon entry into 
the office in the morning. In future it should be either left unfinished or finished with a water-based varnish.
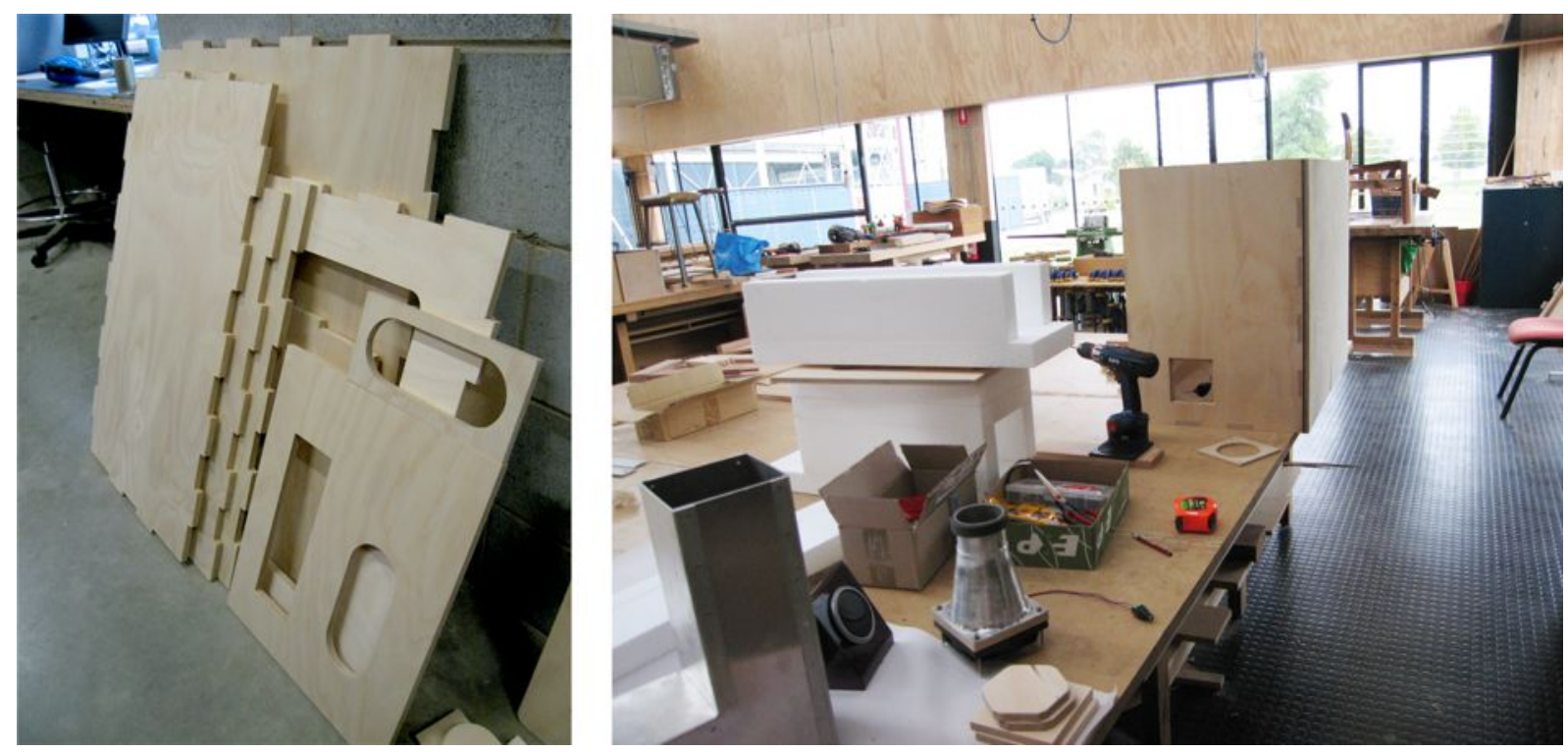

Figure A1.39: (a)12.5mm plywood after being cut by the CNC router (b) assembly and attachment of ironmongery.

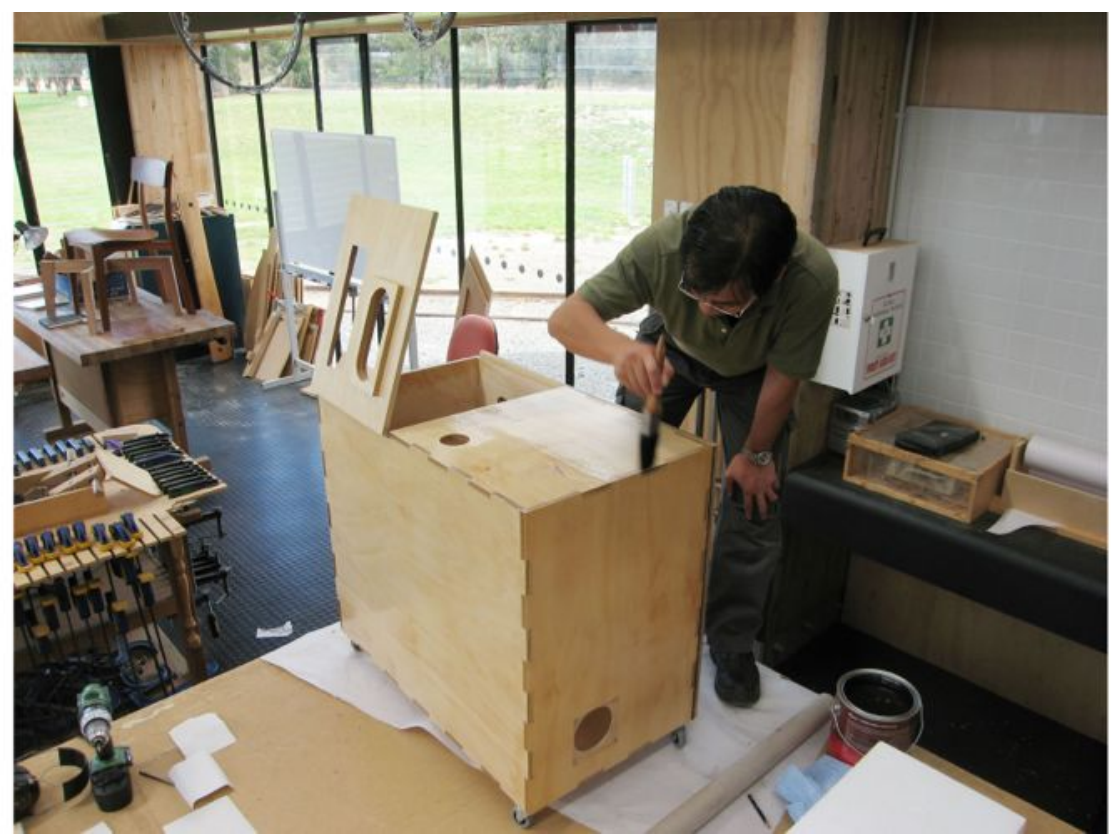

Figure A1.40: Application of polyurethane varnish.

In the early stages of prototype testing, before the cooling fins were enclosed, the indicator used was dT(ini) - the temperature difference between the initial temperature and the current one. This was measured by using a thermocouple connected to a digital multi-meter 
(accuracy $\pm 2 \%$ ) with PC connection and logged for 8 minutes at 1 sec intervals. After 8 minutes the temperature would typically stabilize.

As the conductivity of aluminium is about 10,000 times that of air, any imperfections in the surfaces (like dents and burrs), especially in the $2 \mathrm{~mm}$ aluminium spacers, could push the fins apart. Even a microscopic film of air would reduce the conductivity of the cooling fin assembly by a few orders of magnitude. The dT(ini) tests thus gave early feedback if performance had been compromised at any point in the assembly of DTAC. figure A1.41 shows an example of the tests done during the following stages:

- Tank for PCM, TE modules and cooling fin held by clamps

- Clamps removed

- Tank and cooling fins moved into pedestal

- PCM added, fan off

- Fan switched on

An axial fan (120mm) was used to move the air through a honeycomb and funnelled to a $70 \mathrm{~mm}$ diameter outlet where wind velocity was measured by a vane anemometer. No fan controller was used. When the fan was switched on the velocity was between $2.3-2.4 \mathrm{~m} / \mathrm{s}$.

Similar dT(ini) tests were run at different voltages for the TE modules which were rated for a maximum input voltage of $15 \mathrm{~V}$. Near this maximum voltage the heat produced on the hot side of the modules could not be effectively removed, causing the cold side to rise above ambient temeperature. The best outcome was achieved by running the modules at $7.5 \mathrm{~V}-10 \mathrm{~V}$ as seen in figure A1.42 . 


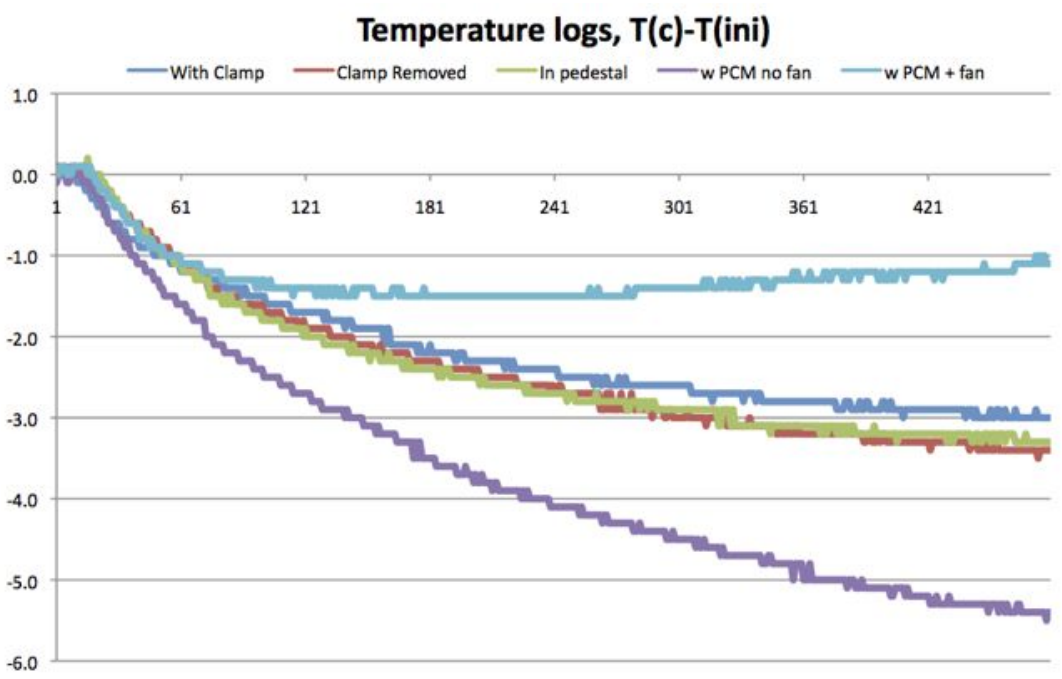

Figure A1.41: $\mathrm{dT}$ from initial temperature at various stages in assembly

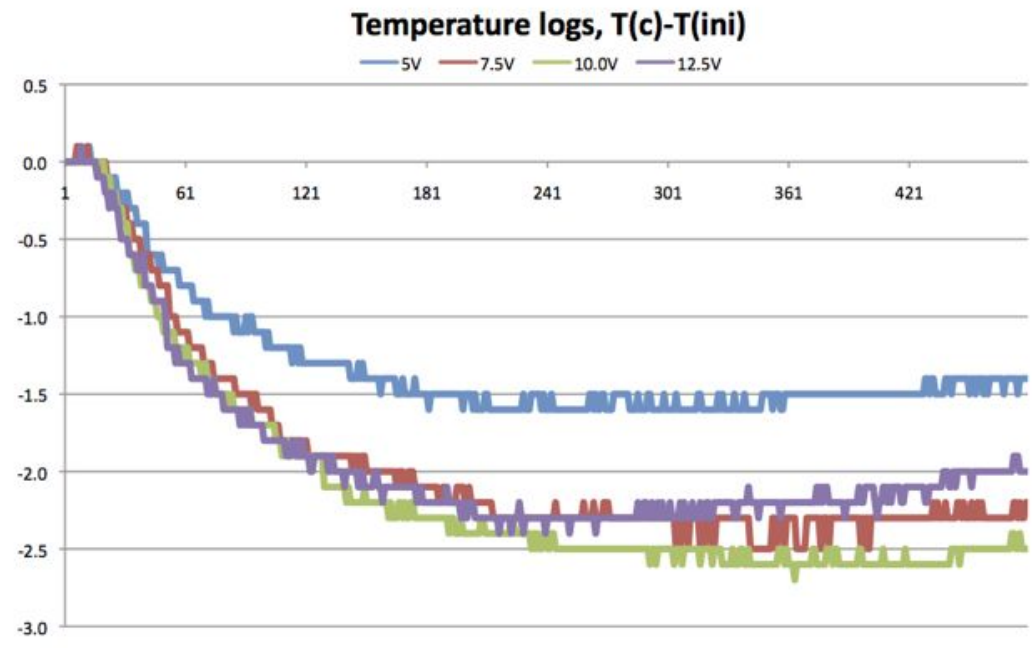

Figure A1.42: dT from initial temperature applying different voltages across TE modules

\section{A1.7 Cooling Fin Assembly}

\section{A1.7.1 Design}

Based on earlier concept of a vertical heat-exchange configuration, it was possible to select an off-the-shelf fan assisted heat sink. However the fin arrangement was not suitable for ensuring that the fin $\mathrm{T}$ and airstream $\mathrm{T}$ were close in magnitude. A cooling fin was designed as a honeycomb with TE modules on either side of the fins (figure A1.43). 

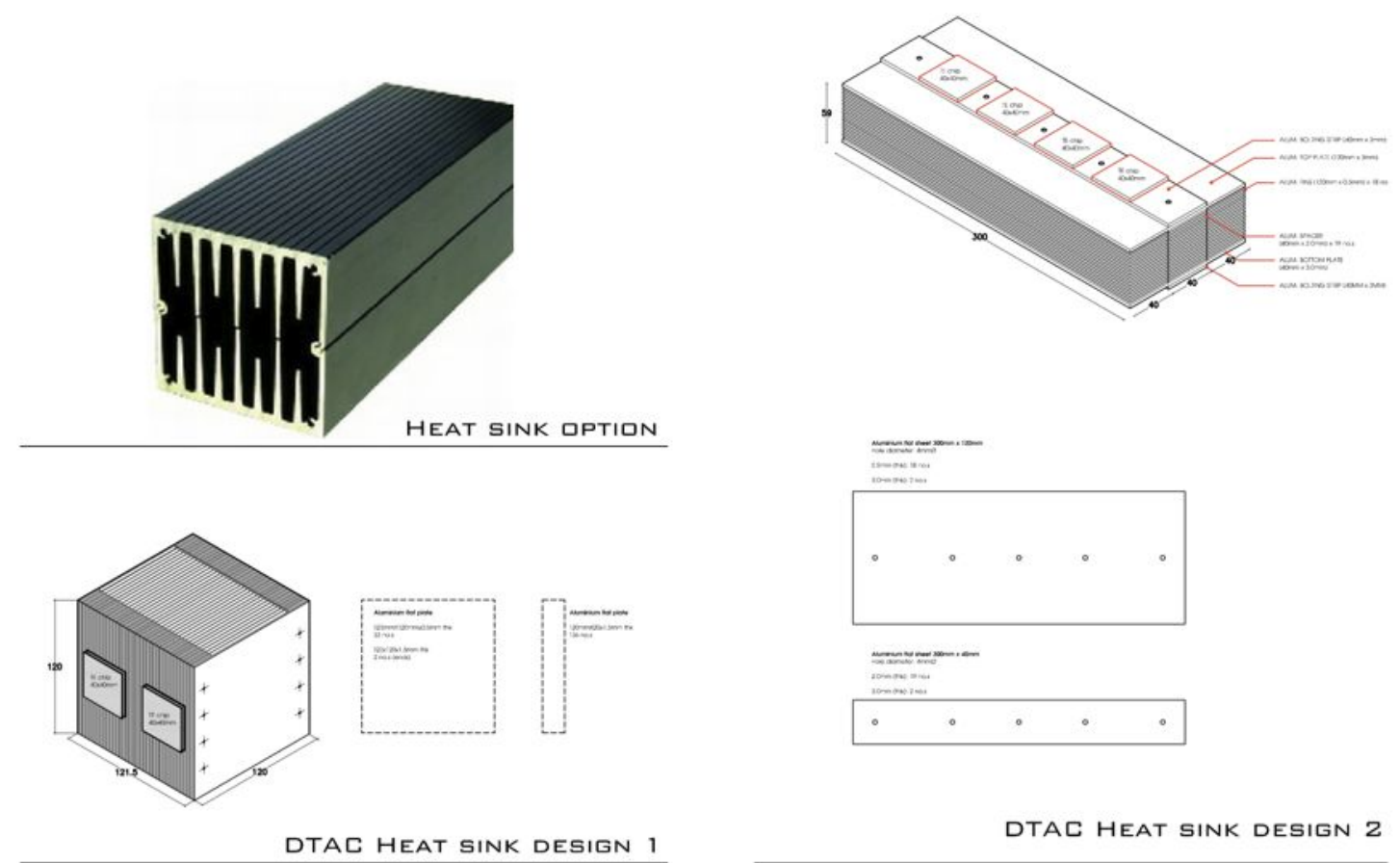

DTAC HEAT SINK DESIGN 2

Figure A1.43: Cooling fin selection and development: "Heat Sink Option" an off the shelf fas-assisted heatsink suitable with an $80 \mathrm{~mm}$ fan was later felt to be unsuitable as the air stream will be moving too quickly through it and remain close to ambient temperature. "Design 1 " was the initial design for cooling fins in a vertical position, later felt to be unsuitable as heat will not conduct well from fins to heat pump. "Design 2" is based on a core where the bulk of conductive heat transfer occurs, before spanning to individual fins.

There were however risks that the heat from the PCM tank had many possible return points into the supply air stream (figure A1.44). This design also required very tight tolerance between PCM heat sink - TE modules - cooling fin honeycomb on both sides. 

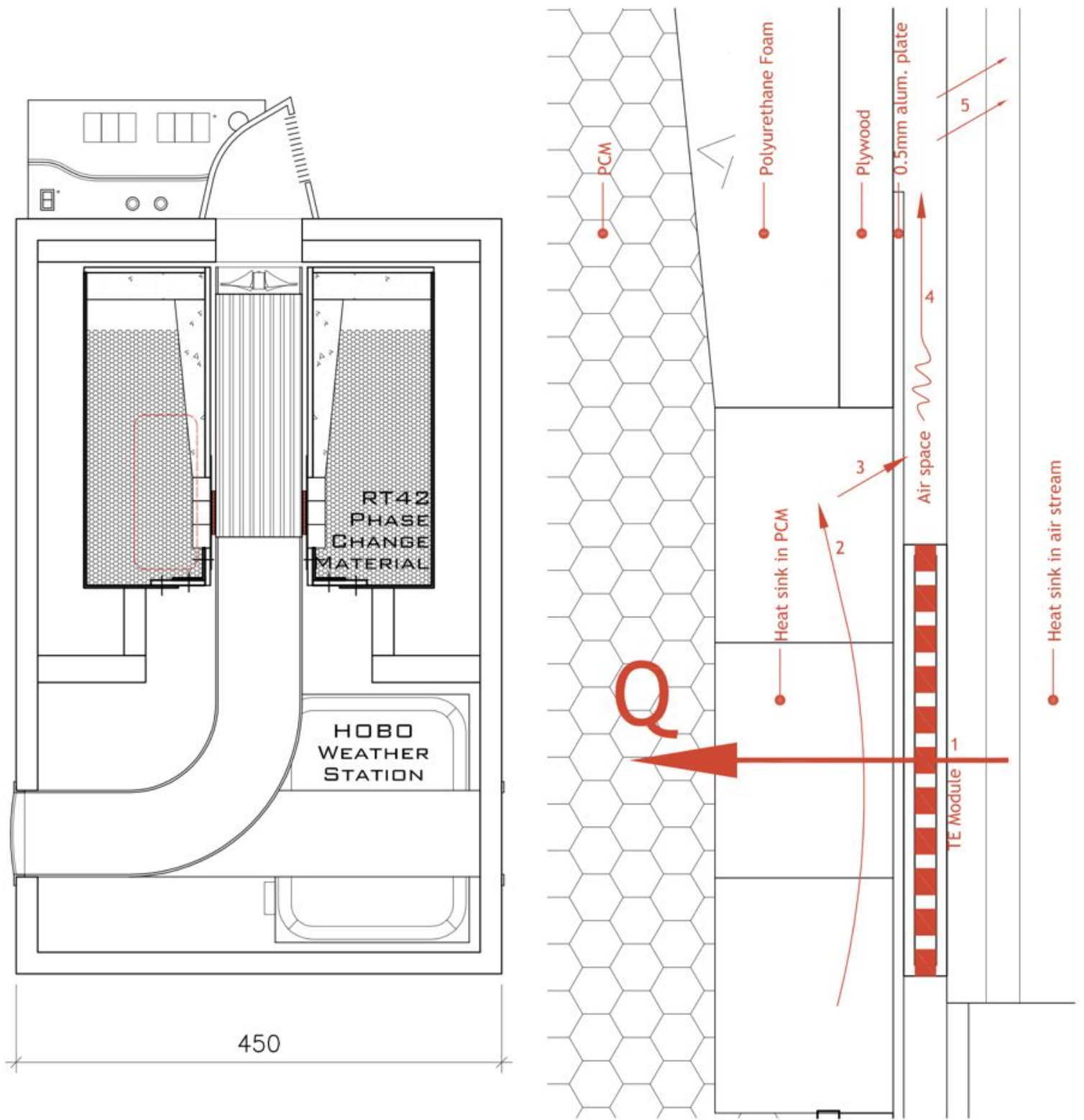

Figure A1.44: Issues found with working with a vertical cooling fin design: (1) Heat removed from air stream by TE modules to the PCM. An aluminium plate is screwed into the plywood with a sealant to precent PCM leakage. (2) To assist in the transport of heat, aluminium fin/pin heat sinks help to dissipate the heat. Polyurethane foam is proposed to prevent heat from PCM returning to the air stream. (3) However heat from the heat sink will still convect in the air cavity. (4) The heated plume will rise the height of the heat sink and may leak back into the supply air stream. Note that TE modules need to be at the bottom as the PCM expands $16 \%$ when melted. (5) Throughout this time, heat will be conducting back into the cooling fins.

For ease of fabrication the cooling fin was redesigned to have all TE modules on only one side (figure A1.45). The fins were protrusions of $0.6 \mathrm{~mm}$ plates sandwiched in $2 \mathrm{~mm}$ spacers as the central core (figure A1.46). The fin density was determined as what was required for forced convection to ensure adequate interaction of the air stream and fins. The heat extracted from the fins would be transport to the central core and pumped to the PCM by 
the TE modules. The central core was designed around the $40 \mathrm{~mm}$ dimensions of the TE modules and the fin lengths were $40 \mathrm{~mm}$ on each side to meet the duct dimensions for fitting a $120 \mathrm{~mm}$ fan.

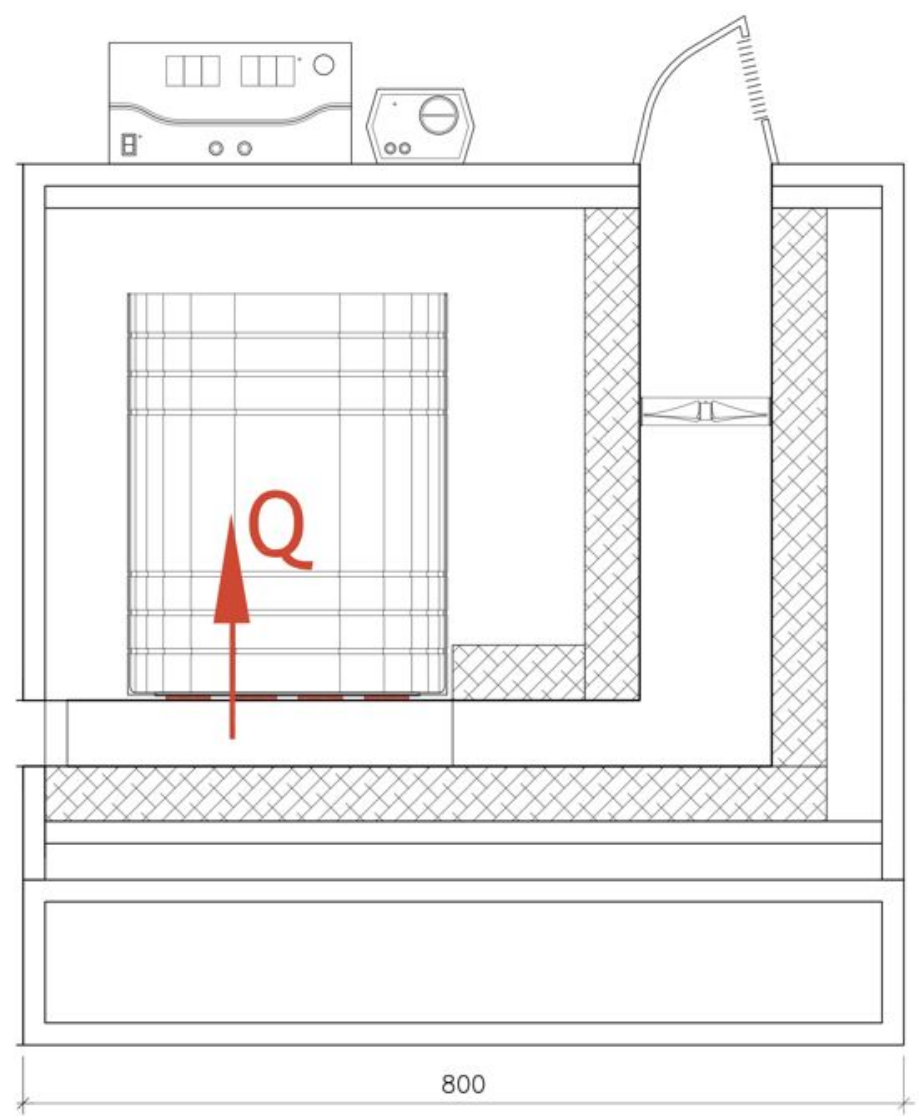

Figure A1.45: Merits of adopting a horizontal heat sink arrangement. By separating the PCM tank from the air stream, much better insulation can be achieved with more economical insulation (50mm expanded polystyrene). The convective effects of a ising hot plume are also avoided by having the PCM above the cooled air stream. The PCM tank, thus separated, can be more accessible for change and will have less leakage problems compared to the previous design. However condensation is not easily drained in this configuration. 


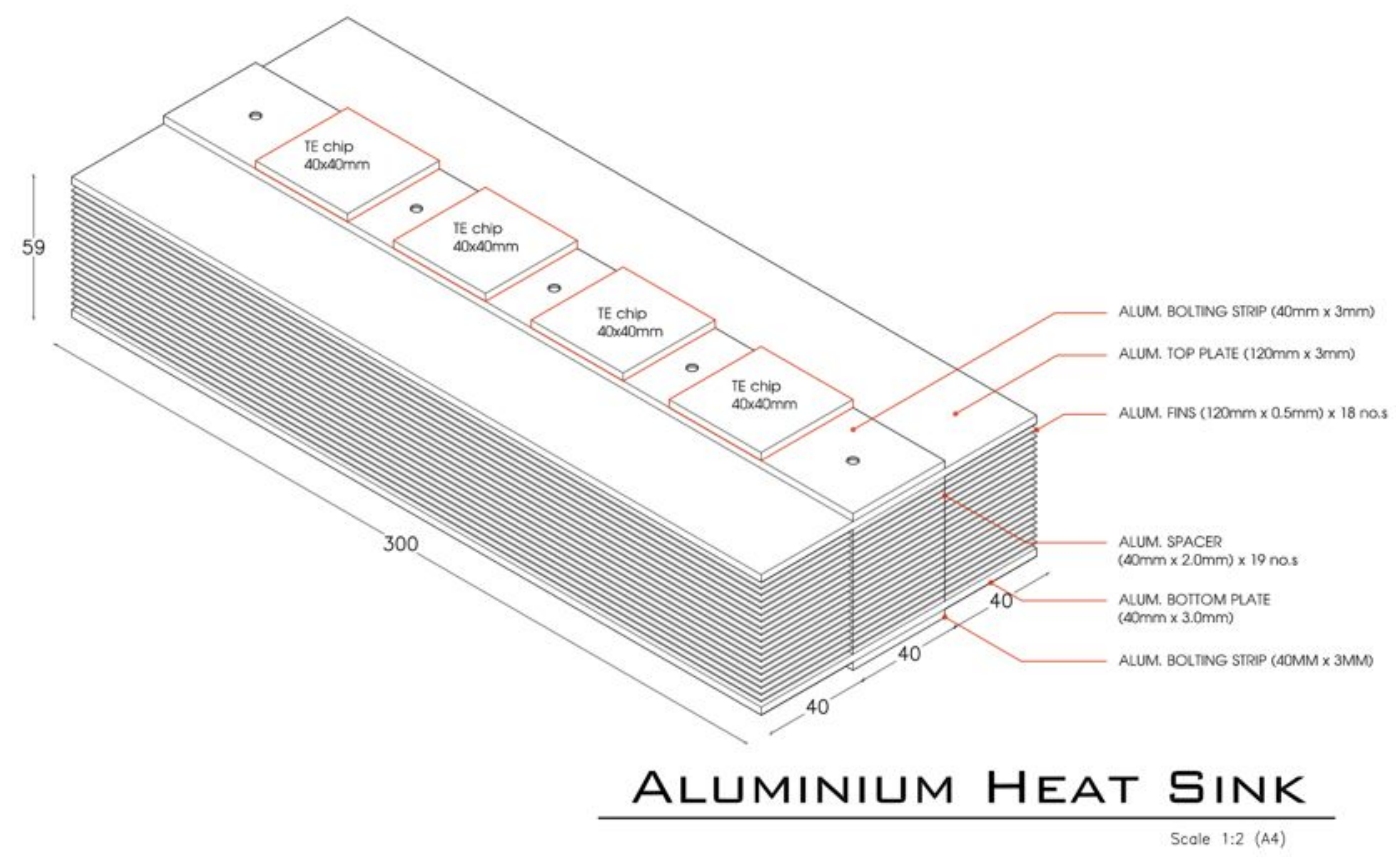

Figure A1.46: Detail of cooling fin assembly.

A1.7.2 Cutting, filing and cleaning

A guillotine was available in the workshop to cut aluminium. However the spacers needed to be 'dead flat' with no bends in the pieces and were thus cut commercially by laser. The laser left burrs on one side of the plates as some of the molten aluminium did not vaporise and re-solidified on the underside. This was found to be a a greater problem with the thicker plates due to the higher conductivity of their larger sections. Burrs on the edge were removed manually with a single-cut file, and from the holes with a countersunk drill (figure A1.47). All the fins and plates were then cleaned with industrial grade (99.8\%) isopropyl alcohol. 

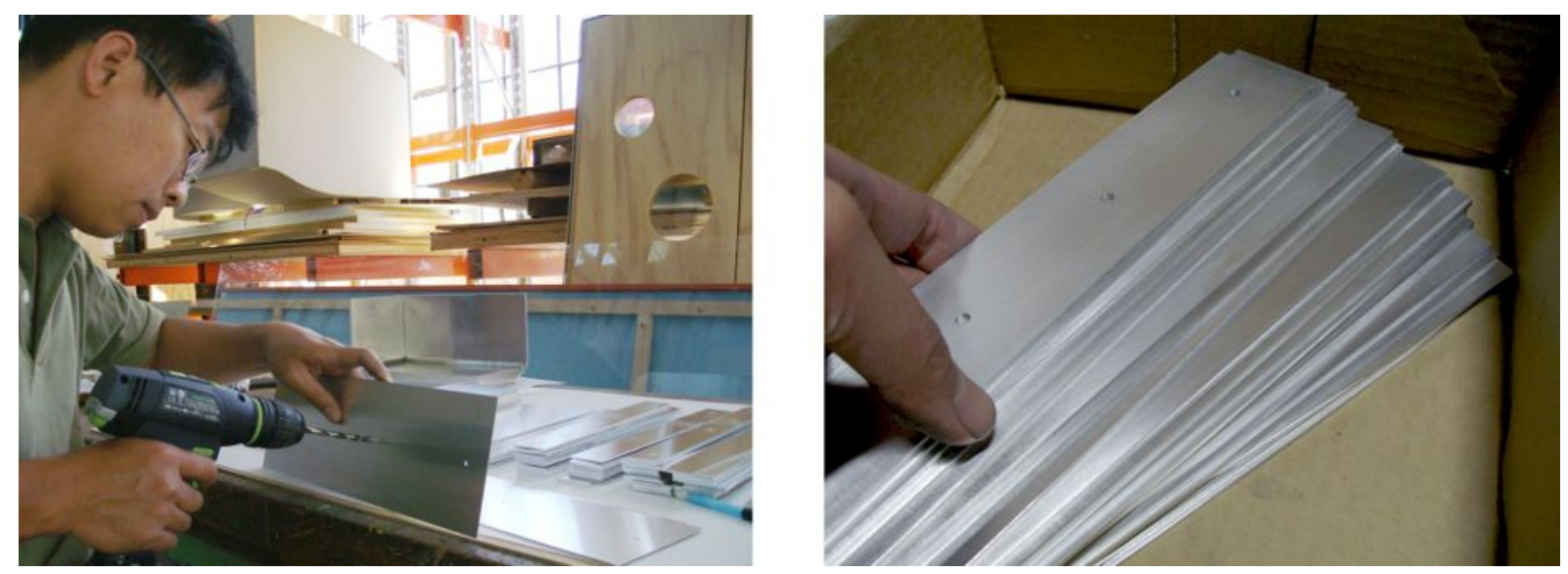

Figure A1.47: (a) Plates being counter sunk to remove any burrs from the laser process (b) Spacers after being filed and cleaned

\section{A1.7.3 Cooling fin selection}

The spacers had a variety of defects. Those with no visible defects were classified as "Grade A". Those with minor scratches and pits were "Grade B" and those with minor bumps "Grade C". Those with scratches and pits would still have the majority of the surface in contact with adjacent plates, whereas those with bumps, often as a result of molten splatter, would trap a film of air, with significantly lower conductivity. The spacers were then assembled in the order A-B-C with the best quality spacers nearest the TE modules.

The assembly was bolted down with small bolts $(\varnothing=4 \mathrm{~mm})$ to keep the spacers in contact with the fins (figure A1.48). 


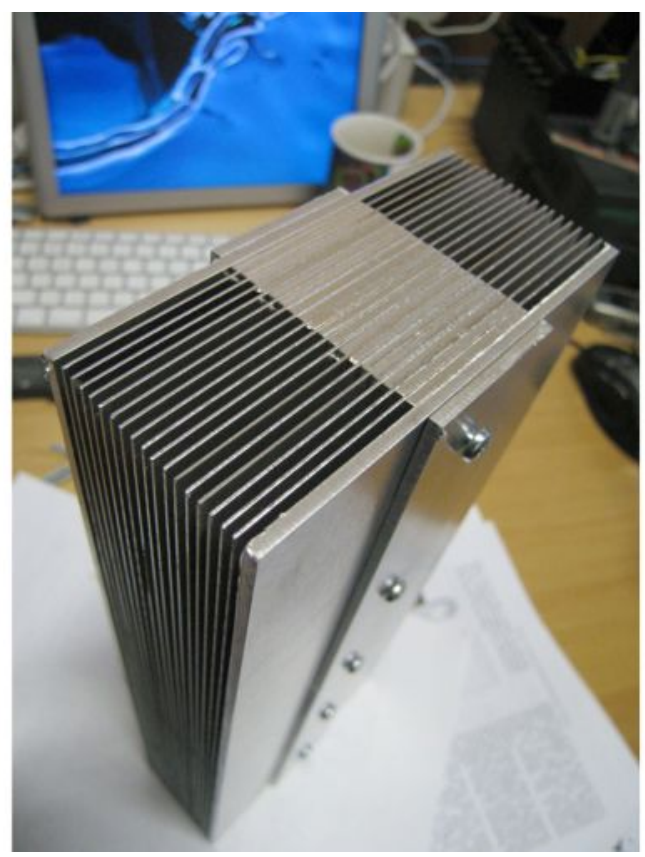

Figure A1.48: Cooling fins assembled with bolts

\section{A1.7.4 Assembling the cooling fin}

The fins were initially intended to be simply bolted together with the bolts pressing the plates together for sufficient contact. A quick test with 2 TE modules and an aluminium heat sink gave a result of $\Delta \mathrm{T}$ of $0.5^{\circ} \mathrm{C}$ below ambient when measured from the furthest fin (figure A1.49). The spacers were rebolted with a layer of MX2 thermal transfer paste (figure A1.50, thermal interface materials will be discussed in depth in the next section) to give $\Delta \mathrm{T}$ of $2^{\circ} \mathrm{C}$ below ambient.
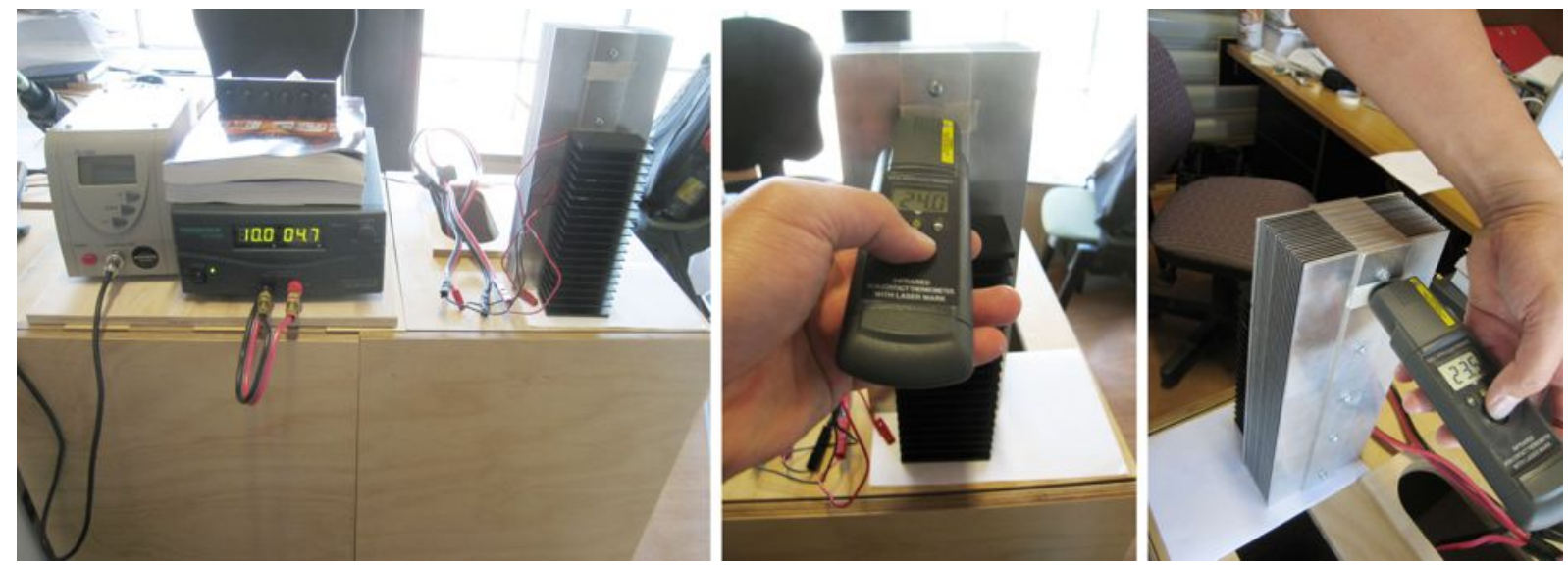

Figure A1.49: Setup to test efficacy of heat transfer through the spacers of the cooling fin 

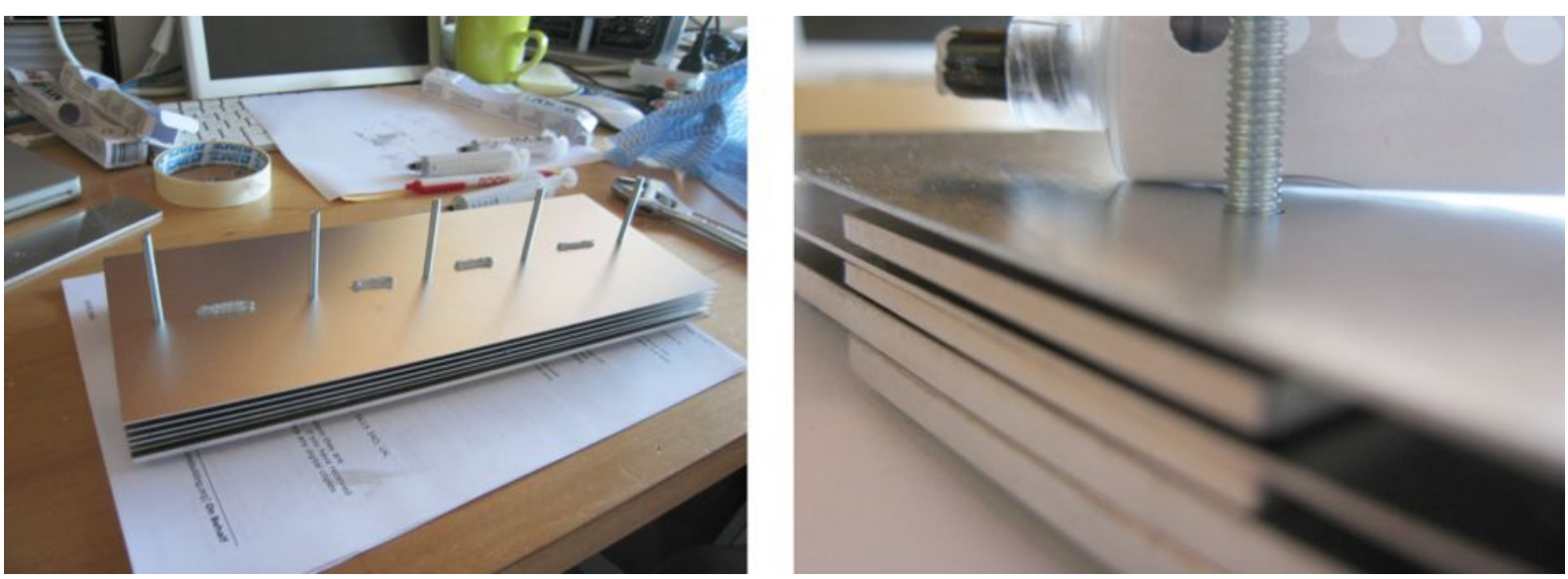

Figure $\mathrm{A}_{1} .50$ : Application of $\mathrm{MX} 2$ thermal paste between layers

To build a more robust cooling fin assembly for transport in Mark-2 and Mark-3, thermal adhesives were used. This required a more complex assembly as the 2-part epoxy-based thermal adhesive would cure within minutes once mixed. Two each of spacers and fins were glued and clamped for 5 minutes before the next batch of adhesive was mixed (figure A1.51). This resulted in an inseparable assembly that also required a long time to fabricate.
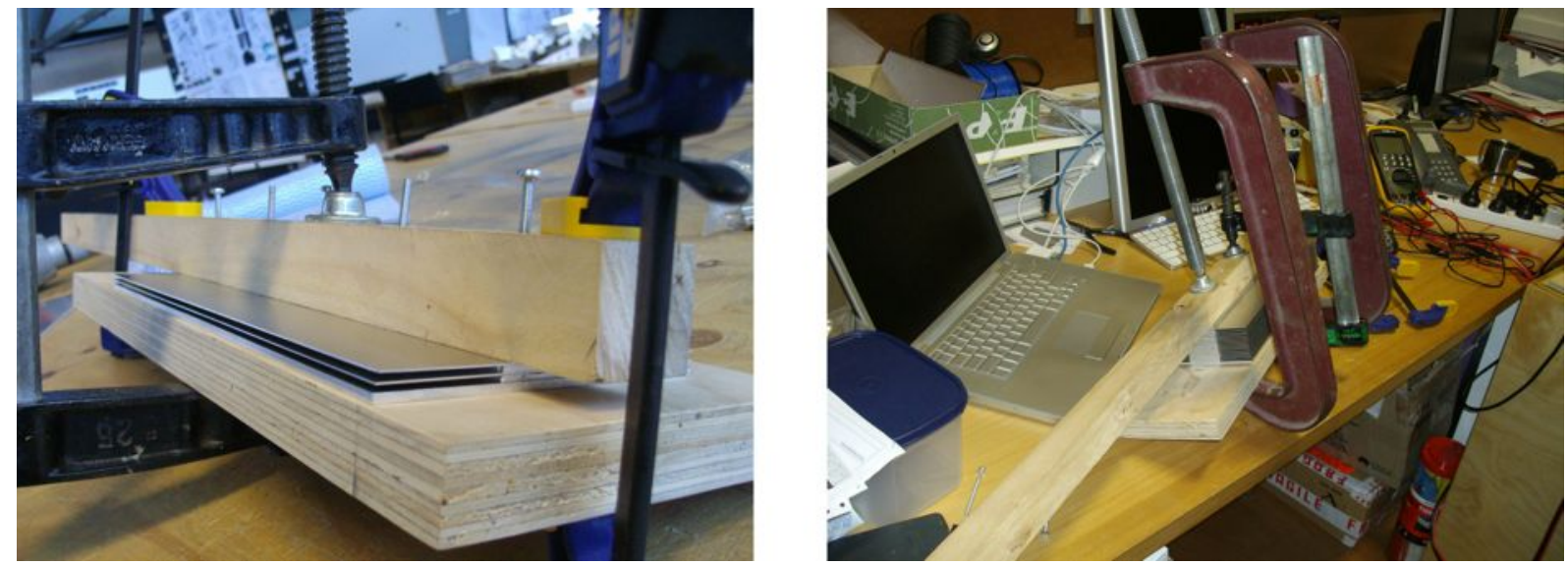

Figure A1.51: Fins were pressed wit clamps to minimise thickness of thermal interface material. With the thermal adhesive it was assumed that the compactness will remain even when the clamps were taken off.

It was difficult to ensure that the cooling fins were being pressed level with clamps, as one side could be tighter than the other. A pressing rig was constructed for Mark 3 to keep the press level (figure A1.52). In Mark 4, the torque was measured with a hanging scale to keep the pressure level on both sides of the rig (figure A1.53). 

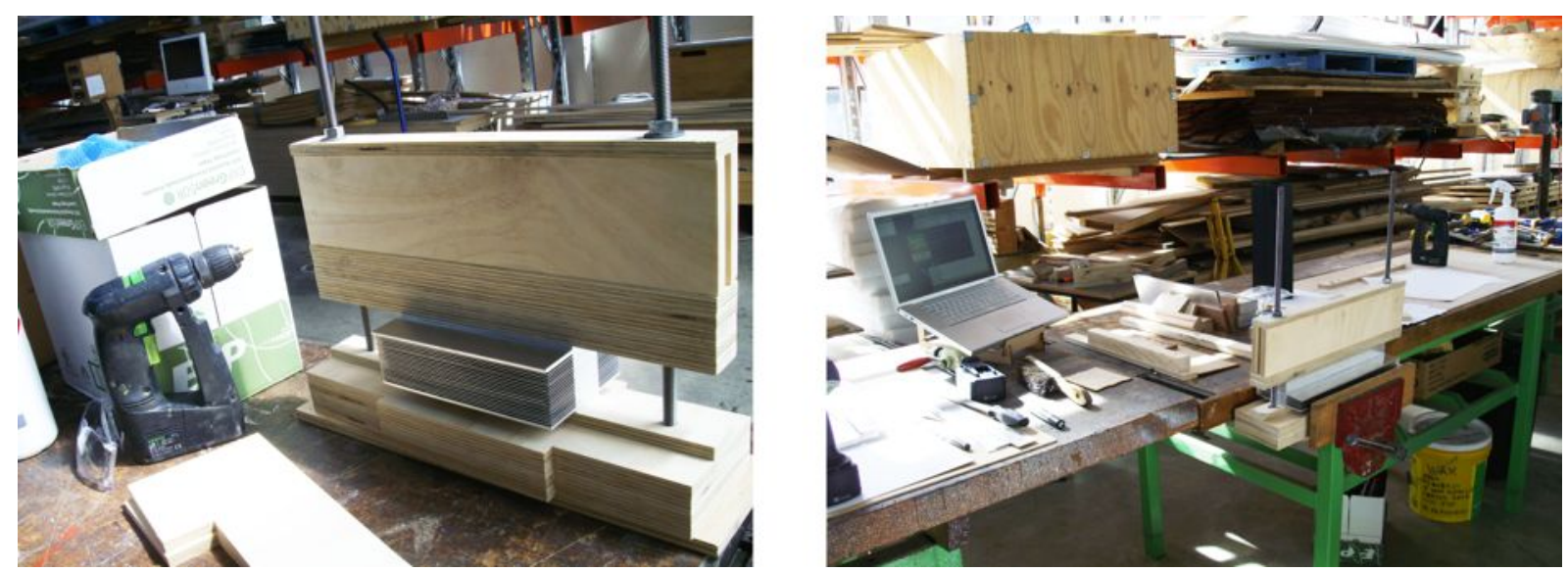

Figure A1.52: (a) Mark-3 fin press (b) Mark-4 fin press
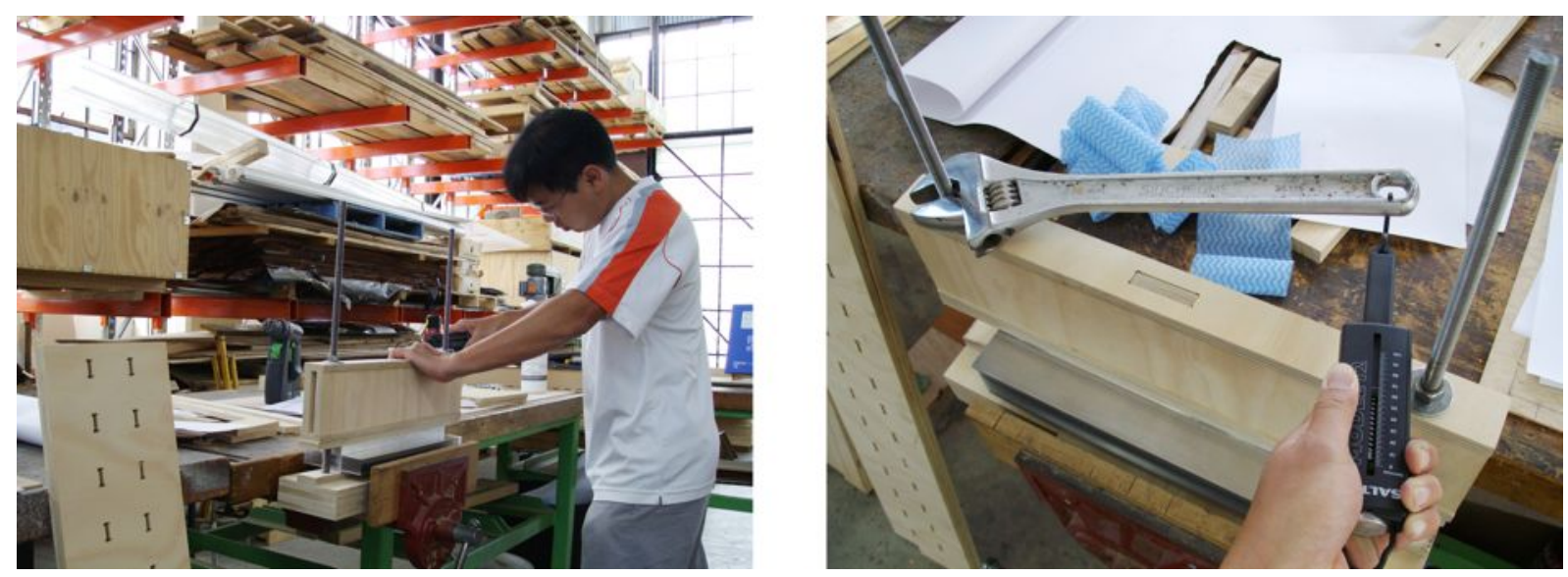

Figure A1.53: Hanging scale being used to determine torque applied equally to both bolts on threaded rods

The force on the press could be determined with the following equation, rearranged from Laird Technologies (2010):

$$
F=\frac{\tau N}{k D}
$$

\begin{tabular}{|l|l|l|}
\hline $\boldsymbol{F}$ & press force & $N$ \\
\hline $\boldsymbol{\tau}$ & torque & $\mathrm{Nm}$ \\
\hline $\boldsymbol{N}$ & number of bolts & 2 \\
\hline $\boldsymbol{k}$ & coefficient of torque & 0.2 \\
\hline $\boldsymbol{D}$ & diameter of bolt & $0.012 \mathrm{~m}$ \\
\hline
\end{tabular}

At a final torque of $90 \mathrm{~N} \times 0.32 \mathrm{~m}$, the press force on the cooling fins assembly was about 2.4 tons. 


\section{A1.7.5 Coating on cooling fins}

Since the radiant transfer could be improved significantly with painting, in the final field trial prototype (Mark-4) the cooling fins were coated in two layers spray paint (figure A1.54 and A1.55).
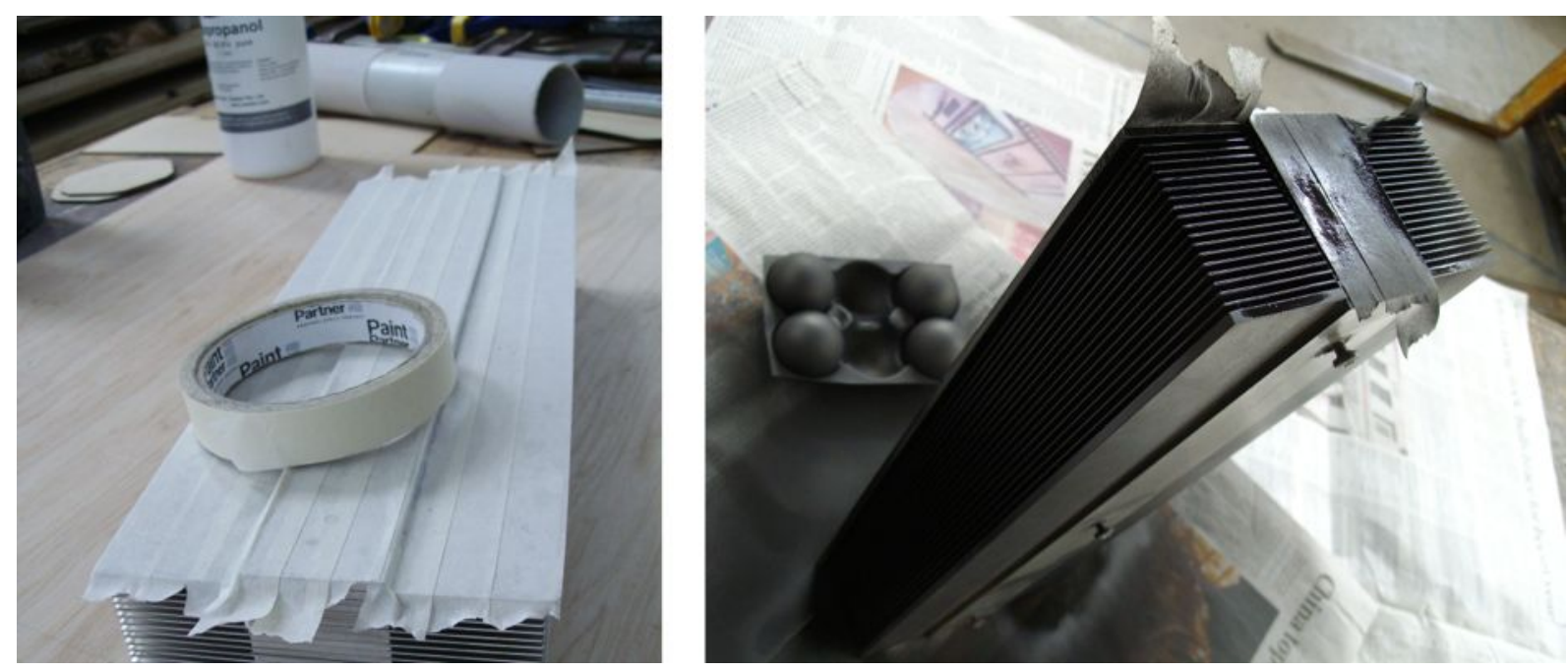

Figure A1.54: (a) The top plate of the cooling fin assembly was masked to retain its low emissivity, and reduce radiant heat gained from the underside of the tank (b) Each sweep of the spray was targeted parallel to the fins to coat as far into them as possible
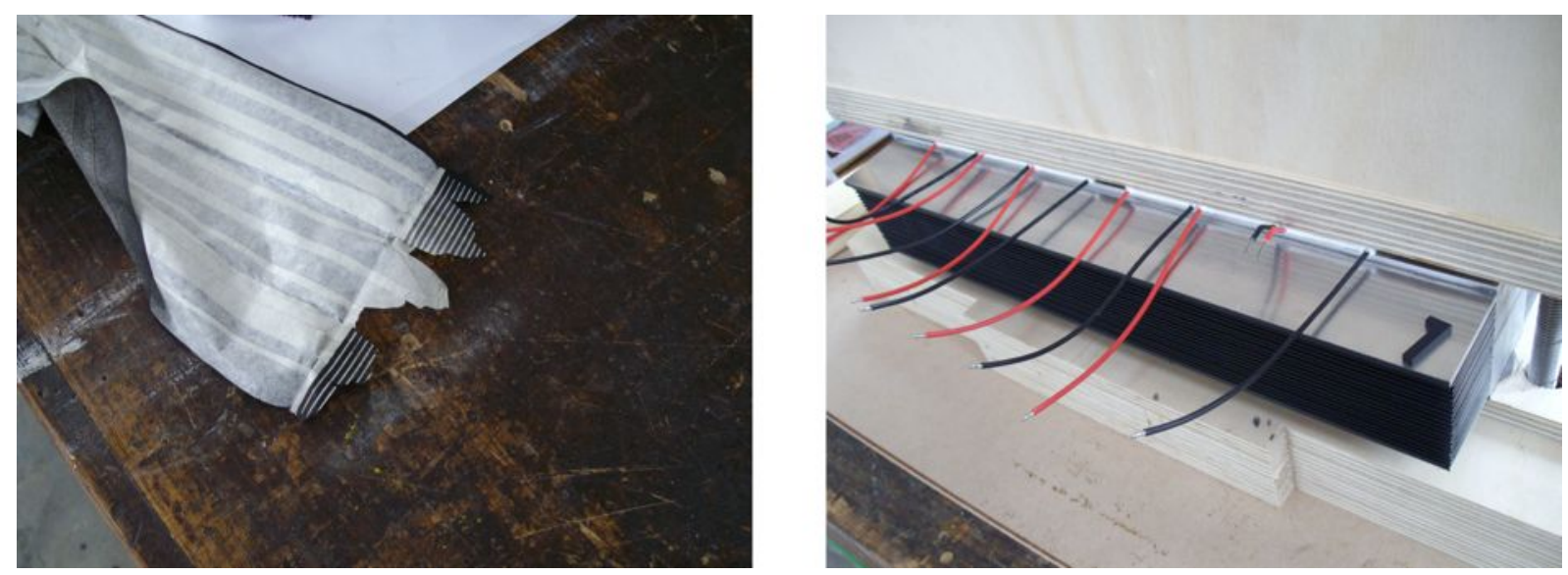

Figure A1.55: (a) Masking tape check to see that the paint had reached the $4 \mathrm{omm}$ depth on either side of the spacers. (b) Painted cooling fins being assembled with TE modules.

\section{A1.7.6 Performance of cooling fins}

The fin bypass efficiency can be determined by the following equation:

$$
\eta_{\text {bypass }}=1-\frac{T_{s s}-T_{a m b}}{T_{c}-T_{a m b}}
$$


However, the cold side temperature was difficult to determine with the fins each having a slightly higher temperature as they were spaced further from the TE modules. Another approach was taken using supply-ambient air temperatures, and the cooling output of the TE modules based on manufacturer's data sheets. It was determined that the cooling fins delivered only $16 \%$ of the potential cooing power (table A1.3).

\begin{tabular}{|c|c|c|}
\hline$T_{a m b}$ & $24^{\circ} \mathrm{C}$ & measured (Hobo logger) \\
\hline$T_{s s}$ & $20^{\circ} \mathrm{C}$ & measured (Hobo logger) \\
\hline$T_{h}$ & $50^{\circ} \mathrm{C}$ & assumed \\
\hline$V$ & $8 \mathrm{~V}$ & read from PSU \\
\hline$I$ & $4.5 \mathrm{~A}$ & manufacturer data sheet \\
\hline$Q_{c}$ & $35 \mathrm{~W}$ per module & manufacturer data sheet \\
\hline$v$ & $0.6 \mathrm{~m} / \mathrm{s}$ & measured (vane anemometer) \\
\hline$H_{a m b}$ & $54.60 \mathrm{~kJ} / \mathrm{kg}$ & psychrometric software (HR: 12g/kg assumed) \\
\hline$H_{s s}$ & $50.48 \mathrm{~kJ} / \mathrm{kg}$ & psychrometric software (HR: 12g/kg assumed) \\
\hline${ }^{v o l} l_{\text {spec }}$ & $0.85 \mathrm{~m}^{3} / \mathrm{kg}$ & psychrometric software \\
\hline vìl & $0.00678 \mathrm{~m}^{3} / \mathrm{s}$ & $v \times \pi \times(\oslash / 2)^{2}$ \\
\hline mäss & $0.007974 \mathrm{~kg} / \mathrm{s}$ & $\mathrm{vol} / \mathrm{vol}_{\text {spec }}$ \\
\hline$P_{\text {cool }}$ & $32.8 \mathrm{~W}$ & $\left(H_{a m b}-H_{s s}\right) \times m \dot{a} s s$ \\
\hline $6 \cdot Q_{c}$ & $210 \mathrm{~W}$ & 6 modules \\
\hline Cooling efficiency & $16 \%$ & $P_{\mathrm{cool} / 6 \cdot Q_{c}}$ \\
\hline
\end{tabular}

Table A1.3: Determination of cooling fin efficiency

\section{A1.8 Thermal Interface Materials}

Thermoelectric modules (TEMs) maintain a $\Delta \mathrm{T}$ between the two sides, often referred to as the hot and cold terminals. The notion of a 'cold' terminal may, however, be misleading. If heat from the hot junction is not removed, a fully loaded TEM $\left(15 \mathrm{~V}, \Delta \mathrm{T}=40^{\circ} \mathrm{C}\right)$ will have the hot side heated in excess of $120^{\circ} \mathrm{C}$ within a few seconds. The 'cold' side would follow closely at a scalding $80^{\circ} \mathrm{C}$. In order for the cold side to be below ambient, the hot side should not be allowed to exceed $60^{\circ} \mathrm{C}$, and ideally should not exceed the melting point of the PCM by a few degrees celsius.

Direct contact with the aluminium heat sink did not provide sufficient conductivity to get T-cold to be under ambient. The conductivity of air is 4 orders of magnitude lower than 
aluminium (table A1.4) and even a microscopic film of it would require a significant dT to conduct heat.

\begin{tabular}{|l|c|c|}
\hline \multicolumn{1}{|c|}{ Material } & Conductivity (W/m·K) & $\Delta \mathrm{T} / \mu \mathrm{m}$ \\
\hline Aluminium \{Szokolay, 2008\} & 236 & $<0.001{ }^{\circ} \mathrm{C}$ \\
\hline Aluminium Grade 5052 (manuf. specs.) & 138 & $<0.001{ }^{\circ} \mathrm{C}$ \\
\hline Aluminium Grade 5083 (manuf. specs.) & 120 & $<0.001{ }^{\circ} \mathrm{C}$ \\
\hline Air \{Szokolay, 2008\} & 0.025 & $1.5^{\circ} \mathrm{C}$ \\
\hline Silicone \{engineeringtoolbox.com\} & 0.1 & 0.375 \\
\hline
\end{tabular}

Table A1.4: Conductivity of materials
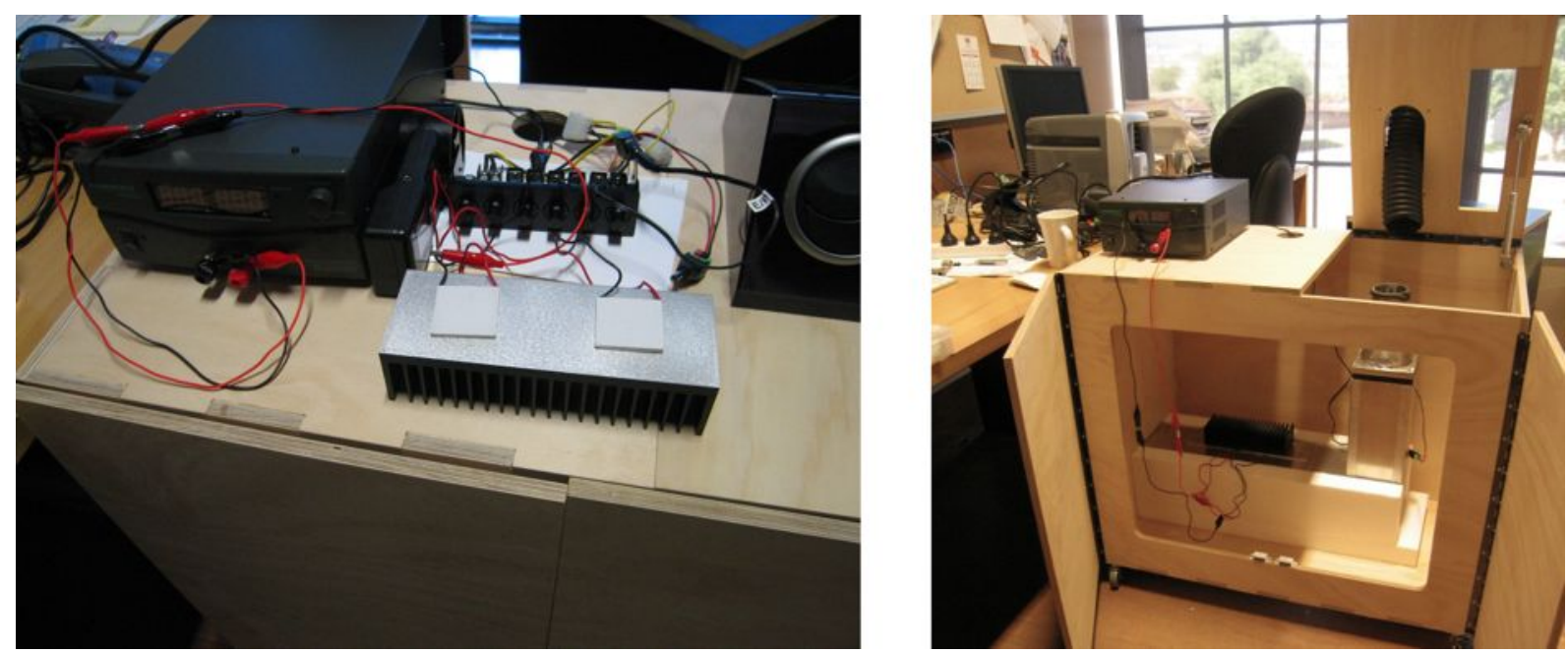

Figure A1.56: TE modules placed in direct contact with heat sink with no effect. Without a TIM the heat transfer was minimal

The $\Delta \mathrm{T}$ required to transmit heat $\mathrm{Q}$ across a micrometer $(\mu \mathrm{m})$ thickness was determined with the following equation:

$$
\Delta T / \mu m=\frac{Q}{k \cdot A \cdot 10^{6}}
$$

\begin{tabular}{|c|l|l|}
\hline $\mathrm{Q}$ & Heat flow & $60 \mathrm{~W}$ \\
\hline $\mathrm{k}$ & Conductivity & $\mathrm{W} / \mathrm{mK}$ \\
\hline $\mathrm{A}$ & area of TE module & $0.04 \times 0.04 \mathrm{~m}^{2}$ \\
\hline
\end{tabular}

In order to exclude air from impeding the heat exchange, a variety of thermal interface materials (TIMs) were used, with the cheapest options tested first. The following factors proved significant to the right selection of TIM:

1. Workability 


\section{Containment \\ 3. Rigidity \\ 4. Conductivity}

\section{A1.8.1 Workability}

Though the generic heatsink compound with $25 \%$ silver particles had reasonably high conductivity it was difficult to work with. Surfaces had to be cleaned before the compound was spread on with a credit card. A measure of skill was required to ensure it was applied evenly. When performed across multiple modules it was difficult to determine if they were all of equal thickness. It was was also humanly impossible to ensure that no air became entrapped when the PCM tank was subsequently pressed over it (figure A1.57).
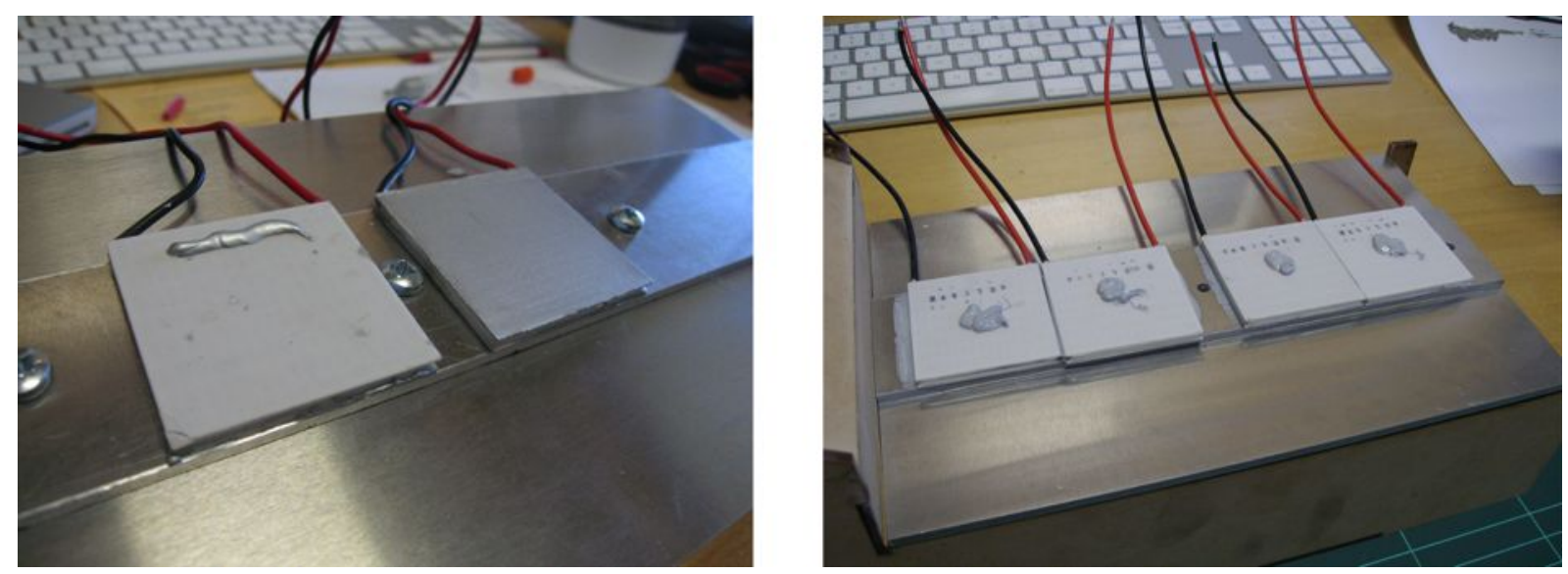

Figure A1.57: (a)TE module on left has a blob of silver particle themal paste. When spread evenly it will look like the module to its right. (b) An alternative TIM, the Arctic Silver ${ }^{\circledR} M X_{2}$ compound. Manufacturer's recommendation to dispense a blob and apply pressure with heat sink to spread it.

\section{A1.8.2 Containment}

The application of proprietary thermal compounds from the Arctic Silver ${ }^{\oplus}$ (a specialist supplier of TIM) could overcome a number of these limitations. Applied as a blob in the centre of a cell, it would spread over the surface when pressure was applied. This excluded the air from the mating surfaces and compensated for the variability in thicknesses between TE modules. To be effective, the compound had to be applied liberally to spread over the surface completely. These products were however designed for CPU applications where it did not matter if it bled over the edge of the chip, as long as it did not conduct electricity. However with TE modules, the hot and cold terminals had to be thermally broken and any 
excess compound that flowed beyond the hot surface could become a thermal short-circuit with the cold junction (figure A1.58).
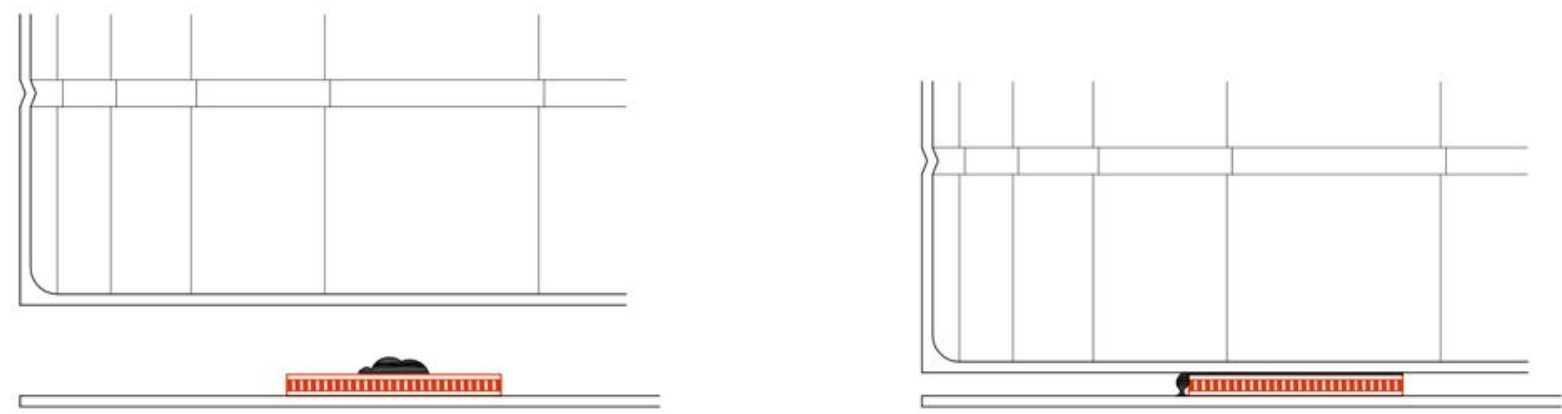

Figure A1.58: Thermal bridging as excess paste bled over the edge

The overflowing of the compound could be overcome by designing a silicone spacer that fitted snugly over the TEM in order to keep the surfaces separate and prevent the compound from overflowing (figure A1.59).

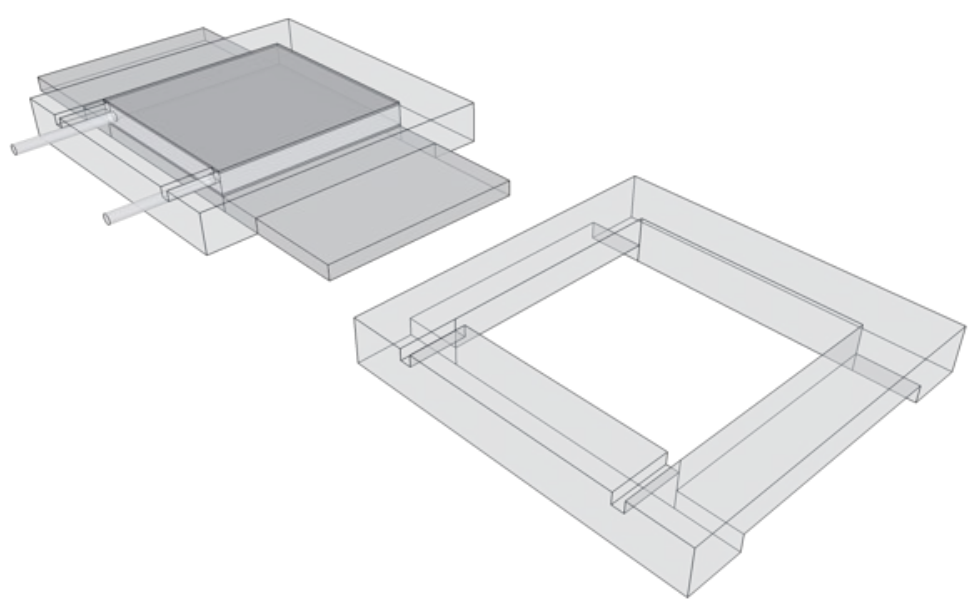

Figure A1.59: CAD of mould silicone jacket for TEM.

The moulding design however required far more expertise than the researcher had and did not cure and release from the mould properly (figure A1.60). 

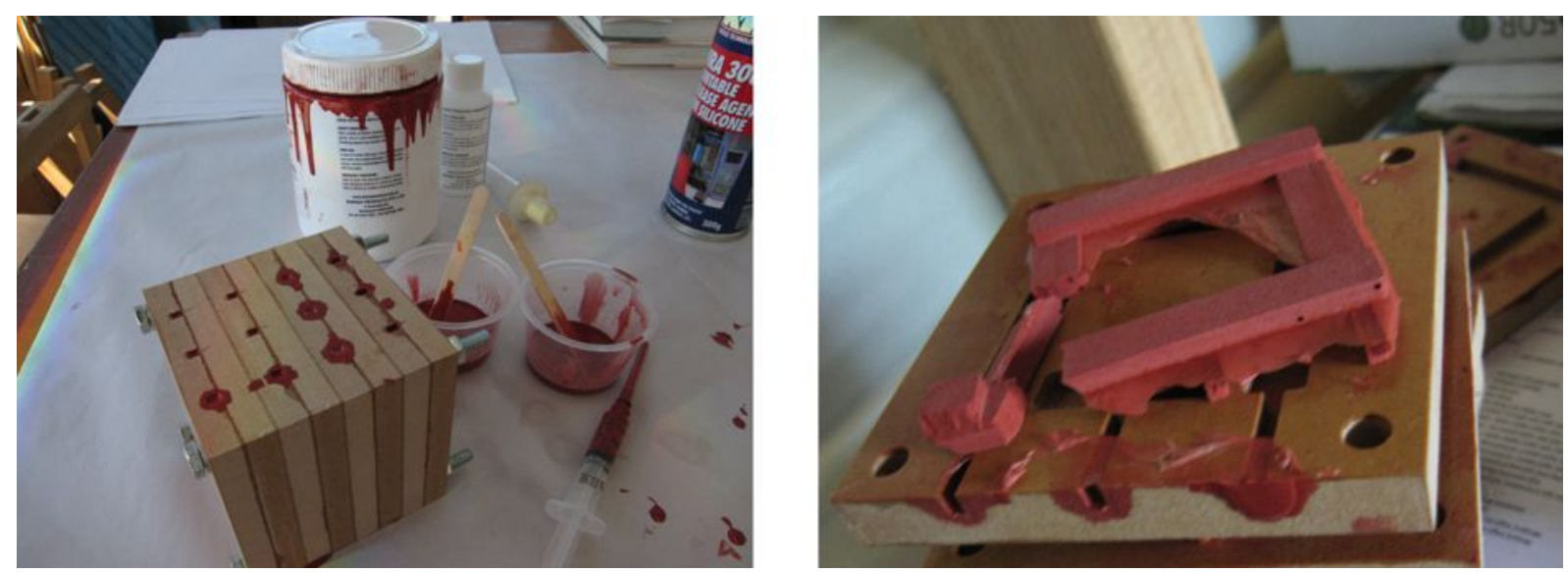

Figure A1.6o: (a) Mould cut into MDF and silicone injected into mould. (b) Silicone pads breaking as they did not release properly from the moulds.

\section{A1.8.3 Rigidity and conductivity}

To circumvent the thermal short-circuit, a solid TIM was evaluated. This was a $0.5 \mathrm{~mm}$ thick thermal transfer pad that had adhesives on both sides, something similar to a foam doublesided tape (figure A1.61). It was easy to cut to the exact dimensions with no bleeding, easy to apply and being slightly compressible, it could tolerate the variation in height across the TE modules, and, more significantly, the PCM container base. The adhesive had a measure of tackiness which could also tolerate vibrations and movement better, being able to re-adhere itself.

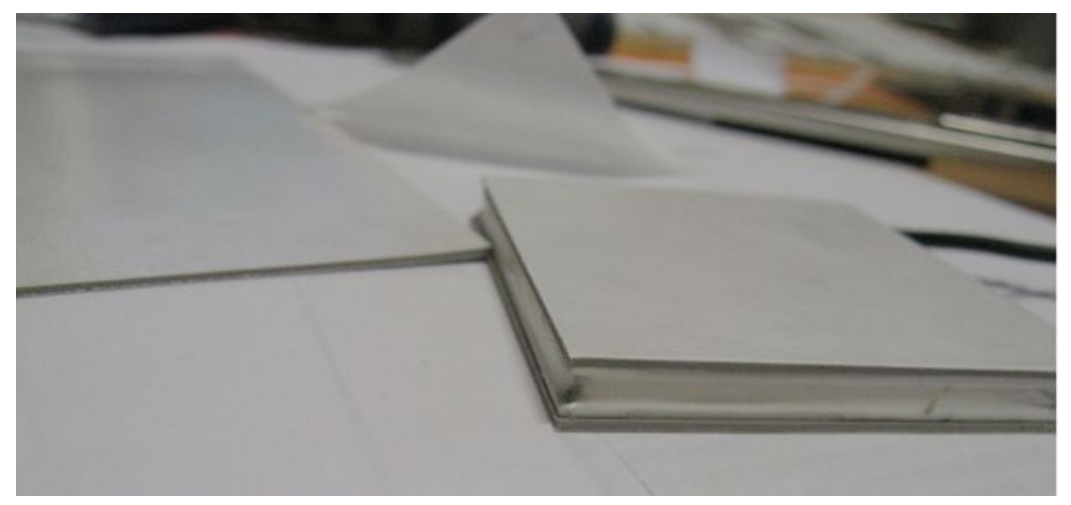

Figure A1.61: Thermal transfer tape affixed to both sides of module

The pads were applied with a $3 \mathrm{~mm}$ aluminium hot-plate sandwiched between the hot junction and the tank (figure A1.62). The infra-red reading of the hot-plate would give an indication of the T-hot, from which the T-cold could be estimated based on the $\Delta \mathrm{T}$ for given voltage-current combinations. As a rule-of-thumb, $\Delta \mathrm{T}$ (TE modules) was taken as $30^{\circ} \mathrm{C}$. 

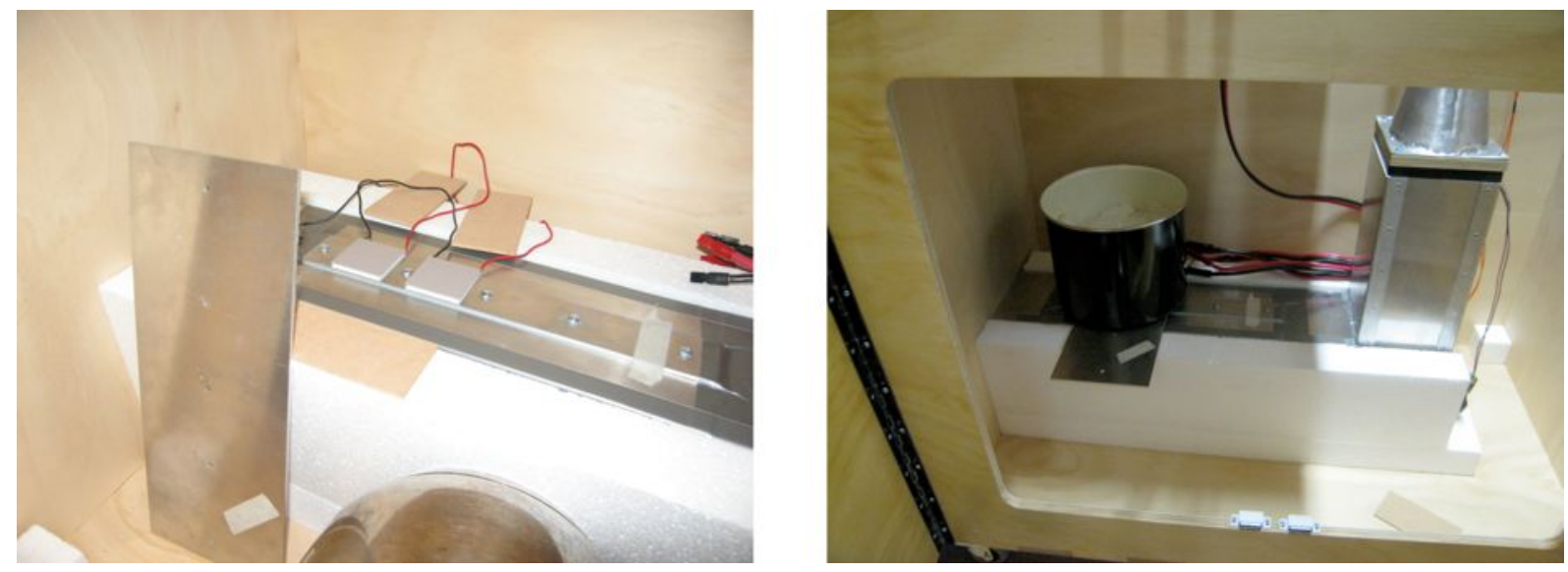

Figure A1.62: An aluminium "hot plate" positioned between TE modules and PCM tank to give a reading of T-hot

Due to its lower conductivity and greater thickness these pads required a significantly higher $\Delta \mathrm{T}$ to drive the same amount of heat (table A1.5). With the thermal transfer pad, the hot side had to be more than $12^{\circ} \mathrm{C}$ above PCM melting point, and the cold side more than $12^{\circ} \mathrm{C}$ below ambient before the any heat could be transferred from air stream to PCM, creating an extra $24^{\circ} \mathrm{C}$ burden on the TE modules to pump heat against. It was clear that this was the crucial failure of a thick and thermally resistive TIM.

\begin{tabular}{|l|c|c|c|c|}
\hline \multicolumn{1}{|c|}{ Thermal Interface Material } & Abbreviation & Conductivity & Nominal thickness & $\Delta \mathrm{T}$ (for 60W) \\
\hline \multicolumn{2}{|l|}{ Generic 25\% Silver Heatsink Compound } & $4 \mathrm{~W} / \mathrm{mkK}$ & $0.1 \mathrm{~mm}$ & $0.9^{\circ} \mathrm{C}$ \\
\hline \multicolumn{2}{|l|}{} & $1.6 \mathrm{~W} / \mathrm{mK}$ & $0.5 \mathrm{~mm}$ & $11.7^{\circ} \mathrm{C}$ \\
\hline Ahermal transfer tape & $\mathrm{MX} 2$ & $\sim 8 \mathrm{~W} / \mathrm{mK}$ & $0.1 \mathrm{~mm}$ & $0.5^{\circ} \mathrm{C}$ \\
\hline Arctic Silver Silver ${ }^{\oplus}$ MX-2 Compound & AS5 & $\sim 8 \mathrm{~W} / \mathrm{mK}$ & $0.1 \mathrm{~mm}$ & $0.5^{\circ} \mathrm{C}$ \\
\hline Arctic Silver & $\sim 8 \mathrm{~W} / \mathrm{mK}$ & $0.2 \mathrm{~mm}$ & $0.9^{\circ} \mathrm{C}$ \\
\hline
\end{tabular}

Table A1.5: Conductivity and thickness of TIM. Conductivities are often not available and are estimated based on comparative performance

\section{A1.8.4 Coming together}

For TIMs to work well, there needs to be minimal thickness. This requires the TE modules to be levelled, and all plies of the cooling fin to be pressed securely (figure A1.63 and A1.64). 

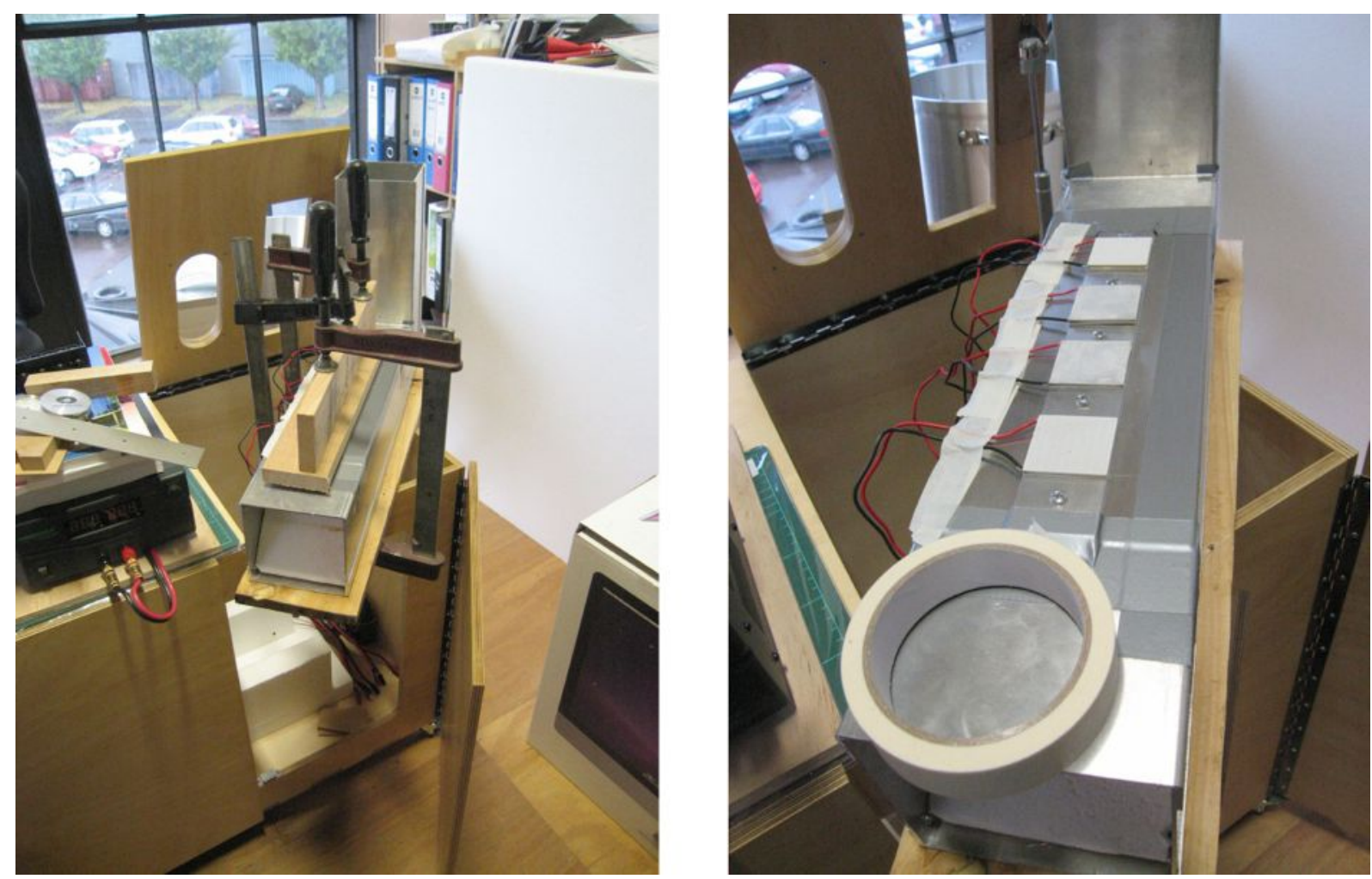

Figure A1.63: (a) TE modules being clamped to cooling fins with an MX2 TIM (b) TE modules after pressing.

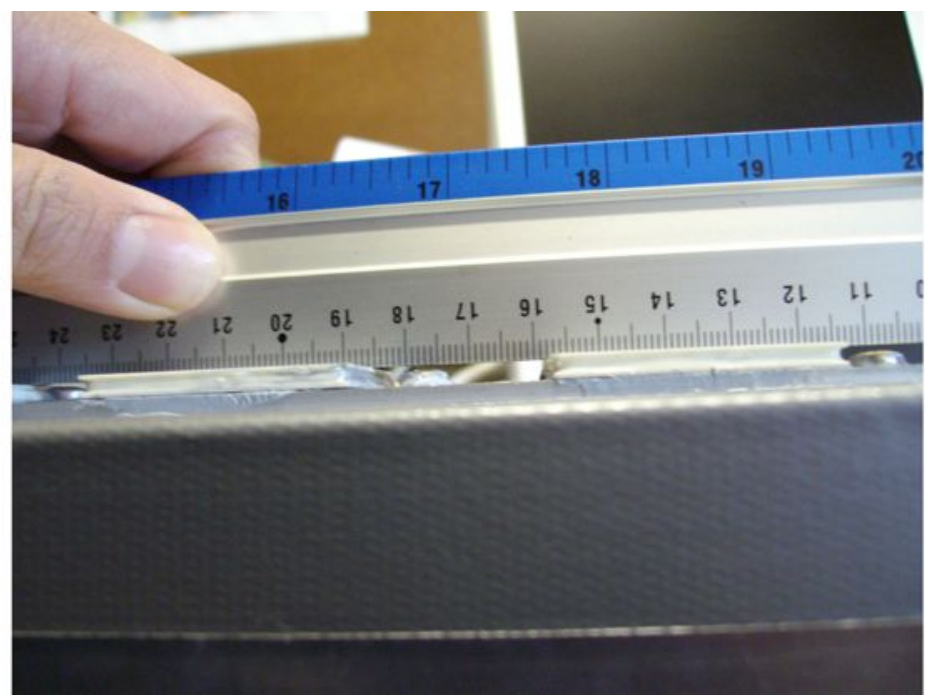

Figure A1.64: Checking levelness of TE modules after pressing

In Mark 1, to simplify the variables a high quality thermal paste was used (MX2). Mark 2 was designed as a portable prototype and 2PEA was used throughout. However this meant that no parts could be recycled. With this consideration, Mark 3 had a permanent bond on the cooling fins (2PEA) and a semi-permanent interface between the TE module and the tank with MX2. Each layer was glued, clamped and left to cure. As this process was very laborious, in Mark 4, the cooling fins were not permanently fixed. A bead of AS5 or MX2 was 
applied on the spacer, and a few layers were pressed together in one go. The TIMs used are tabulated in A1.6.

\begin{tabular}{|r|c|c|c|c|}
\hline & Mark 1 & Mark 2 & Mark 3 & Mark 4 \\
\hline TE hot side & MX2 & 2PEA & MX2 & MX2 \\
\hline TE cold side & MX2 & 2PEA & 2PEA & MX2 \\
\hline Cooling fins & MX2 & 2PEA & 2PEA & AS5 or MX2 \\
\hline Inner tank & - & 2PEA & 2PEA & 2PEA \\
\hline
\end{tabular}

Table A1.6: TIMs used in the prototypes. MX2: AcrticSilver MX-2; AS5: Arctic Silver ${ }^{\circledR}$ 5; 2 PEA: Arctic Silver ${ }^{\circledR}$ 2-part epoxy adhesive

The appropriate use of TIMs are highly specific to manufacturer's specifications. With the use of Arctic Silver ${ }^{\oplus}$ MX2, the best conductivity, according to the manufacturer, is after the CPU has gone through a few cycles of intense use. This is because the paste has a reduced viscosity at higher temperatures $\left(>60^{\circ} \mathrm{C}\right)$ and flows into the microscopic gaps to improve conductivity. If fins were to be manufactured according to the methods for this prototype it would be recommended that heat (e.g. from a heat gun) be applied to the cooling fins to a temperature of $60-80^{\circ} \mathrm{C}$ whilst they are being held in the pressing rig.

\section{A1.8.5 Coating on tank}

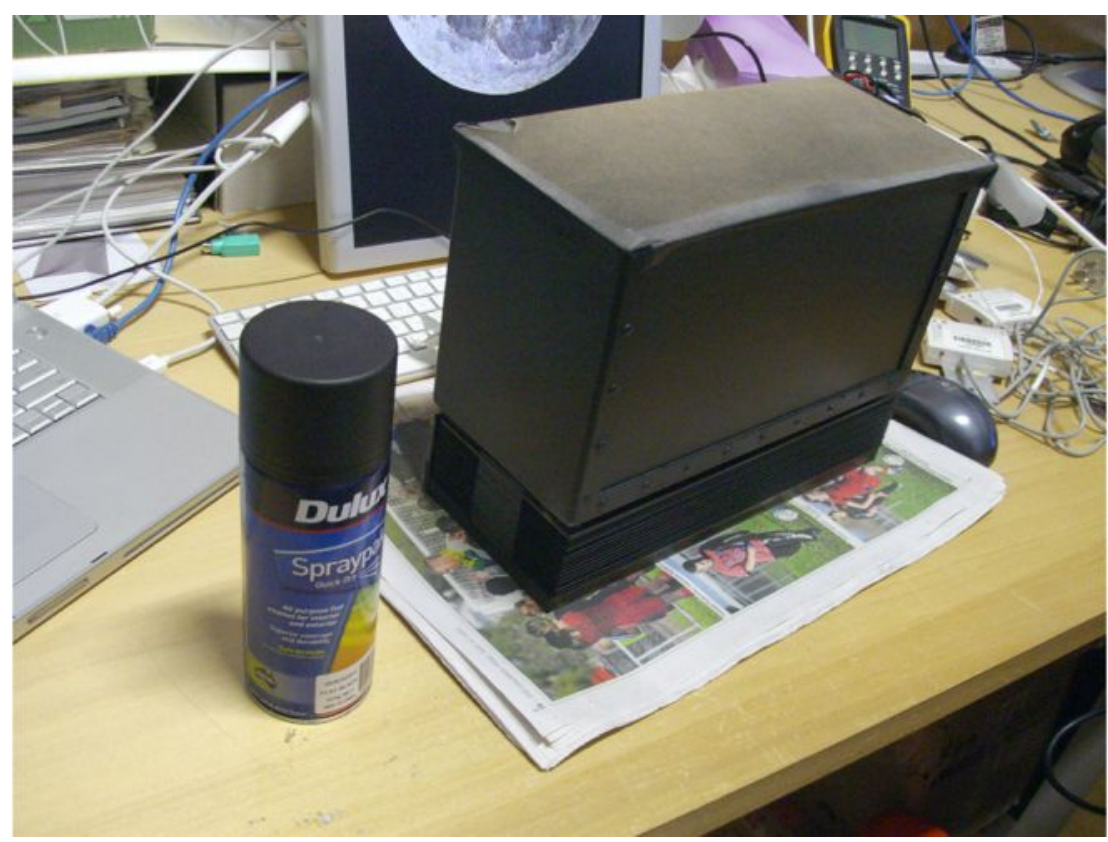

Figure A1.65: Tank and fins coated with 2 layers of matte black spray paint

In order to take accurate thermal images, the tank was painted with two coats of matte black spray paint to increase the emissivity (figure A1.65). This greatly increased the 
accuracy of the thermographs and also reduced the erroneous reading of reflections (figure A1.66). However the angle of incidence had to be maintained at close to the normal. Angles too obtuse rendered a cooler reading than at a normal angle.

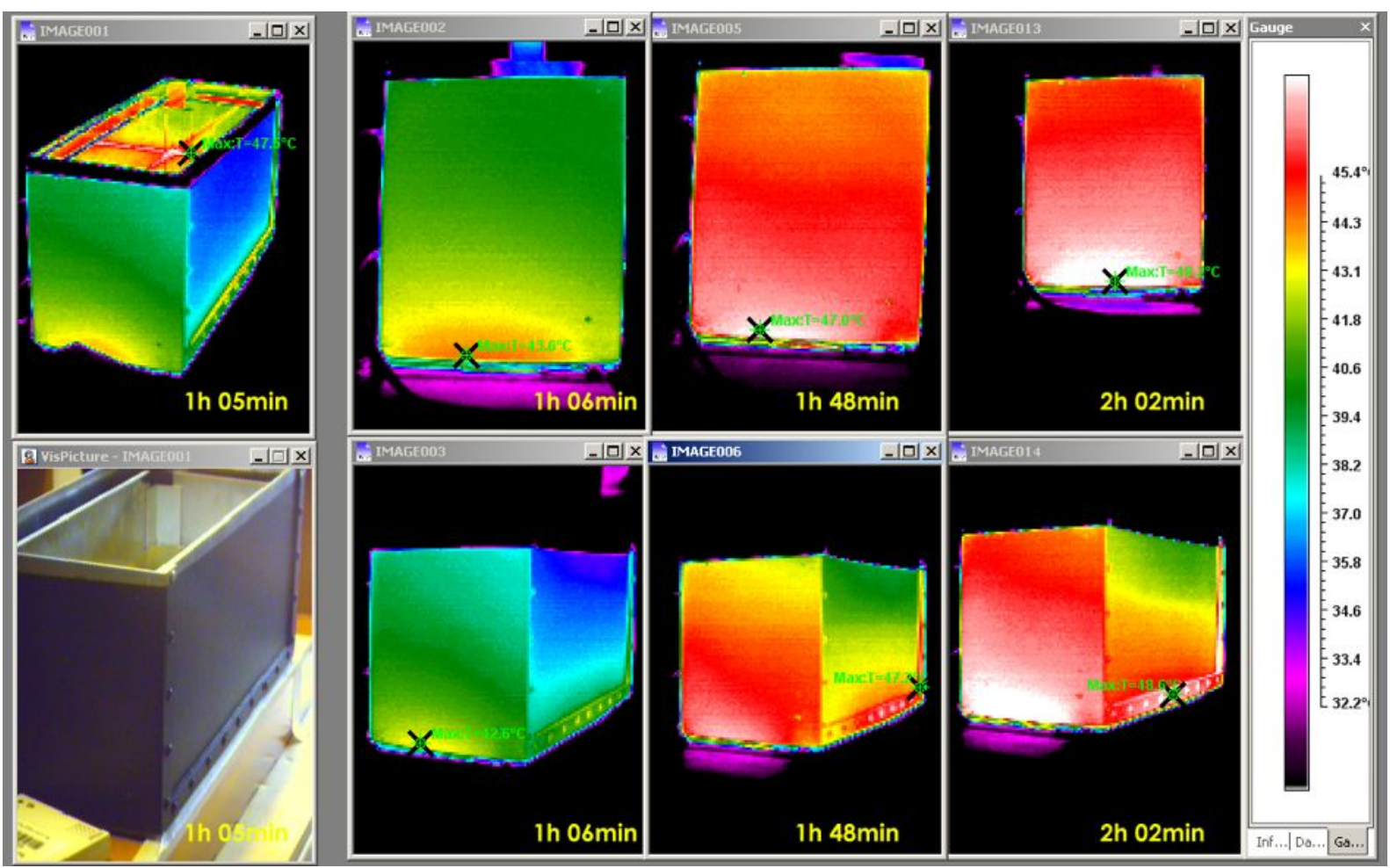

Figure A1.66: Black painted tank with thermographs at normal (above) and at an angle (below) taken within seconds of each other

The tank was expected to be fully molten by under 30 minutes. The experiment however ran for almost 5 hours before the surface of the tank was consistently and clearly above the PCM melting point (figure A1.67). 


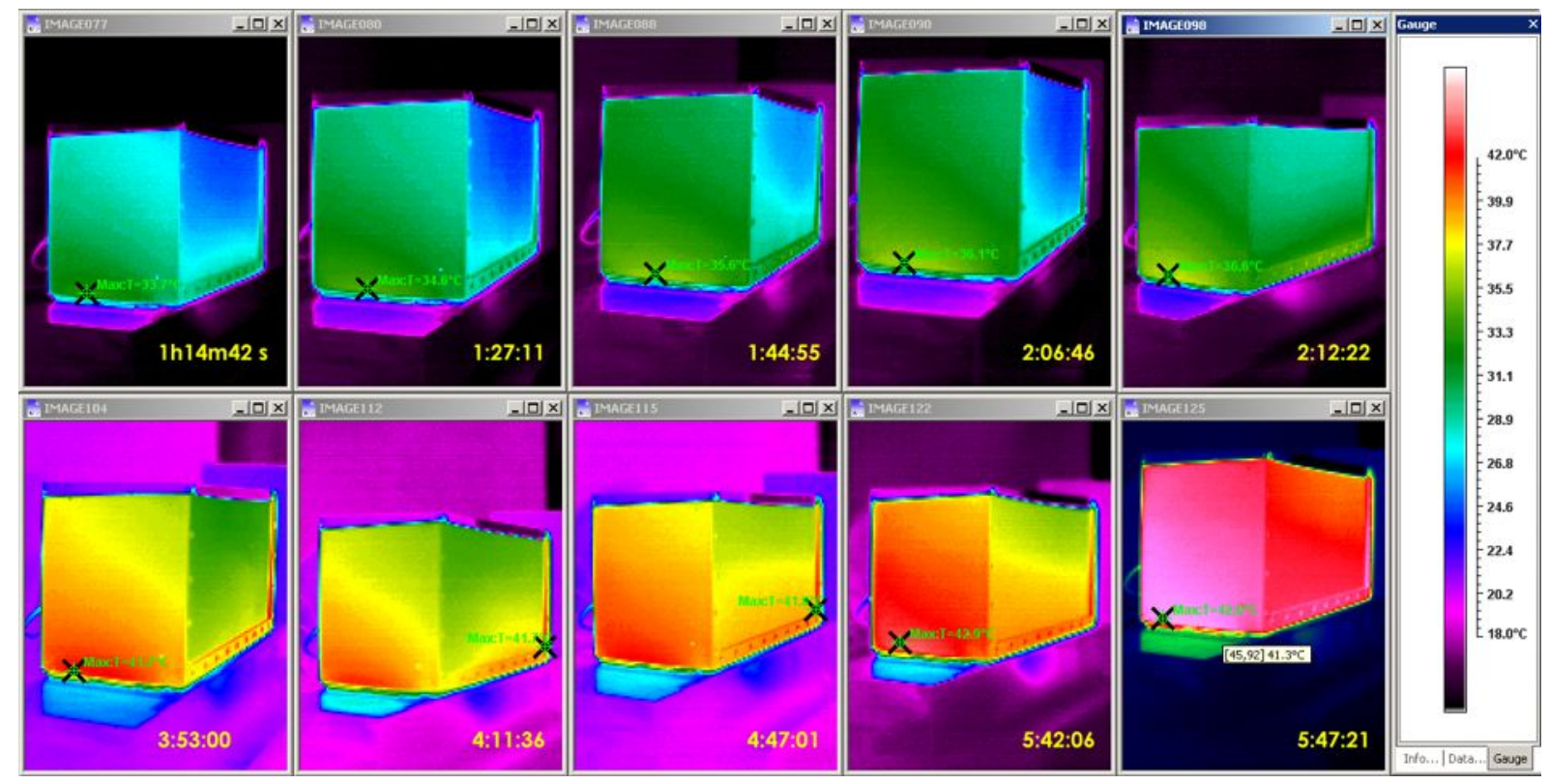

Figure A1.67: Thermographs showing total melting after about 5 hours

Even thought the surface area to volume ratio was significantly higher with a small tank, such an outcome was not expected. This prompted a calculation to compare the convective heat loss with the radiant loss of

1. uncoated aluminium $(\varepsilon=0.10)$

2. matte black paint $(\varepsilon=0.95)$

The calculations are elaborated in the next section and summarised in table A1.7.

\begin{tabular}{|c|c|}
\hline Heat loss mechanism & Heat loss per unit area \\
\hline Convection & $122 \mathrm{~W} / \mathrm{m}^{2}$ \\
\hline Radiation $\varepsilon=0.10$ & $58 \mathrm{~W} / \mathrm{m}^{2}$ \\
\hline Radiation $\varepsilon=0.95$ & $552 \mathrm{~W} / \mathrm{m}^{2}$ \\
\hline
\end{tabular}

Table A1.7: Summary of heat loss quantities

The calculations show how the radiant heat loss of the uncoated aluminium tank would have been about half that from convective heat loss. However, the application of the paint resulted in the radiant heat loss being 4.5 times that of convection. Whist this would allow the same amount of PCM to melt over a longer period, the heat would have been immediately released back into the environment, which would contradict the intent of using the PCM tank as a thermal store. 
The tanks in future prototypes were never painted, but were cleaned instead to reduce emissivity from the layer of dirt accumulated during fabrication. However with the striking difference in the overall heat transfer with a high emissivity paint, the paint was put to a different application, for example on the cooling fins.

A1.8.6 Determining the heat loss of PCM tank to convection and radiation

Calculations following are based on Incropera (2007).

Heat balance of PCM tank:

$$
q=q_{c o n v}+q_{\text {rad }}
$$

To compare the convective and radiant heat loss per unit area,

$$
\begin{aligned}
& \frac{q_{c o n v}}{A}=h\left(T_{s}-T_{\infty}\right) \\
& \frac{q_{r a d}}{A}=\varepsilon \sigma\left(T_{s}^{4}-T_{s u r}^{4}\right)
\end{aligned}
$$

A1.8.6.1 Heat loss from free convection

For a flat plate,

$$
R a_{L}=\frac{g \beta\left(T_{s}-T_{\infty}\right) L^{3}}{\alpha \nu}
$$

\begin{tabular}{|l|c|c|}
\hline${ }^{R} \boldsymbol{a}_{\boldsymbol{L}}$ & Rayleigh number for flat plate & \\
\hline $\boldsymbol{g}$ & & $9.8 \mathrm{~m} / \mathrm{s}^{2}$ \\
\hline $\boldsymbol{\beta}=\frac{\mathbf{1}}{\boldsymbol{T}_{\boldsymbol{f}}}$ & where $T_{f}=300 \mathrm{~K}$ & $3.33 \times 10^{-3} \mathrm{~K}^{-1}$ \\
\hline $\boldsymbol{T}_{\boldsymbol{s}}$ & Surface temperature & $45^{\circ} \mathrm{C}$ \\
\hline $\boldsymbol{T}_{\infty}$ & Ambient air temperature & $20^{\circ} \mathrm{C}$ \\
\hline $\boldsymbol{L}$ & Characteristic length & $0.2 \mathrm{~m}$ \\
\hline $\boldsymbol{\alpha}$ & Thermal diffusivity & $2.25 \times 10^{-5} \mathrm{~m}^{2} / \mathrm{s}$ \\
\hline $\mathbf{v}$ & Kinematic viscosity & $1.59 \times 10^{-5} \mathrm{~m}^{2} / \mathrm{s}$ \\
\hline
\end{tabular}


The free flow convection can be assumed to have laminar flow, with the following expression:

$$
N u_{L}=0.68+\frac{0.670 R a_{L}^{1 / 4}}{\left[1+(0.429 / P r)^{9 / 16}\right]^{4 / 9}}
$$

\begin{tabular}{|c|c|c|}
\hline $\boldsymbol{N} \boldsymbol{u}_{\boldsymbol{L}}$ & Nusselt number for flat plate & \\
\hline $\boldsymbol{R} \boldsymbol{a}_{\boldsymbol{L}}$ & Rayleigh number for flat plate & $1.82 \times 10^{7}$ \\
\hline $\boldsymbol{P r}$ & Prandtl number & 0.707 \\
\hline
\end{tabular}

Heat transfer coefficient:

$$
h=\frac{N u_{L} \cdot k}{L}
$$

\begin{tabular}{|l|c|c|}
\hline $\boldsymbol{h}$ & Convective heat transfer coefficient & $\mathrm{W} / \mathrm{m}^{2} \mathrm{~K}$ \\
\hline $\boldsymbol{N} \boldsymbol{u}_{\boldsymbol{L}}$ & Nusselt number for flat plate & 37.0 \\
\hline $\boldsymbol{k}$ & Thermal Conductivity & $2.63 \times 10^{-2} \mathrm{~W} / \mathrm{mK}$ \\
\hline $\boldsymbol{L}$ & Characteristic length & $0.2 \mathrm{~m}$ \\
\hline
\end{tabular}

So the heat loss due to convention can be derived as follows:

$$
\frac{q_{c o n v}}{A}=h\left(T_{s}-T_{\infty}\right)
$$

\begin{tabular}{|c|c|c|}
\hline $\boldsymbol{h}$ & Convective heat transfer coefficient & $4.87 \mathrm{~W} / \mathrm{m}^{2} \mathrm{~K}$ \\
\hline $\boldsymbol{T}_{\boldsymbol{s}}$ & Surface temperature & $45^{\circ} \mathrm{C}$ \\
\hline $\boldsymbol{T}_{\infty}$ & Ambient air temperature & $20{ }^{\circ} \mathrm{C}$ \\
\hline
\end{tabular}

From which we find $q / A=122 \mathrm{~W} / \mathrm{m}^{2}$

A1 8.6.2 Heat loss from radiation

Radiant heat loss:

$$
\frac{q_{\mathrm{rad}}}{A}=\varepsilon \sigma\left(T_{s}^{4}-T_{s u r}^{4}\right)
$$




\begin{tabular}{|l|c|c|}
\hline $\boldsymbol{\varepsilon}$ & emissivity & \\
\hline $\boldsymbol{\sigma}$ & Stefan-Boltzman Constant & $5.67 \times 10^{-8} \mathrm{~W} / \mathrm{m}^{2} \mathrm{~K}^{4}$ \\
\hline $\boldsymbol{T}_{\boldsymbol{s}}$ & Surface temperature & $318 \mathrm{~K}$ \\
\hline $\boldsymbol{T}_{\boldsymbol{s u r}}$ & Surrounding temperature & $293 \mathrm{~K}$ \\
\hline
\end{tabular}

For uncoated aluminium ( $\varepsilon=0.10), q / A=58 \mathrm{~W} / \mathrm{m}^{2}$ for matte black painted aluminium $(\varepsilon=$ 0.95), $q / A=552 \mathrm{~W} / \mathrm{m}^{2}$

\section{A1.9 Working with phase change materials: the magic's in the box}

The PCM tank was originally envisioned as merely a container for the PCM. Since the solid density was higher than the liquid form of the paraffin wax, it was expected that once melting was initiated, the molten wax would float to the surface and a continuous supply of solid wax will be gravity fed to the base until it was all melted (figure A1.68). In practice, there were more complications than anticipated.

\section{How DTAC works}

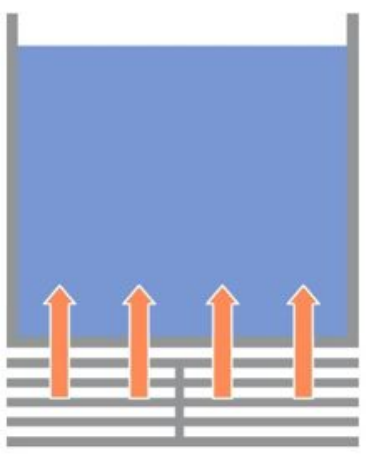

1. Thermo-electric modules pump the heat from the cooling fins to a tank of phase change material (PCM)

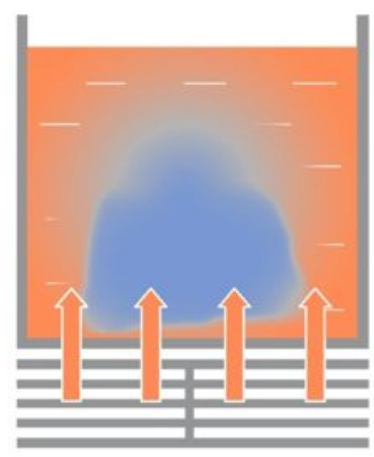

2. The PCM stores the heat by melting through the course of the day.

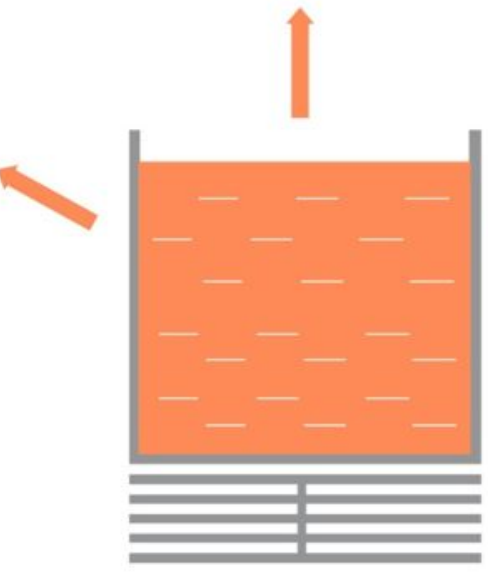

3. The stored heat is gradually released through the night and the PCM is ready for use again by morning.

Figure A1.68: Simplified conceptual illustrations on how the PCM was melted and regenerated.

\section{A1.9.1 Enamel pot}

The tank initially conceived was simply an empty tin of paint. However these tins have a lip on the bottom rim that protrudes beyond the base. As a result the base of the drum will not 
rest on TE modules. A metallic container (with an enamel paint coat) which did not have protrusions was selected to replace the drum (figure A1.69).
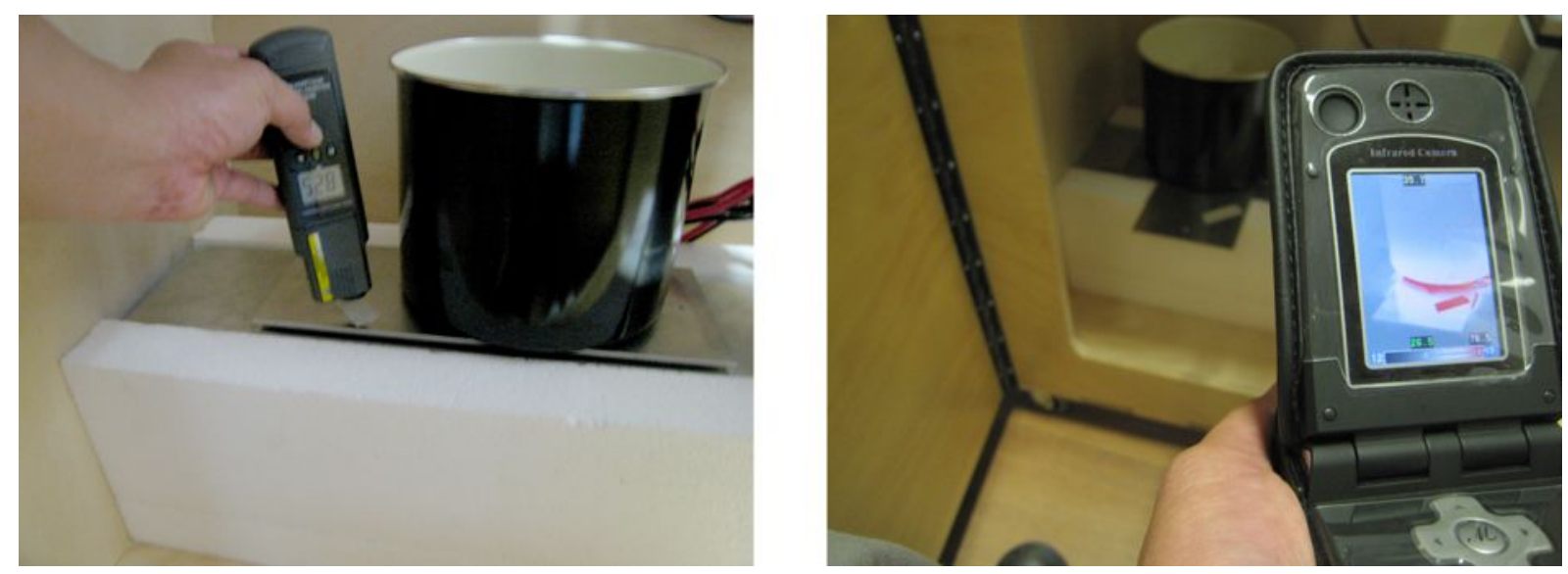

Figure A1.69: An enamel container was used to melt the PCM. To enable a

reading of T-hot, a $3 \mathrm{~mm}$ aluminium plate was used with a contactless

thermometer reading the infrared emission off a piece of masking tape.

A problem quickly emerged: the hot side of TE modules, T-hot, was at $85^{\circ} \mathrm{C}$, or $45^{\circ} \mathrm{C}$ in excess of the melting point of the PCM, before the PCM melted. At this temperature, even the cold side was above ambient and heated air was being supplied from DTAC. Clearly, for the supply air to be chilled, the primary issue was to keep T-hot as close as possible to $40^{\circ} \mathrm{C}$, the $\mathrm{PCM}$ melting point.

Two possibilities would have caused the elevated T-hot:

1. Heat was not reaching the tank

2. Heat in the tank was not effectively dissipated into the PCM

To improve the conductivity from TE module to tank, a silver heat-sink compound was used as TIM. It was found the spread was limited, indicative that the contact areas was much smaller than the TE surface. The enamel pot base was not level enough for effective conduction, and so a heavy-base saucepan was used instead.

\section{A1.9.2 Stainless steel saucepan}

To ensure that the problem was not with the cooling fin assembly, a chilled saucepan (simulating refrigeration from the TE modules) was placed on aluminium spacers (to 
simulate the thickness of TE modules, figure A1.70) and on top of the cooling fins. A dT (supply - ambient) of $-2^{\circ} \mathrm{C}$ was logged for almost three hours.
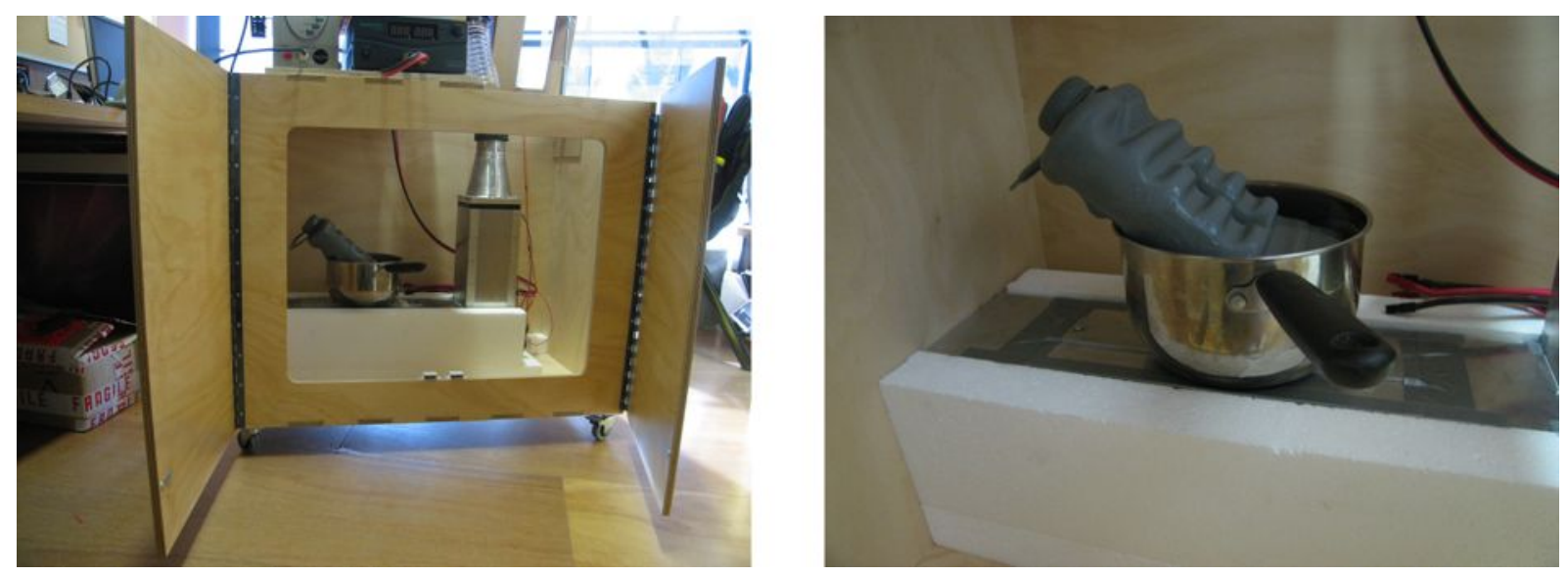

Figure A1.70: Stainless steel saucepan holding a water and a frozen bottle to simulate the refrigeration from TE modules

Satisfied that if cooling was delivered to the fins there would be a recordable difference in air temperatures, the problem was narrowed down to either the TE modules or tank. The aluminium spacers were replaced with TE modules and the PCM melted in the saucepan (figure A1.71).

As fresh solid wax was being manually added to the tank (figure A1.71a), the dT was negative transiently. After the wax had fully melted and re-solidified, the cooling could not be repeated. In fact the molten wax, though less dense, did not float to the surface but was trapped between the hot base and the solid top. Even with a heat sink inserted to help the molten wax breach the surface the solid wax would stick to the tank walls and not sink (figure A1.71b). 

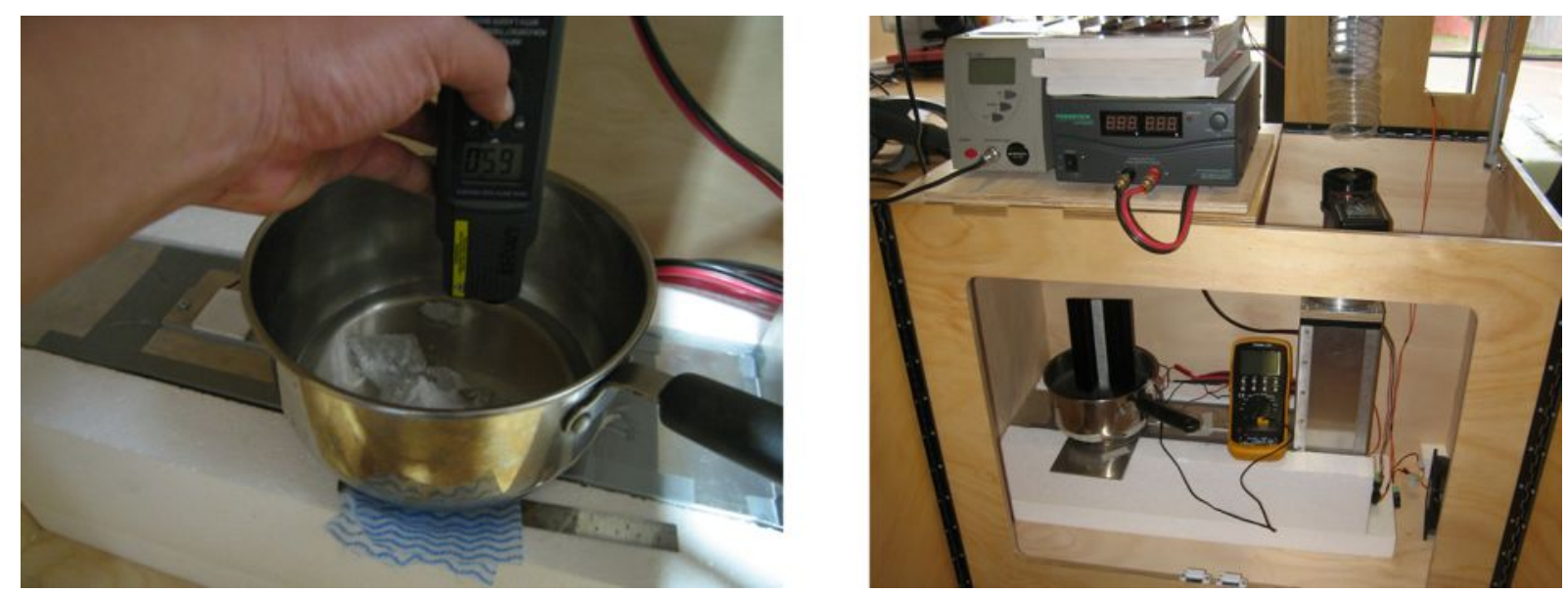

Figure A1.71: (a) Fresh wax being added to the saucepan. T-hot with the saucepan was significantly lower than with the enamel pot but still significantly higher than PCM melting point. (b) A heat sink placed in the middle of the saucepan to allow molten wax to rise. However solid wax continues to stick to the sides, away from the base and heat sink.

If the wax could be made to sink, the base of the tank would naturally be kept close to $40^{\circ} \mathrm{C}$ and enable the cold side of the TE modules to reach below ambient. It was clear that the tank conductivity was a key aspect to solving this challenge.

\section{A1.9.3 Aluminium tiffin tin}

Since the challenge was to get the wax to sink consistently, this part of the problem could be compartmentalised and tested. A TE module was attached to the underside of an aluminium tiffin tin (of approximately $1 \mathrm{~mm}$ thickness), the wax melted, cooled and repeated. Working with a small quantity of wax permitted more tests to be performed each day, and experimenting outside the DTAC gave more flexibility to observe the wax (figure A1.71) and take temperature readings and thermographs (figure A1.73). 

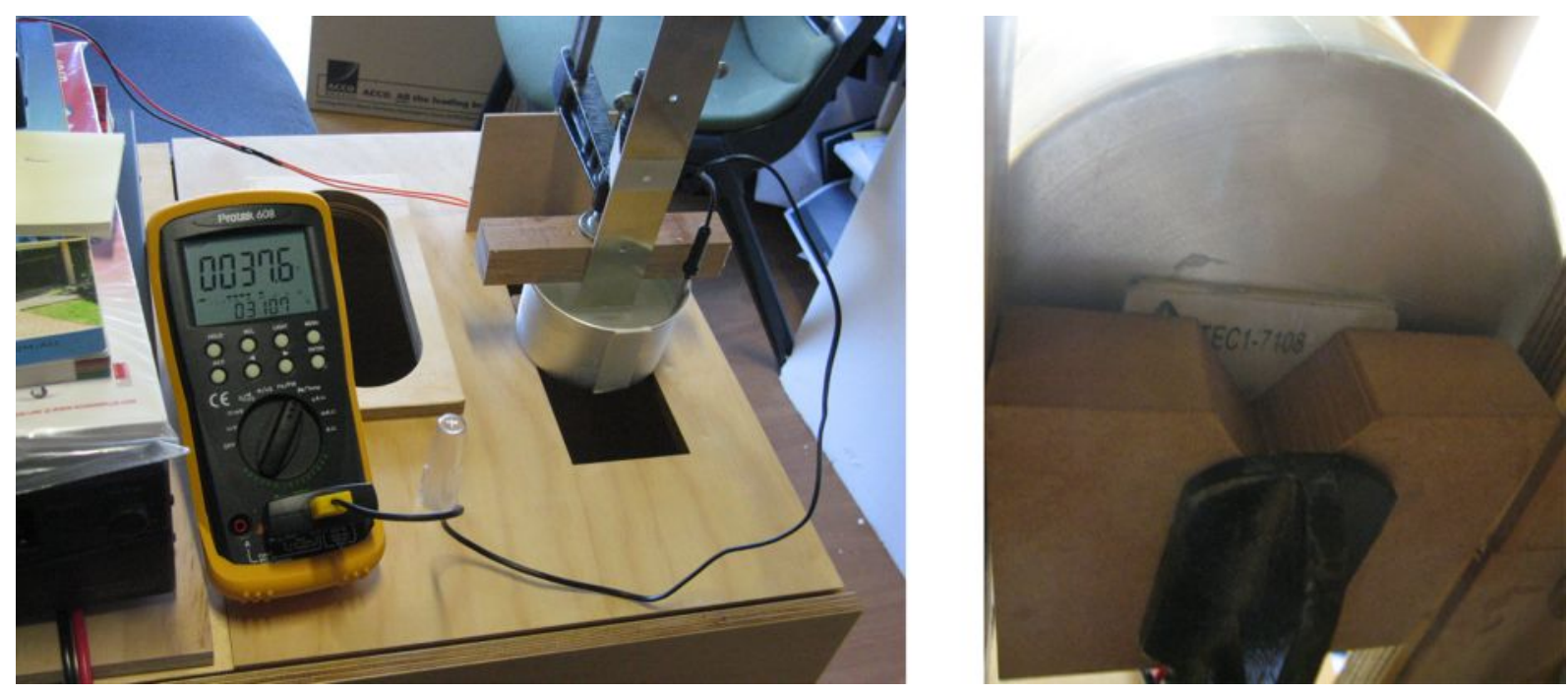

Figure A1.72: (a) Observing if a highly conductive tank with a conductive strip would allow the wax to detach and sink (b)Underside of tiffany tin. A notch allows infrared temperature readings to be taken
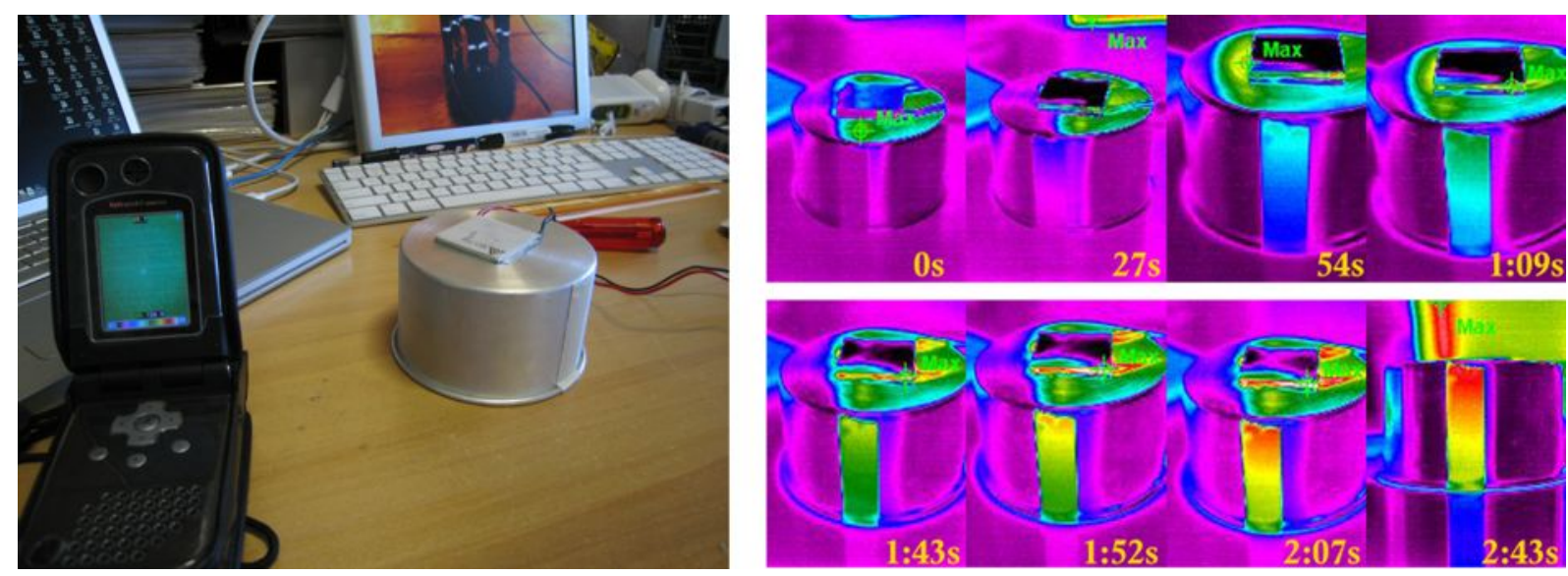

Figure A1.73: Thermal images of test. The rim furthest from the TE module was only $3^{\circ} \mathrm{C}$ higher than the base, where the TE was attached.

After developing a method for getting the wax to detach and sink, the next step would be scale it back up and introduce the new tank to the DTAC.

\section{A1.9.4 Aluminium stockpot, engineered}

A 32-litre aluminium stockpot, 3mm thick was used as PCM tank. Even though the base was visibly flat there was at least $2 \mathrm{~mm}$ variation in the level between the centre and outer base. For cooking $\left(\Delta \mathrm{T}=100^{\circ} \mathrm{C}\right.$ to $\left.200^{\circ} \mathrm{C}\right)$ such a tolerance might be acceptable, but in the DTAC $(\Delta \mathrm{T}$ $<30^{\circ} \mathrm{C}$ ) any gap would compromise performance. The base of the pot was engineered and levelled by a fly cutter. The maximum variation in base level was $0.15 \mathrm{~mm}$ without a heat load . It was expected that even a small temperature variation (as little as $20^{\circ} \mathrm{C}$ ) would result 
in some differential expansion. After measuring the base for levelness (procedure shown in figure A1.74) the stock pot was assembled with the duct using clamps (figure A1.75).
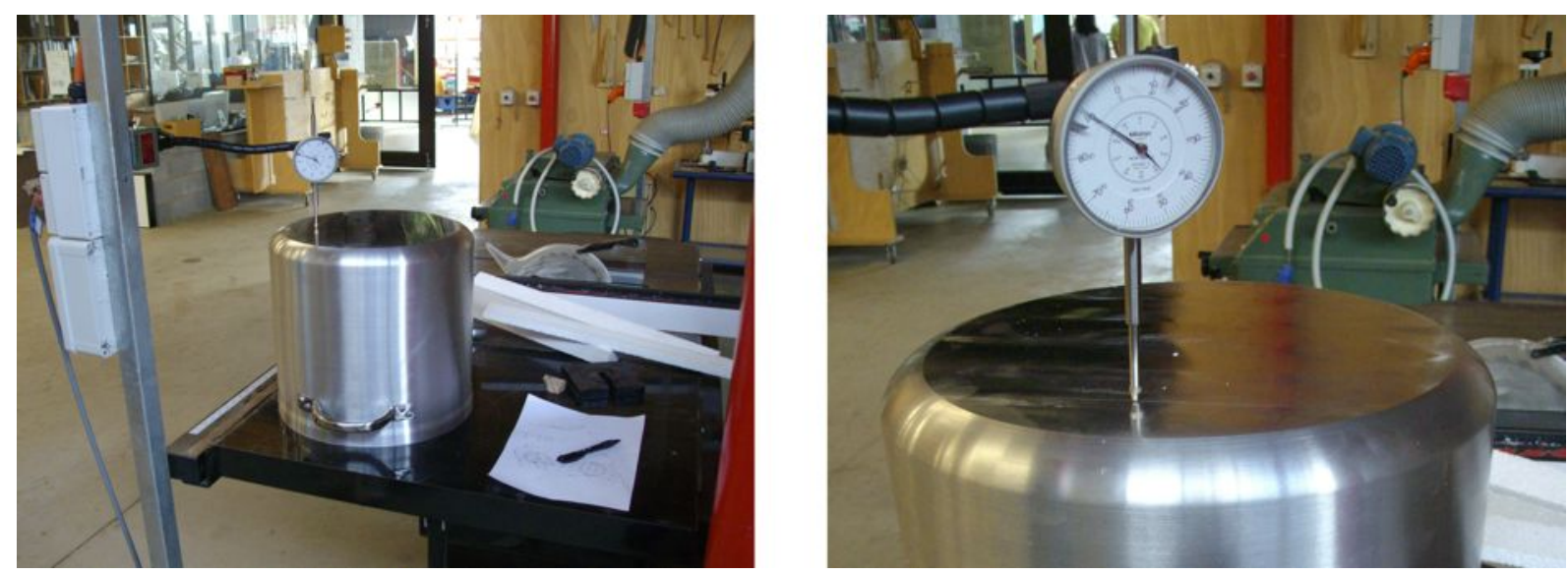

Figure A1.74: Stockpot with additional engineering done to base, being measured for variations in level with a dial gauge.

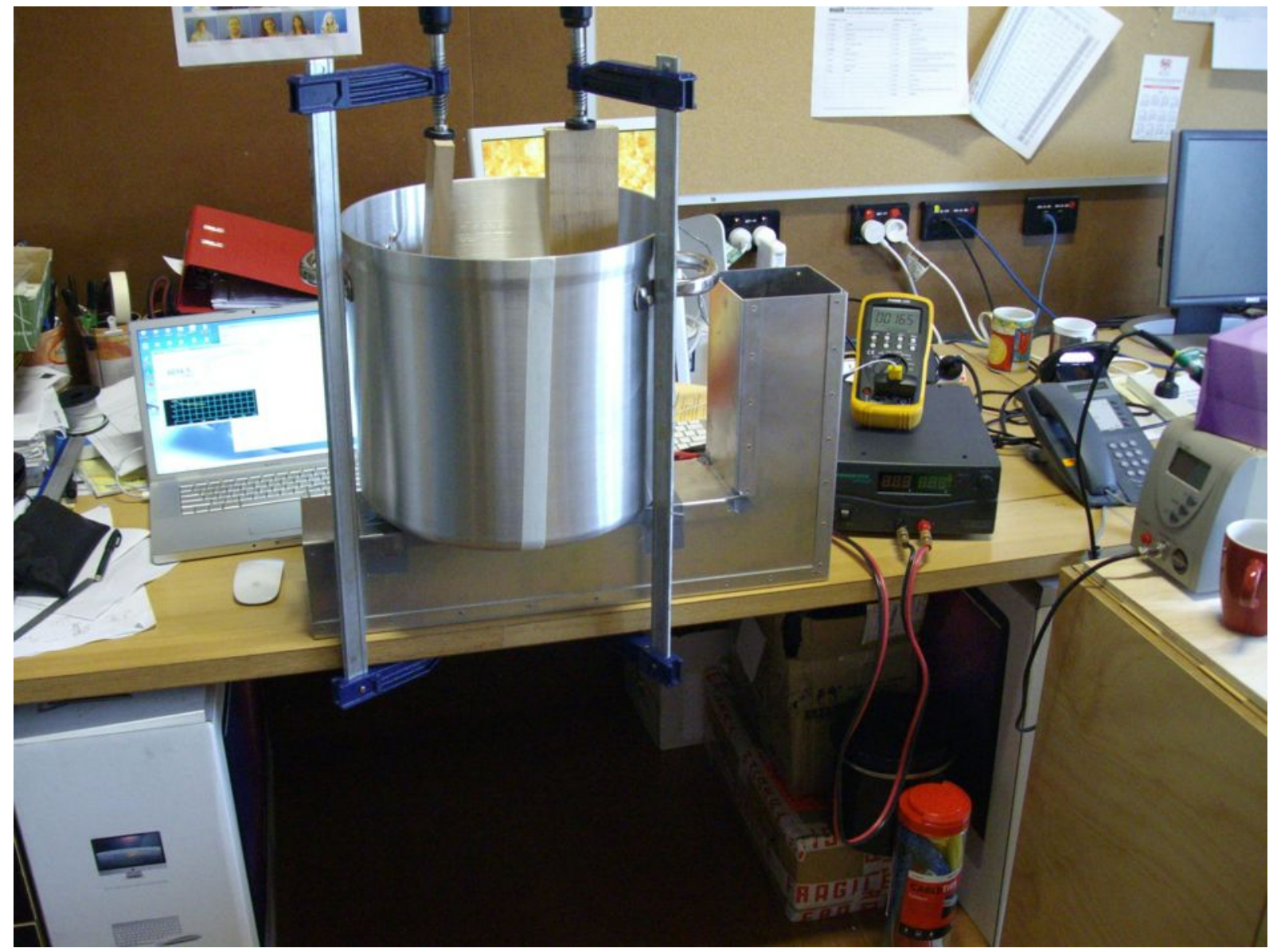

Figure A1.75: Engineered stockpot being clamped to cooling fin assembly in duct. 
A1.9.5 Developing the wax bath

Looking back at the previous attempts we can see that when heat was applied to a stainless steel tank it was not effectively conveyed to all the wax. The steel, as most alloys, was a fairly poor conductor and the wax remained solid against the walls and would not sink without being forced down (figure A1.76).

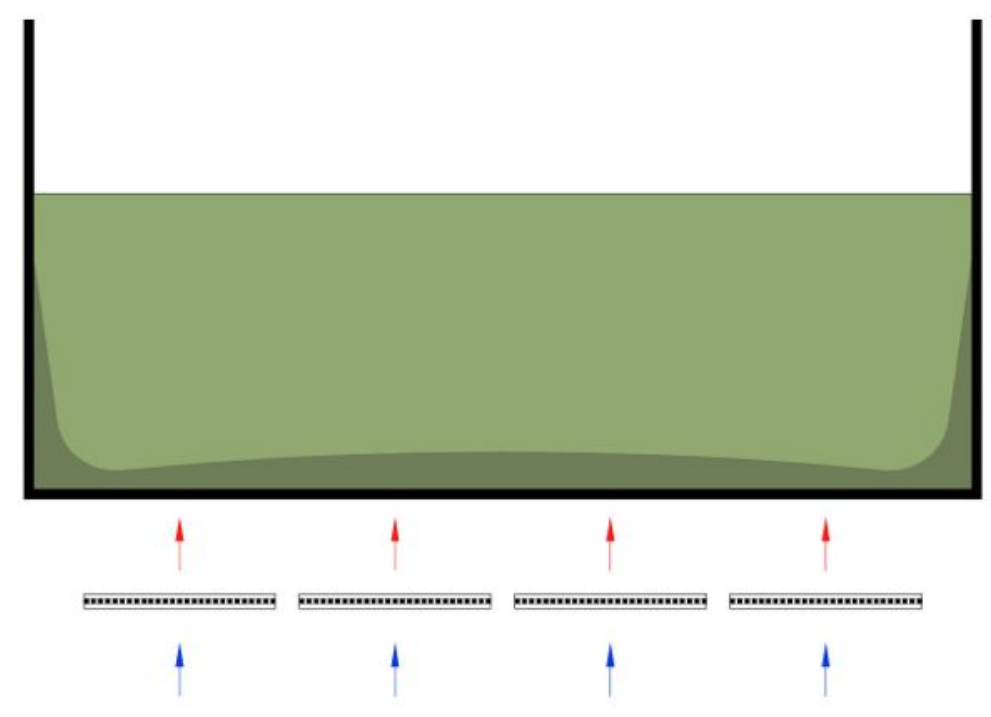

Figure A1.76: Stainless steel tank, due to poor conductivity wax cannot detach from walls to sink

The possible alternatives were to consider containers made of metals other than stainless steel. Whilst copper was more conductive than aluminium (table A1.8) it was about 3-5 times the price per unit weight and was not suitable for laser cutting: molten copper was highly reflective and caused the laser to bounce in unpredictable fashion. Water-jet cutting (where a fine abrasive is carried by a high pressure water jet) or electron discharge machining were the only computer-aided manufacturing methods available for working with copper, and both came at much higher price than laser cutting.

\begin{tabular}{|c|c|}
\hline Material & Conductivity (W/mK) \\
\hline Aluminium & 236 \\
\hline Copper & 384 \\
\hline Stainless steel & 24 \\
\hline
\end{tabular}

Table A1.8: Conductivity of possible materials for use PCM tank (Szokolay, 2008) 
Changing the tank to aluminium (wall thickness $1 \mathrm{~mm}$ ) helped the detachment slightly (figure A1.77) but complete detachment was only achieved with a thick-walled drum (3mm). Two problems became apparent.

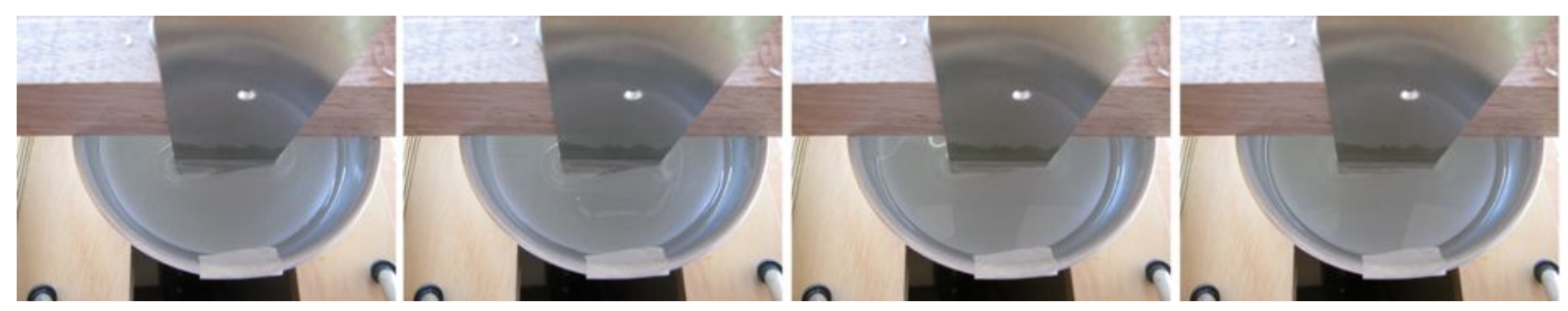

Figure A1.77: Time lapse photography at 1sec intervals. (a) wax detaches from stip and wall (b) some of the molten wax rises to top and flows into the depression (c) wax begins to sink (d) solid wax fully submerged

Firstly, despite the solid wax being denser than the surrounding liquid, the solid wax that had fully detached still remained afloat. Closer inspection revealed a depression in the middle of the wax. When wax solidifies, a skin is formed on the surface - where the heat loss is greatest and hence solidification quickest. As the wax continues to cool it contracts. Since the edges of the top skin have already adhered to the walls of the tank, these edges remain at the same level as the rest of the wax shrinks. The resultant form is a block with a depression in the middle. It is this bowl-shaped geometry that gives the solid wax enough buoyancy to remain afloat despite being "denser" (figure A1.78).

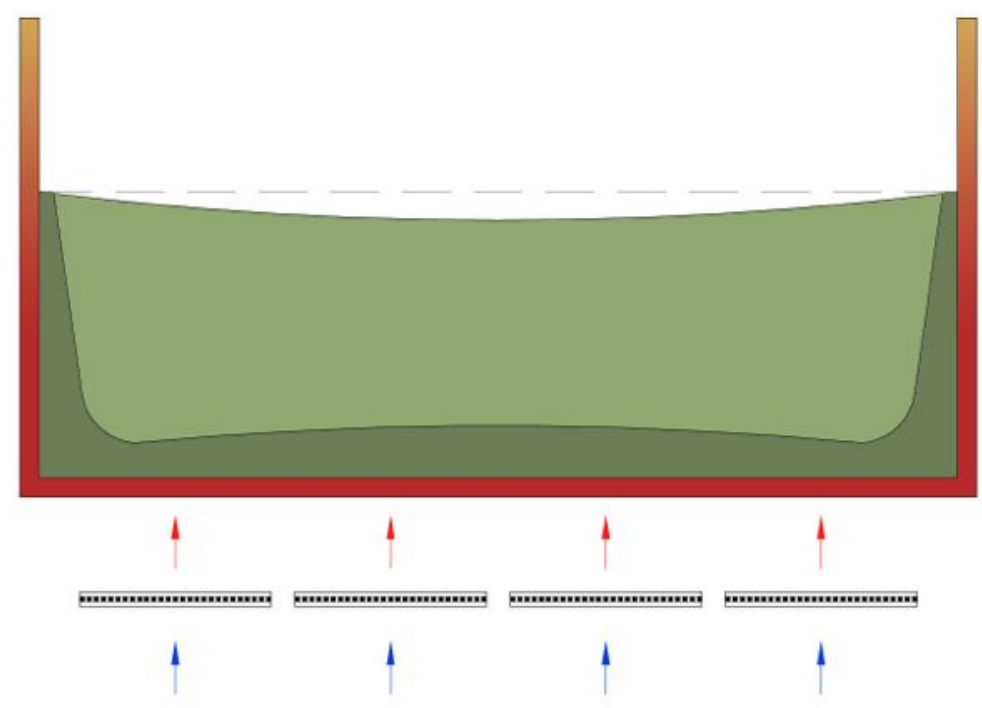

Figure A1.78: Total detachment achieved with thick walled aluminium tank but shape of solid wax, as explained by Archimedes principle, remains buoyant. 
Secondly, heat was emitting on either sides of the thick walls: into the wax as desired, but also out of the tank into the space - something that should be postponed till all the wax had melted. A double-wall tank (figure A1.79) was needed so that the bulk of the heat would be conducted through the thick walls of the internal aluminium tank. The function of the outer walls were only for containment and not heat transfer, these could be made of a thin alloy. With the double-tank the wax could be made to melt inside-out, effectively using the wax in the cavity between the double-wall as an insulator until it melted.

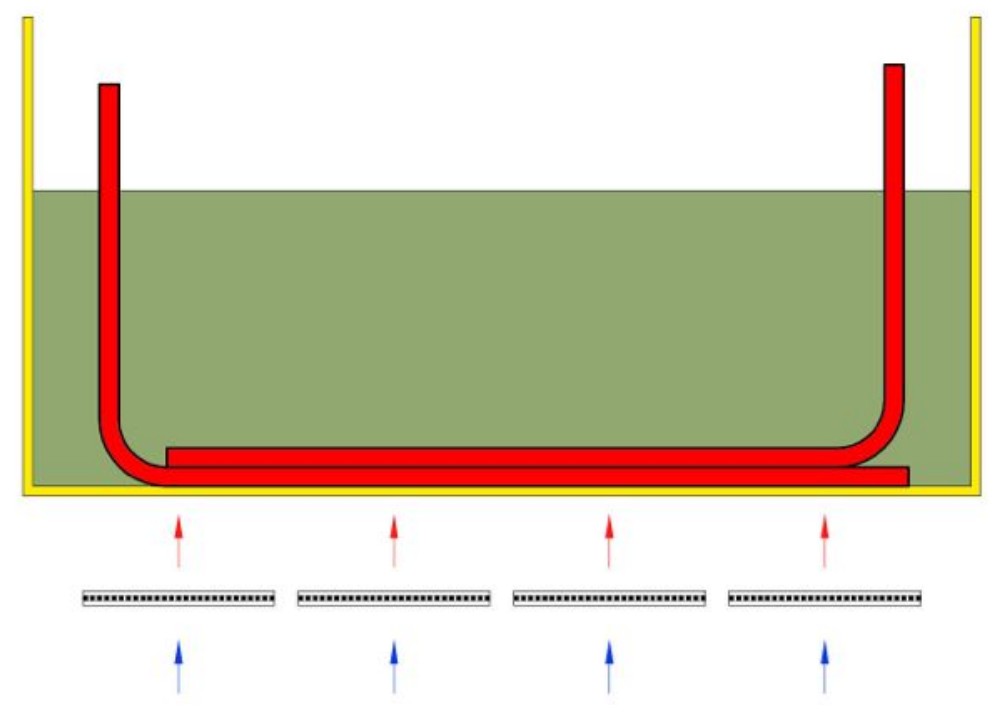

Figure A1.79: Double-tank: an inner highly conductive and thick profiled inner wall, and a low conductive and thin profiled outer wall.

An extruded profile was added to puncture the wax (figure A1.80 and A1.81). It allowed heat from the base to be transmitted to the top, creating a channel for the lighter molten wax to breach the surface. When enough molten wax reached the top, the solid wax sank and provided a continuous feed of solid wax to the base of the tank. 


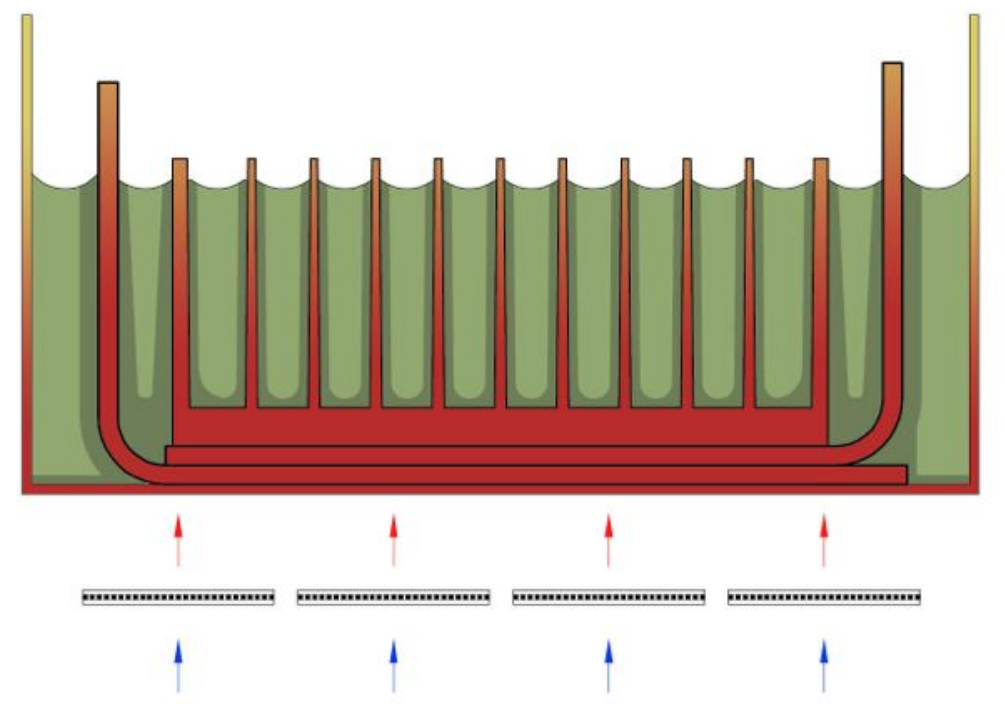

Figure A1.80: Final solution that worked: double-wall bath with a means of perforating the top.
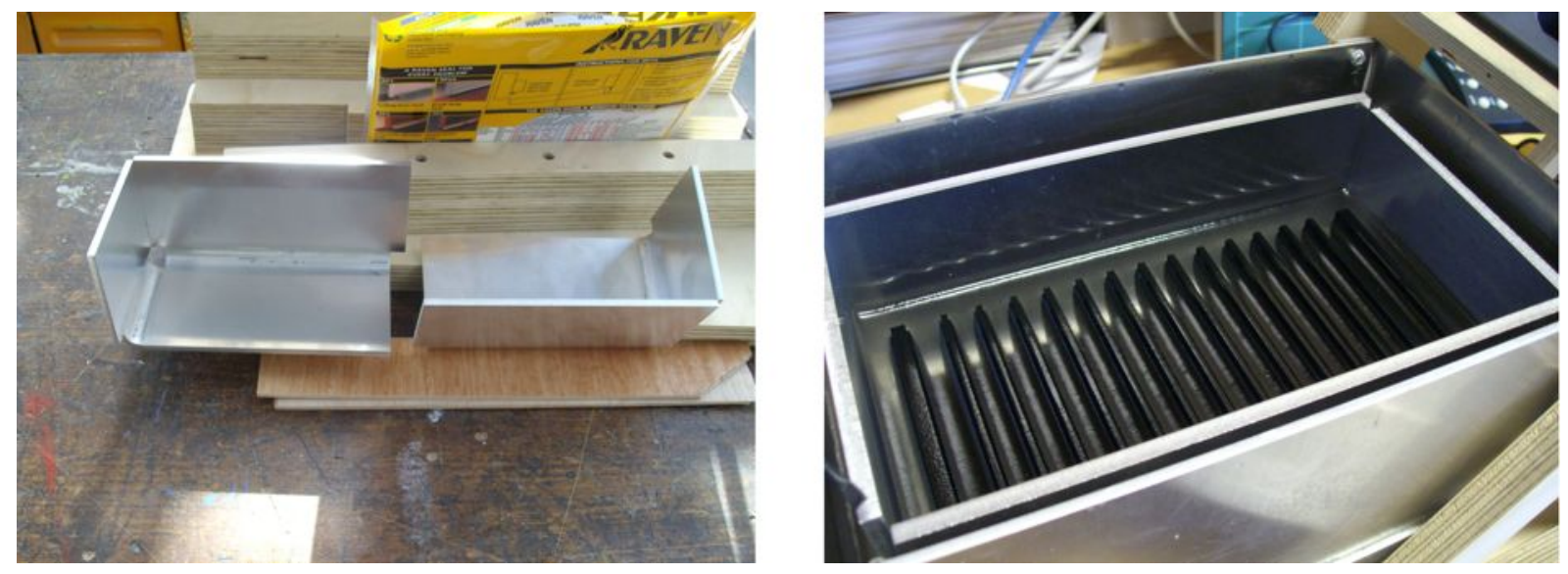

Figure A1.81: (a) The inner-wall made from $4 \mathrm{~mm}$ folded aluminium sheets, and (b) the tank with heat sink and partially melted wax.

\section{A1.10 Prior art}

During the prior art search, Peter Carr's invention (2002, US patent 6481213) emerged as a similar system featuring the use of thermoelectric modules (as heat exchanger) and the use of phase change materials (PCMs, as heat sink). He envisioned the PCMs to be enclosed in an insulated container to store 'coolth'. The proposed PCMs were (1) water-ice or (2) clathrate hydrates. Both substances had their phase change occurring below ambient conditions. 
The main advantage of this selection of PCMs is that very low temperatures can be obtained. However there were a number of significant disadvantages working with a change of phase below ambient temperatures.

1. As proposed in his patent, the PCM needed to be prepared beforehand. A timing mechanism was required to freeze the PCM before its daily operation. If the timer was designed to start the freezing on Monday morning the unit will not be able to provide air-conditioning if someone worked during the weekend. This also limited the use of the air-conditioner to only such applications where demand could be scheduled.

2. When all the units were timed to be charged they will concurrently reject heat into the space. This would become problematic to anyone remaining in the office during that time.

3. The frozen PCM needed to be contained in an insulated container. Standard insulation like extruded polystyrene would add substantial space to the unit. High R-value insulation like polyurethane/silicone would add substantial cost to the unit.

4. Being in a solid state, a secondary fluid was required to carry their stored 'coolth' to the heat exchanger. This required the extra mechanism of pumps and heat exchangers.

\section{A1.10.1 DTAC's differential}

My work with DTAC had been to use a paraffin wax PCM that melted at $40^{\circ} \mathrm{C}$. The outlet temperature of $19-22^{\circ} \mathrm{C}$ are not as low as Carr's at $16-18^{\circ} \mathrm{C}$, but would have been sufficient to provide personal comfort to most people. As the phase change occured above ambient conditions, it has the following advantages:

1. The wax can be solidified passively.

2. No timing and circulating mechanisms were required.

3. Pre-charge the PCM need not be scheduled.

The wax expanded when it melted and this behaviour allowed me to design a tank where solid wax was continuously fed to the hottest part of the heat exchanger. Thermoelectric modules maintain a temperature difference at a certain voltage. So a module at $8 \mathrm{~V}$ can 
maintain a $\Delta \mathrm{T}$ of $20^{\circ} \mathrm{C}$. If the hot side became too hot (e.g. $>60^{\circ} \mathrm{C}$ ) the cold side would not be cold. The key to getting the wax to work with thermoelectric modules was to suppress the hot side temperatures near PCM melting point. This proved to be very challenging technically.

\section{A1.10.2 Uniqueness of DTAC}

Whilst Carr's patent had mentioned the use of phase change materials, his embodiment required the use of an insulated PCM that had a melting point below ambient. Having a PCM that melted above ambient temperatures has many advantages, primarily that once ready it is always ready to be used. However the passive supply of solid wax to the melting surface (bottom of tank in DTAC) has its technical challenges which were overcome with the design of the PCM bath.

\section{A1.11 Stream analysis and conclusion}

In summary, the development of DTAC can be defined in two stages:

1. Proof of concept, contingent on being able to deliver air cooler than the ambient.

2. Optimisation, developing the heat exchange system to deliver air as close to the theoretical limit as possible.

If constructed in a negative, the problem for the proof of concept was that the supply air was too warm. A stream analysis (Adams, 2001) could be constructed by linking the cause of each problems and categorised according to components (figure A1.82). A problem with many arrows in is a key symptom and one worth quantifying by detailed measurements. A problem where many arrows emerge, directly or indirectly, is a core issue. In the prototyping of DTAC, the cooling fin being not cold enough was a key symptom. Thus measuring the cold fin was the main indicator of a successful or failed attempt at airconditioning. Getting the wax to sink in DTAC was the core problem.

The stream analysis helped consolidated the issues and determine the intellectual property strategy. For DTAC, a patent had to be sought particularly for the wax melting mechanism. 
This mechanism presented the most challenge and required the most innovation in resolving.

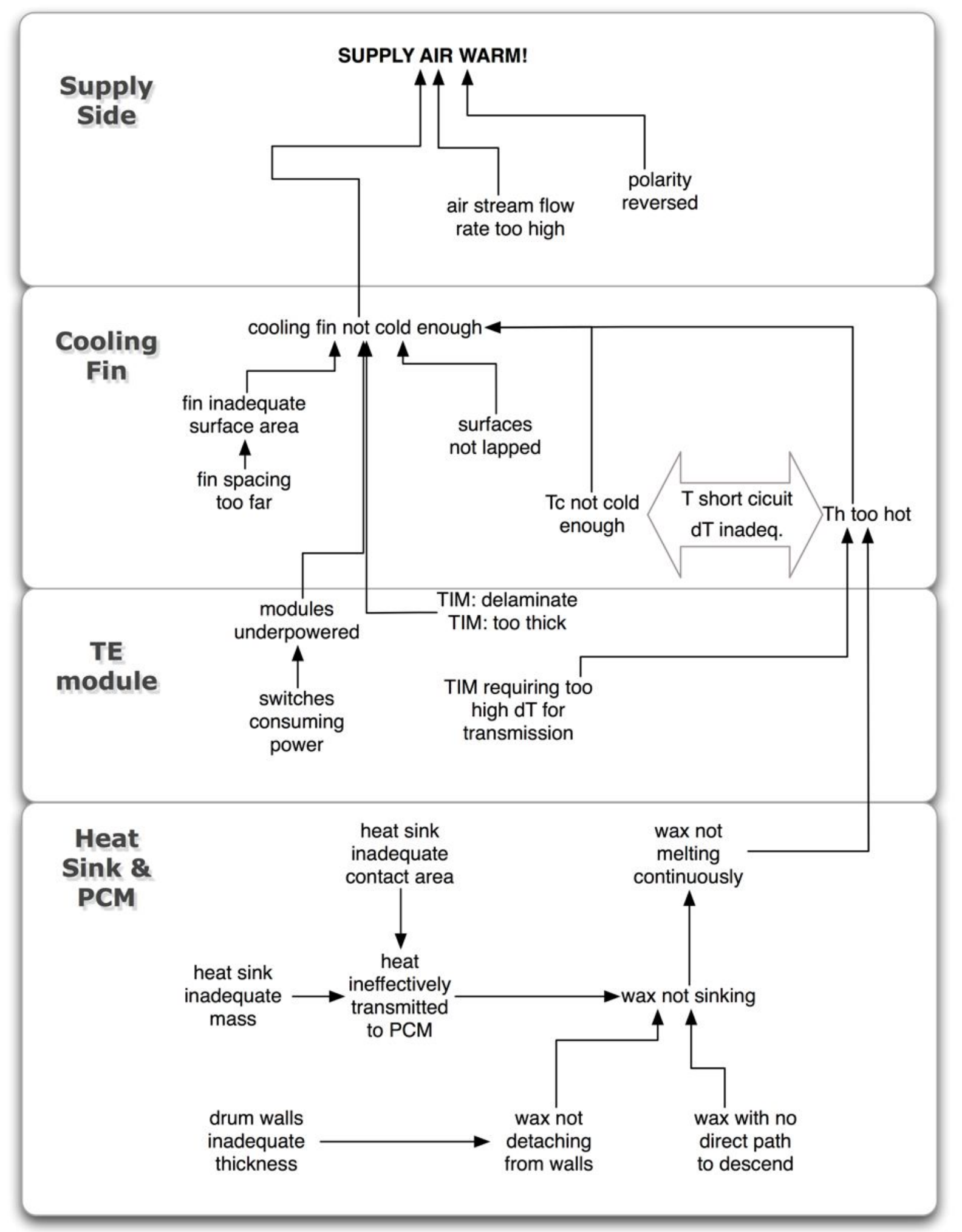

Figure A1.82: Stream analysis of DTAC prototype supplying warm air 
Optimisation of air movement and heat transport has been undertaken with the action research framework: plan $\rightarrow$ act $\rightarrow$ observe $\rightarrow$ reflect.

The ability to undertake digital manufacturing in the School of Architecture \& Design workshops made it possible to have fairly short cycles of action research, and the ability to fabricate many components in-house kept costs low and permitted more iterations.

It is acknowledged that optimisation has only been taken in preliminary steps here. The need to rely heavily on TIM in the fabrication of the cooling fin assembly is a major drawback to the performance of the prototypes. Cooling fins are typically formed with a combination of the following processes: drop-forging, extrusion and brazing. These processes are not available for small scale prototyping. The optimisation of the cooling fins for mass-production will be the primary focus of future work.

Prototyping has been an invaluable part of the learning process, as many complications cannot be anticipated simply by doing calculations and modelling. Furthermore, modelling is eventually subject to validation with real-world experiments and is never a substitute for this process. Prototyping was the vital step that was impossible with the Rain Tower, and extremely difficult for the desiccant wheel AHU without industry support.

For the necessary IP protection, the patent required a reduction to practice: essentially a demonstration of how an idea could be made to work, something more than a mere figment of imagination. Whilst the concept of personal air-conditioning was not novel, and the idea of using TE modules with PCM had prior art, it was still possible to define the characteristic uniqueness of DTAC originating from the PCM bath design. 


\title{
Thermal Comfort, Productivity and Energy Consumption in the Tropical Office Environment: A Critical Overview
}

\author{
Teen-Onn Law ${ }^{1}$ and Roger Fay ${ }^{1}$ \\ ${ }^{1}$ School of Architecture \& Design, University of Tasmania, Australia
}

\begin{abstract}
Thermal comfort has developed along two distinct models: deterministic and adaptive. We investigate the validity of these models against the increasingly urgent call to reduce building energy consumption. The airconditioned office, predicated on the deterministic thermal comfort model, expends about $50 \%$ of its energy on air-conditioning. In a resource-constrained world, while acknowledging the need for thermal comfort, the parameters of thermal comfort should be re-examined. This paper explores the potential for the adaptive thermal comfort model to provide acceptable levels of thermal comfort while reducing cooling demand in office buildings located in the tropics. It links thermal comfort and productivity with the persistence of airconditioning in knowledge-based economies located in the tropics.
\end{abstract}

Conference theme: Performative Ecologies in the Built Environment

Keywords: thermal comfort theories, office productivity, hot-humid tropics

\section{BACKGROUND}

The cost of supplying energy to the office space has historically been insignificant compared to the cost of labour. A study on a typical American office (Holz, Hourigan, Sloop, Monkman, \& Krarti, 1997) found the cost of salaries 100 times more than that of energy. In Singapore, the electrical consumption of offices account for $12 \%$ of the overall non-manufacturing sector's usage, with an average annual energy efficiency of 231 $\mathrm{kWh} / \mathrm{m} 2$ (S. E. Lee, 2001). In an ongoing study by the Energy Sustainability Unit in Singapore (http:///www.esu.com.sg) the average building (in the 25th-75th percentile) uses $49 \%$ of its energy on airconditioning and a further $14 \%$ on mechanical ventilation.

However, the common modern day office is predicated on an uninterrupted supply of affordable electrical energy. Ubiquitous deep plan buildings with fixed windows and office equipment demand air-conditioning, artificial lighting and power. However, in a resource constrained world where there is an increasing need to reduce our energy footprint, what levels of comfort could we forgo without sacrificing undue productivity?

\section{COMFORT THEORIES}

Fanger's seminal work (Fanger, 1970) underlies the standards used both by the International Organization for Standardisation (ISO, 2005) and the American Society for Heating, Refrigeration and Air-conditioning Engineers (ASHRAE, 2004). His climate chamber experiments yielded the PMV (Predicted Mean Vote) formulation that has been widely adopted as the de facto standard for thermal comfort with air-conditioning. For typical office conditions (at $\mathrm{RH}: 50 \%, \mathrm{v}=0.5 \mathrm{~m} / \mathrm{s}, 1 \mathrm{met}, 1 \mathrm{clo}$ ) the neutral temperature is $24.8^{\circ} \mathrm{C}$.

On the other hand, we have the adaptive mode of defining thermal comfort which can be attributed to Aulicem (1969) and extensive field studies by Humphreys and Nicol (M. A Humphreys, 1995; Michael A Humphreys \& J Fergus Nicol, 2004; Fergus Nicol, Michael Humphreys, Sykes, \& Roaf, 1995; Fergus Nicol \& Pagliano, 2007; J. F Nicol \& M. A Humphreys, 2009). They found that compound indices failed to predict accurately the comfort temperature for free-running buildings and a simple regression of outdoor temperatures was a far more reliable gauge:

$$
\mathrm{T}_{\mathrm{c}}=5.41+0.73 \mathrm{~T}_{\mathrm{o}}
$$

Using a typical Singaporean afternoon temperature $\left(T_{0}\right)$ of $30-32^{\circ} \mathrm{C}$ would yield a resultant indoor comfort temperature $\left(T_{\mathrm{c}}\right)$ of $27.3-28.8^{\circ} \mathrm{C}$ (eq. 1), a sensory change $\left(2.7^{\circ} \mathrm{C}<\Delta \mathrm{T}<3.2^{\circ} \mathrm{C}\right.$ ) that can be readily achieved with indoor fans delivering an effective velocity ve $=0.5-0.6 \mathrm{~m} / \mathrm{s}$ (eq. 2 , where $\mathrm{v}_{\mathrm{e}}=\mathrm{v}-0.2 \mathrm{~m} / \mathrm{s}$ (Szokolay, 2000)).

$$
\Delta \mathrm{T}=6 \cdot \mathrm{v}_{\mathrm{e}}-1.6 \cdot \mathrm{v}^{2}
$$


Would the comfort delivered by a ceiling fan at $32^{\circ} \mathrm{C}$ be equivalent to that from an air-conditioner at $24.8^{\circ} \mathrm{C}$ ? How could there be such a vast difference in comfort expectations between the two modes? An ASHRAE report (de Dear, Brager, \& Cooper, 1997) sums up the debate concisely:

The former [PMV model] permits only behavioral adjustments (personal/technological) to heat balance variables such as clothing or air velocity, whereas the original adaptive models were premised on changing physiological (i.e. acclimatization) and psychological (i.e. expectations/habituation) setpoints. While this may seem to be a fine distinction, failure to appreciate it has, in the opinion of the authors, been responsible for unnecessary controversy between the two sides of this debate.

The debate has polarized thermal comfort studies into the following distinct identities:

\section{Deterministic comfort:}

Climate chambers, air-conditioning, equipment-oriented, combined indices, computationally complex, disconnected from nature, universal, institutional.

\section{Adaptive comfort:}

Field studies, natural ventilation, building-oriented, air temperature, computationally simple, correlated to natural patterns, individual, personal.

\section{RESOLVING COMFORT WITH PRODUCTIVITY}

The two camps have been irreconcilable and one of the problems has been the semantics of thermal comfort. The deterministic model comfort is predicated on the notion that comfort is the absence of discomfort. PMV is thus intended to discover the neutral zone in the thermal sensation scale. Adaptive comfort is inclined to the body's acceptance of seasonal fluctuations and considers comfort levels with non-neutral thermal sensation to arrive at the optimum temperature on the Bedford scale, allowing an occupant to say he is warm/cool and still comfortable. A needful way to resolve this divide would be to compare thermal comfort against thermal sensation conducted by field studies on air-conditioned offices: thus using the tools of adaptive comfort to verify the occupant preference in a deterministic environment.

This study was undertaken by Schiller who found that despite the universality alluded to by PMV, office workers in air-conditioned offices had an optimum temperature of $22.5^{\circ} \mathrm{C}$, significantly lower than PMV would have predicted at $24.8^{\circ} \mathrm{C}$ (Schiller, 1990). Field studies have been conventionally accepted as more representative of real-world climate control needs and Schiller's work could be explained by the increased need for cooling caused by real-world stress. Her surveys allowed occupants to provide feedback not just on the neutral temperature, but also on the level of comfort experienced. The need to distinguish thermal sensation from satisfaction is shared by Baker (Baker, 1996). A classroom study in the tropics also showed a preference for cool sensations (Wong \& Khoo, 2003). This leads us to deduce occupants are most comfortable when they are slightly cool, not when they are neutral.

If we accept the assumptions that the ideal temperature is likely to be cooler than neutral, and that field studies reveal a greater demand for cooling than climate chamber studies, we can argue that thermal comfort cannot be defined solely in bodily terms, but that mental work imposes cooling requirements the body alone would not necessitate. This would be particularly true for office workers, where the rigours of mental concentration can account for a preference for cooler environments. This mental load has not been accounted for in comfort studies, where metabolic load is related to physical and not mental activity. The mental metabolic load could also explain why natural ventilation has never been attractive to offices in developed cities in hot and humid climates: the adaptation to warm $\left(30-32^{\circ} \mathrm{C}\right)$ and humid conditions $(\mathrm{RH}=60-$ $80 \%$ ) could come with a penalty in mental performance. Being comfortable in these conditions is not synonymous with being the most productive. Whilst this notion has not been explored in building thermal comfort studies, there is substantial anecdotal evidence in other fields.

Neurons have been studied thermodynamically (Karbowski, 2009) to ascertain that, at an average firing rate of $1.7 \mathrm{~Hz}$ (in grey matter $700 \mathrm{~g}$ in mass), the heat generate was about $7 \mathrm{~W}$. If we consider that "a stimulated neuron might fire 20 or 30 times a second" (Siegfried, 2001) the contribution of mental metabolism to overall metabolism (met=1.2 or $70 \mathrm{~W} / \mathrm{m} 2$ ) is very significant for the typical office worker. Akin to the way computer CPU clock speeds are limited to the availability of cooling, the heat rejection requirements from mental exertion might well justify the need for air-conditioning in offices. This differential need is self-evident in the way we dress: a business suit for the body ( 1 clo to $1.2 \mathrm{clo}$ ) and an uncovered head ( 0 clo).

Heat stress significantly impairs judgment and performance. Several military studies have been conducted to ascertain its relationship and limits (Manton \& Hendy, 1988), to name one). Hancock (Hancock, 1986; Hancock \& Vasmatzidis, 2003) demonstrated that shifts to deep body temperature had pronounced effects in the performance of complex tasks (vigilance, tracking and multi-tasking). However conditions that can cause perturbation to deep body temperature fall well beyond the comfort scales into thermally stressful regions not typically encountered in the office. Of interest is the region where there is sensible discomfort without 
disturbance to deep body temperature: a region where Hancock found no performance deterioration in his subjects.

Humphreys and Nicol, earlier noted for their work in adaptive theory, undertook a field study to determine how comfort affected productivity (Michael A Humphreys \& J. Fergus Nicol, 2007). Unlike Hancock's approach to quantifying performance against thermal stress under controlled conditions, they used field surveys to compare perceived comfort against self-assessed productivity, establishing a strong correlation between the two and a weak one between perceived and predicted comfort (PMV and Standard Effective Temperature). They noted that "perceived productivity fell slightly at temperatures above $25^{\circ} \mathrm{C}$ or below $21^{\circ} \mathrm{C}$ " a range in agreement with Schiller's observation that "office workers' sensitivity to changes in temperature was relatively flat, or at least broadly curved, over $3^{\circ} \mathrm{C}$ range near the optimum [of $22.5^{\circ} \mathrm{C}$ ]" (Schiller, 1990). Similar studies have not been performed in the tropics and one wonders if these productive temperature ranges are not equally applicable to hot-humid regions.

In knowledge-based economies like Singapore, the productivity of the workforce (their only resource) takes primary importance. Singapore's founding prime minister, Lee Kuan Yew, named the air-conditioner as the most significant innovation of the millennium (Wall Street Journal, 1999):

\begin{abstract}
The humble air conditioner has changed the lives of people in the tropical regions. Before air-con, mental concentration and with it the quality of work deteriorated as the day got hotter and more humid. After lunch, business in many tropical countries stopped until the cooler hours of the late afternoon. Historically, advanced civilizations have flourished in the cooler climates. Now lifestyles have become comparable to those in temperate zones and civilization in the tropical zones need no longer lag behind.
\end{abstract}

Lee highlights the mental activity associated with comfort: with cooler conditions being conducive for work as contrasted to warmth for rest. We well know that with long distance driving, the driver and passengers have different requirements for comfort by virtue of their differing mental activity, even if their metabolism and clothing insulation are identical. Mackie and O'Hanlon (Hancock, 1986) found "that drivers exposed to hot environments exhibited decreased precision in steering control and an increased propensity toward error during the first 150 minutes of exposure, compared with performance when driving in thermally comfortable conditions." Thermal comfort cannot be defined without the context of its associated activity.

This is an important contradiction with the observations of Humphreys \& Nichol, who, in their field-studies in Pakistan, found that office workers in the tropics could tolerate much higher temperatures than stipulated in ASHRAE standards (M. A Humphreys, 1995). The comparsion of interest would be to those workers who have experienced working in air-conditioned offices. This would give a benchmark reference to ascertain if performance had been diminished by heat adaptation. Since the brain accounts for such a significant concentration of heat, we postulate that part of the thermoregulatory response would be to reduce the firing rates of neurons to prevent overheating. If a similar experiment was conducted in Singapore, the result might be very different from Pakistan. In a survey on the expectations for air-conditioning in young Singaporeans (Hitchings \& Shu Jun Lee, 2008), it was found:

\footnotetext{
...The demand for air conditioning had largely reached the point where it was an expectation. In the public sphere, with regard to the office and the school, air conditioning was seen as essential not only for enhancing productivity but also as a courtesy towards employees and students who themselves worked hard to ensure the collective organizational success.
}

Prins, an anthropologist, in his polemic on air-conditioning (Prins, 1992) describes air-conditioning as "addictive", "relentless" and "severe". Whilst we may not use such emotive descriptors, there is a sense in which air-conditioning does alter one's preferred temperature. A survey of literary works (Meyer, 2002) between British and Anglo-American writers found a change in preferred winter indoor temperatures from $14^{\circ} \mathrm{C}$ during mid eighteenth century to $22-24^{\circ} \mathrm{C}$ in the periods $1825-1840$. These figures may need to be taken anecdotally (Meyer appears not to differentiate between radiant and air temperature), but we still agree with his thinking that energy efficient innovations coupled with affordable and abundant energy would cause climatic taste to be more exacting, as occupants become less tolerant to compromise. The reverse will happen in the tropics where increased affluence can drive optimum temperatures lower. This acclimatised addiction to air-conditioning parallels the effects of coffee: one does not realise the productivity boost until one has experienced it, after which there is no going back, and without which one gets highly irritable.

We have identified three conditions that have not been considered by either deterministic or adaptive comfort, and could possible explain the strong evidence supporting adaptive comfort with the contradictory strong demand for air-conditioning:

\title{
Mental metabolism
}

The considerable heat given off by our brains requires more cooling there than for the rest of the body. Optimum temperature at an office will always be colder than neutral.

\section{Comfort as a function of mental activity}

Conditions that are comfortable for a body to rest are not the same as that for the mind to work. A thermoregulatory response to heat acclimatisation is for mental activity to throttle down. 


\section{Acclimatised addiction}

A sense of comfort within a naturally ventilated space does not mean that workers are as productive as they could be in an air-conditioned space. With exposure to air-conditioning, workers develop a reliance on artificial cooling to maintain their heightened productivity.

\section{COMFORT AND ENERGY}

How then are we to resolve the need for comfort with energy constraints? If the deterministic model were correct, the primary focus would be on increasing plant efficiency and reducing building thermal load. In the adaptive model, considerable emphasis would be placed on education: to change the mindsets of governments, developers, building designers and building users.

In the popular perception in Singapore, air-conditioning is here to stay. Increased affluence has made it a necessary commodity. In many fast developing Asian cities, air-conditioning is even more imperative to cope with air pollution. Along these lines, we surmise that air-conditioning cannot be denied to office workers, but instead of a single deterministic setting, a range should be provided that corresponds with the mental demands of each space: formal and personal areas being cooler to promote concentration whereas informal, communal and creative spaces being allowed to approach warmer temperatures. Minimal ambient cooling should be provided in the general areas with extra cooling available on-demand, individually controlled and directed mostly to the head.

Such a non-uniform environment builds on the delight of sensory fluctuations (Heschong, 1985), the satisfaction of a larger band with time variance (Baker, 1996) and the awareness of adaptive opportunity (Baker \& Standeven, 1996).

Air-conditioning efficiency need not lie solely in equipment improvements. The largest part on the chiller load is latent: to dehumidify external air. This load is decided by indoor air quality (IAQ) standards dictating relative humidity and air changes per hour. A notable innovation to cope with pollution has been adopted by the Paharpur Business Centre in New Delhi, India: all fresh air is collected at roof level, filtered, circulated through a rooftop greenhouse before entering the air-conditioning system and distributed to the 6-storey building. The plants reduce $\mathrm{CO} 2$ concentration, enrich oxygen levels and remove volatile organic compounds. However the presence of plants further increase the latent load on the air-conditioning system through transpiration. This, and other dehumidification requirements, can be solved with sold adsorption desiccant systems. New generation zeolites which can be regenerated at temperatures achievable from flat-plate solar collectors (P. Mazzei, F. Minichiello, \& D. Palma, 2002; Pietro Mazzei, Francesco Minichiello, \& Daniele Palma, 2005) show great promise in tackling the latent load in a passive way.

Chilled beams should also play a larger role in tropical offices. Radiant cooling studies have shown the efficacy of reducing mean radiant temperature to achieve sensible cooling, especially with the ceiling (Yellott, 1989). The asymmetric heat load of the body, with the head requiring the most cooling, means that the exposed head would benefit most from a chilled ceiling. To cope with the high dew-point of tropical air, chilled beams need to be introduced in conjunction with desiccant systems or conventional chillers that can precondition the air and maintain its humidity at a dewpoint under $13^{\circ} \mathrm{C}$.

It must be added, that the resolution to comfort and productivity is not purely a technical one. Lee Eng Lock, an engineer known for notably improving building energy efficiency says (Berger, 1998):

In engineering, you have to do things elegantly, which sometimes conflicts with doing it for the fees. In a fee, you are driven to jack up capital costs. If you make it elegant and cheap and better, you're working against your own financial interests

Lee's experience with increasing efficiency is not inadequate research, but "most of the problems in going to factor two or factor four reduction in energy are institutional barriers, consultants and architects and project managers and owner's rep[resentative]s stick to the tried and true (truly wasteful and inefficient) and resist any kind of change" (E. L. Lee, 2009).

\section{CONCLUSION}

We have examined the divide between deterministic and adaptive theories and offered a few considerations to account for the gap: mental metabolism, and its associated comfort set point, can explain the reliance office workers develop for air-conditioning through prolonged exposure. Whilst the financial price of providing cooling comfort remains inconsequential to employers, it is not without cost to a resource-constrained world. We have thus offered a few alternatives for future development in the hope that change can be brought by synthesising the two theories to achieve productive comfort in an adaptive interpretation of our desire for airconditioning. 


\section{REFERENCES:}

ASHRAE. (2004). Standard 55: Thermal Environmental Conditions for Human Occupancy.American Society of Heating and Air-conditioning Engineers, Inc. Tullie Circle, NE . Atlanta, 26 pages.

Baker, N. (1996). The Irritable Occupant: Recent Developments in Thermal Comfort Theory. Architectural Research Quarterly, 2(02), 84-90. doi: 10.1017/S1359135500001287.

Baker, N., \& Standeven, M. (1996). Thermal comfort for free-running buildings. Energy and Buildings, 23(3), 175-182. doi: 10.1016/0378-7788(95)00942-6.

Berger, J. J. (1998). Charging Ahead: The Business of Renewable Energy and What It Means for America (1st ed.). University of California Press.

de Dear, R., Brager, G., \& Cooper, D. (1997). Developing an Adaptive Model of Thermal Comfort and Preference. American Society of Heating, Refrigerating and Air Conditioning Engineers, Inc., Macquarie Research, Ltd.

Fanger, P. O. (1970). Thermal Comfort. Copenhagen, Danish Technical Press.

Hancock, P. A. (1986). Sustained attention under thermal stress. Psychological Bulletin, 99(2), 263-281.

Hancock, P. A., \& Vasmatzidis, I. (2003). Effects of heat stress on cognitive performance: the current state of knowledge. International Journal of Hyperthermia, 19(3), 355. doi: 10.1080/0265673021000054630.

Heschong, L. (1985). Thermal Delight in Architecture (4th ed.). Cambridge: The MIT Press.

Hitchings, R., \& Shu Jun Lee. (2008). Air Conditioning and the Material Culture of Routine Human Encasement: The Case of Young People in Contemporary Singapore. Journal of Material Culture, 13(3), 251265. doi: $10.1177 / 1359183508095495$.

Holz, R., Hourigan, A., Sloop, R., Monkman, P., \& Krarti, M. (1997). Effects of standard energy conserving measures on thermal comfort. Building and Environment, 32(1), 31-43. doi: 10.1016/S0360-1323(96)00025$\mathrm{X}$.

Humphreys, M. A. (1995). Thermal Comfort Temperatures and the Habits of Hobbits. In Standards for Thermal Comfort (pp. 3-13). Windsor, UK: E \& FN Spon.

Humphreys, M. A., \& Nicol, J. F. (2004). Do People Like to Feel "Neutral"? Response to the ASHRAE Scale of Subjective Warmth in Relation to Thermal Preference, Indoor and Outdoor Temperature/DISCUSSION. ASHRAE Transactions. Retrieved from http://proquest.umi.com/pqdweb?did=785638461\&Fmt=7\&clientld=20931\&RQT=309\&VName=PQD .

Humphreys, M. A., \& Nicol, J. F. (2007). Self-Assessed Productivity and the Office Environment: Monthly Surveys in Five European Countries. ASHRAE Transactions, 113, 606.

ISO. (2005). ISO 7730:2005 (p. 52). Retrieved June 25, 2009, .

Karbowski, J. (2009). Thermodynamic constraints on neural dimensions, firing rates, brain temperature and size. 0905.3690. doi: doi:10.1007/s10827-009-0153-7.

Lee, E. L. (2009). Private correspondence (Research in Air-conditioning Efficiency).

Lee, S. E. (2001). Energy Efficiency Of Office Buildings In Singapore. Retrieved from http://www.bdg.nus.edu.sg/BuildingEnergy/publication/papers/paper4.html.

Manton, J. G., \& Hendy, K. C. (1988). Thermal stress in RAN Sea King helicopter operations (u) / by J.G. Manton and K.C. Hendy. Aircraft systems report ; 40 (p. 44). Melbourne :: Department of Defence, Defence Science and Technology Organisation, Aeronautical Research Laboratory.

Mazzei, P., Minichiello, F., \& Palma, D. (2002). Desiccant HVAC systems for commercial buildings. Applied Thermal Engineering, 22(5), 545-560. doi: 10.1016/S1359-4311(01)00096-5.

Mazzei, P., Minichiello, F., \& Palma, D. (2005). HVAC dehumidification systems for thermal comfort: a critical review. Applied Thermal Engineering, 25(5-6), 677-707.

Meyer, W. B. (2002). Why Indoor Climates Change: A Case Study. Climatic Change, 55(3), 395-407.

Nicol, F., Humphreys, M., Sykes, O., \& Roaf, S. (1995). Standards for Thermal Comfort. London: Chapman \& Hall.

Nicol, F., \& Pagliano, L. (2007). Allowing for thermal comfort in free-running buildings in the new European Standard EN15251 (pp. 708-711). Crete. Retrieved from http://www.learn.londonmet.ac.uk/about/papers.shtml. 
Nicol, J. F., \& Humphreys, M. A. (2009). New standards for comfort and energy use in buildings. Building Research \& Information, 37(1), 68 - 73.

Prins, G. (1992). On condis and coolth. Energy and Buildings, 18(3-4), 251-258. doi: 10.1016/03787788(92)90017-B.

Schiller, G. E. (1990). A comparison of measured and predicted comfort in office buildings. ASHRAE Transactions, 96(1), 609-622.

Siegfried, T. (2001). A face that rings a bell ... and fires a neuron. The Dallas Morning News. Retrieved from http://klab.tch.harvard.edu/news/media/nature2000/the_dallas_morning_news_science.html.

Szokolay, S. (2000). Dilemmas of warm-humid climate house design: heavy vs. lightweight + cooling effect of air movement. In Architecture, city, environment (pp. 144-149). Cambridge, U.K.: James \& James (Science Publishers) Ltd.

Wall Street Journal. (1999). The Most Influential Innovations of the Millennium. Wall Street Journal. Retrieved July 16, 2009, from http://www.aidsinfobbs.org/articles/wallstj/99/005.

Wong, N. H., \& Khoo, S. S. (2003). Thermal comfort in classrooms in the tropics. Energy and Buildings, 35(4), 337-351. doi: 10.1016/S0378-7788(02)00109-3.

Yellott, J. I. (1989). Evaporative Cooling. In Passive Cooling (p. 132). The MIT Press. 


\section{This article has been removed for copyright or proprietary reasons}

Law, T., Sargison, J., Fay, R., \& Banbury, S. (2012). Ductless task air-conditioning. ASHRAE Transactions, 118, 367-374. 